Prehistoric Life along the Banks of Spring Lake: Results and Analysis of the Southwest Texas State Field Schools (1996-1998) at 41HY165, San Marcos, Hays County, Texas

Carole A. Leezer

Center for Archaeological Studies

Follow this and additional works at: https://scholarworks.sfasu.edu/ita

Part of the American Material Culture Commons, Archaeological Anthropology Commons, Environmental Studies Commons, Other American Studies Commons, Other Arts and Humanities Commons, Other History of Art, Architecture, and Archaeology Commons, and the United States History Commons

Tell us how this article helped you.

This Article is brought to you for free and open access by the Center for Regional Heritage Research at SFA ScholarWorks. It has been accepted for inclusion in Index of Texas Archaeology: Open Access Gray Literature from the Lone Star State by an authorized editor of SFA ScholarWorks. For more information, please contact cdsscholarworks@sfasu.edu. 
Prehistoric Life along the Banks of Spring Lake: Results and Analysis of the Southwest Texas State Field Schools (1996-1998) at 41HY165, San Marcos, Hays County, Texas

Creative Commons License

(c) $(1)$ ( 8

This work is licensed under a Creative Commons Attribution-NonCommercial 4.0 International License 


\section{Prehistoric Life along the Banks of Spring Lake: Results and Analysis of the Southwest Texas State Field Schools (1996-1998) at 41HY165, San Marcos, Hays County, Texas}

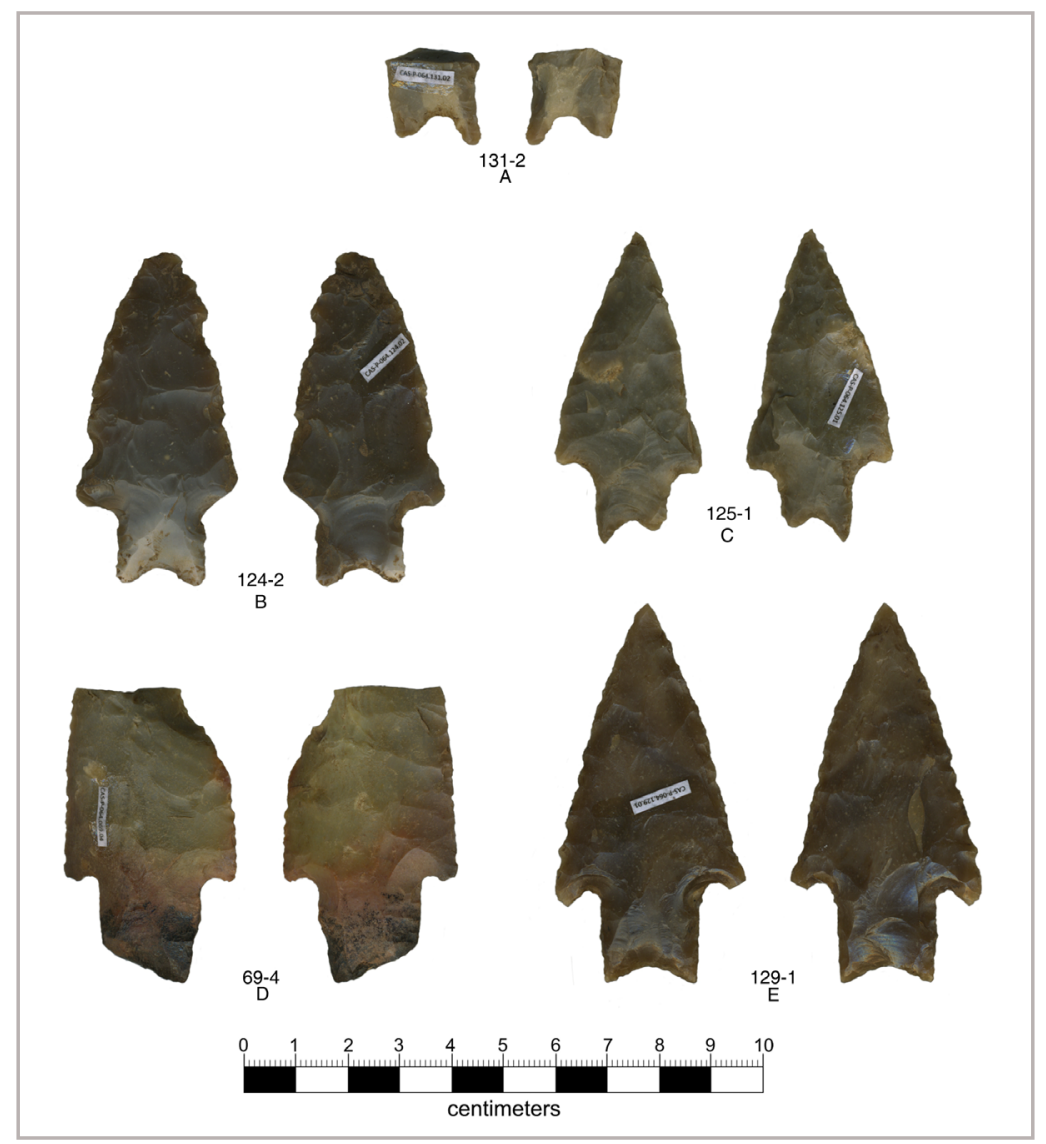

edited by Carole A. Leezer

Principal Investigators:

James Garber, Texas Antiquities Permit No. 1700

Carole A. Leezer, Texas Antiquities Permit No. 5582

Archaeological Studies Report No. 31

Center for Archaeological Studies

Texas State University-San Marcos 



\title{
Prehistoric Life along the Banks of Spring Lake: Results and Analysis of the Southwest Texas State Field Schools (1996-1998) at 41HY165, San Marcos, Hays County, Texas
}

\author{
edited by
}

Carole A. Leezer

with contributions by

John A. Campbell, Kandace D. Hollenbach, Carole A. Leezer, Jon C. Lohse, Lori B. Love, Amy E. Reid, Timothy E. Riley, Cinda Timperley, Steve Tomka, Kristi Ulrich, and David M. Yelacic

Report issued in compliance with Texas Antiquities Permit No. 1700,

James Garber, Principal Investigator

and

Texas Antiquities Permit No. 5582,

Carole A. Leezer, Principal Investigator

Archaeological Studies Report No. 31

CENTER FOR ARCHAEOLOGICAL STUDIES

Texas State University-San Marcos 
The following information is provided in accordance with the General Rules of Practice and Procedures, Title 13, Chapter 26, Texas Administrative Code:

1. Type of investigation: Artifact analysis

2. Project name: $41 \mathrm{HY} 165$

3. County: Hays

4. Principal Investigators: James Garber, Carole A. Leezer

5. Name and location of sponsoring agency: Texas State University-San Marcos

6. Published by the Center for Archaeological Studies, Texas State University-San Marcos, 601 University Drive, San Marcos, Texas, 78666-4616 (2012)

Texas State University-San Marcos is a member of the Texas State University System

Copyright (C) 2013 by the Center for Archaeological Studies at Texas State University-San Marcos

All rights reserved.

No part of this book may be reproduced or utilized in any form or by any means, electronic or mechanical, including photocopying, recording,

or by any information storage and retrieval system

without permission in writing.

For further information on this and other publications by the Center for Archaeological Studies, please contact:

Center for Archaeological Studies

Texas State University-San Marcos

601 University Drive

San Marcos, TX 78666-4616

www.txstate.edu/anthropology/cas/

Editor: Maggie McClain

Cover Photograph: Late Archaic I projectile points.

Printed in the United States of America

by

Ginny's Printing Inc., Austin 


\section{Management Summary}

This report presents the results of archaeological investigations and subsequent analyses of archaeological site 41HY165, located along the banks of Spring Lake in Hays County, Texas. Excavations were conducted at 41HY165 during the 1996, 1997, and 1998 Southwest Texas State University (now Texas State University-San Marcos [Texas State]) field schools. As site 41HY165 was and still is located on property owned by Texas State (formerly Southwest Texas State University), investigations during the 1996-1998 field schools were subject to the Antiquities Code of Texas. Therefore, a Texas Antiquities Permit (Permit No. 1700) was issued by the Texas Historical Commission (THC) on May 30, 1996, with Dr. James Garber serving as Principal Investigator. The permit has since defaulted, and it is the goal of this report to close this permit.

Investigations into the site subsequent to the field school have been limited to analyses of the collections curated at the university, and later with the Center for Archaeological Studies (CAS) at Texas State. These investigations included an analysis of the faunal materials conducted by Jennifer Giesecke in May of 1998, and processing of flotation samples in 2002 by undergraduate students at Southwest Texas State. The only substantive research conducted on the site was the thesis prepared by Christopher Ringstaff as part of his graduate studies at Southwest Texas State University (Ringstaff 2000). While Ringstaff's thesis offers a relatively comprehensive study of the three field school seasons, the focus of his research is on the geoarchaeological properties of the site, and thus the attention given to the artifact assemblage and features at the site is limited to that scope of his research.

As part of the Spring Lake Section 206 Aquatic Ecosystem Restoration Project (SLAERP) being conducted in conjunction with the US Army Corps of Engineers and Texas State, CAS conducted additional analyses and syntheses of the collected materials from 41HY165. The goals were to assess the collections at 41HY165 and synthesize that information within the broader research goals of the SLAERP, as well as to finalize the existing defaulted permit with the THC. This was began by assessing the curated collection and resorting and cataloging the artifacts. After the catalog was compiled, a research design for the analysis of the artifacts was developed. The collections from the 1996-1998 field schools include unit level forms for all units, unit level plan maps, artifact inventory sheets, and collected artifacts. Additionally, student field journals from the 1997 field school and Chris Ringstaff's thesis were also referenced. Ringstaff (2000) provides the only maps showing the general layout of excavation units and shovel tests. Based on the available data, it was possible to reconstruct the distribution of artifacts and features at the site; these reconstructions, supplemented with new radiometric dates, provide the basis for the present analysis. This report, therefore, presents a summary the results of the investigations conducted by Southwest Texas State University from the 1996, 1997, and 1998 field school seasons, and the subsequent analysis and synthesis conducted by CAS at Texas State between 2010 and 2011. 


\section{TABLE OF CONTENTS}

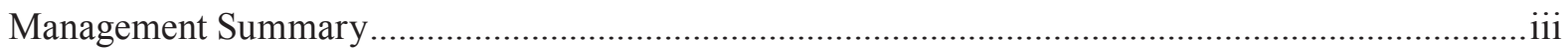

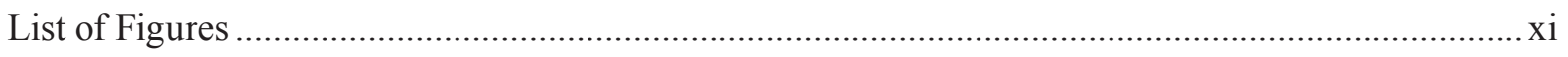

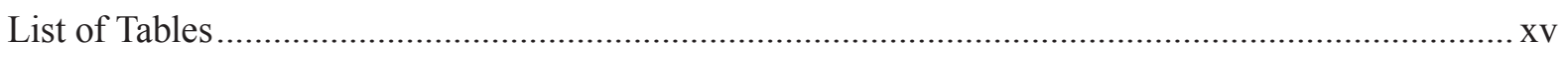

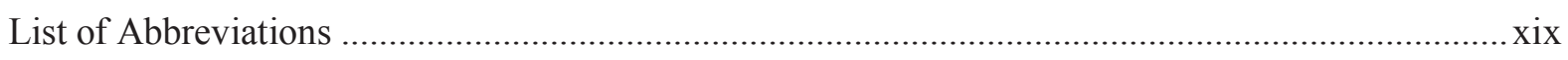

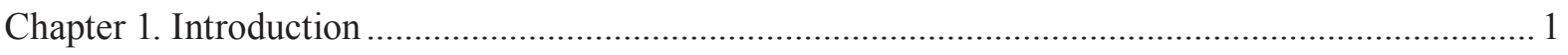

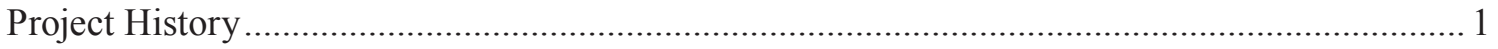

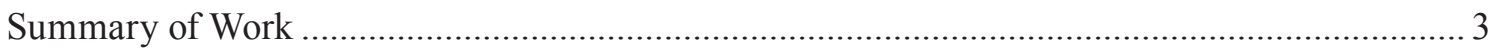

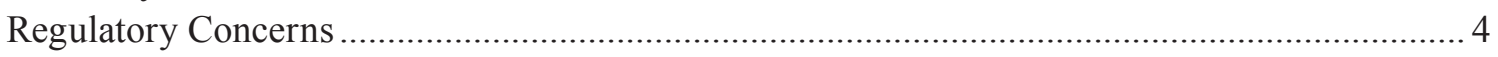

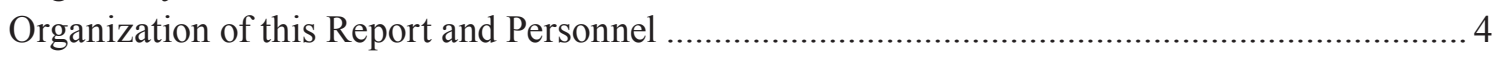

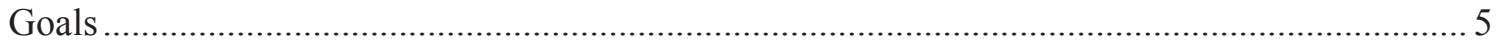

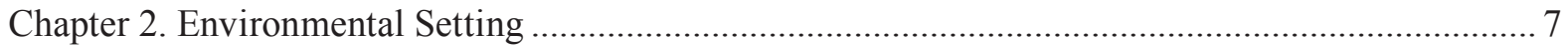

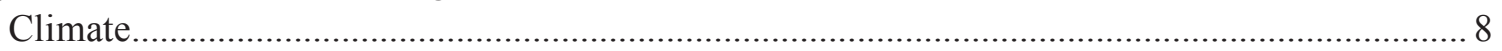

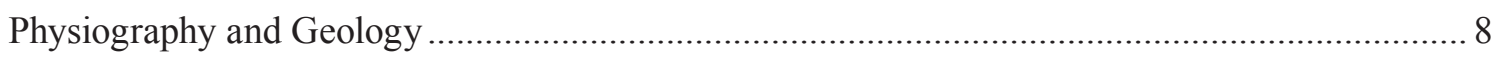

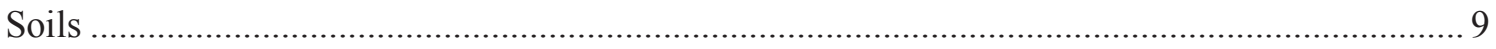

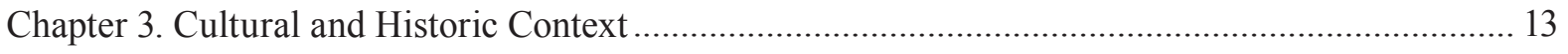

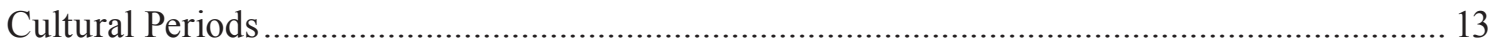

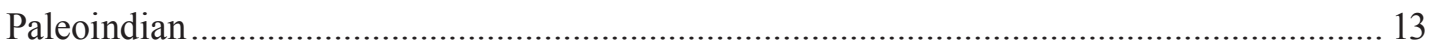

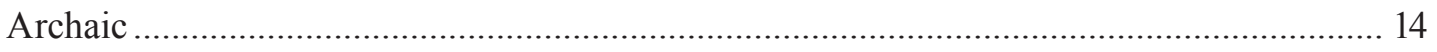

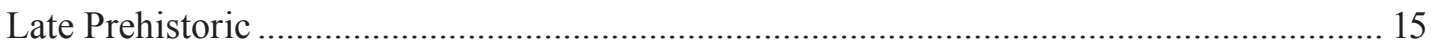

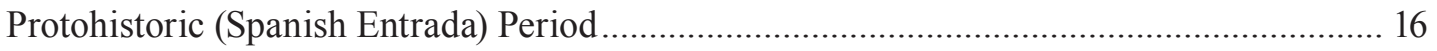

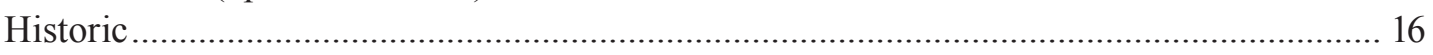

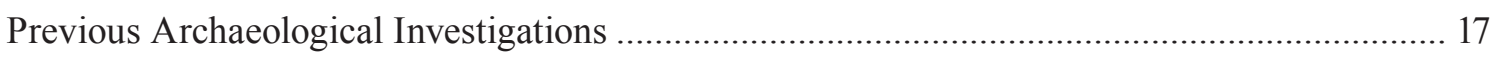

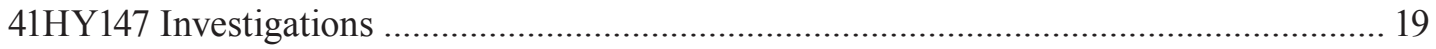

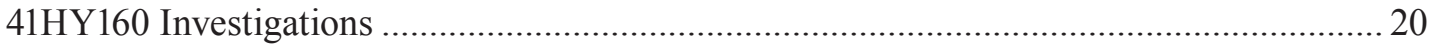

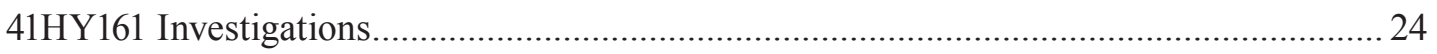

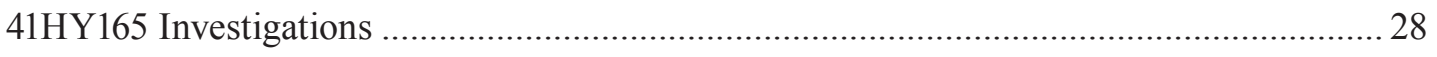

Recent Investigations at Spring Lake (41HY160 and 41HY165) ....................................... 29

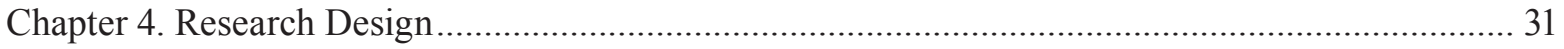

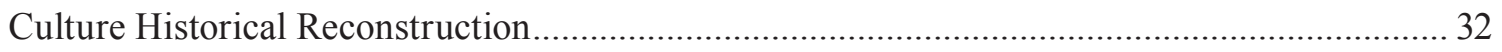

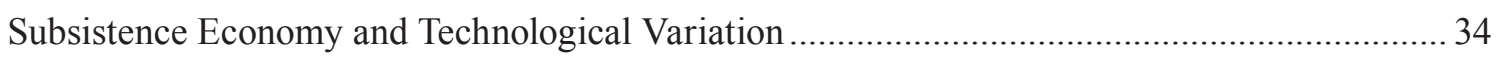

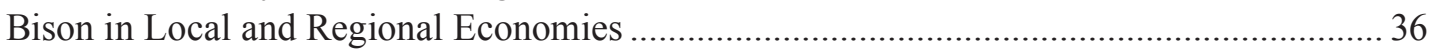

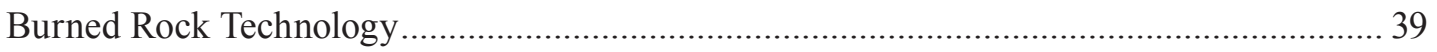

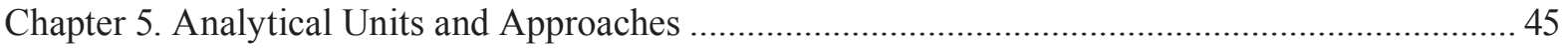

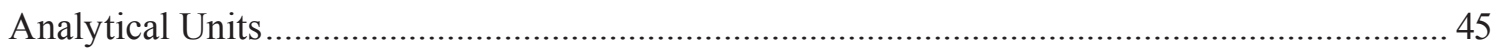

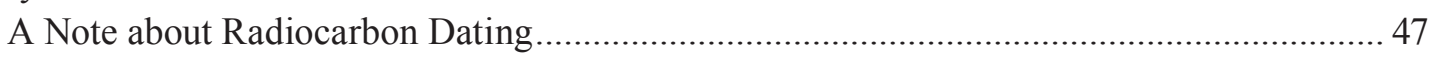

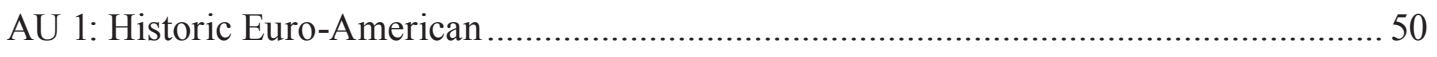

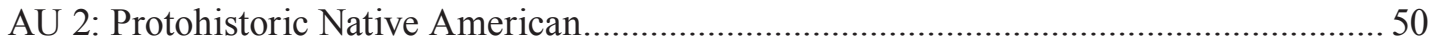

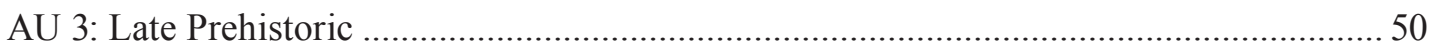

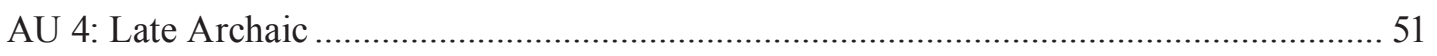

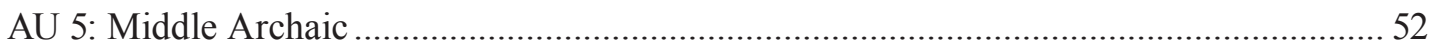




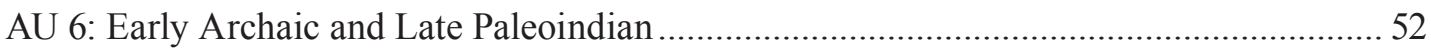

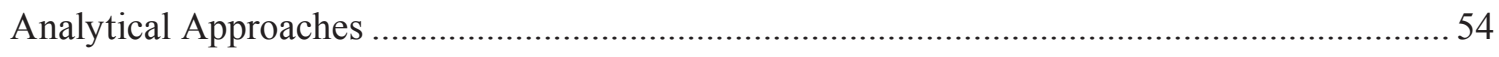

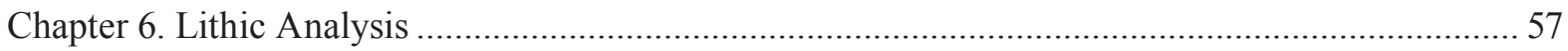

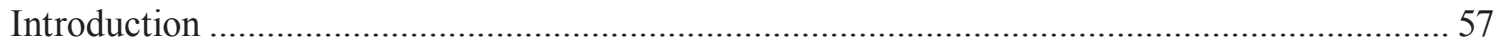

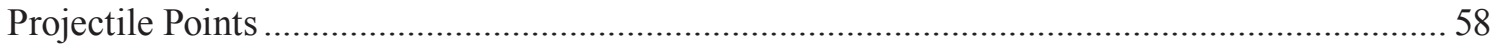

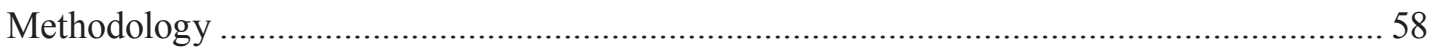

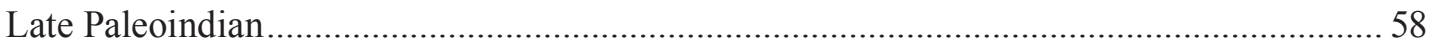

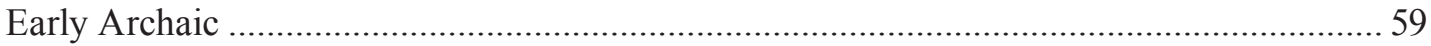

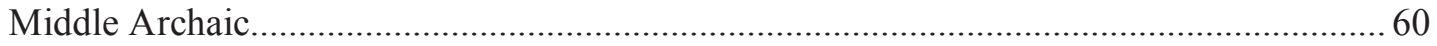

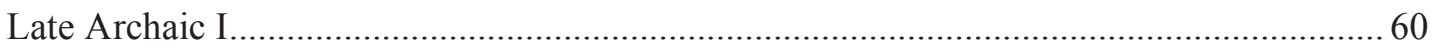

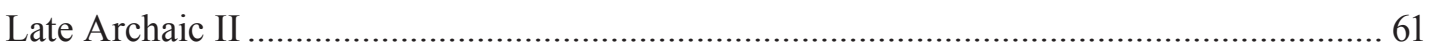

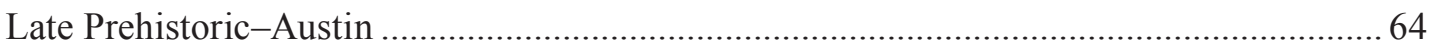

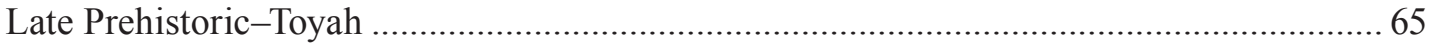

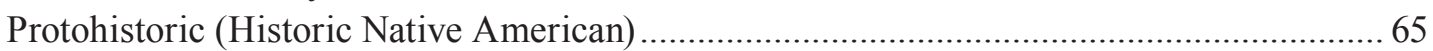

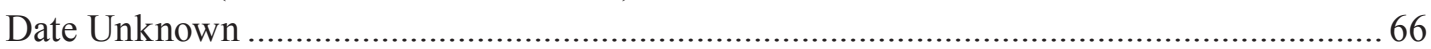

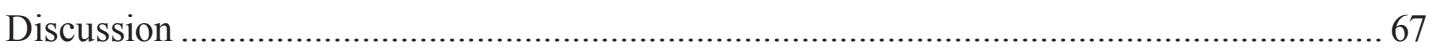

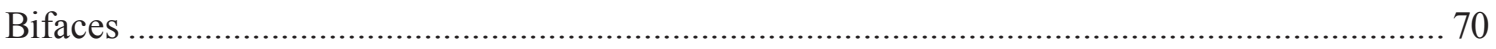

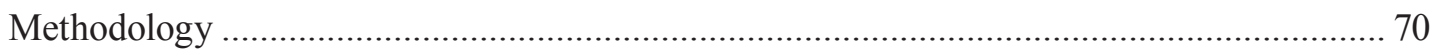

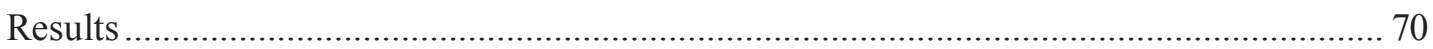

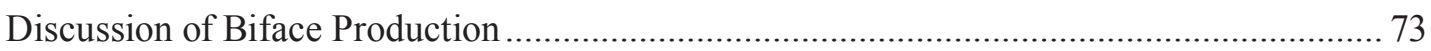

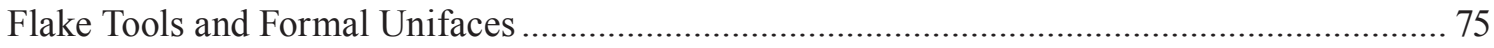

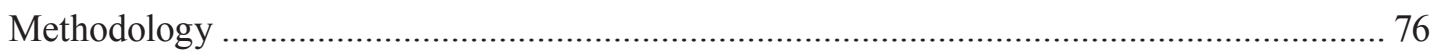

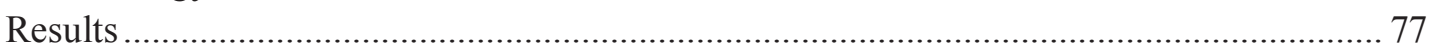

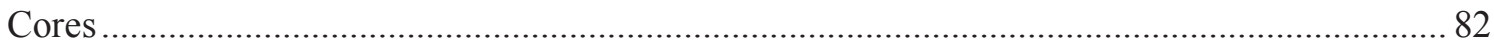

Debitage

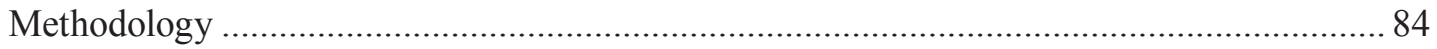

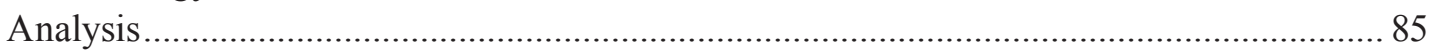

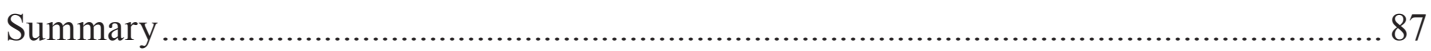

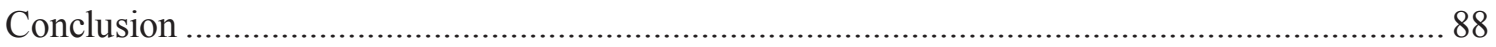

Chapter 7. Ceramic Analysis of Samples from 41HY165, Hays County, Texas ................................. 91

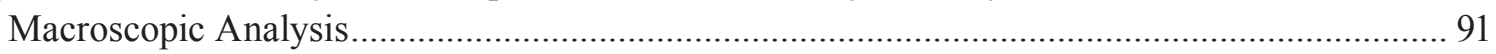

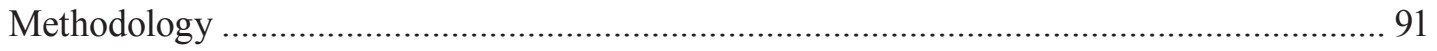

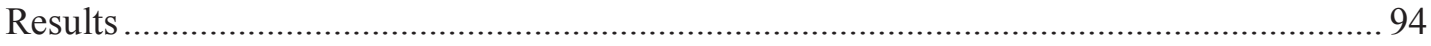

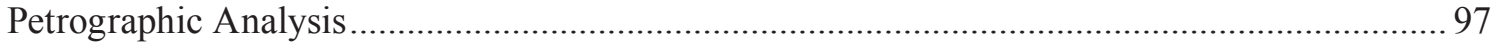

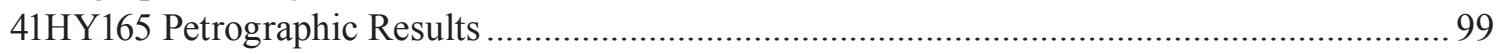

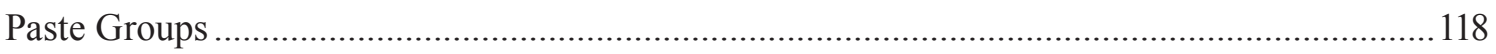

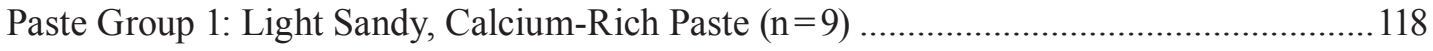

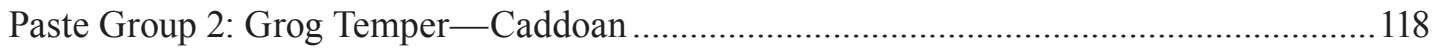

Paste Group 3: Sandy Paste ( $n=5)$; (Sand 14-24\%; Bone 5-20\%) .......................................119

Paste Group 4: Slightly Sandy, Calcium-Rich Paste $(n=6)$; (Sand 6-12\%; Bone

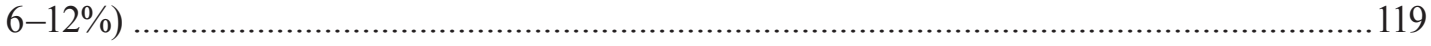

Paste Group 5: Light Sandy, Dense Paste_-No Calcite (Sand 3-4.5\%; Bone 10-23\%).......119

Paste Group 6: Sandy, Chert, and Feldspar-Rich Paste-Unknown No Bone ......................119

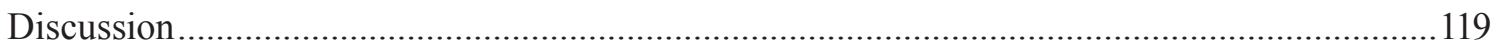

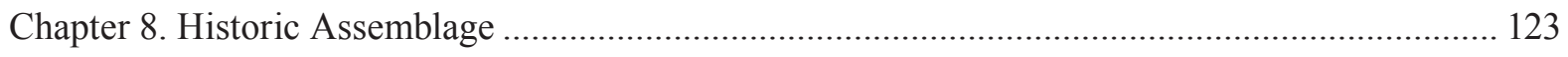




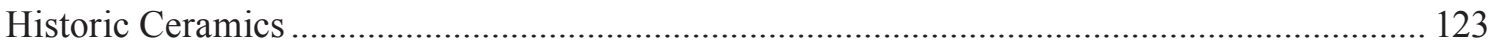

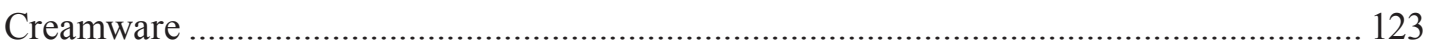

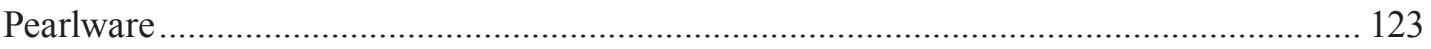

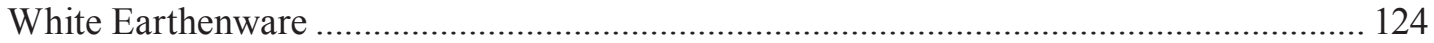

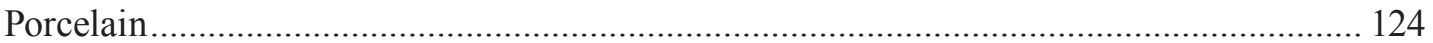

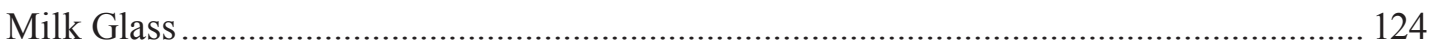

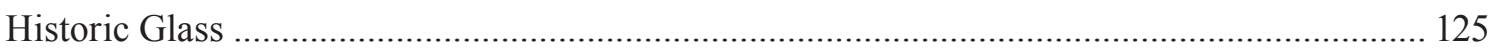

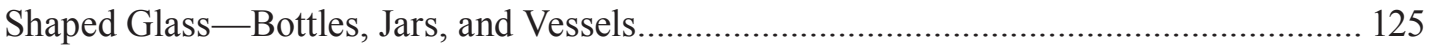

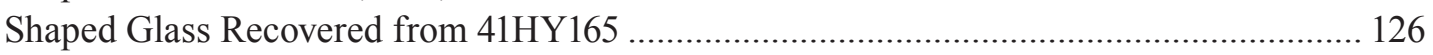

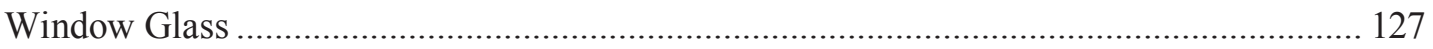

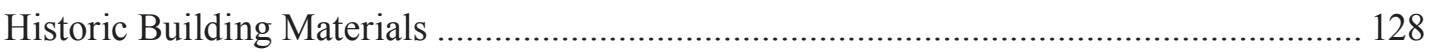

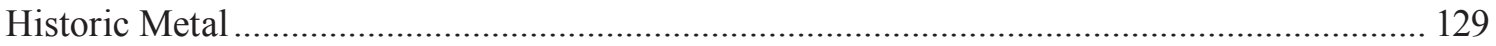

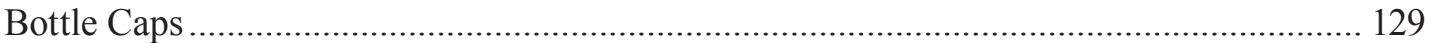

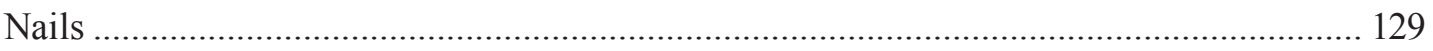

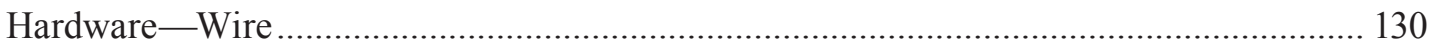

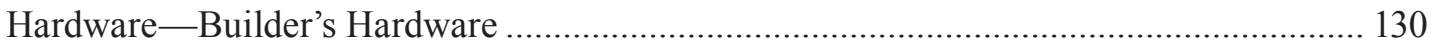

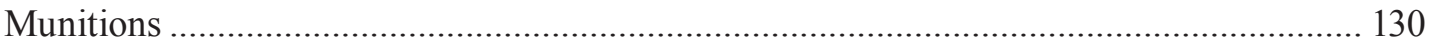

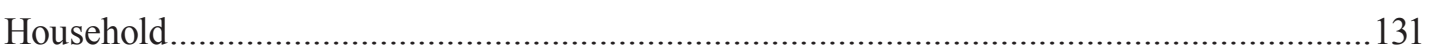

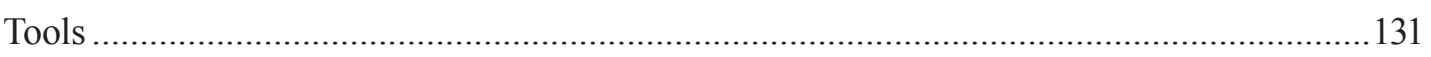

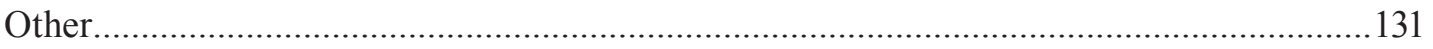

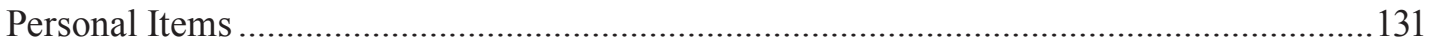

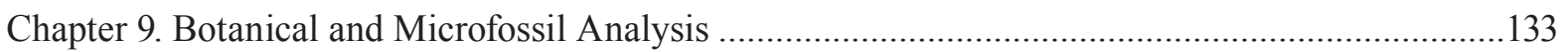

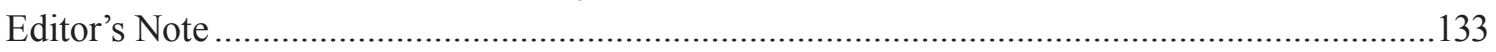

Plant Remains from 41HY165, a Prehistoric Site in Hays County, Texas.................................133

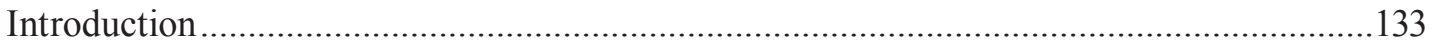

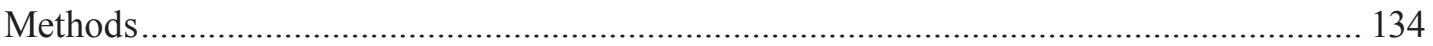

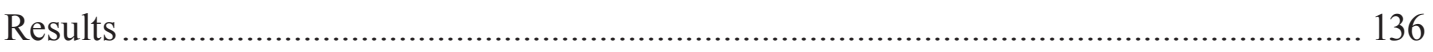

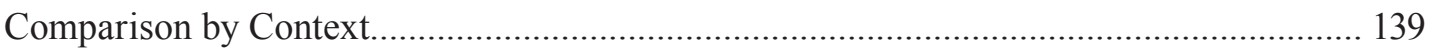

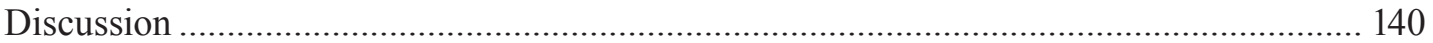

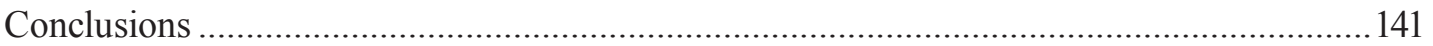

Microfossil Analysis of Fire-Cracked Rock Samples from 41HY165, Hays County, Texas .......142

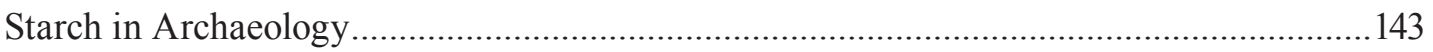

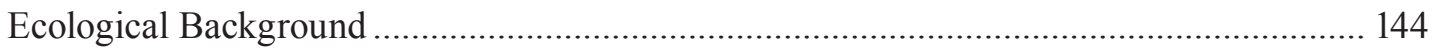

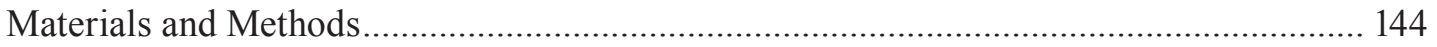

Starch Reference Collection ........................................................................................ 145

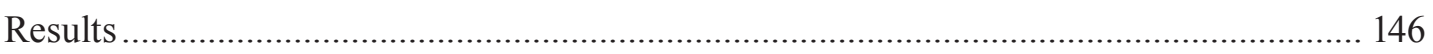

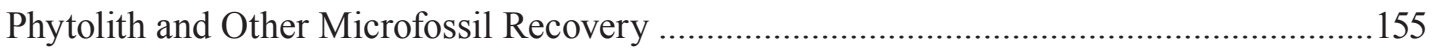

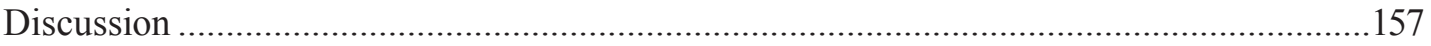

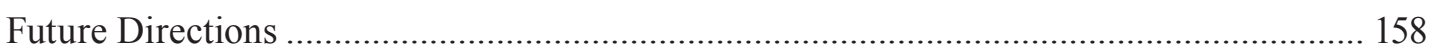

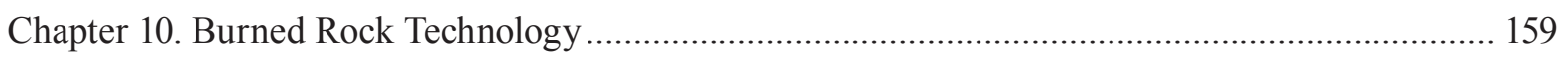

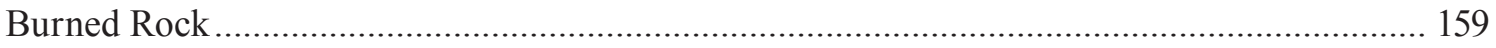

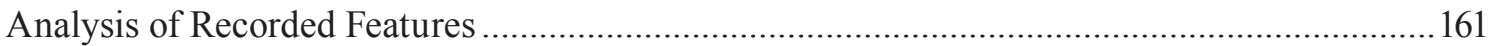

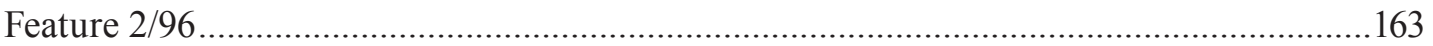

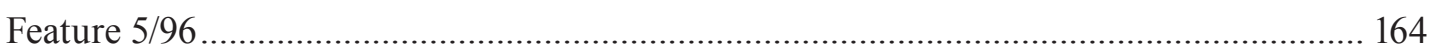

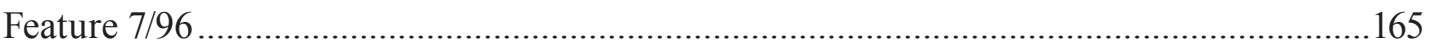




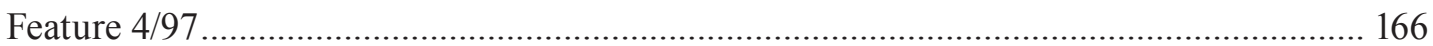

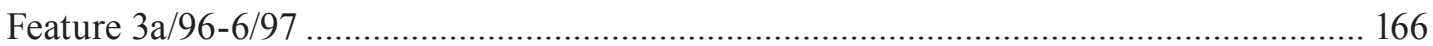

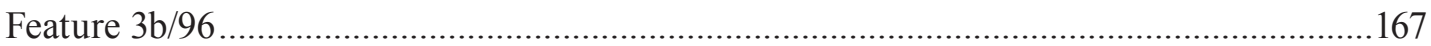

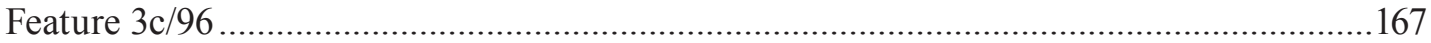

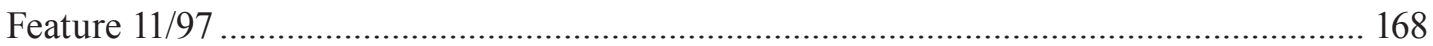

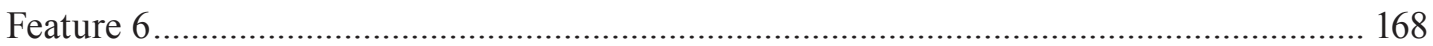

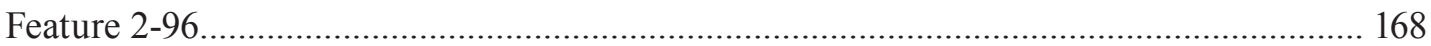

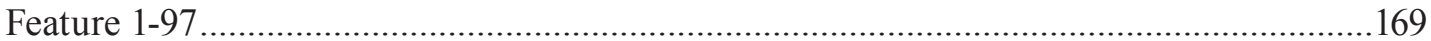

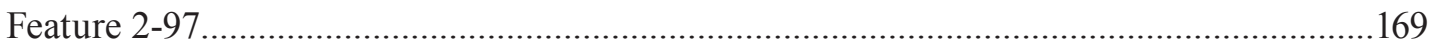

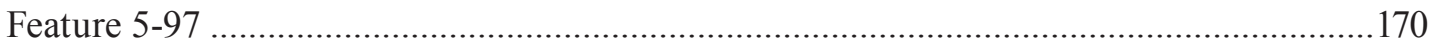

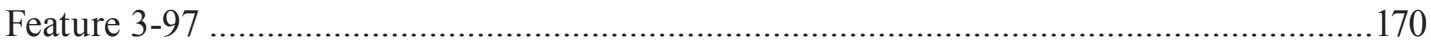

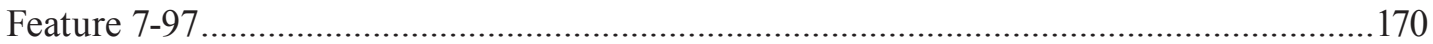

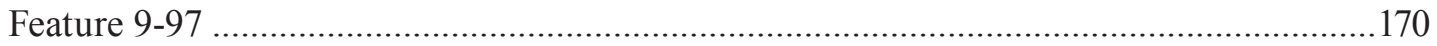

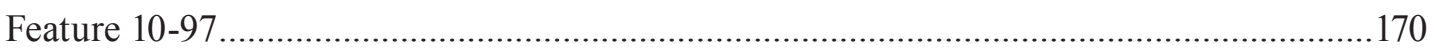

Chapter 11. Zooarchaeological Analysis of Time-Controlled Material from 41HY165 ….................173

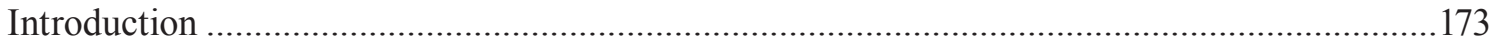

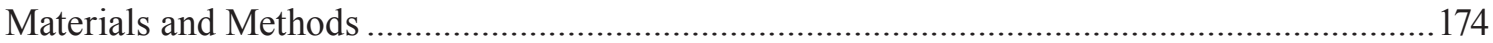

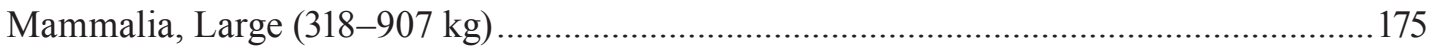

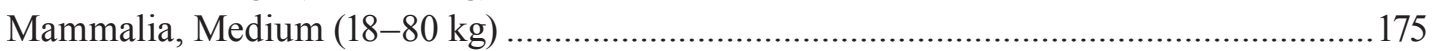

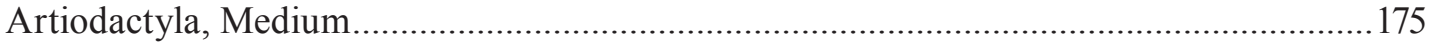

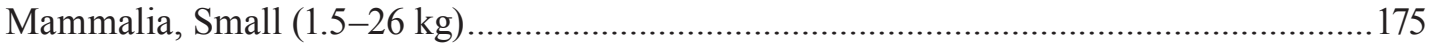

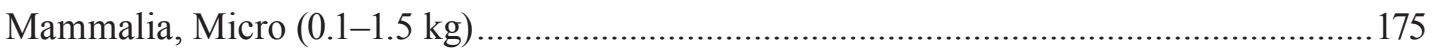

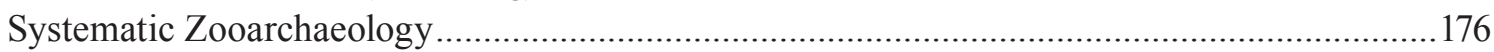

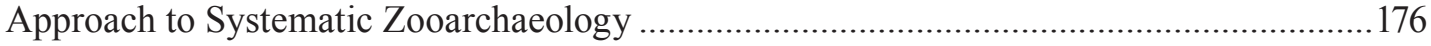

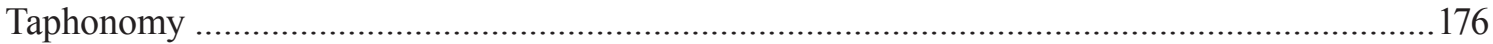

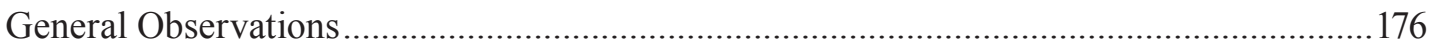

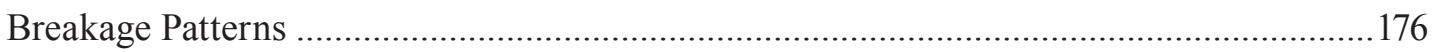

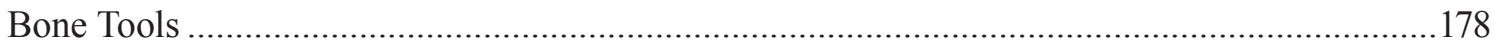

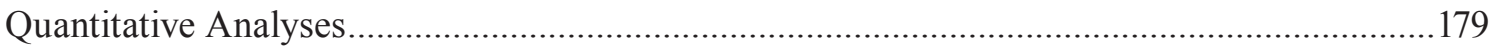

Number of Identifiable Specimens Present (NISP) and Minimum Number of

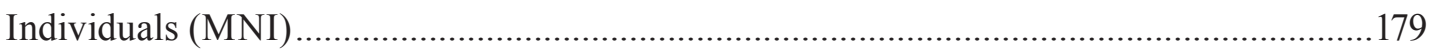

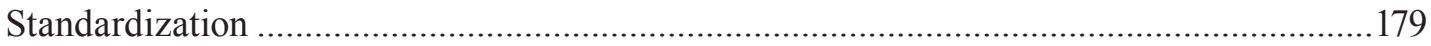

Systematic Comparison of Taxonomic Groups with Burned Rock Proxy............................183

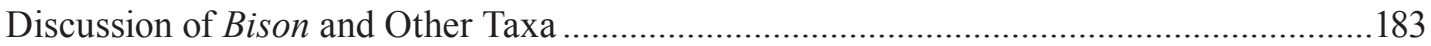

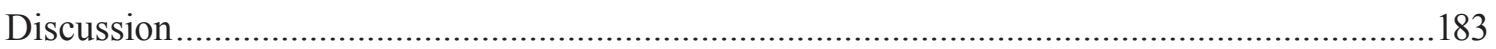

Changes in Faunal Composition Through Time: A Discussion of Fauna by AU .................183

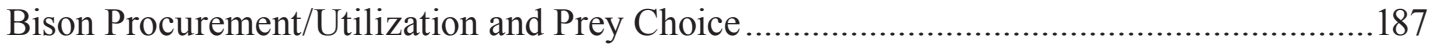

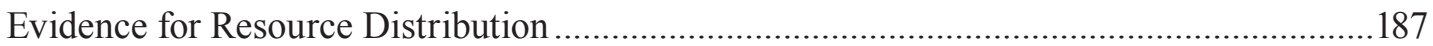

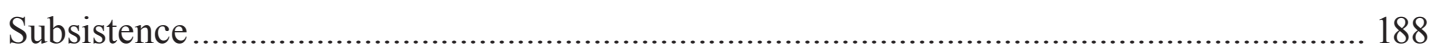

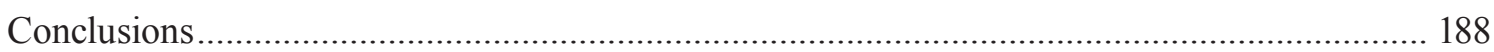

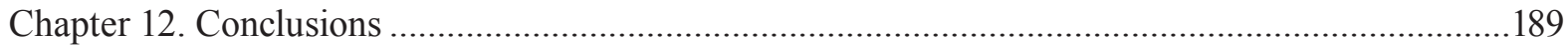

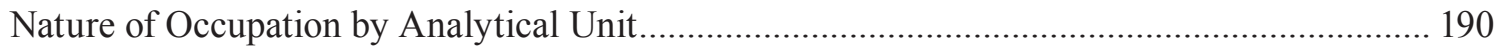

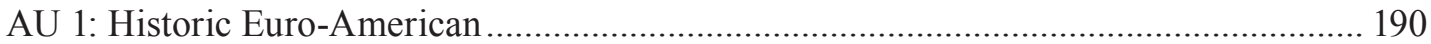

AU 2: Protohistoric Native American...................................................................... 190

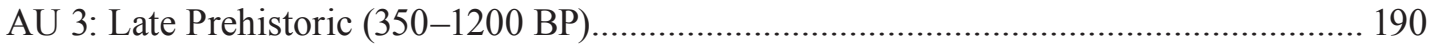




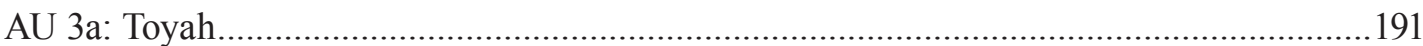

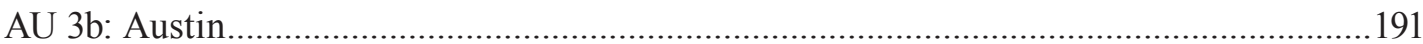

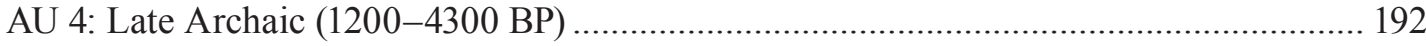

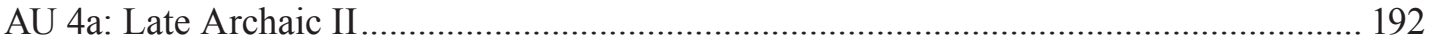

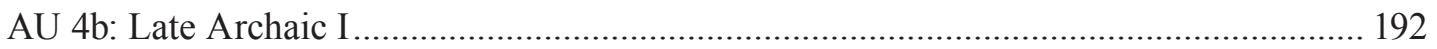

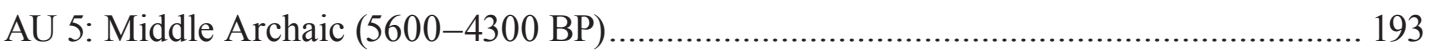

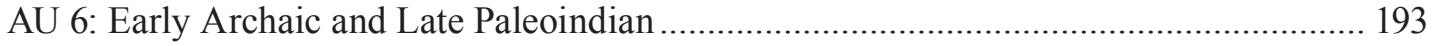

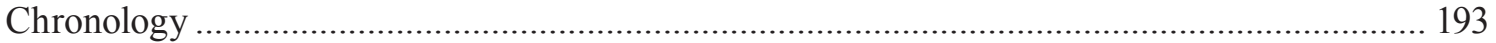

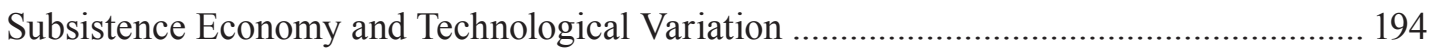

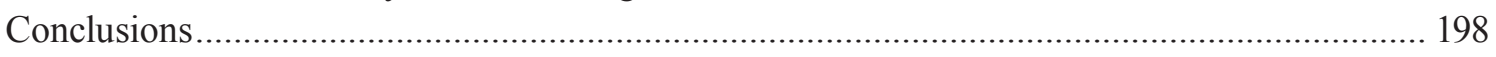

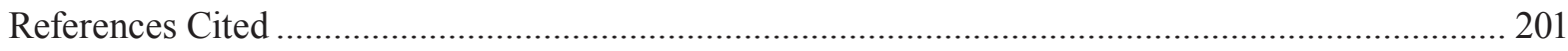

Appendix A. Inventory of Artifacts from Analytical Units ...................................................... 235

Appendix B. Radiocarbon Assays from 41HY165 Excavations ...................................................... 259

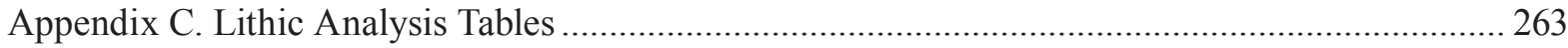

Appendix D. Petrographic Analysis Coding Sheet....................................................................... 281

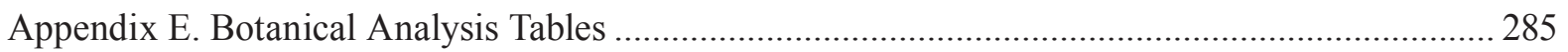

Appendix F. Systematic Catalog of Taxa Identified at 41HY165.................................................... 301 


\section{LiST OF FiguRES}

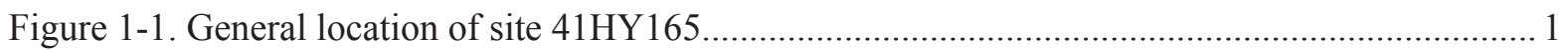

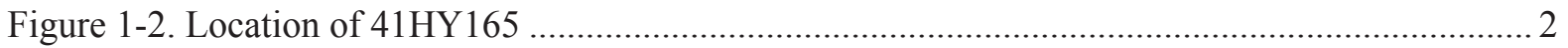

Figure 2-1. Natural regions of Texas with Hays County inset........................................................... 7

Figure 2-2. Soils mapped at Spring Lake and 41HY165 ….......................................................... 9

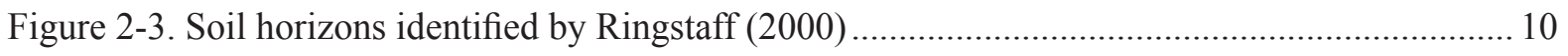

Figure 2-4. Reconstructed geoarchaeological cross section of Sink Creek Valley, looking upstream, illustrating alluvial units and their expected prehistoric preservation (redrawn from Nordt 2010:Figure 6-8)..................................................................... 11

Figure 3-1. Previously recorded archaeological sites adjacent to 41HY165. Dashed line boundaries are recent updates resulting from the SLAERP survey and testing project.

Figure 4-1. Summed probabilities of 55 AMS assays on bison remains from 41HY160, 41HY163, 41HY165, and 41HY188

Figure 4-2. Different kinds of earth oven cooking features. Courtesy of Alston Thoms (Thoms 2008:Figure 3)

Figure 5-1. Site map of 41HY165 showing excavation units (image digitized from map in

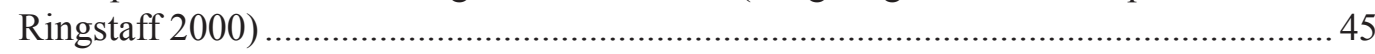

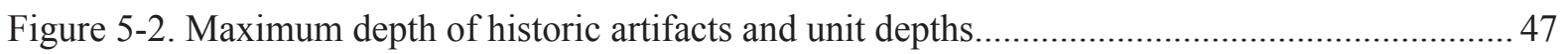

Figure 5-3. SLAERP XU 3 in relation to 1996-1998 excavated field school units ............................ 56

Figure 6-1. Late Paleoindian projectile points: A) Big Sandy; B) Golondrina.................................... 58

Figure 6-2. Early Archaic projectile points: A) Untyped Early Archaic Split-Stemmed;

B) Gower; C) Untyped Early Archaic Stemmed .............................................................5 59

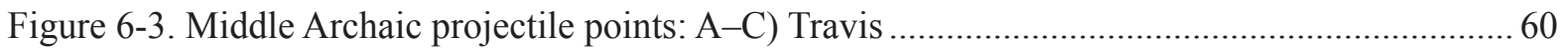

Figure 6-4. Late Archaic I projectile points: A-C, E) Pedernales; D) Morhiss ................................... 61

Figure 6-5. Late Archaic II projectile points: A, B, E) Fairland; C, D, F, G, I, J) Ensor; H) Frio ........ 62

Figure 6-6. Late Archaic II projectile points: A, B) Marcos; C) Ellis; D) Montell ............................. 63

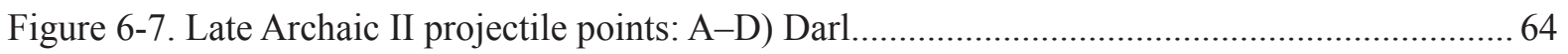

Figure 6-8. Late Prehistoric-Austin projectile points: A) Edwards; B, C) Scallorn............................. 64

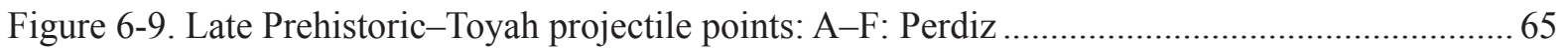

Figure 6-10. Protohistoric/Historic Native American Guerrero projectile point ................................ 65

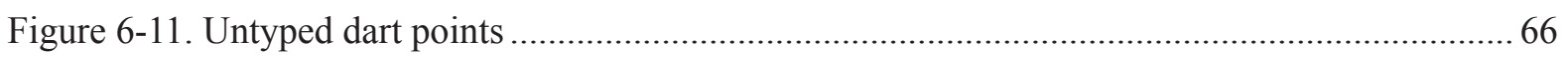

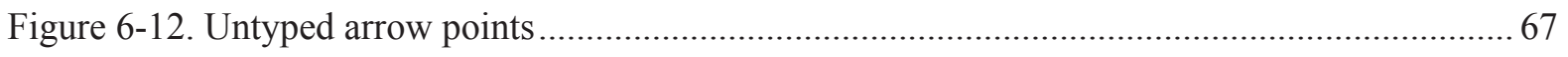

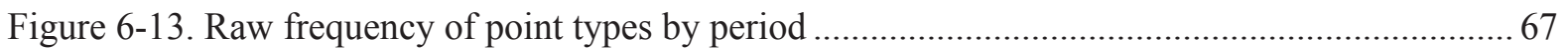

Figure 6-14. Relative intensity of site occupation by period as indicated by discard frequency ......... 69

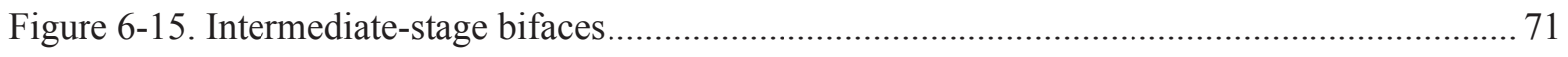

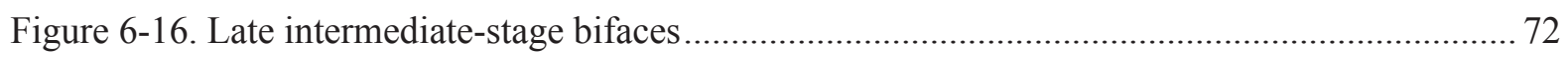


Figure 6-17. Late-stage bifaces.

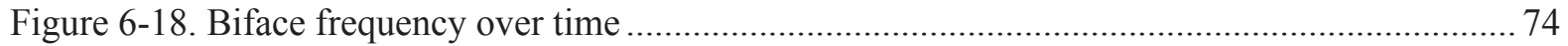

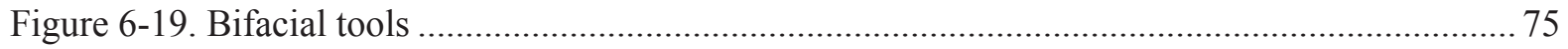

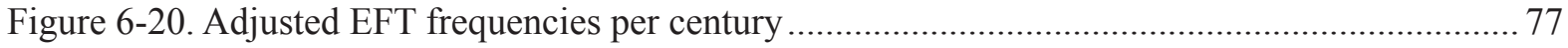

Figure 6-21. Average percentages of utilized or modified edge to potential edge on EFTs by

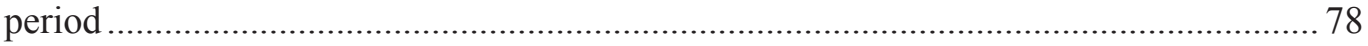

Figure 6-22. Frequency of flake types as tools (percentage of flake types to the total tool count

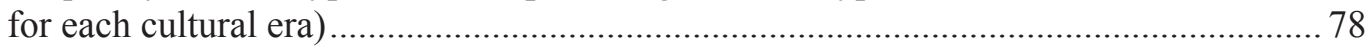

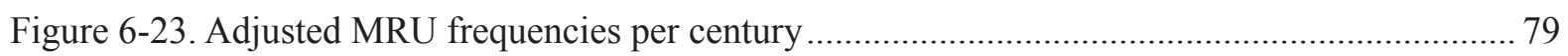

Figure 6-24. Average percentages of modified edge to potential edge on MRUs by period ................ 79

Figure 6-25. Minimally retouched unifaces: A, C-E) MRUs on blade-like flakes; A-E) spurring

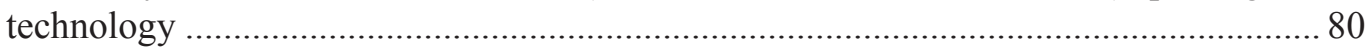

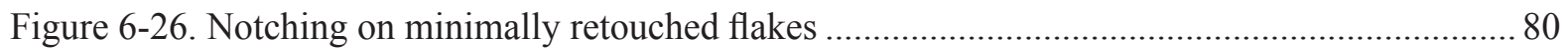

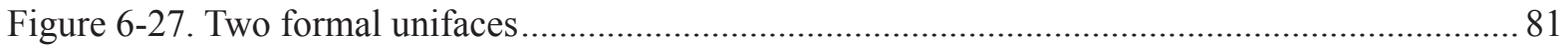

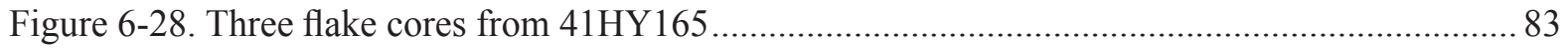

Figure 6-29. Thinning (including billet) vs. non-thinning flakes per century for each period ............. 85

Figure 6-30. Billet flakes (DEB and r) per century for each period ................................................. 86

Figure 6-31. Adjusted frequencies of different flake types ............................................................. 86

Figure 6-32. Percentage of complete flakes that are thinning flakes (not including billet) for

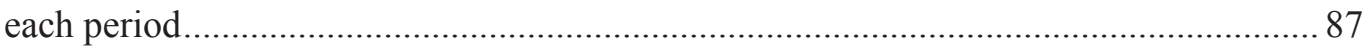

Figure 6-33 Percentage of complete flakes that are non-thinning flakes for each period.................... 87

Figure 6-34. Percentage of complete flakes that are billet flakes for each period .............................. 88

Figure 7-1. Paste of Thin Section No. 10-A 1 in plane light 4x......................................................... 99

Figure 7-2. Paste of Thin Section No. 10-A 1 in cross-polar light 4x ............................................... 99

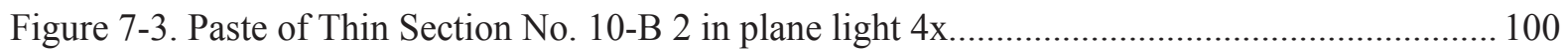

Figure 7-4. Paste of Thin Section No. 10-B 2 in cross-polar light 4x ........................................... 100

Figure 7-5. Paste of Thin Section No. 11-A 3 in plane light 4x........................................................ 101

Figure 7-6. Paste of Thin Section No. 11-A 3 in cross-polar light 4x.............................................. 101

Figure 7-7. Paste of Thin Section No. 11-B 4 in plane light 4x...................................................... 102

Figure 7-8. Paste of Thin Section No. 11-B 4 in cross-polar light 4x.............................................. 102

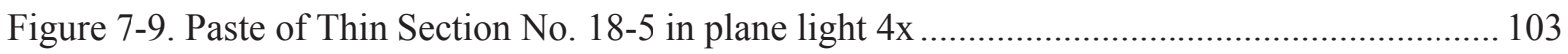

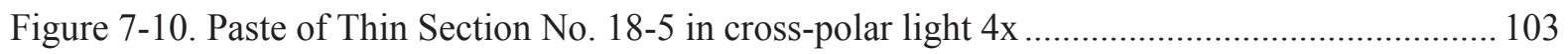

Figure 7-11. Paste of Thin Section No. 26-6 in plane light 4x ...................................................... 104

Figure 7-12. Paste of Thin Section No. 26-6 in cross-polar light 4x ............................................... 104

Figure 7-13. Paste of Thin Section No. 62-A 7 in plane light 4x..................................................... 105

Figure 7-14. Paste of Thin Section No. 62-A 7 in cross-polar light 4x ........................................... 105

Figure 7-15. Paste of Thin Section No. 62-B 8 in plane light 4x..................................................... 105

Figure 7-16. Paste of Thin Section No. 62-B 8 in cross-polar light $4 \mathrm{x}$............................................. 105 
Figure 7-17. Paste of Thin Section No. 86-9 in plane light $4 x$ 106

Figure 7-18. Paste of Thin Section No. 86-9 in cross-polar light 4x ................................................ 106

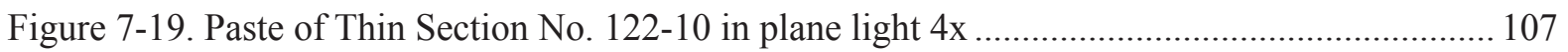

Figure 7-20. Paste of Thin Section No. 122-10 in cross-polar light 4x ............................................ 107

Figure 7-21. Paste of Thin Section No. 133-11 in plane light 4x .................................................. 108

Figure 7-22. Paste of Thin Section No. 133-11 in cross-polar light 4x ........................................... 108

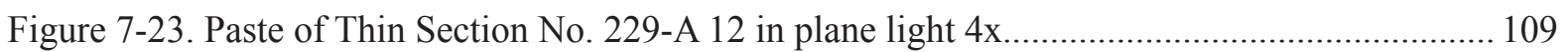

Figure 7-24. Paste of Thin Section No. 229-A 12 in cross-polar light 4x ........................................ 109

Figure 7-25. Paste of Thin Section No. 229-B 13 in plane light 4x................................................. 109

Figure 7-26. Paste of Thin Section No. 229-B 13 in cross-polar light 4x ........................................ 109

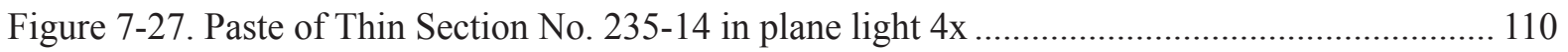

Figure 7-28. Paste of Thin Section No. 235-14 in cross-polar light 4x ........................................... 110

Figure 7-29. Paste of Thin Section No. 253-A 15 in plane light 4x................................................ 111

Figure 7-30. Paste of Thin Section No. 253-A 15 in cross-polar light 4x ........................................ 111

Figure 7-31. Paste of Thin Section No. 253-B 16 in plane light 4x................................................ 112

Figure 7-32. Paste of Thin Section No. 253-B 16 in cross-polar light 4x ....................................... 112

Figure 7-33. Paste of Thin Section No. 296-17 in plane light 4x ..................................................... 112

Figure 7-34. Paste of Thin Section No. 296-17 in cross-polar light 4x …......................................... 112

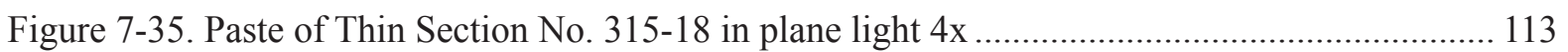

Figure 7-36. Paste of Thin Section No. 315-18 in cross-polar light 4x ........................................... 113

Figure 7-37. Paste of Thin Section No. 316-19 in plane light 4x .................................................... 114

Figure 7-38. Paste of Thin Section No. 316-19 in cross-polar light 4x ........................................... 114

Figure 7-39. Paste of Thin Section No. 339-20 in plane light 4x .................................................. 115

Figure 7-40. Paste of Thin Section No. 339-20 in cross-polar light 4x ........................................... 115

Figure 7-41. Paste of Thin Section No. 347-21 in plane light 4x ................................................... 116

Figure 7-42. Paste of Thin Section No. 347-21 in cross-polar light 4x .......................................... 116

Figure 7-43. Paste of Thin Section No. 381-22 in plane light 4x .................................................. 116

Figure 7-44. Paste of Thin Section No. 381-22 in cross-polar light 4x ............................................ 116

Figure 7-45. Paste of Thin Section No. 492-23 in plane light 4x .................................................... 117

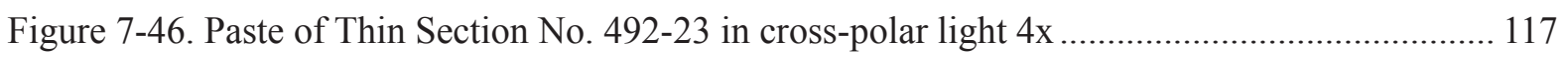

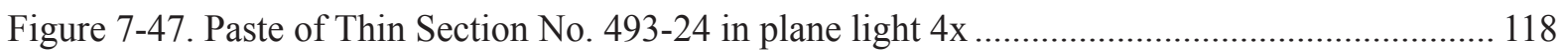

Figure 7-48. Paste of Thin Section No. 493-24 in cross-polar light 4x .......................................... 118

Figure 9-1. Micrographs of starch granules from geophytes, magnified 400x: A) Brightfield micrograph of Callirhoe involucrata; B) Brightfield micrograph of Liatris mucronata; C) Brightfield micrograph of Cooperia drummondi; D) cross-polarized light micrograph of Claytonia virginica; E) $1 / 4 \lambda$ retarded cross-polarized light micrograph of Erythronium sp.; F) Brightfield micrograph of Nothoscordum bivalve; G) Brightfield micrograph of Smilax sp 
Figure 9-2. Micrographs of starch from seeds and meristem, magnified 400x: A) Brightfield micrograph of Amaranthus sp.; B) cross-polarized light micrograph of Carex Comosa; C) Brightfield micrograph of Opuntia sp.; D) cross-polarized light micrograph of Prosopis glandulosa; E) Brightfield micrograph of Yucca bacata caudex; F) $1 / 4 \lambda$ retarded cross-polarized light micrograph of Yucca bacata leaf meristem

Figure 9-3. Cross-polarized light micrographs of starch granules from grass seeds, magnified 400x: A) Achnatherum hymenoides; B) Andropogon gerardii; C) Setaria lutescens;

D) Panicum sonorum; E) Sporobolus asper....

Figure 9-4. Micrographs of starch granules from FCR samples, magnified 400x: A) cf. Hordeum sp.; B) cf. Polygonum sp.; C) cf. Yucca sp.; D) cf. Araceae

Figure 9-5. Micrographs of unknown starch granules from FCR samples, magnified 400x: A) Unknown A; B) Unknown B; C) Unknown C; D) Unknown D

Figure 9-6. Micrographs of damaged starch granules from FCR samples, magnified 400x: A) Specimen 256-23; B) Specimen 164-8; C) Specimen 164-8; D) Specimen 69-13 ....... 154

Figure 9-7. Micrographs of phytoliths from FCR samples, magnified 400x: A) bilobate shape; B) elongate shape; C) saddle shape; D) calcium oxalate stylus

Figure 9-8. Micrographs of plant tissue from FCR samples, magnified 400x: A) cf. Yucca sp. epidermal tissue; B) unknown parenchymous tissue; C) unknown epidermal tissue.... 156

Figure 10-1. Standard vs. normal burned rock frequency ............................................................. 160

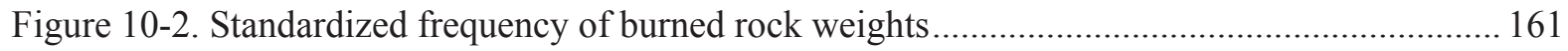

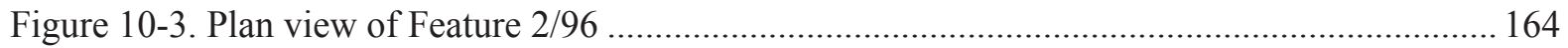

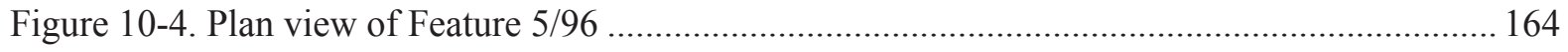

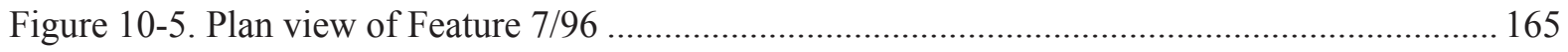

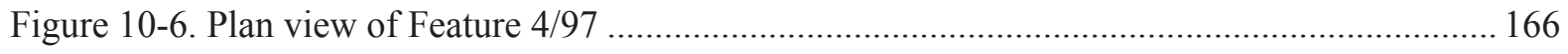

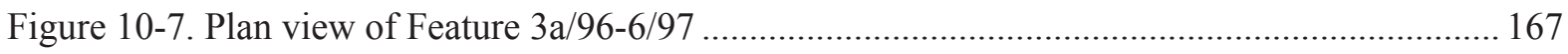

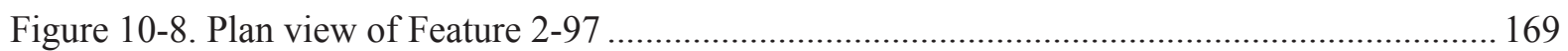

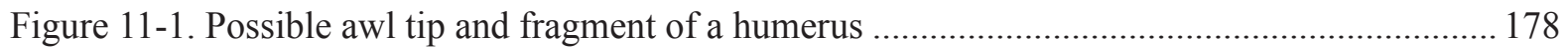

Figure 11-2. Standardized NISP compared to standardized mass of burned rock from 41HY165 ... 180

Figure 11-3. Standardized mass of faunal material from 41HY165 ............................................... 181

Figure 11-4. Comparison of standardized NISP of bison and all large and medium game

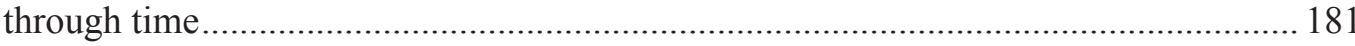

Figure 11-5. Standardized values for bison, small mammals, and burned rock .............................. 182

Figure 11-6. Standardized values for bison, non-mammalian lower vertebrates, and burned rock.... 182 


\section{LiST OF TABLES}

Table 3-1. Previously Recorded Archaeological Sites

Table 4-1. Archaeological Chronology for Central Texas (after Prewitt 1981, 1983) ....................... 33

Table 5-1. AUs Associated with Diagnostic Projectile Points .............................................................. 48

Table 5-2. AUs Associated with Bison Bone Dates............................................................................... 48

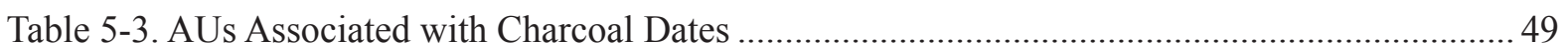

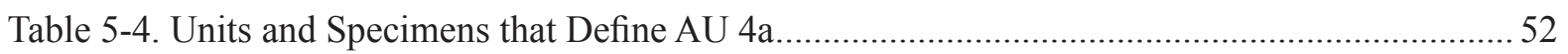

Table 5-5. Artifact Classes and Types Used for This Project............................................................... 55

Table 6-1. Projectile Point Recovery by Period (Untyped Early Archaic Points Included) ................. 68

Table 6-2. Site Occupation Intensity by Period As Determined by Discard Rate ............................... 69

Table 6-3. Raw and Standardized Frequencies of Biface Categories by Period................................... 74

Table 6-4. Raw and Adjusted Expedient Flake Tool Frequencies .................................................... 77

Table 6-5. Raw and Adjusted Minimally Retouched Uniface Frequencies ........................................ 79

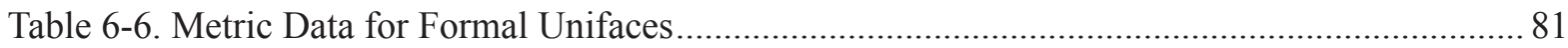

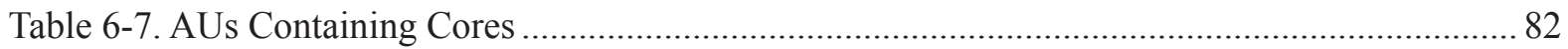

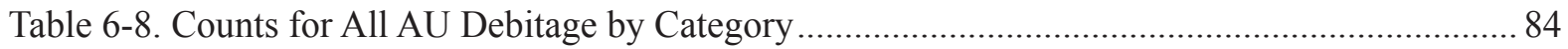

Table 6-9. Raw and Adjusted Frequencies of Complete Flake Types................................................. 85

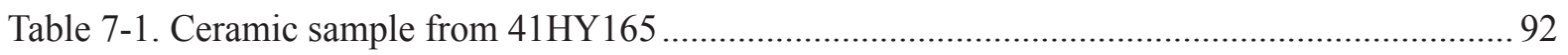

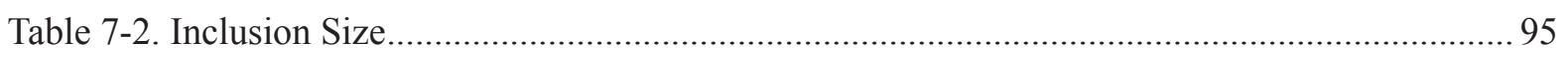

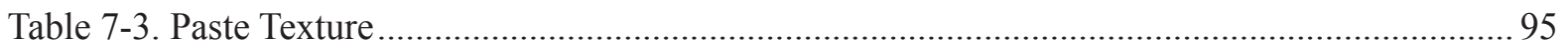

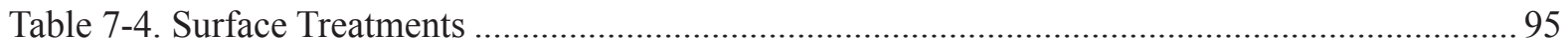

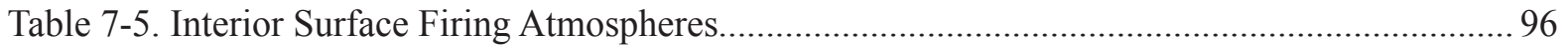

Table 7-6. Exterior Surface Firing Atmospheres ........................................................................... 96

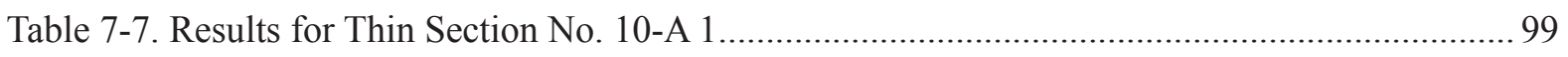

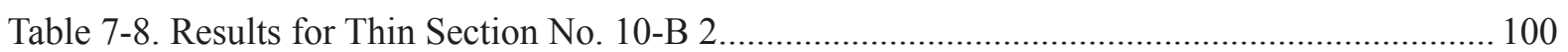

Table 7-9. Results for Thin Section No. 11-A 3 .................................................................................. 101

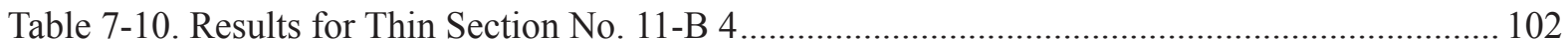

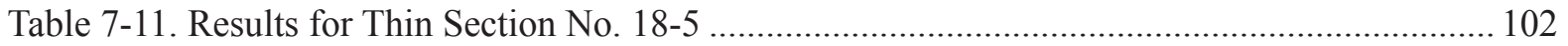

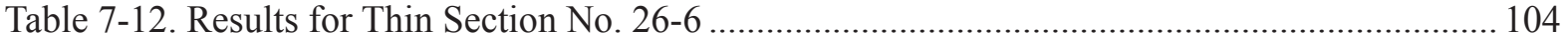

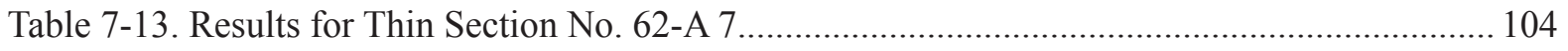

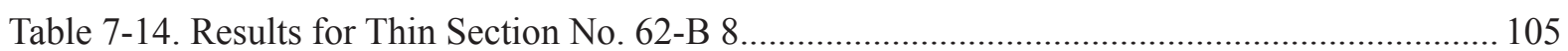

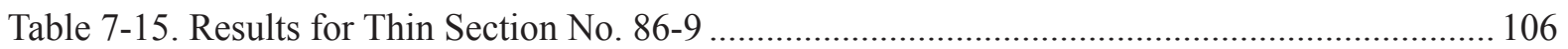

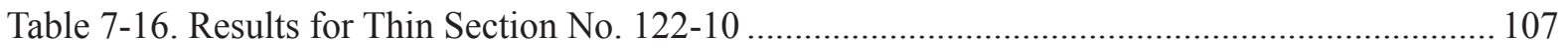

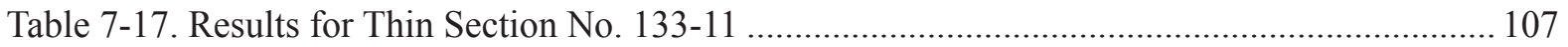

Table 7-18. Results for Thin Section No. 229-A 12 .................................................................... 108 
Table 7-19. Results for Thin Section No. 229-B 13 109

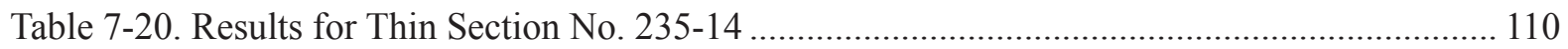

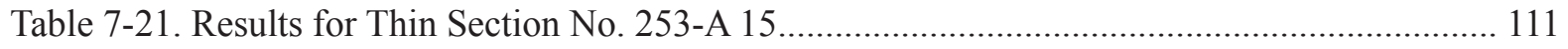

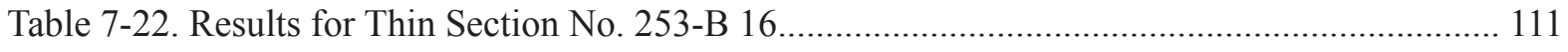

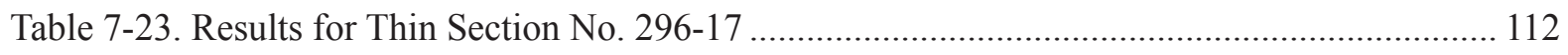

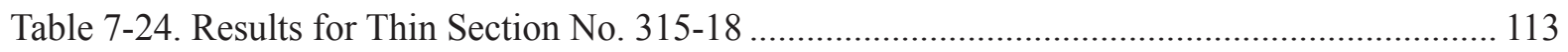

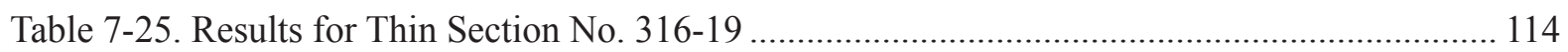

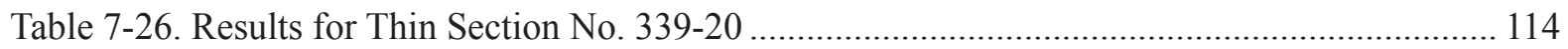

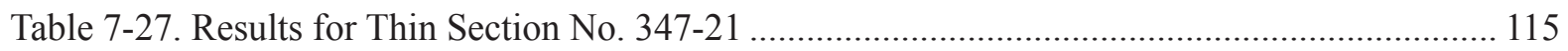

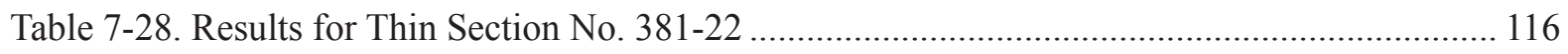

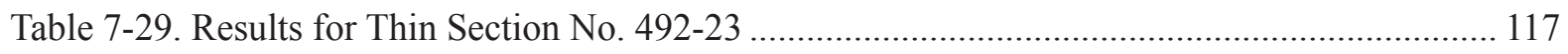

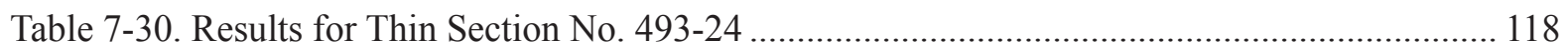

Table 8-1. Ingredients Added to Glass to Produce Color (after Munsey 1970:37)........................... 125

Table 9-1. Botanical Samples Analyzed from Test Unit 3 at 41HY165 ........................................... 135

Table 9-2. Plant Taxa Recovered from 41HY165 Column Samples ............................................... 136

Table 9-3. Carbonized and Uncarbonized Plant Remains from XU 3 ........................................... 139

Table 9-4. Burned Rock Specimens Submitted for Microfossil Analysis ......................................... 142

Table 9-5. Measurements of Starch Granules from Modern Botanical References........................... 147

Table 9-6. Measurements and Identification of Starch Granules from FCR Samples ....................... 151

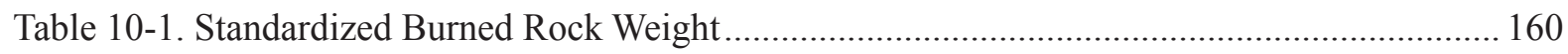

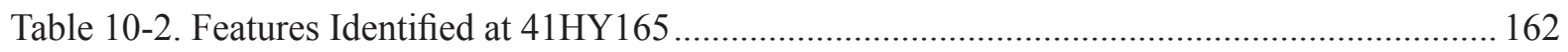

Table 11-1. Taxonomic Classification List with NISP and Mass Data ............................................ 177

Table 11-2. Raw and Standardized Values of NISP and Mass, AU Duration, and Volume ................ 180

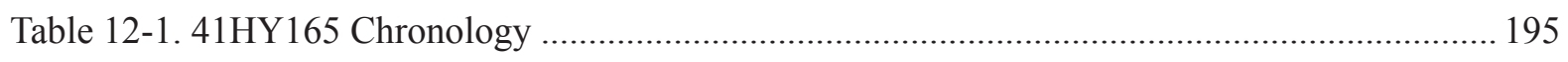

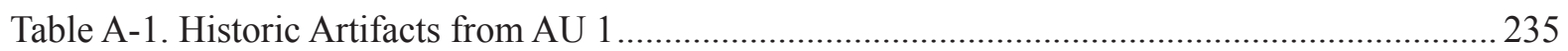

Table A-2. Historic Native American Artifacts from AU 2 …........................................................... 236

Table A-3. Late Prehistoric, Toyah Phase Artifacts from AU 3a .................................................... 238

Table A-4. Late Prehistoric, Austin Phase Artifacts from AU 3b ................................................... 241

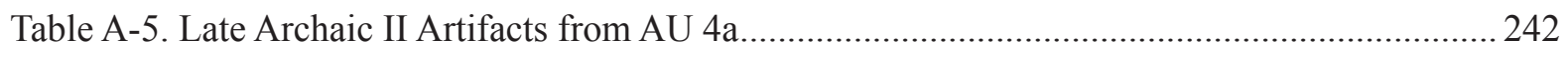

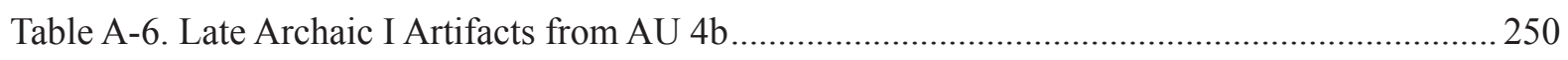

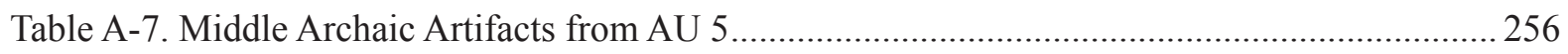

Table B-1. Radiocarbon Assays from 41HY165 Excavations ....................................................... 260

Table C-1. Metric Data for Typed Projectile Points............................................................................. 264

Table C-2. Metric Data for Untyped Projectile Points..................................................................... 267

Table C-3. Observed Data for Typed Projectile Points ..................................................................... 268

Table C-4. Observed Data for Unyped Projectile Points …............................................................. 270

Table C-5. Metric Measurements for Reduction-Stage Bifaces ..................................................... 271 
Table C-6. Metric Measurements for Biface Fragments.

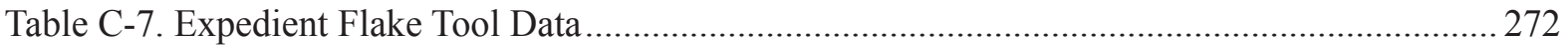

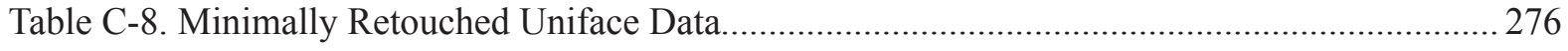

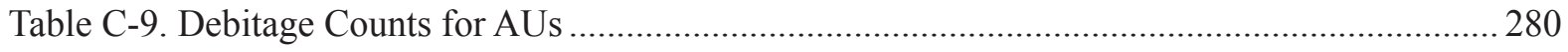

Table E-1. Plant Remains Recovered from Flotation Samples at 41HY165 .................................. 286

Table E-2. Plant Remains Recovered from Waterscreen Samples at 41HY165 ...............................293

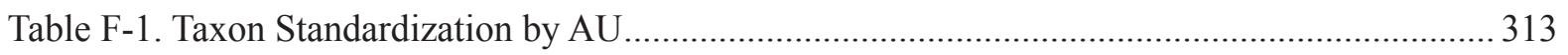


xviii 


\section{List of AbBreviations}

AEL Archaeological Ecology Laboratory, Texas A\&M University

AMS accelerator mass spectrometry

APE $\quad$ area of potential effect

ARL Archaeological Research Laboratory, The University of Tennessee, Knoxville

AU analytical unit

BP before present

CAR Center for Archaeological Research, The University of Texas at San Antonio

CAS Center for Archaeological Studies, Texas State University-San Marcos

$\mathrm{cm} \quad$ centimeters

cmbd centimeters below datum

cmbs centimeters below ground surface

CTA Council of Texas Archaeologists

DEB distinctive expanding billet

EFT expedient flake tool

FCR fire-cracked rock

g gram

kg kilogram

m meter

mbs meters below ground surface

$\mathrm{mm} \quad$ millimeter

MNI minimum number of individuals

MRU minimally retouched uniface

MURR Missouri University Research Reactor

NISP number of identified specimens

PEM Potential Edge Modification 
RCYBP radiocarbon years before present

SAL State Antiquities Landmark

SLAERP Spring Lake Section 206 Aquatic Ecosystem Restoration Project

SWT Southwest Texas State University (now Texas State University-San Marcos)

Texas State Texas State University-San Marcos (formerly Southwest Texas State University)

TEM Total Edge Modification

THC Texas Historical Commission

TPWD Texas Parks and Wildlife Department

USACE US Army Corps of Engineers

USDA-NDL U.S. Department of Agriculture, Agricultural Research Service, Nutrient Data Laboratory

USDA-NRCS U.S. Department of Agriculture-Natural Resources Conservation Service

UTSA The University of Texas at San Antonio 


\section{Chapter 1}

\section{INTRODUCTION}

\section{By John A. Campbell}

\section{Project History}

Site 41HY165 is a deeply buried, multicomponent assemblage of artifacts and features spanning the last 10,000 years of human habitation in Central Texas. The site is located on the campus of Texas State University-San Marcos (Texas State) in San Marcos, Hays County, Texas (Figure 1-1). The site is situated at the confluence of Sink Creek and Spring Lake. Based on the

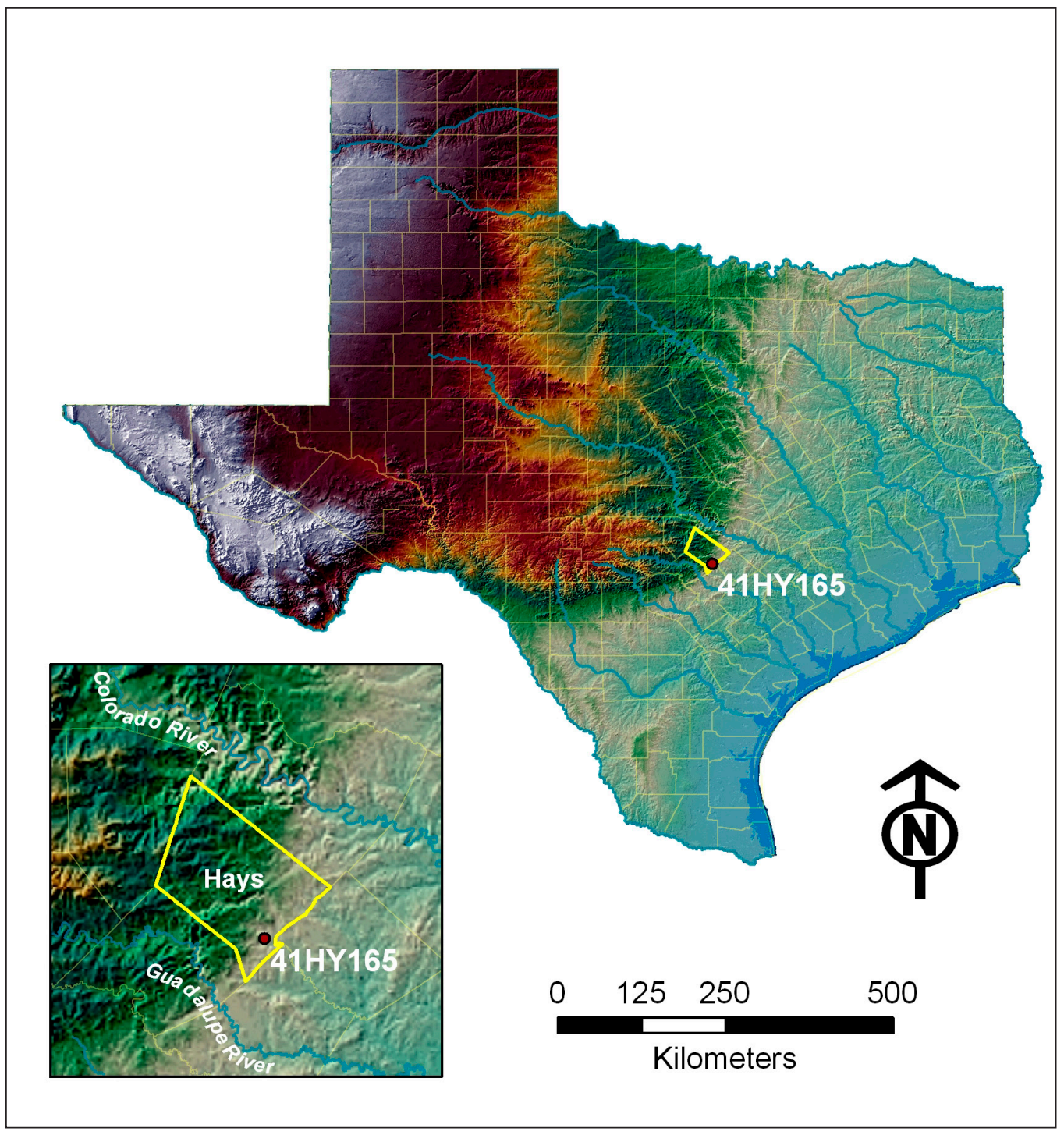

Figure 1-1. General location of site 41HY165. 
FIGURE 1-2. REDACTED

Figure 1-2. Location of 41HY165.

current limits of the manmade Spring Lake, the site occupies a small peninsula that extends out into the eastern half of the lake, and also extends around the south and west lake margins.

Both terrestrial and underwater archaeological investigations have been conducted on various sites in the Spring Lake area since the late 1970s. The first investigations at 41HY165 were conducted in 1984 by Dr. James Garber as part of a field school for Southwest Texas State University (SWT, now Texas State). A second field school was conducted on the site in 1988 by David Driver, along with Garber, and focused on testing and recording the site. Finally, three field schools were conducted on the site in 1996, 1997, and 1998 by Garber and Mary Kathryn Brown. During these three field schools, 11 test units were excavated over the eastern portion of the site. The results of the field investigations during these field schools were used as the basis for Christopher Ringstaff's (2000) Masters' thesis.

The 1996-1998 field schools appear to have been attended primarily by SWT students, with 22 students attending in 1996, 25 in 1997, and nine in 1998. Additionally, seven other individuals have been noted on the field recording forms; presumably, they were volunteers working on the site during non-field school sessions, most likely in support of Ringstaff's data collection for his thesis. Garber served as the Principal Investigator for the field school, with Brown as the field director and Ringstaff as a teaching assistant. In addition to the field excavations, the students also conducted limited laboratory work during inclement weather and attended lectures related to Texas prehistory.

Investigations into the site subsequent to the field school have been limited to analyses of the collections housed at the university and 
now curated with the Center for Archaeological Studies (CAS) at Texas State. The first analysis was conducted in May of 1998 by Jennifer Giesecke, who examined the faunal materials identified at the site in the 1996 and 1997 field seasons. This investigation was part of an independent study by Giesecke for Garber, with the assistance of Mike Quigg of TRC Mariah Associates, Inc. In a short paper summarizing her results, Giesecke stated that the analysis was only preliminary, and recommended additional analysis of the faunal materials from the site (Giesecke 1998). In 2002, undergraduate students processed flotation samples as part of a directed study. However, there is no documentation related to this study, and the only evidence that it occurred is limited to the inventory forms and bag labels of the processed samples. The only substantive reporting of the site was in the thesis prepared by Ringstaff as part of his graduate studies at SWT (Ringstaff 2000). While Ringstaff's thesis offers a relatively comprehensive study of the three field school seasons, the focus of his research is on the geoarchaeological properties of the site, and thus the attention given to the artifact assemblage and features is limited to that scope of his research.

Currently, there are no site maps, photos, or official field notes that exist for 41HY165. The only remaining materials for the site consist of the recovered artifact assemblage, level and feature forms, sketch maps, lab inventory forms, and student field journals from the 1997 field school. While these data are useful, the majority of the information was filled out by students, and is sometimes incomplete; furthermore, accuracy of the data is questionable. Given these existing data, the thesis prepared by Ringstaff currently serves as the best source of information regarding the investigations during 1996, 1997, and 1998.

As part of the Spring Lake Section 206 Aquatic Ecosystem Restoration Project
(SLAERP) being conducted in conjunction with the US Army Corps of Engineers (USACE) and Texas State, CAS conducted additional analyses and syntheses of the materials collected from 41HY165. The goals of this exercise were to assess the collections, synthesize that information within the broader research goals of the SLAERP, and finalize the existing defaulted permit with the Texas Historical Commission (THC). The current efforts began in February of 2010 by assessing the curated collection and resorting and cataloging the artifacts. After the catalog was compiled, a research design for the analysis of the artifacts and completion of the final report was compiled. This report summarizes the results of the investigations conducted by SWT during the 1996, 1997, and 1998 field school seasons, and the subsequent analysis and synthesis by CAS between 2010 and 2011.

\section{Summary of Work}

While two field schools were conducted prior to the 1996, 1997, and 1998 seasons, there is no formal accounting of those investigations aside from the recording of the site with the Texas Archeological Research Laboratory at The University of Texas at Austin. From the 1984 field season, there exist the unit level forms from two excavation units at the site, and some of the original laboratory inventory forms. No field forms or maps appear to exist from this season. In addition, the artifacts collected from the 1984 field season were added to the later collected artifacts from the late 1990s. As part of the current investigation into these collections, the 1984 assemblage has been separated from the later materials and curated at CAS. Nothing remains of the 1988 investigations, and there are no field notes, photos, maps, or drawings from either of the previous two field schools. Due to the uncertain provenience of the 1984 assemblage, 
and since those investigations do not fall under the current permit, it is not included in this report.

The collections from the 1996-1998 field schools include unit level forms for all units, unit level plan maps, artifact inventory sheets, and collected artifacts. Additionally, there are student field journals from the 1997 field school and Ringstaff's thesis. There are no site maps or photos in the collection from these field schools. However, Ringstaff (2000) provides maps in his thesis showing the general layout of excavation units and shovel tests. Based on the available data, it is possible to reconstruct the distribution of artifacts and features at the site; these reconstructions, supplemented with new radiometric dates, provide the basis for the present analysis.

\section{Regulatory Concerns}

The excavations conducted at 41HY165 during the 1996, 1997, and 1998 field schools were for educational purposes only, and not related to cultural resource management. At that time, there was no federal involvement with the investigations related to funding or regulation. However, site 41HY165 was and still is located on property owned by Texas State, and investigations during the 1996-1998 field schools were subject to the Antiquities Code of Texas (Title 9, Chapter 191 of the Texas Natural Resource Code of 1977, as revised). Therefore, Texas State was required under 13 TAC $26.3 \mathrm{~b}$ to apply for a Texas Antiquities Permit, issued by the THC. The permit was issued to Texas State as Texas Antiquities Permit No. 1700 on May 30, 1996, prior to initiating field investigations at the site. The term of the permit was for one year from the initiation date; it was renewed prior to its expiration for an additional year, to expire on December 1, 1998. The permit has since defaulted, and it is the goal of this report to close the permit for the SLAERP. Dr. James Garber is the Principal Investigator listed on the permit.

Currently, a portion of the area of potential effect (APE) for the SLAERP includes 41HY165. The SLAERP is subject to Section 206 of the Water Resources Development Act of 1996 and Section 106 of the National Historic Preservation Act of 1966, as amended. Archaeological investigations for the SLAERP are also being conducted under Texas Antiquities Permit No. 5582, as the property is still owned by Texas State. The analysis and reporting of the 19961998 field school investigations are primarily being conducted as part of the mitigation measures outlined in the SLAERP Historic Properties Treatment Plan. As a result, the current investigations of the field school collection are also subject to the federal regulations outlined above. All of the investigations outlined in this report were conducted in accordance with the Secretary of the Interior's Standards and Guidelines for Archaeology and Historic Preservation (48 FR 44716-44742), the Secretary's Standards for Identification (48 FR 44720-44723), the SLAERP Historic Properties Treatment Plan, and Texas Antiquities Permit No. 1700 and No. 5582.

\section{Organization of this Report and Personnel}

The report is organized into 12 chapters, including this introduction. The second chapter of the report deals with the site's environmental context and the land use history. The third chapter examines the site within the cultural context of Central Texas, and summarizes the previous investigations at 41HY165 and relevant sites in the Spring Lake area. The research design, including the general research goals of the SLAERP, defined analytical units, and the analytical approach to the assemblage, is provided in the fourth chapter. Chapter 5 discusses the analytical units 
and analytical approaches employed. Chapter 6 presents the lithic analysis conducted, while analysis of prehistoric ceramics is presented in Chapter 7. The Historic Assemblage is discussed in Chapter 8, and analysis of botanical and micofossil remains are presented in Chapter 9. Burned rock technology is discussed in Chapter 10, and zooarchaeology is discussed in Chapter 11. Finally, a synthesis and conclusions are presented in Chapter 12.

Dr. James Garber served as the Principal Investigator for this project from its inception, and Carole Leezer, Associate Director of CAS, served as the Principal Investigator for the SLAERP. The report was edited by Carole A. Leezer, with sections authored by John A. Campbell, Kandace D. Hollenbach, Carole A. Leezer, Jon C. Lohse, Lori B. Love, Amy E. Reid, Timothy E. Riley, Cinda Timperley, Steve Tomka, Kristi Ulrich, and David M. Yelacic. Dr. Jon C. Lohse, Director of CAS, and Ms. Leezer served as the supervising archaeologists throughout the current analysis and report writing. The laboratory work related to sorting, cataloging, and analysis of the collection was conducted by graduate and undergraduate student employees of CAS under the supervision of Ms. Leezer, Dr. Lohse, and Mr. Campbell. The laboratory workers include Jacob Hooge, Josh Hamilton, Veronica Suarez, Sarah Scoggins, Amy Reid, Brooke Boyer, Patricia Christmas, Stephanie Williams, and Katherine Pratt. The analysis of the faunal remains was conducted by Cinda Timperley with CAS. Prehistoric ceramics identified within the collection were analyzed by The University of Texas at San Antonio's (UTSA) Center for Archaeological Research (CAR). Radiocarbon samples were identified as to the type of plant material by Dr. Kandace D. Hollenbach at the Archaeological Research Laboratory (ARL) at The University of Tennessee, Knoxville, and dates from charred plant material and bison bone were obtained from the W. M. Keck Carbon Cycle Accelerator Mass Spectrometry Laboratory at the University of California-Irvine, in collaboration with Dr. Douglas Kennett at the University of Oregon. The microfossil analysis of the burned rocks was conducted by Dr. Timothy E. Riley at the Archaeological Ecology Laboratory (AEL) at Texas A\&M University. Our thanks also go to Christopher Ringstaff for providing additional information regarding the field schools.

\section{Goals}

The primary goal of the current research was to finalize the defaulted Texas Antiquities Permit that was obtained for the three field school seasons in 1996, 1997, and 1998. A secondary goal was to assess the collections from 41HY165 within the broader research framework established for the SLAERP, as well as for the previously investigated sites surrounding Spring Lake. As stated previously, the results of the current study are to be used as part of the mitigation efforts for the SLAERP. To accomplish this, the collected data were analyzed and synthesized with regard to the methodologies and research questions established during previous investigations of nearby sites. By using a similar methodology to previous investigations, it is hoped that the similarity in processes will allow for greater intra- and inter- site comparability and analysis at Spring Lake and Central Texas. 


\section{Chapter 2}

\section{Environmental Setting}

\section{By John A. Campbell and David M. Yelacic}

Site 41HY165 is located in San Marcos along Spring Lake, a unique and somewhat dynamic environment near the center of the Balcones Escarpment (Figure 2-1). Here, cool, fresh water issues forth from numerous artesian springs in lower Cretaceous limestone bedrock, and confluences with another springfed stream that also drains a portion of the EscarpmentCanyonlands ecotone, Sink Creek. These sources of water that draw and support vegetation, wildlife, and culture also serve as a mode to preserve the signatures of each. That is, this alluvial system is capable of encapsulating former ground surfaces that contain remnants of past lifeways. Understanding how this landscape changes through time, then, is an important part of understanding the archaeological record.

First, from Nordt (2010), who compiled geological data from across the Spring Lake peninsula and beyond, it is necessary to get an idea of the broad patterns and processes in landscape formation at this location. What Nordt found through the analysis of 22 geological cores was that the earliest extant phase of sedimentation in the valley begins around 11,470 \pm 100 radiocarbon years before present (RCYBP). From a series of cores recently removed from sediments composing the lake bottom (Leezer et al. 2011), two other late Pleistocene dates (i.e., $13,155 \pm 65$ [wood] and 19,160 \pm 140 [bulk humate]

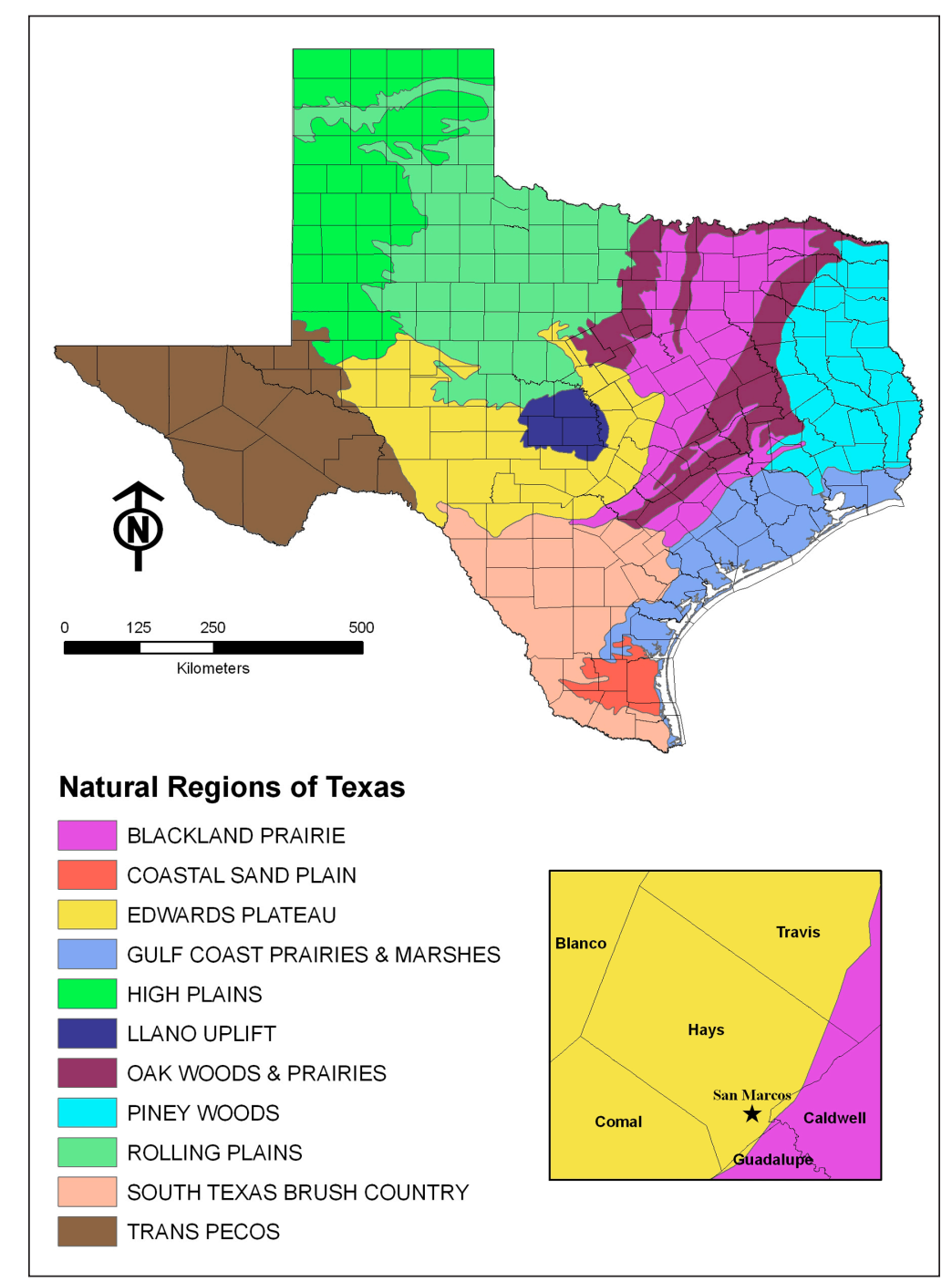

Figure 2-1. Natural regions of Texas with Hays County inset. 
RCYBP) were recovered, which suggest that there are at least patches of sediment predating the late Pleistocene entrenchment and sediment aggradation observed by Nordt. In any event, late Pleistocene to early Holocene sediment accumulation in a wet, marshy environment was terminated by channel entrenchment and subsequent overbank sediment accumulation by approximately 7365 RCYBP. Rapid sedimentation persists through a period of time from approximately 5900 to 3300 RCYBP, and likely represents a relatively dramatic change in the nature of the fluvial system. After 3300 RCYBP, depositional rates diminish, and geomorphology slowly develops into the present landscape.

From a series of excavation units near the confluence of Sink Creek and the San Marcos Springs, Ringstaff (2000) notes the particularities of landform development and site formation of 41HY165. At this location, early Holocene sediments are truncated by mid-Holocene erosion, which creates an unconformity or a period of missing time between 6500 and 4500 RCYBP. This period of sediment loss is followed by slow aggradation of sediments and soil formation during the late Holocene. In this final phase of landscape development, Ringstaff (2000) notes that there is a possible period of erosion, marked by an unconformity, between 2400 and 1400 RCYBP.

\section{Climate}

Site 41HY165 is located within the Subtropical Humid climate region of Texas. This region extends from north to south across the eastern portion of the state, and is characterized by warm summers (Larkin and Bomar 1983). The average annual precipitation within the region is about 81.3 centimeters $(\mathrm{cm})$, which falls mostly as rain in the early summer and fall. Precipitation is highest in the months of May and June (9.6$8.0 \mathrm{~cm})$ and also in the month of September $(9.2$ cm) (Anaya 2004; Carr 1967; Larkin and Bomar 1983). This is due to the direction of prevailing winds coming from the southeast off the Gulf of Mexico during these times (Slade 1986). During these months, these southerly, moisture-laden winds generally clash with cooler, dryer air from the north, causing a release of moisture over the Edwards Plateau. In addition, the warm, moist air from the Gulf of Mexico rises along the Balcones Escarpment and cools, causing precipitation, and oftentimes heavy storms (Carr 1967; Slade 1986). During the winter months, between November and March, precipitation drops to around 4.4-6.4 $\mathrm{cm}$ as colder, dryer air moves in from the plains (Larkin and Bomar 1983).

Average temperatures in Hays County typically reach up to $35^{\circ} \mathrm{C}$ during the summer months, with average low temperatures reaching to just above freezing during the winter (Bomar 1983). The average annual temperature of the region is $21.1^{\circ} \mathrm{C}$ (Carr 1967). January is typically the coldest month, with average low/high temperatures of $2.2 \% 16^{\circ} \mathrm{C}$, while July and August are generally the hottest months, with average low/high temperatures of $21.7^{\circ} / 35.1^{\circ} \mathrm{C}$ degrees (Bomar 1983).

\section{Physiography and Geology}

The Balcones Escarpment represents the remains of the Ouachita Mountains that formed during a tectonic event at the end of the Paleozoic Era (Anaya 2004; Edwards Aquifer Authority 2004). The Ouachita Mountains extended from Mexico to Arkansas and allowed for the formation of shallow seas to the northwest. During the Early Cretaceous, shallow seas advanced across this area, depositing sediments that formed the Glen Rose formation and began formation of the Stuart City Reef Trend (Anaya 
2004). In the Cenozoic Era, faulting along the buried Ouachita Mountains range caused regional uplift, forming the Balcones Fault Zone and displacing Cretaceous and Lower Tertiary sediments (Anaya 2004; Edwards Aquifer Authority 2004). The current landscape has been formed by the continual downcutting of streams and rivers through the Balcones Escarpment as they make their way to the Gulf of Mexico.

Site $41 \mathrm{HY} 165$ is situated at the base of the Balcones Escarpment on a deep, frequently flooded alluvial terrace at the confluence of the headwaters of the San Marcos River and adjacent intermittent tributary, Sink Creek. Clear artesian waters emanate from approximately 200 small springs and three large fissures along the Balcones Fault. Fluvial terrace deposits (Qal) composed of eroded gravel, sand, silt, and clay from the Edwards Plateau formed along the upper San Marcos River from the Late Pleistocene to Late
Holocene. These deposits consist of quartz sand, chert, quartzite, and petrified wood gravels, and limestone (Bureau of Economic Geology 1974). Northwest of the site, the uplands overlooking Sink Creek consist of the undivided Del Rio clay and Georgetown Formation, which are made up of calcareous and gypsiferous clays and finegrained, nodular limestone (Bureau of Economic Geology 1974).

\section{Soils}

The soils at site 41HY165 consist of mollisols that formed under hot conditions in primarily grassland with sparse trees. In some areas, these soils formed under wet conditions with vertic qualities and a high salt content (Batte 1984). Specifically, the soils are mapped as Oakalla clay loam (Ok), with Tinn clay (Tn) (Figure 2-2) occurring along the southeastern portion of the site (Batte 1984). Oakalla clay loam (Ok) soils are

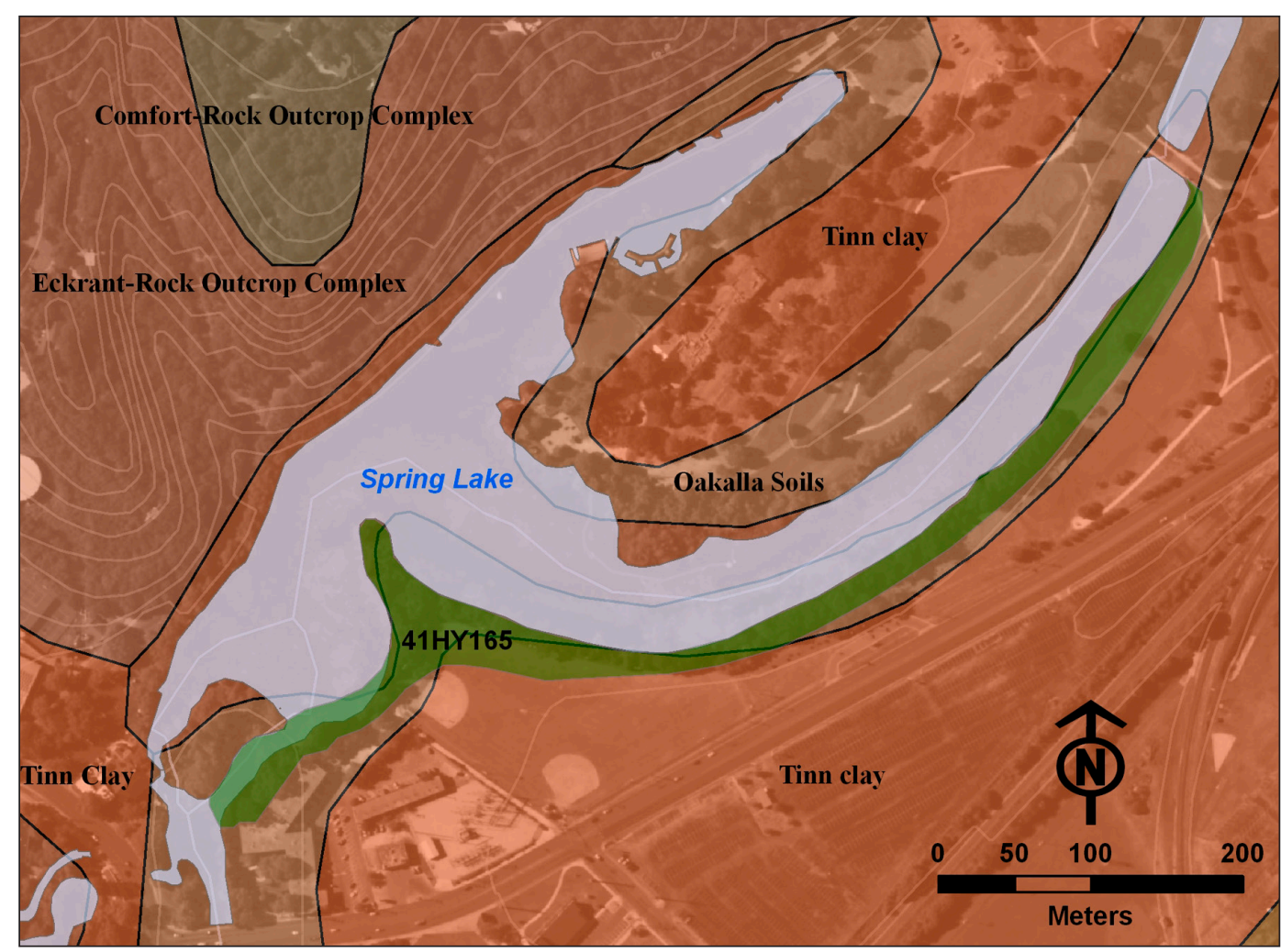

Figure 2-2. Soils mapped at Spring Lake and 41HY165. 
generally dark grayish brown in color, moderately alkaline and calcareous throughout, with approximately 60 percent calcium carbonate, and contain an extremely firm to very hard, moderate, fine subangular blocky clay structure (Batte 1984:34, 75). This compact structure allows for less cracking and movement than other clays. This means that archaeological investigations within these soils should be less hampered by the movement of artifacts as a result of cracking dynamics. Tinn clay ( $\mathrm{Tn}$ ) is generally dark gray to grayish brown in color, and like Oakalla soils, is moderately alkaline and calcareous. Its structure, however, ranges from moderate, medium and subangular to weak, medium, blocky. As a result of its structure and higher clay content, it is more likely to crack, thus allowing for possible vertical movement of artifacts.

As a result of the 1996-1998 field schools, Ringstaff (2000) identified three locally defined soil horizons (Figure 2-3) from three excavation units at the site, which he designated Units I-III. Unit III is the

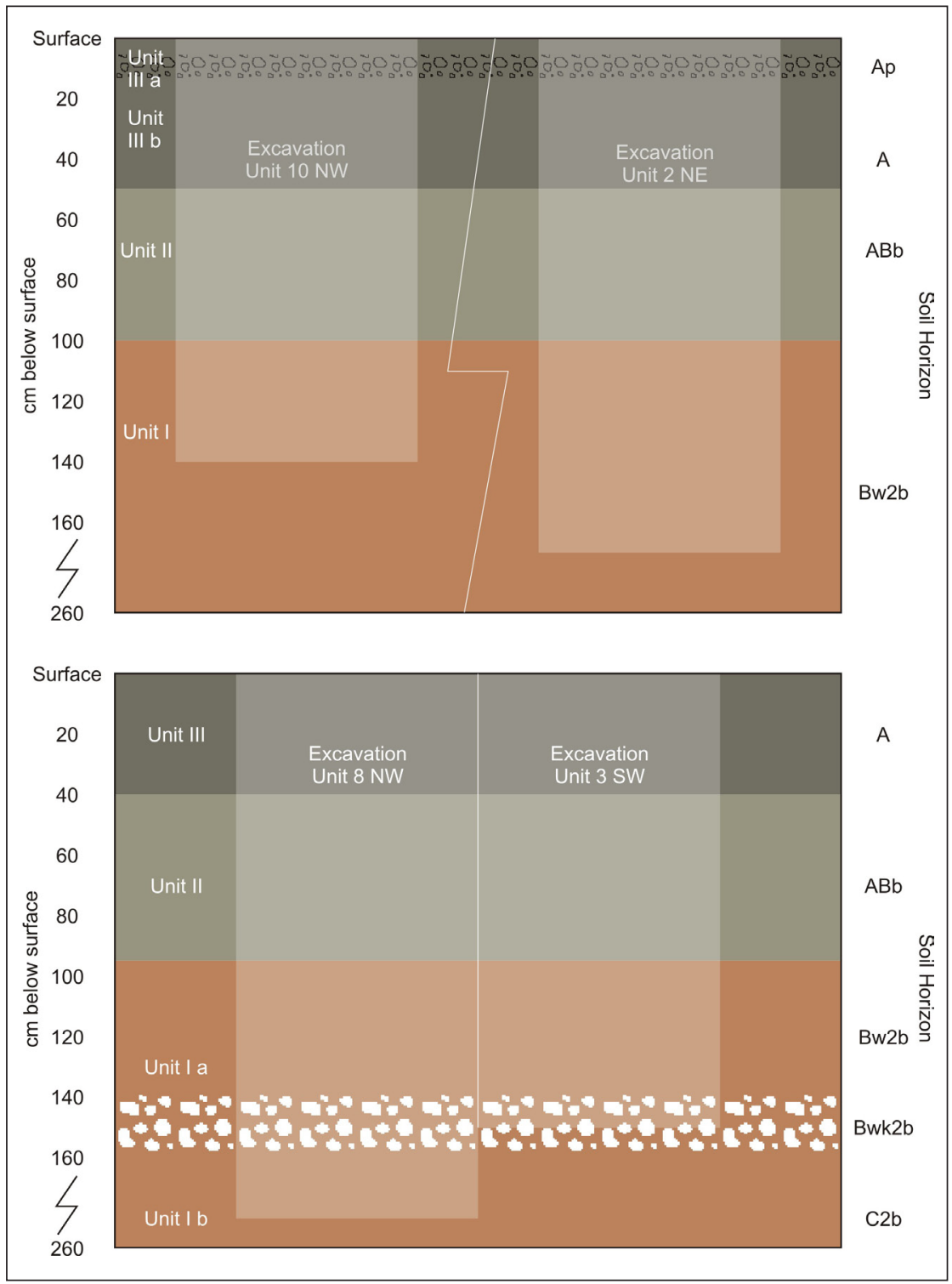

Figure 2-3. Soil horizons identified by Ringstaff (2000). 
uppermost A horizon, and occurs between 15 and $50 \mathrm{~cm}$ below the ground surface (cmbs). This unit is described as a very dark brown silty clay loam with granular structure. Ringstaff (2000:50) identified an Ap horizon (Unit IIIa) in the upper $15 \mathrm{~cm}$ of this horizon as a thin, gravelly, humic zone. Unit II is an ABb horizon between 50 and 90 cmbs, and Ringstaff (2000:50) describes the boundary between Unit III and Unit II as clear and smooth. This horizon consists of dark yellowish brown silty clay with moderate subangular blocky structure due to its higher clay content. Ringstaff (2000:51) noted little evidence of bioturbation in this horizon. The final horizon consists of two soil units occurring from 95 to 110 cmbs to a depth of $280 \mathrm{cmbs}$, where excavation was deepest. The upper portion of this horizon (Unit Ia) ranges from a Bw2b to Bwk2b dark reddish brown silty loam with weak subangular blocky structure. Ringstaff (2000:52) notes some krotovina in this horizon filled with artifacts and sediments from Unit II. Underlying Unit Ia is a $\mathrm{C} 2 \mathrm{~b}$ horizon (Unit $1 \mathrm{~b}$ ) consisting of reddish brown silty clay with moderate subangular block structure. Ringstaff (2000:53) also notes that the soil is friable with little evidence of bioturbation, and may extend to a depth of 6-9 meters (m) below ground surface (mbs).

Lee Nordt (2010) identified six major depositional units of the Aquarena Center during the 2001 investigations of $41 \mathrm{HY} 160$. Units A through $\mathrm{F}$ were defined as reflecting changes in the course of Sink Creek, periods of increased and decreased stream flow, and changes in the resulting depositional regimes. These units were deposited in chronological order, from oldest to most recent, and range from Paleoindian (A) to Late Prehistoric and Historic periods (F) (Figure 2-4).

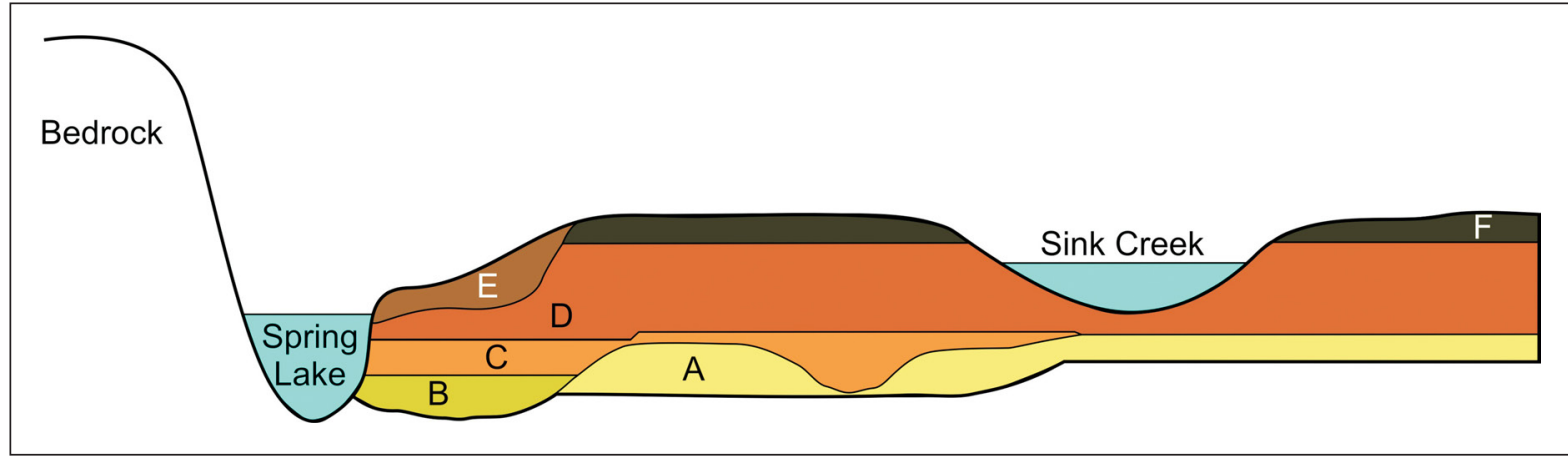

Figure 2-4. Reconstructed geoarchaeological cross section of Sink Creek Valley, looking upstream, illustrating alluvial units and their expected prehistoric preservation (redrawn from Nordt 2010:Figure 6-8). 


\title{
Chapter 3
}

\section{Cultural and Historic Context}

\author{
By John A. Campbell and Carole A. Leezer
}

\section{Cultural Periods}

Human presence within the region is divided into three periods: Prehistoric (including Paleoindian, Archaic, and Late Prehistoric), Protohistoric, and Historic. Evidence for prehistoric occupation in and around the San Marcos Springs extends from the Clovis period, approximately 11,500 years before present (BP), up until the arrival of Spanish explorers about 400 years ago. Historic documents record the use of the springs by Spanish and Native American groups in the seventeenth, eighteenth, and nineteenth centuries, and as early as the midnineteenth century by Anglo settlers such as General Edward Burleson.

Spring Lake is in a transitional zone in terms of cultural influences, with traits present from Central Texas, South Texas, and, to a lesser degree, the Upper Coast of Texas (Goode 1989). Patterson (1995) has synthesized the chronological evidence for Southeast Texas, including the Upper Coastal Region. Black (1995), Hester (1995, 2004), and Collins $(1995,2004)$ have provided recent syntheses of the cultural chronologies for Central and South Texas. Dates for prehistoric periods and parts of the Protohistoric that are derived from archaeological contexts are presented in radiocarbon years BP (or 1950). Dates in the historic period are based on written accounts and are given in calendar years.

\section{Paleoindian}

The Paleoindian stage marks the earliest human occupation of North America and extends until approximately 8000 BP. According to Hester (1995:433-436, 2004), the Paleoindian period occurred between 11,200 and $7950 \mathrm{BP}$ in South Texas. Collins (1995:381-385, 2004) dates it to 11,500-8800 BP in Central Texas. Diagnostic Paleoindian artifacts include Clovis, Folsom, and a variety of later types (Bousman et al. 2004). Early Paleoindian peoples are thought of as highly nomadic cultures that relied heavily on hunting large game animals such as mammoth, mastodon, bison, camel, and horse (Black 1989). Of these, all but bison were extinct by the end of Clovis times. Research has shown that Paleoindians utilized a wide variety of plants and animals, such as raccoons, badgers, mice, alligators, turtles, and tortoises (Black 1989; Bousman et al. 2004; Collins and Brown 2000; Hester 1983; Lemke and Timperley 2008).

A large distribution of Clovis points across North and Central America suggests a wide dispersal of their makers (Wenke 1990:201). These points are lanceolate in shape, have a thinned base resulting from "fluting," or the removal of one or more channel flakes, and are often found associated with remains of large, now-extinct herbivores. Site types include open camp sites, quarries, and caches, though kill sites are the best known. Other artifacts associated with Clovis are specialized bifaces, prismatic blades and blade cores, engraved stones, bone points, stone bolas, ochre, and shaft straighteners. 
Clovis is followed by Folsom and Midland point styles; these latter types overlap slightly (Holliday 1997). Folsom points are fluted and are found in association with ancient bison remains, while Midland points are manufactured through pressure collateral flaking, but lack fluted channels. Very thin bifaces, called ultrathin bifaces, are also found at some Folsom sites (Stanford and Broilo 1981). Folsom peoples are considered to be specialized bison hunters. Most Folsom sites occur as surface scatters, although deeply buried deposits have been uncovered. Artifacts associated with this interval are common throughout Texas (Bousman et al. 2004).

Archaeological evidence suggests that, with the exception of bison, large game animals were extinct in Texas after 10,000 BP. Hunters instead concentrated on deer, antelope, and other game (Bousman et al. 2002, 2004). Between 10,000 and 8000 BP, Central Texas is characterized by a series of cultural groups based on changing projectile point styles that transform from stemmed to lanceolate, and then back to stemmed. Changes in the subsistence base eventually required technological shifts that mark the beginning of a new cultural period known as the Archaic.

\section{Archaic}

Collins $(1995,2004)$ dates the Archaic in Central Texas from approximately 8800 to 1200/1300 BP (other archaeologists suggest that the Archaic began at 8000 BP). Following Weir (1976), this period is divided into Early, Middle, and Late Archaic periods. The Archaic marks several important transitions: a shift from large game hunting to hunting smaller animals; an apparent increase in the use of plant food resources and the use of groundstone in food processing; implementation of stone cooking technology; increased use of organic materials in tool technologies and an increase in the number and variety of lithic tools for wood working; greater population stability and less residential mobility; and systematic burial of the dead. This stage is also distinguished by environmental and climatic changes and oscillations.

The beginning of the Holocene, a significant climate change associated with the extinction of megafauna, stimulated a behavioral change in land use. Groups focused more intensively on the exploitation of local resources such as deer, fish, and plant bulbs. This dietary adjustment is evidenced by the increased number of groundstone artifacts, burned-rock middens, and tools such as Clear Fork gouges and Guadalupe bifaces (Turner and Hester 1999). Early Archaic sites are thinly dispersed, and are seen across a wide area of Texas and northern Mexico (Weir 1976). Hester (1995:436-438; 2004) dates the Early Archaic, characterized by Early Basal Notched and Early Corner Notched dart points, to 7950-4450 BP, while Collins (1995:383, 2004) argues that the Early Archaic spans from 8800 to $6000 \mathrm{BP}$ based on three divisions of projectile point types.

The Middle Archaic in Central Texas dates from 6000 to 4000 BP (Collins 1995, 2004). Collins divides the Middle Archaic into three projectile point style intervals: Bell-AndiceCalf Creek; Taylor; and Nolan and Travis. The beginning of the Middle Archaic (Bell-AndiceCalf Creek) was a mesic period when grasslands expanded southwards into Central and South Texas; this expanding habitat attracted bison herds from the Plains. People associated with Bell-Andice-Calf Creek styles were specialized bison hunters and who maintained a tool kit specifically adapted to killing and processing bison. Points were extremely thin and broad, and made differently from the proceeding period. The Middle Archaic in general is associated with the Altithermal, a prolonged period of 
warmer temperatures and increasing aridity. As the Altithermal progressed through the Middle Archaic, conditions in South and Central Texas became ever warmer and drier, and both bison and bison hunters may have retreated northwards. Taylor bifaces were manufactured during this period; these bifaces are similar to the earlier Bell-Andice-Calf Creek point styles, but lack the deep basal notches that characterize the earlier types. By the latter part of the Middle Archaic, Nolan and Travis points predominate; both are technologically and stylistically dissimilar to the preceding styles (Collins 1995, 2004). The Nolan-Travis interval was also a period when temperature and aridity were at their peaks, and there is evidence of increased utilization of xerophytes such as sotol (Johnson and Goode 1994). These plants were typically baked in earth ovens, associated with middens of burned and fire-cracked rock. During drier episodes of this period, the aquifer-fed streams and resource-rich environments of Central Texas were extensively utilized (Story 1985:40; Weir 1976:125, 128).

The Late Archaic dates to approximately 4,000-1300/1200 BP (Collins 1995:384, 2004). Bison herds began returning to the southern Great Plains (Dillehay 1974), again influencing subsistence. Cemeteries at sites such as Ernest Witte (Hall 1981) and Olmos Dam (Lukowski 1988) provide some evidence that populations increased and that groups were becoming territorial (Story 1985:44-45), though this pattern may have begun in South Texas as early as ca. 6500-7000 BP (Ricklis 2005). Pottery, which often accompanies increased sedentism, territoriality, and population growth, began appearing in limited areas of the South Texas Plains during the Late Archaic (Story 1985). However, most regions remained "pre-ceramic" for another thousand years (Story 1985:45-47). Common projectile points are Ensor and Frio (Turner and Hester 1999), both of which are short, triangular points with side notches. The Frio point also has a notched base (Turner and Hester 1999).

\section{Late Prehistoric}

Collins $(1995,2004)$ dates the Late Prehistoric at 1300/1200-260 BP, and follows Kelley (1947) in dividing it into the Austin and Toyah phases. This stage is marked by the shift away from the dart and atlatl to the bow and arrow, and by the incorporation of pottery in the central and northern parts of the South Texas Plains (Black 1989:32; Story 1985:45-47). Emphasis on bison hunting during the Toyah phase was a significant factor in determining settlement and mobility patterns.

The Austin phase is characterized by small arrow points, including Edwards, Scallorn, and other types, indicating a shift from the use of atlatls to bows. Burned rock middens are sometimes associated with these types (e.g., Houk and Lohse 1993). Ground and pecked stone tools for processing plant food are increasingly common, and burials from this time reveal a high proportion of arrow-wound deaths (Black 1989; Prewitt 1974), perhaps suggesting some disputes over resource availability.

The beginning of the Toyah period (750 BP) in Central Texas is marked by contracting stem points and flaring, barbed shouldered points. Perdiz is the most common example (Black 1989:32; Huebner 1991:346), and this type occasionally occurs on glass in mission contexts (e.g., Lohse 1999:268). This period is also characterized by prismatic blades, blade cores, and scrapers-on-blades, all considered part of a specialized bison hunting and processing toolkit (Black and McGraw 1985; Huebner 1991; Ricklis 1994). The wide variety of ceramic styles and materials seen in Toyah pottery provides information on the social composition 
of these groups (Arnn 2005), with assemblages displaying Caddo, Texas Gulf Coast, and Jornada Mogollon influences. Johnson (1994) contends Toyah culture represents a constellation of traits shared by a limited number of groups sprawled across a very large area of Texas. Ricklis (1994) describes it as a collection of traits that moved through relatively stable regional populations. Recently Arnn (2007) has argued that a large number of cultural groups, many of which were documented by European explorers, interacted with each other over a large area, resulting in the spread of shared styles and technologies.

\section{Protohistoric (Spanish Entrada) Period}

The Protohistoric period was marked by Spanish entradas, formal expeditions into Texas in the late seventeenth and early eighteenth centuries. Hester defines the period as "the transition period between the Prehistoric and Historic period denoting a phase for which few written records are available, and for which most evidence is derived from archaeology" (1995:449-450, 2004). This period began with the venture by the Spanish explorer Cabeza de Vaca and the Narvaez expedition in AD 1528, and extends to the establishment of the Mission San Antonio de Valero (the Alamo) in San Antonio, in AD 1718.

When the Spanish missions were established in East Texas in the late 1600s, entradas began to travel regularly through Central Texas. These expeditions provide the first detailed observations on the original Native American inhabitants of the region. With Alonso de León's expedition of AD 1680, El Camino Real (the King's Road) was established from Villa Santiago de la Monclova in Mexico to East Texas. This roadway followed established Native American trade routes and trails, and became a vital link between Mission San Juan Bautista in Northern Mexico and the
Spanish settlement of Los Adaes in East Texas (McGraw et al. 1991).

Spanish priests accompanying entradas provided most of the available information on indigenous cultures of early Texas. The few surviving accounts of native groups in Texas reveal a dynamic cultural environment where numerous tribes passed through or inhabited Central Texas at different periods. Little is known about the majority of these tribes, but those documented around the springs at San Marcos include the Cantona, Muruam, Payaya, Sana, and Yojuane. Other tribes encountered at San Marcos included mobile hunting parties from villages in South and West Texas, such as Catequeza, Cayanaaya, Chalome, Cibolo, and Jumano, who were heading for bison hunting grounds in the Blackland Prairies (Foster 1995:265-289; Johnson and Campbell 1992; Newcomb 1993). Later groups migrated into the region, displacing the former groups or tribes. These included the Tonkawa from Oklahoma and Lipan and Comanche from the Plains (Campbell and Campbell 1985; Dunn 1911; Newcomb 1961, 1993). Archaeological sites dated to this period typically contain a mix of both European imported goods, such as metal objects and glass beads, and chipped stone tools.

\section{Historic}

Spanish settlement in Central Texas first occurred in San Antonio with the establishment of Mission San Antonio de Valero, and the later founding of San Antonio de Béxar (Bolton 1970 [1915]; de la Teja 1995; Habig 1977). Most knowledge of this period is gained through the written records of the early Spanish missionaries. Between AD 1746 and 1755, three missions, San Francisco Xavier de Horcasitas, San Ildefonso, and Nuestra Señora de la Canderlaria were located somewhere along the San Gabriel (known at the time as the San Xavier) River in presentday Milam County. The three missions were 
eventually coalesced into one, the San Xavier Mission, and moved to the San Marcos River in AD 1755. A petition to permanently establish a mission in Apache territory resulted in the founding of the San Sabá Mission, near presentday Menard, in AD 1757. Neophytes from the San Xavier Mission were transferred to the San Antonio missions and the mission property and presidio were reassigned to the San Sabá Mission. A small group of local San Xavier Indians, the Mayeyes, persuaded the missionaries to set up a new mission for them on the Guadalupe, the San Francisco Xavier Mission, but it only lasted until AD 1758 (Bolton 1970 [1915]). The precise location of the San Francisco Xavier Mission along the San Marcos River has not yet been determined, but it has been speculated that it may have been located on or near the Aquarena Center peninsula (Bousman, personal communication 2004).

Besides the mission town of San Antonio, the only other Spanish settlement in the region was San Marcos de Neve, established in AD 1808, four miles south of present-day San Marcos. San Marcos de Neve was abandoned in AD 1812 as a result of constant raids by local tribes (Dobie 1932). During this time, massive depopulation occurred among Native Americans due to diseases to which indigenous people had little resistance. Those few remaining were gradually displaced to reservations beginning in the mid1850s (Fisher 1998).

Mexico achieved independence from Spain in $\mathrm{AD}$ 1827, opening settlements in what is known today as South Texas. European presence increased as settlers received land grants from the Mexican government until AD 1835. Settlement was difficult, however, due to raids by Native American groups. The Texas Rangers provided protection from these conflicts after Texas secured independence from Mexico in AD
1836. Settlement in the region increased until AD 1845, when Texas gained admission to the United States, resulting in the formation of Hays County in AD 1848 (Bousman and Nickels 2003).

\section{Previous Archaeological Investigations}

There are three archaeological sites that have been previously recorded adjacent to 41HY165. These include 41HY147, 41HY160, and 41HY161. These sites, along with 41HY165, are discussed below (Figure 3-1).

In 1979, Joel Shiner (1983) began underwater excavations at archaeological site 41HY147. This site, a State Antiquities Landmark (SAL), was recorded by John W. Clark in 1979 and is composed of several areas of archaeological debris located along a large terrace under Spring Lake, adjacent to the western bank of the lake. Primary excavations uncovered lithic materials of various ages and faunal remains, mainly consisting of mammoth, mastodon, and bison tooth fragments (Shiner 1983).

Archaeological site 41HY160, an SAL, was originally recorded by James Garber in 1983 during archaeological field school investigations of Tee Box 6 of the Aquarena Golf Course (Garber et al. 1983). These investigations encountered Early Archaic to Late Prehistoric deposits that extended to a depth of $2.4 \mathrm{mbs}$. Encountered artifacts and features included lithic tools, lithic projectile points, faunal remains, stone alignments, a posthole, a trash pit, hearths, small burned rock middens, and an area possibly associated with ceramic production. Additional field school investigations took place across the peninsula during the following years, and the encountered cultural deposits in this area were attributed to archaeological site 41HY160. 


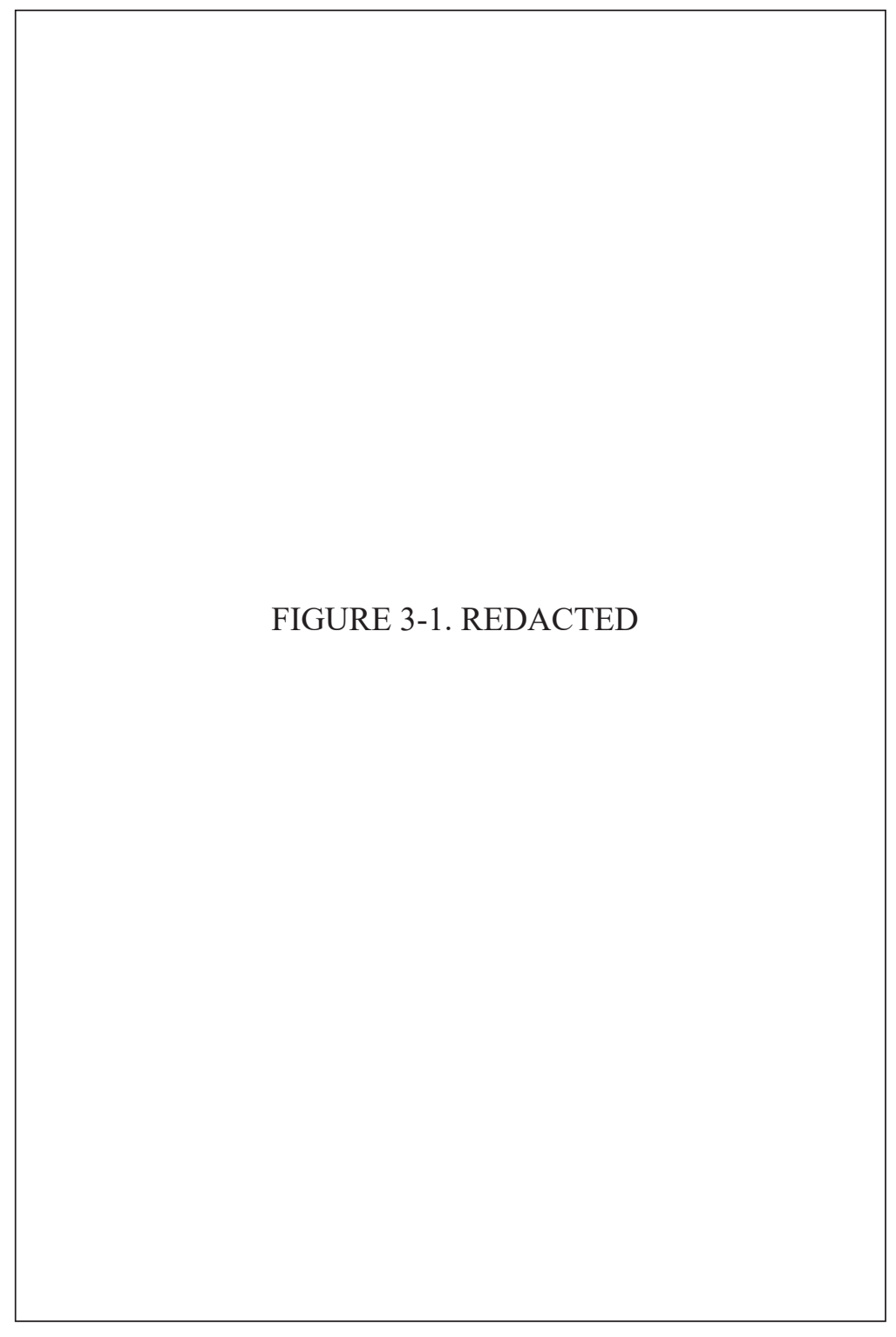

Figure 3-1. Previously recorded archaeological sites adjacent to 41HY165. Dashed line boundaries are recent updates resulting from the SLAERP survey and testing project.

In 1840, the settlers of San Marcos had constructed a large log and earth dam across the San Marcos River to impound the waters for a flour mill. This dam resulted in the creation of Spring Lake, 3-4 $\mathrm{m}$ above the natural river edge (Shiner 1981). In 1979, Dr. Joel B. Shiner of Southern Methodist University began investigations immediately below the falls of this dam, known as the Ice House Falls, and recorded archaeological site 41HY161. Shiner originally characterized this SAL as consisting of Middle Archaic lithic deposits occurring in the sand and gravel at the foot of the Ice House Dam Falls (Shiner 1979). As further archaeological investigations were conducted adjacent to this location, the site boundaries of $41 \mathrm{HY} 161$ were expanded to include the locations of additionally encountered archaeological deposits. These deposits included Late Paleoindian and Late Archaic lithic materials, in addition to two human burials.

Recorded by James Garber in 1984 (Garber 1984), SAL 41HY165 was the site of field school investigations conducted briefly in 1984, and then was investigated more thoroughly in 1996, 1997, and 1998 (Ringstaff 2000). Field school investigations conducted in 1996 and 1997 recorded 18 features (hearths, basins, burned limestone scatters) and collected numerous projectile points, lithic tools, and faunal remains.

Work has been conducted off and on at these sites for a number of years, and brief summaries of these investigations are presented below (Table 3-1).

Based on the results of these previous investigations, cultural materials in good contexts are undeniably present. Remains encountered at the base of the Balcones Escarpment are in 
Table 3-1. Previously Recorded Archaeological Sites.

\begin{tabular}{|c|c|c|c|}
\hline Site & Years Investigated & Components & Citations \\
\hline 41HY147 & $1979,1990,1990$ & $\begin{array}{l}\text { Archaic, late and early } \\
\text { Paleoindian, Pleistocene fauna }\end{array}$ & Shiner 1983; Takac 1990, 1991a, 1991b \\
\hline 41HY160 & $\begin{array}{l}\text { 1982, 1983, 1991, } \\
1997,1998,2001, \\
2002,2003,2004, \\
2006\end{array}$ & $\begin{array}{l}\text { discrete components from } \\
\text { Late Prehistoric through Early } \\
\text { Archaic, domestic features }\end{array}$ & $\begin{array}{c}\text { Garber et al. 1983; Ramsey 1997; } \\
\text { Oksanen 2006; Aery 2007; Nickels } \\
\text { and Bousman 2010; Leezer et al. } 2011\end{array}$ \\
\hline 41HY161 & $\begin{array}{l}1978,1997,1998 \\
2000,2004,2008 \\
2009\end{array}$ & $\begin{array}{c}\text { mixed historic and Archaic, } \\
\text { Late Archaic, late and early } \\
\text { Paleoindian, human remains, } \\
\text { Pleistocene fauna }\end{array}$ & $\begin{array}{l}\text { Shiner 1979, 1981, 1984; Garber and } \\
\text { Glassman 1992; Ford and Lyle 1998; } \\
\text { Lyle et al. 2000; Jones 2002; Oksanen } \\
\text { 2008; Yelacic et al. 2008a, 2008b; } \\
\text { Stull 2009; Leezer et al. 2010; }\end{array}$ \\
\hline 41HY165 & $\begin{array}{c}1984,1988,1996- \\
1998,2000-2001\end{array}$ & $\begin{array}{l}\text { prehistoric, Middle Archaic, } \\
\text { bison, historic, mixed historic } \\
\text { and prehistoric }\end{array}$ & $\begin{array}{c}\text { Giesecke 1998; Ringstaff 2000; Soucie } \\
\text { and Nickels 2003; Soucie et al. 2004; } \\
\text { Leezer et al. } 2011\end{array}$ \\
\hline
\end{tabular}

colluvial deposits with questionable contexts. However, materials in alluvial deposits, such as on the peninsula and along Sink Creek are potentially in intact contexts and contain isolable components. Assemblages encountered here have dated from the Paleoindian or Early Archaic periods continuously to the Archaic and Late Prehistoric periods and even the Colonial and Historical eras. They have demonstrable potential for providing high-quality data that would unquestionably contribute to a better understanding of prehistoric occupations within the APE.

\section{HY147 Investigations}

Investigations at the Spring Lake Site (Shiner 1984) or Terrace Site (Takac 1990) were carried out by Shiner intermittently from 1979 until his death in 1988. The site consists of several areas of archaeological debris located along a large underwater terrace of Spring Lake adjacent to the western bank of the lake. Initial excavations uncovered lithic materials of various ages within a mixed, deflated, 20-cm stratum (Shiner 1983); Clovis, Plainview, Angostura, and Golondrina points were mixed with Archaic points. Additionally, faunal remains, mainly consisting of mammoth, mastodon, and bison tooth fragments were also recovered (Shiner 1983). Subsequent excavations revealed three distinct strata levels. The uppermost gray clay matrix level varied from 20 to $30 \mathrm{~cm}$ in depth, and contained Archaic shouldered and notched projectile points. The second layer, red sand, varied from 10 to $20 \mathrm{~cm}$ in thickness, and artifacts recovered consisted of shouldered projectile points and lanceolate points. The last layer, consisting of red clay, contained the majority of the megafauna remains in addition to Clovis, Plainview, and other lanceolate points (Shiner 1983). Among the artifacts collected were a few "exotic" or non-local materials consisting of redcolored quartzite and quartz crystals and chert from 50 to 75 miles away. In addition several scales of alligator gar were recovered, a species far different from the local spotted gar (Shiner 1981). Shiner (1983) postulates that the presence 
of scrapers, large amounts of lithic "chipping" debris, preforms, and the broken bones of many animal species indicates that the site was a Paleoindian base camp supporting an almost sedentary hunting and gathering existence. In rebuttal, Johnson and Holliday (1984) postulate that the large numbers of lithic artifacts were a direct result of the availability of localized chert outcrops in the area.

In October of 1989, following Shiner's death, Paul R. Takac, a graduate student at Southern Methodist University, attempted to complete the analysis of Shiner's collection, conducted additional excavations in 1990 and 1991, and sought to publish these results (Takac 1990). Takac (1990), like Shiner, contends that the paleoenvironment of the Spring Lake area, the abundance of raw lithic materials, and a permanent and reliable water source may have supported limited mobility hunter-gatherer groups in the past. Takac compared the Spring Lake material to the Early Archaic and Late Prehistoric remains recovered by Garber et al. (1983) at the Tee Box 6 area of 41HY160. There, Garber noted a high incidence of usable flakes that were not utilized or modified. Takac's primary analysis of the Spring Lake materials indicated a similar occurrence. Also similar to Tee Box 6, 41HY147 contained a wide range of tool types, including projectile points, scrapers, knives, drills, perforators, burins, and gouges in addition to bifacial and discoidal cores at various stages of reduction (Takac 1990). Takac's project was eventually abandoned due to the difficulty of doing careful underwater investigations. Combined, Takac's and Shiner's excavations recovered a total of 46 Paleoindian projectile points, most dating to the Late Paleoindian period. Site $41 \mathrm{HY} 147$ was designated an SAL on July 23, 1999 (Texas Historical Commission [THC] 1999a).

\section{$41 H Y 160$ Investigations}

Site 41HY160 was initially investigated during a field school by Garber (Garber 1983) in 1982. 41HY160 occupies the peninsula between Spring Lake and Sink Creek upon which Aquarena Center and a portion of the Texas State University Golf Course are situated. As described by Garber (1983), the site is located near Tee Box 6 of the Texas State University Golf Course, adjacent to Spring Lake. Prehistoric materials were noted on the surface of an area approximately $300 \times 200$ $\mathrm{m}$. In total, $34 \mathrm{~m}^{2}$ of soil were excavated to varying depths, with the deepest unit excavated to $2.4 \mathrm{mbs}$. Intact Late Prehistoric through Early Archaic occupations were exposed (Garber et al. 1983). The terminus of cultural deposits was not determined due to the nature of the water table. Garber et al. (1983) speculate that cultural remains are present beneath the water table level based on Shiner's recovery of artifacts from approximately 10 feet below the water surface of Spring Lake. Excavations indicated that only the upper $15 \mathrm{~cm}$ of soil were disturbed by historic processes, and that the remaining deposits were intact.

Seventy-five projectile points (53 of which were identifiable) were recovered and can be placed in the Late Prehistoric, Late Archaic to Late Prehistoric transition, the Archaic, and the Paleoindian periods. Late Prehistoric projectile points such as Perdiz, Scallorn, Cliffton, and Alba were found between 0 and 20 cmbs. Points characteristic of the Transitional Archaic Period (Darl, Fairland, and Edgewood) were recovered between 20 and $40 \mathrm{cmbs}$. Late Archaic projectile points (Ensor, Frio, Marshall, and Castroville) were excavated between 30 and $50 \mathrm{cmbs}$, while early Late Archaic points (Pedernales) occurred primarily between 50 and $70 \mathrm{cmbs}$. Nolan and Early Stemmed points representing the Middle and Early Archaic intervals were found between 70 and $190 \mathrm{cmbs}$. No projectile points that are 
characteristic of the Paleoindian to Archaic transition phase were noted (Garber et al. 1983). In addition, 429 stone tools representing choppers, scrapers, cores, fine bifaces, moderately worked bifaces, crude bifaces, used-retouched flakes, and intentionally retouched flakes were also collected. Garber et al. (1983) stated that the source of the chert cobbles is a limestone chert outcrop approximately one kilometer to the north of the site. It appears that tool finishing was an important activity at the site, due to the presence of over 35,000 pieces of lithic debitage (Garber et al. 1983). The majority of the lithic debitage has been classified as interior flakes representing the final stages of reduction. In addition to the above, three bone tools were also recovered, consisting of two bone awls and one flesher. Three sandstone grinding slabs were recovered from the Late Prehistoric zone and the Late Archaic to Late Prehistoric transition zone. Twenty-six ceramic sherds were also recovered from this zone, representing Leon Plain ware and Caddoan type vessels (Garber et al. 1983). Faunal remains consisted of bison, deer, and antelope. Thirteen features were encountered and included: five hearths, three stone alignments, two small burned rock middens, a posthole, a trash pit, and an area containing charcoal and pieces of fired, shell-tempered clay possibly indicating ceramic production (Garber et al. 1983).

Garber et al. (1983) summarized their report by stating that preliminary analysis indicates cultural occupations exist at the site from the Early Archaic through to the Late Prehistoric. The presence of Paleoindian projectile points suggests earlier occupations; however, the nature of these deposits is not yet fully understood. Garber et al. (1983) recommended additional investigations at the site to better understand the nature of these earlier deposits. The field school returned to 41HY160 in 1983, but these excavations have not been analyzed or reported.
SWT field school participants returned to the 41HY160 area under the direction of David Driver in 1991. During this field school, three additional units were excavated in the Tee Box 6 area, three in the vicinity of the swimming pool in front of the Spring Lake Hotel (now the Meadows Center for Water and the Environment), and a seventh unit northeast of the previous anthropology field laboratory building (now biology field laboratory building) on the edge of the golf course. Units in the Tee Box 6 area were excavated to a depth of $70 \mathrm{cmbs}$. Units in the area of the swimming pool were excavated to a depth between 50 and 160 cmbs. Most of the upper deposits near the swimming pool were believed to be mixed (James Garber, personal communication 1999), but some of the lower deposits appeared to be intact. The unit next to the anthropology lab was excavated to a depth of $100 \mathrm{cmbs}$. While field notes report the recovery of cultural remains from these units, excavations have not been cataloged, analyzed, or reported.

A 1993 SWT field school was conducted at Tee Box 6 area of 41HY160 under the direction of David Driver. During this field school, an additional six units were excavated and varied in depth from 80 to $160 \mathrm{cmbs}$. Collected artifacts include ceramic fragments, shell, lithic cores, bone, lithic debitage, points, and point fragments. These excavations have also not been fully catalogued, analyzed, or reported.

In 1997, Dawn Ramsey (1997) conducted a pedestrian and shovel-testing survey at Aquarena Center. She excavated 10 shovel tests on the east side (left bank) of Sink Creek and northeast of the entrance road immediately east of the escarpment. All but one shovel test produced prehistoric artifacts.

In 1998, under the direction of Mary Kathryn Brown, participants in the SWT field 
school excavated six units at 41HY160 in the vicinity of the Aquarena Center offices. Units were excavated to depths between 20 and 148 cmbs. Excavations were halted in most of the units due to invasion of the water table. Intact deposits were found immediately below the present surface in two of the units. Artifacts collected included bifaces, shell, bone, lithic debitage, and points. This collection has also not been fully catalogued, analyzed, or reported. Archaeological site 41HY160 was designated an SAL on July 23, 1999 (THC 1999b).

In 1999 Prewitt \& Associates conducted a geological assessment of the Aquarena Center peninsula through the extraction of 1730 -foot (9-m), 3-inch-diameter cores in preparation for potential limited development by Texas Parks and Wildlife Department (TPWD) (Goelz 1999). The cores were drilled by Trinity Engineering Testing Corporation and interpreted by Melinda Goelz (1999). The primary result of this work was to provide an outline of the late Quaternary geological history of the valley and the potential for prehistoric occupations. Goelz's (1999) geological assessment indicated that soil deposits are shallow near the escarpment, but quickly thicken to an average depth of $8.4 \mathrm{~m}$ in the central portion of the peninsula. The recovery of cultural materials in such small cores is not common, and recovery usually indicates reasonably dense occupation. The majority of the core samples produced prehistoric artifacts, indicating a dense concentration of artifacts in the area. Cultural materials were recovered up to a depth of $6.5 \mathrm{~m}$. The estimated age for cultural materials at 6.5 mbs is 10,000 BP (Nickels and Bousman 2010).

In 2001 an archaeological testing project was conducted as part of a master plan and partnership between TPWD and Texas State to develop a public interpretive and educational center on the peninsula (Nickels and Bousman
2010). The purposes of this project were 1) to determine the presence or absence of cultural remains in the areas to be impacted; and 2) to evaluate the integrity of any discovered cultural materials and determine their potential for providing significant archaeological information. Additional geological coring was conducted by the Bureau of Economic Geology of The University of Texas at Austin in order to document the Late Pleistocene and Holocene depositional history of the valley. This produced another set of 22 cores that were extracted in two valley crosssections from east to west. Six $1 \times 1-m$ test units were also excavated to an average depth of $1.7 \mathrm{~m}$ before reaching the water table. Two units were placed in the footprint of a proposed pavilion and restrooms, and four units were placed in the area of the Spring Lake Hotel swimming pool and surrounding parking lot. A number of special samples were collected from the test excavations, including radiocarbon, archaeomagnetic samples of burned rock from features, and macrobotanical samples. During the excavations, over 18,380 pieces of lithic material were collected including: 18 projectile points, 82 bifaces, 19 cores, two groundstones, one hammerstone, 213 unifaces, and 18,046 pieces of lithic debitage (Nickels and Bousman 2010). In addition, 2,650 fire-cracked rocks from 12 thermal features were analyzed in the field, and 4,388 faunal remains and 37,672 snail shells were collected. No ceramic remains were encountered. The testing investigation documented the presence of intact and wellstratified archaeological deposits within the upper $1.7 \mathrm{~m}$. Nickels and Bousman (2010) contented that based on geological core samples and results from previous investigations in addition to their testing investigations, intact alluvial deposits in the floodplain adjacent to the San Marcos Springs contain evidence of human occupations extending from Paleoindian to Late Prehistoric. 
More recent investigations at $41 \mathrm{HY} 160$ include Texas State field schools conducted in 2001, 2002, 2003, and 2006; these results have been partially reported by Aery (2007), and a detailed analysis is currently underway by CAS. Data recovery excavations at $41 \mathrm{HY} 160$ began after the 2001 testing project determined the potential for stratified and intact buried deposits at the site in the pecan grove area adjacent to the Texas River Center Parking lot (Aery 2007). Excavations conducted during the field schools were a result of mitigation measures to compensate for the loss of information from proposed construction in the area. The fieldwork was conducted in June of 2001, 2002, 2003, and 2006.

In 2001, the field school crew was supervised by Brown and Dr. C. Britt Bousman. A $3 \times 4-m$ block was established and excavated in the area of Test Unit 6 (excavated during the Texas River Center Testing Project) within the pecan grove adjacent to the Texas River Center parking lot (Aery 2007). Unit 6 had been excavated to approximately $150 \mathrm{cmbs}$ and yielded several diagnostic artifacts before excavations were halted upon encountering the water table. Four additional units (Units 7, 8, 9, and 10) were excavated adjacent to Unit 6 . Units were excavated in $10-\mathrm{cm}$ levels, and features and diagnostic artifacts were point-provenienced. Unit 7 was excavated to a depth of $80 \mathrm{~cm}$ below datum (cmbd), Unit 8 to $80 \mathrm{cmbd}$, Unit 9 to $100 \mathrm{cmbd}$, and Unit 10 to $80 \mathrm{cmbd}$. The entire excavated matrix was water screened through 1/4-inch hardware cloth (Aery 2007).

During the 2002 field school, supervised by Bousman, students continued excavation on the previously opened units and opened additional units $11,12,13$, and 15 . At the end of the field season, Unit 7 was at $123 \mathrm{cmbd}$, Unit 8 at 119 cmbd, Unit 9 at $114 \mathrm{cmbd}$, Unit 10 at $103 \mathrm{cmbd}$,
Unit 11 at $73 \mathrm{cmbd}$, Unit 12 at $82 \mathrm{cmbd}$, Unit 13 at $69 \mathrm{cmbd}$, and Unit 15 at $55 \mathrm{cmbd}$. At the end of the field season, the units were protected by backfilling with sediment and covered by tarps and plywood (Aery 2007).

During the 2003 field school, also supervised by Bousman, an additional two units (Units 16 and 17) were opened. During this season, archaeomagnetic samples were taken from some of the fire-cracked rocks in identified thermal features (Aery 2007). At the end of the field season, the eastern six blocks were at approximately $110 \mathrm{cmbd}$, and the western six blocks were a $120 \mathrm{cmbd}$ (Aery 2007).

The 2006 field school, supervised by Bousman and Deidra Aery Black, continued excavations throughout the whole block. The entire block was excavated to a depth of $150 \mathrm{cmbd}$ (Aery 2007). During the 2001, 2002, 2003, and 2006 field schools, 31 fire-cracked rock features were identified. Recovered lithic material included groundstone, modified flakes, bifaces, cores, core tools, unifaces, and projectile points. Based on the recovery of chronologically diagnostic materials, the earliest deposits occurred during the Early Archaic period. This period appears to roughly correspond with the B-2 soil horizon, and is found below 135-140 cmbs. The depth of this cultural period is unknown because it is located below the termination of excavation. The transition between the Early and Middle Archaic occurs between 120 and $140 \mathrm{cmbs}$, and is generally situated around $130 \mathrm{cmbs}$. The Middle Archaic is by far the best represented cultural period in the block, and the greatest concentration occurs between 70 and $130 \mathrm{cmbs}$, though in some units this can be as shallow as $50 \mathrm{cmbs}$. The Late Archaic occurs primarily between 60 and 80 cmbs. However, the Late Archaic cultural period is not as well represented as the Middle Archaic, and there is not a noticeable boundary between the 
end of Middle Archaic and the beginning of Late Archaic deposits. The Late Prehistoric cultural period is not represented by diagnostic artifacts in the middle four units, but occurs between 30 and $40 \mathrm{cmbs}$ in the northern four units, and between 40 and $50 \mathrm{cmbs}$ in the southern four units. A Late Historic gravel parking lot, between 15 and $30 \mathrm{cmbs}$ depending on the location, caps the prehistoric deposits and marks the use of the area as a tourist destination. This gravel parking lot is covered by modern soils and detritus. Over 19,000 fragments of faunal remains, 121 pieces of shell, and 29 ceramic sherds were also collected. A detailed analysis of the artifact assemblage collected during the 2001, 2002, 2003, and 2006 field schools is currently underway by CAS.

In August of 2006, CAS conducted monitoring and trench inspection of 1,600 linear feet of proposed fiber optic line conduit to be placed through the Aquarena Springs GolfCourse (Oksanen 2006). A segment of the line passed through the area of Tee Box 6. The remains of three small thermal features were recorded within the localized area of Tee Box 6. The impacts to the archaeological deposits were minimal, and no significant cultural deposits were encountered or disturbed. CAS recommended clearance for the conduit installation to the THC, and the THC concurred.

\section{HY161 Investigations}

In 1840, the settlers of San Marcos constructed a large log and earth dam across the San Marcos River to impound the waters for a flour mill. This dam resulted in the creation of Spring Lake, three to four meters above the natural river edge (Shiner 1981). In 1979, Shiner began investigations immediately below the falls of this dam, known as the Ice House Falls. Spring Lake is fed by five to six major springs that flow from the Edwards Plateau Limestone approximately $600 \mathrm{~m}$ north of the Ice House Dam. Shiner documented the presence of stone artifacts, mostly from the Middle Archaic, occurring in the sand and gravel among large cobbles at the foot of the Ice House dam falls (Shiner 1979). A clay stratum approximately $1 \mathrm{~m}$ below the water level was identified on the west bank that appears to be a relict portion of a prehistoric site (Shiner 1979). Approximately 40 man hours of underwater diving resulted in the random collection of 2,513 artifacts. Collected artifacts consisted of 1,762 pieces of lithic chips, 29 lithic cores, 201 biface thinning flakes, 141 cortex fragments, 234 flakes, and 146 tools that included: seven endscrapers, six side scrapers, two scrapers, six notched tools, an arrow point, 31 dart points, 51 preforms, five burins, six gravers, four borers, a drill, three scaled pieces, six gouges, 12 retouched flakes, a chopper, three hand axes, and a hammer (Shiner 1979). Projectile points included 10 Pedernales, five Bulverdes, six Nolan, three unidentified notched points, and four unidentified triangular points. Almost half of the collected tools consist of broken or incomplete bifaces (Shiner 1979). Shiner contends that the assemblage is reflective of hunter-gatherer groups between 2950 and 5450 BP that occupied the site for a lengthy period of time. The amount of lithic manufacturing debris and the presence of tools, in addition to a lush environment, support the contention of a lengthy occupation (Shiner 1979).

In the fall of 1982, SWT maintenance operations uncovered two burials in the area of the Fish Ponds on the university campus, across Sessoms Drive from the Ice House Falls; the boundaries of 41HY161 were extended to include these deposits. Garber conducted an emergency recovery project (Garber and Glassman 1992). Burial 1 was encountered in the sidewall of a narrow water pipeline trench at $65 \mathrm{cmbs}$. The burial consisted of a small sample of fragmentary remains that prohibited the assessment of a basic osteobiographical profile. Five nonhuman bone 
fragments, one burned nonhuman bone fragment and one nonhuman tooth were recovered in association with the burial. No skeletal pathologies or cause of death were identifiable (Garber and Glassman 1992). Burial 2 consisted of 45 percent of the skeletal remains of a single individual. The cranium was not represented except for four cranial fragments and the left petrous portion of the temporal bone (Garber and Glassman 1992). Nine nonhuman bone fragments, four nonhuman teeth, and one metal bolt were recovered in association with the burial. Two of the recovered bones had been burned, including the right humeral fragment. The individual was identified as an adult female between 64 and 66 inches in height. No skeletal pathologies or cause of death were noted (Garber and Glassman 1992). Archaeological site 41HY161 was designated an SAL on March 13, 1987 (THC 1987).

Additional analyses of the burials recovered from 41HY161 were conducted as a part of the data recovery program of archaeological site 41HY163. These remains were included to enlarge the bioarchaeological population of the San Marcos area for comparative analyses. Analyses consisted of descriptive and isotopic analysis. These recent analyses confirmed and slightly revised the prior stature and age estimates for these individuals, and should be considered the most accurate and current reconstruction.

Archaeological data collected with the 41HY161 burials, in addition to biological indicators and overall taphonomic conditions, indicate that the remains are culturally and biologically affiliated with prehistoric Native American populations. Individual 1 displayed premolar wear consistent with prehistoric huntergatherer populations. Less than 25 percent of the skeletal remains were recovered, and the remains displayed significant postmortem trauma, most likely the result of heavy equipment used during excavation. The remains of Individual 2, specifically, provided limited biological profile information. A metric analysis of the recovered skeletal elements indicate that Individual 1 was a female, aged between 25 to 45 years, and stood between 61 and 66 inches tall (Stull and Hamilton 2011). These remains were dated to $515 \pm 20 \mathrm{BP}$. Due to the condition of the remains from burial two, it can only be determined that Individual 2 was an adult of indeterminate sex and stature. These remains, however, were dated to $3510 \pm 20$ BP (Stull and Hamilton 2011).

Stable carbon and nitrogen isotope analysis of bone collagen collected from the 41HY161 burials were also conducted as part for the 41HY163 data recovery program (Lohse 2011). This analysis was conducted in order to reconstruct paleodietary histories of the individuals in an attempt to determine their point of origin and possible cultural affiliation (Munoz et al. 2011). The dietary values from Individual 2 indicated a subsistence strategy focused on terrestrial plants and animals, with a minor contribution from riverine resources. In contrast, Individual 1 displayed dietary values suggesting a marinebased diet. This suggests that Individual 1 may have migrated inland from a coastal region (Munoz et al. 2011).

In August of 1997, CAR conducted an intensive archaeological survey within 41HY161 for cultural resources at the proposed location of a parking lot at the current location of the Saltgrass Steak House (the Ice House building adjacent to the Ice House Falls; Ford and Lyle 1998). Investigations consisted of pedestrian survey, backhoe trenching, and shovel test excavations to determine the presence of prehistoric and historic cultural remains and the amount, if any, of possible contextual disturbance. Two backhoe trenches were excavated to depths of $1.2 \mathrm{~m}$ and $1.8 \mathrm{~m}$. Eleven shovel tests were excavated; six 
shovel tests were excavated at 13-m intervals in the area of the proposed parking lot, two were placed along the river bank, and three shovel tests were excavated to define the boundaries of a lithic material deposit. Shovel tests were excavated to a depth of $50 \mathrm{~cm}$ whenever possible (Ford and Lyle 1998). The majority of the shovel tests encountered modern construction remains or were terminated due to natural disturbances. A large number of prehistoric materials in a disturbed context were encountered in ST 2 and included lithic flakes and faunal remains. Three shovel tests were excavated in order to define the boundaries of this deposit; only one, ST 9 produced similar materials. CAR determined that modern and historic construction has disturbed this portion of 41HY161, and that the construction of a parking lot would not critically impact undisturbed cultural remains. Concurrence with this finding was sought from the THC and was granted, resulting in clearance for the proposed parking lot construction (Ford and Lyle 1998).

In the spring and early summer of 1998, CAR returned to $41 \mathrm{HY} 161$ to conduct subsurface testing for cultural resources along the proposed route of a water pipeline for SWT. The proposed pipeline included a tract along the banks of the San Marcos River and tracts adjacent to the Aquatic Biology Building. Investigations included the excavation of 27 shovel tests, two backhoe trenches, and three test units, and monitoring of the pipeline installation (Lyle et al. 2000). Twenty-six shovel tests were excavated in three sections; Section 1 (the lawn area south of the Aquatic Biology Building), Section 2 (the breezeway of the Aquatic Biology Building), and Section 3 (the west lawn of the Aquatic Biology Building). The richest artifact recovery was from Section 3, the west lawn of the Aquatic Biology Building. Shovel tests in this location indicated an upper layer of disturbed soils over lower intact soils containing prehistoric material remains
(Lyle et al. 2000). Backhoe trenches in Section 1 and Section 2 also revealed disturbed soils. The Section 1 trench revealed an area highly disturbed by construction and the demolition of historic buildings, while the Section 2 trench displayed disturbed soils over intact soils encountered at 100 to $120 \mathrm{cmbs}$. Backhoe trenches were excavated to a depth of 140-170 cmbs. As Section 3, the west lawn of the Aquatic Biology Building, possessed a high potential for intact prehistoric cultural remains, three test units were excavated in this location. The three test units were excavated to a depth between 70 and $100 \mathrm{cmbs}$. Investigations indicated that the upper $30 \mathrm{~cm}$ of deposits were disturbed and contained a mixture of modern, historic, and prehistoric cultural remains. Deposits located between 30 and $80 \mathrm{~cm}$ appeared to contain intact Early Archaic remains. While Paleoindian remains were encountered below $80 \mathrm{cmbs}$, the nature of the deposits was not determined. CAR recommended to the THC that construction proceed, as impacts would be contained to the upper disturbed $30-\mathrm{cm}$ levels. The THC concurred with this recommendation, and construction proceeded (Lyle et al. 2000).

In the spring of 2000, CAS conducted archaeological monitoring of a 200-m-long irrigation trench located adjacent to 41HY161 (Jones 2002). The area was once the location of a U.S. Federal Fish Hatchery that was established in 1893. Monitoring was conducted to ascertain if intact deposits were present, and if so, if they would be impacted by the construction of an irrigation trench. Evidence of extensive disturbance that possibly dated from the time of the U.S. Federal Fish Hatchery in 1893 was noted during the monitoring of trench excavations. CAS recommended to the THC that no intact deposits would be impacted, and that the project be given clearance to proceed; THC concurred with these recommendations (Jones 2002). 
Between May and September of 2004, CAS conducted data recovery excavations at 41HY161. The excavations were conducted as partial mitigation for the installation of flood control measures on Sessom Creek on property owned by Texas State (Oksanen 2008). Investigations began with the excavation of three backhoe trenches to the depth of expected impact within the footprint of the proposed construction (Oksanen 2008). The excavation of Backhoe Trench 3 revealed potential intact soil deposits at 180 to $190 \mathrm{cmbs}$. A $3 \times 4-m$ excavation block was then established incorporating Backhoe Trench 3. Eight 1 x 1-m units were excavated by hand to a depth of 260 cmbs. Unit profiles indicate the development of a terrace in a slowly aggrading environment. A series of occupation zones dating from $7700 \mathrm{BP}$ were identified during investigations, consisting of three distinct Early Archaic occupation zones and a fourth zone containing a mixture of Early and Late Archaic materials (Oksanen 2008). The lithic assemblages indicates the use of locally available chert sources from stream beds, eroded upland nodules, and weathered nodules on upland terraces to the west of the site. Based on lithic totals, the dense occupations occurred in Occupation Zone 1, followed by Occupation Zone 2 and 3 (Oksanen 2008).

The project was significant in that it provided information about the little-known Early Archaic period in Central Texas. Only one style of projectile point, Gower, was recovered. This point type has been rarely dated and is usually recovered from mixed deposits. The estimated age of deposits span 1,000 years, from ca. 7700 $\mathrm{BP}$ to $6650 \mathrm{BP}$, and three distinct occupational zones were identified. The site was most intensively used during the earliest occupation. The assemblages from the earliest occupation, ca. $7700 \mathrm{BP}$, indicated that the area was utilized for processing large game animals, projectile points refitting, and new lithic supplies were procured, possibly from nearby chert outcrops (e.g., 41HY37; THC 1999c). The third occupation zone, ca. $6650 \mathrm{BP}$, indicated a shift away from large game coupled with a decline in projectile points and other big game processing tools (Oksanen 2008). The decline in locally available large game may be indicative of increasing population pressures and climate changes that resulted in depleted local resources.

In spring of 2008, CAS again conducted archaeological monitoring of a shallow trench excavation to the southwest of 41HY161 (Yelacic et al. 2008a). The trench was excavated in order to bury waterlines supplying water to the decorative ponds around the University's Theatre Center. The trench was approximately $50 \mathrm{~m}$ long, $20 \mathrm{~cm}$ wide and $50 \mathrm{~cm}$ at its deepest point. No cultural remains or features were noted during excavations. The soil appeared to be disturbed by construction of the U.S. Federal Fish Hatchery Ponds in 1893 (Yelacic et al. 2008a). CAS recommended regulatory clearance for the project, as no intact cultural remains were noted or would be impacted. THC concurred, and the construction was allowed to proceed.

CAS conducted additional investigations in the area of 41HY161 in 2008 (Yelacic et al. 2008b). Investigations consisted of the monitoring of the excavation of a shallow trench as part of construction of a new fence and visual barrier fronting the University-owned Clear Spring Apartments. Monitoring of the trench excavation revealed recent sediments overlying an old paved surface. No archaeological deposits were present or were impacted. Based on these results, CAS concluded that no intact and/or significant cultural properties would be impacted, and requested that permission be granted to proceed with the proposed development. THC concurred, and the construction project advanced. 
CAS conducted cultural resources investigations during September 2009, in advance of the construction of a boiler station to be placed adjacent to the Jowers Center on the campus of Texas State. Investigations consisted of excavation of two test units within the proposed foot print of the building. While excavations encountered mixed historic and prehistoric deposits, these deposits were perceived as a continuation of nearby archaeological site 41HY161, and the boundaries of this site were extended to encompass these newly uncovered cultural remains (Leezer et al. 2010).

\section{HY165 Investigations}

Site 41HY165 is located at the confluence of Sink Creek and Spring Lake on a small peninsula that extends out into the eastern half of the lake, and also extends around the lake margins to the southwest. The first investigations at 41HY165 were conducted in 1984 by Dr. James Garber as part of a field school for SWT (now Texas State University). A second field school was conducted on the site in 1988 by David Driver, along with Garber, and focused on testing and recording the site. Finally, three field schools were conducted on the site between 1996 and 1998 by Garber and Mary Kathryn Brown that involved intensive testing of the site. During the 1996, 1997, and 1998 field schools, 11 test units were excavated over the eastern portion of the site.

The results of the 1996, 1997, and 1998 field investigations were used as the basis for Christopher Ringstaff's masters' thesis dated 2000. While Ringstaff's thesis offers a relatively comprehensive study of the three field school seasons, the focus of his research is on the geoarchaeological properties of the site and thus the attention given to the artifact assemblage and features at the site is limited to that scope of his research.
Cultural materials recovered from the 1996 and 1997 field school were also used in a preliminary faunal analysis by Giesecke (1998). Though she clearly states that her report is only a preliminary analysis, Giesecke identified changes in bison concentrations through time, with the greatest concentration occurring during the Middle Archaic. These findings should be verified.

Between 2000 and 2001, CAS conducted archaeological monitoring of a tree-planting project undertaken by the Department of Biology and archaeological monitoring of the construction of the Campus Map Board along Aquarena Springs Drive for Texas State. While numerous prehistoric and historic artifacts were uncovered during these projects, the majority of the encountered deposits appeared in a mixed context. Despite these findings, discrete areas of intact prehistoric deposits were noted. It was recommended that the site boundaries of 41HY165 be extended to incorporate the areas of these projects, as the newly encountered prehistoric deposits may be part of this wellstratified, prehistoric open campsite (Soucie and Nickels 2003). While the recommendation for the extension of the site boundary of 41HY165 was made, no site update form or redrafting of the site boundaries were submitted to the Texas Archaeological Site Atlas.

Additional prehistoric deposits associated with site 41HY165 were encountered again in 2003 during trench excavations conducted in advance of the installation of a new irrigation system on the Texas State University Golf Course. A dense deposit of lithic artifacts were recovered from an area that extends from the boundary of site 41HY165 established during the Front Door Project through the eighth green and fairwary. It was recommended again that the boundaries of site 41HY165 be extended to encompass 
these newly uncovered deposits (Soucie et al. 2004). Again, no site update form was filed, nor was the site boundary redrafted to include this recommended extension of the site.

\section{Recent Investigations at Spring Lake (41HY160 and 41HY165)}

CAS conducted an intensive archaeological survey, subsurface testing, and underwater investigations in advance of the SLAERP. This work fulfilled the required development and implementation of a subsurface testing program to determine the extent of intact cultural deposits within the project area as presented by the Memorandum of Agreement between the USACE, Texas State, and the THC. This testing program, developed and implemented by CAS, included both terrestrial and underwater investigations. Terrestrial investigations consisted of pedestrian survey, shovel test excavation, test unit excavation, auger pit excavation, and backhoe trench excavation. Underwater investigations included a limited reconnaissance survey, test unit excavation, and extraction of sediment cores. Investigations were conducted within or adjacent to SALs 41 HY160 and $41 \mathrm{HY} 165$. As a result of these investigations, six areas were identified as "Archaeologically Sensitive" as they contained or possessed a high probability to contain cultural deposits that would be negatively impacted by proposed demolition, modifications, and construction (see Figure 6-1). These investigations are reported in detail in Results of Cultural Resources Survey for the Spring Lake Section 206 Aquatic Ecosystem Restoration Project (Leezer et al. 2011). CAS recommended the development of mitigation efforts to offset the loss of important information from areas to be negatively impacted. 


\title{
Chapter 4
}

\section{RESEARCH DESIGN}

\author{
By John A. Campbell, Jon C. Lohse, and Carole A. Leezer
}

The Spring Lake sites (41HY160, 41HY161, 41HY165, 41HY147, 41HY37, and 41HY306), although recorded and described as distinct properties, together reflect an integrated complex representing the long history of human occupation in Central Texas. As discussed in Chapter 3, this history begins with Clovis and is virtually uninterrupted all the way through to the Historical period. Importantly, Native Americans who gathered at Spring Lake were described by early Spanish missionaries and explorers; these accounts provide researchers with an unparalleled opportunity to examine and understand prehistoric cultural practices and adaptations. Through a direct historical approach, the latest portion of the prehistoric record, the Toyah phase, can be contextualized by reference to early written accounts. In turn, the Toyah record helps inform archaeological interpretation of Austin deposits. Working backward in time in this fashion, cultural phase by cultural phase, researchers may be able to discern cultural continuity, or to recognize important moments or events of disjuncture. While Spanish Colonial and historical accounts found elsewhere in the state afford the same opportunity to contextualize preceding periods, very few if any other sites have an occupation record lasting the entire Holocene and extending into the Terminal Pleistocene. In this sense, the Spring Lake archaeological complex affords opportunities to develop new understandings of Native American occupation and cultural patterns in Central Texas.
With this interpretive potential in mind, the current analysis focuses on five generalized research domains established for Spring Lake (Lohse and Leezer 2011; see below). Some reflect the constant concerns of ongoing research in Central Texas. Others derive partly from historical information, and are viewed as a way to expand the scientific understanding of Texas history and prehistory. Domains include: (1) filling in the chronology of human occupation at Spring Lake; (2) understanding how aggregation shaped hunter-gatherer settlement mobility systems; (3) defining periods during which bison were important in local and regional economies, and exploring how other resources and their associated technological adaptations increased or decreased in prominence during these periods; (4) reconstructing trade and clarifying its effect on local economic production and subsistence; and (5) examining the status or role of different kinds of individuals on the basis of sex, age, and/or skill/aptitude. These domains overlap considerably and should be considered in conjunction with each other. Additionally, each is approached using different kinds of data and perspectives, and may not necessarily be applied evenly to all archaeological contexts. Not all are equally addressed in the current analysis.

In this study, we employ an inductive approach to evaluate much of the securely contextualized data. We then develop testable hypotheses that are informed in some way by the five research domains. At the core of this analysis is constructing the site's occupation chronology 
based on time-diagnostic artifacts and accelerator mass spectrometry (AMS) dates from charred plant material and select bone samples. Following this, we address the importance of bison within the economy and technology of the site, and consider how these may have changed over time. Using XAD purification of collagen extracted from bison bone, CAS has amassed a series of 44 AMS assays from three sites, two of which (41HY160 and HY165) are part of the Spring Lake complex, and one of which (41HY188) is located within $2 \mathrm{~km}$ of Spring Lake upstream in the Sink Creek Valley. An additional 11 assays (standard pretreatment) are available from 41HY163, located at the base of the Balcones Escarpment at the mouth of Purgatory Creek, approximately $3.75 \mathrm{~km}$ southwest of Spring Lake (Yelacic and Lohse 2011). Using these dates, CAS has established periods of bison exploitation for the general San Marcos-Hays County region as far back in time as the Calf Creek horizon at the beginning of the Middle Archaic, extending through Late Archaic and Toyah intervals to the early Historic period. This chronology not only defines bison exploitation with greater precision than found in previous bison studies, it also provides a baseline against which technological adaptations can be compared, establishing an interpretive framework for assessing shifts in emphasis on other subsistence resources as well. Analyses of other (non-bison) zooarchaeological remains provide some data for assessing these shifts. These analyses are complemented by an examination of the total burned rock at the site, including both features and discarded rock, as a proxy for examining resource-based adaptation and technological variations. Once these variations in economy and technology are established between discrete periods, conclusions regarding settlement mobility, aggregation and dispersion, trade, and (possibly) individual agency can be formulated.
Below, each research domain is discussed in general terms. Specific information is also provided concerning how these are addressed in the current analysis.

\section{Culture Historical Reconstruction}

A significant amount of attention has been given in past decades to reconstructing the culture history of Central Texas, and all of the major periods that have been defined through these efforts are present at Spring Lake. Of syntheses available for this region, the one by Prewitt (1981, 1983 ) is the most detailed, consisting of 14 phases representing the Early Archaic through Late Prehistoric (Table 4-1). Johnson (1987) argues that not all these phases are valid, and indeed material remains from at least one of Prewitt's phases, Jarrell, have yet to be recovered in unmixed contexts in Central Texas suggesting that Calf Creek should be considered a horizon (e.g., Wyckoff 1994). In spite of the potential usefulness of regional master sequences, it is important for local projects to develop their own localized chronologies.

In spite of the fact that all, or nearly all of the major periods comprising the regional chronology are present, how each was expressed at Spring Lake remains somewhat unclear. No synthetic treatment of the Spring Lake area has yet been carried out, and no comprehensive analysis of sizeable collections from the area has been performed. Moreover, the specific timing of important transitions, for example from Austin to Toyah, or how Jarrell phase (Calf Creek) deposits are represented, varies from region to region. This means that while dates presented for these phases are shown as general ranges, the specific adaptations representing each period need to be established specifically as they occurred at Spring Lake. 
Table 4-1. Archaeological Chronology for Central Texas (after Prewitt 1981, 1983).

\begin{tabular}{|c|c|c|c|c|}
\hline Epoch & Period & Phase & $\begin{array}{c}\text { Age (in Years } \\
\text { BP) }\end{array}$ & $\begin{array}{c}\text { Some Diagnostic Artifact } \\
\text { Types }\end{array}$ \\
\hline \multirow{15}{*}{ 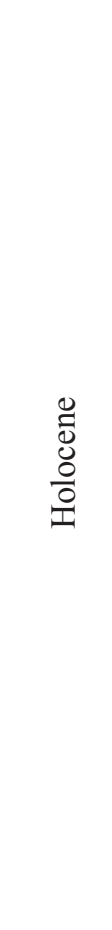 } & Historic & & $\sim \mathrm{AD} 1550$ & European wares, metal tools \\
\hline & Late Prehistoric II & Toyah & $750-<300$ & Perdiz \\
\hline & Late Prehistoric I & Austin & $1200-750$ & Alba, Scallorn, Edwards \\
\hline & \multirow{2}{*}{ Late Archaic III } & Driftwood & $1450-1200$ & Darl, \\
\hline & & Twin Sisters & $1800-1450$ & Ensor, Fairland, Frio, Ellis \\
\hline & \multirow{2}{*}{ Late Archaic II } & Uvalde & $2200-1800$ & Castroville, Marcos, Montell \\
\hline & & San Marcos & $2600-2200$ & Marshall, Lange, Williams \\
\hline & \multirow{2}{*}{ Late Archaic I } & Round Rock & $3400-2600$ & Pedernales, Kinney \\
\hline & & Marshall Ford & $4000-3400$ & Bulverde \\
\hline & Middle Archaic II & Clear Fork & $4500-4000$ & Nolan, Travis \\
\hline & Middle Archaic I & Okalla & $5000-4500$ & Early Triangular (Baird, Taylor) \\
\hline & & Jarrell & $5800-5000$ & Calf Creek (Bell, Andice) \\
\hline & Early Archaic III & San Geronimo (late) & $6800-5800$ & Martindale, Bandy, Uvalde \\
\hline & Early Archaic II & San Geronimo (early) & $8000-6800$ & Gower, Hoxie, Jetta \\
\hline & Early Archaic I & Circleville & $8800-8000$ & Angostura \\
\hline \multirow{2}{*}{ 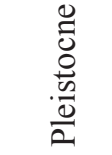 } & Late Paleoindian & & $10,200-8800$ & $\begin{array}{l}\text { Golondrina, Scottsbluff, } \\
\text { Barber, St. Mary's Hall }\end{array}$ \\
\hline & Early Paleoindian & & $11,500-10,200$ & Clovis, Folsom, Midland \\
\hline
\end{tabular}

As an anthropological problem in American archaeology, culture history has fallen out of favor over the past few decades. Over this time, the perceived utility of this objective has become minimized as new paradigms, agendas, and topics have been introduced. Elsewhere, however, efforts at fine-tuning chronologies have persisted at the expense of other possible lines of inquiry, though without realizing the full potential benefits from well-constructed regional sequences. This is especially true of archaeological work in Texas, where many research designs have emphasized chronology-building at the expense of other possible topics (see Arnn 2005; Black 1993). In our view, this issue reflects an underappreciation of the utility of well-made chronologies for facilitating additional, deeper understandings of the full range of human adaptive behavior. Culture-historical reconstructions, then, reflect a two-part problem. One is accurately describing and reconstructing local to regional sequences of events; the other involves examining those events in a comparative way to understand how people responded to external (or internal) stimuli to effect culture change.

An important critique of culture historical reconstructions was what some saw as the primarily descriptive focus on material similarities. Binford (1962; also Taylor 1948) was among the first to bring attention to this issue. Binford (1962:205), in advocating a new approach for archaeology, described culture as "not necessarily shared; (but rather) participated 
in. And it is participated in differentially." A basic characteristic of cultural systems is "the integration of individuals and social units performing different tasks, frequently at different locations." He further urged that "we should partition our observation... so that we may emphasize the nature of variability in artifact populations and facilitate the isolation of causally relevant factors" (1962:205). This critique has two (at least) related implications for chronological reconstructions. First, the stress on variation provides a complementary structuring principle to similarity in local and regional assemblages, and is important in defining archaeological periods by distinctions or differences rather than long periods of apparent continuity. Second, different kinds of driving forces behind cultural changes can occur at a range of temporal and organizational scales, from large-scale climatic regimes and shifts down to localized resource abundance, or from group-level technological behaviors to individual-level decision making. Binford's recognition that individuals participate in cultural systems in different ways remained underdeveloped in most of his research following this statement. Yet individual-scale practices can be important sources of socio-cultural changes that are visible in the archaeological record, and that may result in chronological sequences that have a very high degree of resolution.

These objectives, reconstructing cultural historical events in order to contextualize social and cultural change (sensu Willey and Phillips 2001) while emphasizing scaled variation that extends through group dynamics to individual-level decision making, are not incompatible. Indeed, they ought to be pursued as complementary approaches, leaving the recognition and definition of analytical timespace units the necessary first step in pursuing additional lines of inquiry at Spring Lake. The current report focuses on reconstructing
41HY165's cultural sequence in the context of provisional phases (Prewitt 1981, 1983) defined for the region. As a result of this exercise, analytical units are established based on timediagnostic artifacts recovered during earlier field work and supplemented with absolute dates from selected contexts. Each of these analytical units represents stratigraphically-ordered temporal sequences that are correlated with the cultural/chronological periods of Central Texas. These analytical units are discussed in detail in Chapter 5.

\section{Subsistence Economy and Technological Variation}

As described above and presented in detail in Chapter 5, a relatively precise regional chronology of bison exploitation exists for San Marcos based on 55 directly-dated remains from four sites, including two (HY160 and HY165) at Spring Lake. In addition to defining periods of bison exploitation that are visible in the archaeological record, we use these data to establish a comparative baseline against which other subsistence-related decisions were made. Bison hold particular value in this effort, considering that they would have been one of the, if not the most, highly prized source for protein available during periods of abundance.

One of the central issues addressed throughout this analysis is, for periods defined by a subsistence focus utilizing the largest available game animals on the landscape, how were other subsistence and technological decisions affected? According to optimal foraging theory, hunter-gatherers target the highest-ranked resources in terms of caloric yield compared to the energetic costs of procuring and processing (handling) those resources when they are available (Bettinger 1991; Smith 1981; Smith and Winterhalder 1982). In this model, sources of 
protein routinely outrank plants, herbs, and nuts because of the relatively lower processing costs for animals compared with these other items. While the largest game animals available in any environment are not always the highest ranked (Hawkes et al. 1982), resource ranking in terms of return-versus-handling costs strongly shape hunters' choices about which game animals to pursue (Hawkes et al. 1982). In response to this focus, attention on lesser-ranked resources diminishes, or adjustments are made by foragers to accommodate labor scheduling or to ensure minimally adequate nutritional needs. Bison were the largest game animal on the post-Pleistocene North American landscape (Waguespack and Surovell 2003), and would routinely have been among the highest-ranked food resources during periods of availability throughout the Holocene, based on their caloric returns alone.

Optimal foraging theory predicts that diet optimality will consist of the combination of resources that have the highest returns and lowest handling costs. The model simply predicts that, when available, bison will be pursued by hunters at a higher rate than other sources of protein. However, another important motivating factor for targeting large game has been provided in the show-off hunting hypothesis (Hawkes 1991; also called costly signaling theory; Hawkes and Bliege Bird 2002). This theory explains that, in addition to the nutritional payoffs that come with big game hunting, hunters enjoy and are motivated by social benefits they derive from success in activities that come with higher failure rates or greater physical risks. According to this model, certain males are inclined to undertake riskier food-getting strategies in order to gain access to the social benefits that come with sharing larger portions of meat among the forager band, including opportunities for mating and social prestige. Biological fitness comes from the fact that potential mates see this behavior as indicating or signaling an underlying genotypic or phenotypic quality which will later yield some advantage in mating or social deference (Gurven and Hill 2009).

In the current analysis, we do not favor any particular explanation for why the largest game animals like bison would have been pursued. We only expect that prehistoric hunter-gatherers living close to Spring Lake were probably motivated for several reasons to select bison during periods when they were available. Potential reasons include anticipated social payoffs through security network, access to mating opportunities, the simple ability to provision one's family and dependents that come with larger prey, and even prestige and imbalanced reciprocal obligations that come with providing access to more meat shares available from larger prey (Gurven and Hill 2009). Still, because this resource would have been preferentially taken when it was available, one can also expect these periods to have been defined by additional adjustments to diet choices, by technological innovation for procuring and processing key resources, and by altered balances in sexual divisions of labor.

In order to examine dietary responses as well as technological changes during and between periods of big-game focus, we use data on earth oven use as a general proxy for reconstructing other aspects of a group's subsistence economy and for observing changes in food-related technology over time. As subsistence economies underwent changes to accommodate highlyranked and socially significant resources like bison, we ask: are related adjustments such as increases or decreases in plant processing visible in the record?

In the current analysis, following reconstruction of the site's occupation sequence, our central research focus considers (1) what 
changes can be seen in periods of bison exploitation; (2) what technological adaptations to the tool kit(s) occurred during these intervals; (3) can changes in earth oven use be seen that correlate with the bison exploitation chronology; (4) what technological changes can be seen in the site's tool assemblage that correspond with earth oven usage; and (5) whether these changes, if they can be seen, represent dramatic or fundamental shifts in economy, or merely reflect the addition of these activities to the overall economy during periods of bison abundance. While bison occurrence and earth oven use may not co-vary in a way that represents specific economic shifts, the relative emphasis on these resources (bison and the plant resources presumed to have been processed in earth ovens) may change sharply over time (as bison do, see below) and therefore be useful for constructing precise occupation chronologies for the site, and also represent general behavioral patterns that should be reflected in the tool assemblage. Below, the role of bison in local and regional economies and the current state of thought on the use and technology of earth ovens are discussed in detail.

\section{Bison in Local and Regional Economies}

In addition to the theoretical value of bison for hunter-gatherer economies, bison are understood by archaeologists to have been one of the most significant components of prehistoric subsistence economies in Central Texas, providing meat and fat for food, hide for clothing and cover, and bone for tools. In addition to food, tools, and clothing, bison appear to have held ritual significance among Plains societies from at least the Terminal Pleistocene (Bement 1999) through the Archaic (e.g., Frison 1998) and into the Historic period. After the arrival of Europeans in the seventeenth century onwards, bison were also extensively hunted for trade (see below). After the extinction of Pleistocene megafauna, bison remained the focus of big game hunting in most of North America; while deer, antelope, and other artiodactyls were widely hunted throughout the Holocene, bison appear to have filled a unique niche in Plains society.

The importance of bison in Central Texas in the early Historic was well documented by Europeans. Bison were first recorded here by Henri Joutel, a member of the La Salle expedition of 1684 to 1687 . While Joutel documents over 5,000 bison near La Salle's Fort St. Louis on Garcita Creek in South Texas in 1684, La Salle's expedition also encountered bison near $\mathrm{La}$ Grange during their trek to and from the Texas coast to the Mississippi River in 1687. According to Joutel, bison were present along the southern Guadalupe River throughout most of the year. The largest number of bison recorded by early explorers was by Terán on August 30, 1691, who sighted over 30,000 animals in Burleson County. Based on the early reports of European expeditions through Texas, bison were present and often in large numbers especially in Central Texas. Several early historical documents describe the hostile relationships between Native groups over bison hunting rights (Wade 2002). These accounts make it clear that bison were common in and around Spring Lake in historic times. Archaeological data pertaining to their presence and abundance in prehistoric periods are limited to faunal remains.

Reconstructing bison frequency in the study area is a complex undertaking. Based on previous archaeological findings, bison were abundant during the Paleoindian period; during certain intervals throughout the Early and Middle Archaic, including Calf Creek; during the middle-Late Archaic, particularly Castroville, Montell, and Marcos style intervals; and during the Toyah horizon of the Late Prehistoric (Baugh 1986; Creel 1990; Dillehay 1974; Huebner 1991; Lynott 1979; Mauldin et al. 2012). While early 
models of bison availability (Dillehay 1974; Huebner 1991) focused on periods of presenceabsence, recent considerations (e.g., Mauldin et al. 2012), acknowledging that bison visibility in the archaeological record is affected by many factors, considered periods of "relative abundance." Recent studies note that bison are indicated to varying degrees on sites throughout South and Central Texas during the entire Late Archaic and Late Prehistoric, including during some periods described in previous studies (e.g., Dillehay 1974) as periods of absence. Reasons that potentially affect how bison are recognized on sites include regional climatic trends, localized weather patterns, as well as archaeological visibility (Dillehay 1974; Huebner 1991:345-346).

Based on 55 AMS assays of bison remains from four sites around San Marcos (41HY160, HY163, HY165, and HY188), precise and distinct periods of bison visibility can be recognized for the study area (Figure 4-1). Periods of visibility are based on the summed probabilities of calibrated AMS dates from these four sites, and include the samples from HY165. Cultural periods include
Calf Creek (7 assays), Late Archaic (17 assays), Toyah (26 assays), and post-Toyah historic bison exploitation (5 assays). Within this sample, greater overlap of probabilities for multiple assays is expressed in the vertical axis, and can be taken as a general indication of the relative intensity of focus on bison, within the existing sample of assays. In some instances however, particularly the Toyah horizon, the shape of the probability curves result from the shape of the radiocarbon calibration curve for those periods; these should not be interpreted as indicating distinct and narrowly defined periods of bison exploitation. Although not discussed in detail in this report, all the Calf Creek assays come from a single limited component at HY160; it is possible that multiple specimens from the same individual were submitted in this process, and the probability density for this period should also be viewed cautiously. Nevertheless, beyond the temporal precision indicated by these data, some intriguing patterns are clear. First, no bison dates are available for the long Middle Archaic. Assuming that other important differences can be identified as corresponding with this fact, it may be that Calf Creek can be used to distinguish the

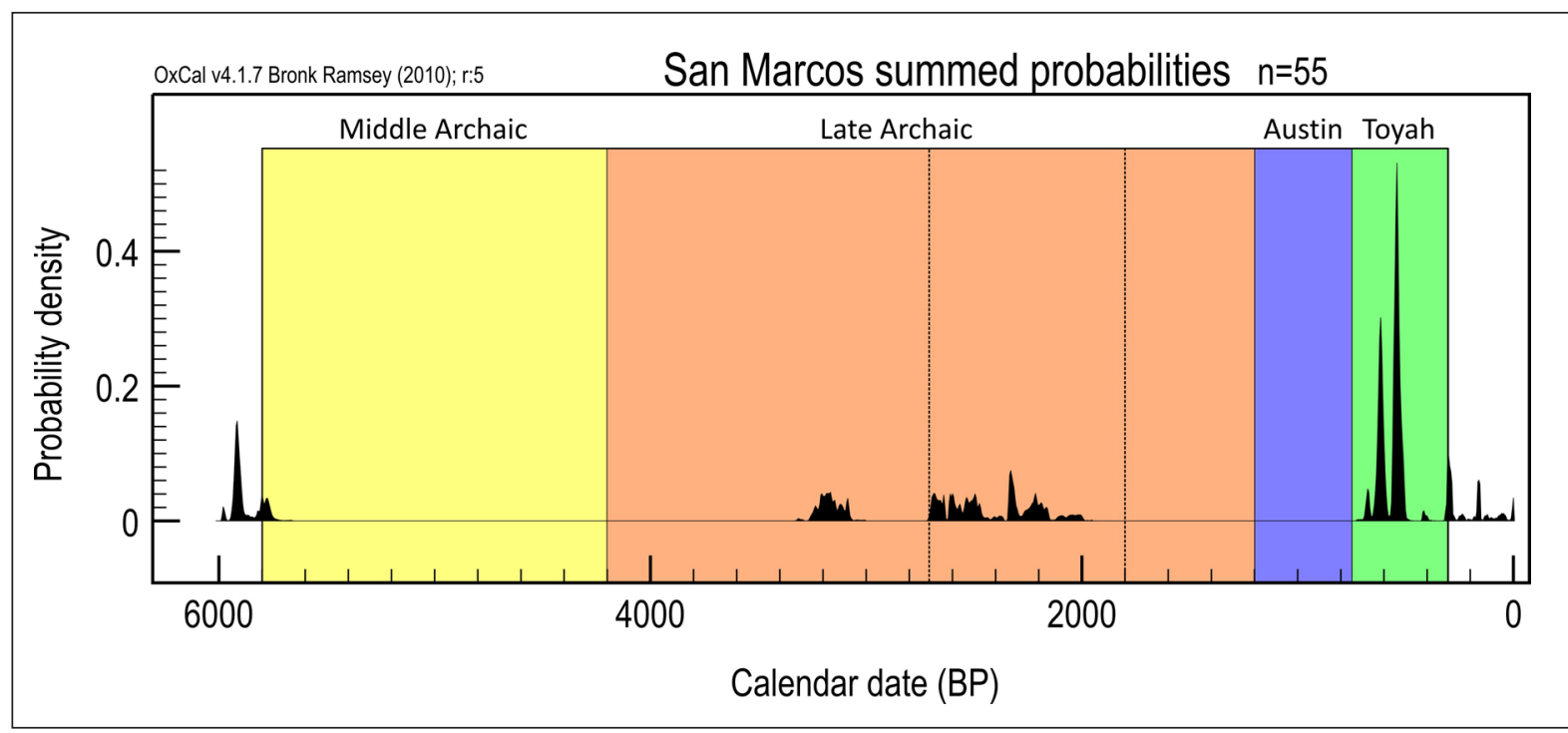

Figure 4-1. Summed probabilities of 55 AMS assays on bison remains from 41HY160, 41HY163, 41HY165, and $41 \mathrm{HY} 188$. 
end of the Early Archaic from the beginning of the Middle Archaic. Also, no dates are available for the Austin phase; future studies should continue to look into the possibility of Austin-period bison exploitation. Finally, there appear to be as many as three periods within the Late Archaic where bison were hunted, at approximately 3050-3300, 2700-2450, and 2350-2050 cal BP. This pattern suggests that at least some dietary decisions made by prehistoric hunter-gatherers can be reconstructed for this period with a relatively high degree of resolution.

Clearly, bison were more plentiful during certain periods than others. Still, during periods when they were relatively abundant, prehistoric peoples appear to have responded not only by centralizing them into their diet and, perhaps, economies and labor schedules. Additionally, in some cases people may have responded by altering settlement and mobility patterns as well. For example, Mauldin et al. (2012:Table 3) hypothesize that bison distribution patterns during Toyah times, when bison are present at 83 percent of 141 components in Central Texas, are a reflection of increased logistical hunting, when bison hunters undertook long-distance treks in pursuit of bison across increasingly large areas. Changes such as this are quite possibly one of the primary factors in the nearly state-wide spread of Toyah traits, furthermore signaling a significant shift in the ways sites were used and occupied in relation to earlier periods. For example, based on radiocarbon assays from the Zatopec site, 41HY163, researchers propose shifts in site occupation histories from approximately once every hundred years for Late Archaic 2-throughAustin times, while Toyah occupation events occurred once every fifty years (Yelacic and Lohse 2011).

In addition to shifts in settlement strategy and food procurement, correlations between technological sophistication and focus on bison are suggested for at least some periods. The Calf Creek horizon, with its specialized, deeply notched triangular points (here including both Bell and Andice types), is seen as a widespread focus on bison exploitation (Bement et al. 2005; Wyckoff 1994, 1995). These points are complex and exceedingly difficult to make, involved specialized tool kits (Collins 1994:93), and may have required as many as 13 discrete steps in their processes of manufacture and finishing (Weber 1994). Creating the deep basal notches required precise workmanship and was associated with high failure rates; so-called practices pieces, showing repeated deep notching but no other standardized form, are common on Archaic sites with Calf Creek components (Turner and Hester 1999). Folsom points, strongly associated with Plains bison hunting, are comparably sophisticated and may have required as many as 14 discrete reduction steps (Lohse 2012). Creel (1991) argues that the thick beveled knives found on Late Prehistoric and early Historic sites in Texas also reflect a technological innovation for processing bison hides. Many Late Prehistoric (Toyah) sites are also characterized by distinctive end scrapers that do not appear in earlier times. Many of these tool forms required specifically developed knowledge and skill sets (Bamforth 1991); involved great attention to manufacturing details, including elaborate reduction sequences that do not characterize other tool forms; communicated stylistic information about their makers in new and meaningful ways; and are likely to have been associated with the emergence of part-time specialization among certain knappers (Lohse et al. 2010).

To understand the role of bison among the inhabitants of 41HY165, the current analysis examines changes in lithic technology evident at the site during periods that correspond with bison frequencies. These periods are reconstructed not 
only by the directly dated assays mentioned above and discussed in detail in Chapter 5, but also by comparative zooarchaeological analyses of the site's well contextualized faunal remains (see Chapter 11). Analysis of the lithic assemblage is carried out with these issues in mind and focuses not only on descriptive attributes of the material from this site, but also compares technological style, including tool form frequencies and approaches to manufacturing, between bison periods and others.

\section{Burned Rock Technology}

While the utilization of bison by the inhabitants of 41HY165 represents a shift in subsistence economy, the increasing use of hot rock cooking facilities may represent a shift towards subsistence intensification. Subsistence intensification is often viewed as a cultural response to increasing population or environmental pressure within a group's occupational range. These pressures require groups to adopt new strategies, primarily increased labor, to increase the food production of a given area, usually resulting in the exploitation of lower ranked or more highly concentrated resources (Binford 2001:188). In general, this means that groups that rely on hunting as a primary subsistence strategy will invest more labor into acquiring aquatic resources and plant foods (Johnson and Hard 2008:138). This process was suggested by Binford (2001:222):

It is reasonable to suggest that if selective forces (such as a reduction in the area needed to sustain a group) are favoring intensification of production, there may be a progression in resource exploitation down the trophic scale in the direction of lower level resources. In such a successional sequence, other things being equal, huntergatherers would shift from terrestrial animals to aquatic resources to, finally, terrestrial plants in settings in which each of these options is feasible. In settings in which some constraint renders impossible one or more options, other trajectories may be expected.

While plant cultivation and animal domestication are often discussed as forms of intensification, Central Texas lacks archaeological or ethnographic evidence of these practices (Johnson and Hard 2008).

The intensification of resources, specifically plants, by hunter-gatherers can be seen in the archaeological record by the presence of plant processing tools and facilities, such as grinding or pounding stones, mortars, and earth oven features. These types of tools and facilities, specifically earth ovens, are used to render plants more digestible and to increase their nutritional value (Wandsnider 1997). Obviously, charred plant remains associated with cooking facilities are another indication of plant exploitation; however, these remains are not always visible in the archaeological record due to poor preservation. The process of cooking food results in increased nutrient density, removal of pathogens and detoxification, and increased storage life (Wandsnider 1997:3). As intensification would require the utilization of a broader range of plant species, the ability to render otherwise inedible plants edible through cooking, as well as transform them into storable units, would have been a key aspect of intensification.

Earth ovens are one of the most visible features on Central Texas archaeological sites. In her review of the ethnographic literature describing earth oven technology, Yu (2006:78) defined some generalized tactics that surround this technology that include the procurement of highly 
seasonal foods, use of otherwise inedible foods, aggregation of population and labor, specialized processing technology, and the repeated use of earth oven locations. The most common plants associated with earth oven use in Central Texas are geophytes, prickly pear, and plants of the Agavaceae family (lechuguilla, sotol, and yucca) that require prolonged cooking times to render them digestible and more nutritious (Dering 2008; Wandsnider 1997). Geophytes, such as wild hyacinth (Camassia sp.) and wild onion/ garlic (Allium sp.) would have been seasonally harvested in the spring and early summer (Boyd et al. 2006), whereas prickly pear and Agavaceae plants would have been available year round. These plants generally require prolonged cooking for 36-48 hours to eliminate toxins in the plants and to convert complex chains of carbohydrates into more simple sugars that are easier to digest (Dering 1999:661; Wandsnider 1997). While the degree to which these plants contributed to the prehistoric diet is still unknown, closed pits or ovens are an efficient way to cook these plants in that heat can be stored in rocks and once buried, will continue to release heat for more than 24 hours (Dering 1999:661; Thoms 2009:576).

Although several methods can be utilized to create an earth oven, the general process involves a layered arrangement of heated rocks, packing material (such as prickly pear, grasses, or other plant material), food, and a cap of sediment to retain heat (Ellis 1997:66-76). The packing material acts as both insulation and a source of moisture for steaming, and in some cases additional water may be added to intensify steaming (Ellis 1997:66-76). Once the food has been cooked, overlying sediments are removed and the food is removed for consumption or additional processing, leaving behind the rocks making up the "oven bed" (Black 1997:259). Use of hot rocks appears to have been the most common means for cooking plants throughout the entire Archaic and Late Prehistoric periods in Central Texas.

Burned rock middens represent the accumulation of waste rock material from these earth oven cooking episodes. Black and Creel (1997:295) argue that burned rock middens result from repeated use of center-focused cooking facilities. The defining characteristic of these midden features is the presence of a primary structural element, such as a centrally located rock-lined pit, which marks the locus of activity (Black and Creel 1997:295). The morphology of the typical Central Texas midden is the result of repeated rearrangement of the waste material around the center; often times manifesting archaeologically as a mounded ring or cone (Black 1997:84-85). Thus, the amount of burned rock waste material will reflect the frequency of use of a particular facility, either during a specific episode of use or repeated uses over time.

The use of earth ovens requires an increased investment of labor to collect the necessary resources, including food, fuel, and rock, for processing plant foods in this way. An increase in the investment of labor most likely required more social organization of foraging and processing activities. Yu (2006) notes that ethnographically, groups in the Pacific Northwest tend to aggregate seasonally in organized foraging groups to collect and process wild hyacinth in earth ovens. This process is normally carried out by the women in the group. However, in the southwest United States, plant processing in earth ovens is more often associated with small, multi-family groups and less gender division of labor ( $\mathrm{Yu}$ 2006). Additionally, earth ovens may have been employed to cook mass quantities of food to take advantage of seasonally available plants and to prevent spoilage after harvest (Wandsnider 1997:23). This short period of resource availability may 
have necessitated the aggregation of labor and subsequent organization.

Although earth ovens were used to process meat, their primary utility is mostly attributed to the processing of inulin-rich geophytes that require extended cooking times. Meat, in general, requires substantially less or no cooking time. Ethnographic accounts reported by Wandsnider (2007:22, Figure 6) indicate some commonly pit-roasted meats (bear, pork, fowl, reptile) require an average of less than 10 hours of roasting time, and larger portions of meats (bison, deer) require between 10 and 20 hours on average. However, Wandsnider (1997:21) suggest that the pit roasting of meats was most advantageous when large portions were required to be cooked or when a large group of people needed to be fed at one time, such as a feast. In 110 ethnographic cases reported by Wandsnider (1997:19), 77.3 percent of earth ovens were used to process plants, 17.3 percent to process animals, and 5.4 percent to process a combination of both.

Earth ovens are obviously not the only source of burned rock. Other sources include open-air hearths for warmth, grilling, drying meat, and heating rocks to use as boiling stones (Figure 4-2) (Thoms 2008, 2009:577). Boiling stones placed in above-ground containers or in water-filled pits were used to cook a variety of foods, both plants and animals. Cabeza de Vaca observed the use of boiling stones to cook beans and squash in gourds by indigenous groups living along the Rio Grande (Krieger 2002). Additionally, boiling water is necessary for extracting the grease from animal bones, as evidenced at the Sanders Site (Quigg
1997) and the Rush Site (Quigg and Peck 1995). The use of open-air cooking facilities requires no investment in hot rock technology and thus reduced labor costs; however, the loss of heat in open-air facilities is considerable when compared to storing heat in rocks and then insulating these from exposure. Open-air facilities would likely result in more fuel consumption focused on shorter-term cooking episodes (Thoms 2009:576). In this sense, the various types of features appear to be selected for processing specific food types rather than for technological efficiency. While burned rocks may be attributed to multiple sources, increasing accumulations of these artifacts indicate an increase in cooking and thus food resource exploitation. As such, high densities of burned rock and the increasing presence of earth oven features within a specific area may indicate a shift towards subsistence 
intensification among a regional population and therefore, these archaeological remains may serve as a proxy for measuring intensification at both the local and regional level (Thoms 2008).

To understand the process of intensification as it relates to hot rock cooking, it is important to also understand the degree to which individual features were utilized, both spatially and temporally. Dering (1999) conducted experimental studies on earth oven cooking in the Lower Pecos using lechuguilla and sotol plants in five experimental earth ovens comparable to Archaic-age features. These experiments found that a single oven firing using $224 \mathrm{~kg}$ of wood fuel and $250 \mathrm{~kg}$ of rock would yield 5.1 person-days of calories and 0.13 $\mathrm{m}^{3}$ of rock waste (Dering 1999:665). Dering's study not only shows how rapidly plant and rock refuse can accumulate in a short period of time, it also indicates how quickly resources may be depleted across the landscape. Leach et al. (1998) also conducted investigations on an experimental earth oven using thermocouples to monitor temperature changes in the oven and the rate of rock reuse and discard. Their experiment utilized only $63 \mathrm{~kg}$ of wood fuel and $91 \mathrm{~kg}$ of limestone rock, estimating that rocks could be reused as many as four times before discard.

Dering's quantitative data with regard to use intensity can be applied to burned rock features in archaeological contexts to determine the relative frequency of these activities. For example, Johnson (2009) used Dering's (1999) experiments to estimate the total number of firing episodes for the extensive burned rock midden at the Barnett Site (41MI77) in Mills County to be between 150 and 1,000 times. The wide range between these figures is the result of the fact that limestone rock fractures randomly when heated, and fractures even more when used repeatedly; these factors make it unlikely that accurate determinations of the number of firing episodes of a burned rock feature can ever be estimated with much accuracy. However, assuming that earth oven features on a site are approximately similar to those used in experiments, overall rock weight is a fairly accurate indication of how intensively these features were used. Studies such as Johnson's (2009) will not yield results accurate enough to determine the use firing history of any specific earth oven or feature. However, when the same criteria are applied across a site, it should be possible to calculate the relative use intensity of these features over time, and to thereby hypothesize changes in the importance of these features to food processing behaviors, such as intensification.

Data from burned rocks will be used in two ways to understand possible shifts in subsistence economies over time at 41HY165. First, qualitative estimates of the relative use intensity of fire-cracked rock features will be generated by standardizing the total rock weight across all analytical units. Burned rock occurrence within these analytical units is then calculated by total burned rock weight, including both from intact or discrete features as well as from more dispersed contexts. Results will approximately indicate the relative degree to which burned rock features were important in the subsistence economies of these different periods. Based on these results, the investigators can then address certain specific research questions, including:

- How does earth oven use-intensity change over time?

- How does earth oven use-intensity correlate with periods of bison presence /absence?

- Can subsistence economy and technology at $41 \mathrm{HY} 165$ be explained through these correlations? 
In order to supplement the frequency data of burned rock, certain residue and plant microfossil analyses are also presented. These studies focus on identifying microfossil (phytolith, starch grains, and other fossil remains) that may adhere to rocks that were part of features used to process important plant resources. These data, while not useful for addressing the use of features for cooking plants versus animals, provide an important additional level of detail concerning how burned rock cooking technology was used in the processing of plant resources. 


\title{
Chapter 5
}

\section{Analytical Units and Approaches}

\author{
By John A. Campbell
}

\section{Analytical Units}

Site 41HY165 was excavated during the summers of 1996, 1997, and 1998 by SWT field schools. Eleven units ranging in size from $1 \times 1 \mathrm{~m}$ to $2 \times 2 \mathrm{~m}$ were excavated on the site, as well as nine shovel tests (Figure 5-1). The depths of the units varied from $25 \mathrm{~cm}$ to as deep as $280 \mathrm{cmbs}$. In addition, the $2 \times 2-m$ units were excavated in 1-m quandrants, and the depth of these quadrants varied across the unit as well. In general, units were excavated in 10-cm levels; however in some cases this interval was reduced to $5 \mathrm{~cm}$ to increase resolution in areas of relatively high artifact density. Artifacts collected from shovel tests are not included in this analysis due to their unreliable context. It should be noted that a previous field school was conducted at the site in 1984, and several artifacts are present in this collection. Unfortunately, the location of the 1984 excavation units is unknown, and therefore the materials collected during that field season are not included in this analysis. Unless stated otherwise, all depths provided are relative to the

FIGURE 5-1. REDACTED

Figure 5-1. Site map of 41HY165 showing excavation units (image digitized from map in Ringstaff 2000). 
ground surface, which is assumed to be level. Primary resources used in the preparation of this analysis include Rigstaff's (2000) Master's thesis, excavation paperwork, and student field journals. Soil horizons discussed in this report were defined by Ringstaff (2000).

The material collection of site 41HY165 consists of over 92,000 artifacts that include projectile points, formal and informal stone tools, debitage, prehistoric and historic ceramics, bone, shell, burned rock, and various historic artifacts. These artifacts represent continuous, multiple episodes of occupation dating from the Late Paleoindian period to the Historic period. In preparing for the analysis of the prehistoric and historic Native American artifacts, analytical units (AUs) were established based on temporally diagnostic projectile points and radiometric dates, including those run on dated bison bone as well as charred plant material. Projectile point types were typed according to definitions of regionally occurring styles presented by Turner and Hester (1999), Prewitt (1995), Bell (1993, 1996), and Perino (1996a, 1996b).

AUs were established based on the contexts of diagnostic artifacts within unmixed and undisturbed deposits, to the extent that this could be determined. Deposits are considered to be mixed or disturbed if younger points or absolute dates occur below older points or dates. Older temporal markers occurring above or in association with younger ones are not necessarily considered indicative of disturbed contexts given the potential for postdepositional collection and curation by subsequent occupations.

Overall, the distribution of projectile points at the site does not indicate highly mixed deposits, with two exceptions. The first of these points is a Fairland point (Specimen 124-1) from the southeast quadrangle of Unit 8 between 65 and $75 \mathrm{~cm}$ depth. The context of this point is questionable due to the presence of Pedernales points in the overlying and underlying levels. However, the Pedernales points in this instance appear to have been reused, and there is no other indication that this area of the site is not intact. Therefore, the AU at this location is associated with the Fairland point. The second exception is an Ensor point (Specimen 68-2) found in the northeast quadrangle of Unit 2 that occurs deeper than all other points, at a depth of $129 \mathrm{~cm}$. However, a review of the field documentation and student journals indicates a series of former rodent burrows across the unit level where this point occurs. In addition, the point was found only one level below where the unit was terminated at the end of the 1996 field season, suggesting a potential for mixing from overlying levels between the 1996 and 1997 field seasons.

Other evidence of mixing occurs in the upper $50 \mathrm{~cm}$ of deposits. This zone consists of the A Horizon as defined by Ringstaff (2000), and contains an array of points ranging from the Middle Archaic into the Late Prehistoric. This mixing may represent disturbance, curation of older tools by subsequent occupations, overprinting of occupational episodes, or all of these factors. (Records from the field school do not indicate any disturbance within this zone.) Finally, areas where prehistoric artifacts are associated with historic items are considered to be a poor context for isolating prehistoric components. Consequently, prehistoric remains from these levels will not be attributed to any $\mathrm{AU}$ and will not be analyzed. This includes the upper 20-40 $\mathrm{cm}$ across virtually the entire site (Figure $5-2)$.

Following these principles, seven AUs were identified based on an analysis of diagnostic projectile points (Table 5-1) and radiocarbon dates of bison bone (Table 5-2) and charcoal 


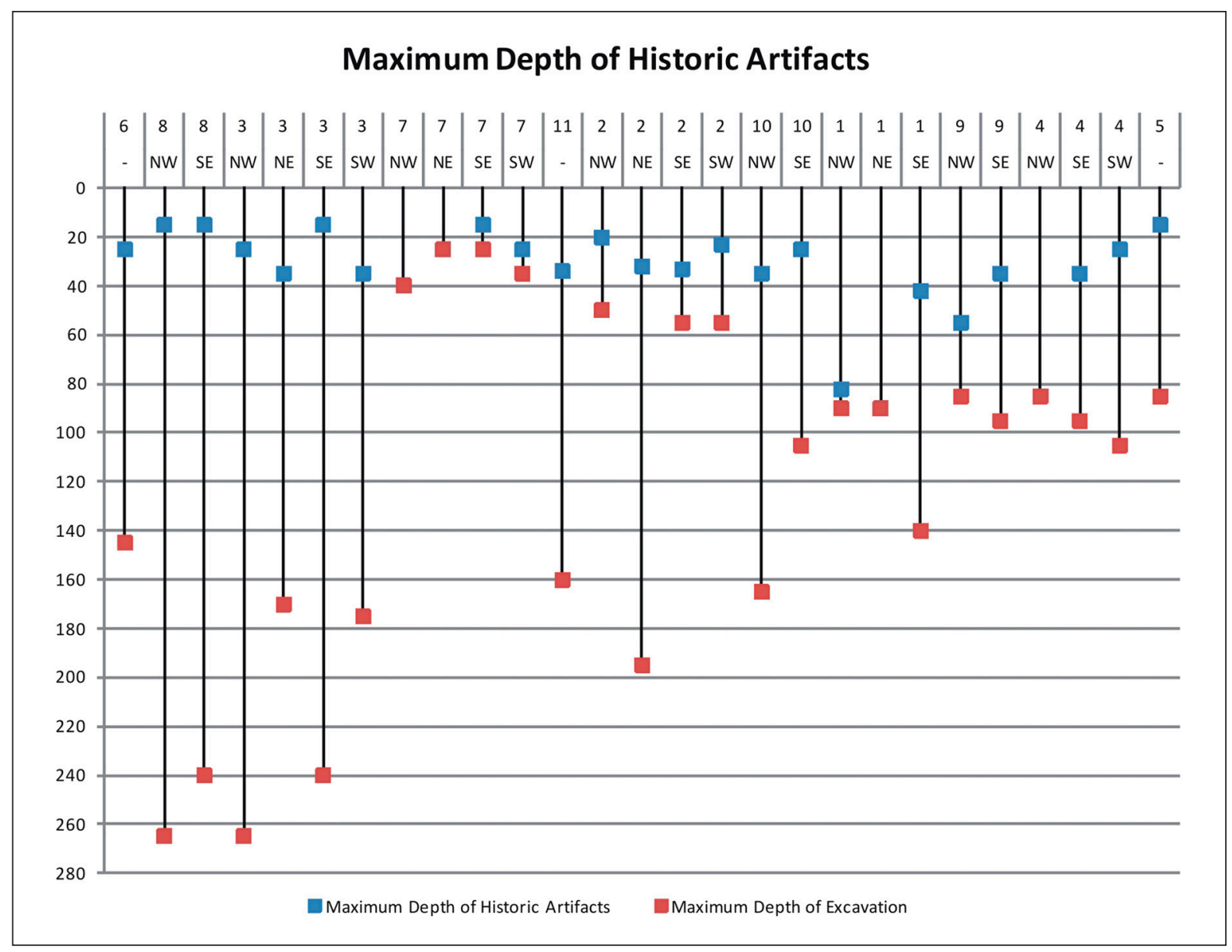

Figure 5-2. Maximum depth of historic artifacts and unit depths.

(Table 5-3). These AUs are: AU 1, Historic EuroAmerican; AU 2, Historic Native American; AU 3a, Late Prehistoric-Toyah; AU 3b, Late Prehistoric-Austin; AU 4a, Late Archaic II; AU 4b, Late Archaic I; AU 5, Middle Archaic; AU 6, Early Archaic; and AU 7, Late Paleoindian. While all temporal periods are represented within the collection, some AUs, specifically AU 1 and AU 2, will be analyzed in a more general fashion due to the imprecise nature of these contexts. Additionally, several diagnostic projectile points, as well five additional bison bone dates were identified at depths associated with historic artifacts. While the projectile points in these contexts hold little utility for analysis, the bison dates are still useful for establishing a time frame for the presence or absence of bison around Aquarena Springs. A list of the artifacts recovered from the AUs is provided in Appendix $A$ at the end of this report. All radiocarbon data from this site are presented by context in Appendix B.

\section{A Note about Radiocarbon Dating}

In total, 24 absolute dates are available from this small area of 41HY165. Twenty two of these were submitted during the present analysis of the extant collection from the site. One (Beta117967) had been processed by Ringstaff and is reported in his 2000 Master's thesis. The final date (ISGS-A1966) was submitted from a controlled excavation that was carried out during the survey and assessment phase of the SLAERP 
Table 5-1. AUs Associated with Diagnostic Projectile Points.

\begin{tabular}{cccccccc}
\hline AU & Period & $\begin{array}{c}\text { Specimen } \\
\text { No. }\end{array}$ & Type & Unit & Quad & Level & $\begin{array}{c}\text { Depth } \\
\text { (cmbs) }\end{array}$ \\
\hline 3b & Late Prehistoric-Austin & $65-2$ & Edwards/Scallorn & 2 & SE & 5 & $33-43$ \\
3b & Late Prehistoric-Austin & $66-5$ & Scallorn & 2 & SW & 5 & $33-43$ \\
3b & Late Prehistoric-Austin & $66-6$ & Darl & 2 & SW & 5 & $33-43$ \\
4a & Late Archaic II & $123-1$ & Marcos & 8 & NW & 4 & $25-35$ \\
4a & Late Archaic II & $124-1$ & Fairland & 8 & SE & 8 & $65-75$ \\
4a & Late Archaic II & $128-1$ & Ensor & 7 & SW & 4 & $25-35$ \\
4a & Late Archaic II & $256-6$ & Ensor & 11 & - & 4 & $24-34$ \\
4a & Late Archaic II & $336-7$ & Fairland & 10 & NW & 5 & $35-45$ \\
4b & Late Archaic I & $129-1$ & Pedernales & 10 & NW & 6 & $45-55$ \\
4b & Late Archaic I & $69-4$ & Morhiss & 2 & NE & 10 & $82-92$ \\
5 & Middle Archaic & $29-4$ & Travis & 1 & SE & 11 & $92-102$ \\
\hline
\end{tabular}

Table 5-2. AUs Associated with Bison Bone Dates.

\begin{tabular}{|c|c|c|c|c|c|c|c|c|}
\hline $\mathbf{A U}$ & Period & Specimen & Unit & Quad & Level & $\begin{array}{l}\text { Depth } \\
\text { (cmbs) }\end{array}$ & $\begin{array}{l}{ }^{14} \text { C Age } \\
\text { (BP) }\end{array}$ & $2 \sigma$ cal $\mathrm{BP}^{1}$ \\
\hline $3 a$ & Late Prehistoric-Toyah & $79-5$ & 2 & SW & 4 & $23-33$ & $575 \pm 20$ & $\begin{array}{l}640-590(60.7 \%) \\
564-536(34.7 \%)\end{array}$ \\
\hline $4 \mathrm{a}$ & Late Archaic II & $240-1$ & 11 & - & 7 & $54-64$ & $2205 \pm 20$ & $2312-2151$ \\
\hline $4 \mathrm{a}$ & Late Archaic II & $238-7$ & 3 & $\mathrm{NE}$ & 6 & $45-55$ & $2475 \pm 15$ & $\begin{array}{l}2467-2619(66 \%) \\
2632-2707(34 \%)\end{array}$ \\
\hline $4 b$ & Late Archaic I & $152-5$ & 3 & $\mathrm{NE}$ & 7 & $55-65$ & $3000 \pm 20$ & $\begin{array}{c}3265-3139(84.2 \%) \\
3320-3295(4.0 \%) \\
3094-3080(3.7 \%) \\
3128-3108(3.6 \%)\end{array}$ \\
\hline $4 b$ & Late Archaic I & $293-1$ & 8 & NW & 11 & $80-85$ & $2965 \pm 20$ & $3217-3069$ \\
\hline $4 b$ & Late Archaic I & $252-13$ & 11 & - & 10 & $84-94$ & $3065 \pm 15$ & $\begin{array}{c}3254-3241(99.6 \%) \\
3225-3224(0.4 \%)\end{array}$ \\
\hline
\end{tabular}

${ }^{1}$ Dates calibrated using IntCal09 (Reimer et al. 2009).

(Leezer et al. 2011). Samples submitted for dating were selected to simultaneously address several questions. Most important was establishing chronological control for the excavations. The earlier analysis had concluded that intact Late Paleoindian strata were present here, and this suggestion required verification. Additionally, a directed study (Giesecke 1998) identified bison 
Table 5-3. AUs Associated with Charcoal Dates.

\begin{tabular}{|c|c|c|c|c|c|c|c|c|}
\hline $\mathbf{A U}$ & Period & Specimen & Unit & Quad & Level & $\begin{array}{l}\text { Depth } \\
\text { (cmbs) }\end{array}$ & $\begin{array}{c}{ }^{14} \text { C Age } \\
\text { (BP) }\end{array}$ & $2 \sigma$ cal $\mathrm{BP}^{1}$ \\
\hline $4 a$ & Late Archaic II & - & 8 & NW & 9 & $70-75$ & $2300 \pm 40$ & $\begin{array}{l}2296-2361(62 \%) \\
2156-2267(38 \%)\end{array}$ \\
\hline $3 b$ & Late Prehistoric & $65-7$ & 2 & SE & 5 & $33-43$ & $930 \pm 20$ & $793-915$ \\
\hline $4 a$ & Late Archaic II & $120-26$ & 3 & SW & 10 & $80-90$ & $1760 \pm 20$ & $1608-1724$ \\
\hline $4 a / 4 b$ & Late Archaic & $126-9$ & 3 & SW & 9 & $75-85$ & $2435 \pm 20$ & $\begin{array}{c}2356-2501(75.4 \%) \\
2596-2613(4.5 \%) \\
2637-2694(20.1 \%)\end{array}$ \\
\hline $4 a$ & Late Archaic II & $146-8$ & 3 & SW & 11 & $90-95$ & $1965 \pm 20$ & $\begin{array}{c}1871-1951(95.2 \%) \\
1960-1971(3.3 \%) \\
1979-1985(1.5 \%)\end{array}$ \\
\hline 5 & Middle Archaic & $164-5$ & 3 & NE & 14 & $125-135$ & $4490 \pm 20$ & $\begin{array}{c}5045-5093(19.2 \%) \\
5096-5144(19.8 \%) \\
5156-5287(61 \%)\end{array}$ \\
\hline $4 a$ & Late Archaic II & $249-4$ & 11 & - & 9 & $74-84$ & $2210 \pm 20$ & $\begin{array}{l}2152-2280(84.6 \%) \\
2285-2313(15.4 \%)\end{array}$ \\
\hline $4 a / 4 b$ & Late Archaic & $290-5$ & 8 & NW & 12 & $85-90$ & $2435 \pm 20$ & $\begin{array}{c}2356-2501(75.4 \%) \\
2596-2613(4.5 \%) \\
2637-2694(20.1 \%)\end{array}$ \\
\hline $4 a$ & Late Archaic II & $291-4$ & 8 & $\mathrm{SE}$ & 4 & $25-35$ & $1580 \pm 20$ & $1412-1524$ \\
\hline $4 \mathrm{~b} / 5$ & $\begin{array}{l}\text { Late Archaic I/ } \\
\text { Middle Archaic }\end{array}$ & $310-8$ & 8 & NW & 20 & $130-135$ & $3860 \pm 20$ & $\begin{array}{c}4162-4167(0.8 \%) \\
4181-4198(4.7 \%) \\
4231-4409(94.5 \%)\end{array}$ \\
\hline $4 \mathrm{~b}$ & Late Archaic I & $114-3$ & 2 & NE & 11 & $92-102$ & $2905 \pm 20$ & $\begin{array}{c}2962-3081(88.4 \%) \\
3092-3114(6.3 \%) \\
3121-3142(5.3 \%)\end{array}$ \\
\hline
\end{tabular}

${ }^{1}$ Dates calibrated using IntCal09 (Reimer et al. 2009).

present during the Middle Archaic. Clearly, the temporal accuracy of this conclusion depends on the precision with which deposits at the site are dated. The absence of any bison from excavated Middle Archaic contexts elsewhere at Spring Lake (Lohse and Cholak 2011) casts doubt on this conclusion. Consequently, providing a more robust sample of directly-dated bison remains was a second priority for the current analysis.
Samples of bison remains were selected for dating based on the general distribution of this taxon. Twelve samples of bison were selected from across the stratigraphic column at 41HY165 (see results by provenience in Appendix B). The results of these assays, when determined to be in proper stratigraphic order, were used to help define AUs. These results supplemented a total of 12 radiocarbon assays on carbon, wood, or carbonized wood in providing absolute dates for 
this deposit. All but two samples (Beta-117967 and ISGS-A1966) were pretreated at the University of Oregon Radiocarbon laboratory, with the prepared targets submitted to the Accelerator Mass Spectrometry Laboratory at the University of California at Irvine. Bone samples were pretreated using the XAD purification technique developed by Thomas Stafford (Stafford et al. 1988, 1991). The result is highly reliable, highprecision AMS dates with standard deviations of as little as 15 years in some cases, and 20 years for most samples. Regional chronologies of bison exploitation, based in part on the record from 41HY165, are presented in Chapter 4.

\section{AU 1: Historic Euro-American}

This AU represents the undefined Historic debris that was recovered primarily from the A Horizon. These artifacts include ceramics, glass, metal, building materials, and a variety of other debris typically associated with Euro-American occupations in the region during the nineteenth and twentieth centuries. This debris occurs in the upper levels of all units and is likely to be mixed given the presence of prehistoric projectile points, some as early as the Middle Archaic, and artifacts in these levels. An analysis of this assemblage may allow for this unit to be further divided (Spanish Colonial, Texas Revolution, post-Civil War, etc.) if distinct spatio-temporal units can be isolated. Therefore, analysis will rely more heavily on diagnostic artifacts with the goal of establishing general periods of settlement with less consideration for spatial context.

\section{AU 2: Protohistoric Native American}

AU 2 consists of a single Guerrero (Mission) point and a single sherd of Goliad ware pottery. These artifacts are characteristic Native American styles from the time of the Spanish entradas and the establishment of missions during the Protohistoric period. The Guerrero point is a small, lanceolate arrow point that is commonly found in association with occupations at Spanish missions (Tomka and Fox 1999:34). The point was found in the northwest quadrangle of Unit 3 between 5 and $15 \mathrm{cmbs}$, within the A Horizon. Due to their association with Spanish missions in Texas, these points generally date from the late seventeenth century into the eighteenth century. A single ceramic sherd found at the site resembles Goliad ware (Figueroa and Mauldin 2005:53). Goliad ware is bone tempered with a red-brown exterior and black interior, and it originated with Native American groups in South Texas (Tomka and Fox 1998:20). This ceramic type is common among Spanish Colonial assemblages (Tomka and Fox 1998:20) but is also occasionally found outside of mission contexts, such as this one. The single piece of Goliad ware was found in the southeast quadrangle of Unit 7 between 5 and $15 \mathrm{cmbs}$. Unfortunately, due to the amount of historic material found in this site's upper levels, it is not possible to identify specific lots that can be included in this AU. However, this AU presents some information regarding Native American presence and occupation at Spring Lake during the Spanish Colonial era.

\section{AU 3: Late Prehistoric}

This AU represents the Late Prehistoric assemblage at 41HY165 and includes all arrow points and ceramics overlying the earlier Archaic components. This unit has been divided into AU 3a and AU 3b. The first, AU 3a, denotes the Toyah phase of the Late Prehistoric, distinguished by the Perdiz arrow point style. The Toyah phase extends from around $800 \mathrm{BP}$ to as late as 350 BP in Central Texas (Johnson 1994:257-258; Johnson and Goode 1994:41). Perdiz points were noted between 10 and $35 \mathrm{cmbs}$, all within the A Horizon. However, these points occur in the same context as later historic material, and are not considered as contributing to the AU. Due to the uncertain context of the Perdiz points at the site, 
a single fragment of bison bone (Specimen 79-5), dating to 536-640 cal BP, was used to establish this AU within the southwest quadrangle of Unit 2 between 23 and 33 cmbs.

$\mathrm{AU} 3 \mathrm{~b}$ represents the Austin phase, characterized by the Scallorn and Edwards arrow point styles. The Austin phase extends from 1200 BP up to the onset of Toyah (Collins 2004:122). At 41HY165, Scallorn and Edwards points are found between 33 and $43 \mathrm{cmbs}$ in the southwest and southeast quadrangles of Unit 2. This AU is also entirely within the A Horizon and may include a reused Darl type projectile point at the lower end of the level. A piece of charred wood (Specimen 65-7) was also submitted for radiocarbon dating from the southeast quadrangle in Unit 2, where it is associated with an Edwards/Scallorn projectile point. The date returned from this sample was between 793 and 915 cal BP, well within the age range of the Austin interval.

As mentioned, some Archaic projectile point styles occur within Late Prehistoric components. The Late Archaic II period, as defined by Johnson and Goode (1994), is represented by Ensor, Darl, Frio, Fairland, and Marcos points. Late Archaic I points (Montell and Lange) and a Middle Archaic (Travis) point are also found in this zone. These older points were likely used and then deposited by subsequent inhabitants of the area, considering that no evidence of disturbance was reported.

\section{AU 4: Late Archaic}

The Late Archaic is an enormously long period that almost certainly incorporates a large volume of otherwise meaningful cultural variation in terms of adaptive behaviors. Problems with recognizing this variation and, consequently, implementing more refined chronological schemes have to do with the degree to which remains from different Late Archaic intervals are often found compressed, mixed, or otherwise poorly resolved. Much of this has to do with climatic processes that are unfavorable to stratigraphic resolution and clarity; Johnson and Goode (1994), for example, define the very dry Edwards Interval as beginning at this time. This xeric period would have been associated with soil erosion or reduced rates of sedimentation. Coupled with cultural processes involving digging shallow pits for earth ovens, strata from this period are commonly mixed or altogether absent. Still, given long enough spans of time, the Late Archaic can be subdivided into finer chronological units.

\section{AU 4a: Late Archaic II}

The Late Archaic II subperiod is represented at the site by two Ensor style points, two Fairland style points, a Marcos style point, a bison bone date, and a radiocarbon date of charcoal. This is the largest $\mathrm{AU}$ at the site, with over 2,400 associated artifacts identified across different units and at different elevations (Table 5-4). This $\mathrm{AU}$ also occurs in both the $\mathrm{A}$ and $\mathrm{ABb}$ horizons defined by Ringstaff (2000). Two Pedernales points (Specimens 125-1 and 124-2), dating to Late Archaic I times, were found above and among this $\mathrm{AU}$ in the southeast quadrangle of Unit 8. Both were recycled and then redeposited in these levels and there is no indication that these levels are disturbed or mixed in any way. It is therefore assumed that the Fairland point in this context represents the occupation at this level.

\section{AU 4b: Late Archaic I}

AU $4 b$ represents the Late Archaic I component at the site, which dates from 4300 BP to 2550 BP (Johnson and Goode 1994:34). This AU consists of a Pedernales point, a single Morhiss point, and two dates obtained from bison bone. This $\mathrm{AU}$ occurs within the $\mathrm{ABb}$ horizon at the site. Turner and Hester (1999) date Pedernales points to the Middle Archaic between $4000 \mathrm{BP}$ and 3200 BP, while Prewitt (1981) places Pedernales 
Table 5-4. Units and Specimens that Define AU 4a

\begin{tabular}{cccccc}
\hline Unit & Quadrangle & $\begin{array}{c}\text { Top Depth } \\
\text { (cmbs) }\end{array}$ & $\begin{array}{c}\text { Bottom } \\
\text { Depth }(\mathbf{c m b s})\end{array}$ & Diagnostic & Specimen \\
\hline 3 & NE & 45 & 55 & bison bone date & $238-7$ \\
7 & SW & 25 & 35 & Ensor point & $128-1$ \\
8 & NW & 25 & 35 & Marcos point & $123-1$ \\
8 & NW & 70 & 75 & radiocarbon date & Ringstaff (2000) \\
8 & SE & 65 & 75 & Fairland point & $124-1$ \\
10 & NW & 35 & 45 & Fairland point & $336-7$ \\
11 & - & 25 & 35 & Ensor point & $256-6$ \\
11 & - & 55 & 65 & bison bone date & $240-1$ \\
\hline
\end{tabular}

points within his Middle Archaic Round Rock phase between 3400 BP and 2600 BP. However, Johnson and Goode (1994:29) argue that due to stylistic, technological, and economical similarities between Pedernales and Montell, the onset of the Late Archaic should be pushed back to include Pedernales around 4300 BP. Collins (2004:121) also puts the start of the Late Archaic around this same time (4000 BP). Morhiss points, while more common in South Texas, also date to the Late Archaic I period, and chronologically precede Castroville and Marshall points (Brown 1983:89). There is no indication that Pedernales and Morhiss points at $41 \mathrm{HY} 165$ represent the same occupation. The Pedernales point was found in the northwest quadrangle of Unit 10 between 45 and $55 \mathrm{cmbs}$, while the Morhiss point was found in the northeast quadrangle of Unit 2 between 80 and $90 \mathrm{cmbs}$. The bison bone dates come from the northeast quadrangle of Unit 3 between 55 and $65 \mathrm{cmbs}$ and in the northwest quadrangle of Unit 8 between 80 and 85 cmbs.

\section{AU 5: Middle Archaic}

The Middle Archaic at 41HY165 is categorized as AU 5, which is represented by a single Travis point. Travis points are considered part of the latter part of the Middle Archaic and are generally associated with Nolan points stylistically and temporally (Collins 2004:120). Collins (2004) dates the Middle Archaic period to around 6000-4000 BP. Johnson and Goode (1994) suggest a narrower range, from 5600 to 4300 BP. Recent radiocarbon dating from the Gatlin Site (Houk et al. 2009) seems to confirm Johnson and Goode's timeline for the Middle Archaic. The Travis point at 41HY165 was found in the southeast quadrangle of Unit 1 between 90 and 100 cmbs. Although Ringstaff (2000) did not define the soils in Unit 1, this unit is close to Unit 10, and the depth of this Travis point corresponds to the $\mathrm{ABb}$ Horizon.

\section{AU 6: Early Archaic and Late Paleoindian}

These two periods at $41 \mathrm{HY} 165$ are represented by five projectile points. However, these artifacts derive from questionable contexts and were not included in this analysis. The Early Archaic period is represented by three projectile points, an Early Archaic Stemmed, an Early Archaic Split-Stemmed, and a Gower point. Recent investigations have identified Gower points in deposits dating to between $8600 \mathrm{cal} \mathrm{BP}$ and $7440 \mathrm{cal} \mathrm{BP}$ at the Icehouse site (Oksanen 2008) and between 7150 cal BP and $6860 \mathrm{cal}$ 
BP at the Gatlin Site (Houk et al. 2009). Clearly, this type was not in use for almost two thousand years, and further refinement in associated ages is necessary. We consider the Gower deposits at the Icehouse site to be more relevant for the current analysis, since this site is located less than $200 \mathrm{~m}$ to the west of 41HY165. In addition, Gower points at Icehouse were the only projectile points from the Early Archaic occupations at that site. The Gower point at 41HY165 was found in the southwest quadrant of Unit 3 between 75 and 85 cmbs. Unfortunately, wood charcoal from this level was dated to 2356-2694 cal BP (Specimen 126-9), leaving the context of this Gower point highly problematic.

Two projectile points date to the Late Paleoindian period, including a Golondrina point and a Big Sandy (early side-notched) point. The Late Paleoindian period dates from between approximately 10,000 BP and $8000 \mathrm{BP}$ and is divided into three subperiods: Wilson, Golondrina-Barber, and St. Mary's Hall (Collins 2004:118). Wilson components date to between 10,000 and $9650 \mathrm{BP}$, while the other two components date from 9500 to 8000 BP. While all of these points occur within Ringstaff's (2000) Bw2b Horizon, they are distributed vertically, with the Golondrina point occurring between 85 and $90 \mathrm{cmbs}$ and the Big Sandy point between 95 and $100 \mathrm{cmbs}$. The Early Stemmed point was found between 125 and 130 cmbs. The Golondrina and Big Sandy points are both found in the southwest quadrant of Unit 3 and the Early Stemmed point is found in the northwest quadrant of Unit 8. Turner and Hester (1999:106) equate the Early Stemmed variety with both Wilson points as well as with Golondrina components. The Big Sandy point, also referred to as early side-notched, is uncommon in Texas and generally dates to the Archaic period in the southeast (Perino 1985:36). Perino (1985:36) argues that Big Sandy points only occur in central
Tennessee and parts of Kentucky and Alabama. However, Justice (1987:60) notes the presence of this point in Late Paleoindian occupations in Alabama and Illinois. In northwestern Louisiana, Webb et al. (1971:41) noted early side-notched projectile points in association with San Patrice points at the John Pearce Site, and in Texas, early side-notched points were found in association with San Patrice at the Wolfshead Site in San Augustine County (Duffield 1963). A Big Sandy point was also found along Cibolo Creek at site 41CM96 (Gerstle et al. 1978:84).

The problematic (late) date from the Gower level above also indicates a poor context for these lower points. Additional dates from the underlying levels also confirm a poor context for the Late Paleoindian projectile points. A charcoal sample from the same level as the Golondrina point dates from 1608 to 1724 cal BP (Specimen 120-26). Below this level and directly above the Big Sandy point, a charcoal sample from 90 to 95 cmbs was dated to 1871-1985 cal BP (Specimen 146-8). Finally, the Early Stemmed point was found between 125 and $130 \mathrm{cmbs}$ in Unit 8 in the northwest quadrant. A charcoal sample from the level below this (130-135 cmbs) came back at $4162-4409$ cal BP. The range of dates from the Gower point level to the level below the Early Stemmed point brackets these levels, and these Late Paleoindian points, within the Late Archaic and possibly as early as the late Middle Archaic. Therefore, the contexts of these points are all problematic and this disparity cannot be explained. Although the field notes from the excavations and Ringstaff's thesis do not indicate that there has been any disturbance within these units, the charcoal dates do not support the earlier dates indicated by the points. While it is possible that the charcoal dates are inaccurate, there is no indication that these have been contaminated during collection or curation. Therefore, AUs for the Early Archaic and the Late Paleoindian periods 
have not been established for 41HY165. Presently, no strata containing intact Early Archaic or Late Paleoindian remains are recognized at the site. Perhaps future investigations may clarify the nature of these deposits.

\section{Analytical Approaches}

The focus of the analysis for 41HY165 is on material contained within the AUs described above. These AUs represent only a portion of the overall collection; however, they are the only samples of the assemblage that can be confidently described as being from non-disturbed deposits based on the spatial distribution of diagnostic projectile points or radiocarbon dates. The remainder of the collection, items not recovered from within these AUs, has been sorted and cataloged, but are not subjected to analysis.

The first task prior to the current analysis involved reorganizing the entire collection by provenience. Lot numbers were assigned to the smallest definable unit of excavation. In most cases, lot numbers represent a single level of one quadrant of an excavation unit. Artifacts from a specific lot were assigned specimen numbers based on the class and type of the artifact. Although artifacts from the 1984 field school were not included in the current analysis, the artifacts were sorted out of the main collection and given lot and specimen numbers as well.

All of the artifacts were sorted and bagged according to the class and type of artifact. Artifact class is a general category such as lithic, ceramic, metal, etc., and type is more specific description such as biface, stoneware, nail, etc. Table 5-5 lists the artifact classes and types used for this project. In some cases, a description was given that related the specific species, raw material, or function of the object. During the sorting, most artifact categories were counted and weighed.
Materials that were not counted included microdebitage, miniscule objects recovered from flotation samples, and small fragments of shell.

Detailed analytical approaches for each of these categories are discussed in the appropriate chapters. They are briefly summarized here, however, for ease of reference. Lithics included all chipped stone and groundstone artifacts recovered during the 1996, 1997, and 1998 field schools. In addition to being counted and weighed, all of the lithics in the assemblage were sorted into categories based on artifact form, function, and material type. Only lithics recovered from AUs were carefully analyzed with the overall research design for this project kept closely in mind. Specific approaches used in this analysis, and the results are presented in Chapter 6.

Ceramics in the collection were initially sorted according to prehistoric or historic origin. The historic ceramics were further subdivided according to type (see Table 5-5). All of the prehistoric ceramics were submitted to CAR at UTSA, and the results are presented in Chapter 7. The Spanish Colonial ceramics recovered from the collection were also submitted with the prehistoric specimens. Carole Leezer conducted the analysis of the historic ceramics, and the result of this analysis is presented in Chapter 8 .

Collected faunal remains were identified to taxon and element, and were weighed, tagged, and bagged individually. Within a given lot, individual specimens identifiable by element and taxon were also assigned specimen numbers. In total, faunal material from 25 lots in six units were examined. Lots were selected for study based on associated temporal data; material not from AUs was not carefully examined. Material examined was recovered from Units 1, 2, 2E, 3, 8,10 , and 11 , comprising a temporally controlled subassemblage of 1,290 whole or partial elements 
Table 5-5. Artifact Classes and Types Used for This Project.

\begin{tabular}{|c|c|}
\hline Artifact Class & Artifact Types \\
\hline Bone & fauna, Homo sapiens, unknown \\
\hline Building Material & brick, cement, concrete, mortar, other, plaster, wattle/daub \\
\hline $\mathrm{C} 14$ & charcoal \\
\hline Ceramic & $\begin{array}{c}\text { creamware, other, pearlware, pipe, porcelain, prehistoric, Spanish Colonial, stoneware, } \\
\text { terra cotta, unknown, white earthenware }\end{array}$ \\
\hline Float Sample & $<0.5 \mathrm{~mm}, 0.5$ to $1.0 \mathrm{~mm}, 1$ to $2 \mathrm{~mm},>2 \mathrm{~mm}$, combined, other \\
\hline Glass & Bottle, unknown, window \\
\hline Lithic & $\begin{array}{l}\text { debitage, biface, blade, broken flakes, burned non-flake debitage, burned rock, complete } \\
\text { flakes, core, Distinctive Expanding Billet (DEB), exotic material, groundstone, mica, } \\
\text { microdebitage, notching flakes, ochre, other, projectile point, proximal flake, r-flake, } \\
\text { uniface, unknown, unsorted }\end{array}$ \\
\hline Metal & $\begin{array}{l}\text { bottle cap, firearms and munitions, hardware, household, other, round nail, scrap, } \\
\text { square nail, tools, unknown }\end{array}$ \\
\hline Organic & nutshell, other, plant, rhizolith, seed, wood \\
\hline Other & - \\
\hline Other Prehistoric & burned clay, unknown \\
\hline Personal Items & bead, button, clothing related, other \\
\hline Sediment & non-cultural, other, soil sample, unsorted \\
\hline Shell & bivalve, fossil, snail, unknown \\
\hline
\end{tabular}

with a combined mass of approximately 538 grams $(\mathrm{g})$. The relative frequencies of faunal material, standardized across AU for consistency in occurrence, were compared. Comparisons were conducted: (1) within each AU in order to understand prey choice as represented by taxon list; and (2) across all AUs in order to understand shifts in prey choice through time. Patterns of taxonomic occurrence through time at 41HY165 were examined for clues to resource distribution, subsistence base intensification, prey choice with respect to bison procurement, and trends in gender-governed labor division. Special attention was given to the occurrence pattern of bison, and its abundance relative to other prominent game species through time such as pronghorn, deer, and rabbit. Results were compared with such patterns found at other sites in Central Texas. Results of the faunal analysis are presented in Chapter 11.

The analysis of plant remains is one avenue of research into a group's foodwaysthe procurement, production, preparation, consumption, display, storage, and discard of food. These practices vary by economic, social, and political situation, and, hence, cultural traditions of a group (Johannessen 1993). As no botanical specimens or soil samples exist from the original field school excavations conducted at $41 \mathrm{HY} 165$, this investigation took advantage of a 1 x 1-m excavation unit (XU3), excavated during the SLAERP directly adjacent to Unit 3 excavated during the 1996-1998 SWT archaeological field schools (Figure 5-3). Data from this test unit was used during the SLAERP to develop detailed 
information regarding the nature of deposits in this areas not previously subjected to extensive excavation. XU 3 was excavated to $150 \mathrm{cmbs}$. A 4-liter bulk soil sample was collected from each unit level. These samples were processed by flotation for the recovery of small fauna, plant remains, and lithic debris that would pass through the $1 / 8$-inch screen. These flotation samples were submitted to Dr. Kandace Hollenbach for analysis. Results are presented in Chapter 9.

All features discussed in the present report were identified during the three field school seasons; the present analysis was limited to a review of the original paperwork. Burned rocks making up these features had been saved, and these were sorted out of the main collection, counted, and weighed. In total, 6,754 burned rocks weighing $316.5 \mathrm{~kg}$ were recovered. The weight of burned rock from each AU was standardized so that the frequency of burned rock cooking could be compared across all of the AUs. Additionally, a select sample of 18 burned rocks was submitted to AEL at Texas A\&M University to extract phytoliths and starch granules. Twelve of these rocks were taken from feature contexts and four were taken from Zone 1/97; the remaining rocks were taken from a level with dated bison bone in Unit 11. All of the rocks are from AUs. The results of the burned rock and feature analysis are in Chapter 10, and the report from Texas A\&M is included in Chapter 9.

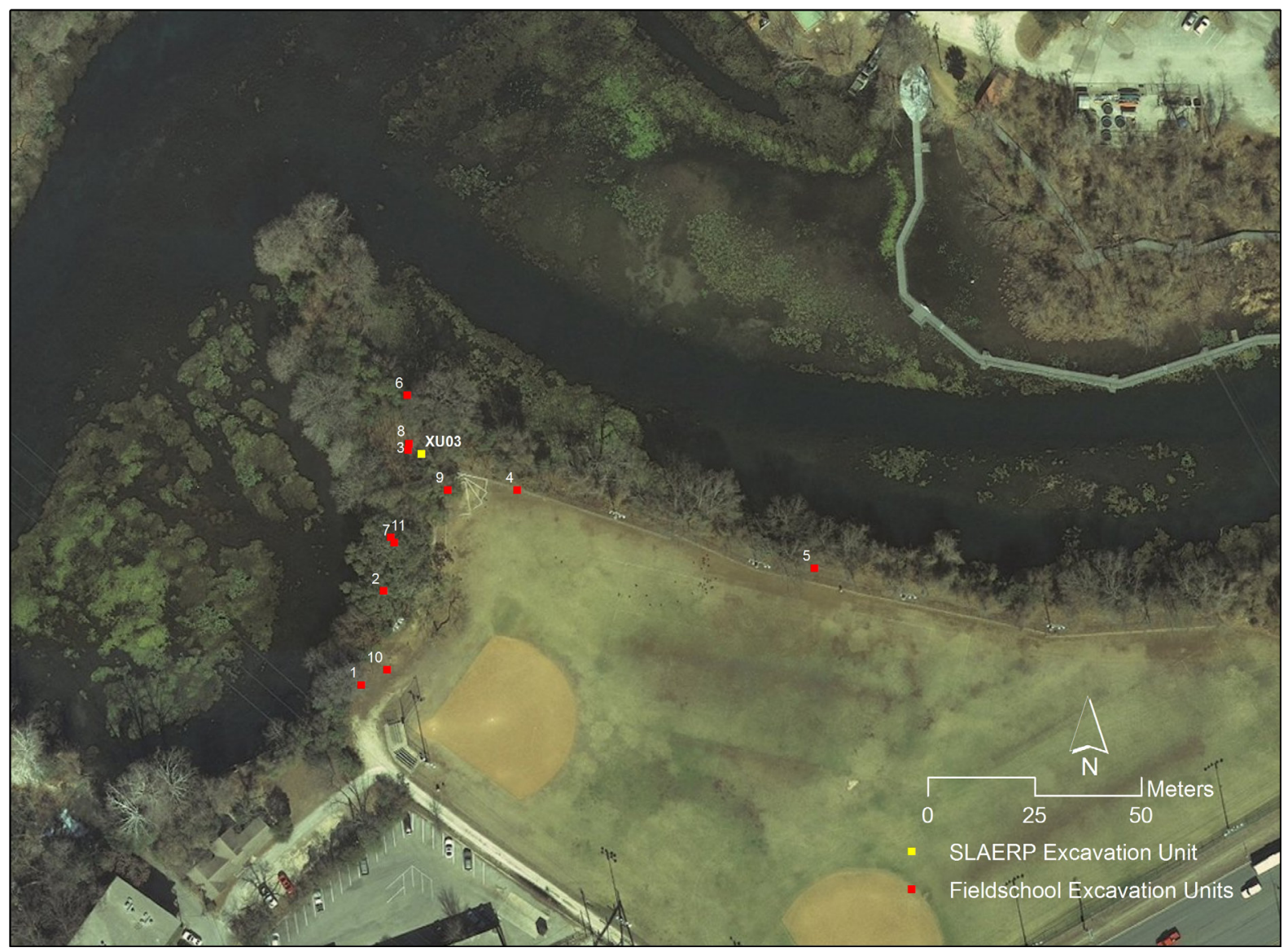

Figure 5-3. SLAERP XU 3 in relation to 1996-1998 excavated field school units. 


\section{Chapter 6}

\section{Lithic AnAlysis}

\section{By Amy E. Reid}

\section{Introduction}

This chapter describes the culturally altered lithic material (chipped stone tools and debris) recovered from investigations at 41HY165. Lithic materials from $41 \mathrm{HY} 165$ were organized into the following categories: projectile points, bifaces, unifaces, flake tools, cores, and debitage. AU lots were further separated into the following: complete flakes, proximal flakes, broken flakes, r-flakes, distinctive expanding billet (DEB) flakes, notching flakes, and burned non-flaked debitage. The analysis of each of these categories is described in the methodology of each section. Lithic analyses were designed to address four of the interrelated research domains outlined in Chapter 4: (1) filling in the chronology of human occupation at Spring Lake; (2) understanding how aggregation shaped hunter-gatherer settlement mobility systems; (3) defining periods during which bison were important in local and regional economies, and exploring how other resources and their associated technological adaptations increased or decreased in prominence during these periods; and (4) reconstructing trade and clarifying its effect on local economic production and subsistence.

The theoretical perspective behind these analyses assumes that the tool assemblage can provide the foundation for differentiating between foraging and collecting strategies. In other words, the work presented below attempts to reconstruct the contexts within which tools were made, used, and discarded by identifying and exploring patterns of curated technologies and tool systems that emphasize expediency at $41 \mathrm{HY} 165$. It is typically believed that if an assemblage is characterized by a majority of expedient tools, then it could be said that the people associated with that assemblage lived in a resource-rich environment (Andrefsky 2005; Binford 1979; Weinstein 2005). It is also hypothesized that expedient tools characterize a "forager" society that is somewhat mobile and extracts foods from a variety of resources (Binford 1979, 1980; Lohse 2011; Weinstein 2005). Conversely, if an assemblage is made up of mostly curated and highly specialized tools, then the society occupied sites for longer periods, made relatively fewer residential moves, and commonly sent out task groups on logistical forays to procure a small number of predictable resources (Binford 1980; Lohse 2011). This type of economic activity is believed to be characteristic of "collector" societies and would require reliable and maintainable tools (Binford 1979, 1980; Lohse 2011). It is our understanding that the concepts of expediency and curation cannot be truly understood by studying associated tool types. Rather, in the present study, we explore how these processes may have influenced tool use.

The result of each analysis is presented below, followed by a brief discussion of their implications. Temporal patterns of lithic technological changes, along with their significance pertaining to earth oven usage and bison exploitation, are discussed in Chapter 10. 


\section{Projectile Points}

Time-diagnostic projectile points help to address research domain (1) filling in the chronology of human occupation at Spring Lake. The current analysis focuses on reconstructing 41HY165's cultural sequence in the context of provisional phases (Prewitt 1981, 1983) defined for the region. Point count data are also analyzed in order to explore site visitation intensity.

\section{Methodology}

In total, 58 projectile points and point fragments were recovered during the 1996-1998 field school excavations at 41HY165. Of these, 41 (70.7 percent) are dart points and 17 (29.3 percent) are arrow points. Seventeen different types were found including: Big Sandy and Golondrina for the Late Paleoindian $(n=2)$; Gower for the Early Archaic $(n=1)$; Travis for the Middle Archaic $(n=3)$; Pedernales and Morhiss for Late Archaic I $(n=5)$; Montell, Marcos, Ellis, Frio, Ensor, Fairland and Darl for the Late Archaic II $(n=18)$; Scallorn, and Edwards for the Austin phase of the Late Prehistoric $(n=3)$; Perdiz for the Toyah phase of the Late Prehistoric $(n=6)$; and Guerrero for the Historic $(n=1)$. In addition, 10 untypable arrow points and eight untypable dart points were recovered. Two of the untyped dart points are stemmed variations from the Early Archaic and are described below. Metric and observed data for each point (typed and untyped) are provided in Appendix C (Tables C-1 through C-4).

\section{Late Paleoindian}

Big Sandy

Phase: N/A

Series: N/A

Specimens: $\mathrm{n}=1$, Specimen No. 121-1 (Figure 6-1A)
Condition and Breakage: This specimen is a proximal fragment with random flake patterning and a stem that has squared corners. At least two episodes of impact damage have caused the entire distal tip to snap off and most of one lateral edge to be removed. The missing lateral edge may have been the result of intentional burination after the distal tip broke off.

Retouch: One edge exhibits bifacial retouch.

\section{Golondrina}

Phase: N/A

Series: N/A

Specimens: $\mathrm{n}=1$, Specimen No. 120-1 (Figure 6-1B)

Condition and Breakage: This proximal fragment has regular, almost parallel flake patterning, but

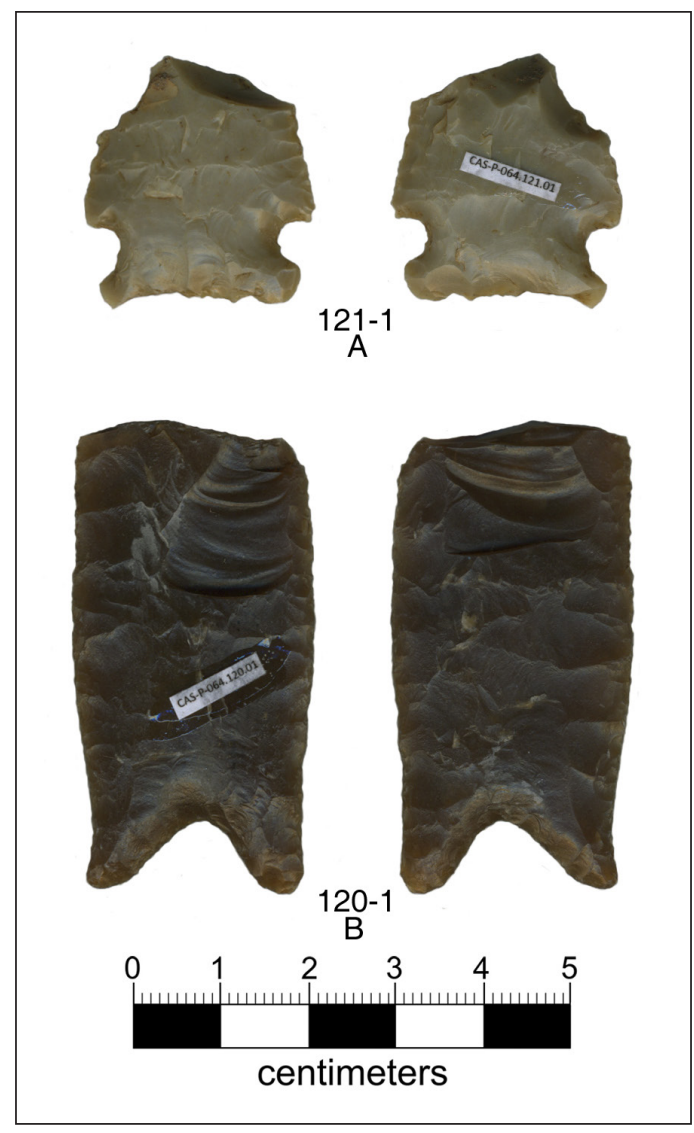

Figure 6-1. Late Paleoindian projectile points: A) Big Sandy; B) Golondrina. 
the flake scars do not extend across the face or form a medial ridge. There are fluted impact scars down both faces of the blade.

Retouch: There is evidence of alternate retouch.

\section{Early Archaic}

\section{Untyped Early Archaic Split-Stemmed Phase: N/A}

Series: Lampasas?

Specimens: $\mathrm{n}=1$, Specimen No. 64-2 (Figure 6-2A)

Condition and Breakage: This specimen is the base of an Early Archaic dart point with a bifurcated stem. It is badly damaged from heat and impact. The shoulders and blade are absent, making it difficult to type.

Retouch: N/A

\section{Gower}

Phase: Early San Geronimo

Series: Lampasas

Specimens: $\mathrm{n}=1$, Specimen No. 126-1 (Figure 6-2B)

Condition and Breakage: This specimen is a proximal fragment with random flake patterning. There is patination on its base and significant impact damage (maybe more than one episode) causing the distal tip and one shoulder to snap off.

Retouch: N/A

\section{Untyped Early Archaic Stemmed}

Phase: N/A

Series: N/A

Specimens: $\mathrm{n}=1$, Specimen No. 137-1 (Figure 6-2C)

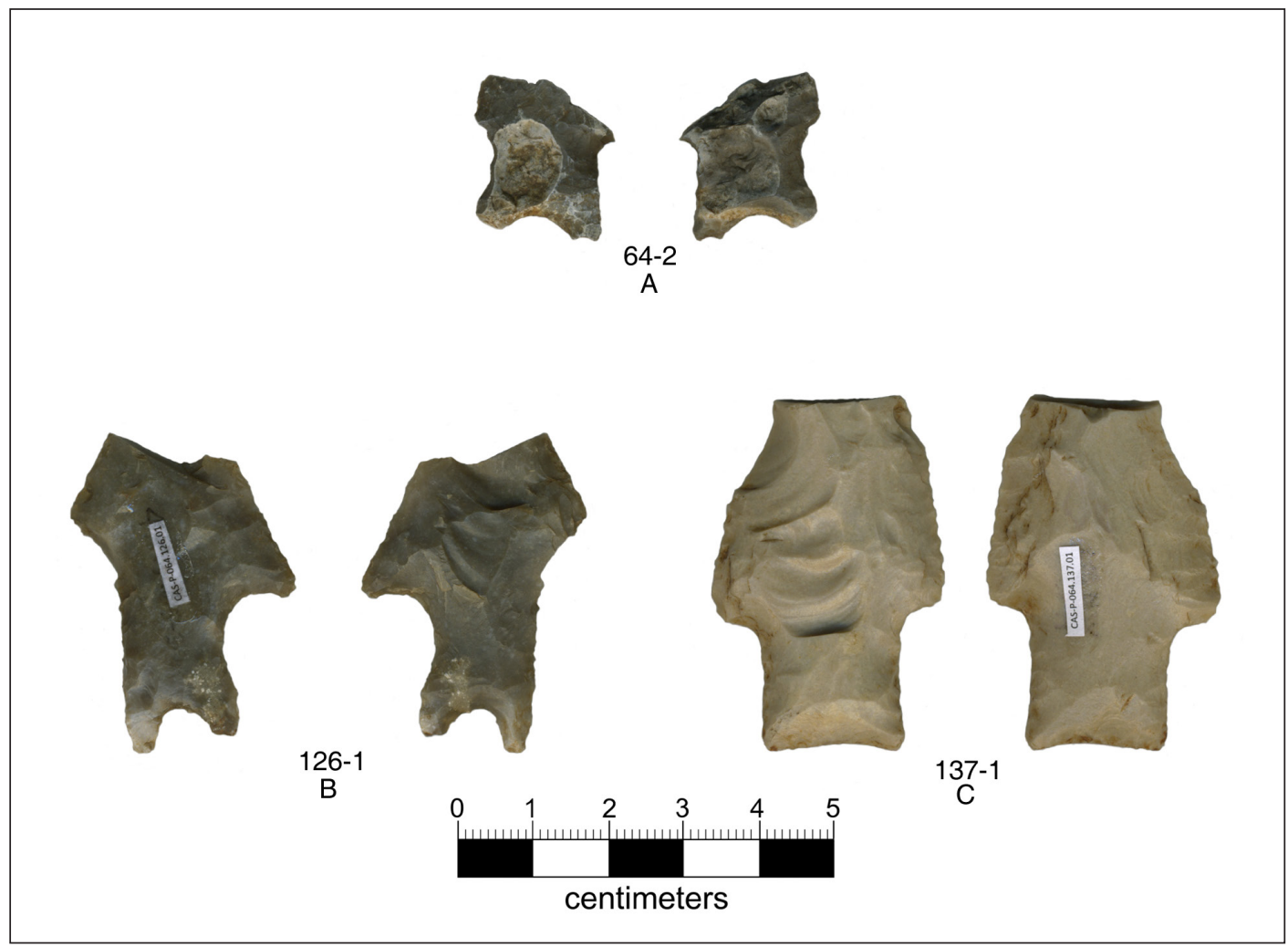

Figure 6-2. Early Archaic projectile points: A) Untyped Early Archaic Split-Stemmed; B) Gower; C) Untyped Early Archaic Stemmed. 
Condition and Breakage: This specimen is a proximal fragment with random flake patterning. The base is ground smooth, and one lateral edge is slightly serrated. This point exhibits impact damage that caused a snap fracture and a large fluted impact scar. Much of one lateral edge of the blade is gone, possibly due to a burin removal.

Retouch: Both lateral edges exhibit retouch.

\section{Middle Archaic}

\section{Travis}

Phase: Clear Fork

Series: Pecos

Specimens: $\mathrm{n}=3$, Specimen Nos. 29-4 (Figure 6-3C), 87-3 (Figure 6-3B), 326-16 (Figure 6-3A)

Condition and Breakage: All three specimens exhibit random flake patterning. Two are complete (29-4 and 87-3) and the other is a proximal fragment with snap medial breakage. Specimen 29-4 has alternate beveling near the distal tip.

Retouch: All three specimens exhibit retouch with step terminations.

\section{Late Archaic I}

\section{Pedernales}

Phase: Round Rock

Series: Pecos

Specimens: $\mathrm{n}=4$, Specimen Nos. 124-2 (Figure 6-4B), 125-1 (Figure 6-4C), 129-1 (Figure 6-4E), 131-2 (Figure 6-4A)

Condition and Breakage: Three specimens are complete $(125-1,124-2,129-1)$, and one is a proximal fragment (131-2). All three complete points exhibit random flake patterning and beveled blades. Specimen 124-2 exhibits patination on its stem and base.

Retouch: The three complete specimens all have a significant amount of retouch on the blade edges.

\section{Morhiss}
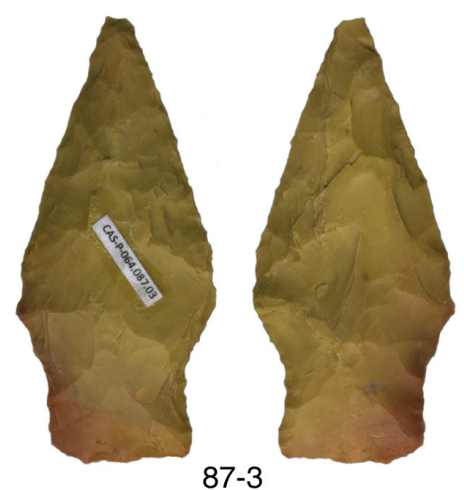

B
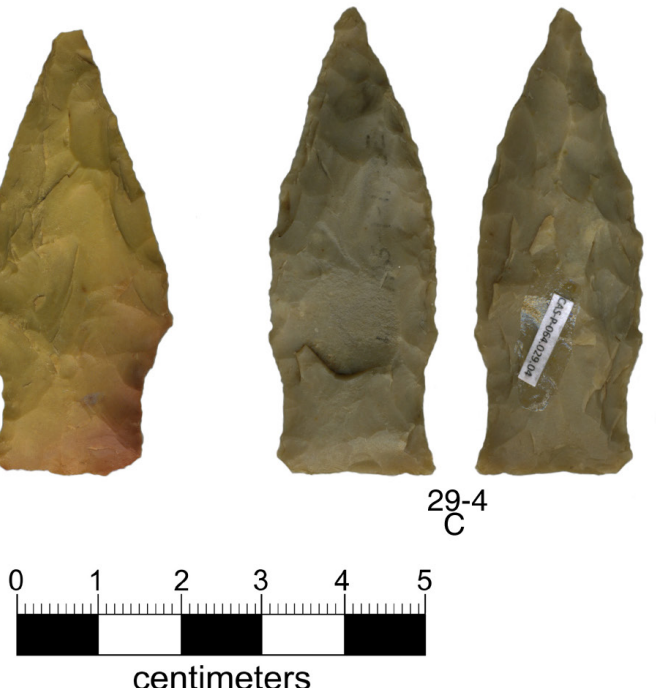

Figure 6-3. Middle Archaic projectile points: A-C) Travis.
Phase:

\section{Series: N/A}

Specimens: $\mathrm{n}=1$, Specimen No. 69-4 (Figure 6-4D)

Condition and Breakage: This specimen is missing both the distal end and a portion of the base. The stem and base contain remnants of asphaltum from hafting. It appears as though it was used and hafted after the base broke since the asphaltum is visible over the break. 


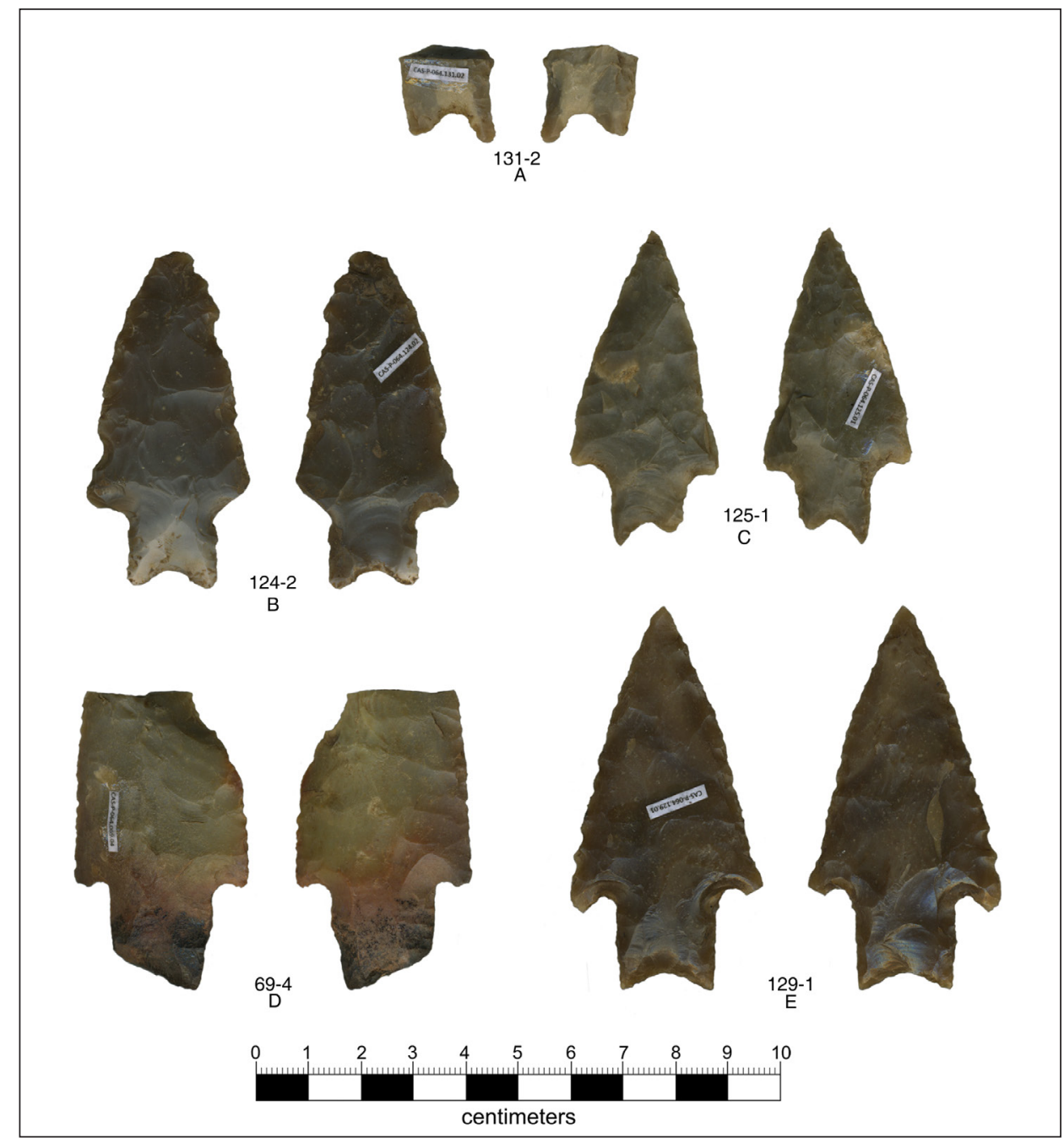

Figure 6-4. Late Archaic I projectile points: A-C, E) Pedernales; D) Morhiss.

Retouch: This specimen exhibits retouch on lateral and basal edges.

\section{Late Archaic II}

\section{Frio}

Phase: Twin Sisters

Series: Rio Bravo

Specimens: $\mathrm{n}=1$, Specimen No. 15-6 (Figure 6-5 $\mathrm{H})$

Condition and Breakage: This proximal fragment has a beveled blade and exhibits fluted impact damage. There is also damage to one shoulder and a basal ear.
Retouch: The blade is beveled from retouch.

\section{Ensor}

Phase: Twin Sisters

Series: Rio Bravo

Specimens: $\mathrm{n}=6$, Specimen Nos. 68-2 (Figure 6-5J), 128-1 (Figure 6-5D), 133-1 (Figure 6-5G), 134-1 (Figure 6-5I), 134-2 (Figure 6-5F), 256-6 (Figure 6-5C)

Condition and Breakage: Two of these specimens (134-2, 128-1) are complete. Specimen 1281 is asymmetrical and made out of quartzite. Specimen 134-2 has a beveled blade and random flake patterning. The fragmented specimens are 


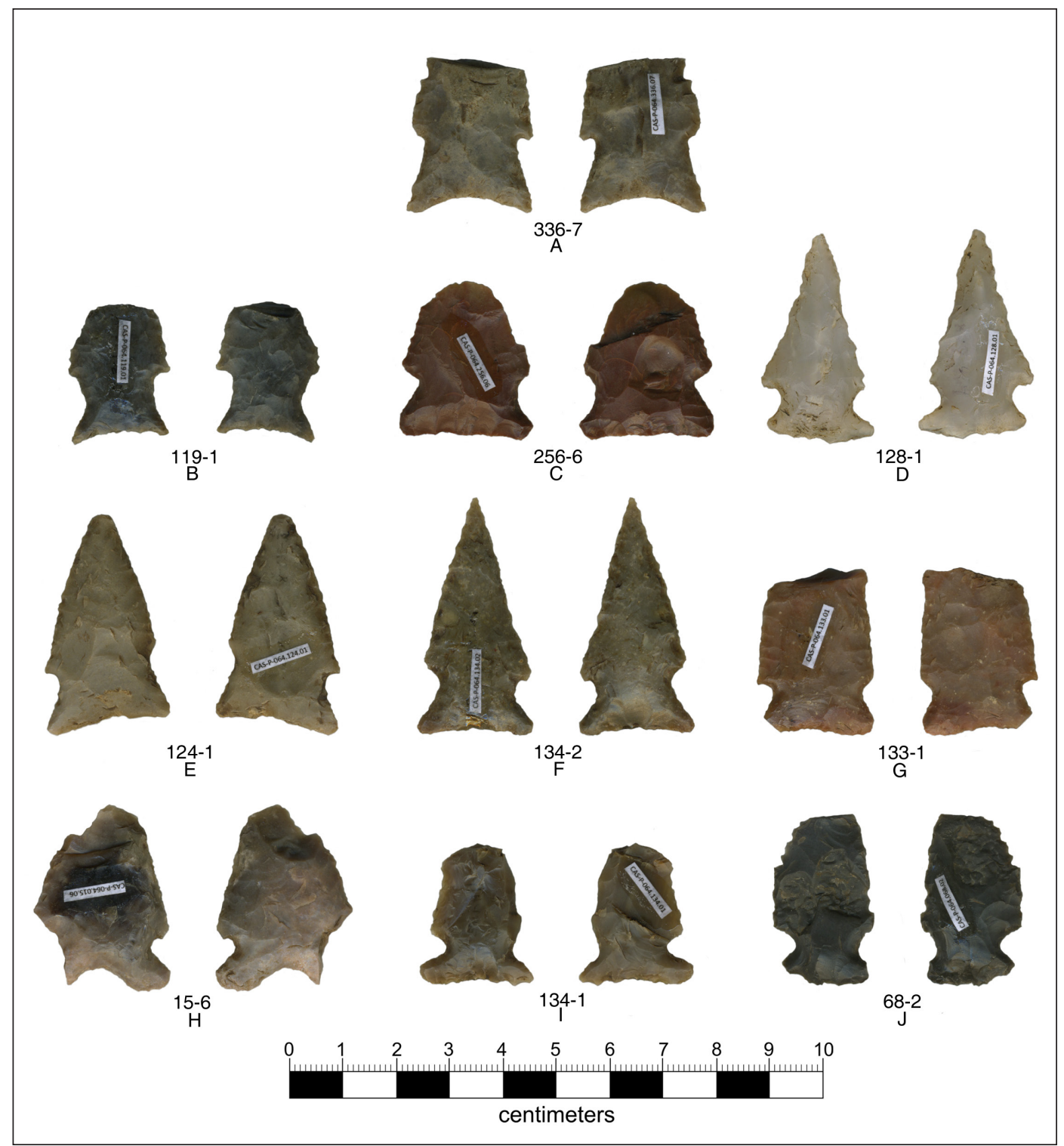

Figure 6-5. Late Archaic II projectile points: A, B, E) Fairland; C, D, F, G, I, J) Ensor; H) Frio.

all missing their distal tips due to impact damage; two (68-2, 256-6) exhibit thermal fracturing and spalling.

Retouch: All specimens with intact lateral edges exhibit retouch.

\section{Fairland}

Phase: Twin Sisters

Series: Rio Bravo
Specimens: $\mathrm{n}=3$, Specimen Nos. 119-1 (Figure 6-5B), 124-1 (Figure 6-5E), 336-7 (Figure 6-5A)

Condition and Breakage: Two of these specimens (119-1, 336-7) are proximal fragments and one (124-1) is mostly complete. Specimen 124-1 has a beveled blade, evidence of crushing impact damage to the base and a small piece missing from its distal tip. All three specimens have damage to one shoulder. Specimen 336-7 has two deep flake scars on one lateral edge. 
Retouch: Specimens 336-7 and

124-1 exhibit retouch. 124-1 displays step terminations.

\section{Marcos}

Phase: Uvalde

Series: Nueces

Specimens: $\mathrm{n}=2$, Specimen Nos. 123-1 (Figure 6-6A), 2356 (Figure 6-6B)

Condition and Breakage: Both specimens are proximal fragments with straight bases and deep corner notches. One exhibits random flake patterning and snap impact damage to its tip (123-1).

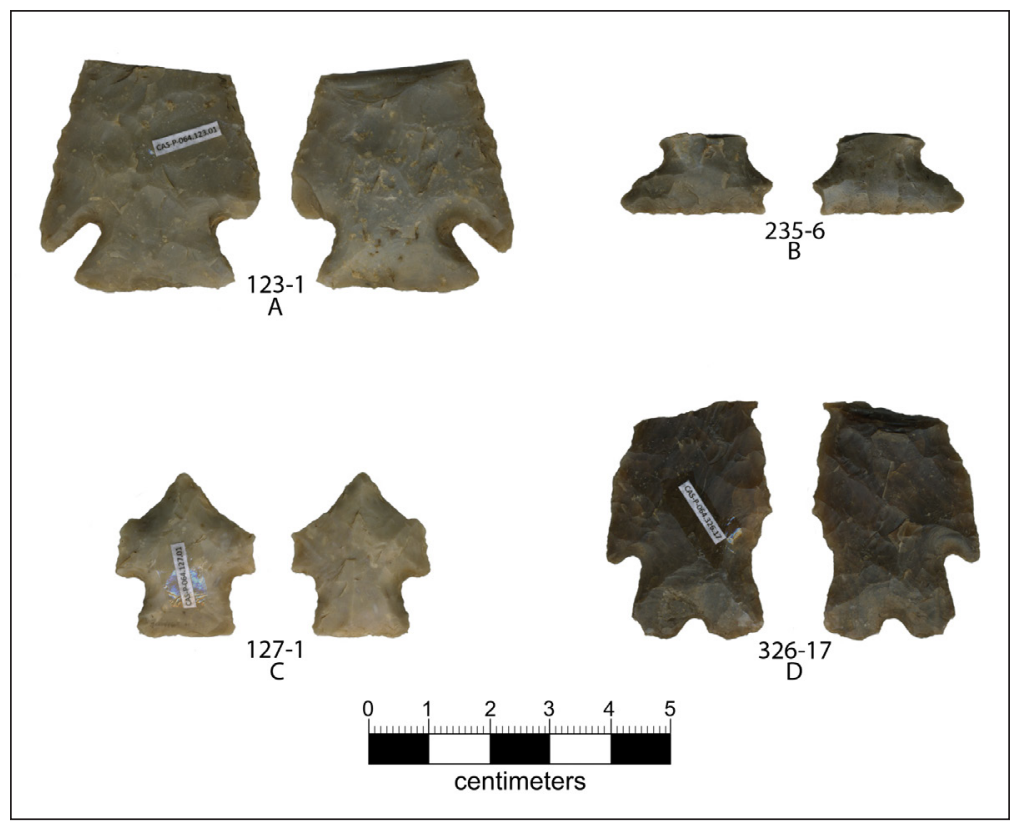

Figure 6-6. Late Archaic II projectile points: A, B) Marcos; C) Ellis; D) Montell.

\section{Retouch: Specimen 123-1} exhibits retouch on its lateral edges with step terminations on one face.

\section{Ellis}

Phase: Twin Sisters

Series: N/A

Specimens: $\mathrm{n}=1$, Specimen No. 127-1 (Figure 6-6C)

Condition and Breakage: This specimen is corner notched with an expanding stem and a straight base. It exhibits basal thinning and unifacial beveling.

Retouch: The blade has been heavily resharpened and worked down into a short triangular form.

\section{Montell}

Phase: Uvalde

Series: Nueces

Specimens: $\mathrm{n}=1$, Specimen No. 326-17 (Figure 6-6D)

Condition and Breakage: This proximal fragment has a bifurcated base with squared ears. There is impact damage to the distal tip, lateral edges, shoulder, and one basal ear. One face has long oblique flake scars, and the other has random flake patterning.

Retouch: There is minimal retouch on what remains of the lateral edges.

\section{Darl}

Phase: Driftwood

Series: Kyle

Specimens: $\mathrm{n}=4$, Specimen Nos. 10-10 (Figure 6-7A), 66-6 (Figure 6-7D), 255-10 (Figure 6-7C), 391-12 (Figure 6-7B)

Condition and Breakage: Two of these specimens (66-6, 255-10) are complete, while the other two $(10-10,391-12)$ are proximal fragments with most of the medial and distal sections missing. Specimen 10-10 has snap impact damage with a hinge termination, badly damaged shoulders, and evidence of heat damage. Specimen 39112 is a finely worked stem that exhibits edge modification and macroscopic use wear or crushing along its broken edge. Specimen 66-6 


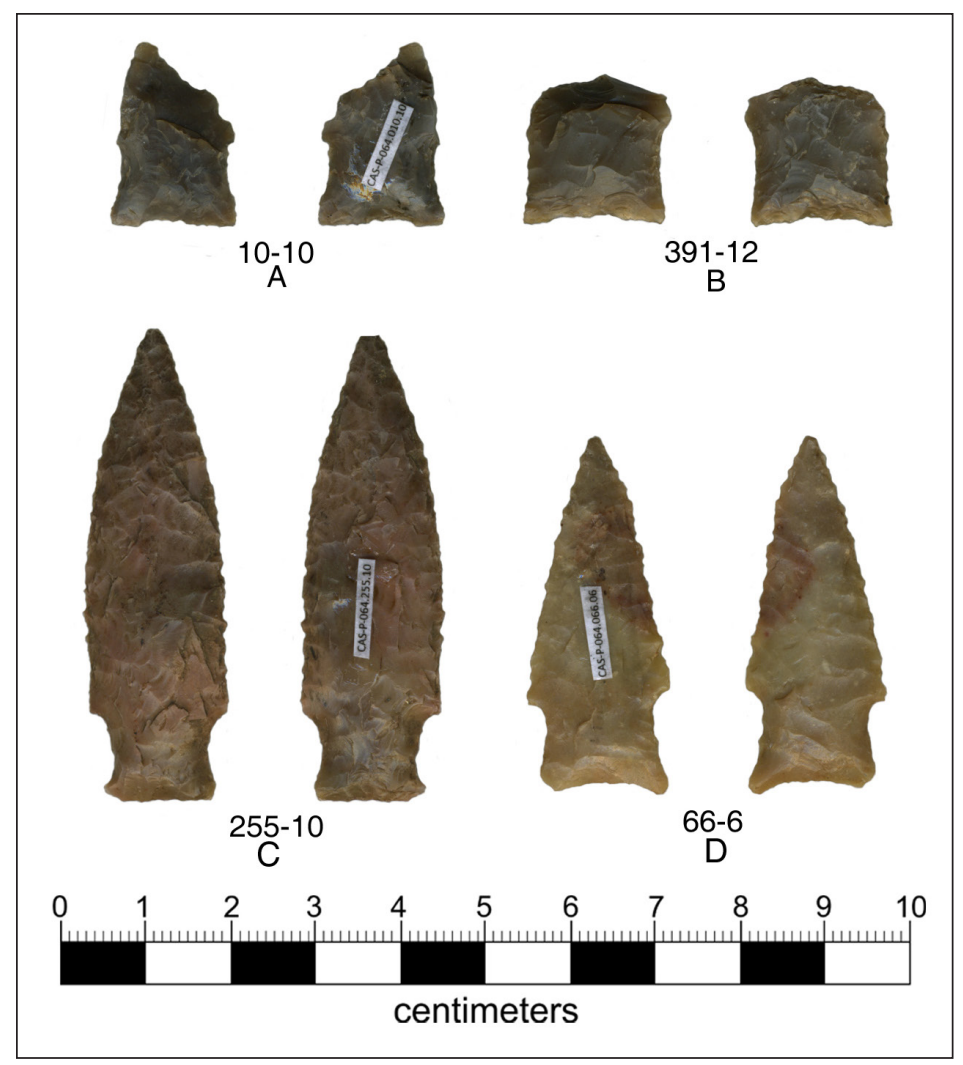

Figure 6-7. Late Archaic II projectile points: A-D) Darl.

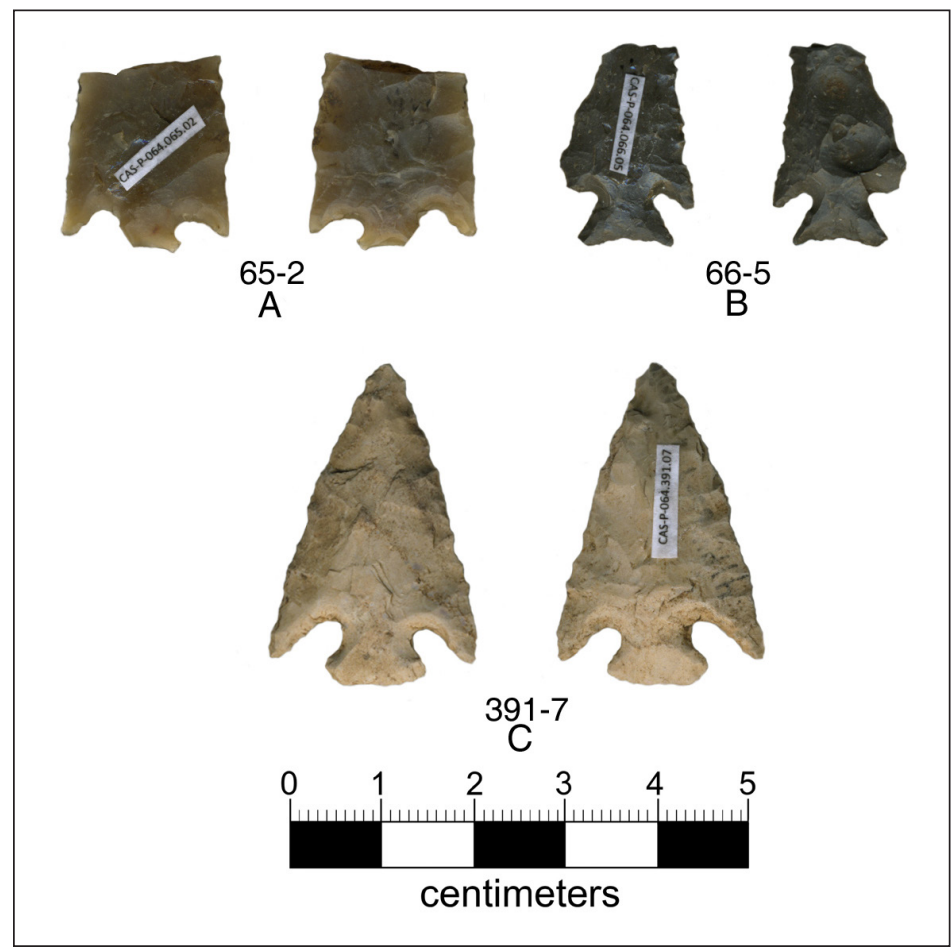

Figure 6-8. Late Prehistoric-Austin projectile points: A) Edwards; B, C) Scallorn. has a slightly serrated blade and displays similar-sized flake scars that extend toward the proximal edge on one blade edge.

Retouch: Specimen 66-6 has been lightly retouched on its stem, and Specimen 255-10 exhibits regular parallel retouch flaking on one blade edge.

\section{Late Prehistoric-Austin}

\section{Scallorn}

Phase: Austin

Series: Austin

Specimens: $\mathrm{n}=2$, Specimen Nos. 66-5 (Figure 6-8B), 391-7 (Figure $6-8 \mathrm{C})$

Condition and Breakage: Specimen 391-7 is a complete point with random flake patterning. Specimen 66-5 is missing its distal tip and one barbed shoulder. It displays heat spalling on one face and a snapped basal ear.

Retouch: Both specimens exhibit light retouch on blade edges.

\section{Edwards}

Phase: Austin

Series: Austin

Specimens: $\mathrm{n}=1$, Specimen No. 65-2

Condition and Breakage: This proximal fragment has slightly convex lateral edges, bifurcated stem, and pointed barbs.

\section{Retouch: None}


Late Prehistoric-Toyah

Perdiz

Phase: Toyah

Series: Blum

Specimens: $\mathrm{n}=6$, Specimen

Nos. 80-8 (Figure 6-9E),

86-6 (Figure 6-9B), 132-1

(Figure 6-9D), 136-1 (Figure

6-9A), 140-6 (Figure 6-9C),

332-8 (Figure 6-9F)

Condition and Breakage:

Three of these Perdiz arrow points (132-1, 1361, 332-8) are complete. All complete specimens have irregular flake patterning. Specimen 136-1 exhibits a very long, finely worked stem. Specimen 322-8 has convex blade edges and is

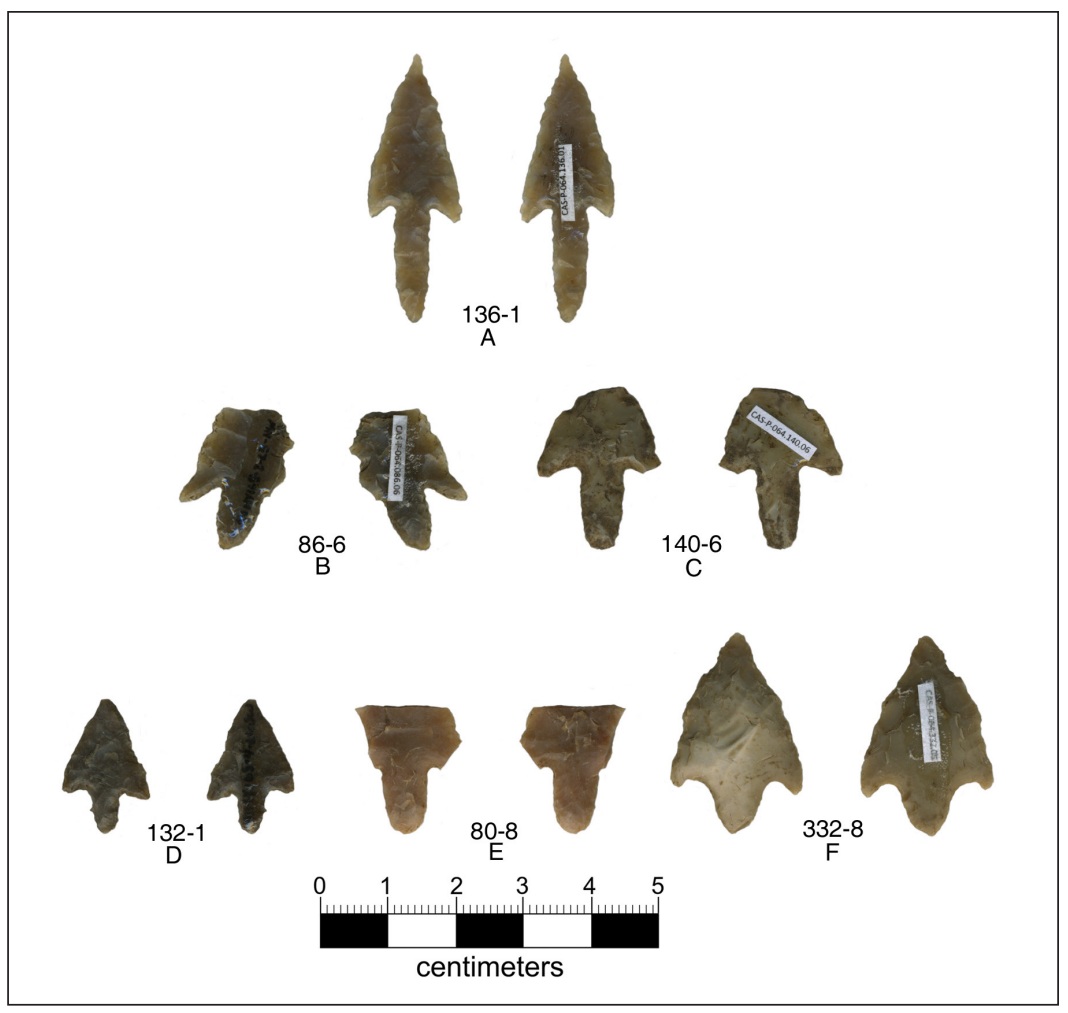

Figure 6-9. Late Prehistoric-Toyah projectile points: A-F: Perdiz. wider than the typical Perdiz point. All of the incomplete specimens exhibit tip snapping.

Retouch: Three of the points are retouched along the lateral edges.

\section{Protohistoric (Historic Native American)}

\section{Guerrero}

Phase: N/A

Series: N/A

Specimens: $\mathrm{n}=1$, Specimen No. 131-1 (Figure 6-10)

Condition and Breakage: This specimen is complete and finely worked. Most of one face lacks flaking, and the other exhibits irregular flake patterning.

Retouch: All edges have very small retouch flake scars.

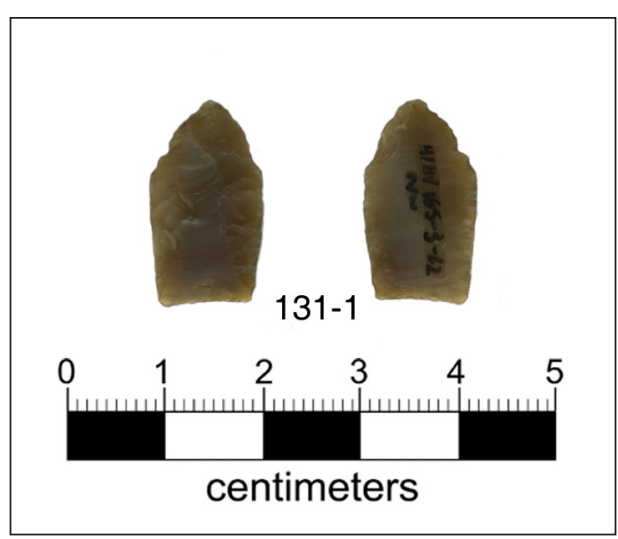

Figure 6-10. Protohistoric/Historic Native American Guerrero projectile point. 


\section{Date Unknown}

\section{Untyped Dart Points}

Phase: N/A

Series: N/A

Specimens: $\mathrm{n}=8$, Specimen Nos. 80-10 (Figure 6-11A), 122-1 (Figure 6-11E), 130-1 (Figure 6-11G), 140-4 (Figure 6-11H), 252-7 (Figure 6-11C), 310-18 (Figure 6-11B), 310-19 (Figure 6-11D), 326-14 (Figure 6-11F)

Condition and Breakage: One specimen is complete and exhibits alternate beveling (130-1). The rest consist of fragmented pieces with snap and crushing damage. Thermal damage is present on five specimens (122-1, 140-4, 252-7, 310-18, 310-19). Specimen 326-14 has one corner notch similar to Pipe Creek bifaces, but is probably a reworked dart point with impact damage.

Retouch: Retouch was noted on seven specimens.

\section{Untyped Arrow Points}

Phase: N/A

Series: N/A

Specimens: $\mathrm{n}=8$, Specimen Nos. 10-11 (Figure 6-12E), 10-12 (Figure 6-12B), 135-1 (Figure 6-12G), 256-5 (Figure 6-12F), 256-64 (Figure 6-12H), 326-15 (Figure D), 337-3 (Figure 6-12C), 479-1 (Figure 6-12A)

Condition and Breakage: All of these arrow point fragments are missing all or part of their stem , and therefore cannot be typed. Three fragments have serrated blade edges $(256-5,10-11,479-1)$.

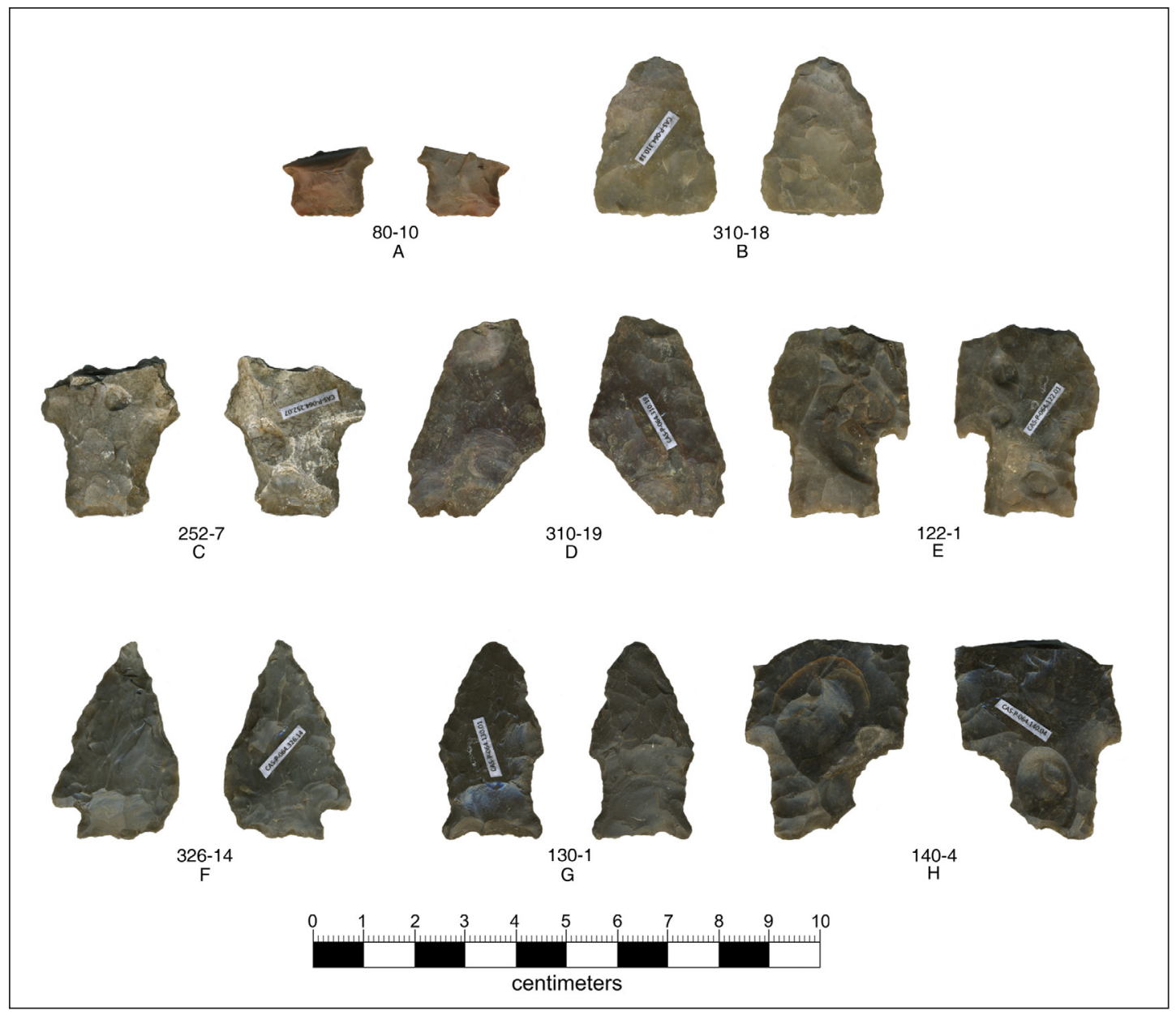

Figure 6-11. Untyped dart points. 


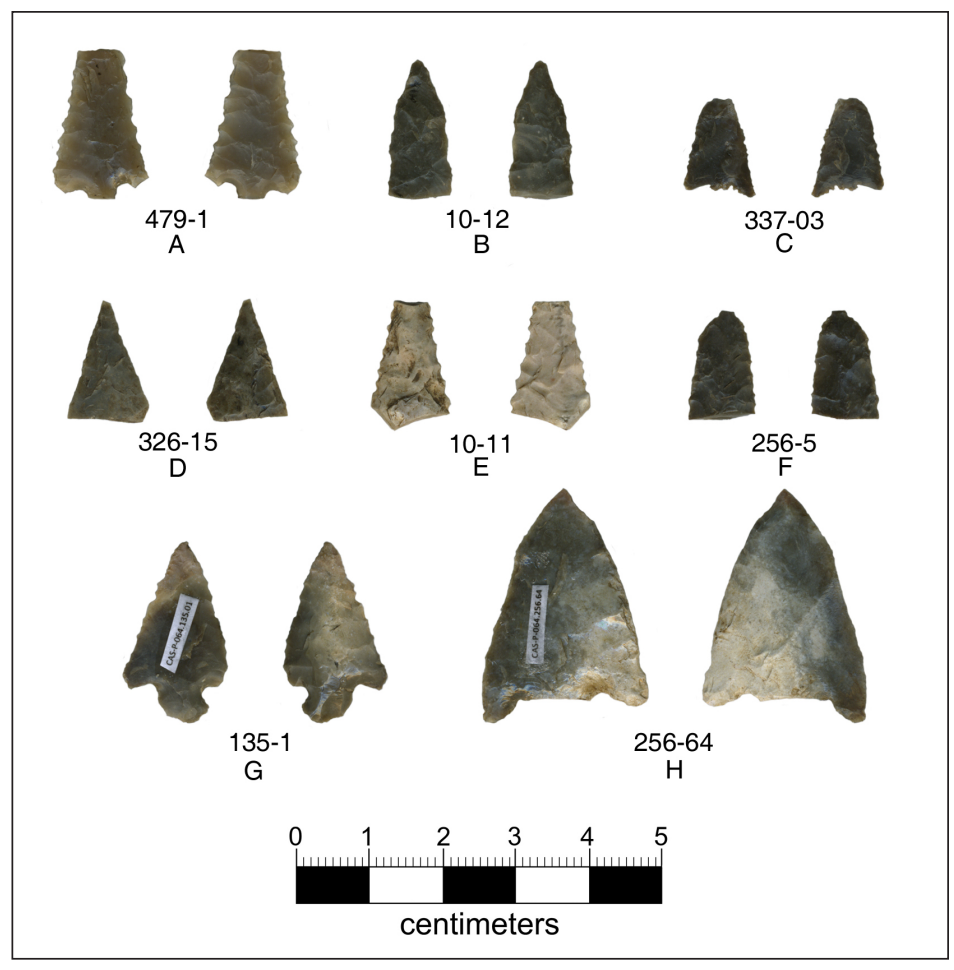

Figure 6-12. Untyped arrow points.

Specimens 256-4, 135-1, and 337-10 seem to be expediently manufactured.
Retouch: Four fragments exhibit retouch along the lateral blade edges.

\section{Discussion}

Of the 58 projectile points and point fragments, $39(67.2 \%)$ can be identified by type. The most common types recovered include Ensor $(n=6)$ and Perdiz $(n=6)$. Resharpening projectile points does seem to be an important task at $41 \mathrm{HY} 165$, as evidenced by retouch on 40 of the 55 specimens $(72.7 \%)$.

Looking at the raw frequencies of point types by period, we see a peak in the Late Archaic II (Figure 6-13). In all, 18 projectile points were recovered from intact and undisturbed contexts, 12 of which could be typed (Table 6-1). The highest frequency of projectile points from these AUs occurs during the Late Archaic II. However,

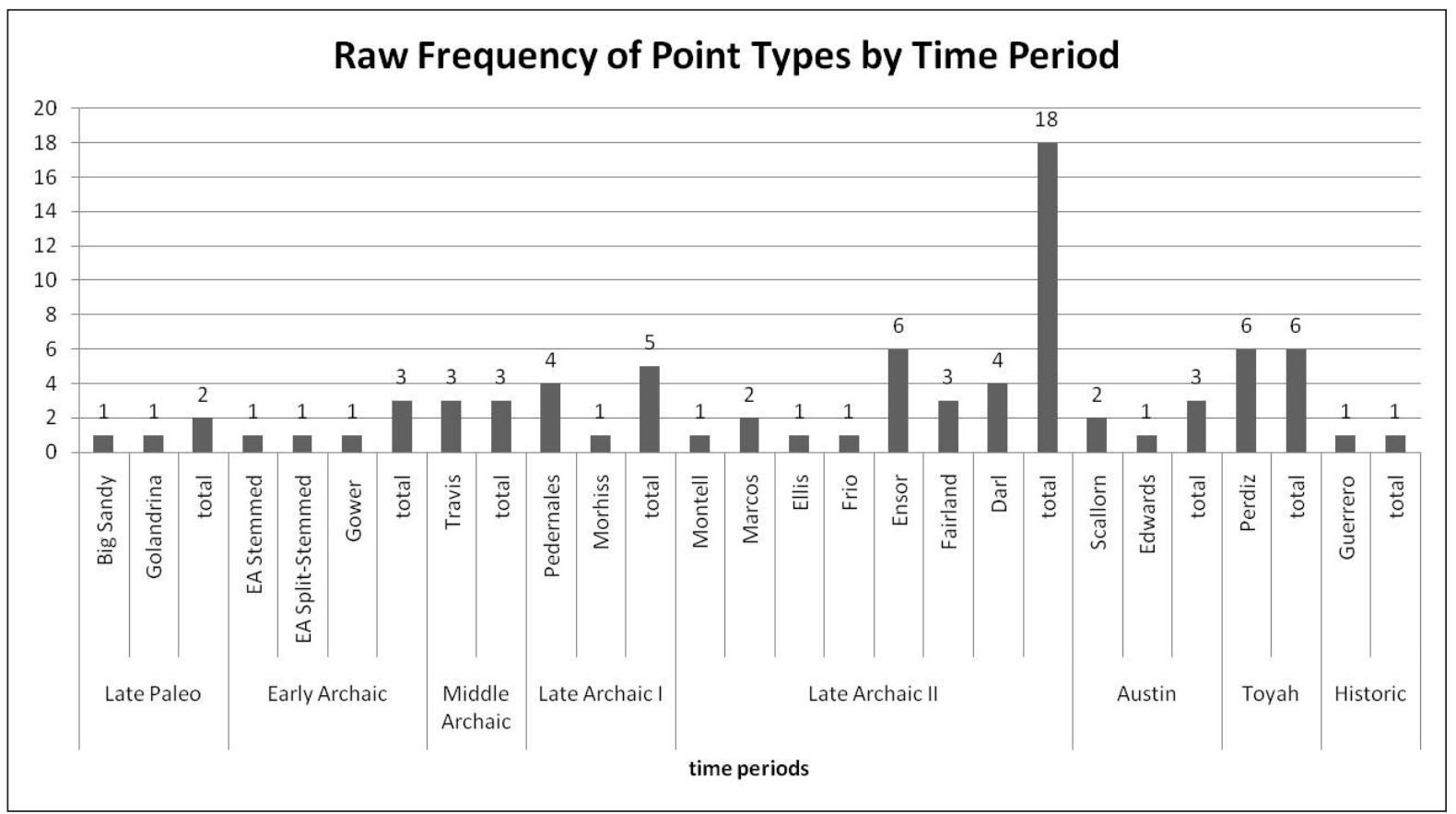

Figure 6-13. Raw frequency of point types by period. 
Table 6-1. Projectile Point Recovery by Period (Untyped Early Archaic Points Included).

\begin{tabular}{|c|c|c|c|c|c|c|}
\hline Period (AU) & $\begin{array}{c}\text { Date } \\
\text { (Years BP) }\end{array}$ & $\begin{array}{l}\text { Duration } \\
(T, \text { Years) }\end{array}$ & $\begin{array}{c}\text { Volume } \\
\left(V, \mathbf{m}^{\mathbf{3}}\right)\end{array}$ & $\begin{array}{c}\text { Total } \\
\text { Points }\end{array}$ & $\begin{array}{c}\text { Points } \\
\text { Found in } \\
\text { AUs }\left(F_{R}\right)\end{array}$ & $\begin{array}{c}\text { Standardized } \\
\text { Frequency }\left(F_{S}\right)\end{array}$ \\
\hline Late Paleoindian & $10,000-8800$ & 1,200 & 0 & 2 & 0 & 0 \\
\hline Early Archaic & $8800-5800$ & 3,000 & 0 & 3 & 0 & 0 \\
\hline $\begin{array}{l}\text { Middle Archaic } \\
\text { (AU 5) }\end{array}$ & $5800-4000$ & 1,800 & 0.2 & 3 & $1(33.3 \%)$ & 0.277 \\
\hline $\begin{array}{l}\text { Late Archaic I } \\
\quad(A U \text { b) }\end{array}$ & $4000-2200$ & 1,800 & 0.65 & 5 & $2(40 \%)$ & 0.171 \\
\hline $\begin{array}{l}\text { Late Archaic II } \\
\qquad(A U \text { 4a) }\end{array}$ & $2200-1250$ & 950 & 1 & 18 & $8(33.3 \%)$ & 0.842 \\
\hline $\begin{array}{l}\text { Late Prehistoric_-Austin } \\
\text { (AU 3b) }\end{array}$ & $1250-750$ & 500 & 0.3 & 3 & $3(100 \%)$ & 2.000 \\
\hline $\begin{array}{l}\text { Late Prehistoric-Toyah } \\
\text { (AU 3a) }\end{array}$ & $750-300$ & 450 & 0.4 & 6 & 0 & 0 \\
\hline $\begin{array}{c}\text { Protohistoric/Historic NA } \\
\text { (AU 2) }\end{array}$ & $300-150$ & 150 & 0.1 & 1 & 0 & 0 \\
\hline
\end{tabular}

these raw counts represent the totals over each $\mathrm{AU}$, which represents various volumes of excavated samples and different durations of time, making them inadequate for an accurate comparison. To account for this disparity, projectile point recoveries were standardized using the equation:

$$
F_{S}=\left(\left(F_{R} / T\right) / V\right) \times 100
$$

In this equation, $F_{R}$ represents the number of points found in the $\mathrm{AU}$, which is divided by the duration of the $\mathrm{AU}(T)$. This value is then divided by the total volume $(V)$ of excavated soil within the AU. Finally, the result is then multiplied by 100 to provide a standardized frequency $\left(F_{S}\right)$ of projectile points for every 100 years.

After standardizing the raw counts, the rate of recovery is highest during the Austin phase of the Late Prehistoric (see Table 6-1). However, neither the total nor standardized projectile point counts should be interpreted as representative of regional population trends. Instead, simple site visitation intensity can be examined temporally by looking at the frequency with which all points, including those not found in AUs, were discarded (LeDoux and Lohse 2011a). This is calculated by dividing the raw counts by the duration of each period and then multiplying the results by 100 (Table 6-2). According to these figures, the Late Archaic II seems to be the most heavily occupied period (Figure 6-14). A sharp incline in site visitation occurs between Late Archaic I and Late Archaic II, and then visitation declines to 0.6 points discarded per century in the Austin phase of the Late Prehistoric period. Site occupation increases again during Toyah times and then decreases in the Historic period. However, even these results have ambiguous implications. LeDoux and Lohse (2011a:220) reason that this approach probably underrepresents Late Prehistoric occupations, since arrow points were produced and used as the tips for weapons and were part of a tool kit consisting of other types of bifaces with various functions. In earlier periods, dart points were produced and used for a wide variety of tasks, including weaponry. 
Table 6-2. Site Occupation Intensity by Period As Determined by Discard Rate.

\begin{tabular}{|c|c|c|c|c|}
\hline Period (AU) & $\begin{array}{c}\text { Date } \\
\text { (Years BP) }\end{array}$ & $\begin{array}{c}\text { Duration } \\
\text { (Years) }\end{array}$ & $\begin{array}{l}\text { Total } \\
\text { Points }\end{array}$ & $\begin{array}{l}\text { Discard } \\
\text { Frequency }\end{array}$ \\
\hline Late Paleoindian & $10,000-8800$ & 1,200 & 2 & 0.167 \\
\hline Early Archaic & $8800-5800$ & 3,000 & 3 & 0.100 \\
\hline $\begin{array}{l}\text { Middle Archaic } \\
\text { (AU 5) }\end{array}$ & $5800-4000$ & 1,800 & 3 & 0.167 \\
\hline $\begin{array}{l}\text { Late Archaic I } \\
\qquad(\mathrm{AU} 4 \mathrm{~b})\end{array}$ & $4000-2200$ & 1,800 & 5 & 0.278 \\
\hline $\begin{array}{l}\text { Late Archaic II } \\
\text { (AU 4a) }\end{array}$ & $2200-1250$ & 950 & 18 & 1.895 \\
\hline $\begin{array}{c}\text { Late Prehistoric_-Austin } \\
\text { (AU 3b) }\end{array}$ & $1250-750$ & 500 & 3 & 0.600 \\
\hline $\begin{array}{l}\text { Late Prehistoric-Toyah } \\
\text { (AU 3a) }\end{array}$ & $750-300$ & 450 & 6 & 1.333 \\
\hline $\begin{array}{c}\text { Protohistoric/Historic NA } \\
\text { (AU 2) }\end{array}$ & $300-150$ & 150 & 1 & 0.667 \\
\hline
\end{tabular}

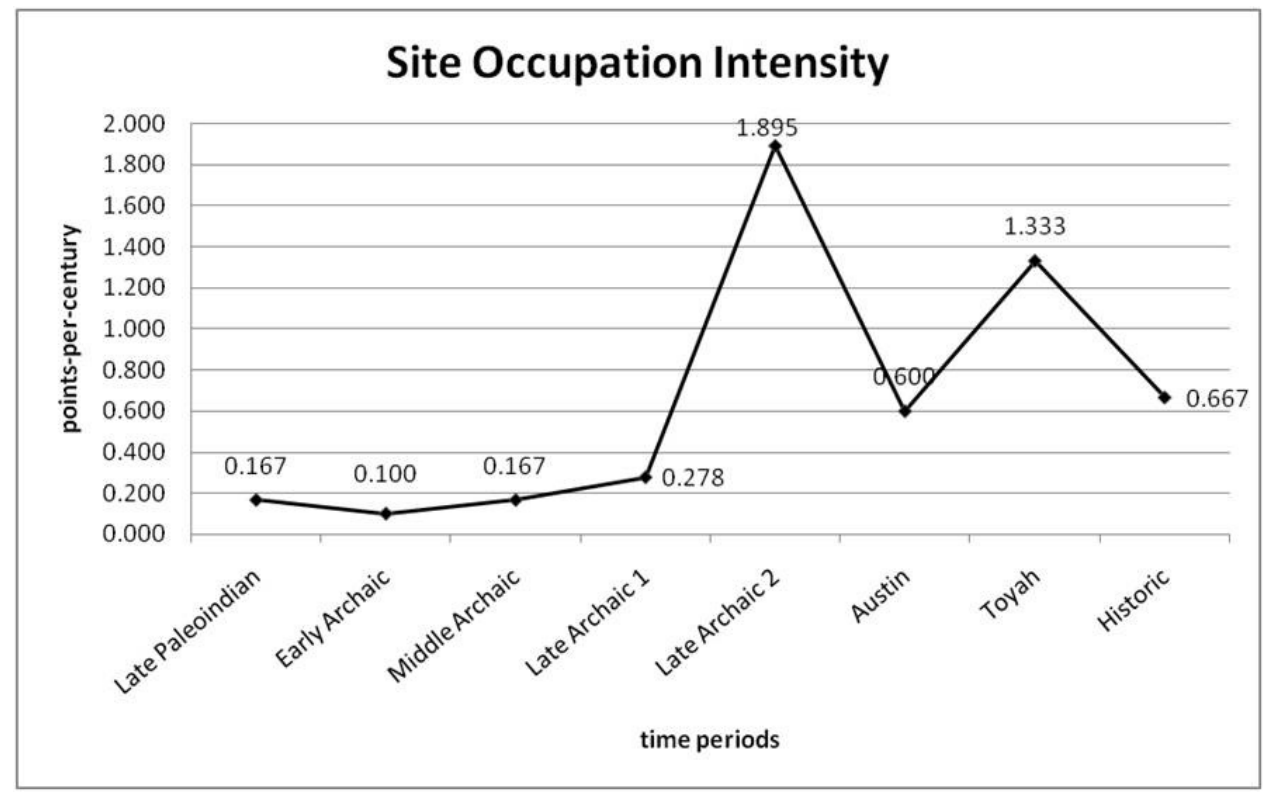

Figure 6-14. Relative intensity of site occupation by period as indicated by discard frequency. 
The projectile points recovered from this investigation add to our understanding of the sequence of deposits that are present in this area of the Spring Lake archaeological complex. However, because the sample is so small, these data ought to be thought of as a generalized indication of site occupation/visitation intensity. For example, one Guerrero point does not constitute a reliable sample for indicating Historic period occupation intensity.

\section{Bifaces}

In total, 172 bifaces and biface fragments were recovered during the 1996-1998 field school excavations at 41HY165. Of those, 24 (15.1\%) are associated with the established AUs. This analysis focused on examining the various reduction stages of the blanks and preforms that were discarded within AUs in order to elucidate technological trends.

\section{Methodology}

Within the AUs, 14 bifaces were recovered and recognized as preforms, four of which were complete. All AU preforms were sorted into one of four reduction stages: early-stage $(n=0)$, intermediate-stage $(n=6)$, late intermediatestage $(n=4)$, and late-stage preforms $(n=4)$. Two bifacial tools that do not fit into any of these four categories are also described below. Measurements of length, width, and thickness to the nearest 0.1 millimeter $(\mathrm{mm})$ as well as weight to the nearest $0.1 \mathrm{~g}$ were recorded for each of the reduction-stage bifaces. Incomplete bifaces were identified as corner fragments, medial fragments, end missing, end only (proximal or distal), or edge missing. The breakage type and raw material characteristics such as cortex, patina, or heat treatment were recorded when present. These fragments were also weighed and inspected for use wear. No measurements of length, width, or thickness were recorded for pieces too small and fragmented to describe. All metric measurements, retouch and use wear data for AU bifaces and biface fragments are included in Appendix C (Tables C-5 and C-6).

\section{Results}

\section{Early-Stage Bifaces $(n=0)$}

No early-stage bifaces were recovered from AUs at 41HY165.

\section{Intermediate-Stage Bifaces $(n=6)$}

The intermediate-stage includes bifaces that have a more established form than earlystage bifaces and have proximal, medial, and distal sections. In addition, intermediate-stage bifaces usually retain a small amount of cortex. Six bifaces were classified as intermediate-stage bifaces, three of which were complete. Specimen 152-7 (Figure 6-15E) is a short, triangular biface with a square proximal end. It is fairly symmetrical in plan view, but has sinuous lateral edges and pronounced bulb scars. Abrupt hinge and step terminations are evident on both faces, as well as cortex. Specimen 279-5 (Figure 6-15 F) is a good example of a large, thick, ovate biface with a convex proximal end. The lateral edges are sinuous with pronounced bulb scars and retouch with step and hinge terminations. Cortex is present on one face as well as a stack formation. There is evidence of crushing on the proximal end and use wear on the lateral edges and distal end. The last complete biface, Specimen 256-2 (Figure 6-15B), is a smaller, thick, ovate biface that also exhibits cortex, sinuous lateral edges, and pronounced bulb scars. There is evidence of crushing on the lateral edges and distal end. Both faces exhibit step terminations. There are three broken biface fragments in this category, two of which have cortex and perverse breaks. Specimen 238-5 (Figure 6-15A) is a corner 


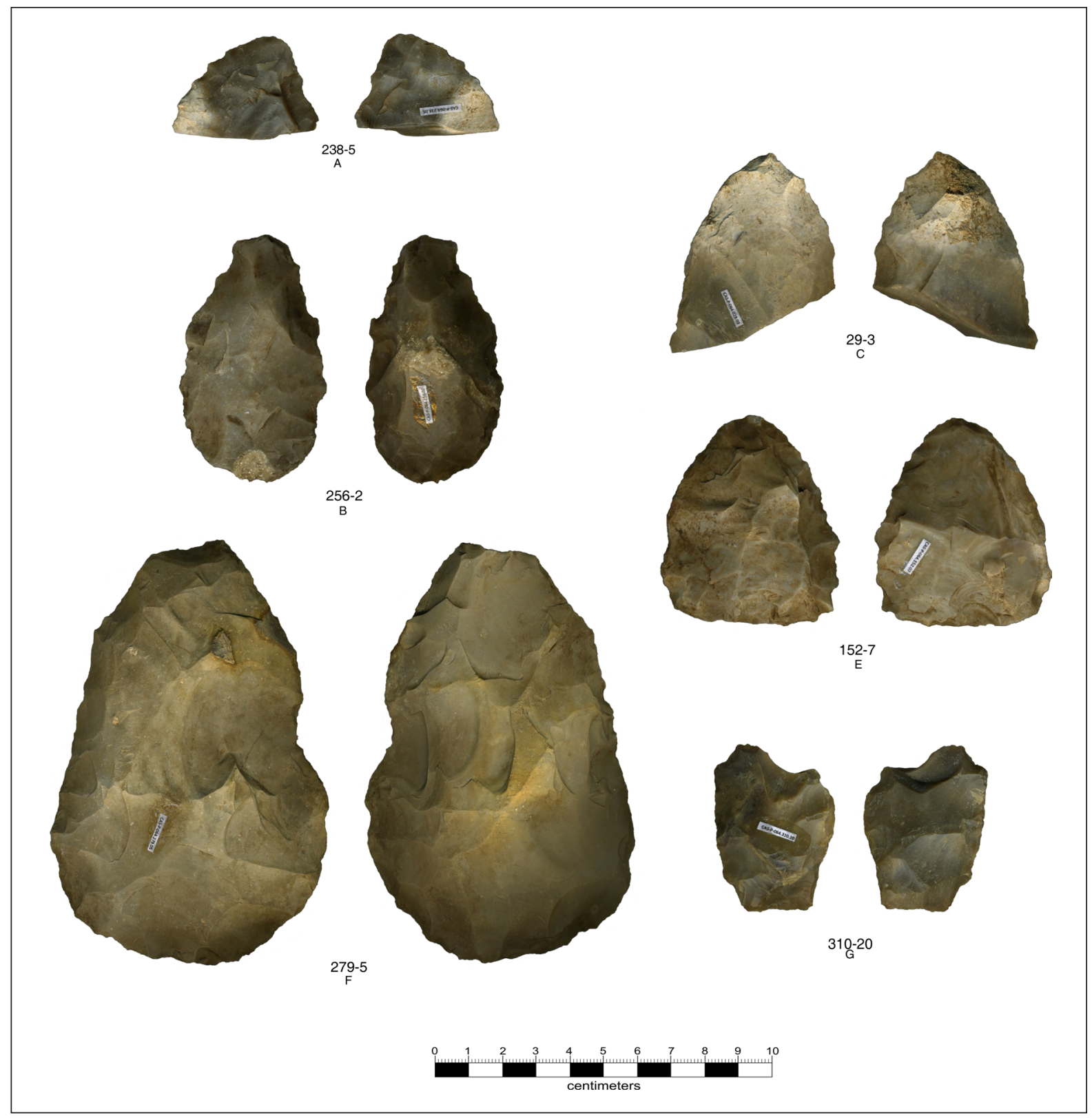

Figure 6-15. Intermediate-stage bifaces.

fragment, Specimen 29-3 (Figure 6-15C) is a distal fragment, and Specimen 310-20 (Figure $6-15 \mathrm{G}$ ) is a proximal fragment with an irregular break.

\section{Late Intermediate-Stage Bifaces $(n=4)$}

This category includes bifaces that have a more clearly established outline. They are generally shorter and/or narrower than earlier stages within the reduction sequence. Four bifaces exhibit these characteristics. Specimen 310-13 (Figure 6-16C) is a complete biface with slightly sinuous lateral edges. Although multiple step and hinge terminations exist, the specimen is symmetrical in plan view and has a large, fluted flake scar on the proximal end from attempting 
to thin the base. This is a good example of a low-skill, late intermediate-stage biface. The remaining bifaces within this category are all well thinned, triangular, distal fragments representing reduction failures. Specimen 256-3 (Figure 6-16B) exhibits a perverse fracture, while Specimen 238-6 (Figure 6-16A) has a horizontal break; both show evidence of use wear. Specimen 310-17 (Figure 6-16D) has two transverse fractures forming a point on the proximal end. It is difficult to determine if this was intentional or caused by heat fracturing. There is also evidence of light retouch and use wear along the lateral edges.

\section{Late-Stage Bifaces $(n=4)$}

Late-stage preforms have established forms, low edge angles, and an absence of retouched lateral margins. They are also thinner and shorter than all other bifaces within the

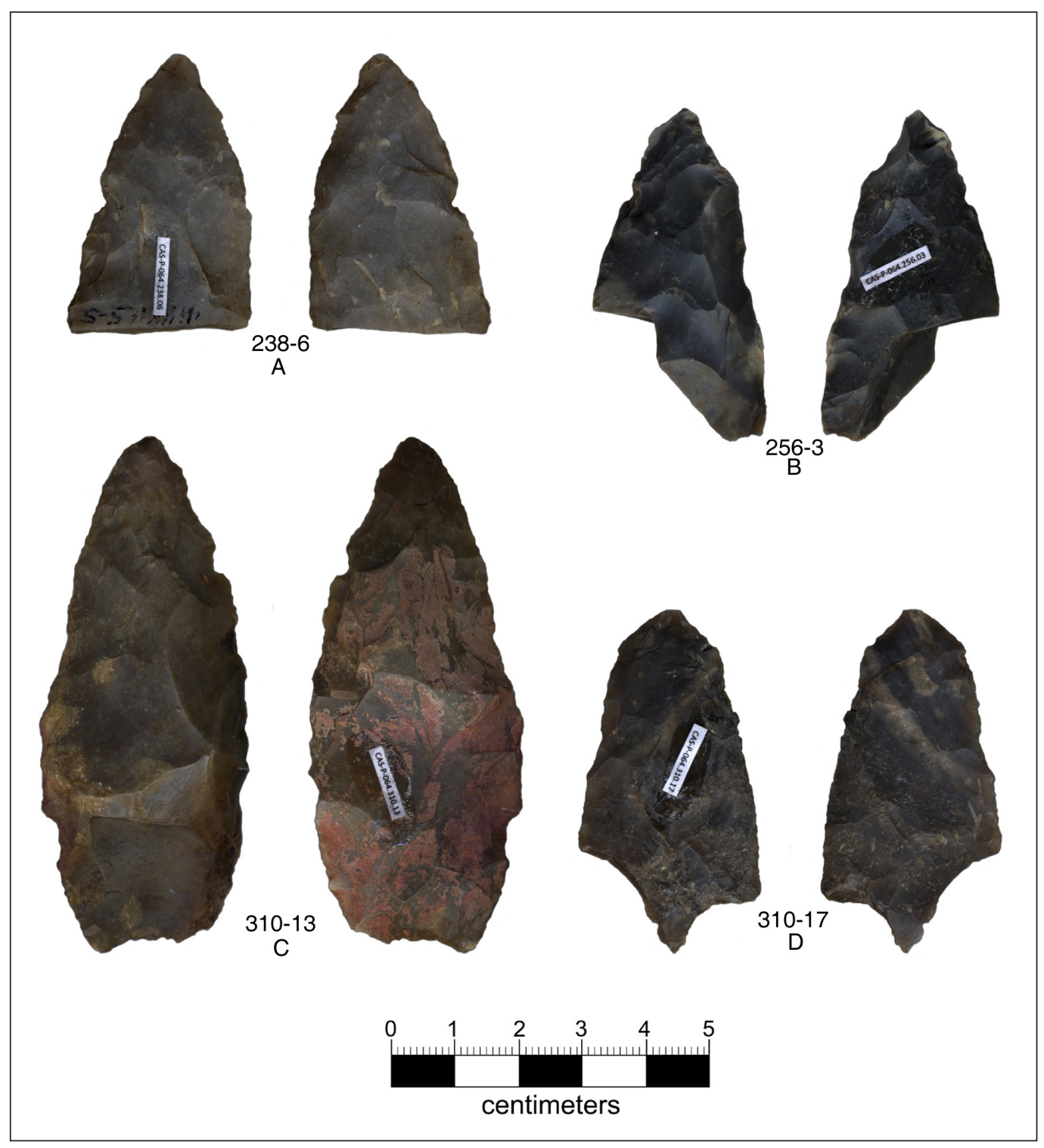

Figure 6-16. Late intermediate-stage bifaces. 
reduction sequence, and are usually made of higher-quality chert. This category contains four specimens. Specimens 238-8 (Figure 6-17B) and 256-16 (Figure 6-17A) are distal fragments with horizontal fractures. Specimen 291-5 (Figure 6-17C) is a corner fragment, and Specimen 31016 (Figure 6-17D) is a medial fragment with perverse and horizontal fractures. Three of the specimens $(291-5,238-8,310-16)$ in this category exhibit heat spalling and use wear.

\section{Discussion of Biface Production}

In general, biface production at 41HY165 can be described as relatively low-intensity, midto late-stage production. No early-stage bifaces were found within reliable contexts at 41HY165. Intermediate-stage bifaces seem to have been preferred over other stages at this site (Table 6-3). Six bifaces were associated with the Middle Archaic, one with the Late Archaic I, and seven with the Late Archaic II (Figure 6-18). However, this small sample precludes any discussion of trends over time.

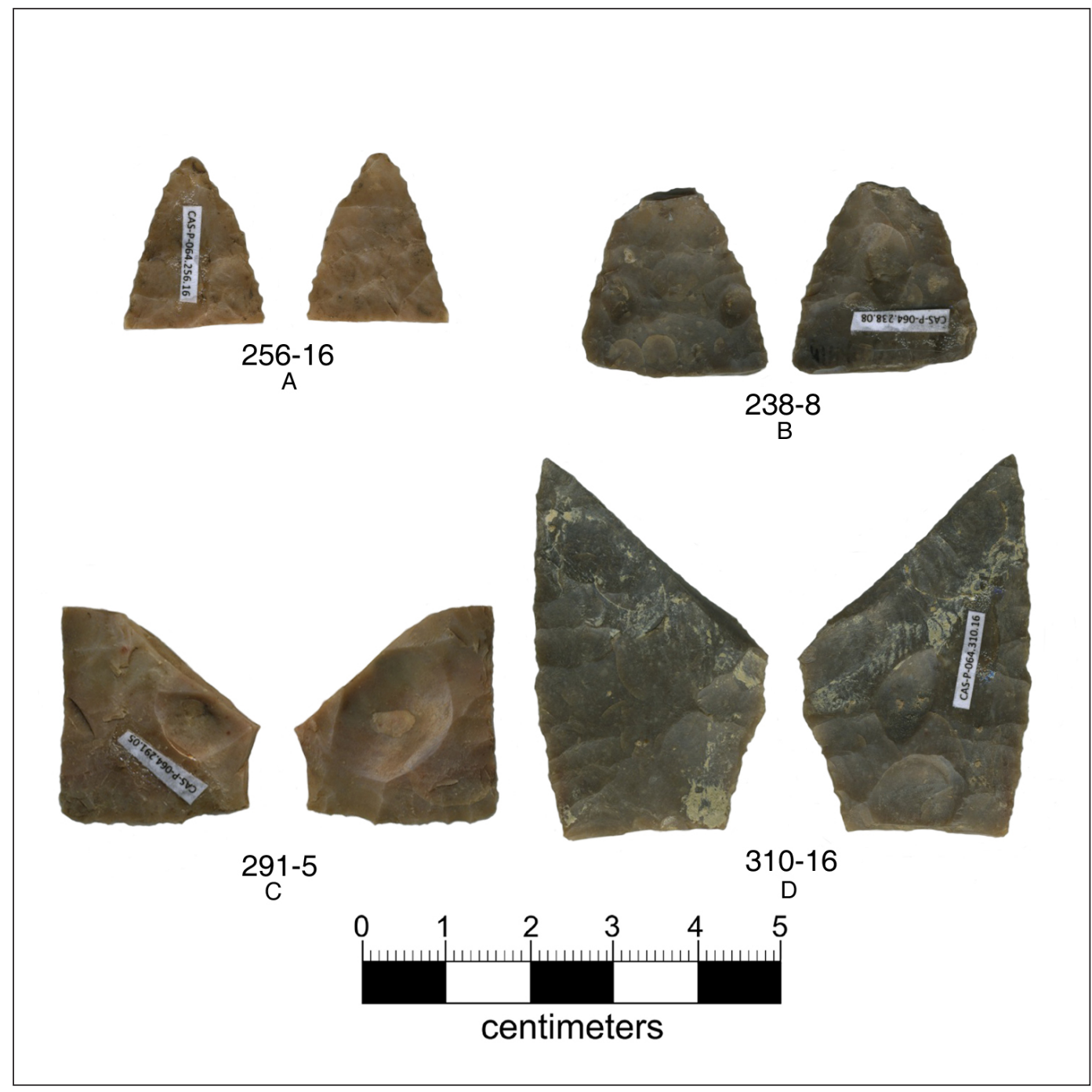

Figure 6-17. Late-stage bifaces. 
Table 6-3. Raw and Standardized Frequencies of Biface Categories by Period.

\begin{tabular}{lccc}
\hline Period (AU) & Biface Category & Count & $\begin{array}{c}\text { Standardized } \\
\text { Frequency }\end{array}$ \\
\hline Middle Archaic (AU 5) & Early Stage & 0 & 0 \\
& Intermediate Stage & 3 & 0.83 \\
& Late Intermediate Stage & 2 & 0.56 \\
& Late Stage & 1 & 0.28 \\
\cline { 2 - 4 } & Total & 6 & 1.67 \\
\hline Late Archaic I (AU 4b) & Early Stage & 0 & 0 \\
& Intermediate Stage & 1 & 0.09 \\
& Late Intermediate Stage & 0 & 0 \\
& Late Stage & 0 & 0 \\
\cline { 2 - 4 } & Total & 1 & 0.09 \\
\hline Late Archaic II (AU 4a) & Early Stage & 0 & 0 \\
& Intermediate Stage & 2 & 0.21 \\
& Late Intermediate Stage & 2 & 0.21 \\
& Late Stage & 3 & 0.32 \\
\cline { 2 - 4 } & Total & 7 & 0.74 \\
\hline
\end{tabular}

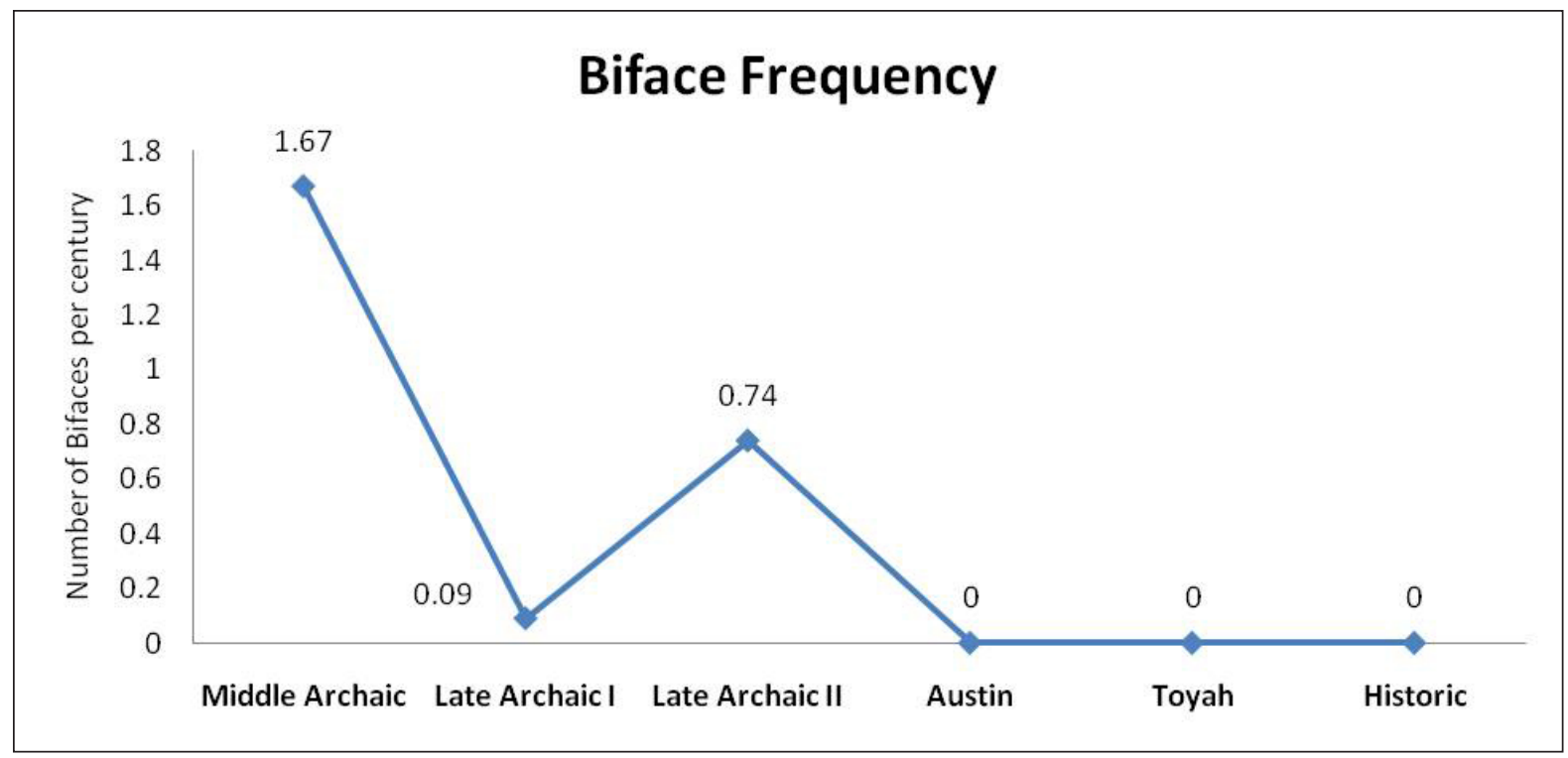

Figure 6-18. Biface frequency over time. 


\section{Bifacial Tools}

Drills/Perforators $(n=2)$

Two bifaces were recovered from two different AUs that do not fit into one of the four categories described above. Both specimens are distal fragments of a perforator or drill. Specimen 152-28 (Figure 6-19A) is triangular in cross section and plan view, and has a sharp point. Specimen 310-15 (Figure 6-19B) has more pronounced bulb scars, making the lateral edges beveled and sinuous. It also has a blunt tip and exhibits a bending fracture.

\section{Biface Fragments}

Eight biface fragments were recovered from 41HY165 AUs. These specimens could not be placed into any category because of their fragmentary condition. Weights and recorded attributes for all biface fragments can be found in Appendix C-6.

\section{Flake Tools and Formal Unifaces}

In total, 177 flake tools and formal unifaces are present in 41HY165's AUs. Of those, two were classified as formal unifaces. According to Hall et al. (1982:348), formal unifaces contain flake scars over the majority of their dorsal face, assume a standard form, and have unmodified ventral surfaces. In addition, extensive modification completely alters the original morphology of the flake to the extent that its original size and shape cannot be determined. Flake tools, on the other hand, include any flake that is unifacially edgemodified or used, and has little to no modification on its dorsal face. Flake tools are generally thought of as expedient tools that can be easily prepared, but have low reliability. Expedient flake tools (EFTs) are infrequently maintained and often discarded and replaced with a new tool when they attain an undesirable amount of wear. Flake tools can be distinguished from formal

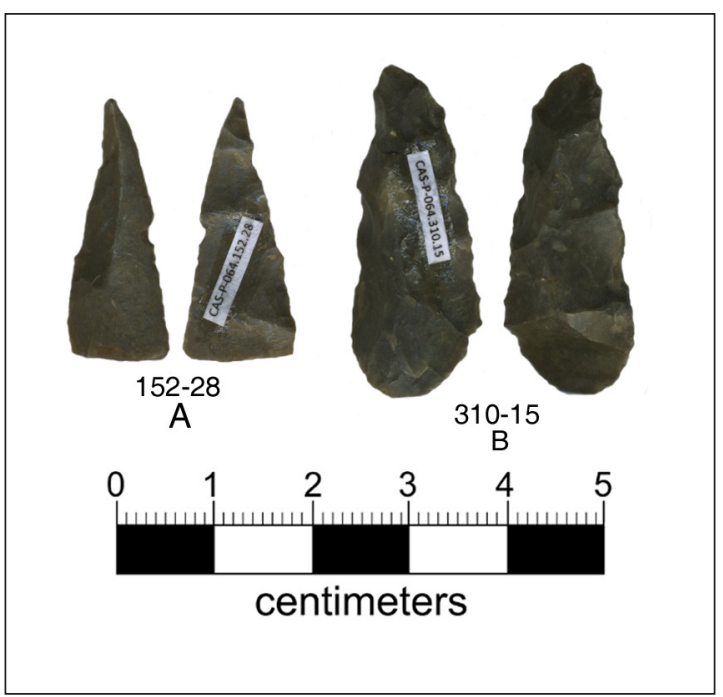

Figure 6-19. Bifacial tools.

unifaces by the ability to identify the original morphology of the flake.

Nickels and Bousman (2010) refer to four subcategories of unifaces: expedient, minimal, formal, and indeterminate. Expedient unifaces are flakes that have been modified through use, but not by intentional flaking or shaping. The minimal category includes minimally retouched unifaces (MRUs) that have not been drastically altered from their original form, but one or more of its edges has been modified through intentional flaking. Formal unifaces have one or more significantly shaped edges through deliberate patterning of flake removals. Nickels and Bousman (2010) also describe formal unifaces as "artifacts functionally classified as scrapers, gouges, or unifacial knives." However, the present study avoids a functional classification system since inferences made regarding prehistoric use are best supported with microwear analysis.

The above-described system, with a few modifications, was used to analyze the flake tools and unifaces found within AUs at 41HY165. The term "expedient uniface" is not used in this study for these types of tools since some uses could 
modify the flake bifacially (slicing, chopping, etc.). Therefore flakes that were not intentionally flaked, shaped, or modified and exhibited macroscopic use wear were categorized as EFTs. This category was then further separated into unifacial or bifacial EFT categories. The same criteria Nickels and Bousman (2010) used for MRUs was used in our study. In some cases, flake edges that have been prepared or ground (similar to the way a platform is prepared) could be mistaken for use wear. Experimental studies combined with microwear confirmation would be a valuable effort to differentiate between prepared/ground flake tool edges and utilized edges. It is also important to note that unidentified postdepositional damage can cause single-flake random and irregular detachments on a flake edge. This type of edge morphology could also represent accretional chipping acquired during use. However, microscopic examination would be necessary to confirm this. Because of these subjective and complex issues, the total number of EFTs is unknown for this assemblage.

In general, this study realizes that MRUs are less expedient and more curated than the EFT category. Furthermore, "curated" tools are often associated with collectors and "expedient" tools are often associated with foragers. However, it is our understanding that the concept of curation cannot be truly understood by relating it with any type of tool. Alternatively, we understand curation as a process associated with tool use. Therefore, we wanted to look at degrees of curation within both categories of tools by looking at the Total Edge Modification (TEM) and the Potential Edge Modification (PEM). This method (detailed below in the Methodology section) allows us to note changes in expediency in different parts of the tool kits at $41 \mathrm{HY} 165$ over time (LeDoux and Lohse 2011b).
Presented below are descriptions and preliminary interpretations of the 41HY165 AU flake tools and unifaces. Unfortunately, the sample size for flake tools and unifaces recovered from reliable AUs is relatively small and does not allow for detailed statistical analyses. Although the interpretive potential of this group of artifacts is limited by its small sample size, artifact descriptions and descriptive statistics help to document general trends in how flake tools and unifaces might have been designed and procured, and how intensively they were used over different periods at $41 \mathrm{HY} 165$.

\section{Methodology}

All 4,237 pieces of chipped stone (broken and complete) from the AUs were scanned for EFTs. Specimens were classified as an EFT if the original morphology of the flake remained and contained evidence of macroscopic edge modification (unifacial or bifacial) acquired through tool utilization, but lacked regular and intentional flaking or shaping. A specimen was classified as an MRU if regular and intentional flaking (retouch) was evident on one or more of its edges, but its original flake form was still distinguishable. A uniface was designated as formal if it exhibited significant shaping and deliberate patterning of unifacial flake removals on one or more edge.

All specimens were weighed to the nearest 0.1 g. Using the method developed by Prilliman and Bousman (1998) for flake tool analysis at the Wilson-Leonard site in Williamson County, metric measurements were taken for the MRUs as well as the formal unifaces. First, maximum length, width, and thickness of each artifact were measured with calipers to the nearest 0.1 $\mathrm{mm}$. Then, a nylon string was used to measure the circumference. The string was wrapped around the circumference of the artifact as near 
as possible to the ventral face. Once marked, the string was laid out along a ruler and the circumference was measured to the nearest millimeter and recorded.

TEM and PEM were measured for all flake tools and unifaces using the string in the same method. TEM is defined as any edge that shows continuous flake scaring for at least $2 \mathrm{~mm}$ along its length. PEM is the modified edge combined with any unmodified edge that could have been flaked, not including the platform nor any fractured edges. Last, a TEM:PEM ratio was calculated by dividing the TEM by the PEM. The TEM:PEM ratio, when multiplied by 100 , indicates the intensity of artifact usage as a percentage to three decimal places (LeDoux and Lohse 2011b:248). Metric and observed data for EFTs and MRUs is included in Appendix C (Tables C-7 and C-8).

In order to see what kinds of flakes were selected for use, complete EFTs were analyzed. A complete EFT is defined as a flake that shows use wear or edge modification and has a striking platform as well as an intact distal end with a feather or hinge termination (LeDoux and Lohse 2011b:252). All complete flakes were sorted into thinning flakes, non-thinning flakes, DEBs, and r-flakes (see debitage analysis for description of DEBs and r-flakes). Then, flakes in each category were scanned for macroscopic use wear or modification.

\section{Results}

\section{All Expedient Flake Tools $(n=88)$}

In total, 88 EFTs were identified within the AUs at 41HY165. The majority $(n=78)$ exhibited unifacial modification from use wear, while 10 exhibited bifacial modification due to utilization. Although raw counts show that AU 4a (Late Archaic I) contained the most EFTs, the adjusted numbers suggest that they were most frequent during Austin times (Table 6-4, Figure 6-20). TEM:PEM ratios for EFTs suggest that they were most heavily used during the Late Archaic I (Figure 6-21). Interestingly, EFTs seem to be used

Table 6-4. Raw and Adjusted Expedient Flake Tool Frequencies.

\begin{tabular}{cccc}
\hline Period (AU) & $\begin{array}{c}\text { Duration } \\
\text { (Years) }\end{array}$ & $\begin{array}{c}\text { EFT } \\
\text { Total }\end{array}$ & $\begin{array}{c}\text { Adjusted } \\
\text { Frequency } \\
\text { (EFTs/100 } \\
\text { Years) }\end{array}$ \\
\hline Middle Archaic (AU 5) & 1,800 & 6 & 1.67 \\
Late Archaic I (AU 4b) & 1,800 & 33 & 2.82 \\
Late Archaic II (AU 4a) & 950 & 26 & 2.74 \\
Austin (AU 3b) & 500 & 22 & 14.67 \\
Toyah (AU 3a) & 450 & 1 & 0.56 \\
\hline
\end{tabular}

\section{Expedient Flake Tool Frequency}

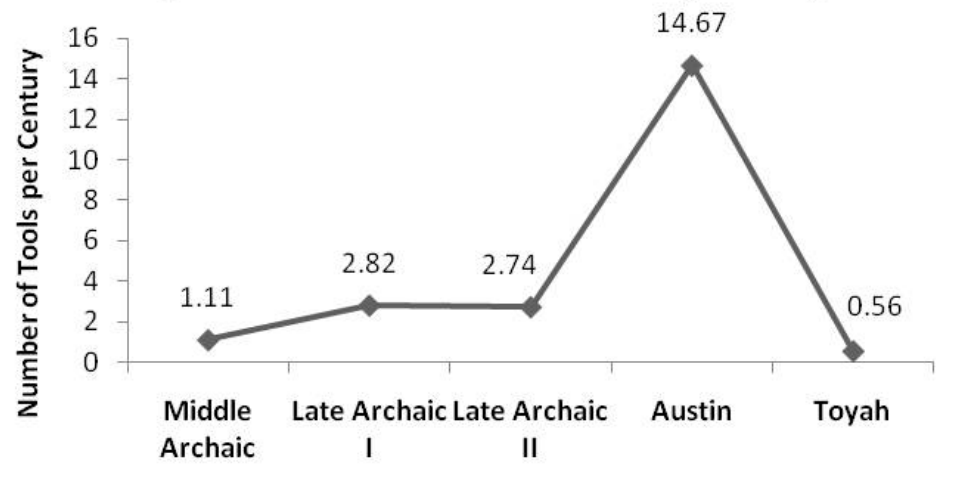

Figure 6-20. Adjusted EFT frequencies per century. 
the most expediently during the Austin phase.

\section{Complete Expedient Flake} Tools $(n=48)$

Of all the flake types, thinning flakes were the most common type used as expedient tools (Figure 6-22). DEBs and r-flakes are subgroups of thinning flakes and their count is included in the All Thinning:Total.

\section{Minimally Retouched}

\section{Unifaces $(\mathbf{n}=89)$}

Eighty-nine

MRUs

were identified within the larger assemblage. After standardizing the MRU artifact recovery, we can see that they were most numerous during Austin times (Table 6-5 and Figure 6-23). The TEM:PEM ratio averages in Figure 6-24 illustrate that MRUs were most intensively used in the Middle Archaic.

There is a high degree of morphological variability among the MRUs. This variability is a product of both the types of flakes that are chosen for use and the technology implemented for modification. For example, unifacial retouch is often found on blade-like flakes at 41HY165 (Figure 6-25). Also, notching seemed to be an important technology in flake modification (Figure 6-26). Another variety of MRUs includes flakes that exhibit a spurred edge (Figure 6-25). Spurred edges can be formed along a natural

\section{TEM:PEM ratio over time} $37.03 \%$

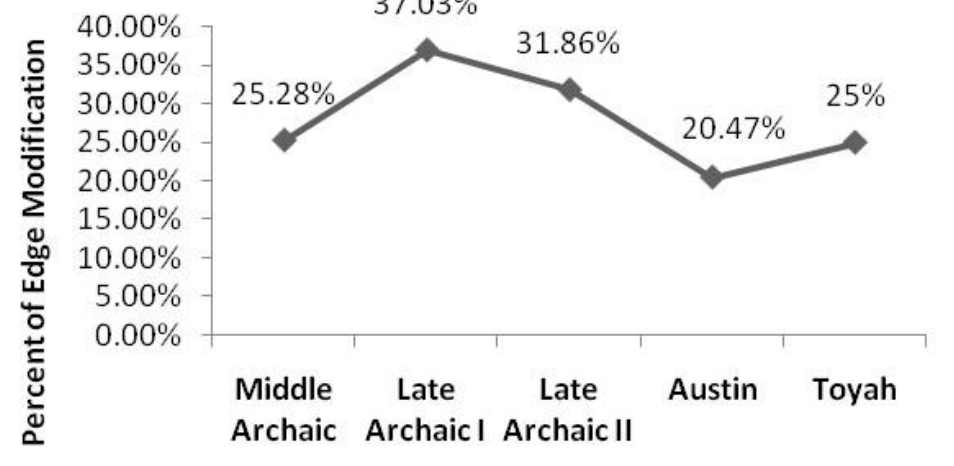

Figure 6-21. Average percentages of utilized or modified edge to potential edge on EFTs by period.

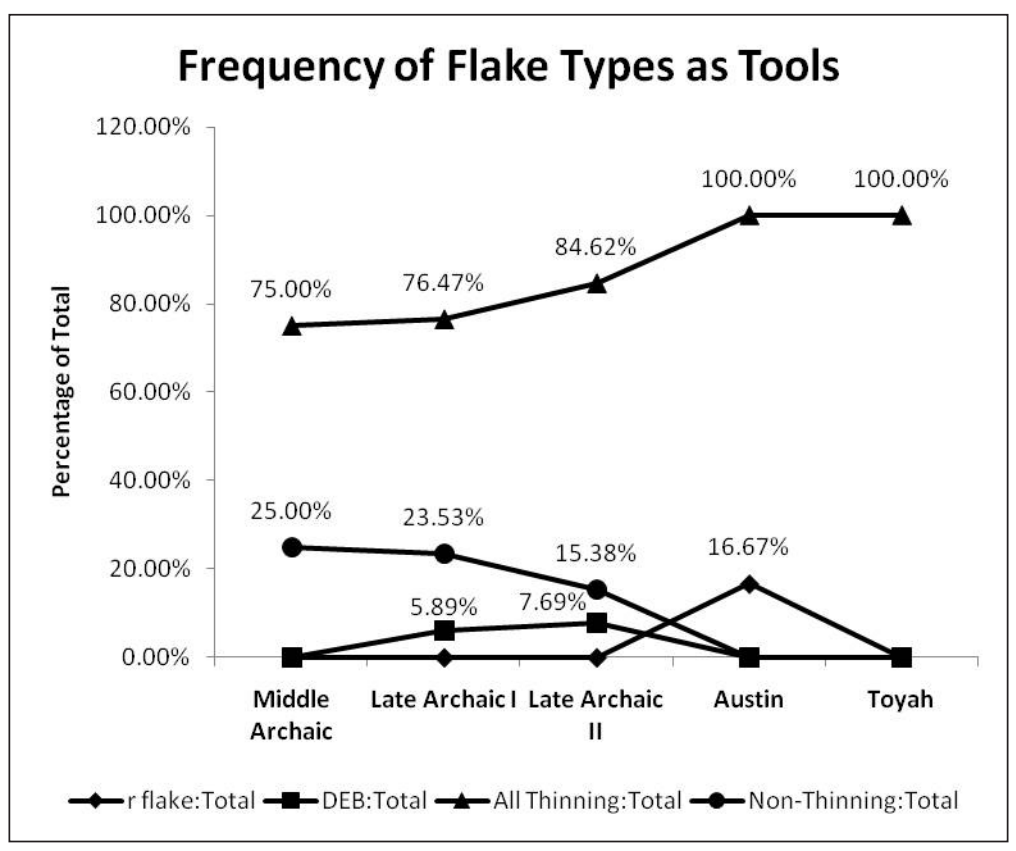

Figure 6-22. Frequency of flake types as tools (percentage of flake types to the total tool count for each cultural era).

acute angle flake margin, by retouching along a broken flake margin, or by retouching an acute angle into the unbroken flake margin (Prilliman and Bousman 1998:613). Spur morphology often occurs on the distal ends of flakes at 41HY165. Specimen 66-7 is an amorphous tool with one prominent spur on the distal end (Figure 6-25A). One edge has been unifacially modified, used, 
Table 6-5. Raw and Adjusted Minimally Retouched Uniface Frequencies.

\begin{tabular}{cccc}
\hline Period (AU) & $\begin{array}{c}\text { Duration } \\
\text { (Years) }\end{array}$ & $\begin{array}{c}\text { MRU } \\
\text { Total }\end{array}$ & $\begin{array}{c}\text { Adjusted } \\
\text { Frequency } \\
\text { (MRUs/100 } \\
\text { Years) }\end{array}$ \\
\hline Middle Archaic (AU 5) & 1,800 & 14 & 3.89 \\
Late Archaic I (AU 4b) & 1,800 & 16 & 1.37 \\
Late Archaic II (AU 4a) & 950 & 40 & 4.21 \\
Austin (AU 3b) & 500 & 16 & 10.67 \\
Toyah (AU 3a) & 450 & 3 & 1.67 \\
\hline
\end{tabular}

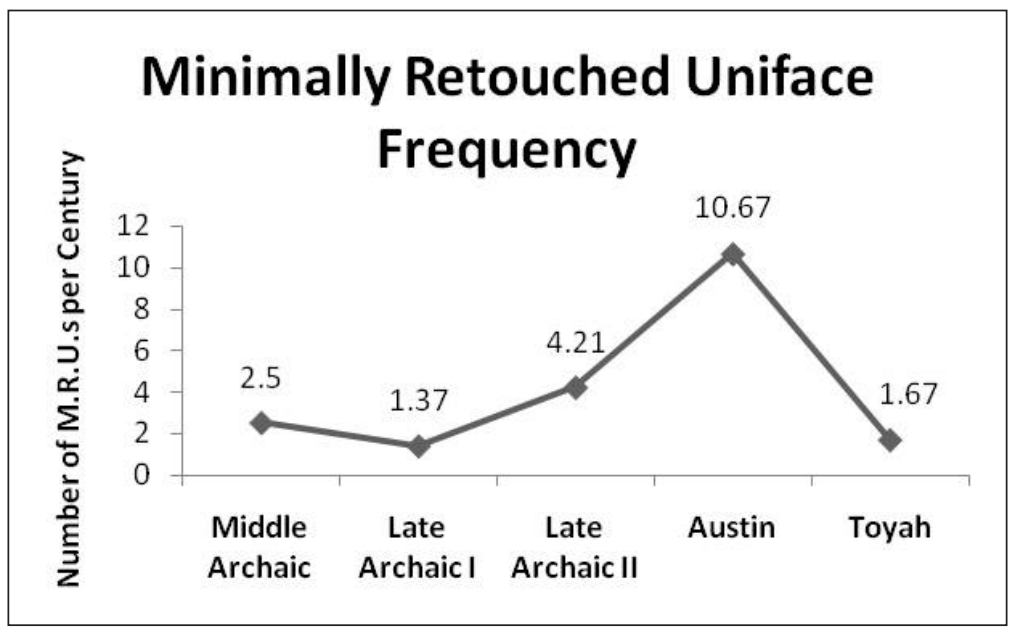

Figure 6-23. Adjusted MRU frequencies per century.

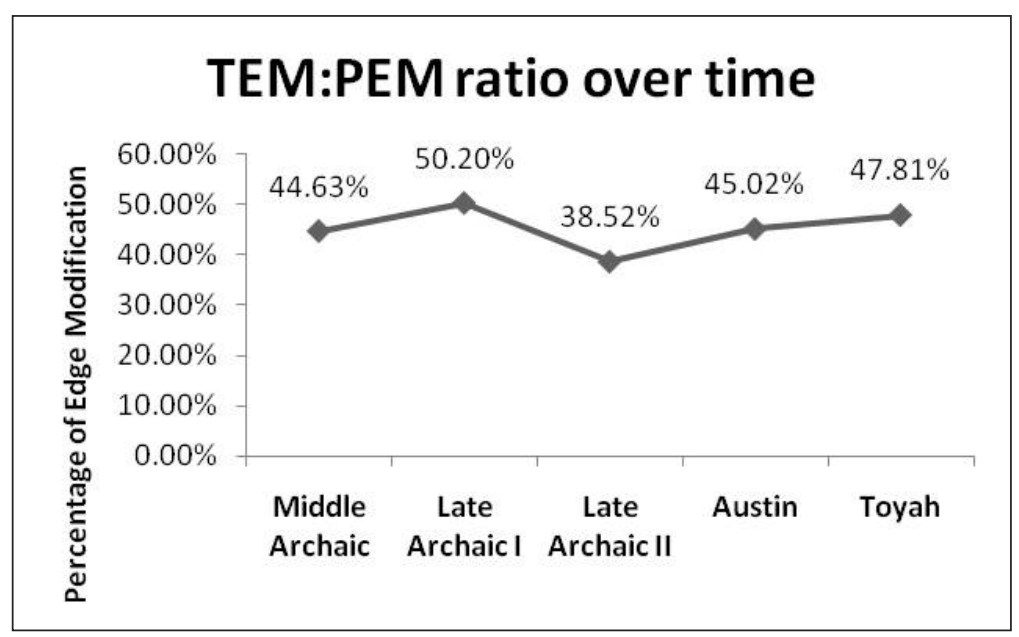

Figure 6-24. Average percentages of modified edge to potential edge on MRUs by period. and retouched. The retouch is irregular but continuous, and the edge angle is shallow. Cortex is present around the platform.

\section{Formal Unifaces $(n=2)$}

Two formal unifaces were identified, and both were recovered from the same unit and level dating to the Middle Archaic. Specimen 310-14 (Figure 6-27A) is a triangular-shaped uniface that has cortex around the platform and unifacial shaping on the ventral face. The dorsal face exhibits scars from previous flake removals before this flake was removed from its core. The retouch is continuous, regular, and invasive, creating a steep edge angle. The other formal uniface was also recovered from an AU associated with the Middle Archaic. This uniface, specimen 310-12, has a steep dome-shaped modified edge on its distal end and a large platform and bulb of percussion on its proximal end. The ventral face is unmodified, and the dorsal face has cortex with invasive flake scars. Macroscopic use wear is evident all along the modified edge (Figure 6-27B). According to TEM:PEM ratios, specimen 310-12 was used less expediently than specimen 310 14 (Table 6-6). 


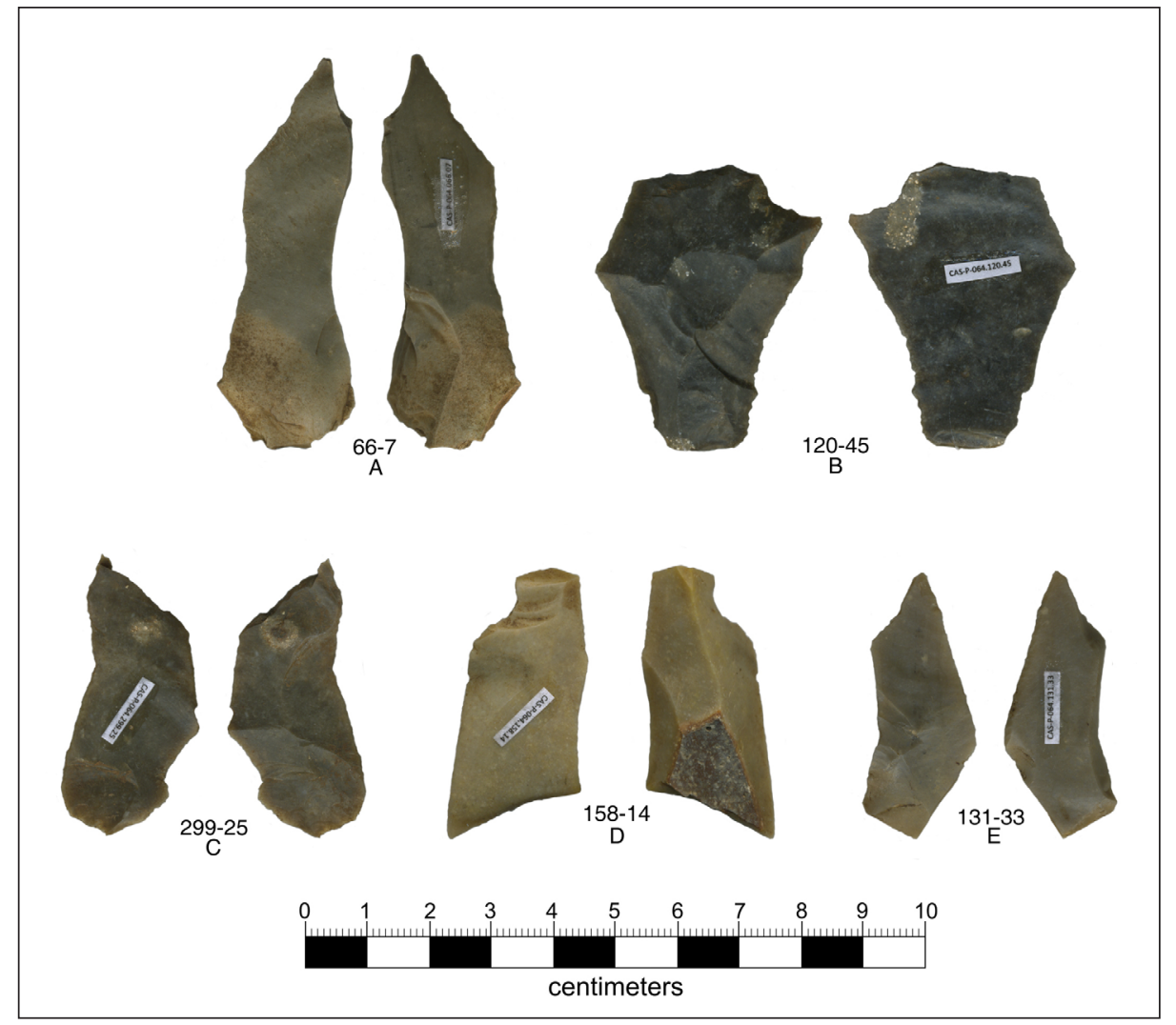

Figure 6-25. Minimally retouched unifaces: A, C-E) MRUs on blade-like flakes; A-E) spurring technology.

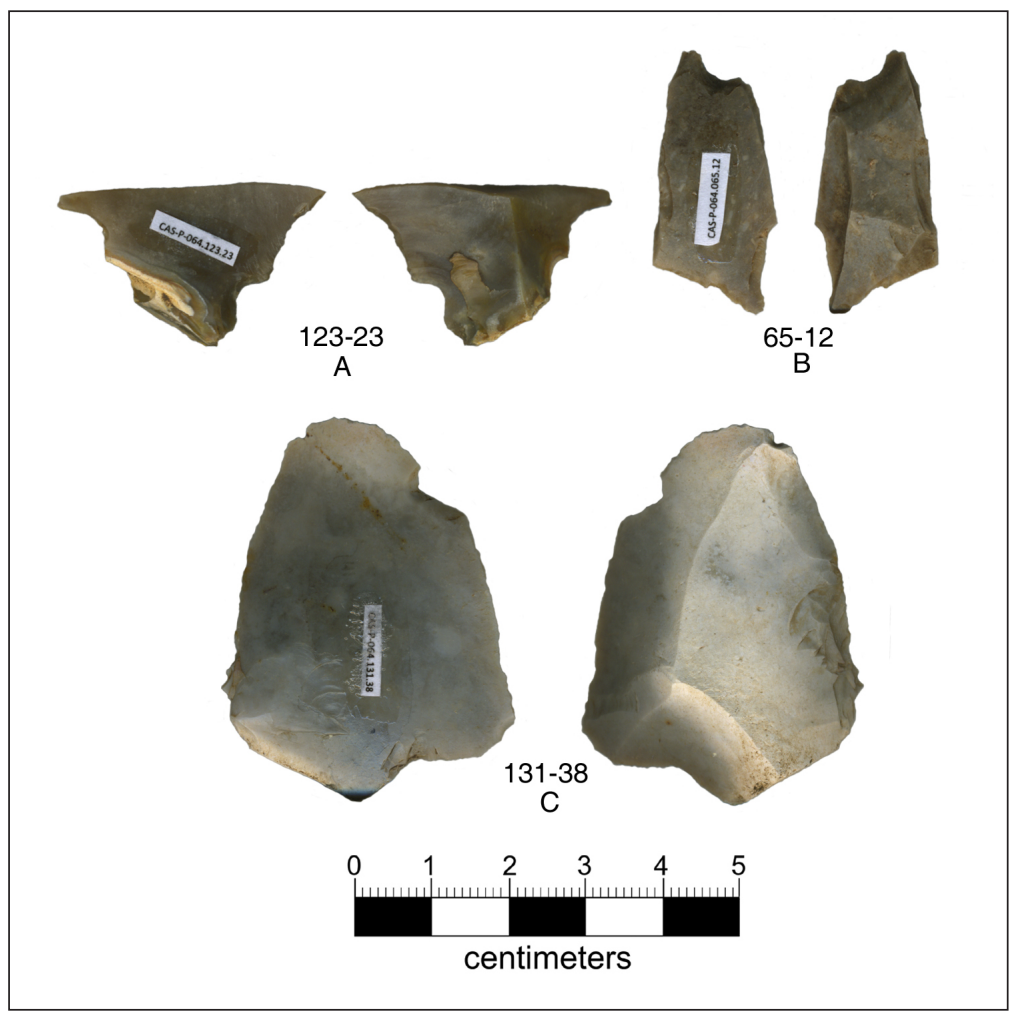

Figure 6-26. Notching on minimally retouched flakes. 


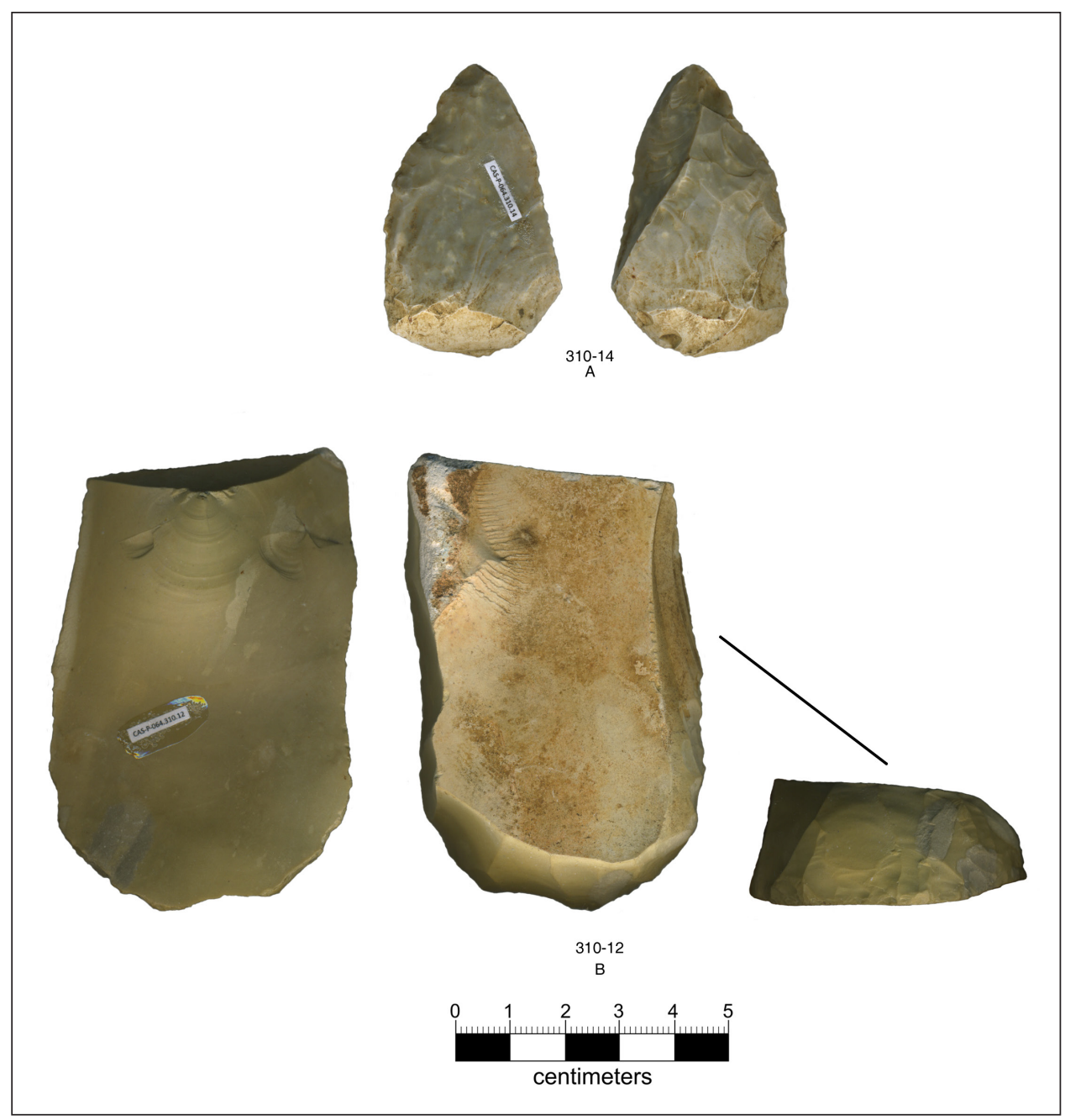

Figure 6-27. Two formal unifaces.

Table 6-6. Metric Data for Formal Unifaces.

\begin{tabular}{cccccccccc}
\hline Specimen & AU & $\begin{array}{c}\text { Max } \\
\text { TH }\end{array}$ & $\begin{array}{c}\text { Max } \\
\text { L }\end{array}$ & $\begin{array}{c}\text { Max } \\
\text { W }\end{array}$ & $\begin{array}{c}\text { Weight } \\
\text { (g) }\end{array}$ & Circ. & TEM & PEM & TEM:PEM \\
\hline $310-14$ & 5 & 10.15 & 52.83 & 32.73 & 17.7 & 141 & 28 & 90 & $31.1 \%$ \\
$310-12$ & 5 & 25.22 & 80.02 & 54.99 & 125.7 & 253 & 157 & 199 & $78.9 \%$ \\
\hline
\end{tabular}

\section{Discussion}

Overall, the limited number of EFTs and unifaces recovered from dated contexts prevents detailed temporal analysis. However, the available data elucidate a few important trends. One is that both EFTs and MRUs are most numerous in Austin times. This suggests that more people were producing and using
EFTs as well as MRUs during this time than any other period. According to the TEM:PEM ratios, EFTs were used significantly less during the Austin period than in any other. This means that while there were many EFTs being produced during the Austin period, they were only lightly used, making them truly expedient tools. The data presented above also established that while 
TEM:PEM ratios for EFTs are highest during the Late Archaic I, TEM:PEM ratios for MRUs are highest during the Middle Archaic. This would suggest that informally fashioned flake tools were more heavily used during the Late Archaic I, making them less expedient. This observation, combined with higher TEM:PEM ratios for Middle Archaic MRUs, indicates a more maintainable and curated tool kit, which suggests that people visiting 41HY165 during the Middle Archaic and the onset of the Late Archaic may have practiced collector strategies. Interestingly, the only two formal unifaces recovered from reliable contexts were associated with the Middle Archaic. To better understand the hunter-gatherer technological organization at $41 \mathrm{HY} 165$, this information should be considered along with relative changes in the frequencies of different tool types over time and related to bison exploitation and earth oven use.

\section{Cores}

Three cores were recovered from AUs at 41HY165 (Table 6-7). The definition for a flake core follows the description in Sitters et al. (2011:300): objects that show at least three flake removals or attempted removals from a discernable platform(s). Due to the very small sample size, only weights and detailed descriptions were included in the analysis and are presented below.

Specimens 238-04 and 65-6 are ad hoc, multidirectional flake cores (Figure 6-28 A and

Table 6-7. AUs Containing Cores.

\begin{tabular}{ccc}
\hline Specimen & Period (AU) & $\begin{array}{c}\text { Weight } \\
\text { (g) }\end{array}$ \\
\hline $238-4$ & Late Archaic II (AU 4a) & 49.40 \\
$74-5$ & Late Archaic I (AU 4b) & 41.60 \\
$65-6$ & Late Prehistoric-Austin (AU 3b) & 133.90 \\
\hline
\end{tabular}

C). Multidirectional cores are characterized by flake removals from multiple directions and from more than one platform. Ad Hoc cores are a subcategory of multidirectional flake cores that show some rotation, but no patterned faces or platforms have been developed. They also have little to no platform maintenance and some flake removals appear exploratory in nature. Specimen 65-6 is a broken flake core that has been recycled into a uniface. Two edges have been unifacially modified, forming a point. There is evidence of use wear along the modified edges on both the ventral and dorsal faces. Specimen 74-5 is a thin flake core with cortex covering the dorsal face (Figure 6-28 B). The flaking platform probably alternated between the dorsal face and a number of resulting platforms until the core became too thin to utilize.

\section{Debitage}

In total, there were 4,972 pieces of debitage recovered during the 1996-1998 field schools. Debitage is defined as waste material from lithic reduction, including flakes and shatter that have not been used as cores or tools (Sullivan and Rozen 1985:755). As individual tools approach completion, the debitage becomes progressively smaller and the amount of cortex on debitage specimens lessens. Thus, from the perspective of a debitage population, a trend of smaller debitage with little or no cortex would indicate a later stage of core reduction (Andrefsky 2005). If cobbles with complete cortical surfaces are brought to the site and then reduced, the resulting debitage would show greater amounts of cortex. However, if the raw materials were reduced to flake blanks before they were brought to the site for tool manufacture, it is likely that the debitage sample would have significantly low percentages of dorsal cortex regardless of the reduction stage (Andrefsky 2005). 


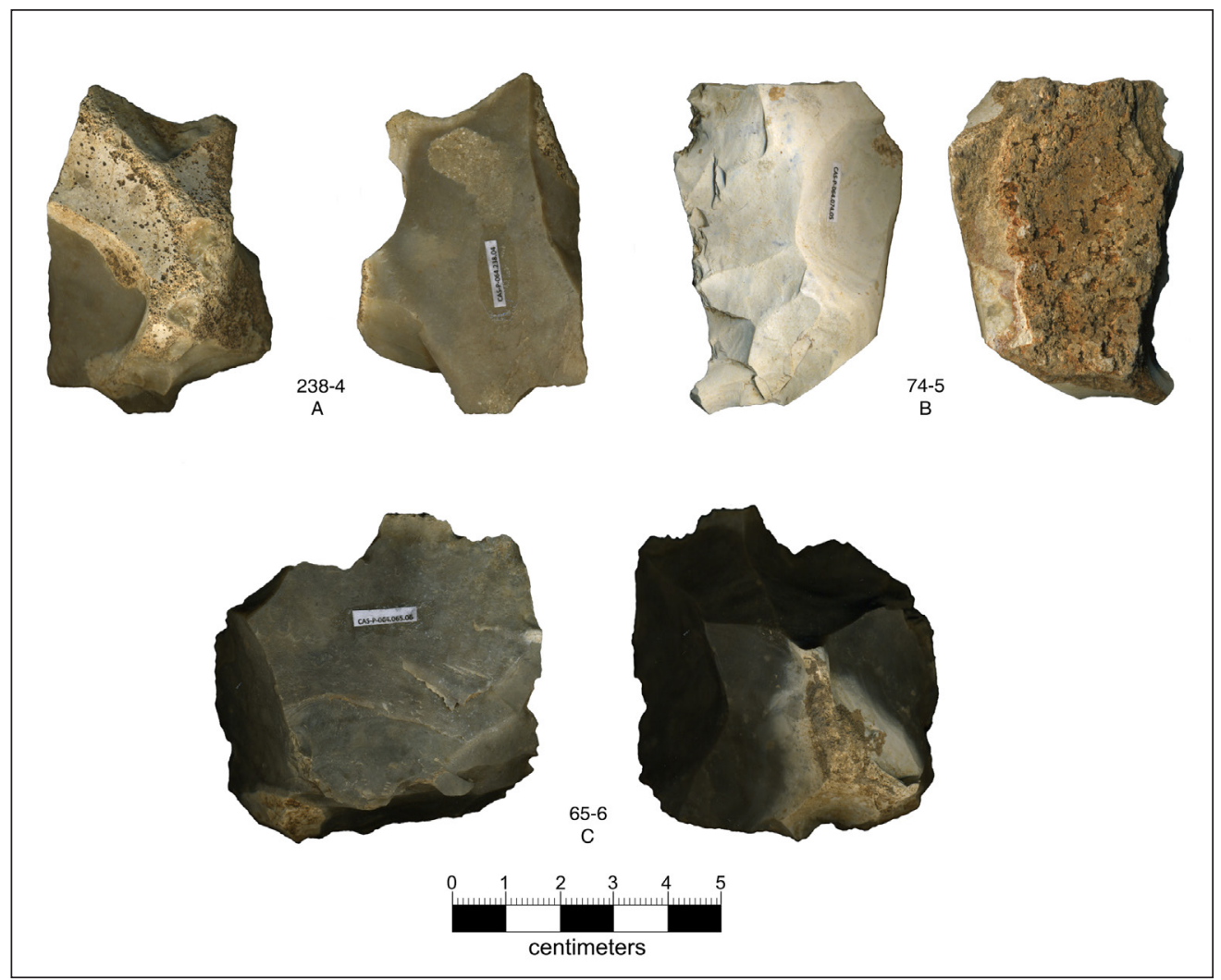

Figure 6-28. Three flake cores from 41HY165.

Debitage can also be analyzed to classify the type of load application used in its production. Some researchers believe that soft-hammer percussion flakes can be recognized by difuse or no bulbs of force and pronounced lips. Although size is a difficult and unreliable measure for determining load application, pressure flakes are sometimes defined as being smaller, thinner and lighter in weight than percussion flakes. Flakes produced by hard-hammer percussion have "pronounced bulbs of force, no lipping and slightly crushed striking platform areas" (Crabtree 1972:44).

The method of creating a technological typology based on debitage can be important in making behavioral interpretations and has its own theories. For example, debitage types are often used to infer the use of specific tool types at a site. Bifacial thinning flakes are flakes removed to thin or trim a biface. They can vary in sizes and attribute values depending upon the size and shape of the biface as well as the trimming method. This flake type usually has complex or faceted striking platforms, indicating platform preparation. Also, since the flake is removed from a biface, it will usually have ridges between flake scars on the dorsal surface. These flakes can be associated with both the production of and the resharpening of biface tools. Flakes produced from retouching or resharpening end scrapers are created by using the ventral surface as a striking platform. Therefore, they usually have flat striking platforms and rarely have dorsal cortex (Andrefsky 2008:123).

Overall, the different attributes associated with bifacial thinning flakes and striking platforms can be used to differentiate between biface production and core reduction as well as 
determine the relative amount of time invested in production. Flakes with single facets (flat striking platforms) are usually the result of detaching flakes from non-bifacial tools like unidirectional cores. Since bifacial thinning flakes usually have complex striking platforms and pronounced lips, which are produced by soft-hammer percussion on a prepared platform, a more time consuming process can be associated with the production of biface tools. Additionally, some researchers believe that platform preparation is indicative of the knapper being more careful when removing flakes from an objective piece that is close to being finished or has had a large amount of investment put in its production (Andrefsky 2005). Some researchers have observed that a "trend with decreasing relative amounts of bifacial thinning flakes suggests that bifacial technology decreases with increased amounts of relative sedentism" (Andrefsky 2005). Thus, the relative amount of bifacial thinning flakes at a site could be used to infer the degree of sedentism at that site (Parry and Kelly 1987). Through consideration of the theoretical perspectives described above, debitage types and attributes were analyzed from the data recovered from site $41 \mathrm{HY} 165$ and are presented below.

\section{Methodology}

The present study includes only debitage that has not been modified through utilization or retouch. Debitage from the AUs was sorted into the following categories: complete flakes, proximal flakes, broken flakes, burned nonflaked debitage, and angular debris (shatter). Total counts are presented in Table 6-8. Proximal flakes, broken flakes, and burned non-flake debitage were counted and weighed and then excluded from further analysis. A complete listing of debitage counts and weights for each AU is provided in Appendix C (Table C-9).

Complete flakes were the focal point of this analysis, as they were believed to be most informative. Therefore, complete flakes were sorted into thinning and non-thinning flakes. Non-thinning flakes are typically thick, have a relatively large amount of cortex, and smooth, unprepared platforms. Their ventral faces have little to no concave curvature and can sometimes be convex. Thinner flakes with concave ventral surfaces are characteristic of biface thinning. Biface thinning flakes also often lack cortex and have prepared (faceted) platforms.

Subcategories of biface thinning flakes include r-flakes and distinctive expanding billet flakes (DEBs). R-flakes result from a manufacture error where the knapper strikes too deeply on the platform, removing a wider section of the biface edge than intended. The platforms on r-flakes are large and are usually the widest area of the flake. The ventral surfaces of r-flakes are characterized by a bending fracture that often creates a profile resembling the shape of the letter "r." DEBs are very thin, curved flakes that have extremely narrow platforms and lateral edges that expand for more than half the length of the flake. Both r-flakes and DEBs can be reliably associated with a billet percussion method of flake removal (Hayden and Hutchings 1989).

Table 6-8. Counts for All AU Debitage by Category.

\begin{tabular}{cccccc}
\hline $\begin{array}{c}\text { Complete } \\
\text { Flakes }\end{array}$ & $\begin{array}{c}\text { Proximal } \\
\text { Flake } \\
\text { Fragments }\end{array}$ & $\begin{array}{c}\text { Flake } \\
\text { Fragments }\end{array}$ & Burned & $\begin{array}{c}\text { Shatter/ } \\
\text { Chunks }\end{array}$ & Total \\
\hline 410 & 771 & 2,157 & 193 & 12 & 3,543 \\
\hline
\end{tabular}


The assemblage was also scanned for notching flakes. Notching flakes are flakes created during the notching of haft elements on bifacial tools by pressure flaking. They are smaller, thinner and weigh less than flakes removed by percussion flaking.

\section{Analysis}

Frequencies of general thinning, nonthinning, r-, and DEB flakes were looked at temporally in order to understand changes in technological behavior related to biface versus non-biface production over time. Total counts were adjusted to standardize the artifact recovery for comparison (Table 6-9). General thinning flakes (not including billet flakes) are the most common type of complete flake in each period. R-flakes are the least common, with an adjusted count of 2.67 during the Austin phase. Once adjusted, the frequencies of thinning and non-thinning flakes increase greatly from the Late Archaic II to the Austin (Figure 6-29). The

Table 6-9. Raw and Adjusted Frequencies of Complete Flake Types.

\begin{tabular}{|c|c|c|c|c|c|c|c|c|c|c|}
\hline & \multicolumn{2}{|c|}{$\begin{array}{l}\text { Middle } \\
\text { Archaic }\end{array}$} & \multicolumn{2}{|c|}{$\begin{array}{c}\text { Late Archaic } \\
\text { I }\end{array}$} & \multicolumn{2}{|c|}{$\begin{array}{c}\text { Late Archaic } \\
\text { II }\end{array}$} & \multicolumn{2}{|c|}{ Austin } & \multicolumn{2}{|c|}{ Toyah } \\
\hline & $\begin{array}{l}\text { Total } \\
\text { Count }\end{array}$ & $\begin{array}{c}\text { Adjusted } \\
\text { Count }\end{array}$ & $\begin{array}{l}\text { Total } \\
\text { Count }\end{array}$ & $\begin{array}{c}\text { Adjusted } \\
\text { Count }\end{array}$ & $\begin{array}{l}\text { Total } \\
\text { Count }\end{array}$ & $\begin{array}{c}\text { Adjusted } \\
\text { Count }\end{array}$ & $\begin{array}{l}\text { Total } \\
\text { Count }\end{array}$ & $\begin{array}{c}\text { Adjusted } \\
\text { Count }\end{array}$ & $\begin{array}{l}\text { Total } \\
\text { Count }\end{array}$ & $\begin{array}{c}\text { Adjusted } \\
\text { Count }\end{array}$ \\
\hline General thinning & 29 & 7.78 & 82 & 7.01 & 145 & 15.26 & 36 & 24 & 36 & 20 \\
\hline Billet: DEB & 1 & 0 & 2 & 0.17 & 1 & 0.11 & 6 & 4 & 1 & 0.56 \\
\hline Billet: r-flakes & 1 & 0 & 0 & 0 & 0 & 0 & 4 & 2.67 & 0 & 0 \\
\hline Non-thinning & 6 & 1.67 & 4 & 0.34 & 16 & 1.68 & 32 & 21.33 & 1 & 0.56 \\
\hline $\begin{array}{l}\text { All thinning } \\
\text { (including billet) }\end{array}$ & 31 & 7.78 & 84 & 7.18 & 146 & 15.36 & 46 & 30.67 & 37 & 20.56 \\
\hline
\end{tabular}

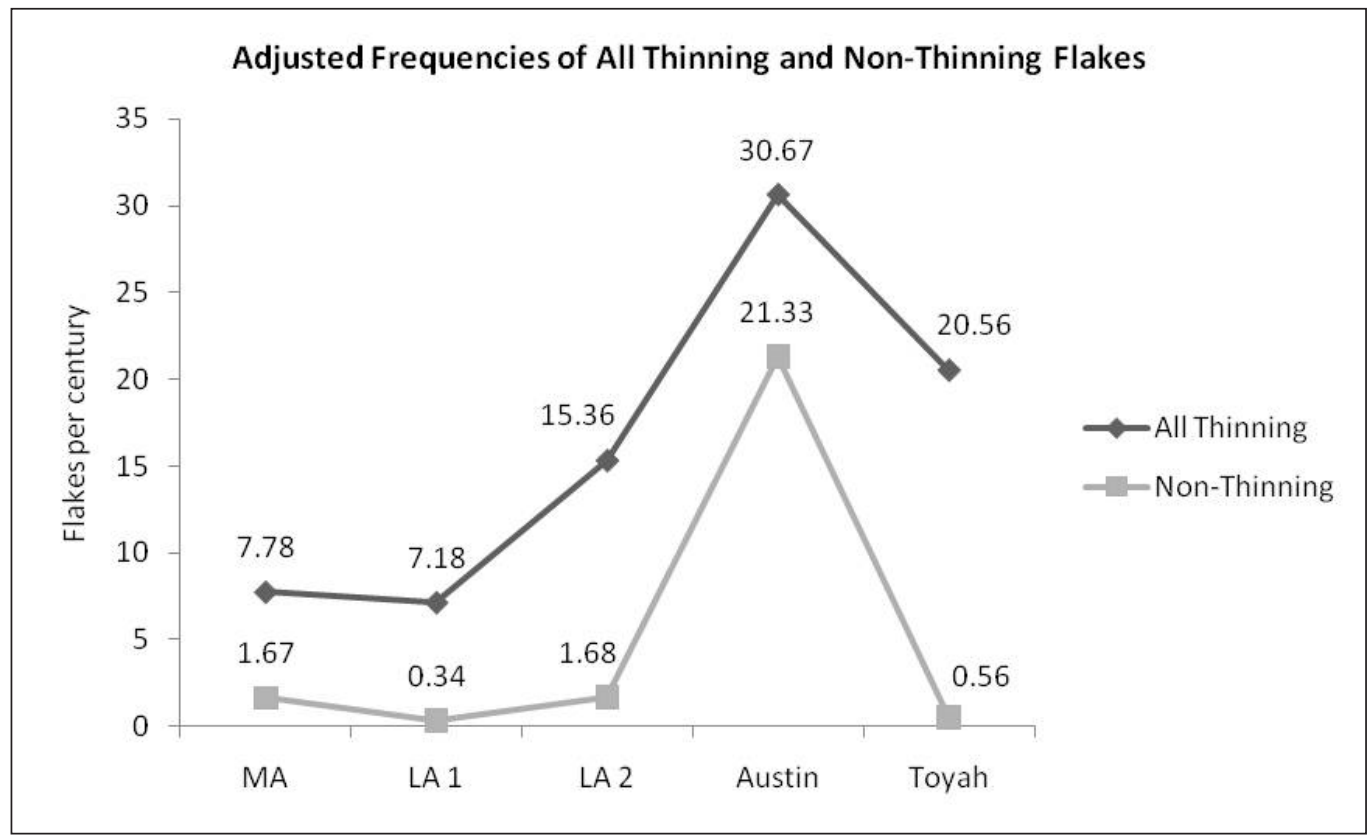

Figure 6-29. Thinning (including billet) vs. non-thinning flakes per century for each period. 
frequency of billet flakes per century is also greatest during Austin times (Figures 6-30 and 6-31).

Ratios of thinning flakes and non thinning flakes to the total number of complete flakes were observed (Figures 6-32 and 6-33) and more specifically, ratios of billet flakes to the total number of complete flakes were looked at in order to consider increased and decreased billet flaking technology over time (Figure 6-34). These ratios indicate that as a percentage of all complete

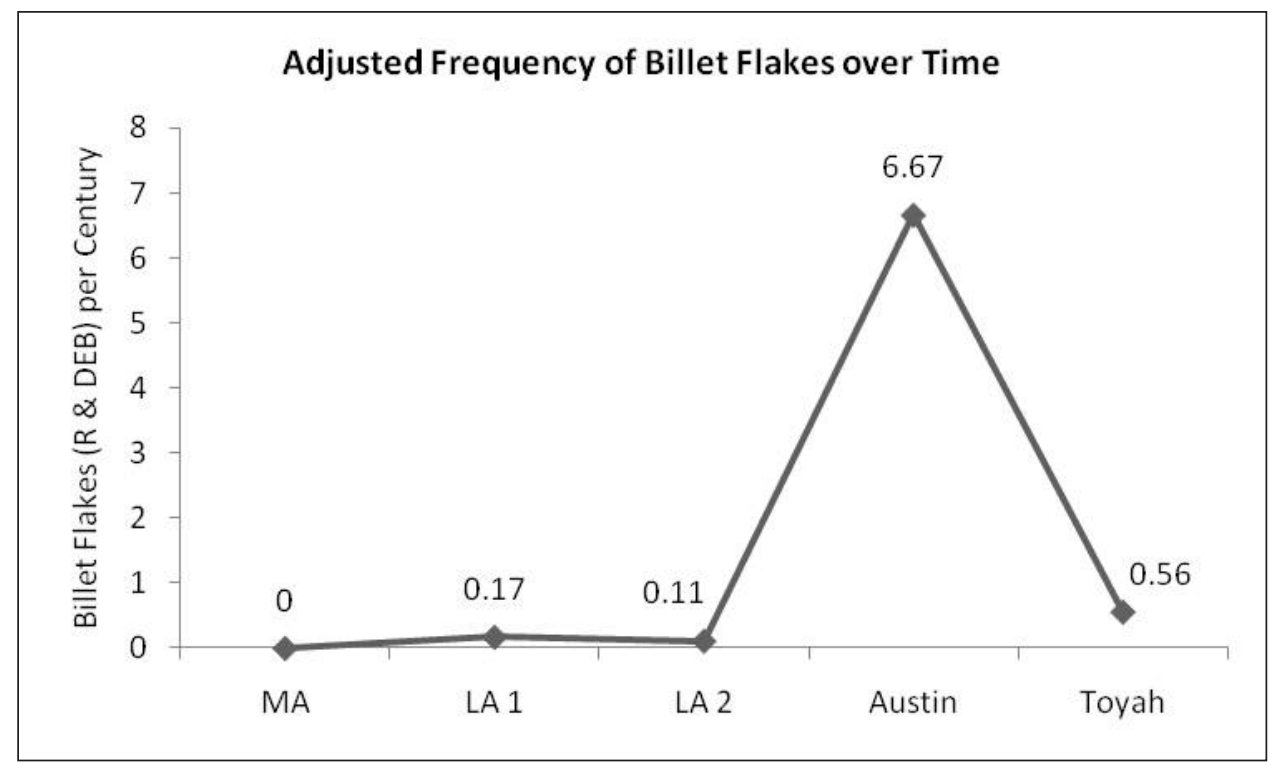

Figure 6-30. Billet flakes (DEB and r) per century for each period.

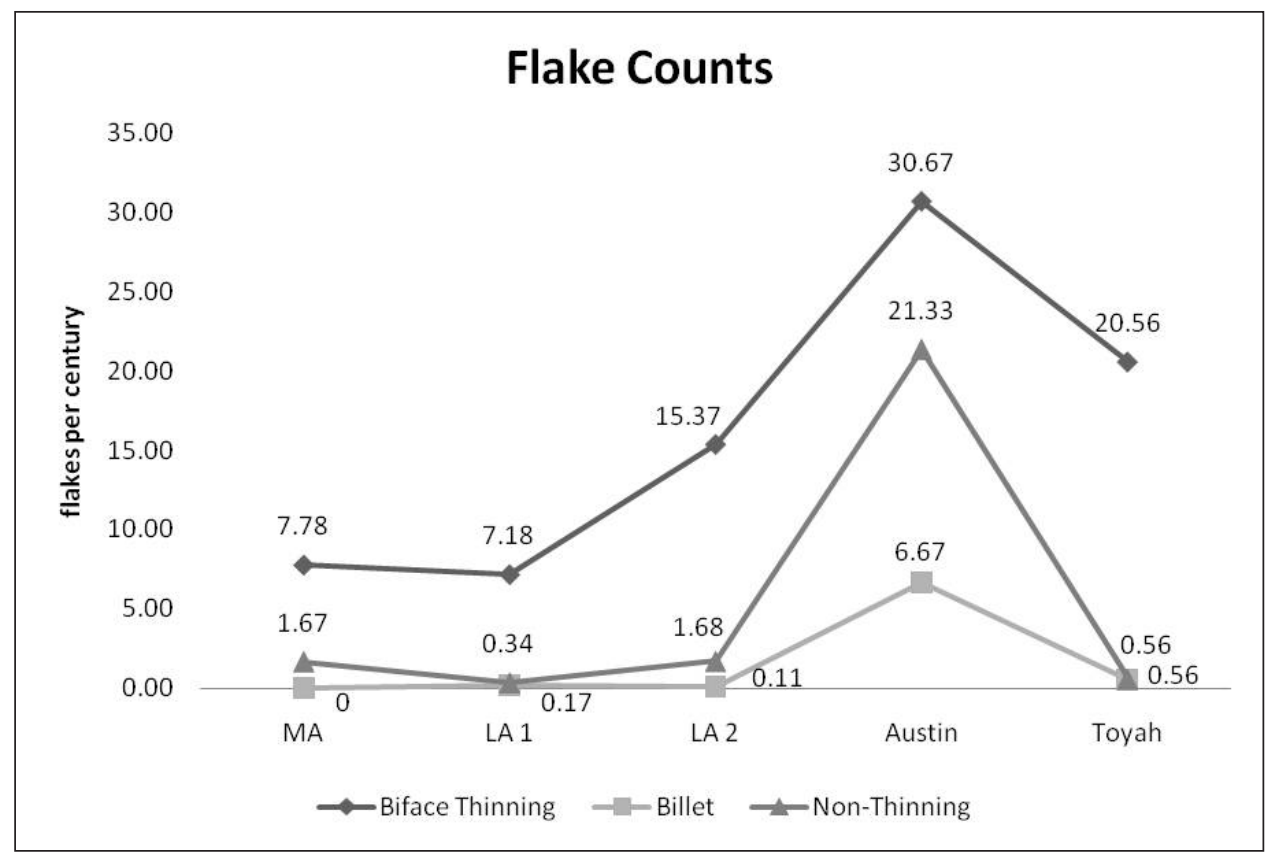

Figure 6-31. Adjusted frequencies of different flake types. 


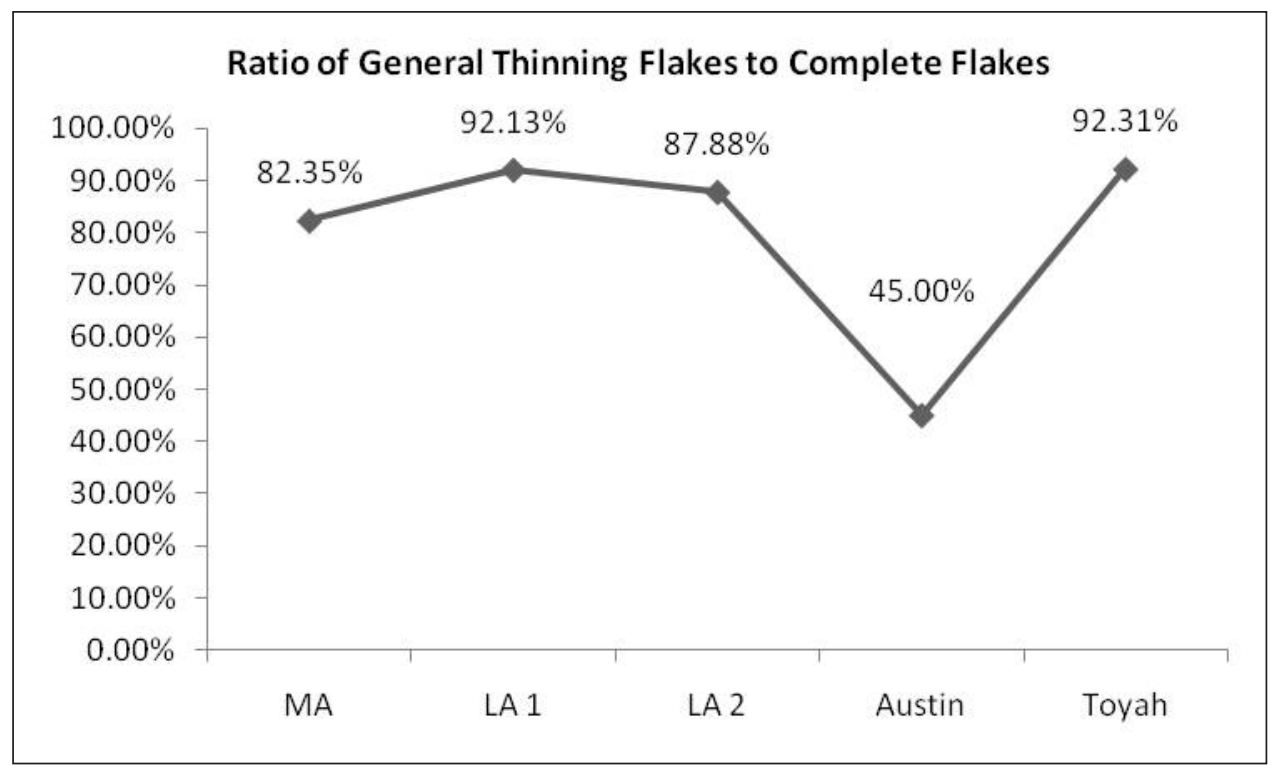

Figure 6-32. Percentage of complete flakes that are thinning flakes (not including billet) for each period.

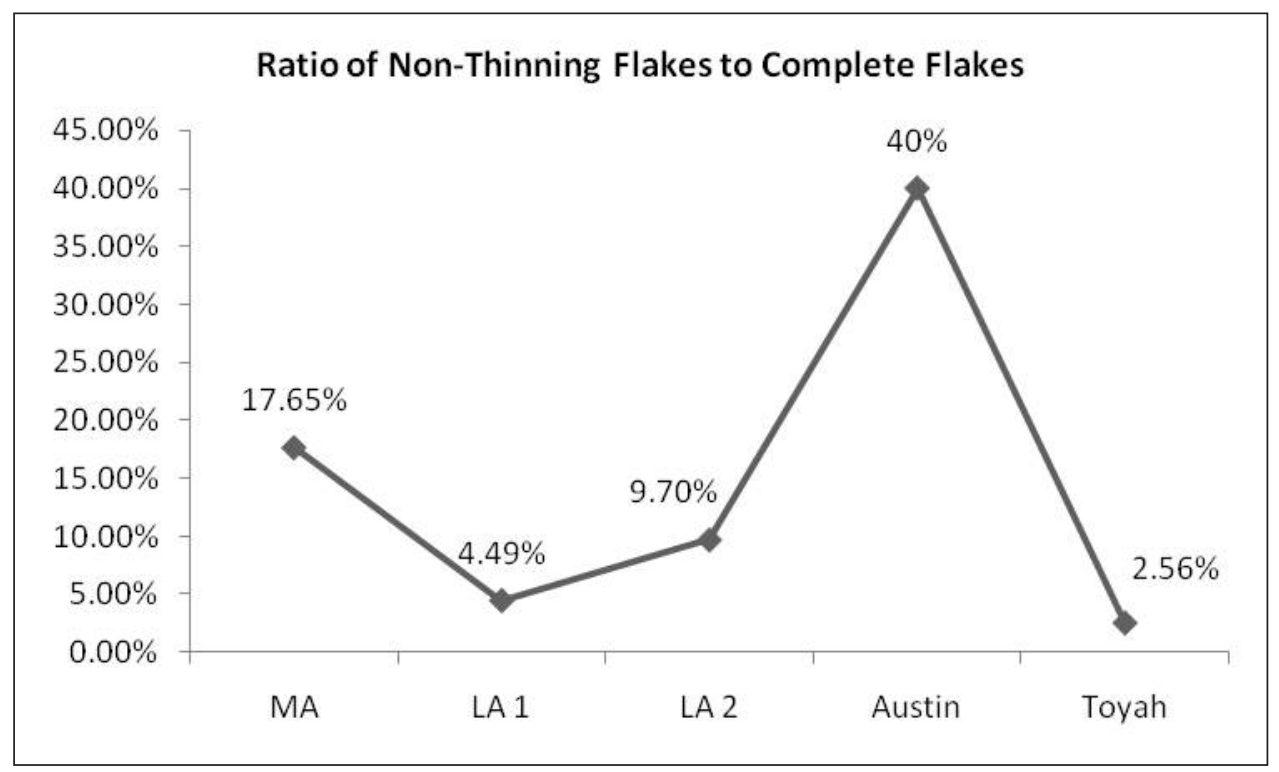

Figure 6-33 Percentage of complete flakes that are non-thinning flakes for each period.

flakes, thinning flakes actually decrease during Austin times. However, the billet to complete flake ratio is highest during Austin times.

\section{Summary}

Several trends can be established from the analysis of debitage at 41HY165. Biface thinning via billet technology was the least common during the Late Archaic. The Austin phase contained the highest frequency of biface 


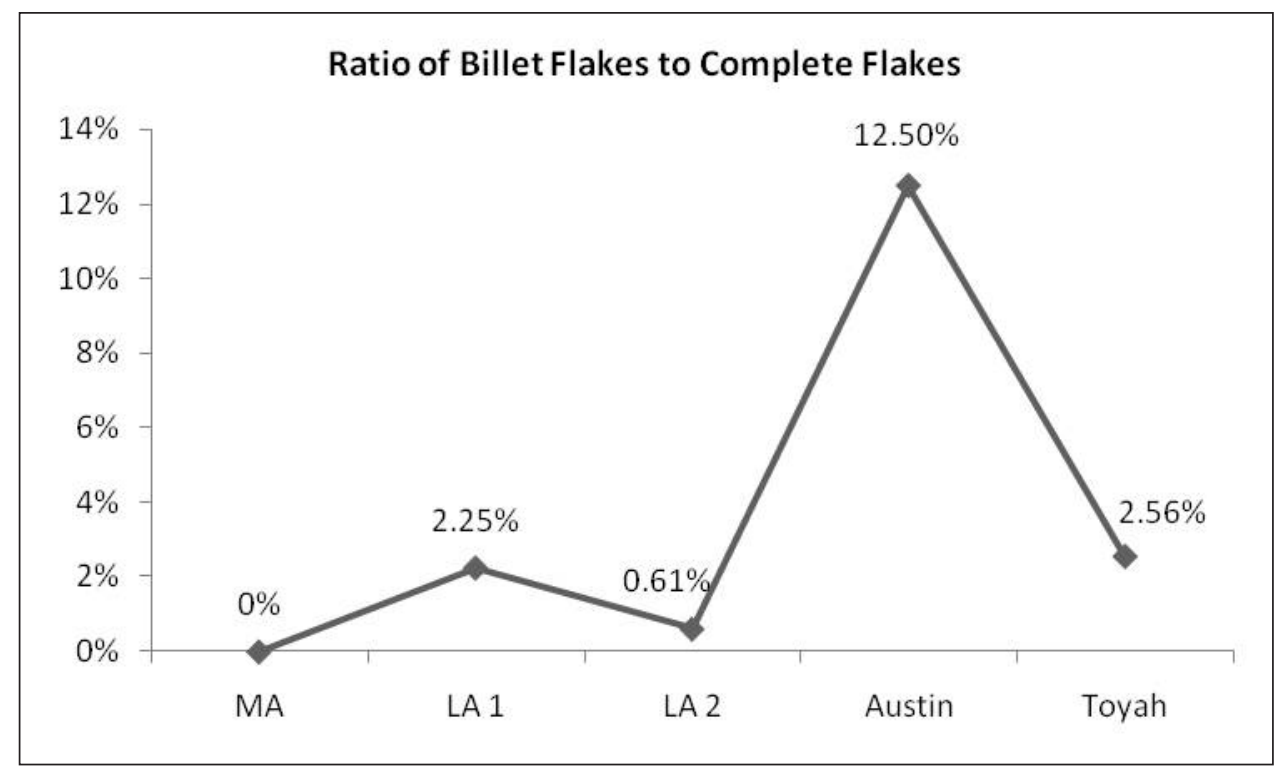

Figure 6-34. Percentage of complete flakes that are billet flakes for each period.

thinning flakes. This period also represents an increase in non-thinning flakes. These two trends contribute to a comparatively low ratio of thinning flakes to complete flakes. Compared to the other periods, the Austin phase of the Late Prehistoric is characterized by an increase in on-site core reduction as well as an increase in later stages of tool production evidenced by billet flaking technology. There was only a 5 percent difference between the percentages of complete flakes that are general thinning and complete flakes that are non-thinning. Therefore, the data suggest that an almost equal amount of bifacial thinning and core reduction techniques took place at 41HY165 during Austin times. Also, if biface thinning flakes can also be associated with biface resharpening, then this must have been an important activity during this period as well. From the data, it is clear that tool production techniques were the most diverse during Austin times.

\section{Conclusion}

The lithic assemblage from 41HY165 consists of reliable, maintainable tools such as projectile points and bifaces as well as EFTs and MRUs. Temporally, these assemblages vary and are shaped by population changes as well as changes in subsistence that required technological shifts.

The frequency of discarded projectile points suggests that there was a significant population increase at 41HY165 from the Late Archaic I to Late Archaic II. It has also been established that EFT use intensified during the Late Archaic I and MRU use intensified during the Middle Archaic. In other words, informally fashioned flake tools were used more heavily during the Late Archaic I, making them less expedient. Interestingly, the Late Archaic I has the fewest MRUs. MRUs seem to be used more heavily in the Middle Archaic. These observations point towards a more maintainable and curated tool kit, which suggests that people visiting 41HY165 during the Middle Archaic and Late Archaic I may have practiced collector strategies. What caused people to curate and maintain their flake tools and unifaces more 
during these occupations? The demand for these tools must have increased to a point where the effort required to produce new ones outweighed the effort required to recycle them.

Unfortunately, the sample sizes for some of our analytical categories recovered from reliable AUs are too small to allow for detailed statistical analyses, nor any discussion of temporal trends. Only 24 bifaces were recovered from reliable proveniences, so what looks like a meaningful paucity of bifaces during certain periods may actually just be a reflection of fundamentally flawed data due to the small sample size. Our small sample of formal unifaces $(n=2)$ results in similar difficulties. Furthermore, the lack of prismatic blades and blade cores at 41HY165 (especially during Toyah times) is surprising considering their supposed association with a specialized bison hunting and processing tool kit. However, there is evidence that blade- like flakes were often used as scrapers, perhaps for processing bison.

Overall, tool production was highest in Austin times. Both EFTs and MRUs are most numerous during the Austin phase. Biface thinning via billet technology was most prevalent during the Austin phase. The Austin phase is also represented by an increase in non-thinning flakes contributing to a comparatively low ratio of thinning flakes to complete flakes. Compared to the other periods, the Austin phase of the Late Prehistoric is characterized by an increase in on-site core reduction as well as an increase in later stages of tool production evidenced by billet flaking technology. The small difference between the percentages of complete flakes that are general thinning and complete flakes that are non-thinning suggests that an almost equal amount of bifacial thinning/resharpening and core reduction techniques took place at 41HY165 during Austin times. One flake core was recovered from a unit and level dating to the Austin phase, adding to the evidence supporting on-site core reduction.

The organization of tool production and effort reflected in the analyzed flake tools, unifaces, and debitage shows that a variety of economic activities and available resources necessitated a relatively generalized tool kit of highly versatile and efficient formal and informal tools at 41HY165. In particular, this diversity is most significant in the Austin tool kit. From these data, we can conclude that visitation was more common at 41HY165 during the Austin period. This visitation is evidenced by more projectile points (standardized), more EFTs, and more MRUs than in any other period. Additionally, knappers were participating in more biface thinning, billet flaking, and flaking associated with core reduction during Austin occupation than in any other. Whatever cultural shifts that occurred with the transition from dart and atlatl to bow and arrow may have caused or can be associated with a fundamental shift in how 41HY165 was occupied and used during Austin times. Furthermore, from their sample of 46 AMS dates, Lohse and Cholak (2011) suggest that bison were absent from Central Texas for approximately 1,500 years prior to the Toyah phase of the Late Prehistoric period. Changes in the availability of key species, like bison, may have resulted in new technological approaches to ensure sustainability. Another factor which likely affected the archaeological record at $41 \mathrm{HY} 165$ is climate. Around AD 1200, there was a drought that affected parts of the Edwards Plateau (Johnson and Goode 1994). During this drought, streams and rivers would have dried up causing people to aggregate around the everpresent springs that currently form Spring Lake. Although conditions did not support bison in Central Texas during this time, the springs were capable of supporting smaller-bodied game like 
deer and fish, and probably supported larger human populations during times when water was scarce elsewhere. Chert resources were also readily available to 41HY165 occupants. This site was high in aggregate resources even when bison were absent and the climate was dryer. Therefore, foragers would have returned to 41 HY165 year after year, increasing their archaeological visibility. The Austin tool kit seems to reflect a forager society exploiting nearby available resources. All of these lines of evidence, considered together, help to explain the significant increase in tool production as well as the diverse tool kit during the Austin period at $41 \mathrm{HY} 165$. 


\title{
Chapter 7
}

\section{Ceramic Analysis of Samples from 41HY165, Hays County, Texas}

\author{
By Steve A. Tomka, Lori Barkwille Love, Kristi M. Ulrich, and Carole A. Leezer \\ In June 2011, CAR obtained 24 ceramic \\ sherds from CAS for petrographic analysis. The \\ sherds were from archaeological site 41HY165 on \\ the Texas State campus, adjacent to Spring Lake. \\ Tasks and analyses performed by CAR on the \\ samples included the following: \\ focused on attributes that could be seen under \\ low magnification (10-20x) or without the aid \\ of magnification. The analytical methods used \\ were derived from previous analyses as well \\ as guidelines provided by the Council of Texas \\ Archaeologists (CTA).
}

(1) macroscopic ceramic analysis of each sherd prior to subsampling;

(2) subsampling of sherds for petrographic analysis;

(3) creation of petrographic thin-sections; and

(4) petrographic analysis and reporting.

The first task was to inspect the large original sample, determine how many vessels the sherd fragments represent, and within each sherd cluster that represents a single vessel, select a sufficiently large sherd that could be used in the production of a petrographic slide. Once the samples were identified, and prior to their subdivision, the fragments were to undergo macroscopic ceramic analysis.

The goal of the macroscopic analysis was to define the surface treatment attributes of the vessels represented in the sample and also define the technological attributes associated with their manufacture. Specifically, we wanted to characterize the steps taken by the prehistoric/ historic potters in manufacturing the vessel from the clays used, the a-plastic (tempers) additives in the raw clays, and the firing conditions employed. All of these sherds are unglazed, native made wares. This "macro" analysis
Macroscopic findings were to be compared with findings derived from the petrographic analysis which typically is able to quantify more precisely the technological aspects of paste preparation and clay sources employed in fabrication. The original sample of sherds provided to CAR was tagged and some tags indicated that the sherds were preliminarily categorized into prehistoric and Spanish Colonial wares. In addition, some of the prehistoric wares were classified as Leon Plain, Doss Redwares, or unknown prehistoric. Thin-sections for petrographic analysis were created from all 24 original sherds submitted. Table 7-1 provides the original list of sherd samples.

\section{Macroscopic Analysis}

\section{Methodology}

For each of the 24 sherds, the following attributes were examined and recorded: sherd paste color (interior and exterior), visible inclusions, inclusion size, paste texture (fine or coarse), surface treatments (interior and exterior), decoration (interior and exterior), size measurements (length, width, and thickness), sherd segment (i.e., body, base, or rim), orifice diameter, vessel form, rim profile, rim form, 


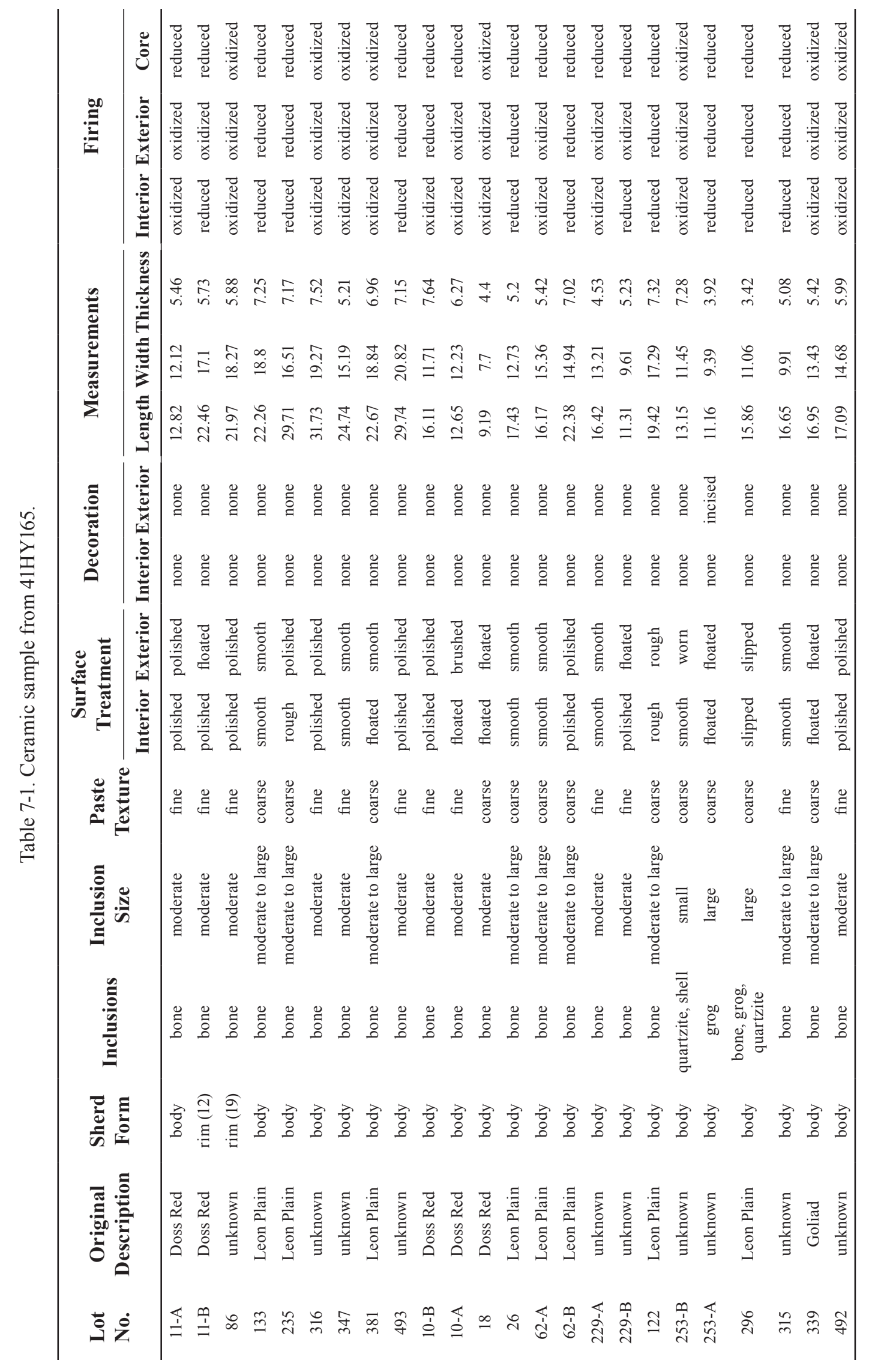


lip profile, lip form, lip decoration, and firing atmosphere. The attributes were noted with the naked eye and recorded in an Excel database. Fresh breaks were made on sherds large enough to be broken. On small sherds, paste color was observed on the exterior and interior surfaces.

The recording of color was precipitated by one of the author's experiments with clay sources from various locations, and the colors that different clay formations fire. It appears that distinct clays fire different colors, thereby providing clues to the origins/formations of clays employed in pottery manufacture. The inclusions noted within the fabric were closely examined to determine what was being used to temper the clay prior to firing. Typically bone was found within the sherd paste, but evidence of grog and quartzite were noted in a couple of sherds. The size of inclusions was noted as small, moderate to large, and large. In addition to the inclusion characteristics, the paste texture was recorded. The texture was determined by observation and feel. The speciemens either had coarse or fine paste.

Surface treatments of the vessels were recorded as smooth, polished, floated, rough, slipped, or brushed. Both surfaces of the sherd's interior and exterior were examined, and the characteristic recorded. A smooth surface was one that was smooth to the touch, but did not show signs of polishing that produced sheen. Smoothing usually was done with the fingers to produce an even surface. Polished surfaces exhibited a slight to high gloss. These were purposefully smoothed to an extent that is near burnishing. Floated surfaces are a result of using water or clay slurry and a polishing technique that would bring the finer clay particles to the surface. This action would mask most of the temper particles and produce a thin layer that is evident to the naked eye. This process was typically done just before the vessel was allowed to dry. Rough surfaces are characteristic of poor smoothing or no smoothing at all. Also, rough surfaces may be a result of the erosion of the sherd. Slipping is similar to the floating technique, although the main difference is that a floated surface is selfslipped, whereas a slipped surface usually utilizes a different clay slurry. The use of a different clay produces a distinct difference between the sherd paste and the color of the surface. A brushed surface exhibits strations that are likely the result of using a brush-like tool to smooth the surface. This process is done when the clay is still wet.

The sherds were examined to determine if evidence of decoration was present. Typically, decoration consists of the application of a substance, such as asphaltum, to produce designs on the surface of the vessel. Also, incising is another technique used to apply decoration to the vessel.

The length, width, and thickness of the sherds were measured in millimeters using a pair of digital calipers. In most analyses, the ceramic assemblage is subject to minimum measurement criteria for a sherd to be part of the sample. However, due to the small nature of the assemblage in this study, all 24 sherds were included.

The sherd segment was recorded as base, body, or rim during this analysis. The description identified what part of the vessel that the sherd originated. In this case, the majority of the sherds were body, with only two sherds identified as a rim fragments. Rim sherds typically provide much more information than body sherds, but due to the small sample size, all sherd types were utilized in the analysis.

When analyzing rim sherds, the orifice diameter is obtained by placing the rim of the sherd on a concentric circle chart. The arc that it 
lines up with will give the diameter of the opening of the vessel. This is useful in determining the vessel form. In addition to the orifice diameter, rim sherds are examined for rim form, rim profile, lip form, and lip decorations. The rim form and rim profile are also helpful tools when determining the vessel form. The orientation of the rim profile aids in determining between bowls and jars. Very little information was gathered during the analysis of this assemblage concerning rim and lip attributes, as there were only two rim sherds in the collection.

The firing atmospheres of the sherds were recorded according to the color that the sherds exhibited. A reduced atmosphere would produce colors from black to light grey. The dark color derives from the presence of organic carbon that is retained within the fabric because the firing temperature is not sufficiently high to burn off the organic matter. An oxidizing atmosphere produces sherds that have buff to red colors. It is indicative of firing temperatures that were sufficiently high to burn off the organic carbon present in the clay fabric. It is important to note, however, that in the typical open-air bonfire type ceramic firing that is assumed to have been conducted by prehistoric potters, fires rarely reach high enough temperatures to fully oxidize the vessel walls. Even within the same vessel, some portions of the vessel may have fully oxidized, while other, thicker portions that were located away from the flames may retain a reduced core. The firing atmosphere was recorded for the interior, exterior, and core of the presented sherds.

\section{Results}

Twenty-four sherds from 41HY165 were examined. These sherds had been provisionally classified into ceramic types prior to arriving at CAR. Five sherds were labeled as Doss Red, eight as Leon Plain, one as Goliad, and 10 as unknown. The Doss Red Ware classification originated in the 1940s. The type was described as a native bone-tempered ware that appeared to have a red slip. The majority of bone tempered wares recovered from Central Texas prehistoric sites, however, are usually identified as Leon Plain wares. Doss Red ware is virtually identical to Leon Plain except in coloration and surface finish, which is almost always burnished/slipped/ polished. It has been recently suggested that what is now recognized as Leon Plain may have begun as Doss Red ware and simply weathered to a buff or pale orange color. This may be the case, as Doss Red wares occur less frequently than Leon Plain, suggesting Leon Plain wares may be a result of poor preservation, a problem endemic to much of Central Texas. Both pottery types are associated with the Toyah phase.

Goliad wares are defined by a study of a large sample of sherds obtained in the 1950s from the third location of Mission Espíritu Santo de Zuñiga on the bank of the San Antonio River in Goliad. This manifestation of the mission was occupied between 1749 and 1830. It is further classified into Goliad Plain, Goliad Red-on-buff, and Goliad Black-on-buff. Goliad Plain is the dominant type in most collections from the inland coastal plains and San Antonio missions. While many researchers argue that Goliad ware is a historic descendent of prehistoric Leon Plain ware, there is of yet no direct evidence linking the two types. The two types are now primarily distinguished on the basis of their archaeological context; when found in Spanish Colonial missions, the wares are identified as Goliad, while in apparent prehistoric contexts, and often in association with Toyah phase cultural materials, they are identified as Leon Plain wares.

\section{Inclusions and Inclusion Size}

All but three of the sherds in the sample $(87.5 \%)$ contain bone as the only inclusions 
present in the fabric (Table 7-2).

One sherd (4\%) contains pieces of quartz and shell. It is possible that neither is a purposefully introduced tempering element, but rather was contained within the parent clay material. A second sherd (4\%) contained inclusions of grog, but bone is entirely absent from the fabric. Grog is ground-up pieces of previously fired ceramics. The grog particles are distinctive because they have a bright brick red color within the paste. A third sherd fabric contains quartzite particles in addition to grog and bone. It is possible that the quartzite was unintentionally added, but its presence differs from the remainder of the collection. The bone tempering in the fabrics observed tended to consist of moderate and moderate to large particles. This suggests that when preparing the temper, the potters were not overly concerned with producing finely ground bone.

\section{Paste Texture}

The sherd paste textures were split evenly between the fine and coarse categories (Table 7-3). Coarse-textured sherds primarily contained large $(n=2)$ to moderate to large $(n=8)$ inclusions. The fine-textured sherds contained mainly moderate-sized inclusions $(n=11)$.

\section{Surface Treatments}

The surface treatments were examined on both the interior and the exterior of the sherds (Table 7-4). The majority of the sherds had either smoothed or burnished inner and outer surfaces (smoothed $\mathrm{n}=7$, polished $\mathrm{n}=8$ ). Only five specimens had
Table 7-2. Inclusion Size.

\begin{tabular}{|c|c|c|c|c|c|}
\hline \multirow{2}{*}{$\begin{array}{c}\text { Inclusion } \\
\text { Type }\end{array}$} & \multicolumn{4}{|c|}{ Inclusion Size } & \multirow[b]{2}{*}{ Total } \\
\hline & Large & Moderate & $\begin{array}{c}\text { Moderate- } \\
\text { Large }\end{array}$ & Small & \\
\hline Bone & 1 & 12 & 9 & 0 & 21 \\
\hline Quartz, shell & 0 & 0 & 0 & 1 & 1 \\
\hline Grog & 1 & 0 & 0 & 1 & 1 \\
\hline $\begin{array}{c}\text { Bone, grog, } \\
\text { quartz }\end{array}$ & 1 & 0 & 0 & 0 & 1 \\
\hline Total & 3 & 12 & 9 & 2 & 24 \\
\hline
\end{tabular}

Table 7-3. Paste Texture.

\begin{tabular}{cccc}
\hline \multirow{2}{*}{ Inclusion Size } & \multicolumn{2}{c}{ Paste Texture } & Total \\
\cline { 2 - 3 } & Coarse & Fine & \\
\hline Large & 2 & 0 & 2 \\
Moderate & 1 & 11 & 12 \\
Moderate to large & 8 & 1 & 9 \\
Small & 1 & 0 & 1 \\
\hline Total & 12 & 12 & 24 \\
\hline
\end{tabular}

Table 7-4. Surface Treatments.

\begin{tabular}{ccccccc}
\hline \multirow{2}{*}{ Interior } & \multicolumn{5}{c}{ Exterior } & Total \\
\cline { 2 - 5 } & Floated Polished Rough Slipped Smooth & \\
\hline Brushed & 1 & 0 & 0 & 0 & 0 & 1 \\
Floated & 3 & 2 & 0 & 0 & 0 & 5 \\
Burnished & 0 & 7 & 1 & 0 & 0 & 8 \\
Rough & 0 & 0 & 1 & 0 & 0 & 1 \\
Slipped & 0 & 0 & 0 & 1 & 0 & 1 \\
Smooth & 1 & 0 & 0 & 0 & 6 & 7 \\
\hline Total & 5 & 9 & 2 & 1 & 6 & $23^{*}$ \\
\hline
\end{tabular}

*The surfaces of a single sherd were heavily worn and surface treatment could not be determined.

a surface that appeared to be floated. Of these, three had floated inner and outer surfaces, and two had polished outer surfaces. It is possible, however, that the wear erosion of the inner surface 
may have removed any surface treatment present there. One sherd exhibited a rough surface, and only one sherd appeared to have both its interior and exterior surfaces slipped.

When examining the surface treatment in relation to the paste texture, it appears that the fine-pasted sherds were more often burnished $(n=8)$ and smoothed $(n=3)$. Coarse-pasted sherds tended to be smoothed $(n=4)$ or floated $(n=4)$.

\section{Decoration}

Only one sherd exhibited evidence of decoration, which was in the form of incising. This sherd was recovered in Level 3 of Quad 6. The decoration was noted on the exterior surface of the sherd. The remaining sherds did not exhibit any form of decoration.

\section{Size Measurements}

The average length of the sherds examined was $18.75 \mathrm{~mm}$. The length of the sherds ranged from $9.2 \mathrm{~mm}$ to $31.7 \mathrm{~mm}$. Fifteen of the sherds are smaller than $20.0 \mathrm{~mm}$ in maximum length. The average width of the assemblage was 14.2 $\mathrm{mm}$. The minimum measurement was $7.7 \mathrm{~mm}$, and the maximum was $20.8 \mathrm{~mm}$. The average thickness of the sherds was $5.9 \mathrm{~mm}$. The minimum thickness recorded was $3.42 \mathrm{~mm}$, and the maximum recorded was $7.6 \mathrm{~mm}$.

\section{Firing Atmosphere}

Half of the sample consists of specimens with oxidized interior and exterior surfaces

Table 7-5. Interior Surface Firing Atmospheres.

\begin{tabular}{cccc}
\hline \multirow{2}{*}{$\begin{array}{c}\text { Exterior } \\
\text { Surface }\end{array}$} & \multicolumn{2}{c}{ Interior Surface } & Total \\
\cline { 2 - 3 } & Oxidized & Reduced & \\
\hline Oxidized & 12 & 2 & 14 \\
Reduced & 1 & 9 & 10 \\
\hline Total & 13 & 11 & 24 \\
\hline
\end{tabular}

(Tables 7-5 and 7-6). Specimens with reduced interior and exterior surface are, however, nearly as common $(n=9)$. Only two specimens have oxidized exteriors and reduced interiors, and only one has a reduced exterior but oxidized interior.

Not surprisingly, given the bonfire-type firing conditions for most of the sherds in this sample, only $14(58 \%)$ of the specimens have an oxidized core. Experiments by the senior author indicate that, depending on the thickness of the wares and the amount of temper present in the fabric, temperatures in excess of $900^{\circ} \mathrm{C}$ may be needed for extended times to create a oxidized core on ceramics measuring 6-7 $\mathrm{mm}$ in wall thickness. The mean thickness of the sherds with oxidized cores is $6.01 \mathrm{~mm}$, while the mean thickness of the sherds with reduced cores is $5.9 \mathrm{~mm}$. However, this mean is affected by the two fragments tempered by bone and grog and also bone, grog, and quartzite, which are each less than $4 \mathrm{~mm}$ in thickness (3.32 and $3.42 \mathrm{~mm}$, respectively). Removing these two specimens results in a mean of $6.2 \mathrm{~mm}$ for reduced core sherds. This pattern does suggest that the oxidation of the sherds may be affected by the thickness of the vessel wall. In general, vessels with thicker walls have more crumbly, easily eroded surfaces compared to sherds from higher-fired vessels.

Paste color also was recorded on sherds because the color of the fired clay is in part conditioned by the constituent elements present within the clay, and this in turn may vary by clay

Table 7-6. Exterior Surface Firing Atmospheres.

\begin{tabular}{cccc}
\hline \multirow{2}{*}{ Core } & \multicolumn{2}{c}{ Exterior Surface } & \\
\cline { 2 - 3 } & Oxidized & Reduced & \\
\hline Oxidized & 8 & 6 & 14 \\
Reduced & 0 & 10 & 10 \\
\hline Total & 8 & 16 & 24 \\
\hline
\end{tabular}


formation. Therefore, to gauge the number of possible clay sources that may have been used to fabricate the vessels present in the analysis, we also recorded the color of the ceramic fabric as exhibited on both surfaces and the core. Clearly, fabric color was not useful on sherds with reduced surfaces given their typically uniformly black or dark gray surfaces.

Three general color groupings were noted in the sherd samples analyzed. The majority of the sherds had a reddish color. The senior author has replicated the reddish color of vessels using Navarro Formation clays from the upper San Antonio River Basin. Navarro Formation clays tempered with bone regularly produced a reddish outer and inner surface under oxidized firing conditions. Their cores typically remained reduced, except in rare conditions when firing temperatures were maintained above $900^{\circ} \mathrm{C}$ for extended time. A second group of colors noted in the archaeological specimens were light gray. The author has not been able to reproduce this fabric color in experimental firings using locally available clays. Finally, the third color group, exhibited by a smaller number of sherds, was tan. This color was reminiscent of vessel colors attained by firing Houston Black clay mixed with the Navarro Formation clay. By itself, Houston Black clay has a very high shrink rate that makes it very difficult to construct vessels and have them dry without cracking. However, the mixing of Houston Black clay with Navarro Formation clays reduces the shrinkage rate and results in a fired clay color that is similar to the latter group of clay colors noted in the ceramic sample.

As mentioned earlier, two sherds are rim fragments. Both have everted rim profiles; one has a rounded rim while the other has a flattened rim form. They are 5.73 and $5.88 \mathrm{~mm}$ in wall thickness, and it is estimated that the vessels they represent measured 12 and $19 \mathrm{~mm}$, respectively, in mouth diameter.

The overlapping of the coils once built up along the body of the vessel is typically done through finger pressure. However, even once the coils overlap they do not present a smooth surface. The smoothing is accomplished using a tool such as a smooth pebble that is pulled tangentially across the horizontal coils to blend them into each other more completely. Once this blending is achieved, and the vessel is dried to a leather-hard state, the same tool may be used to burnish the surface of the vessel. This burnishing smooths the surface of the fabric and provides a sheen to the clay, which in part results from fine particles of clay being concentrated onto the surface of the fabric. When these fine particles form a consistent and continuous surface on the vessel wall, the surface is described as floated. The typical horizontal rubbing of the fabric through which this burnishing is accomplished leaves track marks on the surface of the vessel that are easily visible during the process and even after firing.

In the senior author's experience, such burnishing has increased the rates of firing failures because it impeded the escape of the moisture through the ceramic fabric during firing, often resulting in extensive pot-liding of the vessel's outer surface. To lessen this likelihood, experimentally constructed vessels were allowed to dry for up to six weeks, yet the same failures recurred during the subsequent firing. How the high rates of this failure were dealt with and reduced by prehistoric potters is unclear.

\section{Petrographic Analysis}

The sherds were sent to the National Petrographic Services in Houston, Texas, for the creation of thin sections. The thin sections were 
created following industry standard procedures. A small piece of the sample was removed and placed in blue-dyed epoxy and vacuum impregnated. In most cases, the initial cut was transverse to the plane of the sherd so that a slip could be identified, if present. A slice of the cured specimen was then removed and mounted on a $1 \times 2$-inch microscope slide and ground down to $0.03 \mathrm{~mm}$ in thickness. A permanent cover slip was not used on the thin sections. A blue-dyed epoxy was chosen over clear epoxy to allow for easier identification of voids and bone.

The thin sections were examined with a Leica petrographic microscope with a mechanical stage attached. A two-stage process was used to examine the thin sections. Given that a permanent cover slip was not used on the thin sections, a drop of distilled water and a temporary glass cover slip was placed on the thin section to aid in viewing. The first step involved recording the general characteristics and taking photomicrographs of the thin section. The general characteristics recorded included paste matrix description, paste color, b-fabric (Stoops 2003:95), estimated size of quartz inclusions (based on Wentworth scale), slip, and description of edges. The Petrographic Analysis Coding Sheet (Appendix D) provides a description and codes used for the general characteristics. For the photomicrographs, at least one set (plane light and cross-polar light) were taken of each thin section at $4 \mathrm{x}$ magnification. At least one additional set of photomicrographs were taken of the edges, inclusions, or paste at $4 \mathrm{x}, 10 \mathrm{x}$, or 40x magnification for each thin section.

The second step involved point counting, using the Glagolev-Chayes method. The GlagolevChayes method involves using the mechanical stage, which allows one to move the thin section at a given interval beneath the crosshairs in the ocular, and identifying and recording each point encountered in the crosshairs (Galehouse 1971:389-390). For the point counting sampling, the microscope was set at $10 \mathrm{x}$ magnification and the stage was set so that the vertical and horizontal increments were both $0.4 \mathrm{~mm}$. For each point encountered in the crosshairs, the point was identified as paste matrix, void, or nonplastic inclusion. Paste matrix, voids, and all nonplastic inclusions except bone were recorded by tally. For all bone inclusions, estimated size, based on ocular scale, bone color, and if space was present around the bone were recorded. The Petrographic Analysis Coding Sheet provides a description and codes used for the point counting. Nonplastic inclusions were only counted once, even if they were encountered more than once in the crosshairs; however, voids were counted more than once if they were encountered more than once on the horizontal transect, but not on the vertical transect. The maximum size that the ocular scale could record was $1.2 \mathrm{~mm}$; therefore, even if the bone inclusions were greater than 1.2 $\mathrm{mm}$ they were recorded as $1.2 \mathrm{~mm}$. In addition to the point counting, mineral/temper present but not encountered in the crosshairs was noted.

Although the goal was 300 points, 300 points could only be reached on 54.17 percent of the thin sections due to the size of the sherd piece. The minimum number of points reached was 99 on sample 253-a-15. Another problem encountered with the point counting was that the quality of the thin sections was generally poor. Several of the thin sections had spots that were ground too thick and/or inclusions had been plucked out, leaving a clear void. The decision was made to only include voids filled with the blue epoxy. Although it is possible that a weak vacuum process could also cause weak voids; however, given the overall poor quality of the thin sections, clear voids were skipped in order to not inflate the void percentage on the thin section. 


\section{HY165 Petrographic Results}

Thin Section No. 10-A 1 (Table 7-7, Figures 7-1 and 7-2)

Paste Matrix: continuous

Paste Color: dark yellowish brown (10YR 4/6)

Paste Description: silty

B-fabric: speckled
Slip/Edges: no; one face lighter (10YR 6/6) brownish yellow; slightly striated/active

Comments: macro-crystalline with triangular crystals; possible altered feldspar

Bone: fairly sorted

Mean size: $0.369 \mathrm{~mm}$

Range: $0.006-0.82 \mathrm{~mm}$

Table 7-7. Results for Thin Section No. 10-A 1.

\begin{tabular}{ccc|ccc}
\hline Body & Count & Percent & Nonplastics & Count & Percent \\
\hline Paste & 210 & 76.0 & Bone & 17 & 26.1 \\
Nonplastics & 65 & 23.6 & Quartz & 30 & 46.1 \\
Voids & 1 & 0.4 & Calcium carbonate & 1 & 1.5 \\
\cline { 1 - 2 } Total & 276 & & Chert & 6 & 9.2 \\
\cline { 1 - 2 } & \multirow{3}{*}{} & Chalcedony & 2 & 3.1 \\
& & Polycrystaline quartz & 1 & 1.5 \\
& & Opaque & 3 & 4.6 \\
& & Calcite & 4 & 6.1 \\
& & Unknown & 1 & 1.5 \\
\hline
\end{tabular}

Present but not sampled: shell, mafic minerals, plagioclaste feldspar.

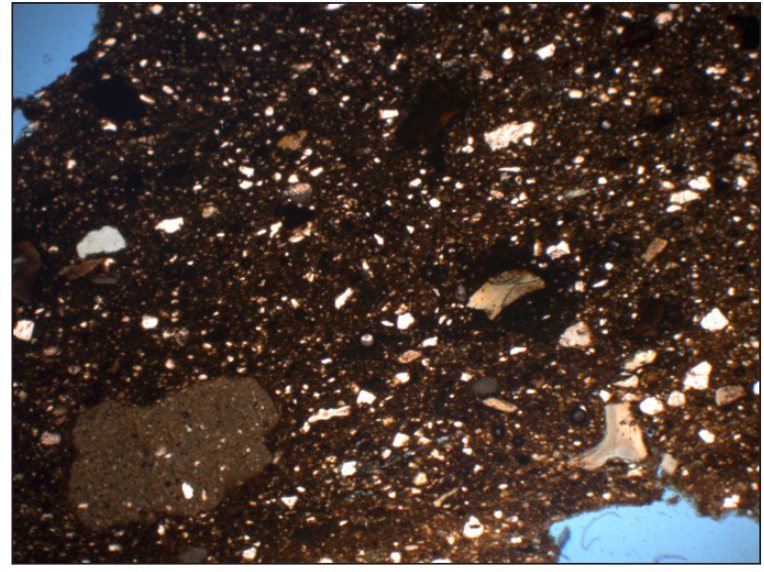

Figure 7-1. Paste of Thin Section No. 10-A 1 in plane light $4 x$.

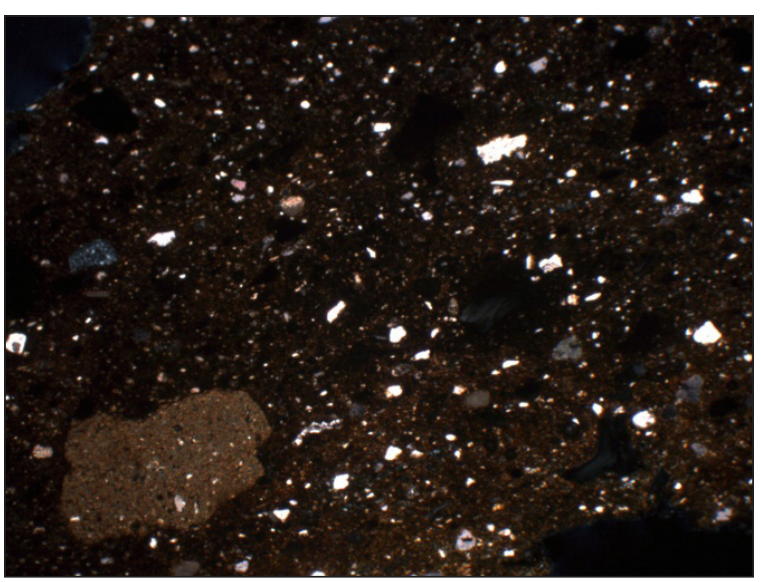

Figure 7-2. Paste of Thin Section No. 10-A 1 in cross-polar light $4 \mathrm{x}$. 
Thin Section No. 10-B 2 (Table 7-8, Figures 7-3 and 7-4)

Paste Matrix: slightly mottled

Paste Color: strong brown (7.5 YR4/6; spots of brownish yellow (10 YR6/8)

Paste Description: silty

B-fabric: speckled, slightly active

Slip/Edges: no; one edge darker than other; dark brown (7.5YR3/4)

Comments: quartz with yellow streak inclusions

Bone: fairly sorted

Mean size: $0.467 \mathrm{~mm}$

Range: $0.02-1.2 \mathrm{~mm}$
Thin Section No. 11-A 3 (Table 7-9, Figures 7-5 and 7-6)

Paste Matrix: continuous but split in center

Paste Color: light olive brown (2.5Y 5/6) and yellow (2.5Y7/6)

Paste Description: silty

B-fabric: speckled

Slip/Edges: no; same as paste

Comments: hornblend, microline, calcium carbonate; latter common in the fabric

Bone: fairly sorted

Mean size: $0.491 \mathrm{~mm}$

Range: 0.04-1.2 mm

Table 7-8. Results for Thin Section No. 10-B 2.

\begin{tabular}{ccc|ccc}
\hline Body & Count & Percent & Nonplastics & Count & Percent \\
\hline Paste & 241 & 72.6 & Bone & 54 & 65.8 \\
Nonplastics & 82 & 24.7 & Quartz & 23 & 28.1 \\
Voids & 9 & 2.7 & Calcium carbonate & 1 & 1.2 \\
\cline { 1 - 1 } Total & 332 & & Polycrystalline Quartz & 1 & 1.2 \\
\cline { 1 - 1 } & & & Opaque & 3 & 3.7 \\
& & Total & 82 & \\
\hline
\end{tabular}

Present but not sampled: shell, fossils, macrocrystalline quartz, calcite, muscovite.

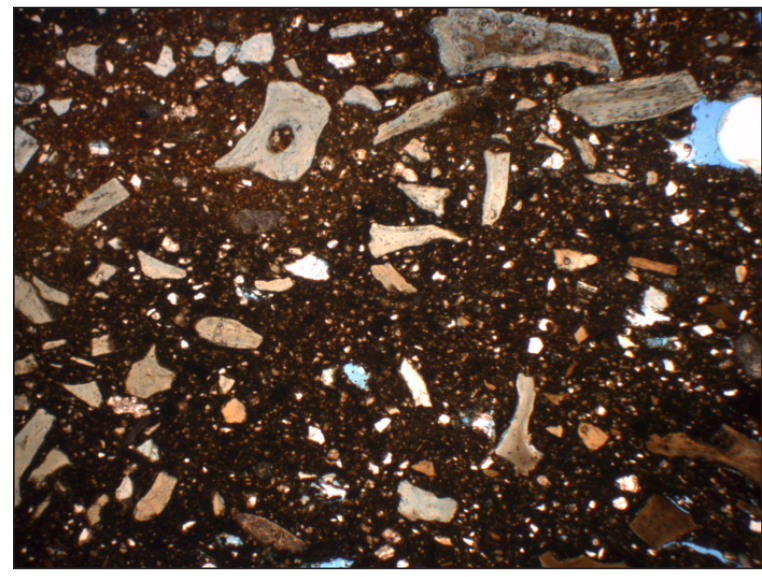

Figure 7-3. Paste of Thin Section No. 10-B 2 in plane light $4 \mathrm{x}$.

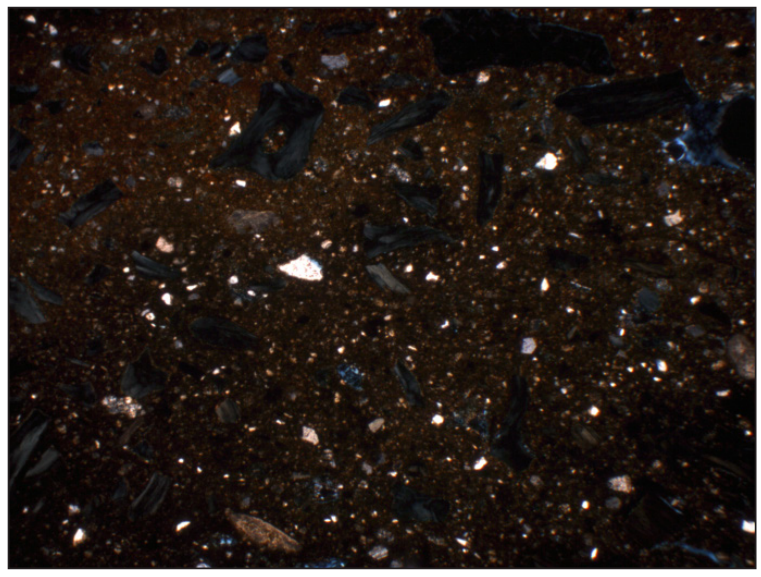

Figure 7-4. Paste of Thin Section No. 10-B 2 in cross-polar light $4 \mathrm{x}$. 
Table 7-9. Results for Thin Section No. 11-A 3.

\begin{tabular}{ccc|ccc}
\hline Body & Count & Percent & Nonplastics & Count & Percent \\
\hline Paste & 221 & 70.2 & Bone & 54 & 62.1 \\
Nonplastics & 87 & 27.6 & Quartz & 24 & 27.6 \\
Voids & 7 & 2.2. & Calcite & 1 & 1.1 \\
\cline { 1 - 2 } Total & 315 & & Polycrystaline quartz & 1 & 1.1 \\
\cline { 1 - 2 } & \multirow{3}{*}{} & & Macrocrystalline quartz & 4 & 4.6 \\
& & Opaque & 2 & 2.3 \\
& & & Unknown & 1 & 1.1 \\
& & Total & 87 & \\
\hline
\end{tabular}

Present but not sampled: hornblend, shell, microline, alkali feldspar, calcium carbonate.

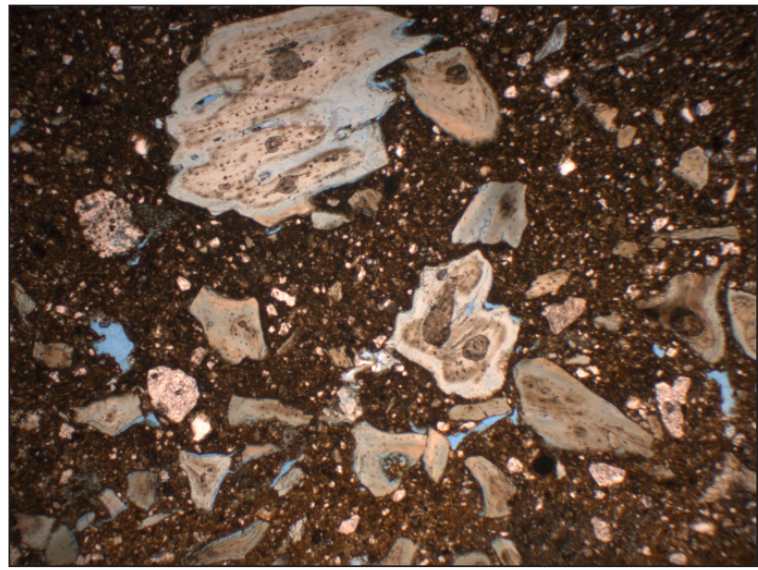

Figure 7-5. Paste of Thin Section No. 11-A 3 in plane light $4 x$.

Thin Section No. 11-B 4 (Table 7-10, Figures 7-7 and 7-8)

Paste Matrix: continuous but split in center

Paste Color: yellowish brown (10YR 5/6)

Paste Description: silty

B-fabric: speckled

Slip/Edges: no; edges don't appear to be present

Comments: macrocrystalline with triangular crystals; possible altered feldspar

Bone: fairly sorted

Mean size: $0.311 \mathrm{~mm}$

Range: $0.04-0.82 \mathrm{~mm}$

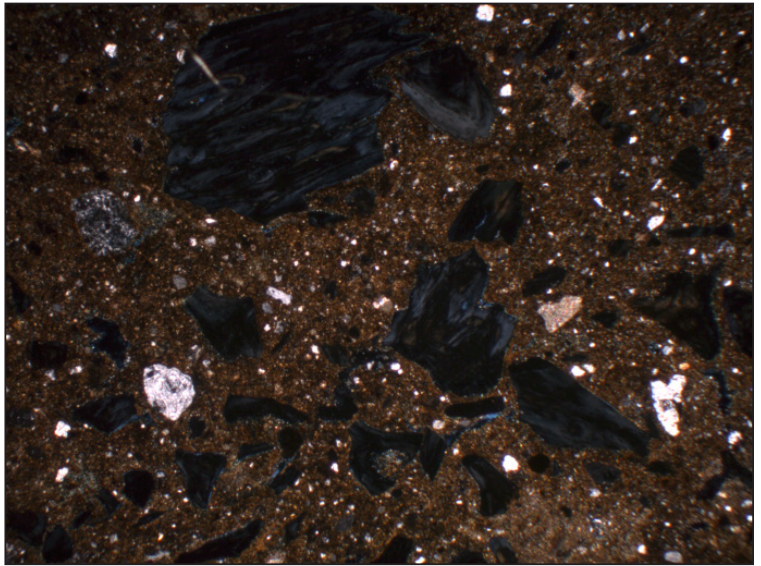

Figure 7-6. Paste of Thin Section No. 11-A 3 in cross-polar light $4 \mathrm{x}$.

Thin Section No. 18-5 (Table 7-11, Figures 7-9 and 7-10)

Paste Matrix: continuous

Paste Color: strong brown (7.5YR 5/8)

Paste Description: fine sand

B-fabric: striated; active

Slip/Edges: no; one edge slightly darker in PP\& XP light; strong brown (7.5YR4/6) don't appear to be present

Comments: large quartz crystals; very angular

Bone: fairly sorted

Mean size: $0.335 \mathrm{~mm}$

Range: 0.04-1.2 mm 
Table 7-10. Results for Thin Section No. 11-B 4.

\begin{tabular}{ccc|ccc}
\hline Body & Count & Percent & Nonplastics & Count & Percent \\
\hline Paste & 212 & 74.4 & Bone & 22 & 32.3 \\
Nonplastics & 68 & 23.9 & Quartz & 27 & 39.7 \\
Voids & 5 & 1.7. & Calcite & 3 & 1.1 \\
\cline { 1 - 2 } Total & 285 & & Polycrystalline Quartz & 1 & 1.5 \\
\cline { 1 - 1 } & & Shell & 2 & 2.9 \\
& & & Calcium carbonate & 10 & 14.7 \\
& & Opaque & 3 & 1.1 \\
& & Total & 68 & \\
\hline
\end{tabular}

Present but not sampled: amphibole (poss. Biotite), macrocrystalline quartz, alkali feldspar.

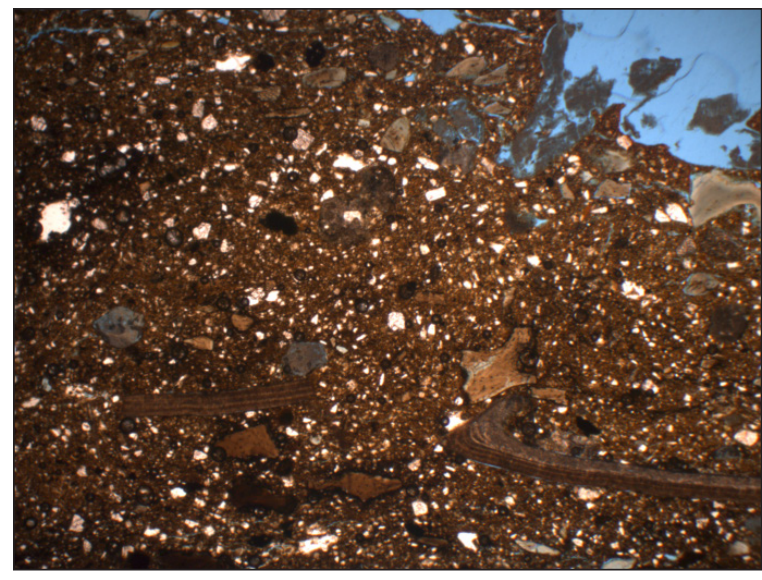

Figure 7-7. Paste of Thin Section No. 11-B 4 in plane light $4 \mathrm{x}$.

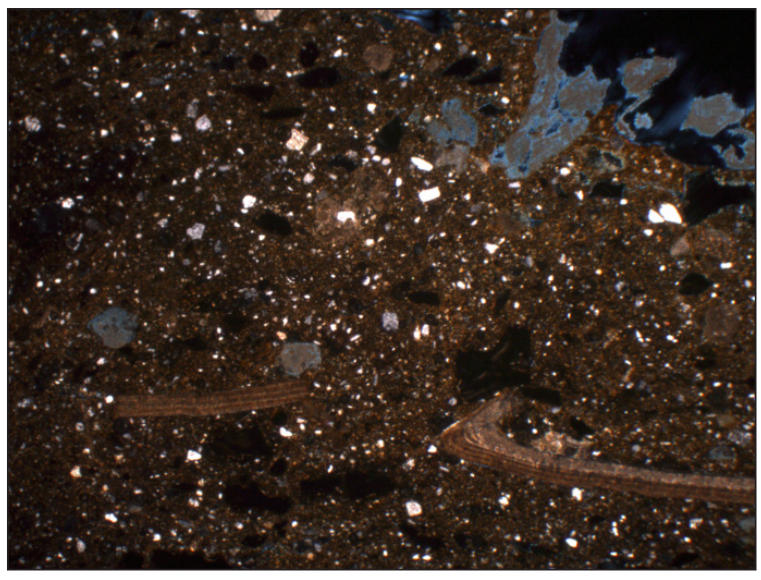

Figure 7-8. Paste of Thin Section No. 11-B 4 in cross-polar light $4 \mathrm{x}$.

Table 7-11. Results for Thin Section No. 18-5.

\begin{tabular}{ccc|ccc}
\hline Body & Count & Percent & Nonplastics & Count & Percent \\
\hline Paste & 129 & 55.84 & Bone & 30 & 33.33 \\
Nonplastics & 90 & 38.96 & Quartz & 46 & 51.11 \\
Voids & 12 & 5.19 & Plagioclase feldspar & 1 & 1.11 \\
\cline { 1 - 1 } Total & 231 & Alkali feldspar & 6 & 6.67 \\
& & Perthite & 1 & 1.11 \\
& & Macrocrystalline quartz & 3 & 3.33 \\
& & Polycrystaline quartz & 1 & 1.11 \\
& & Opaque & 2 & 2.22 \\
\cline { 5 - 5 } & & Total & 90 & \\
\hline
\end{tabular}

Present but not sampled: microcrystalline quartz, microline. 


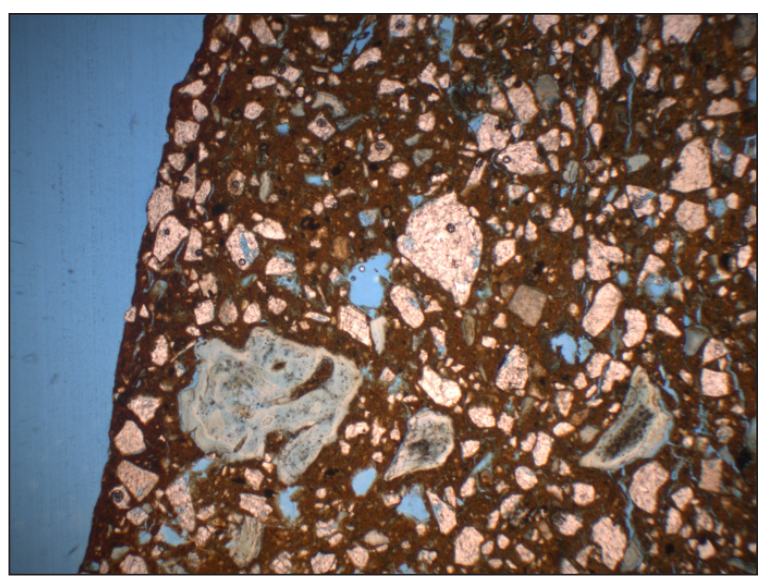

Figure 7-9. Paste of Thin Section No. 18-5 in plane light $4 x$.

Thin Section No. 26-6 (Table 7-12, Figures 7-11 and 7-12)

Paste Matrix: continuous

Paste Color: light olive brown (2.5Y 5/6)

Paste Description: silty

B-fabric: undifferentiated; slightly active , speckled

Slip/Edges: no; one edge olive brown (2.5YR4/4)

Comments: quartz crystals mostly small and rounded

Bone: fairly sorted

Mean size: $0.388 \mathrm{~mm}$

Range: $0.06-1.2 \mathrm{~mm}$

Thin Section No. 62-A 7 (Table 7-13, Figures 7-13 and 7-14)

Paste Matrix: continuous

Paste Color: yellowish brown (10YR 6/6)

Paste Description: silty

$B$-fabric: speckled; slightly active,

Slip/Edges: no; one edge darker brown (7.5YR5/6); slightly striated and active

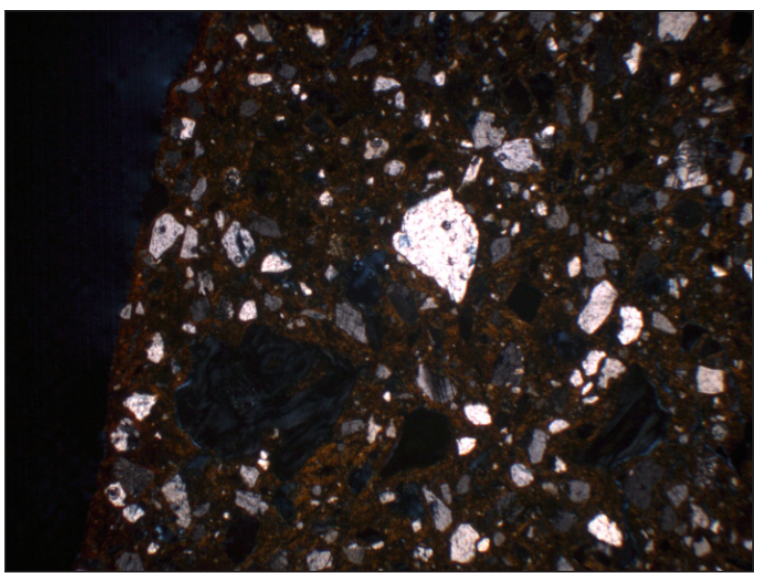

Figure 7-10. Paste of Thin Section No. 18-5 in crosspolar light $4 \mathrm{x}$.

Comments: large gaps between paste fragments; not counted as voids; quartz mostly small and rounded

Bone: fairly sorted

Mean size: $0.344 \mathrm{~mm}$

Range: $0.08-0.54 \mathrm{~mm}$

Thin Section No. 62-B 8 (Table 7-14, Figures 7-15 and 7-16)

Paste Matrix: continuous

Paste Color: yellowish brown (10YR 5/6)

Paste Description: silty to fine sand

B-fabric: striated

Slip/Edges: no; one edge darker; dark yellowish brown (10YR4/6)

Comments: rocky frags are plagioclase feldspar and quartz

Bone: fairly sorted

Mean size: $0.613 \mathrm{~mm}$

Range: $0.1-1.2 \mathrm{~mm}$ 
Table 7-12. Results for Thin Section No. 26-6.

\begin{tabular}{ccc|ccc}
\hline Body & Count & Percent & Nonplastics & Count & Percent \\
\hline Paste & 220 & 70.06 & Bone & 39 & 46.99 \\
Nonplastics & 83 & 26.43 & Quartz & 38 & 45.78 \\
Voids & 11 & 3.50 & Alkali feldspar & 2 & 2.41 \\
\cline { 1 - 1 } Total & 314 & & Macrocrystalline quartz & 2 & 2.41 \\
& & Opaque & 2 & 2.41 \\
& & Total & 83 & \\
\hline
\end{tabular}

Present but not sampled: microcrystalline quartz, microline.

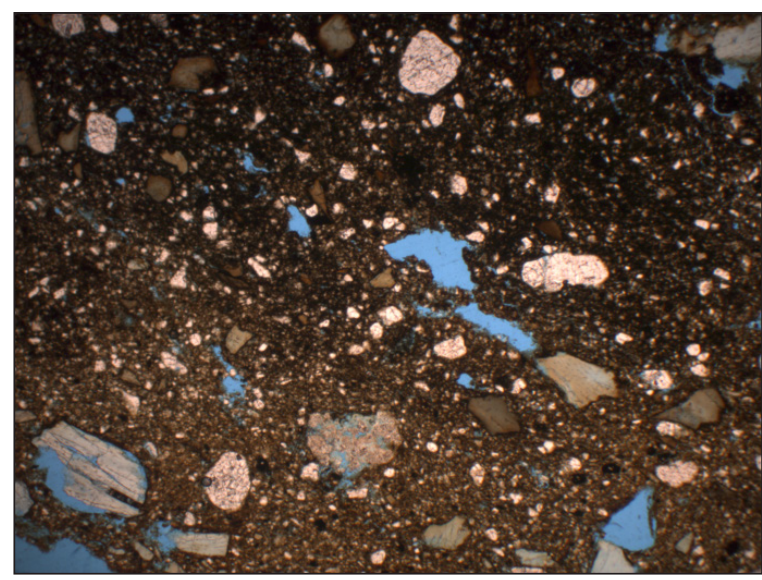

Figure 7-11. Paste of Thin Section No. 26-6 in plane light $4 x$.

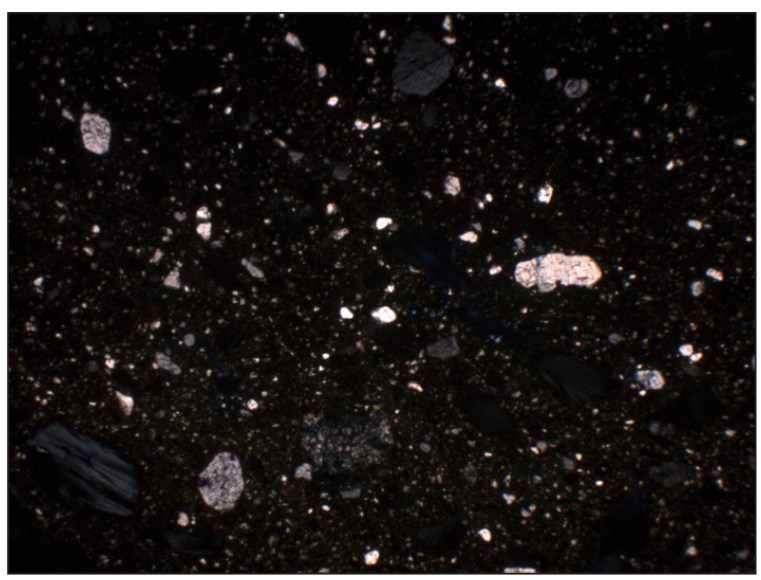

Figure 7-12. Paste of Thin Section No. 26-6 in crosspolar light $4 \mathrm{x}$.

Table 7-13. Results for Thin Section No. 62-A 7.

\begin{tabular}{ccc|ccc}
\hline Body & Count & Percent & Nonplastics & Count & Percent \\
\hline Paste & 138 & 72.63 & Bone & 16 & 35.56 \\
Nonplastics & 45 & 23.68 & Quartz & 22 & 48.89 \\
Voids & 7 & 3.68 & Calcium carbonate & 0 & 0.00 \\
\cline { 1 - 1 } Total & 190 & & Calcite & 3 & 6.67 \\
\cline { 1 - 1 } & & & Macrocrystalline quartz & 2 & 4.44 \\
& & Opaque & 2 & 4.44 \\
& & Total & 45 & \\
\hline
\end{tabular}

Present but not sampled: shell, calcium carbonate, mafic minerals, muscovite, and calcite. 


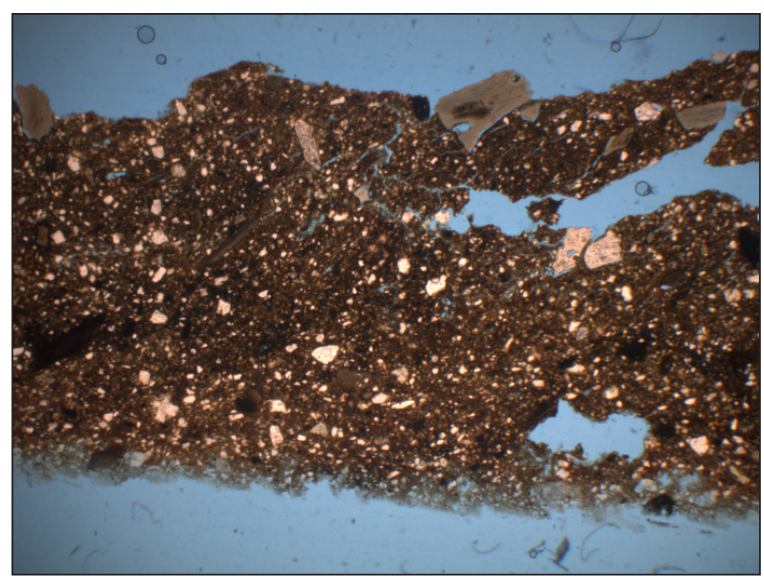

Figure 7-13. Paste of Thin Section No. 62-A 7 in plane light $4 x$.

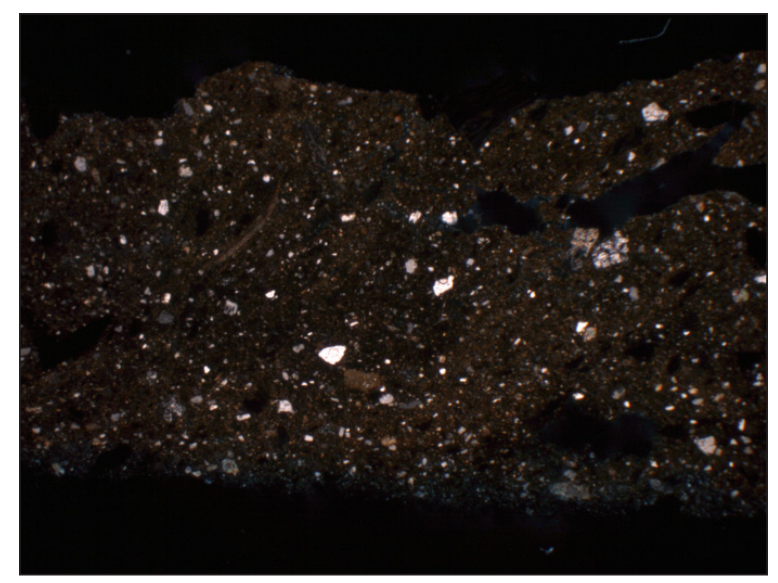

Figure 7-14. Paste of Thin Section No. 62-A 7 in cross-polar light $4 \mathrm{x}$.

Table 7-14. Results for Thin Section No. 62-B 8.

\begin{tabular}{ccc|ccc}
\hline Body & Count & Percent & Nonplastics & Count & Percent \\
\hline Paste & 191 & 56.85 & Bone & 19 & 15.70 \\
Nonplastics & 121 & 36.01 & Quartz & 80 & 66.12 \\
Voids & 24 & 7.14 & Conglomerate (rock, quartz, feldspar) & 3 & 2.48 \\
\hline Total & 336 & & Alkali feldspar & 6 & 4.96 \\
& & Perthite & 3 & 2.48 \\
& & Macrocrystalline quartz & 3 & 2.48 \\
& & Microline & 1 & 0.83 \\
& & Polycrystaline quartz & 3 & 2.48 \\
& & Opaque & 1 & 0.83 \\
& & Shell & 0 & 0.00 \\
& & Clay pellets & 2 & 1.65 \\
\hline & & Total & 121 & \\
\hline
\end{tabular}

Present but not sampled: augite, plagioclase, feldspar, muscovite, and biotite.

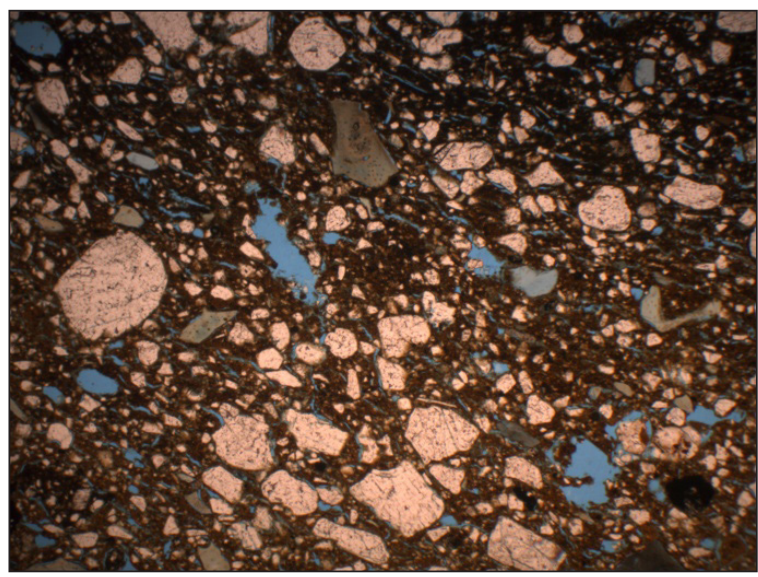

Figure 7-15. Paste of Thin Section No. 62-B 8 in plane light $4 x$.

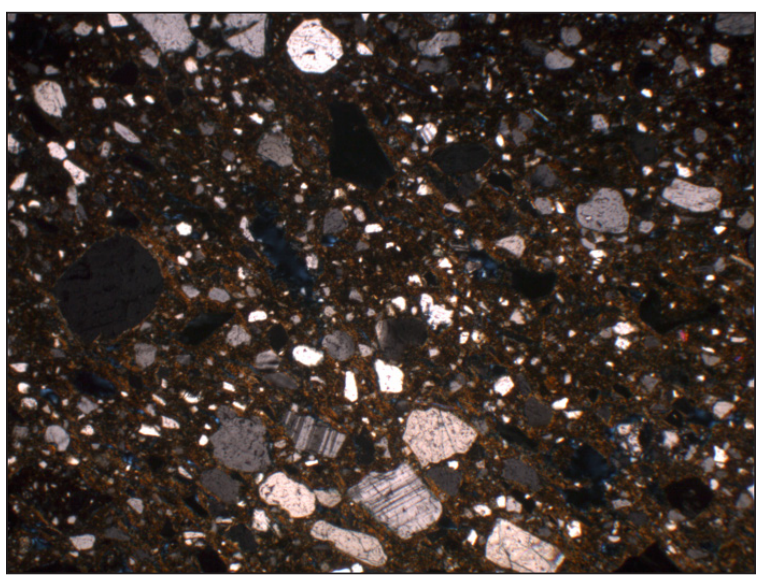

Figure 7-16. Paste of Thin Section No. 62-B 8 in cross-polar light $4 \mathrm{x}$. 
Thin Section No. 86-9 (Table 7-15, Figures 7-17 and 7-18)

Paste Matrix: continuous

Paste Color: yellowish brown (10YR 5/6)

Paste Description: silty

B-fabric: speckled; slightly active

Slip/Edges: no; same as rest of paste

Comments: very dense paste, color of paste almost the same in both PP and XP light

Bone: fairly sorted

Mean size: $0.369 \mathrm{~mm}$

Range: $0.04-1.2 \mathrm{~mm}$
Thin Section No. 122-10 (Table 7-16, Figures 7-19 and 7-20)

Paste Matrix: continuous

Paste Color: yellowish brown (10YR 5/6)

Paste Description: silty to fine sand

B-fabric: striated; active

Slip/Edges: no; same as rest of paste

Comments: porous fabric

Bone: fairly sorted

Mean size: $0.373 \mathrm{~mm}$

Range: $0.04-1.0 \mathrm{~mm}$

Table 7-15. Results for Thin Section No. 86-9.

\begin{tabular}{ccc|ccc}
\hline Body & Count & Percent & Nonplastics & Count & Percent \\
\hline Paste & 247 & 78.91 & Bone & 49 & 79.03 \\
Nonplastics & 62 & 19.81 & Quartz & 4 & 6.45 \\
Voids & 4 & 1.28 & Calcite & 3 & 4.84 \\
\cline { 1 - 1 } Total & 313 & & Fossil & 1 & 1.61 \\
& & Opaque & 5 & 8.06 \\
& & Total & 62 & \\
\hline
\end{tabular}

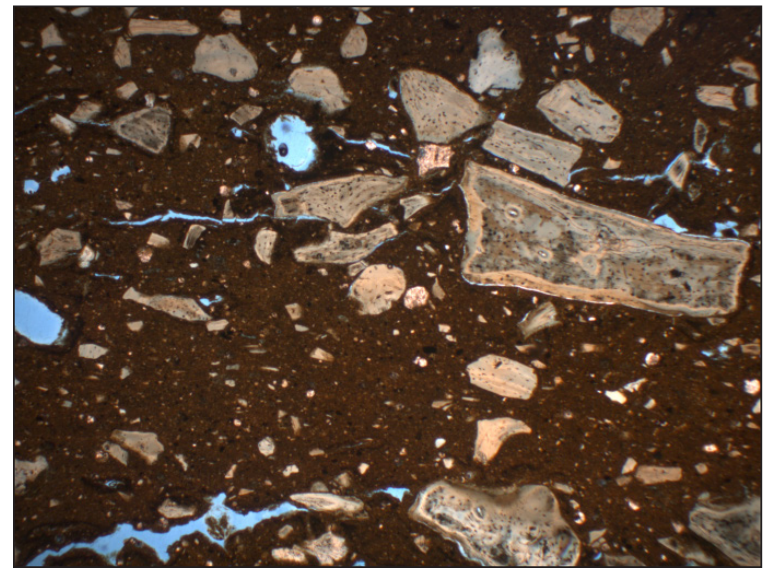

Figure 7-17. Paste of Thin Section No. 86-9 in plane light $4 \mathrm{x}$.

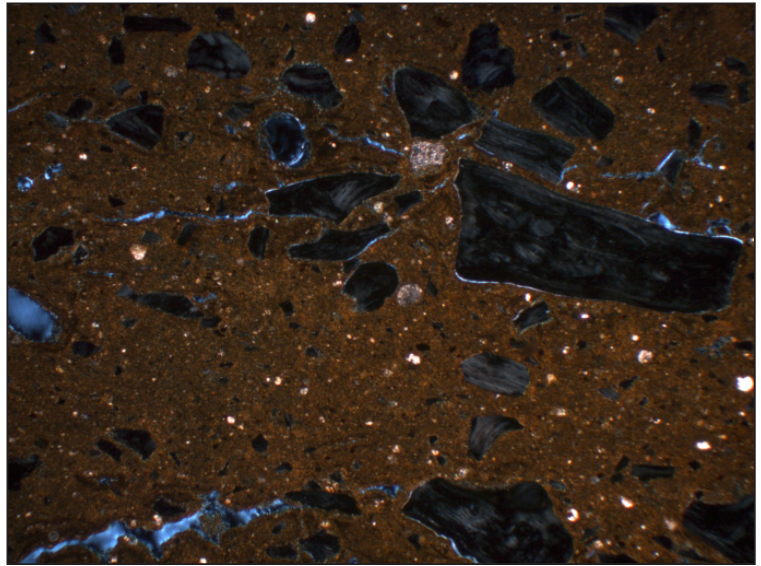

Figure 7-18. Paste of Thin Section No. 86-9 in crosspolar light $4 \mathrm{x}$. 
Table 7-16. Results for Thin Section No. 122-10.

\begin{tabular}{|c|c|c|c|c|c|}
\hline Body & Count & Percent & Nonplastics & Count & Percent \\
\hline Paste & 175 & 56.82 & Bone & 55 & 50.93 \\
\hline Nonplastics & 108 & 35.06 & Quartz & 45 & 41.67 \\
\hline Voids & 25 & 8.12 & Chert & 1 & 0.93 \\
\hline \multirow[t]{3}{*}{ Total } & 308 & & Alkali feldspar & 1 & 0.93 \\
\hline & & & Polycrystaline quartz & 6 & 5.56 \\
\hline & & & Total & 108 & \\
\hline
\end{tabular}

Present but not sampled: hornblende, garnet, plagioclase feldspar, perthite, amphibolie; muscovite, opaque and microcline.

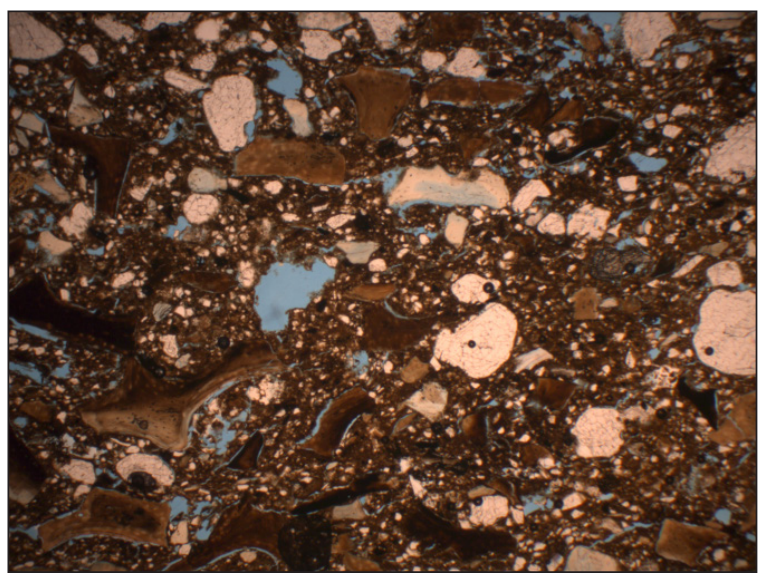

Figure 7-19. Paste of Thin Section No. 122-10 in plane light $4 x$.

Thin Section No. 133-11 (Table 7-17, Figures

\section{7-21 and 7-22)}

Paste Matrix: continuous

Paste Color: strong brown (7.5YR 4/6)

Paste Description: silty

B-fabric: striated; active

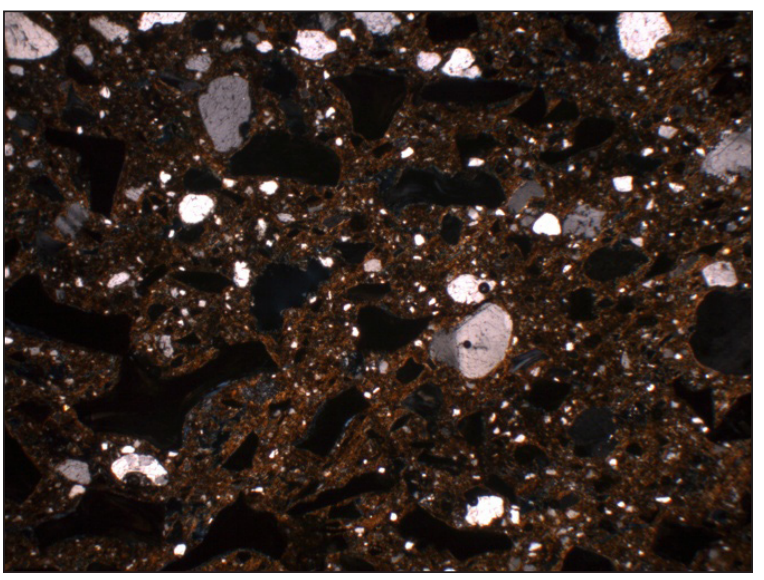

Figure 7-20. Paste of Thin Section No. 122-10 in cross-polar light $4 \mathrm{x}$.

Slip/Edges: no; same as rest of paste

Comments: slide over-ground, several areas too thin for analysis

Bone: fairly sorted

Mean size: $0.29 \mathrm{~mm}$

Range: $0.04-1.2 \mathrm{~mm}$

Table 7-17. Results for Thin Section No. 133-11.

\begin{tabular}{ccc|ccc}
\hline Body & Count & Percent & Nonplastics & Count & Percent \\
\hline Paste & 137 & 66.83 & Bone & 48 & 81.36 \\
Nonplastics & 59 & 28.78 & Quartz & 9 & 15.25 \\
Voids & 9 & 4.39 & Calcium carbonate & 0 & 0.00 \\
\cline { 1 - 2 } Total & 205 & & Opaque & 2 & 3.39 \\
\hline \multicolumn{2}{r}{} & & Total & 59 & \\
\hline
\end{tabular}




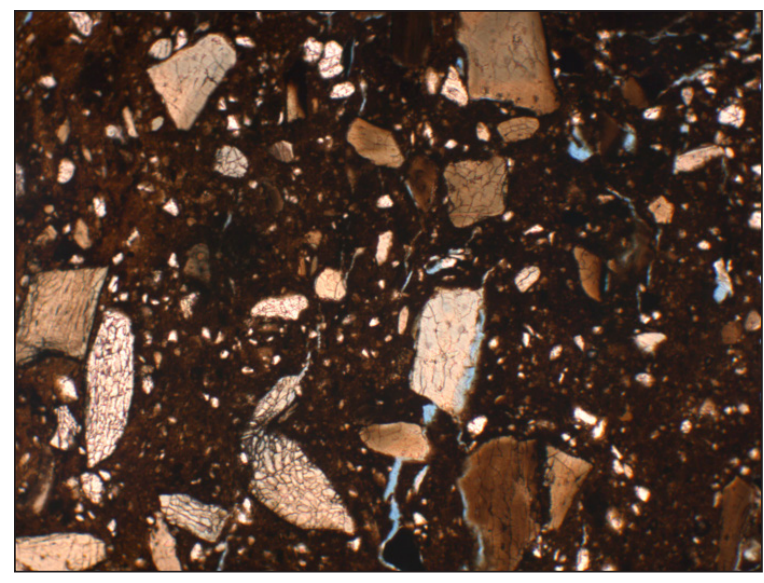

Figure 7-21. Paste of Thin Section No. 133-11 in plane light $4 \mathrm{x}$.

Thin Section No: 229-A 12 (Table 7-18, Figures 7-23 and 7-24)

Paste Matrix: mottled

Paste Color: light olive brown (2.5Y 5/4)

Paste Description: silty

B-fabric: speckled; slightly active

Slip/Edges: no; same as rest of paste

Comments: calcium carbonate common in the paste

Bone: fairly sorted

Mean size: $0.571 \mathrm{~mm}$

Range: $0.04-1.2 \mathrm{~mm}$

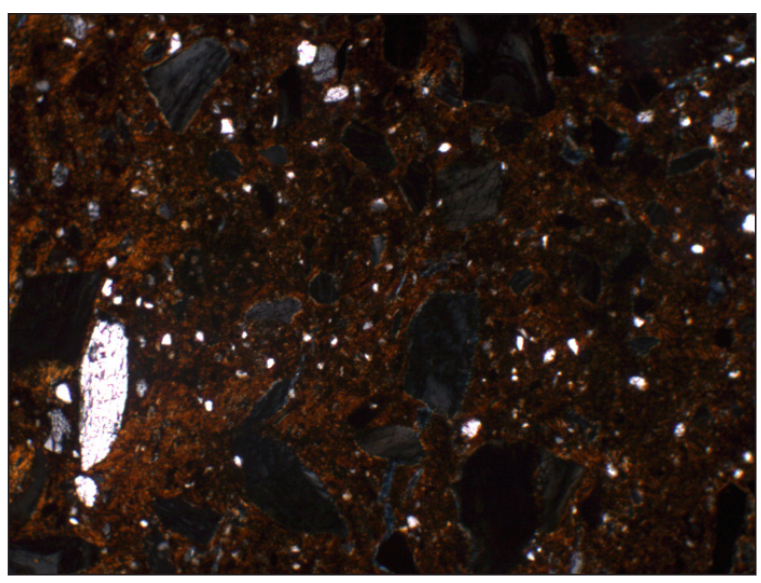

Figure 7-22. Paste of Thin Section No. 133-11 in cross-polar light $4 \mathrm{x}$.

Thin Section No. 229-B 13 (Table 7-19, Figure 7-25 and 7-26)

Paste Matrix: continuous

Paste Color: dark brown (10YR 3/3)

Paste Description: silty

B-fabric: undifferentiated;

Slip/Edges: no; localized spots along both edges brownish yellow (10YR6/8) same as rest of paste Comments: fabric is very porous

Bone: fairly sorted

Mean size: $0.385 \mathrm{~mm}$

Range: $0.04-1.1 \mathrm{~mm}$

Table 7-18. Results for Thin Section No. 229-A 12.

\begin{tabular}{ccc|ccc}
\hline Body & Count & Percent & Nonplastics & Count & Percent \\
\hline Paste & 175 & 77.09 & Bone & 31 & 70.45 \\
Nonplastics & 44 & 19.38 & Quartz & 10 & 22.73 \\
Voids & 8 & 3.52 & Calcium carbonate & 2 & 4.55 \\
\cline { 1 - 2 } Total & 227 & & Opaque & 1 & 2.27 \\
\hline \multicolumn{2}{r}{} & & Total & 44 & \\
\hline
\end{tabular}

Present but not sampled: fossils; calcite. 


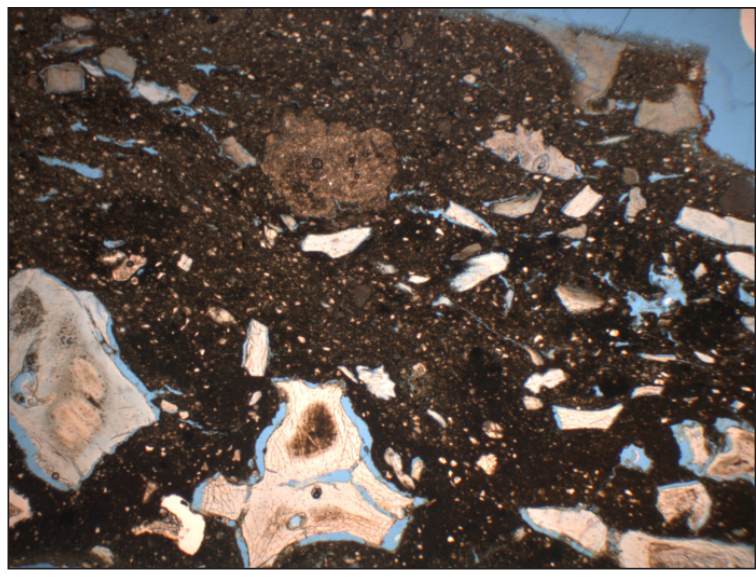

Figure 7-23. Paste of Thin Section No. 229-A 12 in plane light $4 x$.

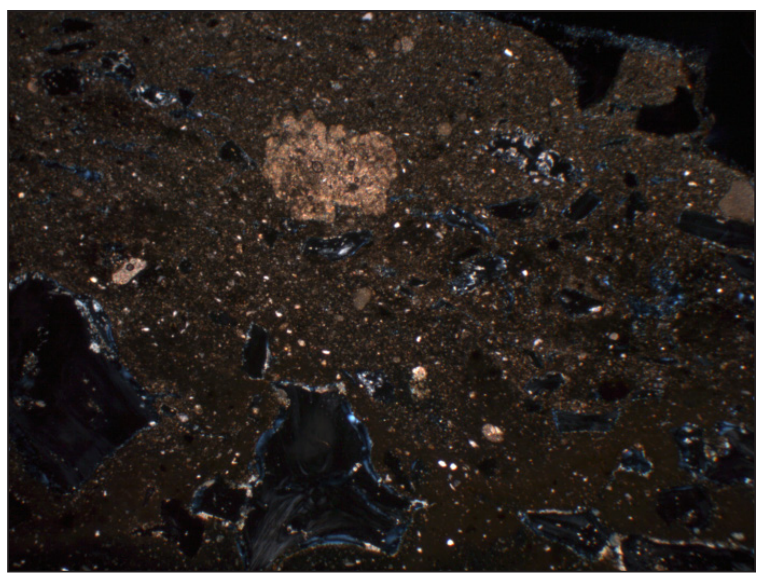

Figure 7-24. Paste of Thin Section No. 229-A 12 in cross-polar light $4 x$.

Table 7-19. Results for Thin Section No. 229-B 13.

\begin{tabular}{ccc|ccc}
\hline Body & Count & Percent & Nonplastics & Count & Percent \\
\hline Paste & 75 & 60.48 & Bone & 26 & 61.90 \\
Nonplastics & 42 & 33.87 & Quartz & 11 & 26.19 \\
Voids & 7 & 5.65 & Calcium carbonate & & 0.00 \\
\cline { 1 - 2 } Total & 124 & & Chert & 3 & 7.14 \\
\cline { 1 - 1 } & \multirow{2}{*}{} & & Hornblend & 1 & 2.38 \\
& & Opaque & 1 & 2.38 \\
& & Total & 42 & \\
\hline
\end{tabular}

Present but not sampled: shell, calcium carbonate, calcite, chalcedony.

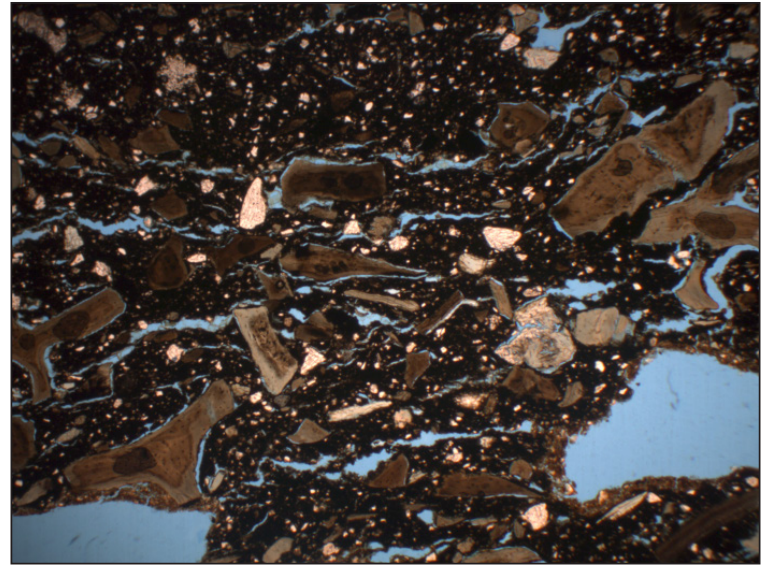

Figure 7-25. Paste of Thin Section No. 229-B 13 in plane light $4 x$.

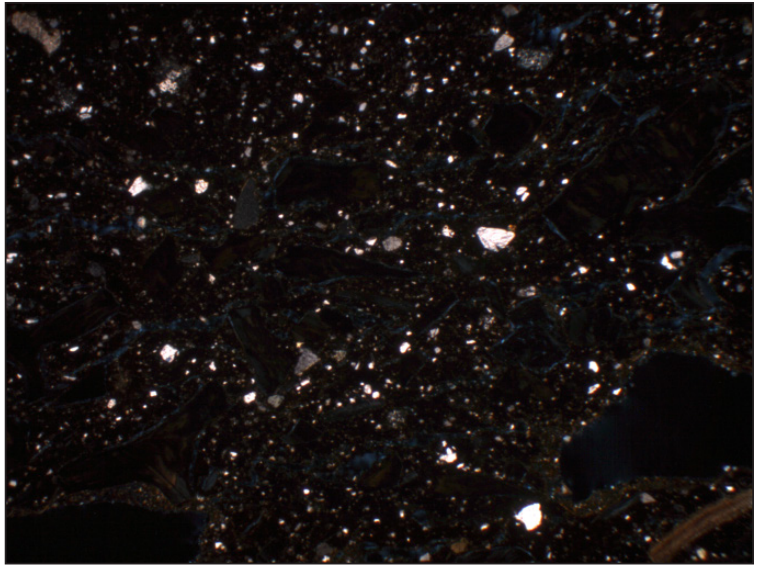

Figure 7-26. Paste of Thin Section No. 229-B 13 in cross-polar light 4x. 
Thin Section No. 235-14 (Table 7-20, Figures

\section{7-27 and 7-28)}

Paste Matrix: continuous

Paste Color: edges brownish yellow (10YR6/8); core dark yellowish brown (10YR4/6)

Paste Description: silty to fine sand

B-fabric: striated; paste active; core slightly active

Slip/Edges: no; same as rest of paste

Comments: porous paste; speckled with hematite

Bone: fairly sorted

Mean size: $0.292 \mathrm{~mm}$

Range: $0.04-0.7 \mathrm{~mm}$
Thin Section No. 253-A 15 (Table 7-21, Figures

7-29 and 7-30)

Paste Matrix: continuous

Paste Color: olive yellow (2.5Y 6/6)

Paste Description: silty

B-fabric: striated; active

Slip/Edges: no; same as rest of paste

Comments: outer and inner surfaces may have been eroded

Bone: None

Table 7-20. Results for Thin Section No. 235-14.

\begin{tabular}{ccc|ccc}
\hline Body & Count & Percent & Nonplastics & Count & Percent \\
\hline Paste & 160 & 47.62 & Bone & 67 & 44.67 \\
Nonplastics & 150 & 44.64 & Quartz & 72 & 48.00 \\
Voids & 26 & 7.74 & Calcium carbonate & & 0.00 \\
\cline { 1 - 1 } Total & 336 & & Chert & 3 & 2.00 \\
\cline { 1 - 1 } & & Alkali feldspar & 1 & 0.67 \\
& & Perthite & 1 & 0.67 \\
& & Polycrystaline quartz & 6 & 4.00 \\
& & Total & 150 & \\
\hline
\end{tabular}

Present but not sampled: plagioclase feldspar; muscovite; mafic minerals.

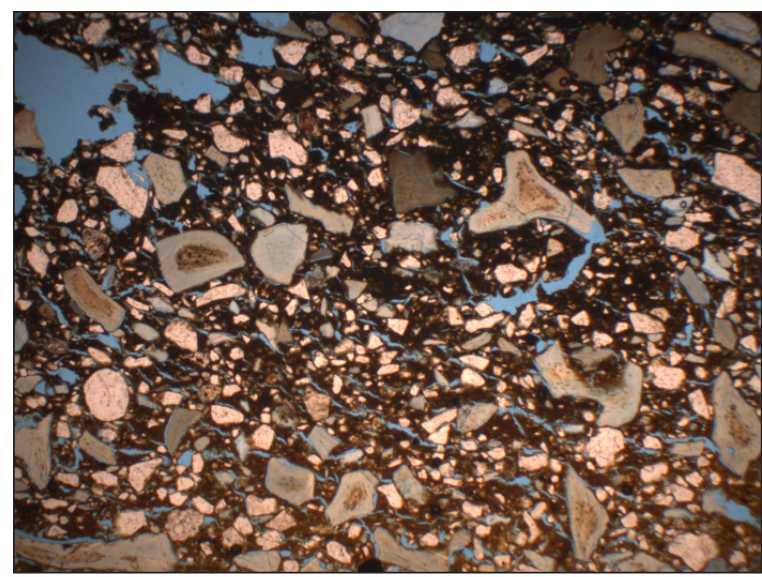

Figure 7-27. Paste of Thin Section No. 235-14 in plane light $4 \mathrm{x}$.

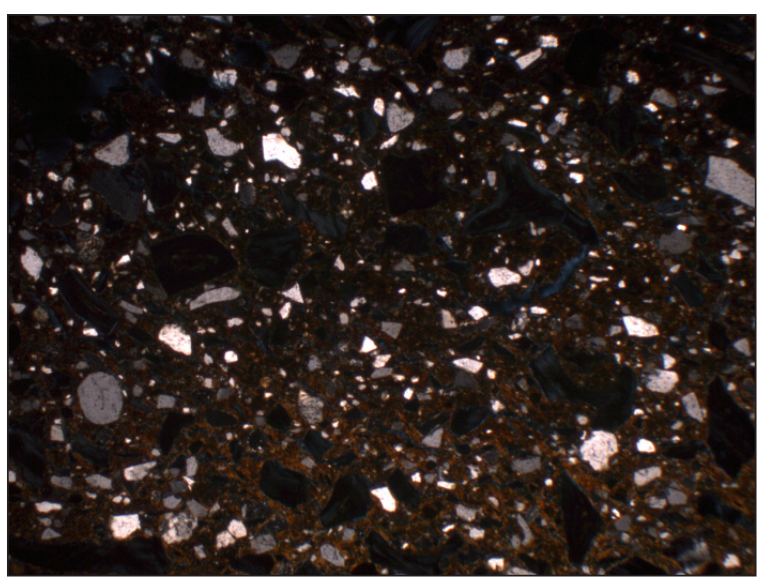

Figure 7-28. Paste of Thin Section No. 235-14 in cross-polar light 4x. 
Table 7-21. Results for Thin Section No. 253-A 15.

\begin{tabular}{ccc|ccc}
\hline Body & Count & Percent & Nonplastics & Count & Percent \\
\hline Paste & 73 & 73.74 & Bone & 0 & 0.00 \\
Nonplastics & 23 & 23.23 & Quartz & 13 & 56.52 \\
Voids & 3 & 3.03 & Calcium carbonate & 0 & 0.00 \\
\cline { 1 - 2 } Total & 99 & Muscovite & 1 & 4.35 \\
\cline { 1 - 1 } & \multirow{3}{*}{} & & Opaque & 1 & 4.35 \\
& & Sherds & 8 & 34.78 \\
\cline { 5 - 6 } & & Total & 23 & \\
\hline
\end{tabular}

Present but not sampled: clay pellet; burnt organics.

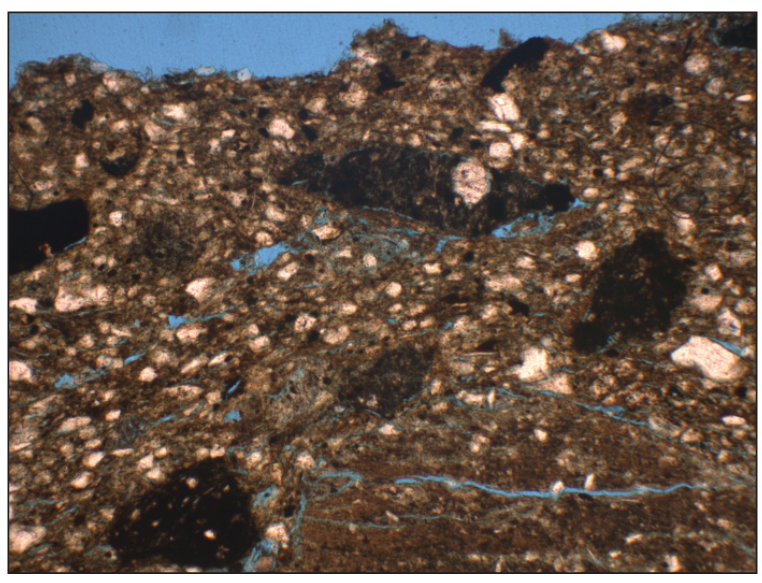

Figure 7-29. Paste of Thin Section No. 253-A 15 in plane light $4 x$.

Thin Section No. 253-B 16 (Table 7-22, Figures 7-31 and 7-32)

Paste Matrix: continuous

Paste Color: yellowish brown (10YR 5/8)

Paste Description: silty

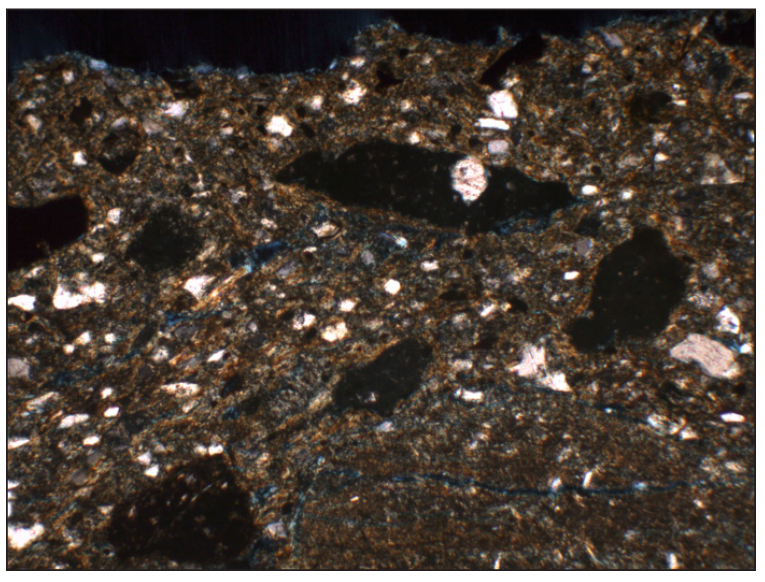

Figure 7-30. Paste of Thin Section No. 253-A 15 in cross-polar light $4 \mathrm{x}$.

B-fabric: speckled; active

Slip/Edges: no; not an edge cut thin section

Comments:

Bone: None

Table 7-22. Results for Thin Section No. 253-B 16.

\begin{tabular}{ccc|ccc}
\hline Body & Count & Percent & Nonplastics & Count & Percent \\
\hline Paste & 271 & 82.87 & Bone & 0 & 0.00 \\
Nonplastics & 50 & 15.29 & Quartz & 38 & 76.00 \\
Voids & 6 & 1.83 & Calcium carbonate & 2 & 4.00 \\
\cline { 1 - 1 } Total & 327 & Chert & 5 & 10.00 \\
& \multirow{3}{*}{} & & Amphibole & 1 & 2.00 \\
& & Chalcedony & 1 & 2.00 \\
& & Muscovite & 1 & 2.00 \\
& & Polycrystaline quartz & 2 & 4.00 \\
& & Total & 50 & \\
\hline
\end{tabular}

Present but not sampled: hornblend; calcite. 


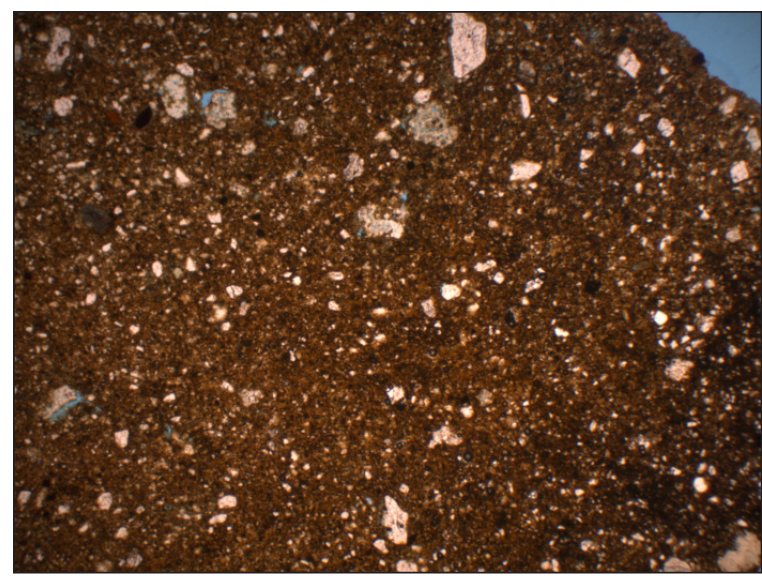

Figure 7-31. Paste of Thin Section No. 253-B 16 in plane light $4 \mathrm{x}$.

Thin Section No. 296-17 (Table 7-23, Figures 7-33 and 7-34)

Paste Matrix: slightly mottled

Paste Color: dark brown (10YR 3/3) with streaks of light yellowish brown (10YR5/6)

Paste Description: silty

$B$-fabric: slightly striated; slightly active

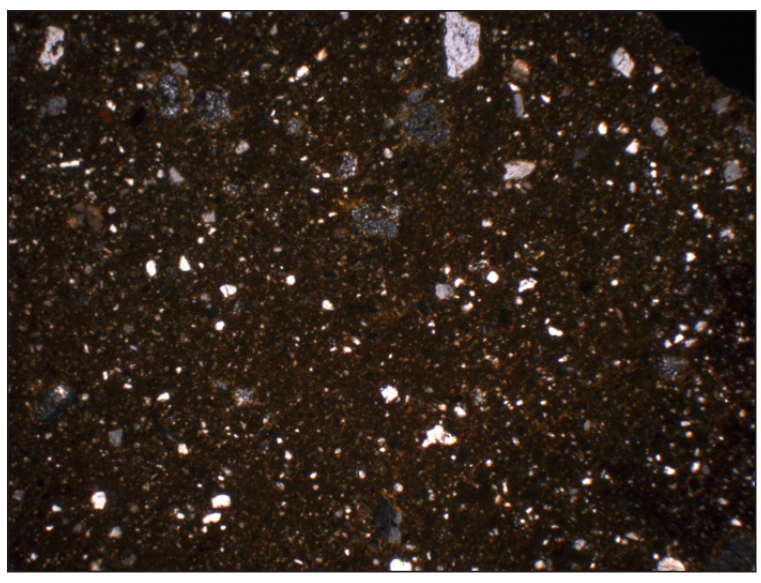

Figure 7-32. Paste of Thin Section No. 253-B 16 in cross-polar light $4 \mathrm{x}$.

Slip/Edges: Indeterminate-difficult to define edge; may be eroded

Comments: very dense paste, slide is of poor quality

Bone: fairly sorted

Mean size: $0.312 \mathrm{~mm}$

Range: $0.1-1.2 \mathrm{~mm}$

Table 7-23. Results for Thin Section No. 296-17.

\begin{tabular}{ccc|ccc}
\hline Body & Count & Percent & Nonplastics & Count & Percent \\
\hline Paste & 107 & 82.95 & Bone & 13 & 72.22 \\
Nonplastics & 18 & 13.95 & Quartz & 5 & 27.78 \\
\cline { 4 - 6 } Voids & 4 & 3.10 & Total & 18 & \\
\hline Total & 129 & & & & \\
\hline
\end{tabular}

Present but not sampled: alkali feldspar; calcite.

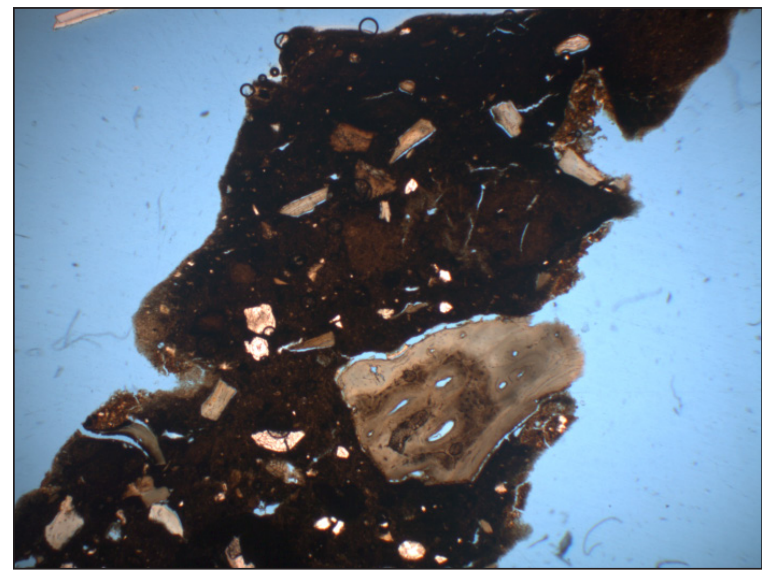

Figure 7-33. Paste of Thin Section No. 296-17 in plane light $4 \mathrm{x}$.

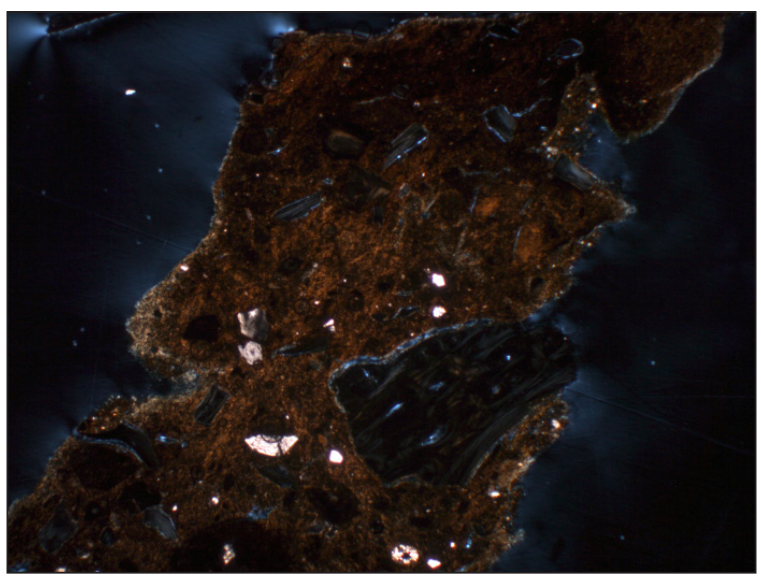

Figure 7-34. Paste of Thin Section No. 296-17 in cross-polar light $4 \mathrm{x}$. 
Thin Section No. 315-18 (Table 7-24, Figures

\section{7-35 and 7-36)}

Paste Matrix: continuous

Paste Color: brownish yellowish (10YR 6/6)

Paste Description: silty

B-fabric: speckled; active

Slip/Edges: no; same as rest of paste

Comments: calcite common and fossils present; quartz grains very small

Bone: fairly sorted

Mean size: $0.323 \mathrm{~mm}$

Range: $0.04-1.02 \mathrm{~mm}$
Thin Section No. 316-19 (Table 7-25, Figures 7-37 and 7-38)

Paste Matrix: mottled

Paste Color: yellow (2.5Y7/6) with spots of olive brown $(2.5$ Y $5 / 4)$

Paste Description: silty

$B$-fabric: speckled; slightly active

Slip/Edges: no; same as rest of paste

Comments: calcite is common in the paste; slide is poor quality;

Bone: fairly sorted

Mean size: $0.322 \mathrm{~mm}$

Range: $0.04-0.98 \mathrm{~mm}$

Table 7-24. Results for Thin Section No. 315-18.

\begin{tabular}{ccc|ccc}
\hline Body & Count & Percent & Nonplastics & Count & Percent \\
\hline Paste & 213 & 67.41 & Bone & 77 & 76.24 \\
Nonplastics & 101 & 31.96 & Quartz & 6 & 5.94 \\
Voids & 2 & 0.63 & Calcium carbonate & 1 & 0.99 \\
\cline { 1 - 2 } Total & 316 & & Calcite & 6 & 5.94 \\
\cline { 1 - 1 } & \multirow{3}{*}{} & & Muscovite & 1 & 0.99 \\
& & Opaque & 9 & 8.91 \\
& & Shell & 1 & 0.99 \\
& & Total & 101 & \\
\hline
\end{tabular}

Present but not sampled: fossil.

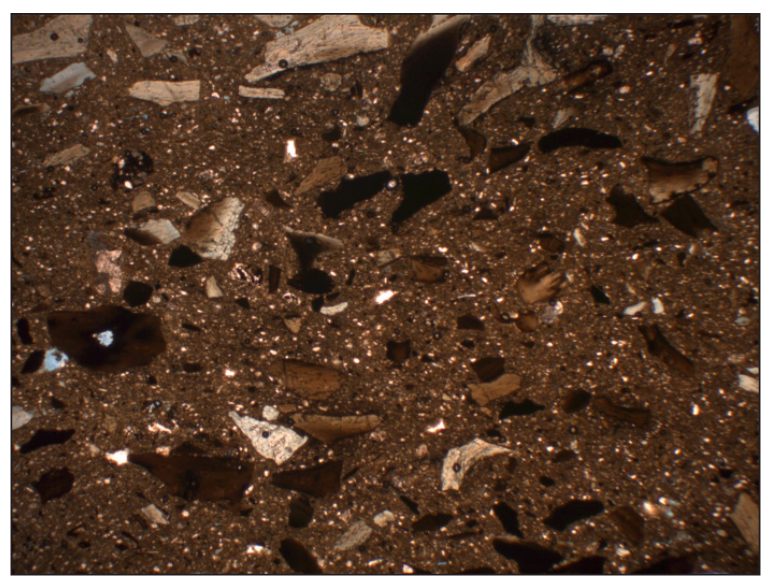

Figure 7-35. Paste of Thin Section No. 315-18 in plane light $4 \mathrm{x}$.

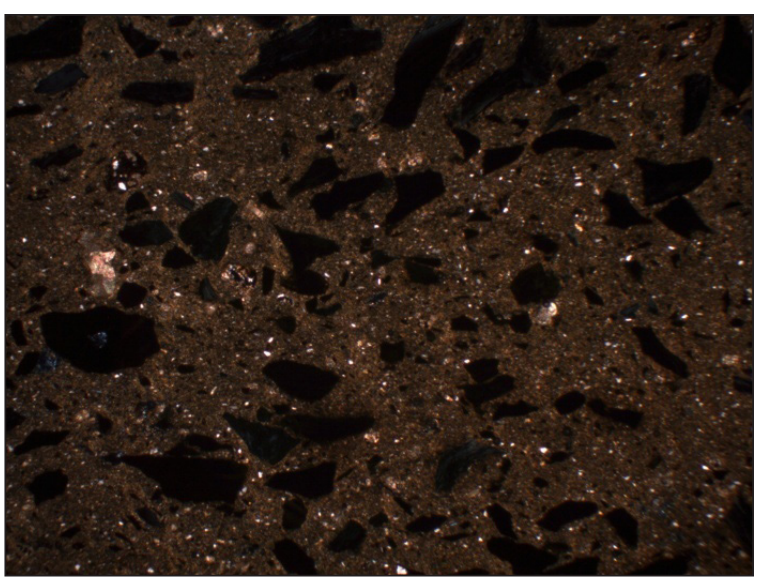

Figure 7-36. Paste of Thin Section No. 315-18 in cross-polar light $4 \mathrm{x}$. 
Table 7-25. Results for Thin Section No. 316-19.

\begin{tabular}{ccc|ccc}
\hline Body & Count & Percent & Nonplastics & Count & Percent \\
\hline Paste & 236 & 76.13 & Bone & 50 & 81.97 \\
Nonplastics & 61 & 19.68 & Quartz & 2 & 3.28 \\
Voids & 13 & 4.19 & Calcium carbonate & 1 & 1.64 \\
\cline { 1 - 1 } Total & 310 & & Opaque & 4 & 6.56 \\
& & Calcite & 4 & 6.56 \\
& & Total & 61 & \\
\hline
\end{tabular}

Present but not sampled: fossils; muscovite.

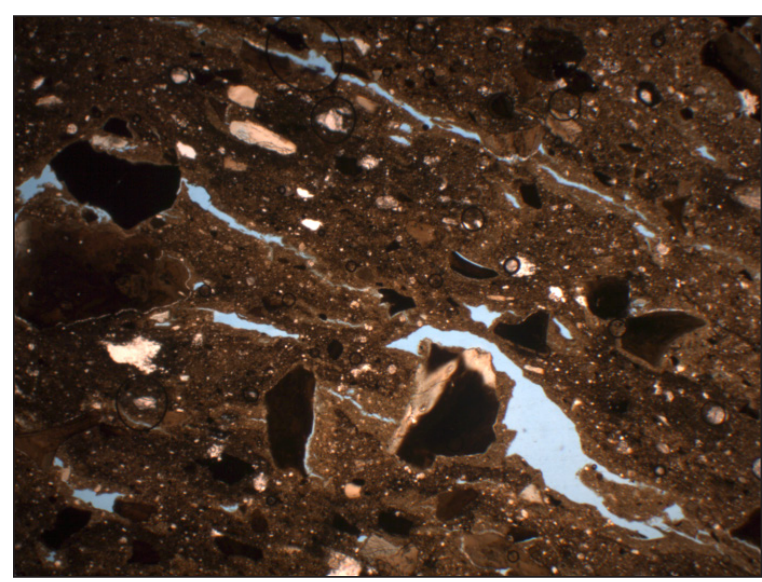

Figure 7-37. Paste of Thin Section No. 316-19 in plane light $4 \mathrm{x}$.

Thin Section No. 339-20 (Table 7-26, Figures 7-39 and 7-40)

Paste Matrix: continuous

Paste Color: light yellowish brown (2.5Y 6/4)

Paste Description: silty

B-fabric: undifferentiated;

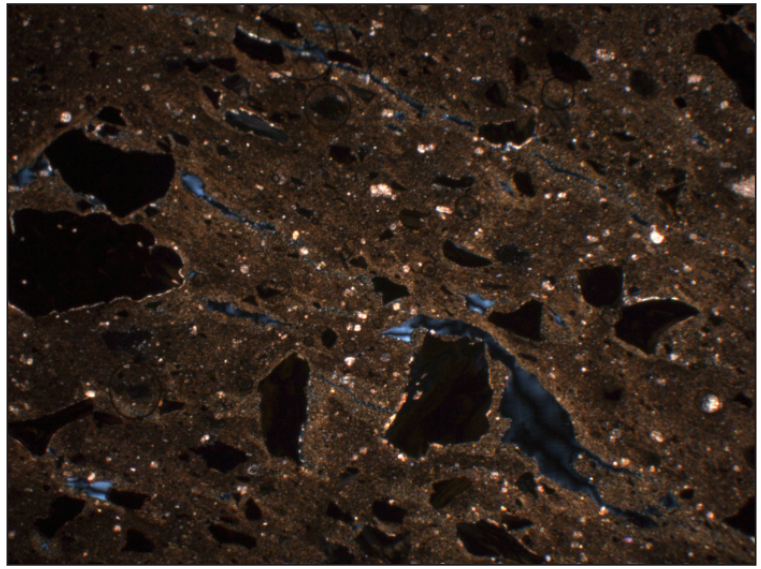

Figure 7-38. Paste of Thin Section No. 316-19 in cross-polar light $4 \mathrm{x}$.

Slip/Edges: no; same as rest of paste

Comments: calcium carbonate and fossils common in paste

Bone: fairly sorted

Mean size: $0.365 \mathrm{~mm}$

Range: $0.06-1.2 \mathrm{~mm}$

Table 7-26. Results for Thin Section No. 339-20.

\begin{tabular}{ccc|ccc}
\hline Body & Count & Percent & Nonplastics & Count & Percent \\
\hline Paste & 229 & 72.70 & Bone & 37 & 52.86 \\
Nonplastics & 70 & 22.22 & Quartz & 6 & 8.57 \\
Voids & 16 & 5.08 & Calcium carbonate & 21 & 30.00 \\
\cline { 1 - 1 } Total & 315 & & Calcite & 3 & 4.29 \\
\cline { 1 - 1 } & & Fossil & 1 & 1.43 \\
& & Opaque & 1 & 1.43 \\
& & Shell & 1 & 1.43 \\
& & Total & 70 & \\
\hline
\end{tabular}

Present but not sampled: muscovite. 


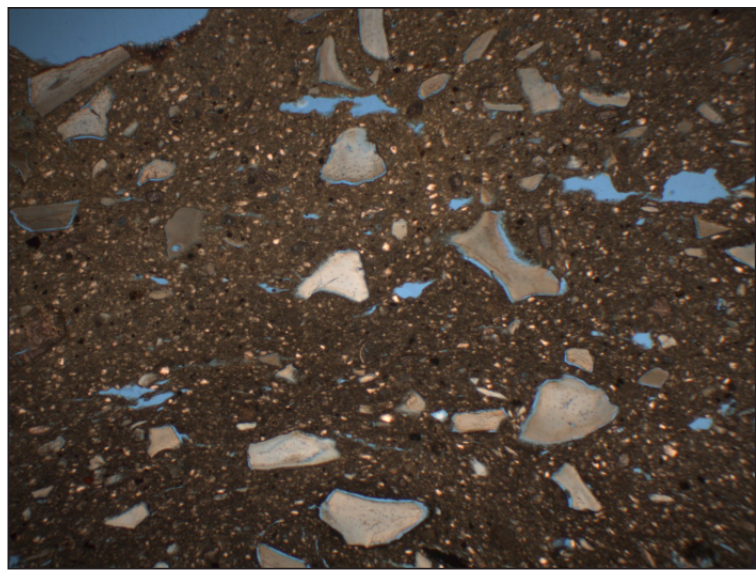

Figure 7-39. Paste of Thin Section No. 339-20 in plane light $4 x$.

Thin Section No. 347-21 (Table 7-27, Figures 7-41 and 7-42)

Paste Matrix: continuous

Paste Color: olive yellow (2.5Y 6/6)

Paste Description: silty

B-fabric: undiferentiated

Slip/Edges: no; same as rest of paste

Comments: calcite and calcium carbonate common in paste

Bone: fairly sorted

Mean size: $0.439 \mathrm{~mm}$

Range: $0.06-1.2 \mathrm{~mm}$

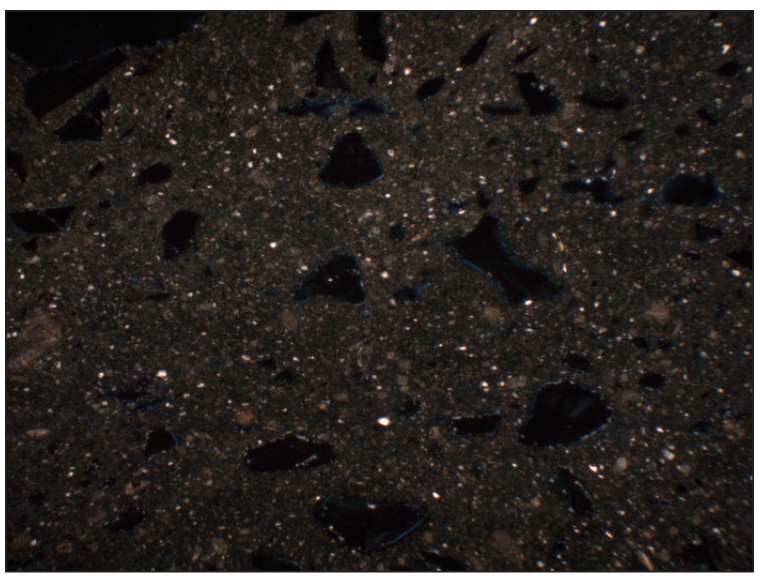

Figure 7-40. Paste of Thin Section No. 339-20 in cross-polar light $4 \mathrm{x}$.

Thin Section No. 381-22 (Table 7-28, Figures 7-43 and 7-44)

Paste Matrix: continuous

Paste Color: light yellowish brown (2.5Y 6/4)

Paste Description: silty

$B$-fabric: undifferentiated

Slip/Edges: no; paste is mottled along one edge with olive brown spots $(2.5 \mathrm{Y} 4 / 4)$

Comments: calcium carbonate common in paste as are fossils; quartz is very small grained

Bone: fairly sorted

Mean size: $0.360 \mathrm{~mm}$

Range: $0.04-1.12 \mathrm{~mm}$

Table 7-27. Results for Thin Section No. 347-21.

\begin{tabular}{ccc|ccc}
\hline Body & Count & Percent & Nonplastics & Count & Percent \\
\hline Paste & 248 & 75.15 & Bone & 50 & 76.92 \\
Nonplastics & 65 & 19.70 & Quartz & 5 & 7.69 \\
Voids & 17 & 5.15 & Calcium carbonate & 2 & 3.08 \\
\cline { 1 - 1 } Total & 330 & & Shell & 1 & 1.54 \\
\cline { 1 - 1 } & \multirow{2}{*}{} & Calcite & 4 & 6.15 \\
& & Opaque & 3 & 4.62 \\
& & Total & 65 & \\
\hline
\end{tabular}

Present but not sampled: fossil. 


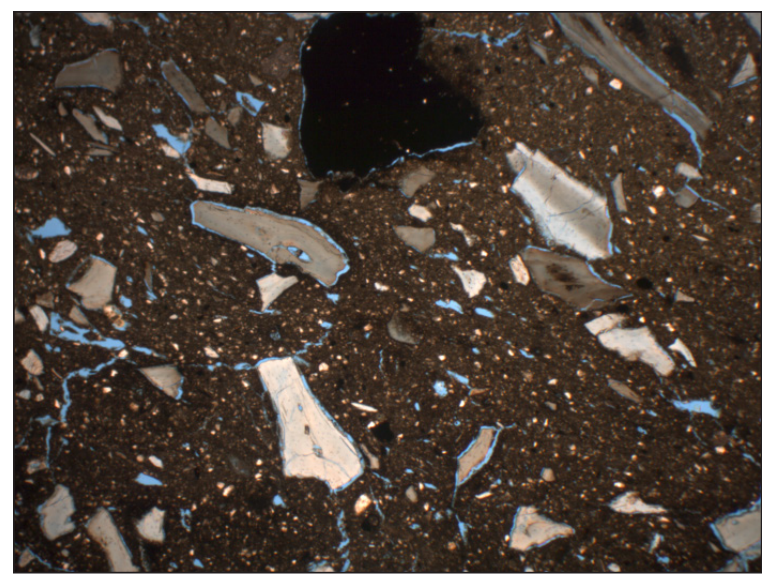

Figure 7-41. Paste of Thin Section No. 347-21 in plane light $4 \mathrm{x}$.

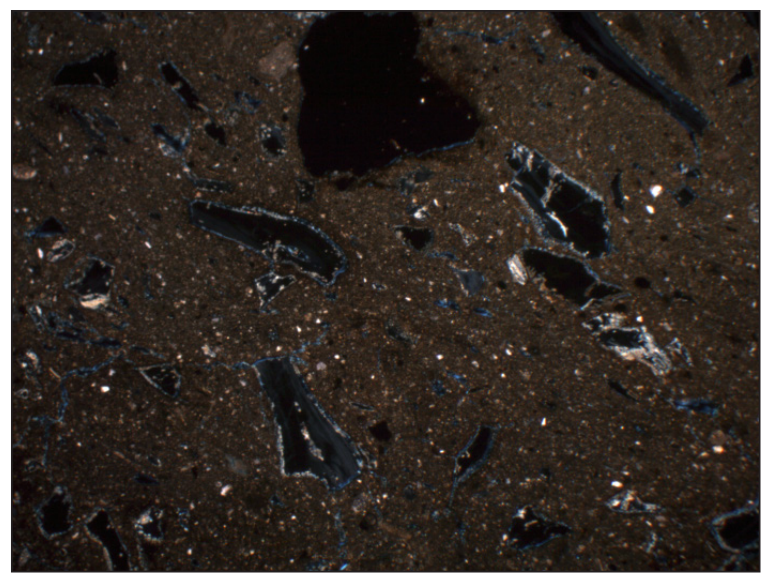

Figure 7-42. Paste of Thin Section No. 347-21 in cross-polar light $4 \mathrm{x}$.

Table 7-28. Results for Thin Section No. 381-22.

\begin{tabular}{ccc|ccc}
\hline Body & Count & Percent & Nonplastics & Count & Percent \\
\hline Paste & 218 & 73.90 & Bone & 36 & 51.43 \\
Nonplastics & 70 & 23.73 & Quartz & 12 & 17.14 \\
Voids & 7 & 2.37 & Calcium carbonate & 18 & 25.71 \\
\cline { 1 - 1 } Total & 295 & & Opaque & 2 & 2.86 \\
& & Fossil & 2 & 2.86 \\
& & Total & 70 & \\
\hline
\end{tabular}

Present but not sampled: fossil.

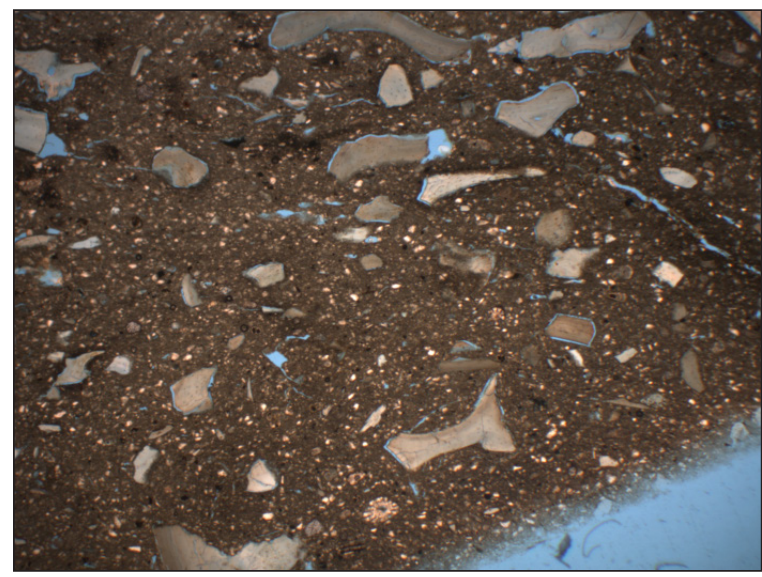

Figure 7-43. Paste of Thin Section No. 381-22 in plane light $4 \mathrm{x}$.

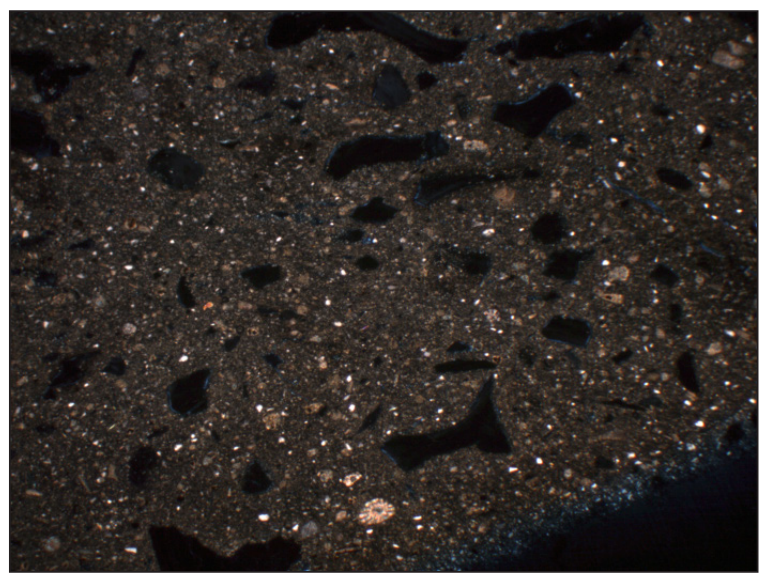

Figure 7-44. Paste of Thin Section No. 381-22 in cross-polar light $4 \mathrm{x}$. 
Thin Section No. 492-23 (Table 7-29, Figures

\section{7-45 and 7-46)}

Paste Matrix: mottled

Paste Color: yellow (2.5Y7/6) with olive brown patches $(2.5 \mathrm{Y} 4 / 3)$

Paste Description: silty

B-fabric: speckled; active

Slip/Edges: no; same as rest of paste

Comments: slide is of poor quality; calcite and fossils common in paste; quartz is of small grain size

Bone: fairly sorted

Mean size: $0.307 \mathrm{~mm}$

Range: $0.02-1.18 \mathrm{~mm}$
Thin Section No. 493-24 (Table 7-30, Figures 7-47 and 7-48)

Paste Matrix: slightly mottled

Paste Color: brownish yellow (10YR6/60 with dark yellowish brown spots (10YR4/4)

Paste Description: silty

$B$-fabric: speckled

Slip/Edges: no; same as rest of paste

Comments: secondary calcite common around bones but not on bones themselves; quartz is very small grained

Bone: fairly sorted

Mean size: $0.371 \mathrm{~mm}$

Range: $0.04-0.92 \mathrm{~mm}$

Table 7-29. Results for Thin Section No. 492-23.

\begin{tabular}{ccc|ccc}
\hline Body & Count & Percent & Nonplastics & Count & Percent \\
\hline Paste & 169 & 62.59 & Bone & 71 & 73.20 \\
Nonplastics & 97 & 35.93 & Quartz & 16 & 16.49 \\
Voids & 4 & 1.48 & Calcium carbonate & 1 & 1.03 \\
\cline { 1 - 1 } Total & 270 & & Shell & 1 & 1.03 \\
\cline { 1 - 1 } & \multirow{2}{*}{} & Calcite & 7 & 7.22 \\
& & Opaque & 1 & 1.03 \\
& & Total & 97 & \\
\hline
\end{tabular}

Present but not sampled: fossil; muscovite.

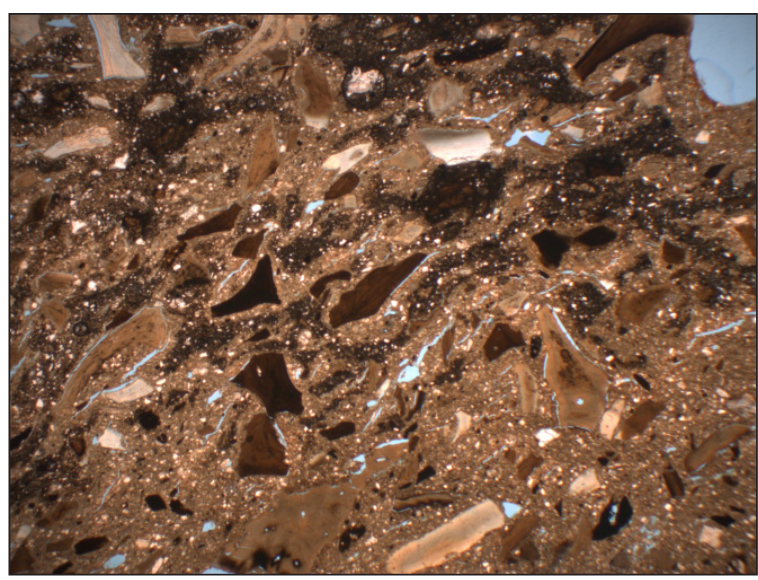

Figure 7-45. Paste of Thin Section No. 492-23 in plane light $4 \mathrm{x}$.

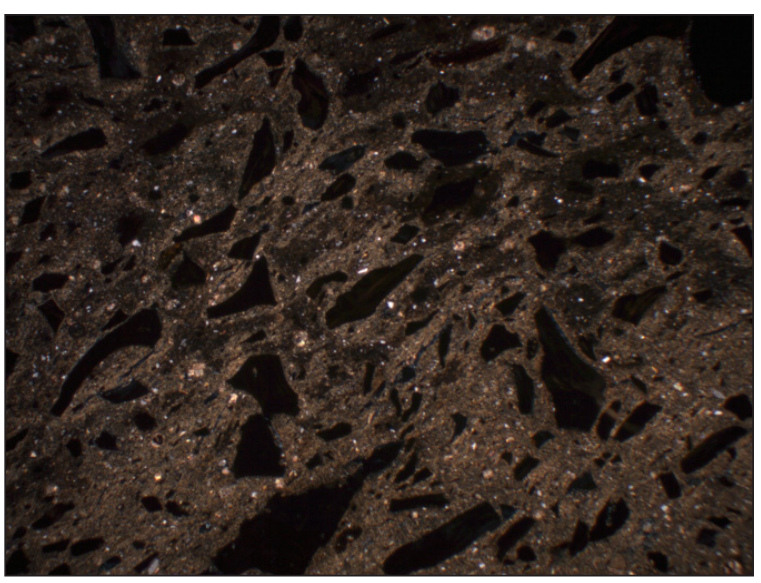

Figure 7-46. Paste of Thin Section No. 492-23 in cross-polar light $4 \mathrm{x}$. 
Table 7-30. Results for Thin Section No. 493-24.

\begin{tabular}{ccc|ccc}
\hline Body & Count & Percent & Nonplastics & Count & Percent \\
\hline Paste & 233 & 74.92 & Bone & 52 & 75.36 \\
Nonplastics & 69 & 22.19 & Quartz & 4 & 5.80 \\
Voids & 9 & 2.89 & Calcite & 7 & 10.14 \\
\cline { 1 - 1 } Total & 311 & & Secondary Calcite & 1 & 1.45 \\
\cline { 1 - 1 } & & Fossil & 1 & 1.45 \\
& & & Opaque & 4 & 5.80 \\
& & Total & 69 & \\
\hline
\end{tabular}

Present but not sampled: calcium carbonate; shell, muscovite.

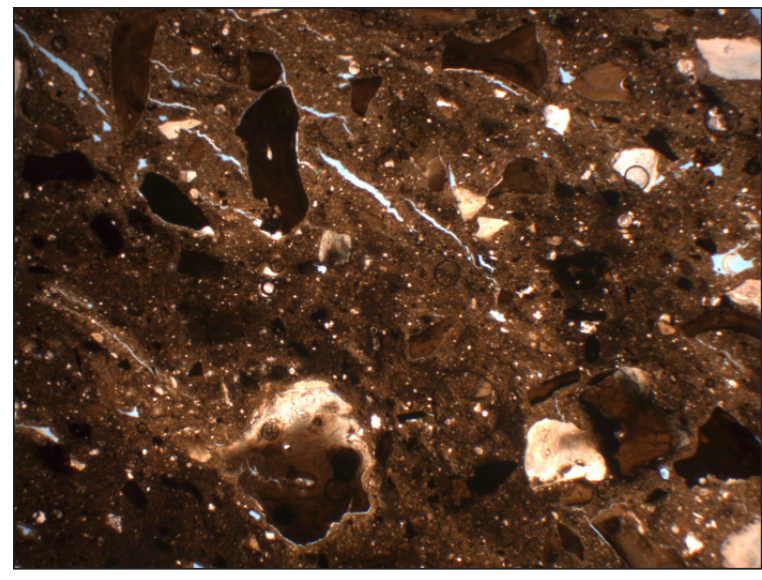

Figure 7-47. Paste of Thin Section No. 493-24 in plane light $4 \mathrm{x}$.

\section{Paste Groups}

The petrographic analysis of the 24 sherds identified six past groups based on the proportions of constituent elements present in the paste fabric.

\section{Paste Group 1: Light Sandy, Calcium- Rich Paste $(n=9)$}

Nine specimens (38\%) were classified as part of this paste group (Thin Section Nos. 86-9, 229A 12, 315-18, 316-19, 339-20, 347-21, 381-22, 49223, and 493-24). The group is defined on the basis of the percentage of bone, quartize, and calcium carbonate inclusions. The amount of bone ranged from 12.2 to 26.3 percent of the total points. The mean bone size for this group is $0.37 \mathrm{~mm}$ and ranged from 0.02 to $1.2 \mathrm{~mm}$. The amount of

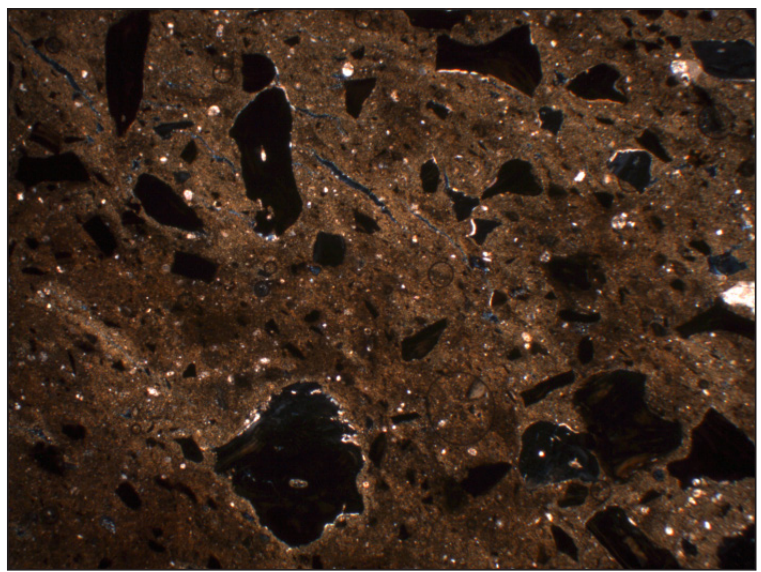

Figure 7-48. Paste of Thin Section No. 493-24 in cross-polar light $4 \mathrm{x}$.

quartz ranged from 0.65 to 5.93 percent of the total points. The quartz is uniformly fine silt size. Calcium carbonate, calcite, shell and/or fossils are common in all samples. This was the only paste group in which secondary calcite on the bone was found. Chert, chalcedony, and polycrystalline quartz was not present in this group.

\section{Paste Group 2: Grog Temper-Caddoan}

One sherd (4\%) was classified into this paste group (Thin Section No. 253-A 15). The primary distinguishing characteristic of the paste group is the presence of grog temper ( 8.08 percent of the total points). The mean percentage of quartz is 17.04 of the total points counted, and ranges from 13.13 to 21.67 percent. The paste is in general a 
fine, silty paste with numerous small muscovite rods.

Paste Group 3: Sandy Paste $(n=5)$; (Sand 14-24\%; Bone 5-20\%)

Five specimens (21\%) are part of this paste group (Thin Section Nos. 18-5, 26-6, 62-B 8, 12210, and 235-14). The ceramic fabric contains both bone and quartz aplastic inclusions. The mean bone temper percentage is similar to Paste Group $1(16.05 \%)$, as is the range $(5.65-23.71 \%)$. The size of the bone ranged from 0.04 to $1.2 \mathrm{~mm}$, with a mean bone size of $0.36 \mathrm{~mm}$. However, what sets this group apart from Paste Group 1 is the high mean quartz percentage (17.29\%) and range (12.10-23.85\%). The quartz was generally fine sand size. Chert, feldspars, and muscovite were common in all samples. Calcium components were absent. All samples had an active, striated b-fabric.

\section{Paste Group 4: Slightly Sandy, Calcium- Rich Paste (n=6); (Sand 6-12\%; Bone 6-12\%)}

Six sherds $(25 \%)$ fall into this paste group (Thin Section Nos. 10-A 1, 10-B 2, 11-A 3, 11-B 4, 62-A 7, and 229-B 13). In this group, the amount of quartz ranged from 5.11 to 12.62 percent of the total points. The quartz was generally silt size. Calcite and/or calcium carbonate was common in all samples. Shell and chert were also found in all samples. The amount of bone ranged from 6.16 to 20.97 percent. The size of the bone ranged from 0.02 to $1.2 \mathrm{~mm}$, with a mean bone size of 0.42 $\mathrm{mm}$.

Paste Group 5: Light Sandy, Dense Paste-No Calcite (Sand 3-4.5\%; Bone $10-23 \%$ )

Two sherds (8\%) were classified as Paste Group 5 (Thin Section Nos. 133-11 and 296-17).
In this group the percentage of quartz ranged from 3.88 to 4.39 percent. The quartz was generally silt size. The paste was very dense with few other mineral or lithic inclusions found. The percentage of bone ranged from 10.08 to 23.41 percent. The size of the bone ranged from 0.04 to $1.2 \mathrm{~mm}$, with a mean bone size of $0.29 \mathrm{~mm}$.

\section{Paste Group 6: Sandy, Chert, and Feldspar-Rich Paste-Unknown No} Bone

One specimen (4\%) was included in this paste group (Thin Section No. 253-B 16). In this group, the amount of quartz ranged from 11.62 to 41.4 percent. The quartz was generally silt size. The paste was very dense, with few other mineral or lithic inclusions found. No bone temper was noted in any of the thin sections.

\section{Discussion}

Macroscopic analyses of sherd samples provide information that is complimentary to fine-grained data obtained from petrographic analysis. For instance, observations regarding paste color, firing temperature, and metric data on thickness have significant relationships to clay sources, ceramic manufacture practices, and vessel function. Petrographic analyses do not address these aspects of pottery manufacture and use.

The analysis of sherd color coupled with experimental work in ceramic manufacture using locally available clay sources indicates that Navarro Formation clays that are yellow in color and rich in iron-oxides fire a brick red color that easily replicates the Doss Red ware type. A similar red surface effect can be achieved by adding a slip made of the Navarro clay onto a fabric made of another clay formation. Given that the Doss Redware is defined primarily on the basis of the color, and this color has been shown 
to correlate with the iron content of the clay employed, it may be necessary to more critically evaluate the validity of the Doss Redware type.

Experimental ceramic production using local clays has also shown that bonfires using mesquite and/or oak can reach and maintain sufficiently high temperatures $\left(850-950^{\circ} \mathrm{C}\right)$ to vitrify the clay body even when the vessel walls are 7-9 $\mathrm{mm}$ thick, as are many of the bone-tempered wares noted in this collection. Upon breakage, the cores of these sherds do retain a dark reduced center similar to the prehistoric and/or historic wares. Only experimental vessels with wall thicknesses measuring less than $5 \mathrm{~mm}$ in thickness could be fired consistently in bonfires to result in fully oxidized cores. The fact that some of the sherds from the $41 \mathrm{HY} 165$ collection measured at least $7 \mathrm{~mm}$ in thickness and had oxidized cores indicates that prehistoric potters could produce and maintain temperatures in the vicinity of $900^{\circ}$ $\mathrm{C}$ for sufficient time to fully oxidize the walls of the vessels they constructed.

Vessel form, let alone function, could not be defined from the small sherd fragments that were the subject of this analysis. Nonetheless, the breakdown of ceramic sherd thickness suggests some variability in either construction techniques or function. Four specimens range in thickness from 3.42 to $4.53 \mathrm{~mm}, 11$ specimens fall between 5.08 to $6.27 \mathrm{~mm}$, and the remaining nine range from 6.96 to $7.64 \mathrm{~mm}$ in maximum thickness. If vessel wall thickness correlates with functional requirements of the pottery, the above three groups suggest three distinct functional groups or potentially, three distinct manufacture traditions.

The six paste groups identified during the petrographic analysis vary based on the percentage of quartz and bone present in the fabric as well as the presence/absence of shell and chert. Quartz is present in six groups, but given its size, it is likely indicative of its presence in the parent clay rather than its purposeful inclusion as temper. The Group 3 specimens have quartz that is generally of fine sand size, suggesting perhaps that the clay source is different from the others in the sample. Group 1 and 4 specimens have similar percentages of bone and also contain shell, but the latter group has no chert in the fabric. This difference between the two groups may be indicative of different manufacture traditions or more likely differences in clay sources. The presence of grog in one of the sherd fragments (Group 3) is likely indicative of a Caddoan vessel fragment. Caddoan sherds often contain both bone in small proportions as well as ground sherd fragments as temper. Finally, three very dense sherds stand out and are classified into different groups based on the presence/absence of bone within the fabric. The Group 5 specimens have moderate amounts of bone temper, while the Group 6 specimen is devoid of bone, and the fabric contains moderate amounts of quartz. The dense fabric is definitely suggestive of a very different technological tradition from the other four groups, and while it shares affinities with the Group 6 sherd, it may be a technological or idiosyncratic variant of this tradition.

The comparison of the results of the macroscopic analysis with the petrographic work indicates major discrepancies in terms of the identification of inclusions and temper types. It is difficult to correctly identify temper macroscopically, and when feasible, only the larger inclusions can be identified with any degree of certainty. Smaller inclusions such as shell may be missed or misidentified as can be grog and burned calcite, which are often a constituent elements of the raw clays of the region. Therefore, it is suggested that future macroscopic analyses should exclude the identification of inclusions to 
reduce the disagreements with the results of the fine-grained petrographic analysis.

Finally, it is proposed that the fragments of the samples from 41HY165 analyzed for this study be submitted for Neutron Activation Analysis to the Missouri University Research Reactor (MURR). Since the receipt of these samples and their analysis, a number of samples of ceramic cherds and raw clays have been submitted to and analyzed by MURR from the state of Texas and South-Central Texas specifically. A number of intriguing sherd mineralogical groupings are emerging from these analyses that appear to correlate to manufacture traditions and/or clay formations and procurement localities. These new results may help establish or connect the specimens analyzed here with other technological traditions, and may relate the clays employed in their manufacture to regionally specific clay formations. 


\section{Chapter 8}

\section{Historic Assemblage}

\section{By Carole A. Leezer}

\section{Historic Ceramics}

Analysis of historic ceramics is often based on typologies established by the examination of seventeenth- and eighteenth-century artifacts. These typologies rely on ware classifications. While these classifications are reflective of the classification systems in use during the seventeenth and eighteenth centuries, they are, however, not reflective of the classification systems employed by individuals in the nineteenth century. By the nineteenth century, the success of the English ceramic industry resulted in the reduction of the range of wares available. Fine ware types such as tin-glazed earthenware and white salt-glazed stoneware were replaced with English white earthenware (Miller 1980:3-4). Classification of this ware by nineteenth-century manufactures and consumers shifted to a reliance on decoration type (Miller 1980).

In total, 24 historic-era ceramic pieces were examined for this project. Ceramic sherds were classified into creamware $(n=5)$, undecorated white earthenware $(n=12)$, decorated white earthenware $(n=2)$, milk glass $(n=2)$, pearlware $(n=1)$, and porcelain $(n=2)$. This classification system was utilized as it appeared to be most reflective of the classification system employed by the users of these examined ceramic sherds.

\section{Creamware}

Creamware is a hard paste/refined earthenware. Hard-paste earthenwares are the end product of highly fired, refined clays with vitreous glazes and wide-ranging decoration styles (Stothert et al. 1992). This ceramic classification is characterized as thin, hardfired, cream or pale yellow earthenware that was dipped into a clear glaze following a preliminary firing (Noël Hume 1969:125). Creamware glaze is a thin, watery, glass-based compound applied to ceramic vessels prior to firing. The glaze melts during firing and provides an impervious glassy layer with decorative qualities.

The development of creamware is considered to be the most important ceramic development of the eighteenth century (Noël Hume 1969:123). England's conquest of the world ceramic market was greatly enhanced by the production of creamwares beginning in the late eighteenth century (Miller 1980:4). By 1762, Josiah Wedgewood had perfected its appearance (Noël Hume 1969:124). It is from creamware that bluetinted pearlware evolved in the $1780 \mathrm{~s}$, then white earthenwares in the 1830s, and finally ironstone in the 1850s. Five sherds of creamware were recovered during the 1996-1998 field school excavations at $41 \mathrm{HY} 165$.

\section{Pearlware}

Pearlware evolved from the development of creamwares in the late eighteenth century. Its development was influenced by a decline in the demand for creamwares and the ability of potters to incorporate Cornish china clays into ceramic production. This allowed potters to develop a ceramic product that was very 
similar to high-end, hard-paste porcelain. The success of pearlware was further enhanced by the establishment of English tariffs against the importation of porcelain; in 1799, the tax rate on Chinese porcelain was over 100 percent. Pearlware is distinguishable from its creamware predecessor by the incorporation of a bluish tint in the glaze that produced a whiter, porcelainlike appearance (Miller 1980:14). Only one sherd was recovered from the 1996-1998 field school excavations at $41 \mathrm{HY} 165$.

\section{White Earthenware}

The majority of recovered historic ceramics from the 1996-1998 field school excavations at 41 HY165 are white earthenwares $(n=14) ; 12$ are undecorated, while two exhibit some type of decoration. White earthenware was first produced in England in the 1830s (Tennis 1997:2). When placed next to creamware, it appears dull white due to a lack of lead in the glaze (Moir 1987a:98). White earthenware generally has a whiter paste than its creamware predecessor (Moir 1987a:98), and is often lighter and more porous than its ironstone successor (Miller 1980:14). While white earthenware most commonly appears undecorated, it also occurs in molded forms and with transfer prints (Moir 1987a:98).

Two of the recovered white earthenware pieces exhibit decoration. One piece has portions of two brown-colored, circular designs, while the second has a brown band along its rim. The former piece is currently unknown, but the latter can be further classified as banded- or hotel ware. Prior to 1900, English ceramics were considered to be the finest available, with American products considered to be second-class imitations. In 1898, the American Potters Guild was formed to promote American-made tableware. By the early 1900s, American potters became famous for their sturdy and simply decorated vitreous earthenwares, which were commonly known as "Hotel China."

\section{Porcelain}

Porcelain ceramics result from the high firing of fine-grained clays containing the mineral kaolin (Tennis 1997:15). These translucent, vitrified ceramics were first developed by the Chinese and later copied by Europeans and Americans (Husfloen 2000:3). English porcelain was first manufactured at Chelsea, England, by Nicholas Sprimmons in 1744 (Mackay 2002:1314). Decorated porcelain is often relied upon as an economic marker because it was more expensive than similarly decorated white earthenwares (Miller 1991:15). Only one sherd of plain, undecorated porcelain was recovered during the 1996-1998 field school excavations of 41HY165.

\section{Milk Glass}

Two sherds of milk glass were recovered during the 1996-1998 field school excavations of 41HY165. While milk glass is considered to be glass and not a ceramic, it is included here as the two recovered sherds are clearly dinnerware pieces, and dinnerware milk glass is often confused with tableware ceramics to the untrained eye.

Milk glass originated in Venice, Italy, in the sixteenth-century. At this time, it was produced in various colors including yellow, brown, black, pink, and blue. While some of these colors still exist, the opaque, or milky color, remains the most popular. Although originating in the sixteenth century, the term "milk glass" was not used until relatively recently. Milk glass became very popular at the end of the nineteenth and the beginning of the twentieth century. During this time, the American Gilded Age, milk glass was synonymous with prosperity and wealth. 
However, this quickly changed, as milk glass manufactured during the Depression (1930s) was considered to be less elegant and delicate and seen as a product of the harsh time. As a result, milk glass manufactured during the 1930s and 1940s is considered to be of an inferior quality.

\section{Historic Glass}

In total, 798 pieces of historic-aged glass were recovered from 41HY165. These pieces were sorted into two major categories: shaped glass and window glass. Shaped glass includes all pieces of glass that can be attributed to bottles, jars, and vessels.

\section{Shaped Glass-Bottles, Jars, and Vessels}

The most reliable method of identifying historic bottle, jar, and vessel glass is by the dating of maker's marks. These marks provide information on approximate date and place of manufacture. In the absence of maker's marks, the manufacturing technique, labeling, and the color of the glass can provide clues to the approximate date of manufacture.

The shapes of bottles, jars, and vessels also provide information on its inferred use and possible contents. While the intended use of bottles and jars are fairly evident, vessel glass can be a little tricky. Vessel glass consists of tableware glass associated with the consumption of food and beverages and includes serving dishes, drinking glasses, but it also consists of decorative vessels such as vases (Jones and Sullivan 1989:127).

Glass color is often relied upon to provide approximate dates of manufacture and or use. Glass bottles most commonly appear in varying hues of green and aqua. Amber, olive green, and
Table 8-1. Ingredients Added to Glass to Produce Color (after Munsey 1970:37).

\begin{tabular}{cc}
\hline Ingredient & Color Produced \\
\hline Copper, selenium, gold & red \\
Nickel, manganese & purple \\
Chromium, copper & green \\
Cobalt, copper & blue \\
Carbon, nickel & brown \\
Iron & green, yellow \\
Selenium & yellow, pink \\
Tin, zinc & opal, milk glass \\
Iron slag & black \\
\hline
\end{tabular}

brown are natural colors that were produced during the early stages of glass manufacture in the United States and Europe. Most bottles produced prior to 1900 were aqua with varying hues of green and blue. Glass color is dependent upon the compounds present in the glass mixture (Munsey 1970:37). Glass compound ingredients and their resulting colors are present in Table 8-1.

Up until the mid-nineteenth century, dark glass, or blackglass, was the preferred type of glass container. This was based on the discovery that wines and spirits kept better in darker containers. By 1880, a demand for clear containers was spurred by the development of food preservation in glass containers (Munsey 1970:37). In answer to this demand, American manufacturers began adding manganese to their base glass mixtures in 1880 to produce a colorless, clearer glass. This manufacturing process continued until 1915, when the German source of manganese was cut off due to World War I. By 1916, American glass manufactures shifted to selenium, which was a more expensive decolorizing compound. Selenium was eventually replaced by arsenic around 1930 (Munsey 1970:55). 
Unknown to American glass manufacturers at the time, the use of manganese and selenium in glass compounds caused the glass to change color when it was exposed to ultraviolet sunlight. Glass that contains manganese turns an amethyst color when exposed to sunlight, while glass containing selenium turns a light amber color. How much the glass changes color depends on the amounts of manganese and selenium and how long the glass is exposed to sunlight (Munsey 1970:55).

\section{Shaped Glass Recovered from 41 HY165}

In total, 427 fragments of bottle glass, 27 fragments of vessel glass, and 47 fragments of unknown glass types were collected during excavations at 41HY165. Of the collected shaped glass fragments, 27 were of an olive or brown (dark olive amber) color. These colors can be found in a lot of different types of bottles from different eras, however, were more commonly used in the nineteenth century. Olive amber is a very uncommon color in any type of bottle after about 1890, and almost unknown after about 1900. After 1900 it is primarily found in wine/champagne bottles. Olive greens are very uncommon after about 1900 in most all types of American-made bottles except some liquor bottles (e.g., scotch) and wine and champagne bottles that still are made in olive colors (McKearin and Wilson 1978; Wilson 1972; Zumwalt 1980). The fragments therefore may be representative of the oldest glass types recovered from the site.

Of the total collected shaped glass fragments, 201 were of an amber color. Amber-colored bottles were very common during both the nineteenth and twentieth centuries. As such, these fragment types provide little dating or typing utility. Amber was and still is the most common color for beer bottles. This glass color provides the best light protection from the light wavelengths that are responsible for most photochemical reactions. Too much light (natural or artificial) causes beer to become "light struck," which results in a distinctive "skunky" off-flavor. The amber-colored glass sherds collected during excavations most likely represent beer bottles of an indeterminate age.

Only 21 fragments of aqua glass were collected. Aqua color in glass is a "natural" result of the iron impurities found in most sands. Aqua was a very common color in all types of American-made bottles prior to the 1920s and as far back as the early nineteenth century. No specific type or class of bottles was made with aqua glass, so this color type does not provide much utility in determining vessel types. One of the collected aqua glass fragments is of an old Coke bottle and displays the familiar hobble-skirt shape that is still used today. The first hobbleskirts bottles were patented on November 16, 1915 , and came in a variety of colors that included aqua.

Sixty-two fragments of green bottle glass were collected. A wide variety of green colors and shades of green can be found in just about any type or age of bottle, resulting in a poor diagnostic utility for this category of colors. The collected green-colored shaped glass fragments possessed no additional qualities, other than their determination as bottles, that would provide additional diagnostic clues. Very bright green is almost exclusively a twentieth-century feature and is not seen on bottles that date before this period. The collected green bottle fragments most likely represent green beer or soda bottles from the twentieth century.

Only one fragment of unknown red glass was recovered. Red-colored glass is highly uncommon, as true red glass is a result of the use of oxide of gold (Hunter 1950). True redcolored bottle glass can be primarily dated to the 
era between the 1840 s and early 1880 s; they are rarely seen before or after this date range. The collected red glass fragment is most likely from a bottle dating between 1840 and 1880 .

Only one fragment of white or "milk glass" attributed to non-dinner ware was collected during excavations (with the exception of those classified under ceramic/table ware). Milk glass, sometimes referred to as opal or white glass, was typically produced by the addition of tin or zinc oxide, fluorides (fluorspar), and phosphates (Dillon 1958; Kendrick 1968). Milk glass was used in the production of cosmetic and toiletry bottles, but is most commonly seen in the form of jar lid liners. John Mason patented the "Mason Jar" in 1858. These glass jars had a zinc lid with a rubber ring that effectively made the jar airtight. One problem facing canners, however, was keeping the food from touching the metal lid, which would spoil the food's taste. In 1859, Mason sold his Mason Jar patent to Lewis R. Boyd of the Sheet Metal Screw Company, who invented milk glass liners for the metal lids. The liners, when placed over the top of the glass bottle before the lid was put on, formed a barrier between the jar's contents and the metal lid. The collected milk glass fragment is a piece of one of these jar lid liners.

A total of 181 clear-colored shaped glass fragments were recovered during excavations at 41HY165. This color is the actually the absence of any color. Colorless glass was a goal of glass manufacturers for centuries, and was difficult to produce because it required the use of virtually impurity-free materials. It wasn't until the late nineteenth and early twentieth centuries that through the use of improved chemistry and glassmaking methods that colorless glass became easier and much cheaper to produce. Colorless glass has more utility in dating and typing than most other colored glasses, with the best dating reliability for bottles with manganese dioxide. Upon exposure to sunlight, glass with manganese dioxide will turn a light pink or lavender to moderately dark amethyst or purple color. As manganese was used as an additive to glass prior to 1915 , solarized glass with this color-hue can be dated to this period. Colorless glass bottles were relatively uncommon prior to the 1870 s but became quite common after the widespread use of automatic bottle machines in the mid- to late 1910s (Fike 1987; Kendrick 1968; Toulouse 1969). The majority of clear glass fragments are bottles, and noted among them is the bottom half of a Dr. Pepper bottle. Dr. Pepper was created in the 1880s by Charles Alderton of Waco, Texas, and first served around 1885, and was nationally marketed in the United States in 1904. The collected bottle fragment is characterized by embossed lettering stating "Good for Life" and a clock featuring hands pointing to 10,2 , and 4 o'clock. The "Good for Life" slogan was one used by the company during the 1940s. "Dr. Pepper Time," according to one promotion, was at 10, 2, and 4 o'clock. During World War II, a syndicated radio program, The 10-2-4 Ranch (later titled 10-2-4 Time), aired in the South and other areas where Dr. Pepper was distributed. Based on the bottle fragment's characteristics, the bottle can be generally dated to the 1940s-1950s (Wright 2006)

\section{Window Glass}

While the measurement of window glass collected from archaeological contexts has been used in the past to provide valuable cultural and architectural information (Moir 1987b, 1988), the amount of window glass collected from excavations at 41HY165 was determined not to meet the criteria establish by Moir for this type of artifact analysis. In total, 399 window glass sherds were collected from four different proveniences. Moir (1987b, 1988) contends 
that window pane thickness increased during the nineteenth century, and that important information concerning house construction can be derived from the study of window pane thickness. He developed an equation that dates the manufacture of window glass based on the mean thickness in millimeters:

Manufacture date $( \pm 7 \mathrm{yrs})=$

$84.22 \mathrm{x}$ (glass thickness in $\mathrm{mm})+1712.7$

Moir asserts that this method would work best for sites that were occupied for short durations (Moir 1987b, 1988), providing information on initial construction dates. As there was no visible evidence of a historic structure that could have been located at one time in the area of the excavations associated with 41HY165, no effort was put forth to date the window glass and thus establish a date of initial construction. In total, 399 shards of window glass were collected during the 1996-1998 field school excavations at 41HY165. The window glass recovered from the excavation at the site may be the result of dumping window glass trash, and not from the construction of a historic structure at the site.

\section{Historic Building Materials}

In total, 228 artifacts classified as Building Materials were collected during excavations at 41HY165. This classification includes brick, concrete, mortar, asphalt plaster, and wattle and daub. The collected brick $(n=95)$ primarily consisted of small fragments less than $1 \mathrm{~cm}$ in size. While bricks are often overlooked by archaeologists as a diagnostic artifact class, bricks do possess several diagnostic characteristics. Despite the small size of the recovered brick fragments, 25 fragments were identified as being manufactured by hand. Handmade bricks are manufactured from clay with water content between 20 and 30 percent. The clay is then molded in a wooden or iron clad mold (Gurcke
1987:15). Sand, water, oil, lard, or even soap is then used as a lubricant to allow the molded brick to slip free of its mold. Handmade bricks require up to three weeks for drying, depending upon the water content of the clay and the weather and humidity levels (Gurcke 1987:26). Bricks were predominately made by hand until the late eighteenth century. By the mid-nineteen century, bricks were increasingly being made via machine, and by the beginning of the twentieth century the entire process had been mechanized (Gurcke 1987:84).

Besides the brick fragments described above, 110 fragments of concrete were also collected during excavations. Concrete is a versatile building material composed of a mixture of sand, gravel, crushed stone, or other coarse materials, that are bound together with lime or cement. This mixture undergoes a chemical reaction and hardens when water is added. Concrete was first introduced to the New World by the Spanish in the first decades of the sixteenth century (Gaudette and Slaton 2007). It did not gain popularity in US building construction until the late nineteenth century (Gaudette and Slaton 2007). Unfortunately, the collected concrete fragments did not possess enough characteristic to provide time-diagnostic information. The collected samples most like date to the early twentieth century, when this type of building material gained greater popularity.

In addition to the above-described building materials, insignificant amounts of mortar, asphalt, and plaster were collected. While the recovery of these types of artifacts is usually indicative of a structure, no foundation or other types of building material (roofing shingles, wooden clapboard, etc.) were collected. The small amount of building material supports the contention that a structure was once located in this area. The collected material, therefore, may 
be the result of a trash dump in modern or recent historic times.

\section{Historic Metal}

\section{Bottle Caps}

Bottle caps are a type of metal closure originally designed to be pressed over and around the top of a glass bottle, grabbing a small flange on the bottleneck. They are usually made of steel with plastic backing. The crown cork was patented by William Painter on February 2, 1892 (U.S. Patent 468,258). Originally the cap had 24 teeth and a cork seal with a paper backing that would prevent contact between the contents and the metal cap. The version that is currently utilized has 21 teeth and a plastic backing. To open these bottle tops, a bottle opener is generally required; however, a "twist-off" version is also currently used. The twist-off version is pressed around screw threads instead of a flange located on the bottleneck. This bottle cap can be taken off by merely twisting the cap, eliminating the need for an opener (Lief 1965).

In 1962, Ermal Cleon Fraze of Dayton, Ohio, invented an integral rivet pull tab opener for can beverage containers. This pull tab opener, also known as a ring pull, utilized an attached ring at a rivet that was used for pulling, enabling a portion of the can top to be completely removed and discarded. He received U.S. Patent No. 3,349,949 for his design in 1963, and the design was introduced on Iron City Beer cans. The first soft drinks to be sold in all-aluminum cans were RC Cola and Diet Rite Cola, made by Royal Crown Cola in 1964. A stay-on-tab was designed by Daniel F. Cudzik for Reynolds Metals Co. aluminum cans in 1975. This design reduced injures from open edge cans and reduced litter from disposable pull-tabs. The redesigned mechanism uses a lever to depress a scored opening of the can top, which folds underneath the top of the can and out of the way of the resulting opening. Mountain Dew introduced a "wide mouth" version of this stay-on-tab in the late 1990s (Keen 1982).

In total, 147 bottle caps (whole or fragments) were collected during excavations at 41HY165. Of these, two were identified as pull tabs, one as a stay on tab, and one as a twist-off crown cap. As the vast majority of the bottle caps were highly eroded, determining additional twist of crown caps was not possible. The collected bottle caps most likely date to the early to mid-twentieth century. The pull tabs can be dated to the 1960s, and the stay-on-tab to the 1970s until present.

\section{Nails}

Nails are used in the construction of dwellings, buildings, barns, fences, and outbuildings, and therefore, are often relied upon in the interpretation of historic sites. They enter the archaeological record through various means, such as unintentional discard during construction and reuse, discard resulting from loosening, and intentional discard occurring during demolitions (Jurney 1988). As part of the archaeological record, they provide valuable information on building chronology, dating of additions, and changes and maintenance to structures. There are three main classifications of nails: hand-wrought, square-cut, and round (wire) nails (Nelson 1968).

The only nails available in the United States throughout the seventeenth and most of the eighteenth century were hand-wrought nails; however, they continued to be used into the nineteenth century. The heads of hand-wrought nails varied depending upon their intended use with the rose-head the most commonly used variety. L-headed nails were generally used as flooring and trim nails, while T-headed nails, 
consisting of a flat disc head, were generally used for flooring (Noël Hume 1969:252-254). Handwrought nails were in common use in the United States until the 1880 s. Square-cut nails were introduced in the 1830s and gradually replaced hand-wrought nails in popularity (Nelson 1968). Square-cut nails were mass-produced cheaply, and it soon became more cost effective to buy these mass-produced nails in nearby centers of commerce than to make them by hand.

The square-cut nail was an American invention that was first produced around 1790. These types of nails were sliced from sheet iron by machine, and their heads were individually shaped by the hand hammering. Square-cut nails with hand-hammered heads were popular in the United States between 1790 and 1825. By 1815 the heads of square-cut nails were also made by machine. The machine-made headed squarecut nail eventually replaced the previous handhammer headed nail in popularity by 1825 , and the use of this type of nail continues to the present (Nelson 1968).

A round-shafted, steel-wire nail was perfected in Europe in the mid-nineteenth century. By the 1850 s, round-wire nails were manufactured in New York (Noël Hume 1969:252-254). While manufacturing began in the early 1850 s, roundwire nails did not become popular until the 1890s. While the wire nail is the most popular type of nail used today, square-cut nails continue to be used for flooring, boat carpentry, and masonry needs (Nelson 1968).

In total, 2,249 nails were collected during excavations at 41HY165. Of these, 2,163 were identified as round (wire) nails and 86 as square nails. Of the collected square nails, only one could be classified as hand wrought; 68 were classified as machine-cut square nails, and 18 were classified as unknown square nail types.

\section{Hardware-Wire}

Seven pieces of wire were collected during excavations at 41HY165. Of these pieces, four were classified as plain wire, while three were classified as barbed wire. No single item has made a greater impact on the history of the American West than the invention and implementation of the barbed wire. A man named Michael Kelly is credited with the invention of barbed wire in 1868 (Clifton 1970); however, the idea of using wire and barbed wire for fencing livestock had been around for several years. In 1874, Joseph Gliddens, an Illinois farmer, improved Kelly's invention creating a simple wire barb locked on to a double-strand wire. This design was cheap, easy to mass produce, and it soon spread across the Plains, forever changing its landscape (Glover 1969; Hagemeir 2001). The identified barbed wire appear to be of the hanging-bar variety (Clifton 1970:30).

\section{Hardware-Builder's Hardware}

Three pieces of metal hardware were collected during excavations. These pieces were classified as builder's hardware, and include a door hinge, a door key/knob plate, and a cabinet hinge.

\section{Munitions}

While no firearm pieces were recovered during excavations at 41HY165, a number of munitions remains were recovered. Expended firearm cartridges (metallic cartridge cases) are common components of many post-1850s sites and are very useful as temporal markers. The self-contained metallic cartridge is a relatively recent invention, having been perfected only within the last 125 years. In total, 26 collected metal pieces were classified as munitions. Of these, three pieces were identified as .22-caliber bullet tips, one piece was identified as a hand- 
wrought lead bullet, and four were identified as 16-gauge shotgun cartridge shells. Two of the shotgun cartridges were identified as Winchester Repeating No. 16 gauge shot, manufactured between 1896 and 1938 (Logan 1959).

\section{Household}

Two metal items collected during excavations were classified as Metal-Household. These items were a large serving spoon and a straight pin.

Tools

Three collected items were classified as Metal-Tools. These pieces were a large metal file and two fish hooks.

\section{Other}

Items that were collected and classified as Metal-Other include pieces of aluminum foil, which was introduced in 1947 (Panati 1987:113). Four of the collected pieces appear to be foil bottle cap liners. Objects identified as Scrap or Unknown are artifacts that cannot be identified as to type or function. Many of these artifacts may be fragments of decomposed nails or other metals.

\section{Personal Items}

Twenty-two objects were collected during excavations of 41HY165 that were classified as Personal Items. These items were further divided into: buttons, clothing related, and other items. Clothing-related items included one metal buckle and metal grommets and snaps. Items designated as other included an eyeglass ear stem, the wooden handle of a steak knife, a simulated wood grain plastic handle of a fishing spinning reel, and a fragment of basket fiber.
Of the six buttons recovered during excavations, three were plastic, two were made of shell, and one was made of bone. The nineteenth century marked a technological change in the manufacturing of buttons that allowed for the inclusion of more varieties of materials, and more variation of styles (Epstein and Safro 1991:76). Shell buttons, which were once made by hand, were now machine made. By 1870, synthetic plastic and celluloid buttons were introduced, replacing those manufactured with bone, ivory, tortoiseshell, and marble (Epstein and Safro 1991:78). The rich and colorful buttons of the eighteenth century were replaced by small glass or jeweled buttons on men's fashions. Buttons for women, however, became more ostentatious, resembling brooches and decorative jewels. These button types were manufactured from porcelain, pearls, and silver (Epstein and Safro 1991:80). Most buttons, however, were of a utilitarian nature. While the Sears Roebuck catalog for 1897 included two styles of fancy dress buttons, most of their buttons were intended for practical use. These included plain metal buttons for pant flies and bone buttons for underwear, and plain shell buttons that were sold by the gross (Israel 1968:319-320). The collected plastic buttons most likely represent those used on either men's or women's garments. The larger embossed creamcolored plastic button most likely was used on a women's outer garment. The collected small bone button was most likely used on a women's undergarment. Shell buttons are non-iridescent buttons manufactured from freshwater shells. The freshwater pearl industry was introduced to America by John Boepple, a German immigrant, who discovered freshwater mussels near Muscatine, Iowa. By 1890, high import taxes forced reliance upon domestic sources of shell buttons, and Iowa became the main producer, with over 200 button factories emerging in the state by the turn of the century. Shell buttons in the United States were manufactured for use as 
fasteners for shirts, underwear, and children's clothing (Pool 1987:283). The two shell buttons collected during excavations at 41HY165 were most likely used in this capacity. Several metal grommets and snaps were also collected $(n=10)$, and most likely represent items typically found on work clothing.
Additional items collected but classified as Other and not included within the Personal Item classification included one piece of string, and 37 pieces of plastic that included fragments of fishing line, vinyl, a whisky bottle cap, a sprinkler head, a seal, and several unknown plastic types. 


\section{Chapter 9}

\section{Botanical And Microfossil Analysis}

\section{Editor's Note}

A single 1x 1-m test unit (XU 3) was excavated at 41HY165 in association with the intensive archaeological survey and subsurface testing investigations of the APE of the SLAERP (Leezer et al. 2011). This test unit was excavated in an attempt to identify intact, stratified, and/ or clearly definable cultural components. Data from this test unit is used to develop detailed information regarding the nature of deposits in areas not previously subjected to extensive excavation. XU 3 was excavated to a depth of $150 \mathrm{cmbs}$. A 5-gallon bucket of soil was collected from each excavated level. The matrix was water screened through nested $1 / 4$-inch and $1 / 8$-inch screens in order to recover fine-sized cultural materials and faunal remains. A 4-liter bulk soil sample was also collected from each unit level. These samples were processed by flotation for the recovery of small fauna, plant remains, and lithic debris that would pass through the $1 / 8$-inch screen. These flotation samples were then turned over to Kandace Hollenbach for botanical analysis.

Eighteen burned rock samples were submitted to AEL at Texas A\&M University to recover and identify plant microfossil remains from the surfaces of the rocks. These rocks were selected from five features, Ringstaff's archaeological Zone 1/97, and a level in Unit 11 with dated bison bone. All of the rocks were chosen from levels that correspond to AUs. Out of the 18 samples, only 12 contained plant microfossils that included starch granules and phytoliths. Dr. Timothy E. Riley conducted the analysis.

Four of the burned rocks submitted for analysis were from archaeological Zone 1/97. This occupational zone was encountered across Units 3 and 8 between 125 and $135 \mathrm{cmbs}$, and four burned rocks were selected from this zone for analysis by AEL. Two of the four rocks contained starch granules, one from Unit 3 and one from Unit 8. The rock from Unit 3 had three starch granules, two of which resemble geophytes, while the remaining one resembles grass. The rock from Unit 8 had one granule that is consistent with yucca. Two rocks were also submitted from Unit 11, Level 7, and both of these contained starch granules. Starch granules from these rocks were consistent with Araceae family plants, while three of the granules could not be identified as to type.

\section{Plant Remains from 41HY165, a Prehistoric Site in Hays County, Texas}

\section{By Kandace D. Hollenbach}

\section{Introduction}

The analysis of plant remains is one avenue of research into a group's foodwaysthe procurement, production, preparation, consumption, display, storage, and discard of food. These practices vary by economic, social, and political situation, and thus give us an 
entry to study the cultural traditions of a group (Johannessen 1993).

This report details the analysis of carbonized plant remains from site 41HY165, a Late Paleoindian through Historic period site in Hays County, Texas. The site is located below the Balcones Escarpment, placing it in a prime ecotonal position between the Edwards Plateau to the west and the Blackland Prairies to the east. The former is characterized by oak (Quercus spp.) and juniper (Juniperus sp.) savannah with an understory of grasses. The Blackland Prairie is dominated by tall grass species, with oaks and mesquite (Prosopis sp.) on uplands and slopes, and denser forests of oak, pecan (Carya illinoinensis), walnut (Juglans sp.), hackberry (Celtis sp.), sumac (Rhus sp.), bald cypress (Taxodium distichum), and cottonwood (Populus sp.) in rich stream valleys (Ricklis and Collins 1994:33).

Perhaps more importantly, 41HY165 is situated on the shore of Spring Lake, and very close to the intermittent drainage Sink Creek. While Sink Creek may have been a seasonal source of water in the past, the numerous springs underlying present-day Spring Lake would have supplied water from the Edwards Aquifer year-round (Eckhardt 2010). The springs surely contribute to the long sequence of occupation at the site.

Previous investigations at Spring Lake, at sites such as $41 \mathrm{HY} 160$, indicate a long sequence of serial occupations associated with the springs, beginning at least in Clovis times and extending to Spanish contact (Jon C. Lohse, personal communication 2011). Excavations at 41HY165, performed by SWT field schools in the summers of 1996, 1997, and 1998, yielded over 92,000 artifacts and similarly demonstrate periodic occupation of the southern side of Spring Lake from the Late Paleoindian through the Historic period.

Over the three field seasons, 11 test units were excavated, ranging in size from $1 \mathrm{~m}^{2}$ to $4 \mathrm{~m}^{2}$, and ranging in depth from $25 \mathrm{~cm}$ to 280 cmbs. The plant remains analyzed here derive from XU 3 excavated adjacent to the previously excavated field school test units. The samples include a column of 4-liter flotation samples collected from 15 levels of the unit, as well as corresponding waterscreen samples from those levels (Table 9-1; Appendix A).

Uncarbonized plant materials are unlikely to be preserved outside of dry rock shelters and caves in the relatively moist, acidic soils of eastcentral Texas, even from relatively recent historic contexts (Reitz and Scarry 1985:10; Yarnell 1982). Therefore, only carbonized plant remains are considered here to be part of the archaeological record, while uncarbonized plant materials are generally assumed to be modern contaminants that reflect the present-day local habitat. One exception is hackberry, the stones of which can be preserved without carbonization due to their high calcium carbonate content (Wang et al. 1997).

\section{Methods}

The flotation and waterscreen samples were processed by CAS at Texas State in San Marcos. Personnel from CAS sorted plant remains and other materials from the samples, and the plant remains were sent to the ARL at The University of Tennessee, Knoxville, for analysis. CAS personnel divided the flotation samples into materials captured in nested 1/4-inch and 1/8-inch screens, and "light" fraction materials collected in fine mesh. The waterscreen samples were collected in $1 / 4$-inch and $1 / 8$-inch mesh. 


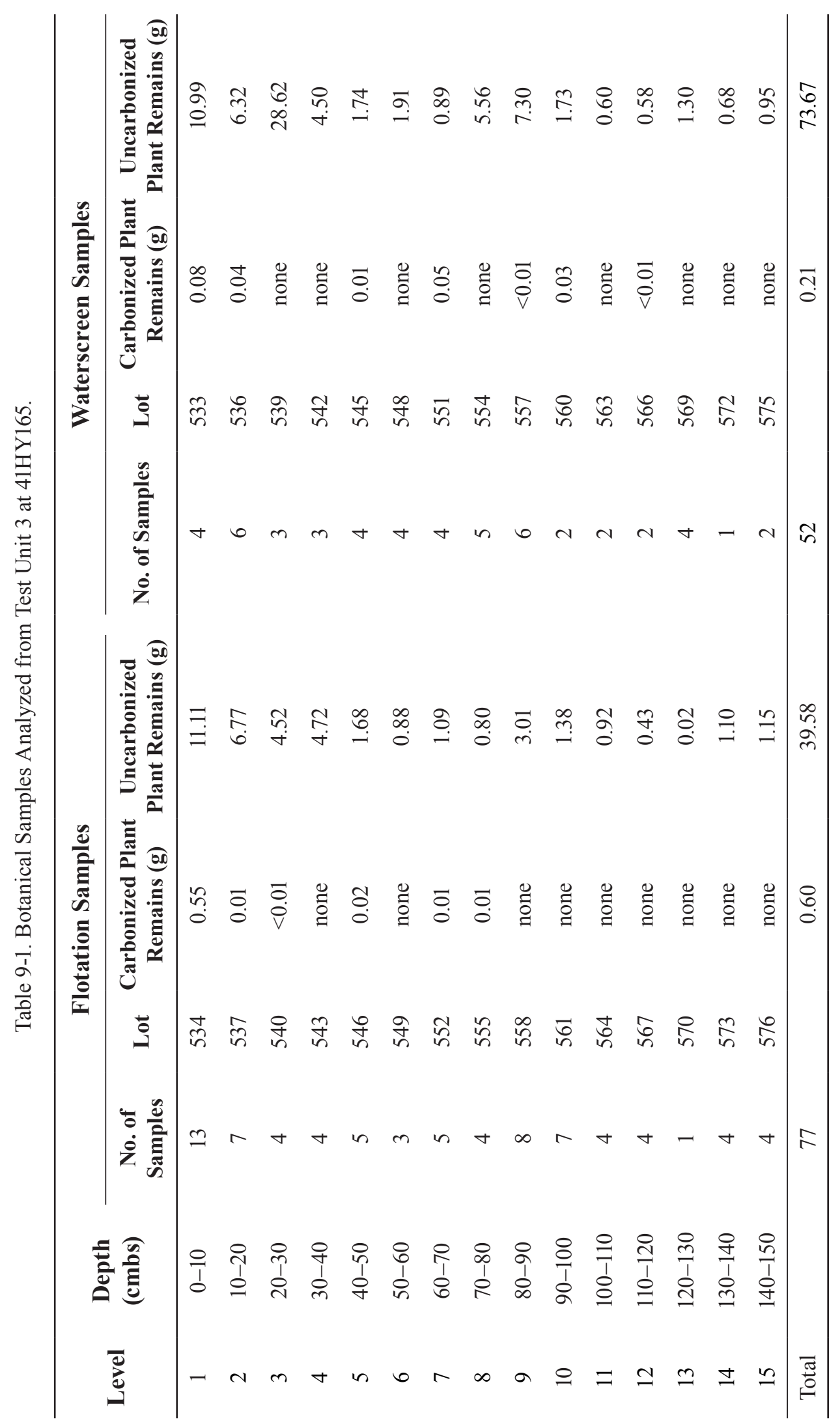


The size-graded samples were weighed and examined using a stereoscopic microscope with 10-40x magnification. Shell, bone, lithics, burnt clay, and plant remains were sorted from the larger-sized samples (1/4-inch and 1/8-inch flotation and waterscreen samples). The light fraction samples were first passed through nested geologic sieves. Materials greater than $2.00 \mathrm{~mm}$ were sorted into categories such as shell, bone, and plant remains. Plant remains were further identified to the lowest possible taxonomic level. Materials less than $2.00 \mathrm{~mm}$ in size were scanned for seeds and plant remains not represented in the larger fraction. If present, acorn remains were pulled from the $1.40-\mathrm{mm}$ sieve to mitigate biases against their preservation. All materials were then counted and weighed, although shell was only weighed. Plant identifications were made with reference to Martin and Barkley's (1961) Seed Identification Manual and the PLANTS Database (U.S. Department of Agriculture, Natural Resources Conservation Service [USDA-
NRCS] 2011), as well as modern comparative specimens housed at the ARL.

\section{Results}

The flotation and waterscreen samples from the 15 unit levels yielded $0.81 \mathrm{~g}$ of carbonized plant remains, only $0.18 \mathrm{~g}$ ( 22 percent) of which is wood (see Table 9-1). The non-wood plant materials include nuts, fruits, and miscellaneous taxa (Table 9-2; see Appendix E for a listing of plant taxa recovered from each sample).

\section{Nuts}

Nut taxa recovered from the samples include acorn, hickory, pecan, and walnut (see Table 9-2). None are represented by more than two definitive fragments, but walnut significantly outweighs the others, in part because of its robust nature. In comparison, pecan is thinner shelled, and acorn even thinner and more fragile. In general, acorn shell is often underrepresented at archaeological sites when compared with members of the Walnut

Table 9-2. Plant Taxa Recovered from 41HY165 Column Samples.

\begin{tabular}{|c|c|c|c|c|c|c|}
\hline \multirow{2}{*}{ Category/Taxon } & \multirow{2}{*}{ Taxonomic Name } & \multirow{2}{*}{ Seasonality } & \multicolumn{2}{|c|}{ Flotation } & \multicolumn{2}{|c|}{ Waterscreen } \\
\hline & & & Count & Weight (g) & Count & Weight (g) \\
\hline \multicolumn{7}{|l|}{ Nuts: } \\
\hline Acorn shell & Quercus sp. & Fall & & & 2 & 0.00 \\
\hline Hickory & Carya sp. & Fall & & & 1 & 0.00 \\
\hline Pecan & Carya illinoinensis & Fall & 2 & 0.02 & & \\
\hline Pecan cf. & Carya illinoinensis $\mathrm{cf}$. & Fall & 1 & 0.00 & & \\
\hline Walnut & Juglans sp. & Fall & 2 & 0.37 & & \\
\hline Walnut family & Juglandaceae & Fall & & & 4 & 0.07 \\
\hline \multicolumn{7}{|l|}{ Fruits: } \\
\hline Hackberry & Celtis sp. & Fall & 5 & 0.03 & 12 & 0.14 \\
\hline \multicolumn{7}{|l|}{ Miscellaneous: } \\
\hline Pitch & & & & & 1 & 0.00 \\
\hline Wood & & & 3 & 0.18 & 4 & 0.00 \\
\hline Total & & & & 0.60 & & 0.21 \\
\hline
\end{tabular}


family, which include walnut, hickory, and pecan (Yarnell and Black 1985:97-98).

Hickory nuts and acorns are routinely recovered from sites in the Eastern Woodlands, as both were important staples in the diets of prehistoric peoples in the region (Gardner 1997; Scarry 2003; Yarnell and Black 1985). Acorns were used widely throughout North America by prehistoric and historic native groups, as various oak species enjoy a wide distribution throughout the continent (Hammett 1997). The range of hickories is more limited, however. Central Texas is generally the western limit of the geographical distribution of most hickories (Hammett 1997:203; USDA-NCRS 2011), but it lies in the heartland of the natural distribution of pecans, which are generally limited to the Mississippi Valley and its western tributaries (Hall 2000:Figure 1). Central Texas is also the western extent of black walnut (Juglans nigra), but the eastern limit of little walnut $(J$. microcarpa) and Arizona walnut (J. major) (USDA-NCRS 2011).

All of the trees are masting, producing significant quantities of nuts every two to three years. The various nuts would have been collected in autumn and could be stored and eaten through winter, until fresh plant foods became available again in spring. Because of their high yields, nutritive qualities, and ready storability, acorns, walnuts, pecans, and hickory nuts were significant foodstuffs for foragers in this region and the greater Eastern Woodlands (Gardner 1997; Hall 2000; Hammett 1997:203205; Scarry 2003).

Despite their similarities, the various nuts serve very different dietary roles and require significantly different processing techniques. Hickory nuts are high in fat and protein (U.S. Department of Agriculture, Agricultural Research
Service, Nutrient Data Laboratory [USDA-NDL] 2004), and were often crushed and boiled down to make an oil or milk. The resulting liquid could be drunk as a beverage or used in stews or porridges (Carr 1895:171, 182-183; Kuhnlein and Turner 1991:209; Swanton 1946:265). Pecans have a similar nutrient content, but are not likely to have been crushed and boiled. They have much thinner and less convoluted shells, making it much easier to pick the nutmeats directly from the shell than other species of hickory. In addition, pecans have a thin, woody septum between the two halves of the nutmeat that floats in water; fragments of this bitter, woody septum would effectively spoil the liquid (Scarry 2003:61). Similarly, walnuts cannot be boiled and processed in bulk like hickory nuts because the bitter outer hull remains attached to the nutshell and spoils the liquid. Instead, walnut meats must be picked by hand from the shells, leading to higher processing costs that may have discouraged greater use of these flavorful nuts (Gardner 1997; Talalay et al. 1984).

In contrast to walnuts, hickory nuts, and pecans, acorns are high in carbohydrates and therefore served as a starchy component to the diet (USDA-NDL 2004). They are also high in tannins, which are often removed by leaching with successive changes of boiling water. After leaching the tannins, the nutmeats were commonly ground into a meal and subsequently made into a mash or bread (Carr 1895:172; Densmore 1974:320; Kuhnlein and Turner 1991:200-2001; Palmer 1871:409-410).

The collection of nuts requires few implements other than baskets or bags to carry loads back to camp, but may demand a significant labor investment, particularly for groups whose diets include considerable quantities of nuts. This is certainly true for native groups in California, for whom acorns were a staple food. "[A]11 competent family members, male and female, 
and adult and child" (Jackson 1991:303-304) participated in collecting acorns, primarily to harvest as many as possible before birds and animals did. Hickories, pecans, and oaks tend to grow in stands or groves, but walnuts grow as solitary trees, making collection of large quantities of walnuts more difficult (Scarry 2003:64).

Gatherers more likely brought collected nuts back to camp instead of processing them in the field. While field-processing would allow gatherers to bring larger quantities of nutmeats and lesser quantities of low-utility nutshell back to camp, the time required to process nuts in the field prohibits this (Metcalfe and Barlow 1992). Bettinger and colleagues (1997) estimate that gatherers would have to travel one-way distances of roughly $50 \mathrm{~km}$ to make field-processing of acorns worthwhile. Since oak, hickory, pecan, and walnut trees are common in the plant communities in the vicinity of 41HY165, the occupants almost certainly would have processed nuts at the site.

While all family members were enlisted to collect nuts, ethnographic accounts indicate that processing fell primarily to women (Jackson 1991). Therefore, features and implements used to process nuts, such as roasting/parching features, nutting stones, and mortars, were likely the domain of women. To the extent that processing stations were fixed loci on the landscape, clusters of food-processing features and artifacts, as well as stands of highly productive trees, likely figured prominently in gatherer's mental maps of the landscape (Jackson 1991).

\section{Fruits}

Carbonized fruit remains recovered from the samples are limited to hackberry seed fragments (see Table 9-2). Hackberry seeds present an interesting interpretative dilemma. Due to their high calcium carbonate content (Wang et al. 1997), uncarbonized hackberry seeds may be preserved in archaeological sites. However, the trees produce significant numbers of fruits that, at the end of the season, leave significant quantities of seeds on the ground. Therefore, it is prudent to consider uncarbonized hackberry seeds to be modern inclusions. The four uncarbonized specimens from the flotation samples and 25 from the waterscreen samples (see Appendix A) are thus treated as modern contaminants.

Carbonized hackberry seeds are another matter. The five fragments recovered from flotation samples and 12 from waterscreen samples may have been carbonized by anthropogenic efforts, rather than natural fires. Hackberry seeds have also been recovered from other prehistoric sites in Texas, such as the Vargas site in Edwards County, the Lower Pecos rockshelters in southwest Texas (Dering 2006), and the nearby sites of Zatopec (41HY163; Hollenbach 2011a) and 41HY160 (Hollenbach 2011b).

Although small, hackberries are good sources of nutrients such as sugar and calcium (Dering 2006). These small berries can be eaten fresh (Niethammer 1974:72; Peterson 1977:194) or pounded into a meal. This meal can then be shaped into cakes and dried for use in the winter (Niethammer 1974:72), used to flavor meat (Kindscher 1987:242; Kurz 1997:74; Yanovsky 1936:19), or mixed with parched corn and fat (Dering 2006; Yanovsky 1936:19).

Hackberries ripen in fall, but often persist on trees through mid-winter (Kennedy 1990; Krajicek and Williams 1990). The trees grow in a variety of settings, but prefer alluvial soils and disturbed grounds (Radford et al. 1964). 


\section{Miscellaneous Taxa}

The few miscellaneous plant remains recovered from the samples provide little information. The one fragment of pitch, or amorphous vitrified material, may represent carbonized tree resin, or some other material high in sugar or starches. The recovered wood specimens all appear to be hardwoods, although more detailed identifications were not attempted.

\section{Comparison by Context}

The vertical nature of the column samples allows for some evaluation of possible changes in plant deposition through time. The standard volume collected for each flotation sample also enables us to directly compare the raw data. A brief review of the materials recovered by level indicates that the majority of the carbonized plant remains derive from the uppermost level, and the lower levels often yielded no carbonized plants (Table 9-3). This suggests that preservation decreases to some degree with depth at the site. However, recovery of plant remains from general site contexts is often low, particularly when compared with contexts such as features and middens. The levels where carbonized plant remains were recovered, namely Levels 1, 2, 3, 5, $7,8,9,10$, and 12 , likely correspond to deposits that reflect more frequent and/or more intensive use of the site.

Similarly, the recovery of uncarbonized plant materials decreases with depth. This is expected, as the upper humic layers generally include greater quantities of organic debris, such as leaf litter, twigs, etc. It is also interesting to note that uncarbonized chinaberry was recovered from flotation samples up to a depth of $20 \mathrm{~cm}$

Table 9-3. Carbonized and Uncarbonized Plant Remains from XU 3.

\begin{tabular}{|c|c|c|c|c|c|c|c|}
\hline \multirow[b]{2}{*}{ Level } & \multirow{2}{*}{$\begin{array}{l}\text { Depth } \\
\text { (cm) }\end{array}$} & \multicolumn{3}{|c|}{ Flotation Samples } & \multicolumn{3}{|c|}{ Waterscreen Samples } \\
\hline & & $\begin{array}{c}\text { Carbonized } \\
\text { (g) }\end{array}$ & $\begin{array}{c}\text { Uncarbonized } \\
\text { (g) }\end{array}$ & Chinaberry & $\begin{array}{c}\text { Carbonized } \\
\text { (g) }\end{array}$ & $\begin{array}{l}\text { Uncarbonized } \\
\text { (g) }\end{array}$ & Chinaberry \\
\hline 1 & $0-10$ & 0.55 & 11.11 & yes & 0.08 & 10.99 & yes \\
\hline 2 & $10-20$ & 0.01 & 6.77 & yes & 0.04 & 6.32 & yes \\
\hline 3 & $20-30$ & $<0.01$ & 4.52 & & & 28.62 & yes \\
\hline 4 & $30-40$ & & 4.72 & & & 4.50 & yes \\
\hline 5 & $40-50$ & 0.02 & 1.68 & & 0.01 & 1.74 & \\
\hline 6 & $50-60$ & & 0.88 & & & 1.91 & yes \\
\hline 7 & $60-70$ & 0.01 & 1.09 & & 0.05 & 0.89 & \\
\hline 8 & $70-80$ & 0.01 & 0.80 & & & 5.56 & yes \\
\hline 9 & $80-90$ & & 3.01 & & $<0.01$ & 7.30 & yes \\
\hline 10 & $90-100$ & & 1.38 & & 0.03 & 1.73 & \\
\hline 11 & $100-110$ & & 0.92 & & & 0.60 & \\
\hline 12 & $110-120$ & & 0.43 & & $<0.01$ & 0.58 & \\
\hline 13 & $120-130$ & & 0.02 & & & 1.30 & \\
\hline 14 & $130-140$ & & 1.10 & & & 0.68 & \\
\hline 15 & $140-150$ & & 1.15 & & & 0.95 & \\
\hline
\end{tabular}


(Level 2), and from waterscreen samples up to 90 cmbs (Level 9). Chinaberry (Melia azedarach) was introduced to the United States circa 1787 by Andre Michaux, who founded a botanical garden in Charleston, South Carolina (Gardner 1986:F-3). The tree is very weedy in nature and quickly naturalized throughout the southern United States, but is also commonly used as an ornamental (Bonner 2008; Radford et al. 1964). Its recovery from the upper two levels of the flotation column suggests the relatively recent nature of the uncarbonized remains, and perhaps the historic nature of the upper deposits. The presence of chinaberry in deeper levels in the waterscreen samples most likely simply reflect the open nature of the test unit, into which uncarbonized remains may accidentally fall during the course of excavation.

\section{Discussion}

The plant remains recovered from XU 3 at $41 \mathrm{HY} 165$ indicate that, among other activities, the site's occupants gathered and processed nuts, such as acorns, hickory nuts, pecans, and walnuts, and wild fruits such as hackberries. These foodstuffs would have been gathered in fall; collection of nuts in particular would have been an important activity, as these dietary staples are also quickly eaten by wildlife. Hackberries, however, often persist on trees through early winter. These resources can be readily stored and consumed throughout the year.

The quantity and range of plant taxa in the assemblage is relatively limited, with no smaller seeds recovered from the samples. This low recovery is not particularly surprising, however, since the density of plant remains in general site contexts is often relatively sparse when compared with feature or midden contexts. The lack of seeds, bulbs, and other fruit remains in the assemblage does not suggest that the occupants of the site did not use herbaceous plants, bulbs, tubers, and other fruits for economic and/or medicinal purposes; evidence of their use simply was not recovered from these samples.

Assemblages from other Archaic and Late Prehistoric sites on the Edwards Plateau and Central Texas do indicate the use of a range of plant resources in addition to nuts and hackberries. Early and Middle Archaic features at nearby 41HY160 similarly reflect use of acorns, hickory nuts, and hackberries, but also bedstraw (Galium sp.), cheno/am (Chenopodium/Amaranthus), Grass family (Poaceae) seeds, and possibly grape (Vitis sp.), persimmon (Diospyros virginiana), and prickly pear (Opuntia sp.) (Hollenbach 2011b). In addition to acorn, hickory, and hackberries, Late Archaic and Late Prehistoric contexts at 41HY163 yielded chenopod, purslane (Portulaca sp.), verbena (Verbena sp.), Aster family (Asteraceae), and Pink family (Caryophyllaceae) seeds, as well as tentatively identified sumac (Rhus sp.), Nightshade family (Solanaceae) seeds, and onion (Allium sp.) bulbs (Hollenbach 2011a). At the Britton site (41ML37), McMillan site (41ML162), and Higginbotham site (41ML195), bulbs were commonly identified from Late Archaic deposits (3220-1200 BP), including camas (Camassia sp.) bulbs. In addition, acorns, knotweed (Polygonum sp.), pokeweed (Phytolacca americana), hawthorn (Crataegus sp.), prickly pear, stretchberry (Forestiera sp.), Grape family (Vitacaea), Spurge family (Euphorbiacaea), Grass family, and Mallow family (Malvaceae) seeds indicate use of nuts, weedy plants with edible greens and seeds, and wild fruits (Bush 2008). Late Archaic deposits at the Mustang Branch (Bluff) site (41HY209-M) included hickory nutshell, a cheno-am seed, and a grape/peppervine (Vitis/ Ampelopsis) seed (Cummings 1994:393). Early and Late Archaic contexts at the Wilson-Leonard site (41WM235) yielded wild bulbs, including wild hyacinth (Camassia scilloides), as well as 
walnut shell fragments, grass seeds, and one carbonized hackberry seed (Dering 1998).

Dering (2008) has compiled subsistence data from several sites on the plateau dating to the Austin (1250-750 BP) and Toyah (750-300 BP) phases of the Late Prehistoric period, and notes that those in the northern and eastern portions of the plateau seem to focus on baking bulbs, roots, and tubers (Dering 2008:68). Large numbers of wild onion bulbs were recovered at the Kyle site (41HI1, $\mathrm{n}=65)$, and onion/camas bulbs were at the Camp Bowie sites (41BR250, $\mathrm{n}=91$; and 41BR253, $\mathrm{n}=110$ ) (Dering 2008:Table 9-3; Karbula et al. 2001:27-28). In contrast, assemblages from sites in the western portion of the plateau regularly include agave leaves and fibers (Agave spp.) (Dering 2008:68, Table 9-3). Leaf stalks identified as sotol/yucca (Dasylirion/ $Y u c c a$ ), prickly pear pads and seeds, and hedgehog cactus (Echinocereus sp.) are additional resources prepared in earth ovens that have been recovered from sites in the region (Dering 2008:62, Table 9-3; Karbula et al. 2001:27-28, 31-32). Gourd roots were also apparently recovered from the Kyle site (Karbula et al. 2001:27-28).

Acorns are also commonly recovered from Late Prehistoric sites, including the Kyle site $(\mathrm{n}=49)$ and Honey Creek site (41MS32, $\mathrm{n}=58)$ (Dering 2008:Table 9-3; Karbula et al. 2001:27$28,31-32$ ). Additional nut taxa include walnuts, hickory nuts, and pecans (Dering 2008:Table 9-3; Karbula et al. 2001:27-28, 31-32). At the Biesenbach site (41WN88), 254 hickory nutshell fragments were recovered (Dering 2008:Table 9-3).

Fruit taxa are notably scarce. Wild plum/ cherry (Prunus sp.) was recovered from the Kyle and Biesenbach sites; grape from Mustang Branch (41HY206); hackberry from the Kyle and Rush sites (41TG346); hawthorn from the Honey
Creek site; and mesquite seeds and pods from the Rush site and Varga site (41ED28), both of which are located in the western portion of the plateau, (Dering 2008:Table 9-3; Karbula et al. 2001:2728, 31-32).

Seeds of weedy taxa with edible greens and seeds, as well as medicinal properties, are also recovered in low numbers at sites in the region. These include sunflower (Heliathnus sp.), grass (mostly Poaceae, and Muhlenbergia sp. at the Kyle site), cheno-am, dock (Rumex sp.), purslane, plantain (Plantago lanceolata), and dropseed (Sporobolus sp.) (Dering 2008:Table 9-3; Karbula et al. 2001:27-28, 31-32, B12-17). Also notable is evidence for limited use of maize (Zea mays) at the Kyle site, suggesting some level of agricultural investment (Dering 2008:Table 9-3; Karbula et al. 2001:27-28).

The plant food remains recovered from 41HY165, limited to durable nutshell and fruit seeds, are thus relatively narrow compared with contemporaneous sites in the region. The lack of smaller and more fragile taxa, such as seeds and bulbs, likely reflects the nature of the samples rather than lack of use at the site.

\section{Conclusions}

The plant assemblage recovered from 41HY165, while limited, provides some information regarding the foodways of the site's occupants. These groups collected wild food resources, including acorns, hickory nuts, pecans, walnuts, and hackberries. Because of the dietary importance of nuts, a highly storable and nutrient-rich resource, it is likely that most of the able-bodied members of the group participated in their collection in autumn. The various nuts and hackberries are easily stored for use throughout the year. While evidence for other plant resources was not recovered from the samples analyzed 
here, it is quite likely that the occupants of the site used a variety of plants, including those with edible greens, seeds, bulbs, tubers, and fruits, similar to Archaic and Late Prehistoric peoples at other sites in the region.

\section{Microfossil Analysis of Fire- Cracked Rock Samples from 41HY165, Hays County, Texas}

By Timothy E. Riley, Ph.D., RPA

This report presents the results of a microfossil analysis performed on 18 pieces of fire-cracked rock (FCR) recovered from earth oven features during excavation of a prehistoric archaeological site (41HY165), Hays County, Texas (Table 9-4). Starch was recovered from 12 of the 18 FCR samples submitted for analysis. Each sample was examined for the presence of diagnostic phytoliths as well as other microfossils such as plant epidermal tissue. Phytoliths were rarely encountered, occurring in only three samples. This may be due to the preservational context of the site. The recovery of abundant starch from these FCR samples demonstrate a novel approach to understanding past subsistence practices in Central Texas.

Table 9-4. Burned Rock Specimens Submitted for Microfossil Analysis.

\begin{tabular}{ccccccccc}
\hline $\begin{array}{c}\text { Analytical } \\
\text { Unit }\end{array}$ & Specimen & Unit & Quad & Level & $\begin{array}{c}\text { Top } \\
\text { Depth } \\
\text { (cmbs) }\end{array}$ & $\begin{array}{c}\text { Bottom } \\
\text { Depth } \\
\text { (cmbs) }\end{array}$ & Feature & $\begin{array}{c}\text { Weight } \\
\text { (g) }\end{array}$ \\
\hline 3a & $79-14$ & 2 & SW & 4 & 23 & 33 & $2 / 96$ & 146.3 \\
3a & $79-15$ & 2 & SW & 4 & 23 & 33 & $2 / 96$ & 199.2 \\
4a & $123-29$ & 8 & NW & 4 & 25 & 35 & $3 a / 96-6 / 97$ & 435.0 \\
4a & $123-30$ & 8 & NW & 4 & 25 & 35 & $3 a / 96-6 / 97$ & 415.0 \\
$4 a$ & $134-10$ & 3 & SW & 4 & 25 & 35 & $3 a / 96-6 / 97$ & 350.9 \\
$4 a$ & $134-11$ & 3 & SW & 4 & 25 & 35 & $3 a / 96-6 / 97$ & 201.6 \\
$4 a$ & $256-23$ & 11 & - & 4 & 24 & 34 & $2-97$ & 90.5 \\
$4 a$ & $240-7$ & 11 & - & 7 & 54 & 64 & - & 470.0 \\
$4 a$ & $240-8$ & 11 & - & 7 & 54 & 64 & - & 565.0 \\
$4 a$ & $299-26$ & 8 & NW & 9 & 70 & 75 & $9-97$ & 40.2 \\
$4 a$ & $299-27$ & 8 & NW & 9 & 70 & 75 & $9-97$ & 38.2 \\
$4 b$ & $69-13$ & 2 & NE & 10 & 82 & 92 & $7-96$ & 199.1 \\
$4 b$ & $74-7$ & 2 & NE & 11 & 92 & 102 & $7-96$ & 700.0 \\
$4 b$ & $74-8$ & 2 & NE & 11 & 92 & 102 & $7-96$ & 291.6 \\
\hline 5 & $164-8$ & 3 & NE & 14 & 125 & 135 & Zone 1/97 & 92.5 \\
\hline 5 & $164-9$ & 3 & NE & 14 & 125 & 135 & Zone 1/97 & 43.0 \\
\hline 5 & $310-24$ & 8 & NW & 20 & 130 & 135 & Zone 1/97 & 110.3 \\
\hline 5 & $310-25$ & 8 & NW & 20 & 130 & 135 & Zone 1/97 & 122.1 \\
\hline
\end{tabular}




\section{Starch in Archaeology}

Starch granules have been observed in archaeological contexts since the late 1970s (Anderson 1980; Ugent et al. 1981, 1982, 1984), but this line of evidence has only recently become a major component of microbotanical research (Fullager et al. 2006; Loy et al. 1992; Torrence and Barton 2006). Starch analysis can provide evidence of the use of plants as food resources where macrobotanical remains are rare or uninformative. In some cases, starch granules have been found that predate other evidence of domestication (Perry et al. 2007). Piperno and Holst (1998) examined groundstones and found maize (Zea mays), cassava (Manihot esculenta), yam (Dioscorea sp.), and arrowroot (Maranta arundinacea) starch grains from Central Panama, providing evidence for the use of tuber crops since 8000 BP. Loy et al. (1992) studied lithic flakes from 28,000-year-old cave sediments on the Solomon Islands and recovered starch grains from them. Some of the granules were identified as taro (Colocasia $\mathrm{sp}$ ).

To date, most starch research has focused on tools and soils recovered from the tropics, with very little focus on the potential of this line of research in temperate climates (Fullagar and Field 1997; Fullagar et al. 1996, 1998, 2006; Horrocks et al. 2002, 2004; Horrocks and Lawlor 2006; Horrocks and Nunn 2007; Horrocks and Weisler 2006; Irwin et al. 2004; Lentfer et al. 2002; Pearsall et al. 2004; Perry 2004, 2005; Perry et al. 2007; Piperno 1998; Piperno and Holst 1998; Piperno et al. 2004; Smith et al. 2001). A handful of temperate Old World sites have been investigated. Shibutani (2008) studied anvil stones, grinding slab, and grinding stones from four archaeological sites in southern part of Japan, dating from Japanese Paleolithic to incipient Jomon period. She recovered intact and damaged starch grains from grinding surfaces of the tools.
The recovered starch grains are not identified to taxa conclusively. Piperno et al. (2004) reported the earliest evidence of grass seed processing. They identified starch grains of barley (Hordeum vulgare) and possibly wheat (Triticum sp.) from an Upper Paleolithic groundstone found in Israel.

While Loy had some early publications on starch recovered from North American artifacts, only three recently published studies examines starch recovered from North America (Boyd et al. 2006; Messner 2008; Zarrillo and Kooyman 2006). The Zarrillo and Kooyman (2006) article focuses on the recovery of maize and berry starch on Late Prehistoric groundstone from the northern Great Plains. In addition, there have been a handful of studies done for contract projects, mostly from the Southwest and Great Basin (Cummings 1992 a-c, 1993 a-b, 1997 a-b). Only two studies evaluating starch recovered in Texas has been encountered in the current literature review (Cummings 1993c; Perry 2008). The paucity of publications on the recovery of starch from North American archaeological sites highlights some of the potential for this line of research, as well as the dearth of qualified researchers currently investigating starch with a regional focus on North America. This is surprising in light of the fact that much of the continent has copious artifacts associated with both incipient horticulture and hunter-gatherer sites. As Piperno et al. (2004) state, the association of macroscopic remains from economically important plants with potential plant processing tools such as grinding slabs, mortars, and pestles is rarely evident. Starch analysis of groundstone and cooking features provides direct evidence of past human food processing.

To date, there has been very little research on the recovery of starch from known cooking features in the archaeological record. Recent 
experimental studies have shown that earth oven cookery results in the dispersal of starch granules and other microfossils throughout the oven feature, depositing residue related to the cooked foodstuffs and packing material used in the oven on many of the rocks used as heating elements (Messner and Schindler 2010).

\section{Ecological Background}

Hays County is located in the Balcones Canyonlands (Ecoregion 30c) near the ecotonal boundary with the Blackland Prairie (Ecoregion 32) (Griffith et al. 2004). The Balcones Canyonlands from a physiographic barrier between the mesic prairie to the east and the xeric woodland to the west (Griffith et al. 2004). This ecoregion is part of the larger Edwards Plateau ecoregion, which is primarily distinguished from the surrounding regions by a distinctive mollisol soil order. The vegetation of the region is characterized by oak-juniper savanna and mesquite-Acacia savanna. A number of known ethnographic food resources are available within this ecoregion (Griffith et al. 2004).

The Blackland Prairie is a tall grass prairie characterized by high plant community diversity, due in part to the variety in soil texture and $\mathrm{pH}$ associated with the different soil orders represented within this ecoregion (Diamond et al. 1987; Diamond and Smeins 1985). Despite the diversity within this prairie, the region can be characterized by a general pattern of tall grass prairie on the uplands with riverine woodlands and forest across much of the bottomland (Diamond and Smeins 1993). This characterization of the modern vegetation provides a known set of wild food resources that would have been accessible to the site's prehistoric inhabitants.

\section{Materials and Methods}

All 18 FCR samples in this study were processed in AEL, Department of Anthropology, Texas A\&M University. Each sample was subjected to a two-part brushing procedure to minimize the potential for modern starch contamination. After initial examination of a sample, a $3 \times 3-\mathrm{cm}$ area was selected for sampling. This subsampling method was designed to reserve as much of the artifact as possible for future corroborative studies while yielding enough microfossil residue for the current study. This area was sprayed with a dilute $(10 \%)$ solution of $\mathrm{HCl}$ to dissolve any calcium carbonate buildup. Following this, the sampling area was brushed and washed into a collection beaker until the water was visibly clear. The same area was then brushed again with a sonicating brush (Phillips Sonicare E Series), and the resultant residue was washed into a second collection beaker. While this method undoubtedly removes some potential microfossil residue that is directly associated with the use of the earth oven feature, it is an important step in limiting the mis-interpretation of the feature based on microfossil evidence that postdates the use of the feature. This removal of potential contaminants allows for a much more secure interpretation of the second residue sample, which contains only those microfossils that required sonication to remove.

The resultant residue samples were transferred to $15 \mathrm{ml}$ centrifuge tubes and placed in a 5 percent Calgon solution for six hours. Following this treatment, each sample was washed in water several times. The samples were then placed in a heavy density solution of $\mathrm{ZnBr}$ at a specific gravity of 2.38. After thorough mixing, the samples were centrifuged for five minutes at low speed, followed by five minutes at high speed. The light fraction resulting from this was pipetted off, and the procedure repeated. 
Following this step, the light fraction was washed several times in water and transferred to a dram vial for storage. The heavy fraction was examined microscopically to determine that all starch granules and phytoliths had been recovered in the light fraction. The heavy fractions consisted primarily of weathered minerals, and no microfossils were observed in any of the heavy fractions. Following this extraction procedure, a slide was made of the light fraction residue from each sample. This slide was examined under brightfield and cross-polarized light for starch granules and phytoliths.

\section{Starch Reference Collection}

Archaeological starch research has seen little application to hunter-gatherer sites in North America (Messner 2008; Zarrillo and Kooyman 2006). This is partly due to the need for a reference collection of major potential food resources for each region. The development of this collection is hindered by the rare recovery of geophytes and small seeds from the archaeological record, as well as the imprecision of the observations available in the the ethnohistoric record (Thoms 2008). This section presents an overview of the starch reference collection developed over the course of this research following a brief review of the microscopic methods useful in starch grain analysis.

The identification of starch granules recovered from archaeological contexts has become one of the more important components of recent paleoethnobotanical studies over the last decade (see Torrence and Barton [2006] for an recent overview). While this is a relatively new subfield in archaeology, starch microscopy has long had a place in food science (Flint 1994) and botany (Cortella and Pochettino 1994). Starch was first observed and identified microscopically in 1719 by Antonie van Leeuwenhoek (Thomas and Atwell 1999). Since then, many researchers have shown that starch granules can be microscopically associated with botanical source material based on distinguishing morphological characteristics, the most important being shape and size (Badenhuizen 1965; Cortella and Pochettino 1994; Czaja 1978; Evers 1979; Moss 1976; Reichert 1913). This section provides an overview of some of the techniques used in the light microscopy of starch. Many of the diagnostic features of starch used by paleoethnobotanists, such as differences in the lamellae and hilum location, have been observed and described under brightfield light. Transmitted brightfield light can be used to observe starch granules, but it can be very difficult to observe the features necessary to distinguish individual differences between starch grains (Barton and Fullagar 2006). Additionally, because starch grains generally exhibit very low contrast in most mounting media, it can be very difficult to observe granules from an unknown specimen with other microscopic components. For these reasons, much of the initial microscopy used to identify the presence of starch in an archaeological sample relies on polarized light microscopy.

All undamaged starch grains have a high degree of molecular orientation (Evers 1979). This structured organization of the granule results in a characteristic birefringence pattern when starch is viewed in cross-polarized light (Thomas and Atwell 1999). This uniaxial birefringent pattern is known variously as an extinction cross or a maltese cross (Barton and Fullagar 2006; Weaver 2003). Birefringence is a complex optical property of many ordered compounds. Light entering the specimen is split into two components which are plane polarized perpendicular to each other. The refractive index of a birefringent specimen varies with the direction of passage, causing one of the components to be retarded relative to the other 
component. This optical path difference creates either constructive or destructive interference when the two component waves recombine after leaving the specimen. When the resultant recombined light passes through a second polarizing filter (the analyzer) set at a right angle to the original polarizing filter, any light that has not passed through a birefringent compound will be prevented from passing the analyzer. This microscopic method is very useful for the initial investigation of unknown samples since starch grains are readily visible and relatively distinct from other birefringent biological compounds (Canti 1997, 1998, 1999; Haslam 2006; Loy 2006).

While the extinction cross does provide some distinguishing features and is useful for the initial indication of starch ubiquity, many of the attributes used to differentiate between starch types are obscured in polarized light microscopy. This method may also not detect damaged or gelatinized starch grains, which lose birefringence as the molecular order of native starch is disrupted (Evers 1979). Starch grains with very high amylopectin content may also not exhibit birefringent optical properties (Evers 1979).

Under traditional food preparation methods, starch grain structure can be modified by mechanical damage from grinding and milling techniques or gelatinized through wet cooking methods (Babot 2003). Freezing, dehydration, roasting, and charring can also cause damage to starch granules that alters diagnostic features necessary for the identification of native starch granules (Babot 2003). Starch grains recovered in coprolites or latrines may also exhibit enzymatic damage from partial digestion (Autio 2001; Evers 1979). Mechanical damage can result in four different types of modification: 1) radial cracking associated with the hilum, 2) chipping and splitting along the margins of the granule, 3) abrasions, and 4) a partial loss of granule structure resulting in a "ghost" granule (Williams 1968).

The current study utilized cross-polarized light microscopy for the initial identification of starch granules in the FCR specimens. Granules identified as starch were further examined under brightfield light to detect features important for botanical source identification.

Reference starch granules were examined for a total of 18 plant taxa known or suspected to be food resources for Texas hunter-gatherer populations. These resources include grass seeds and geophytes. Table 9-5 presents summary data for the starch granules for these resources. Figures 9-1 through 9-3 provide micrographs of the starch granules encountered in each taxa examined. Recovered starch granules were also compared to the botanical resources presented in Messner (2008) and Reichert (1913), with particular emphasis on those resources identified in Thoms (2008), including arrow-root (Sagittaria sp.), cattail (Typha sp.), ground nut (Apios americana), and water-chinquapin (Nelumbo lutea).

\section{Results}

Starch granules were encountered in the discrete sonicated subsample from 12 of the 18 FCR samples submitted for analysis. The metric data for these granules is presented in Table 9-6. Due to the limited processing of each sample necessary to ensure starch recovery, the slides of these samples contained a great deal of organic and mineral detritus that was not identifiable. This did not limit the identification of starch granules in the samples. The remainder of this section will present the starch data by feature. This will be followed by a brief section focused on the phytolith and other plant microfossils recovered from these samples. 


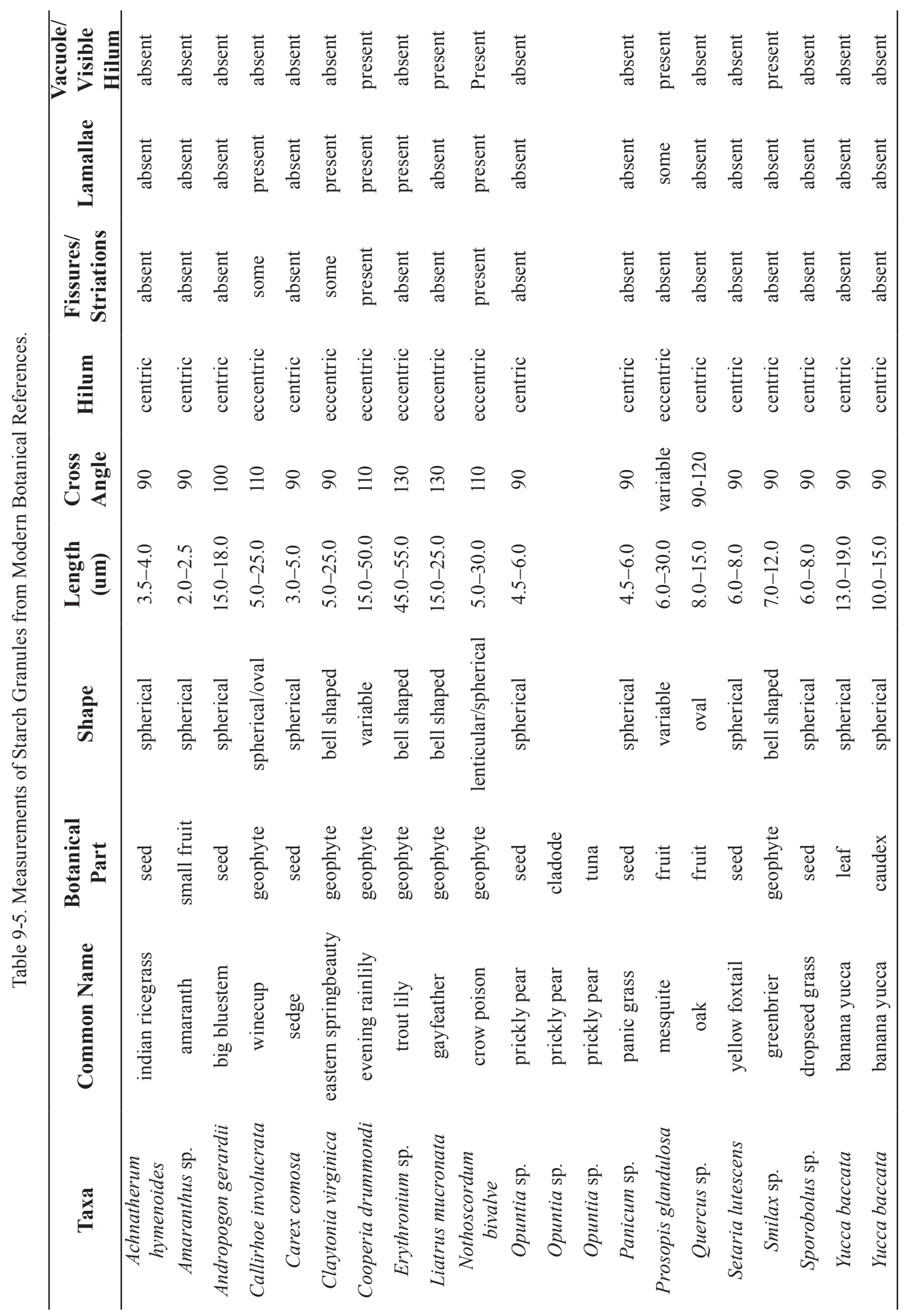




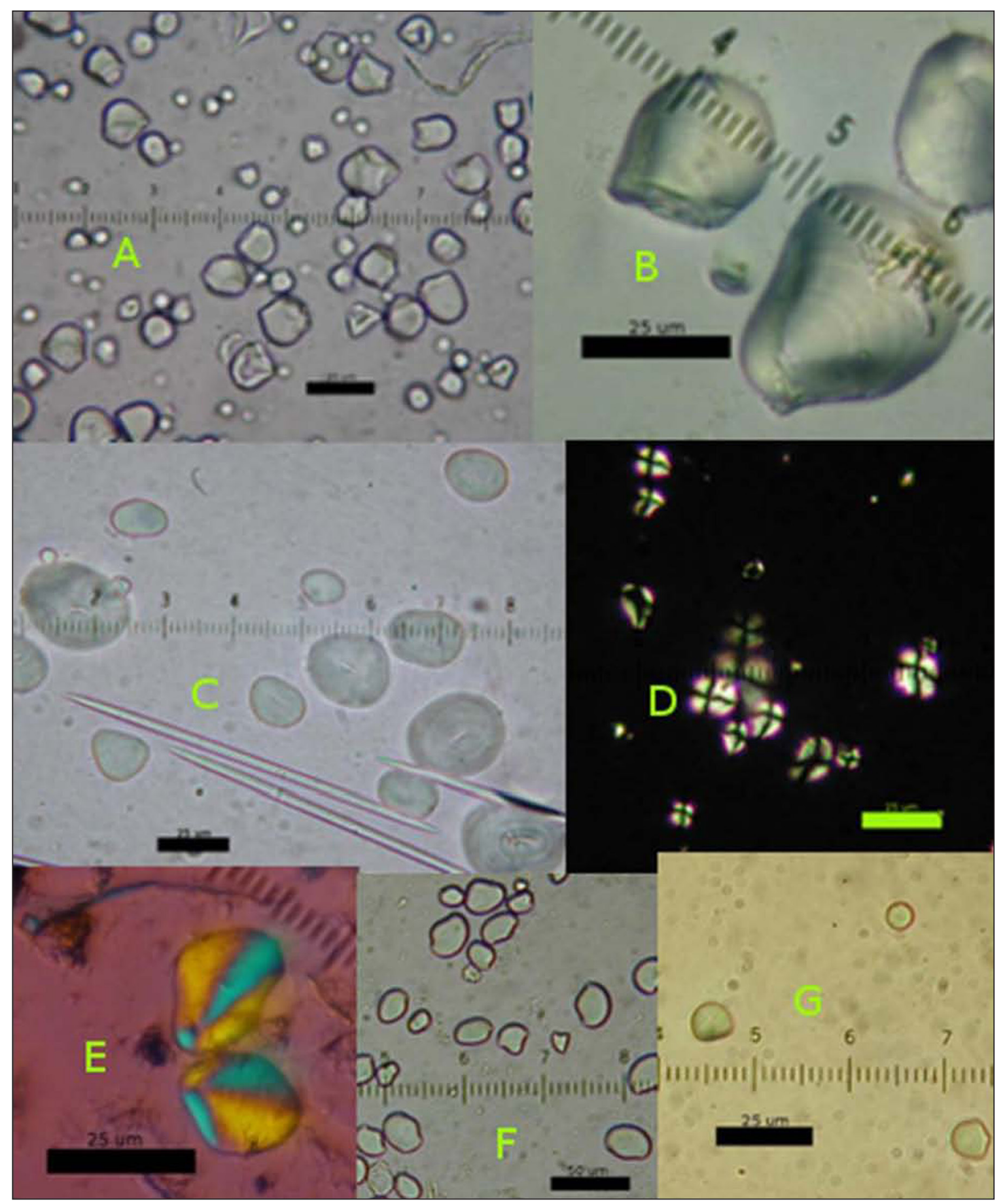

Figure 9-1. Micrographs of starch granules from geophytes, magnified 400x: A) Brightfield micrograph of Callirhoe involucrata; B) Brightfield micrograph of Liatris mucronata; C) Brightfield micrograph of Cooperia drummondi; D) cross-polarized light micrograph of Claytonia virginica; E) $1 / 4 \lambda$ retarded crosspolarized light micrograph of Erythronium sp.; F) Brightfield micrograph of Nothoscordum bivalve; G) Brightfield micrograph of Smilax sp. 


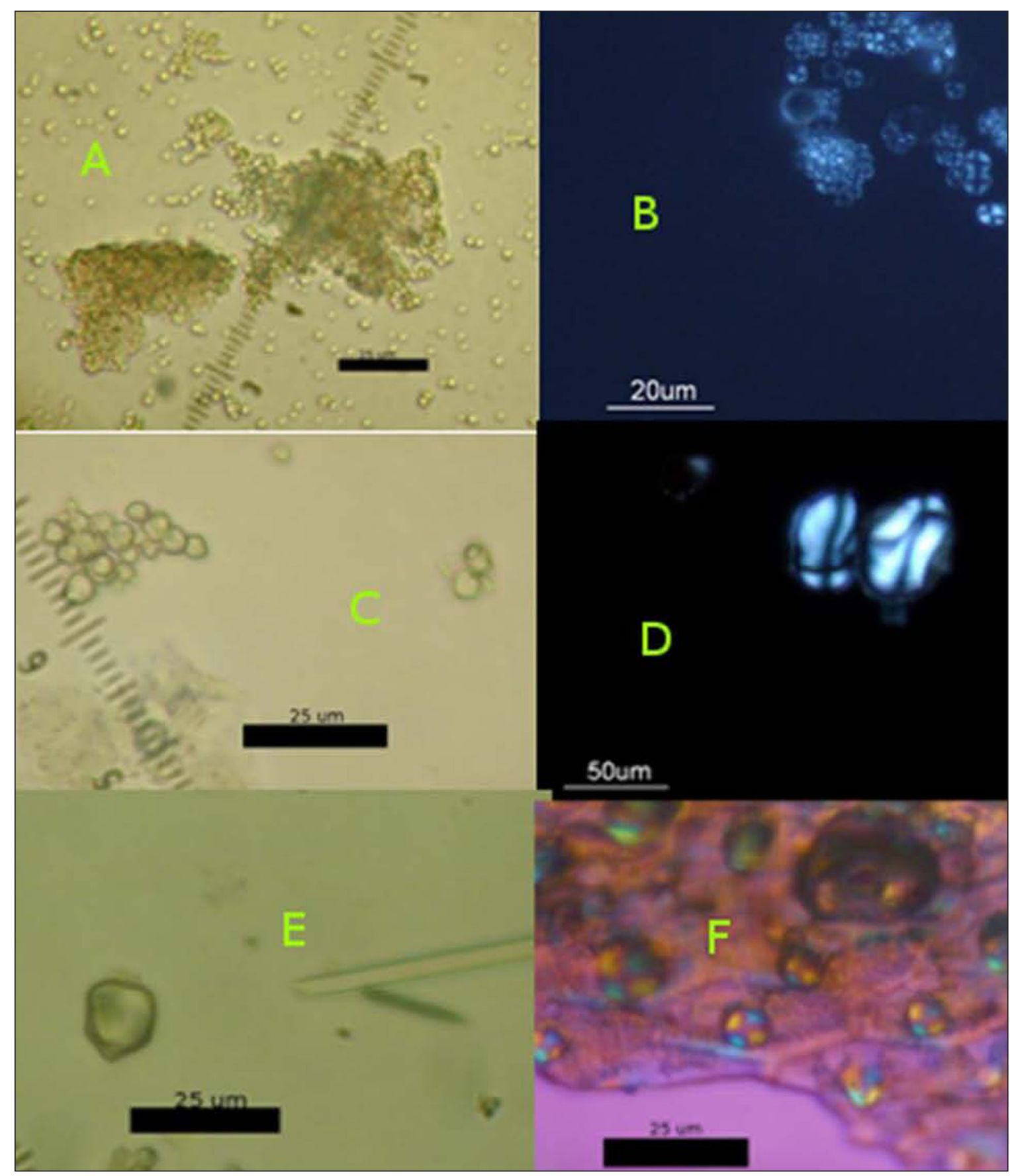

Figure 9-2. Micrographs of starch from seeds and meristem, magnified 400x: A) Brightfield micrograph of Amaranthus sp.; B) cross-polarized light micrograph of Carex Comosa; C) Brightfield micrograph of Opuntia sp.; D) cross-polarized light micrograph of Prosopis glandulosa; E) Brightfield micrograph of Yucca bacata caudex; F) 1/4 $\lambda$ retarded cross-polarized light micrograph of Yucca bacata leaf meristem. 


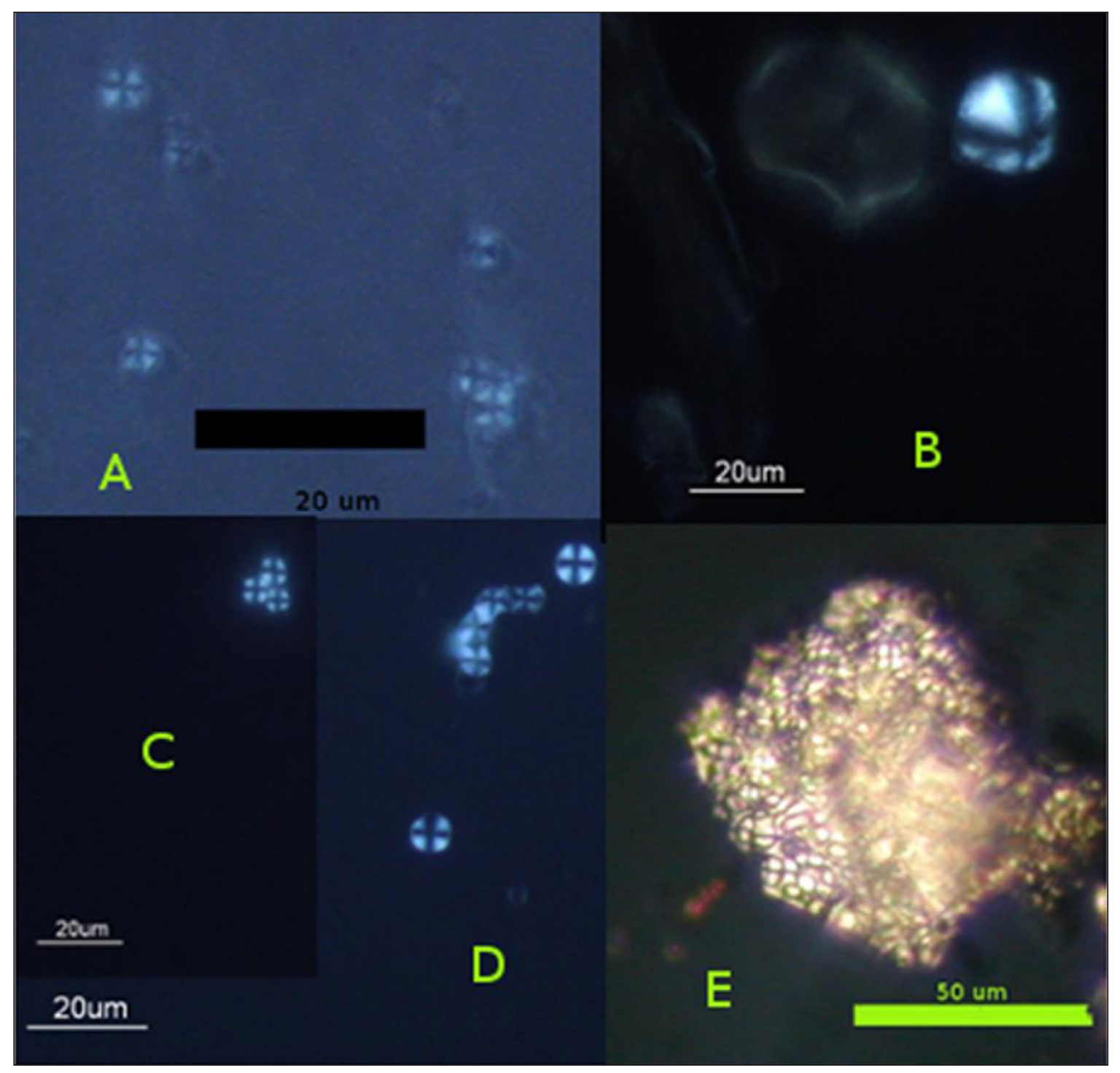

Figure 9-3. Cross-polarized light micrographs of starch granules from grass seeds, magnified 400x: A) Achnatherum hymenoides; B) Andropogon gerardii; C) Setaria lutescens; D) Panicum sonorum; E) Sporobolus asper.

\section{Feature 7-96}

All three samples taken from FCR specimens associated with this feature contained starch. Three separate starch morphotypes were encountered in the samples (see Table 9-6). Sample 69-13 contained a single starch grain. This type (Figure 9-4A) appears similar to references collected from Hordeum sp., a genus in the grass family that includes little barley (Hordeum pusillum) and other perennial and annual grasses. It seems likely that this starch granule is associated with the use of grass as a packing material in the oven.

The sample taken from specimen 74-7 contained two different starch granules, each a different morphotype. The first granule is consistent with reference starch from knotweed or other Polygonum sp., based on the thickened border and overall gross morphology. The other granule recovered from this sample exhibits edge chipping consistent with mechanical 


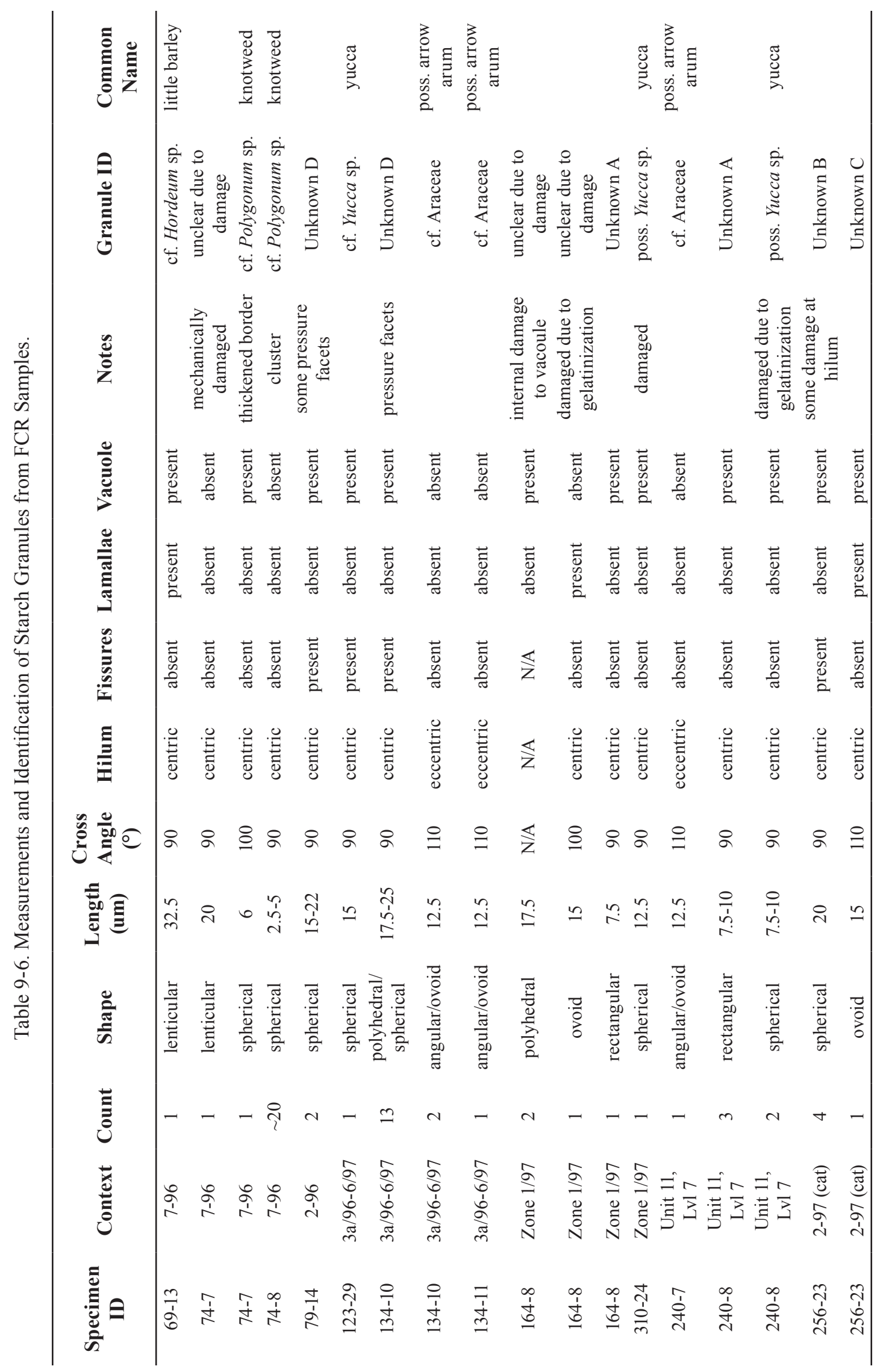




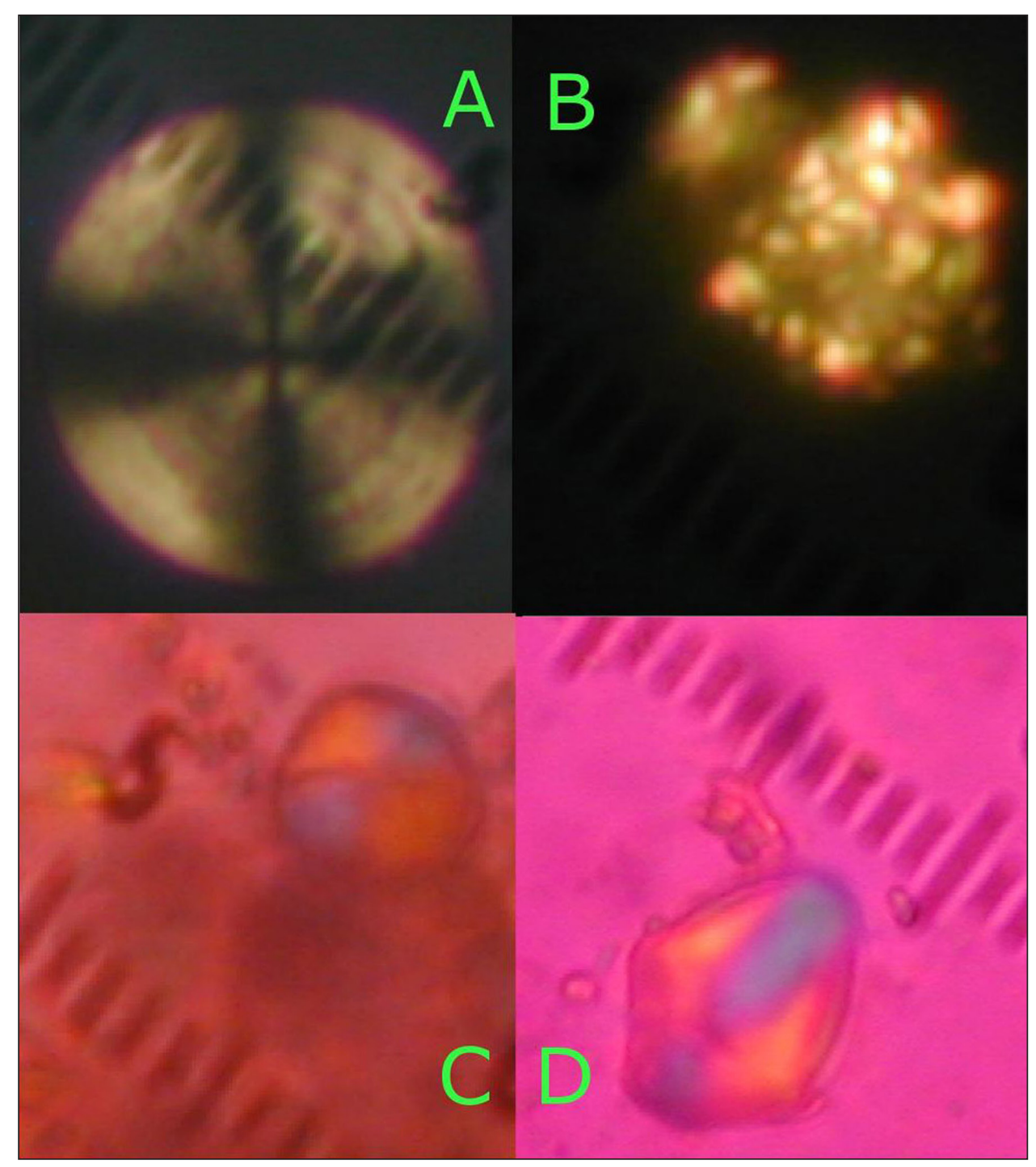

Figure 9-4. Micrographs of starch granules from FCR samples, magnified 400x: A) cf. Hordeum sp.; B) cf. Polygonum sp.; C) cf. Yucca sp.; D) cf. Araceae.

damage (Figure 9-5D). This specimen also exhibits a partial loss of birefringence that limits identification. A large cluster of starch was encountered in the sample from Specimen 74-8 (see Figure 9-4B). This cluster is also consistent with reference starch from a Polygonum sp. fruit.

\section{Feature 2-96}

One of the two samples of FCR specimens from this feature contained starch (see Table 9-6). The sample from Specimen 79-14 contained two starch granules of the same morphotype. This morphotype, Unknown D (see Figure 9-5D), does not appear to be similar to any reference starch known at this point. While it has some similarities with starch granules recovered from mesquite (Prosopis sp.) seedpods, such as the longitudinal fissures and wavy crossarms (Giovannetti et al. 2008), the presence of several large facets on each granule and the overall angularity of the granules suggest a different, currently unknown botanical source. This is most likely a geophyte based on the size, shape, and birefringence characteristics of the granules. 


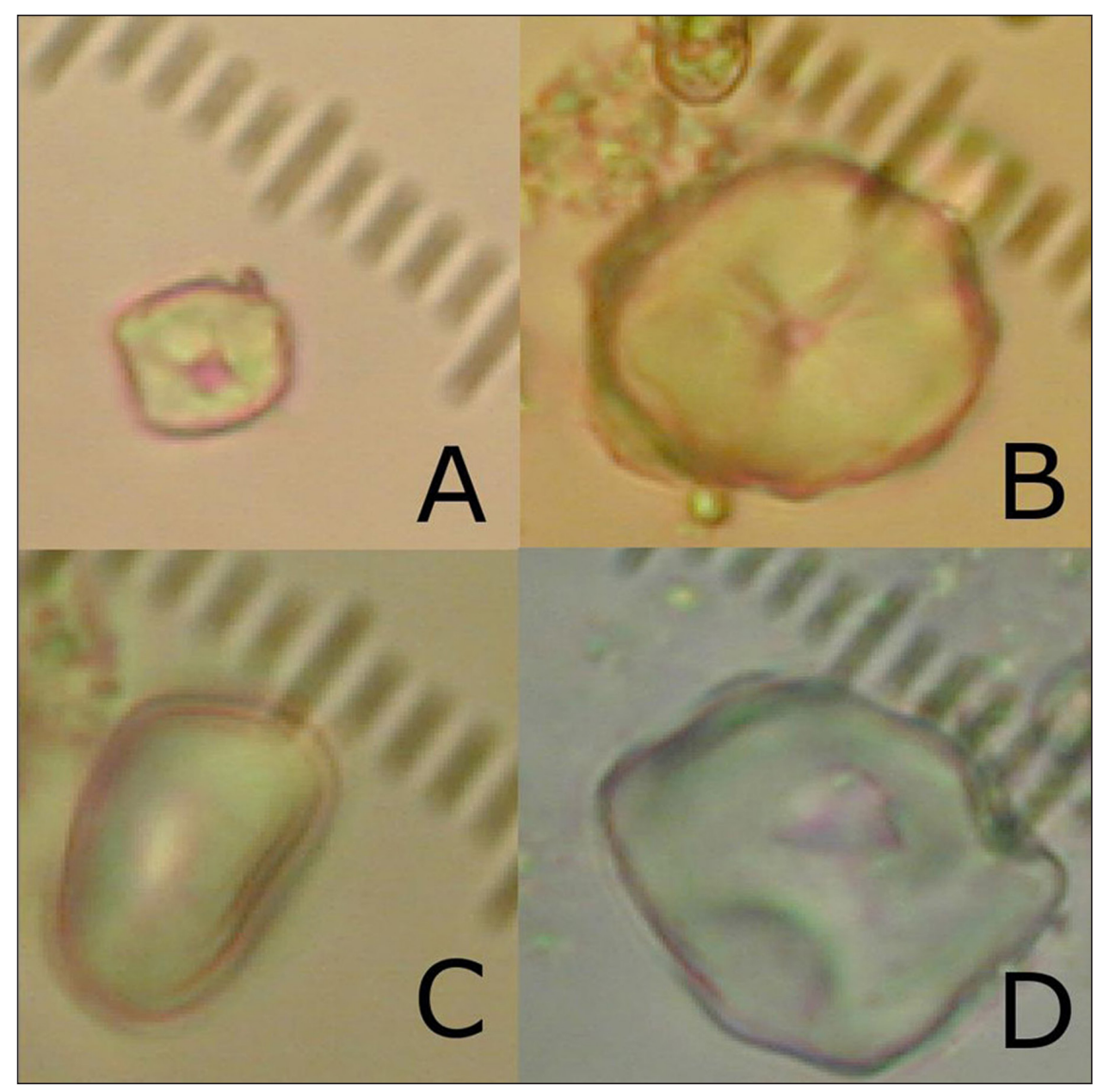

Figure 9-5. Micrographs of unknown starch granules from FCR samples, magnified 400x: A) Unknown A; B) Unknown B; C) Unknown C; D) Unknown D.

\section{Feature 3a/96-6/97}

Three of the four samples from FCR specimens associated with this feature contained starch granules (see Table 9-6). Three different morphotypes were recovered from the specimens associated with this feature. A single granule, consistent with yucca (Yucca sp.), was encountered in the sample from Specimen 12329 (see Figure 9-4C). This granule is partially obscured by detritus. Specimen 134-10 contained an abundance of starch from two morphotypes. The majority of these granules (13) are classed as Unknown D, described above for Feature 2-96. The remaining two granules from this specimen are similar to granules observed in the rhizomes of plants in the family Araceae, specifically arum (Arum sp.) and arrow arum (Peltandra sp.) (Messner 2008; Reichert 1913). The starch granule from Specimen 134-11 also fits this morphotype.

\section{Zone 1/97}

Two of the three samples of FCR specimens associated with this zone contained starch. The sample from Specimen 164-8 contained three different morphotypes of starch. Two of the types (Figure 9-6B and C) exhibited damage consistent with gelatinization. Neither type is consistent with a taxonomically distinct reference. The ovoid form exhibited by the granule in Figure 9-6C is fairly common in a variety of geophytes 


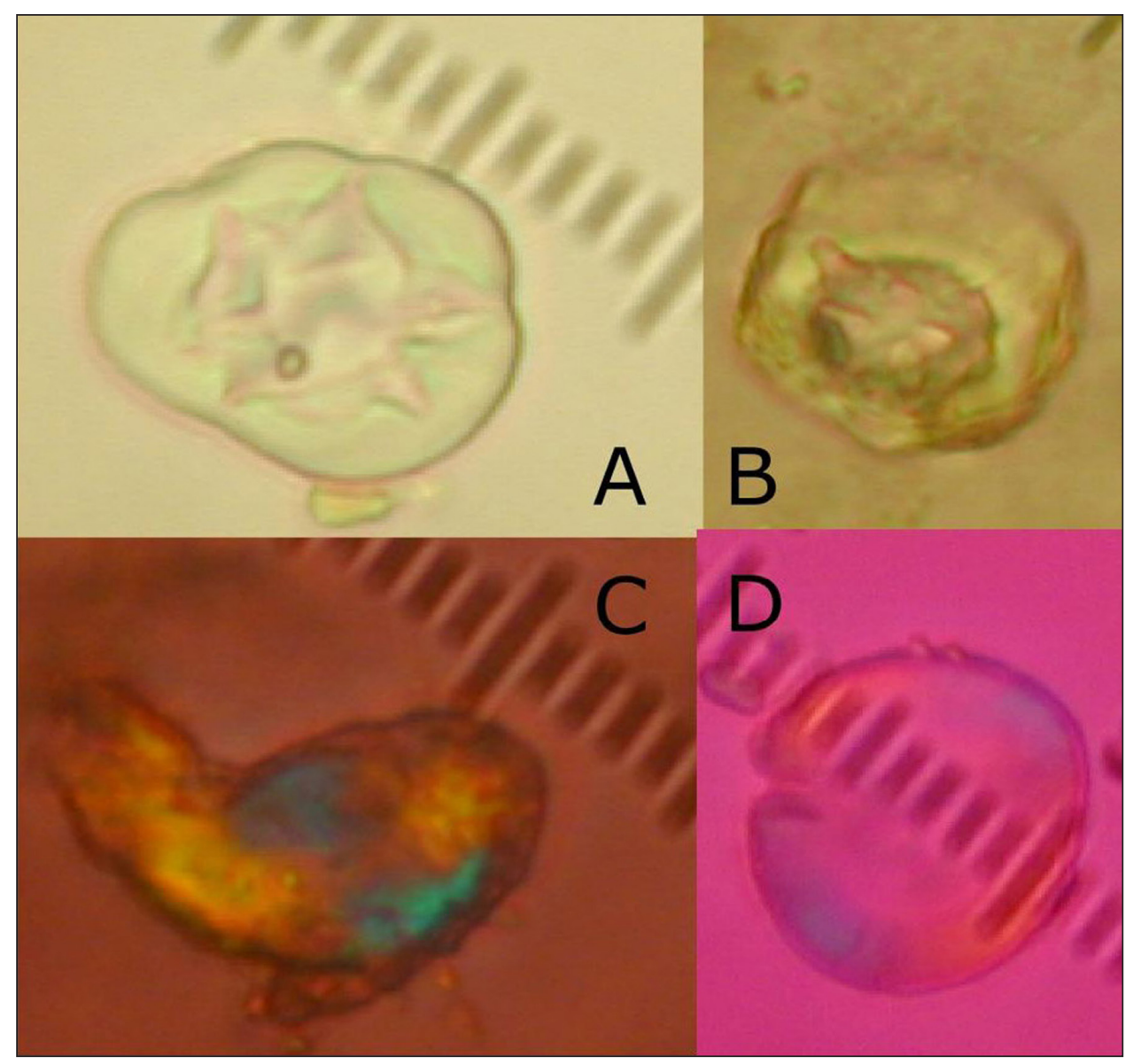

Figure 9-6. Micrographs of damaged starch granules from FCR samples, magnified 400x: A) Specimen 256-23; B) Specimen 164-8; C) Specimen 164-8; D) Specimen 69-13.

(Reichert 1913), but this particular specimen does not have any taxonomically distinct features, perhaps due to the damage. The final granule recovered from this specimen is a small, rectangular to subangular form designated Unknown A. This granule appears similar to the starch encountered in a variety of grasses, but has a conspicuous vacuole over the hilum. One granule was recovered from the sample taken from Specimen 310-24. The granule has some damage associated with the hilum. The overall morphology of the granule is consistent with starch from yucca.

\section{Feature 2-97}

One of the two samples from FCR specimens from this feature contained starch. The sample from Specimen 256-23 contained a total of five starch granules. Four of these granules are of a similar type, designated Unknown B (see Figure 9-5B). This type is a subangular spherical shape with radial fissures emanating from the open hilum. The remaining granule observed in this sample is an ovoid shape with several visible lamellae seen in Figure 9-5C. The small size precludes any secure identification, but the general morphology is consistent with a number of known geophytes (Reichert 1913).

\section{Unit 11, Level 7}

Two of the three samples from FCR specimens associated with this level contained starch. Specimen 240-7 contained a single granule consistent with Araceae starch granules (see 
Figure 9-4D). Specimen 240-8 contained three granules, all consistent with Unknown A (see Figure 9-5A).

\section{Phytolith and Other Microfossil Recovery}

Six phytoliths were encountered in the 18 samples analyzed in this study (Figure 9-7). Three phytoliths were encountered in sample 134-10 (Feature 3a/96-6/97). All three are phytolith shapes associated with the grass family (Poaceae). Interestingly, at least two of the forms are associated with different subfamilies within the family. The saddle shape is associated with the Chloridoideae grasses, which includes dropseed grasses (Sporobolus sp.). The bilobate or dumbbell shape is associated with the Panicoideae grasses, including panic grass (Panicum sp.) as well as big bluestem (Andropogon sp.) (Twiss et al. 1969). The remaining elongate form is common across all the subfamilies. A saddle-shaped phytolith was also encountered in sample 256-23 (Feature 2-97), and a bilobate shaped phytolith was present in sample 299-27 (Feature 9-97). It is probable that these grass phytoliths are remnants of the packing material used in the construction and use of these cooking features rather than a direct indicator of the subsistence resources prepared in these ovens.

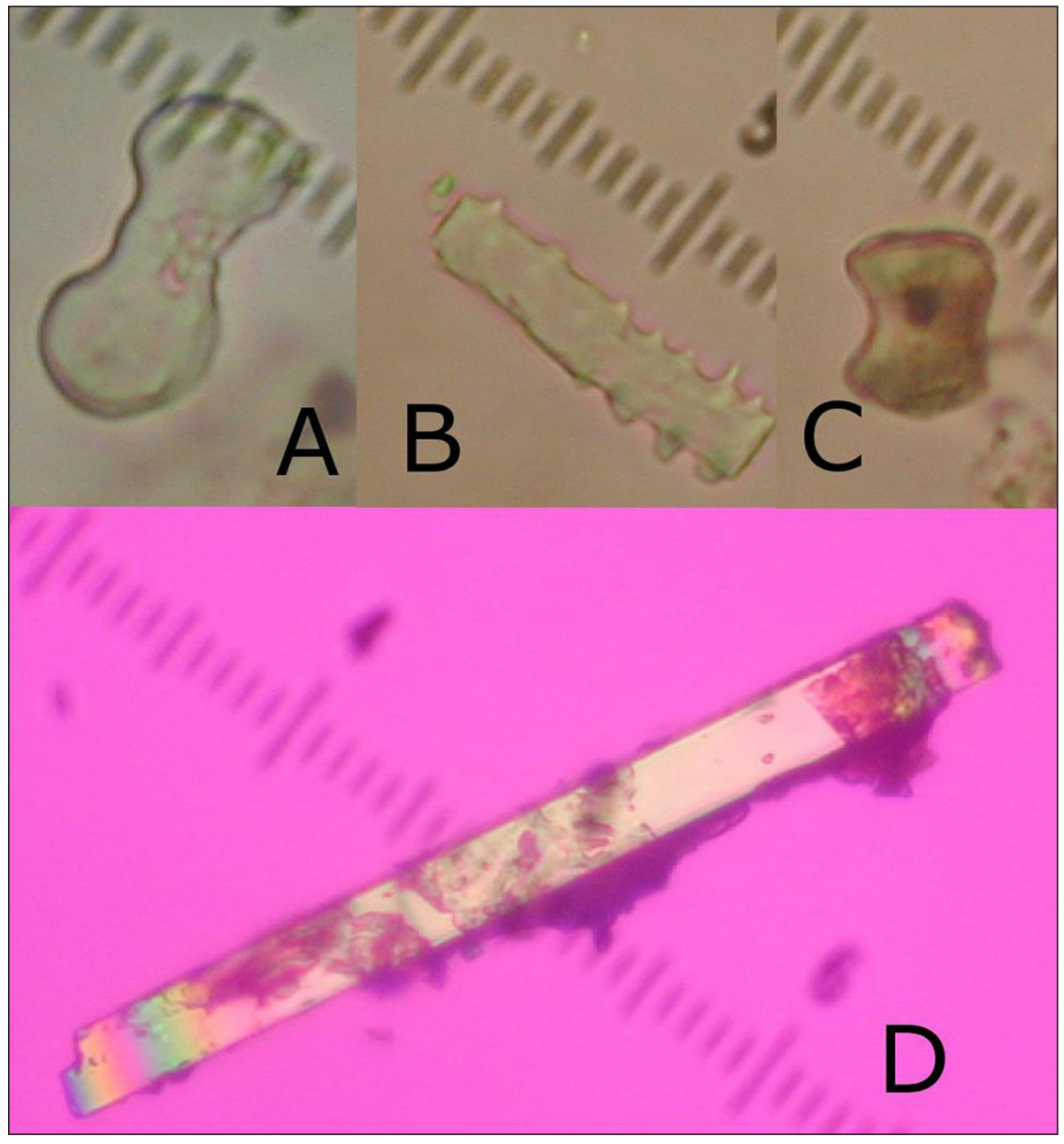

Figure 9-7. Micrographs of phytoliths from FCR samples, magnified 400x: A) bilobate shape; B) elongate shape; C) saddle shape; D) calcium oxalate stylus. 
The remaining phytolith is a calcium oxalate crystal rather than a silicified plant cell. This stylus shape is common in Yucca sp., Dasylirion sp., and Agave sp., but is also encountered in other botanical resources as well. While it is non-diagnostic, the association of this crystal with a probable Yucca sp. starch granule in the same sample (123-29 [Feature 3a/96-6/97]) suggests that the stylus is most likely from the same botanical source. Arrow arum rhizome also contains abundant calcium oxalate crystals, though only raphide and druse shapes are reported for the Araceae family in the literature (Keating 2004; Prychid and Rudall 1999).

Other plant microfossils were encountered in this study as well (Figure 9-8). Fibers were relatively common in some of the samples, butwere not documented or recorded, as individual fiber ultimates have little diagnostic use from such a

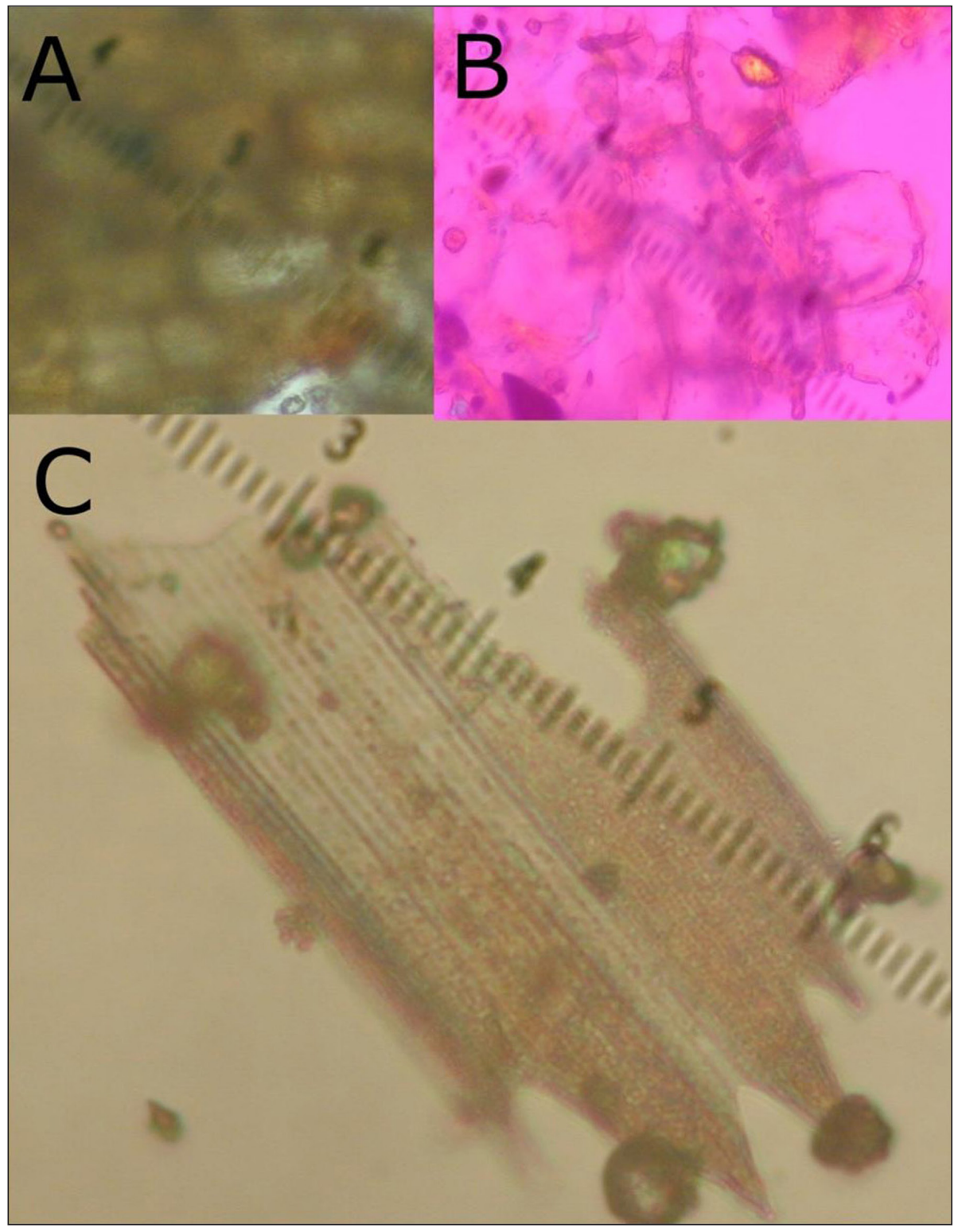

Figure 9-8. Micrographs of plant tissue from FCR samples, magnified 400x: A) cf. Yucca sp. epidermal tissue; B) unknown parenchymous tissue; C) unknown epidermal tissue. 
context. Several other plant tissues were also encountered, including unknown parenchymous tissue in sample 69-13 (Feature 7-96) and two different types of plant epidermal tissue. Sample 74-8 (Feature 7-96) contained a piece of plant epidermal tissue consistent with Yucca sp. (Sobolik 1992). While the lack of visible stomata on the fragment precludes any strong statement of identification, this association of yucca as either a food resource or packing material for the region is corroborated by the starch granule and phytolith recovered from sample 123-29. The remaining epidermal fragment, encountered in sample 7915 (Feature 2-96) remains unidentified.

\section{Discussion}

Approximately 57 starch granules from at least eleven distinct starch morphotypes were recovered from the FCR specimens submitted for analysis from 41HY165. While several of these are from unknown botanical sources, the remaining granules are from a variety of botanical sources reflecting both the food resources and packing materials associated with cooking features. Eleven of the granules exhibited damage consistent with gelatinization (Table 2). Many of these were damaged enough that a reliable identification could not be made. Several of the FCR samples contained starch granules consistent with geophytes in the Araceae family. The most likely source is arrow arum (Peltandra sp.), an important ethnographic food resource in the Eastern Woodlands (Messner 2008). While there is no historic record of this resource being consumed in Texas, at least one species, Peltandra virginica, does occur in the state. There are also several granules morphologically consistent with the starch encountered in Yucca sp. throughout the assemblage. This could either be from the roasting of yucca flower stalks as a food resource or possibly the use of yucca leaves as a packing material during roasting. The use of yucca in these cooking features is supported by the presence of a calcium oxalate stylus and epidermal tissue consistent with yucca.

The other identifiable starch granules both occur in Feature 7-96 and are most likely associated with packing material. One large granule consistent with reference starch from Hordeum sp. was encountered. As this starch is associated with a grass seedhead, there is little reason to infer the purposeful roasting of this resource, although it is possible that the granule is associated with stone boiling. Grass phytoliths were also recovered in small quantities from several other features, indicating that grass stems were a common packing material. Approximately 20 granules consistent with a Polygonum sp. fruit were also recovered from two different FCR specimens in this feature. Again, this is likely to be from the use of this botanical resource as a packing material, although it could also be associated with stone boiling. Analysis of feature form and function could inform on this (Black et al. 1997)

Four unknown morphotypes were also encountered in this analysis. Unknown A is most likely from a grass seedhead or other small, hard fruit. Unknown B could be from either a geophyte or seed/fruit source, although the radial fissures, size, and angularity are more suggestive of a geophyte. Unknown $\mathrm{C}$ is a form that is similar to small starch granules in many geophytes. The thick lamellae and open hilum may be diagnostic, but this granule has not been encountered in reference samples. The final Unknown, D, was the most common starch granule encountered in this study. It has some similarities with a mesquite starch type in Giovannetti et al. (2008), but the large facets and overall angularity limit a secure identification. Based on the size, angular shape, and open hilum, the botanical source for this starch morphotype is probably a geophyte or 
aquatic resource that has not been incorporated into the reference collection to date.

\section{Future Directions}

Clearly there are still large gaps in the current understanding of prehistoric subsistence strategies in Central Texas and surrounding ecoregions. While this study shows the utility and promise of FCR starch residues, the limited ethnohistoric and archaeological understanding of the comprehensive subsistence resource universe exploited by the human populations in this region severely limits the interpretation of this data. A more rigorous examination of ethnographically known subsistence resources across the region would further develop the known starch references and allow for more secure interpretation of unknown starch granules recovered from archaeological contexts. Expanding this beyond the ethnographic and ethnohistoric record to encapsulate all potential geophytes in Central Texas may be necessary.

Very few starch granules were encountered on most of the FCR samples examined in this study. This is primarily due to the minimal sampling technique employed, which leaves a bulk of the sample's microscopic residue intact for further studies. In addition to limiting the overall quantity of starch granules recovered from each sample, this technique may also limit the number of types of starch recovered on any one sample. This could be avoided by a more complete sampling strategy on each artifact, but this in turn would limit the replicability of this study, as well as any attempts at future biochemical residue studies. 


\title{
Chapter 10
}

\section{BuRned Rock TeChNOLOGY}

\author{
By John A. Campbell
}

\section{Burned Rock}

In total, 6,754 burned rocks and fragments weighing $316.52 \mathrm{~kg}$ were collected during the 1996, 1997, and 1998 field school seasons. Of this rock, the vast majority consists of limestone cobbles; however, fragments of burned chert and burned fossils also occur. The majority of the burned rock was collected from features identified during the excavations at the site. Unfortunately, the provenience of the rock collected from feature contexts is not included on all bags or in previous inventories from the field school. As such, the data are not wholly reliable for ascertaining the mass of burned rock occurring by feature. Therefore, estimates on burned rock mass in feature contexts were derived by correlating the depth indicated on the field bags with the depth the features occurred; the depth indicated by the level from which it was collected. Additionally, due to the fragmentary nature of burned rock, the count of burned rocks is not entirely useful and so only weights of the rocks were used during the analysis.

An examination of the burned rock weights throughout the AUs shows high peaks of burned rock in the Late Archaic II (AU 4a) and the Toyah phase (AU 3a). However, these weights represent the totals over each $\mathrm{AU}$, which have varying durations and thus do not provide for an accurate comparison. To account for the disparity in the duration of AUs, the weight frequencies were standardized to reflect the total weight of burned rock per 100 years over the length of each AU. The standardized frequency for burned rock weight is calculated by first dividing the recorded frequency $\left(F_{R}\right)$ of burned rock weight by the duration of the AU $(T)$. This value is then divided by the total volume $(V)$ of the excavated areas within the AU. Finally, the result is then multiplied by 100 to provide a standardized frequency of burned rock in grams $\left(F_{S}\right)$ for every 100 years. This application can be expressed in the following equation:

$$
F_{S}=\left(\left(F_{R} / T\right) / V\right) \times 100
$$

To apply this formula, the total weight of burned rock from each AU was determined from the artifact catalog. The burned rock weights from quadrants adjacent to AUs and at the same elevation were also included. Features were not accounted for in these calculations. The resulting distribution of standardized frequencies is provided below in Table 10-1. Figure 10-1 shows the distribution of both the normal and standardized frequencies for each $\mathrm{AU}$, which demonstrates the problems with using nonstandardized frequencies in cross comparisons. Figure 10-2 provides a line graph of the distribution of the standardized frequencies, also showing peaks in the Late Archaic II (AU 4a) and the Toyah phase (AU 3a). However, in contrast to the normal weight frequencies, the standardized frequencies show that the Toyah phase has a much larger increase in burned rock in relation to the other AUs. The Austin phase (AU 3b) has the lowest amount of burned rock of all the AUs. 
Table 10-1. Standardized Burned Rock Weight.

\begin{tabular}{ccccccc}
\hline Period (AU) & $\begin{array}{c}\text { Date } \\
\text { (Years BP) }\end{array}$ & $\begin{array}{c}\text { Duration } \\
(T, \text { Years) })\end{array}$ & $\begin{array}{c}\text { Volume } \\
\left(V, \mathbf{m}^{3}\right)\end{array}$ & $\begin{array}{c}\text { Weight } \\
\left(F_{R}, \mathbf{g}\right)\end{array}$ & $\begin{array}{c}\text { Standardized } \\
\text { Weight }\left(F_{S}, \mathbf{g}\right)\end{array}$ & $\begin{array}{c}\text { Percent } \\
\text { Total }\end{array}$ \\
\hline $\begin{array}{c}\text { Middle Archaic } \\
\quad \text { (AU 5) } \\
\text { Late Archaic I } \\
\quad \text { (AU 4b) }\end{array}$ & $5800-4000$ & 1,800 & 0.2 & $1,956.6$ & 543.50 & 3.40 \\
$\quad \begin{array}{c}\text { Late Archaic II } \\
\quad \text { (AU 4a) }\end{array}$ & $2200-1250$ & 950 & 1 & $28,890.8$ & $3,041.14$ & 19.04 \\
$\begin{array}{c}\text { Late Prehistoric-Austin } \\
\quad \text { (AU 3b) }\end{array}$ & $1250-750$ & 500 & 0.3 & 46.6 & 31.07 & 0.19 \\
$\begin{array}{c}\text { Late Prehistoric-Toyah } \\
\text { (AU 3a) }\end{array}$ & $750-300$ & 450 & 0.4 & $19,402.8$ & $10,779.33$ & 67.49 \\
$\quad \begin{array}{c}\text { Historic NA } \\
\text { (AU 2) }\end{array}$ & $300-150$ & 150 & 0.1 & 35.8 & 238.67 & 1.49 \\
\hline Total & & & & & $15,971.79$ & 100.00 \\
\hline
\end{tabular}

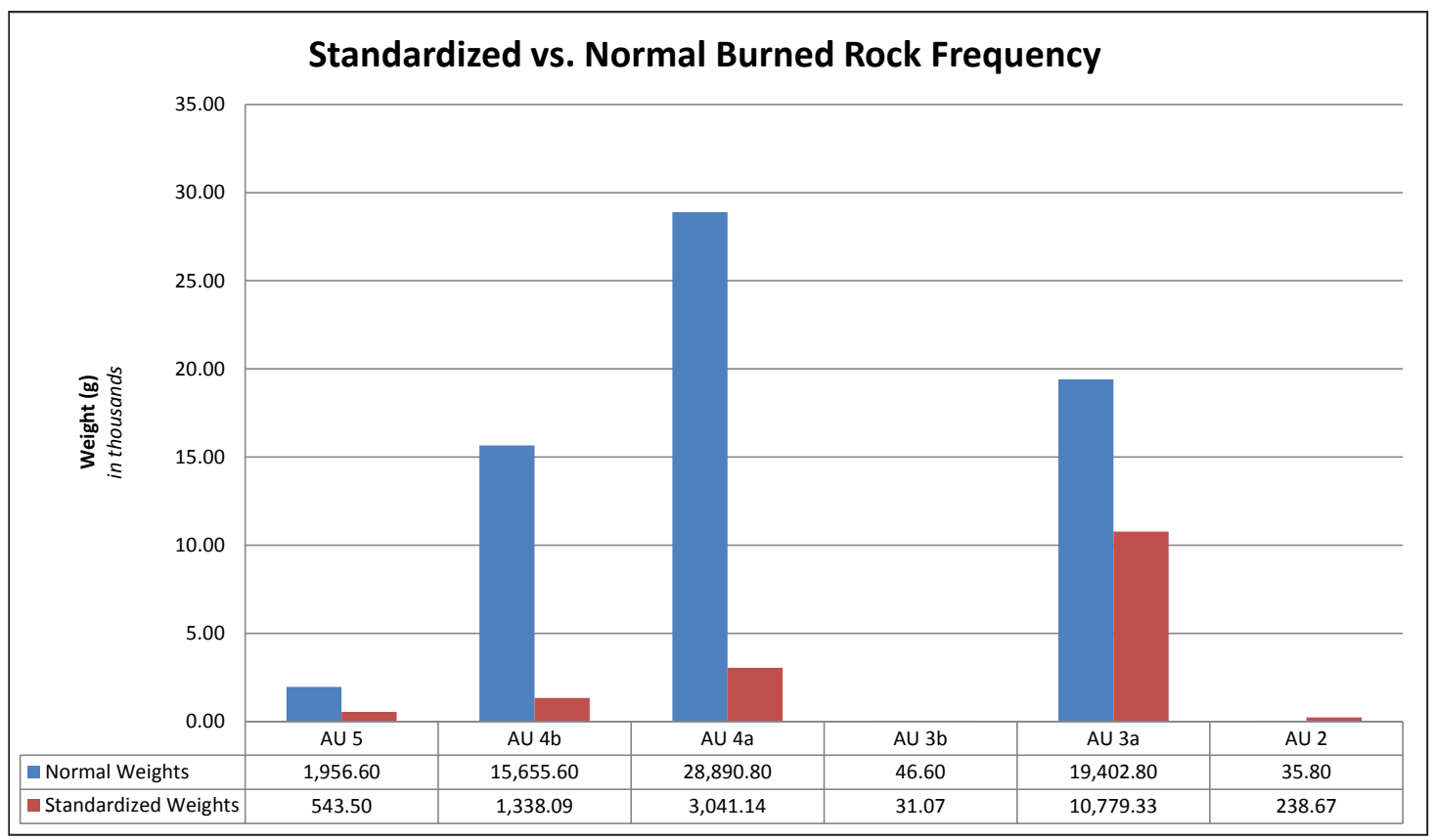

Figure 10-1. Standard vs. normal burned rock frequency.

As outlined in Chapter 4, the frequency of burned rock weights can be used as a proxy for measuring subsistence intensification within a local or regional population. The standardized frequency of burned rock weights at 41HY165 peaks during the Late Archaic II (AU 4a) and also during the Toyah phase (AU 3a) of the Late
Prehistoric. There is also a notable drop in the frequency of burned rock between these two phases, during the Austin phase (AU 3b) of the Late Prehistoric. The increase of burned rock in both subperiods of the Late Archaic reflects an increasing use of the site and may also be the result of the subsistence economy shifting 


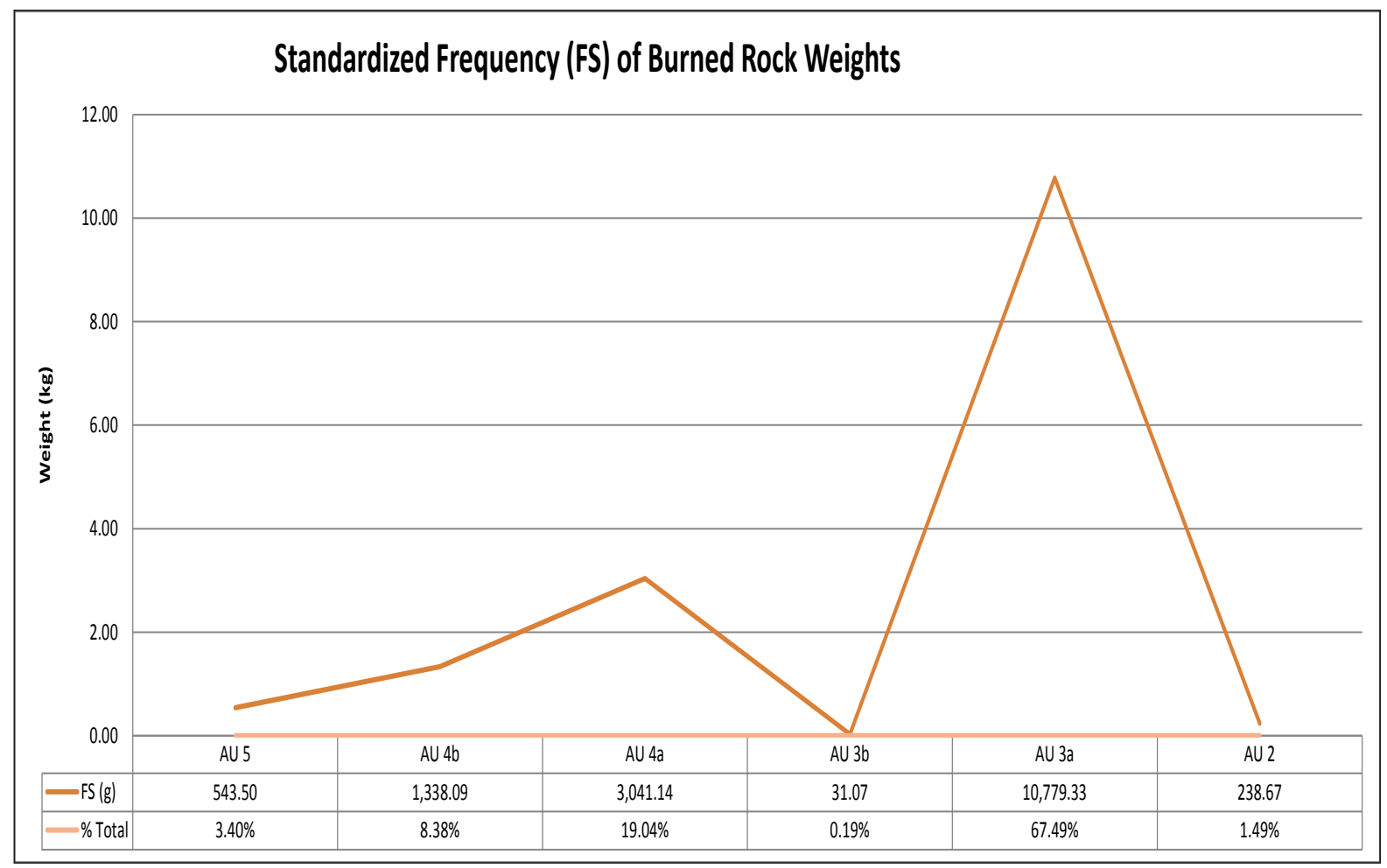

Figure 10-2. Standardized frequency of burned rock weights.

towards bison exploitation or the intensification of plant resources. The drop in the frequency of burned rock during the Austin phase suggests more infrequent use of the site, which may be the result of fewer bison in the area, or the lack of Austin phase artifacts from as secure context at the location of excavations. The Toyah phase sees a dramatic increase in the frequency of burned rock, and this is likely due to both renewed exploitation of bison as well as intensification of plant resources (Thoms 2008). This increase in burned rock also likely reflects changing mobility and settlement patterns related to increased regional population.

\section{Analysis of Recorded Features}

During the course of excavations in the three field schools, 18 features were identified (Table 10-2). Of these 18 features, eight were described in detail by Ringstaff (2000) as part of his analysis of the site, and the remaining 10 features were recorded on unit level or feature forms. All of the observed features, except for Features 6 and 3-97, consisted of burned rock concentrations or "hearths." Feature 6 is a postmold feature and Feature 3-97 is a historic artifact concentration. Ringstaff (2000) also identifies four "archaeological zones" that consist of areas with "no discernible shape or form and are only represented by a sharp increase in artifact frequency." Unfortunately, the features identified at the site could not be evaluated entirely as part of this investigation. Therefore, the following descriptions are largely based on Ringstaff's descriptions, information from field forms, assumptions based on burned rock distribution by unit and level, and additional analysis of selected samples of burned rock.

It was unclear which artifacts in the collection were associated with features and, although some artifacts were labeled with feature numbers, features were not always completely 
Table 10-2. Features Identified at 41HY165.

\begin{tabular}{|c|c|c|c|c|c|c|c|c|}
\hline Feature & $\mathbf{A} \mathbf{U}$ & Type & Unit & Level & $\begin{array}{c}\text { Top } \\
\text { Depth } \\
\text { (cmbs) }\end{array}$ & $\begin{array}{c}\text { Bottom } \\
\text { Depth } \\
\text { (cmbs) } \\
\end{array}$ & $\begin{array}{l}\text { Diagnostic } \\
\text { Artifacts }\end{array}$ & Comments \\
\hline $2 / 96$ & $3 a$ & scatter & 2 & $3-4$ & 12 & 32 & $\begin{array}{l}\text { Perdiz (2), } \\
\text { Scallorn }\end{array}$ & $\begin{array}{c}\text { lithics clustered in SE } \\
\text { quad }\end{array}$ \\
\hline $5 / 96$ & $3 b$ & cluster & 2 & $5-6$ & 30 & 50 & Darl in SE & $\begin{array}{l}\text { semi-circular cluster in } \\
\text { NW quarant and ovate } \\
\text { cluster in SE quadrant }\end{array}$ \\
\hline $4 / 97$ & & scatter & 3 & $2-3$ & 5 & 25 & Perdiz & clustered in NE quad \\
\hline $7 / 96$ & $4 b$ & cluster & 2 & $10-11$ & 82 & 102 & Morhiss & ovate, no charcoal \\
\hline $3 a / 96-6 / 97$ & $4 a$ & scatter & 3,8 & $4-6$ & 25 & 55 & Marcos & $\begin{array}{l}\text { clustered in SW quad; } \\
\text { Marcos point in Unit } 8\end{array}$ \\
\hline $3 \mathrm{~b} / 96$ & $4 b$ & scatter & 3 & $7-8$ & 55 & 75 & & $\begin{array}{l}\text { clustered across NE and } \\
\text { SE quads; basin shaped }\end{array}$ \\
\hline $3 c / 96$ & & scatter & 3 & $8-9$ & 65 & 85 & Pedernales & $\begin{array}{c}\text { clustered in NW quad; } \\
\text { basin shaped; continues } \\
\text { west }\end{array}$ \\
\hline $11 / 97$ & & scatter & 3 & $10-11$ & 80 & 105 & $\begin{array}{l}\text { Angostura, } \\
\text { Golondrina }\end{array}$ & $\begin{array}{l}\text { quasi-clusters between } \\
\text { NW \& SW quads }\end{array}$ \\
\hline 6 & & & 5 & 8 & 65 & 75 & & \\
\hline $2-96$ & & & 4 & $5-7$ & 35 & 65 & & \\
\hline $10-96$ & & & 8 & & & & & \\
\hline $1-97$ & $4 a$ & & 7 & $1-4$ & 0 & 35 & & Level $4 \mathrm{NW}$ quad for $\mathrm{AU}$ \\
\hline $2-97$ & $4 a$ & & 11 & $3-5$ & 14 & 44 & & Level 4 for $\mathrm{AU}$ \\
\hline $3-97$ & & & 9 & 3 & 15 & 25 & & \\
\hline $5-97$ & & & 11 & 5 & 34 & 44 & & \\
\hline $7-97$ & & & 7 & 4 & 25 & 35 & & \\
\hline $9-97$ & $4 a$ & & 8 & 9 & 70 & 75 & & \\
\hline $10-97$ & & & 8 & 9 & 75 & 85 & & \\
\hline
\end{tabular}

defined in the field. Therefore, it was not prudent to associate artifacts with features for this report to avoid under- or overrepresenting the number of artifacts recovered from feature contexts. The exception to this is projectile points, which were typically drawn on plan maps in the field and, given their diagnostic traits, are much easier to correlate with the feature. The artifacts and their counts provided in the feature descriptions below are the data given in Ringstaff's thesis; they are presented here for informational purposes. The reader should also note the nomenclature used for identifying these features. The feature numbers listed below are written exactly as they were on the feature forms and in Ringstaff's thesis (e.g., Features 2/96 and 2-96 are two different features, 2-97 would be a different, third feature). These numbers were retained to maintain continuity 
between previous work at the site and the current investigation.

Prehistoric cooking technology commonly consists of open-air hearths (grilling), closed pits or ovens (roasting and steaming), and open pits for boiling that use rocks heated in surface hearths (Thoms 2009:577). The process of cooking food will result in increased nutrient density, removal of pathogens and detoxification, and increased storage life (Wandsnider 1997:3). Prehistoric subsistence in the region consisted of a broadspectrum diet that included xerophytic plants such as sotol and yucca as well as other plants like camas and onion, which require prolonged cooking for 36-48 hours to increase their nutritional value and/or eliminate toxins (Dering 1999:661; Thoms 2009:576). While the degree to which these plants contributed to the prehistoric diet is still unknown, closed pits or ovens are an efficient way to cook these plants, as heat can be stored in rocks that, once buried, will continue to release heat for more than 24 hours (Dering 1999:661; Thoms 2009:576). In addition, the storage of heat in buried rocks allows for less fuel consumption as open fires will rapidly dissipate heat into the surrounding air or ground, requiring more fuel for longer cooking times (Thoms 2009:576). Although there are several methods that can be utilized to create an earth oven, the general process involves a layered arrangement of heated rocks, packing material (such as prickly pear, grasses, or other plant material), food, and a cap of sediment to retain heat (Ellis 1997:66-76). While the packing material acts as both insulation and a source of moisture for steaming, in some cases water may be added to intensify steaming (Ellis 1997:66-76). Once the food inside has been cooked, the overlying sediment is removed, and the food is removed for consumption or additional processing, leaving behind the rocks making up the "oven bed" (Black 1997:259).
Burned rock middens represent the accumulation of waste rock material from these cooking episodes. Black and Creel (1997:295) argue that burned rock middens are the result of repeated use of center-focused cooking facilities. The defining characteristic of these midden features is the presence of a primary structural element, such as a centrally located, rock-lined pit, which marks the locus of activity (Black and Creel 1997:295). The morphology of the typical Central Texas midden is the result of repeated rearrangement of the waste material around the center; often times manifesting archaeologically as a mounded ring or cone (Black 1997:84-85).

\section{Feature 2/96}

On the unit level forms and some of the bags associated with this feature, it is identified as Feature 1, but Ringstaff (2000) refers to this feature as Feature 2/96 (Figure 10-3). The feature consisted of a burned rock scatter that occurred across the entirety of Levels 3 and 4 in Unit 2, with a denser concentration of burned rock occurring in the northeast quadrant. The feature was observed to be $15 \mathrm{~cm}$ thick and contained two Perdiz points and one Scallorn arrow point. In addition, lithic tools $(n=35)$, ceramics $(n=4)$, and debitage $(n=1,791)$ were reported from this feature by Ringstaff. Ringstaff notes that there were 139 burned rocks weighing $15.5 \mathrm{~kg}$ in this feature, and the current collection includes 19.40 $\mathrm{kg}$ of burned rock from Level 4 Unit 2. The lithics reported from this feature were found across the entire unit at these levels, but were concentrated in the southeast quadrant. Several pieces of charred wood were also observed within the feature. Ringstaff identified this feature as a hearth; however, the amount of burned rock recovered and the distribution of scattered burned rocks around a central concentration suggest that this feature is the remains of an earth oven. The scattered burned rock on the periphery 


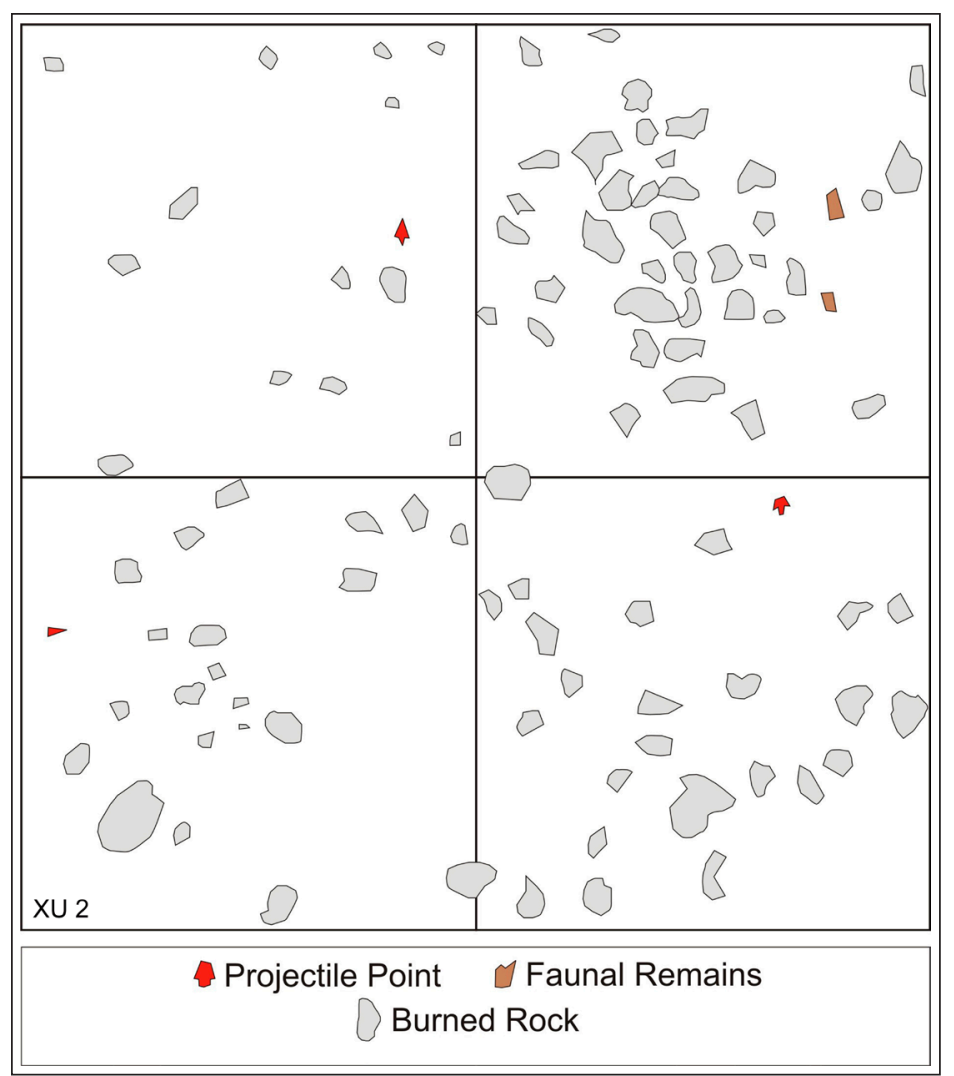

Feature 5/96

This feature was referred to as Feature $5 b$ on the field forms and Feature 5/96 by Ringstaff (2000), and also occurred in Unit 2 (Figure 10-4). Observed between Levels 5 and 6 in Unit 2, this feature consisted of a semicircular concentration of burned rock in the northwest quadrant and an ovate concentration of burned rock in the southeast and southwest quadrants. The semicircular concentration was estimated to be $50 \times 70 \mathrm{~cm}$ in size and the ovate concentration measured $60 \times 65 \mathrm{~cm}$. Both of these concentrations were $8-10 \mathrm{~cm}$ in thickness. Ringstaff (2000) reports a total of 36 burned rocks weighing $15.5 \mathrm{~kg}$ for this feature, and the

Figure 10-3. Plan view of Feature 2/96.

represents the waste rock discarded from previous uses. Given the small size of the feature, it may have been used only a few times.

A date for this feature was recovered from a bison bone that was found in the southwest quadrant of Unit 2, Level 4. The bone dated from 640 to $536 \mathrm{cal}$ BP and, along with the Perdiz points, places this feature in the Late Prehistoric Toyah phase, AU 3a. Two burned rock samples, also from the southwest quadrant of Level 4, were submitted to the AEL. Only one of these samples (Specimen 79-14) contained starch granules, which were not able to be identified, but resemble starch granules from mesquite seedpods.

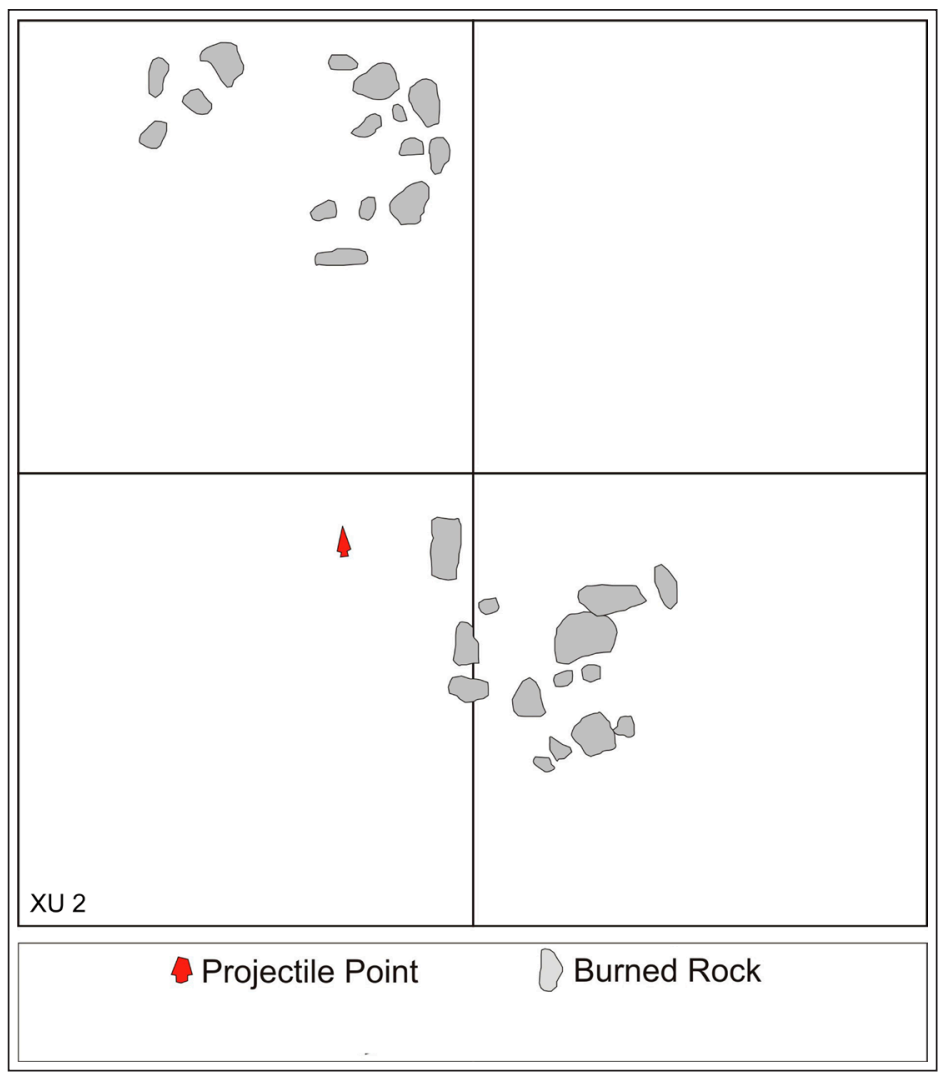

Figure 10-4. Plan view of Feature 5/96. 
current collection includes 12.03 $\mathrm{kg}$ of burned rock from Levels 5 and 6 of Unit 2. Other artifacts reported from the feature include a single Darl dart point, lithic tools $(n=7)$, debitage $(n=689)$, and faunal remains $(n=45)$. The Darl point was recovered from the southwest quadrant on the periphery of the ovate concentration. Ringstaff (2000) mentions that only a few pieces of charcoal were observed in the feature and he concludes that these discrete clusters of rock most likely represent dump piles from stone boiling. Based on the unit plan map of this level by Ringstaff (2000), both of the features are separated by over $50 \mathrm{~cm}$ horizontally, and may likely represent two different episodes of activity. Without additional information it is impossible to ascertain any other function for this feature.

\section{Feature 7/96}

Feature 7/96 was observed as an isolated concentration of burned rock in the northeast quadrant of Unit 2 in Levels 10 and 11 (Figure 10-5). The feature measured $80 \times 55 \mathrm{~cm}$, had an ovate shape, and was approximately $20 \mathrm{~cm}$ thick. No charcoal was reported from the feature, but a single nutshell fragment was identified in the collection from Unit 2, Level 11. A Morhiss dart point with asphaltum on its stem was also recovered from the interior of the feature. Additional artifacts reported in the field included lithic tools $(n=4)$, faunal remains $(n=8)$, and debitage ( $n=381)$. Ringstaff (2000) reports that 45 burned rocks weighing $5 \mathrm{~kg}$ were recovered, and the current collection has $5.75 \mathrm{~kg}$ of burned rock from these two levels. Due to the lack of charcoal and thus no in situ burning, Ringstaff

(2000) suggests that this feature likely is a dump pile from another cooking feature. While this feature appears fairly discrete, the surrounding quadrants were not excavated to this depth to examine the potential of adjacent deposits.

Radiocarbon dating of the charred nutshell from the feature returned a date of 2962-3142 cal BP. That date, along with the Morhiss point (Late Archaic I), puts this feature within the early Late Archaic and in AU 4b. Three burned rock samples from this feature were submitted to the AEL, and starch grains were identified on each sample. One of the samples (Spec. 69-13) contained a starch grain from the genus Hordeum, which are grasses. The other two samples (Spec. 74-7 and 74-8) had starch granules from the knotweed plant (Polygonum sp.). Sample 74-8 also had a fragment of plant epidermal tissue that is consistent with yucca. Since there is no clear 
function to the feature, there is no indication as to how these plants may have been used. Both of these plants are common in Texas and both have been used by Native Americans as food and medicine (Moerman 1998).

\section{Feature 4/97}

This feature was observed in Unit 3, Levels 2 and 3 as a scatter of burned rock across the majority of the unit (Figure 10-6). The main portion of this feature is located in the northeast quadrant and consisted of a concentration of burned rock approximately $70 \times 35 \mathrm{~cm}$ that was amorphous in shape. This concentration extends into the north wall of the unit, leaving the feature only partially exposed. Artifacts reported from the feature include a single Perdiz arrow point, lithic tools $(n=4)$, faunal remains $(n=44)$, and debitage $(n=361)$. The burned rock recorded during the field school totaled 32 rocks weighing $3.5 \mathrm{~kg}$, and the current collection has $0.15 \mathrm{~kg}$ from these two levels. Ringstaff (2000) concluded that the function of the feature could not be determined due to its incomplete exposure. However, given the low density of burned rock on the periphery of the feature in the northwest, southwest, and southeast quadrants, and tightly clustered rock in the northeast quadrant, the feature may represent the remains of an earth oven, with the concentration representing a central cooking element and the surrounding rock being waste material from this feature.

\section{Feature 3a/96-6/97}

This feature consists of a burned rock scatter that extends across Unit 3 and part of Unit 8 in Levels 4, 5, and 6 (Figure 10-7). It was identified as a broad scatter of burned rock across the entire unit with a denser concentration of burned rock in the southwest quadrant. In the plan view, the feature exhibited an amorphous shape, measured $115 \times 95 \mathrm{~cm}$ in size, and extended into the northwest quadrant of Unit 8. Artifacts reported from the feature included a single Marcos point in Level 4 of Unit 8, lithic tools $(n=20)$, faunal remains $(n=298)$, and debitage $(n=1,151)$, all occurring within a $20-\mathrm{cm}$ zone between these three levels. Burned rock recovered during the field school totaled 81 pieces weighing $5.5 \mathrm{~kg}$, and the current collection has $10.36 \mathrm{~kg}$ burned rock across all three levels; however, some of the rocks in the current collection may be associated with the underlying Feature 3b/96. Ringstaff (2000) does not assign a function to this feature, nor does he note any charcoal in the feature.

Figure 10-6. Plan view of Feature 4/97. 


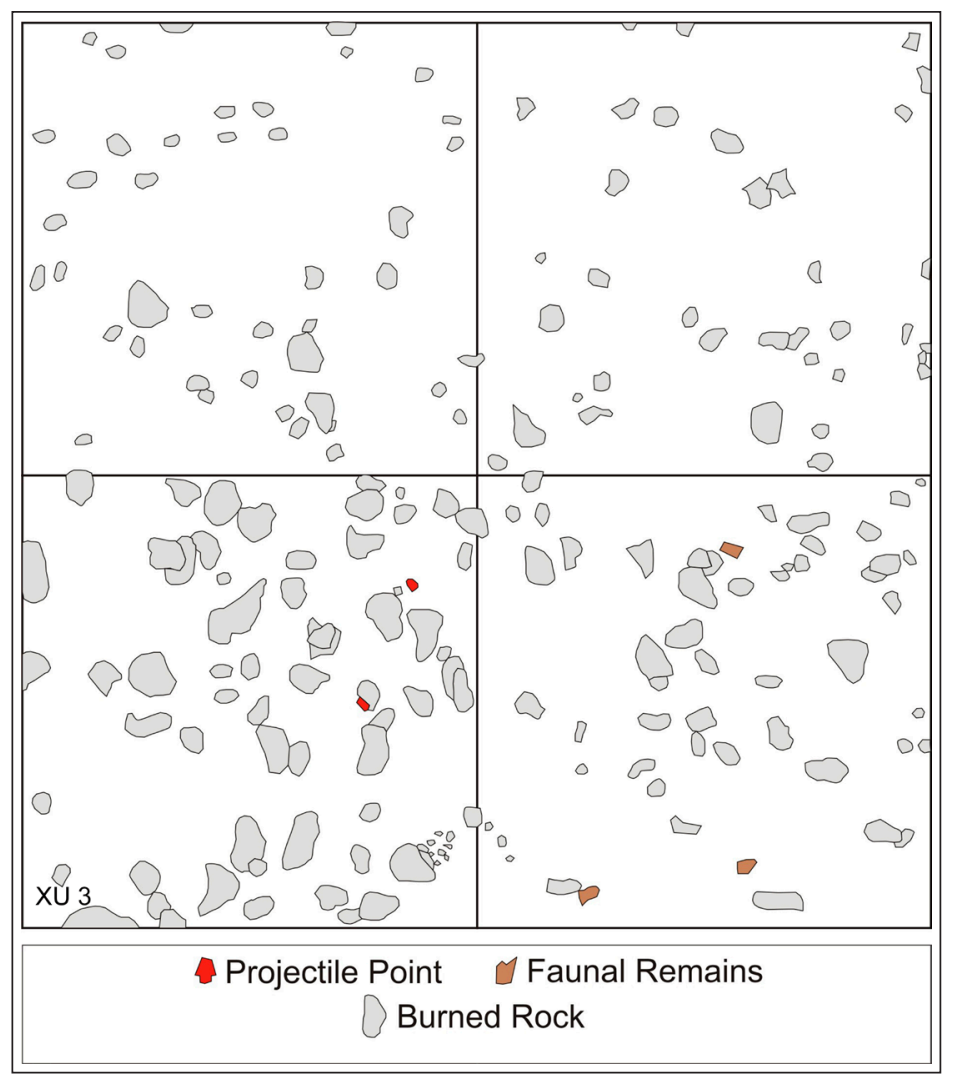

Figure 10-7. Plan view of Feature 3a/96-6/97.

In addition to the Marcos projectile point, an Ensor point was also found in the southwest quadrant of Unit 3, Level 4. Wood charcoal from this feature was dated from 1412 to 1524 cal BP within the Late Archaic II period and AU 4a. This assignation also is supported by the recovered projectile points. Four burned rock samples were submitted to the AEL for starch grain analysis. Three of these samples contained starch granules, one similar to yucca (Yucca sp.), two similar to arum family plants (Araceae), and the remainder unidentifiable. Four phytoliths were also recovered from these rocks. Three of the phytoliths are associated with the Poaceae family of grasses (e.g., dropseed grasses, panic grass, and big bluestem) the remaining phytolith is a calcium oxalate crystal with a stylus shape that is common in yucca, sotol, or agave. The presence of yucca in this feature is one line of evidence to suggest this feature was an earth oven facility, since yucca plants require prolonged cooking to render them edible. Plants of the Araceae family are also cooked in earth ovens, and these plants may have been common in the wet environment around Spring Lake. However, the starch granules from these plants are more likely to be destroyed in a rock-heated oven with more moisture, and may not be visible in the archaeological record (Messner and Schindler 2010:334).

\section{Feature 3b/96}

Feature 3b/96 was identified immediately below Feature 3a/966/97 in Levels 7 and 8 of Unit 3. The feature is a broad scatter of burned rock across the entire unit with a central, circular concentration of rock in the northeast and southeast quadrants that measures $110 \times 95 \mathrm{~cm}$ and is approximately $20 \mathrm{~cm}$ thick. In profile, the concentration exhibits a basin-shaped morphology, suggesting that this is the central cooking element of an earth oven with scattered waste rock around the remainder of the unit. Artifacts reported from the feature include lithic tools $(n=23)$, faunal remains $(n=274)$, and debitage $(n=1,046)$. Burned rock noted by Ringstaff (2000) totaled 307 weighing $21.25 \mathrm{~kg}$; the current collection has $27.48 \mathrm{~kg}$. No charcoal is noted from this feature, but Ringstaff (2000) concludes that it is a hearth feature. Based on the amount of rock and the morphology of the feature, it is likely that this feature is the remains of an earth oven and associated midden.

\section{Feature 3c/96}

Feature 3c/96 was identified in Unit 3 in Levels 8 and 9 as broad burned rock scatter with associated concentrations of rock. Ringstaff 
(2000) notes only one concentration of burned rock in the northwest quadrant, but based on his map of the feature, there appears to be a second concentration in the northeast and southeast quadrants. The concentration identified in the northwest quadrant measured $75 \times 90 \mathrm{~cm}$ with a thickness of $15 \mathrm{~cm}$, was basin shaped, and contained charcoal, suggesting in situ burning. The west portion of this concentration extends into the western wall of the unit. Artifacts reported from the feature include a single Pedernales dart point, lithic tools $(n=12)$, faunal remains $(n=143)$, and debitage $(n=693)$. In total, 328 pieces of burned rock weighing $17.5 \mathrm{~kg}$ were noted during the field school, and the current collection has $35.54 \mathrm{~kg}$ of burned rock from these two levels. Ringstaff (2000) identifies this feature as a hearth, but given the amount of burned rock and the two rock concentrations, this feature likely represents one or two central cooking features of earth ovens with associated midden deposits.

\section{Feature 11/97}

This feature was observed in Unit 3 in Levels 10 and 11 as a dense scatter of burned rock occurring across the entire unit, approximately $20 \mathrm{~cm}$ thick. Ringstaff (2000) identifies two quasi-clusters of burned rock in the northwest and southwest quadrants; however, these are not very apparent in his feature map. Two projectile points were recovered from the feature and included a Golondrina point and an Angostura-like point. Additional artifacts include lithic tools $(n=15)$, faunal remains $(n=102)$, and debitage $(n=700)$. Burned rock was noted as 503 pieces weighing $35 \mathrm{~kg}$, and the current collection has $38.75 \mathrm{~kg}$ of burned rock from these two levels. Given the scattered morphology of the feature, Ringstaff (2000) does not assign a function to the feature and no additional conclusions are presented here.

\section{Feature 6}

This feature was identified in Unit 5 within Level 8. Feature 6 was recorded as a possible postmold. The feature exhibited a circular shape approximately $23 \mathrm{~cm}$ in diameter, with an interior area approximately $13 \mathrm{~cm}$ in diameter. The interior area of the feature was a darker stained matrix with charcoal. Surrounding this interior area is an area of dense, burned clay. In profile, the feature has approximately vertical sides and tapers at the base, which terminates $17 \mathrm{~cm}$ below the observed surface of the feature. The presence of the darker matrix and the surrounding burned clay suggests the in situ burning of a post. Although it is possible that the feature may represent the remains of a burned tap root of a tree, the profile drawing does not indicate any roots extending from the central feature. The feature was partially mapped in plan view and then pedestaled. The pedestaled portion was then bisected along the middle of the feature to observe it in profile. While this information is derived solely from the unit level forms, the description of the feature and the plan and profile drawings strongly support the function of this feature as a postmold. There is no indication that any other postmolds were identified on the site.

\section{Feature 2-96}

This feature was identified in the southwest and southeast quadrants of Unit 4 in Levels 5, 6, and 7. The majority of this feature consists of a low-density scatter of burned rocks, bone, and lithics. However, in Level 6 within the southwest quadrant, there is a circular concentration of burned rock with an interior diameter of approximately $50 \mathrm{~cm}$. This interior area is devoid of artifacts (at least in the plan view map) and may represent either a small pit roasting facility or an area used for stone boiling, either as a pit or central location to boil water in a skin bag 
or other container. Although there is no strong indication that this feature was used for stone boiling, some evidence supports this supposition. The excavators note that, in general, the burned rocks are small to medium in size, and there is also no evidence of charcoal within the feature, although the absence of charcoal is not explicitly stated. The density of land snails also increases, which as a food source that presumably would have been boiled, but there is no indication as to whether the collection of snails is a naturally occurring population or a collected one. While it is possible that this feature may represent the remains of stone boiling activities, the evidence is not strong enough to confirm this, and therefore the function is unknown.

\section{Feature 1-97}

Feature 1-97 was identified in Unit 7 in all four quadrants within Levels 1-4. The feature consisted of a dense, circular cluster of burned rock approximately $130 \times 140 \mathrm{~cm}$. There are about 10 rocks that are over $20 \mathrm{~cm}$ in size in the feature, as well as dozens of other smaller rocks. Based on the plan map drawn in the field, the feature most resembles an earth oven feature, with the rocks from the last cooking episode occupying the central portion of the feature. Several historic artifacts are found in all four levels of this feature, as well as prehistoric artifacts. Due to the uncertain temporal context of the feature it is not possible to assign it to an analytic unit. The function of the feature, given the shape and large quantity of rock, is most likely associated with pit roasting either in prehistoric or historic times.

\section{Feature 2-97}

Feature 2-97 is a low-density scatter of debris identified in Unit 11, Levels 3 through 5, between 14 and $44 \mathrm{cmbs}$ (Figure 10-8). The debris within the feature consisted of burned rock, mussel shell, bone, charcoal, and lithic debitage. A small concentration of this debris was noted in the northeast corner of Level 4. The excavators reported that three projectile points were found among the debris. One of these points is an Ensor point (256-6) and another is an untypable point (256-4); a third point has not been identified within the current collection. Based on the arrangement of the debris within the unit, this is most likely a trash scatter, rather than a cooking feature. The excavators noted that this feature may be part of Feature 5-97, discussed below, and

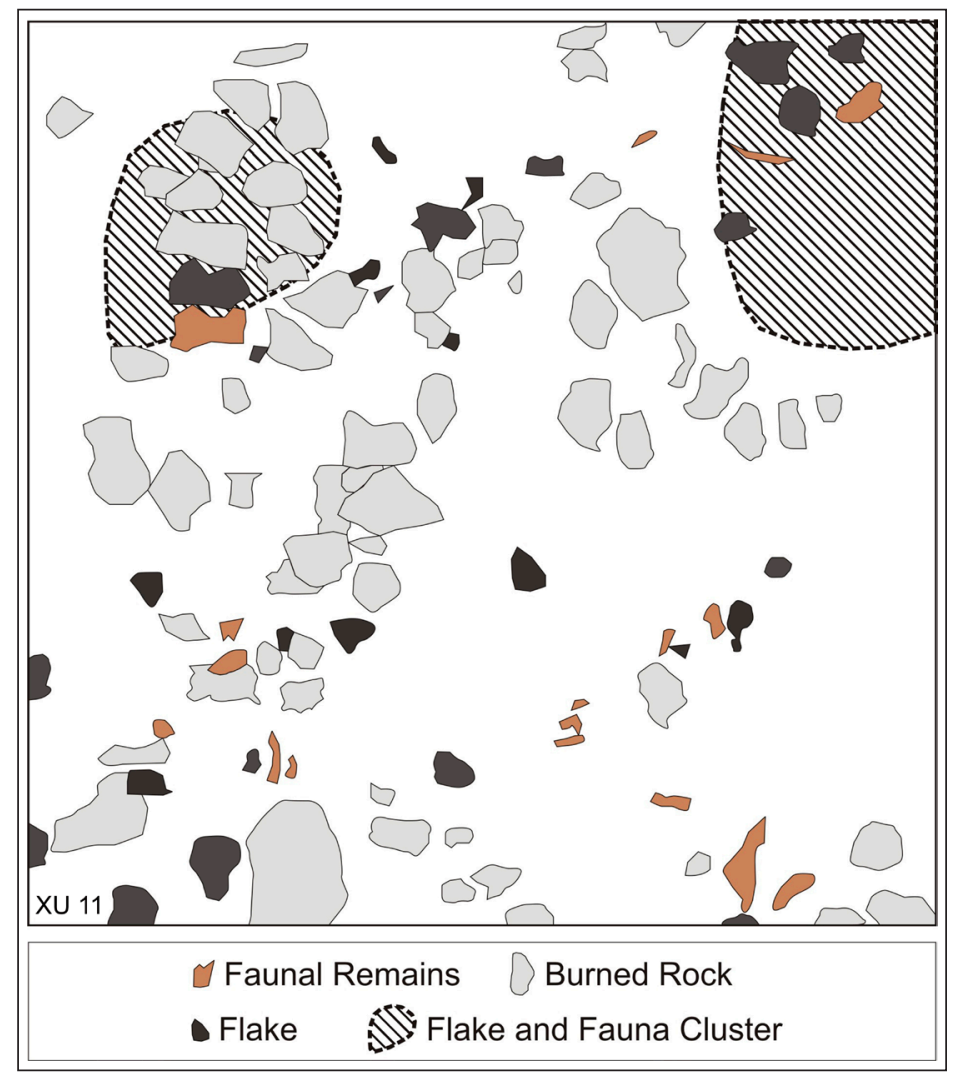

Figure 10-8. Plan view of Feature 2-97. 
the plan map drawn in the field suggests that this debris scatter may extend to the north.

The only diagnostic artifact from this feature was an Ensor projectile point from Level 4 of the feature. This places the feature within the Late Archaic II and AU 4a. Two burned rocks were submitted to AEL for analysis and one of the rocks contained five starch granules. While four of these granules were all of a similar type, none of them could be identified specifically. However, AEL suggest that, based on the morphology of the granules, they resemble granules from geophytes. A grass phytolith was also recovered from this same burned rock.

\section{Feature 5-97}

This feature is a small concentration of burned rocks $(n=11)$ arranged in a semicircular pattern approximately $40 \times 50 \mathrm{~cm}$ in size. The feature was identified in Unit 11, Level 5, between 34 and 44 cmbs. There is little information available for this feature; however, the excavators did note charcoal, bone, and debitage within the surrounding matrix. The excavators also suggest that this feature may be an extension of Feature 2-97. Due to the paucity of information from the field notes, the small size, and the low number of burned rocks, it is not possible to assign a function to this feature.

\section{Feature 3-97}

Feature 3-97 was identified in the southeast quadrant of Unit 9, Level 3, between 15 and 25 cmbs. The feature primarily consists of a dense concentration of window glass. The current collection has 293 pieces of window glass from this quadrant and level. Charcoal, lithic debitage, nails, and a Darl point were also noted within this feature. There is no other information available for this feature.

\section{Feature 7-97}

This feature was identified in the northwest quadrant of Unit 7, Level 4, between 25 and 35 cmbs. Feature 7-97 is a dense cluster of burned rocks arranged in a circular pattern approximately $75 \mathrm{~cm}$ across. The excavators report finding arrowpoints within the feature, but the current collection does not include any arrowpoints from this feature. Overall, Unit 7 is poorly documented, with no clear distinction between Feature 7-97 and Feature 1-97 other than separate plan views. Moreover, there are numerous historic artifacts through Unit 7 that are mixed with prehistoric artifacts. Therefore, no function can be assigned to this feature.

\section{Feature 9-97}

Feature 9-97 was identified in the northwest quadrant of Unit 8, Level 9, between 67 and 77 cmbs. The feature consists of a dense cluster of burned rocks approximately $1 \mathrm{~m}$ across; several of the rocks are approximately $10 \mathrm{~cm}$ in size. Charcoal, lithic debitage, and moderate to heavy concentrations of deer bone were reported by the excavators. It was also noted that the lithics appear to be mostly later-stage debitage. Two burned rock samples were submitted to AEL for analysis, but neither rock contained plant microfossils. As part of his thesis, Ringstaff (2000) dated a single piece of charcoal from this feature, which produced a date of $2300 \pm 40$ RCYBP. Based on its size and shape, the feature is likely a small cooking facility associated with deer processing.

\section{Feature 10-97}

Feature 10-97 was identified in the southeast quadrant of Unit 8, Levels 9 and 10, between 75 and 85 cmbs. This feature is a low-density scatter of burned rock with a small concentration 
of burned rock extending into the east wall. Charcoal, debitage, and deer bone were among the artifacts reported from this feature. It is likely that this feature is an extension of Feature 9-97, discussed above; however, only the northwest and southeast quadrants of this unit were excavated, and therefore connecting these two features is problematic. Due to the low density of material and the lack of any structure, it is not possible to assign any function to this feature. 


\section{Chapter 11}

\section{Zoonrchaeological Analysis of Time- Controlled Material From 41 HY165}

By Cinda Timperley and Carole A. Leezer

\section{Introduction}

Site 41HY165 is one of several archaeological sites identified in the vicinity of Spring Lake in San Marcos, Hays County, Texas. The site was the subject of several archaeological field school excavations between 1984 and 1998. These field schools excavated several test units that have yielded a significant amount of cultural material, ranging from Middle Archaic through Protohistoric periods. Soundness of archaeological context across these units varies widely, necessitating a need to limit the current study to material recovered from secure stratigraphic context. These determinations were based on association with diagnostic lithic artifacts, and/or by association with radiocarbon dated charcoal or bison bone (see Table 4-9).

This is a preliminary analysis of faunal material from Spring Lake site 41HY165. A more comprehensive study that includes all the recovered faunal material remains to be conducted.

The main purpose of this study is to determine any patterns through time regarding procurement of bison, its plentitude or scarcity, other subsistence options, and modes of resource intensification. Once these patterns are outlined, an attempt will be made to place them within the larger context of regional procurement and subsistence practices.
Patterns of taxonomic occurrence through time at 41HY165 were examined for clues to resource distribution, subsistence base intensification, and prey choice with respect to bison procurement. A brief discussion covers the occurrences and condition of the remains of various taxa through time at 41HY165. The occurrence pattern of bison will be highlighted, as will its abundance relative to other prominent game species through time such as pronghorn, deer, and rabbit.

Relative frequencies of fauna material, standardized across AUs for consistency in occurrence, are compared. These comparisons are conducted within each $\mathrm{AU}$ in order to understand prey choice as represented by taxon list, and across all AUs in order to understand shifts in prey choice through time. Number of identified specimens (NISP) and minimum number of individuals (MNI) are calculated as means of quantifying taxonomic occurrence. Skeletal element/portion is identified for wellidentified taxa to the genus level in order to discuss distribution patterns across the site. Due to the low recovery rate of faunal remains from AU 6 (Early Archaic/Late Paleoindian) and AU 7 (Paleoindian), analysis of data from these AUs has been omitted from this chapter. This discussion culminates in the interpretation of resource intensification efforts on the part of the ancient residents of Spring Lake. 
The faunal material from 28 lots in six units was examined. These lots were selected for study because they had reliably associated temporal data. Material in this sample was recovered from Units 1, 2, 2E, 3, 8, 10, and 11 (see Figure 5-1), comprising a temporally controlled subassemblage of whole or partial elements from fine- and coarse-screen fraction.

Each specimen identified to taxon and element was weighed, tagged, and bagged individually. Within a given lot, individual specimens identifiable by element and taxon were assigned specimen numbers. The subassemblage examined here will be curated by taxon, subdivided by AU. Data are organized in a catalog spreadsheet by lot, with specimens within the lot listed taxonomically, then by element.

\section{Materials and Methods}

In analyzing this assemblage, one lot at a time was examined. Specimens within a lot were separated by taxon and element, and by whether or not the specimen was cut, burned, or otherwise altered. Each specimen was initially examined with unaided eye and a 10x Bausch and Lomb hand lens and strong lighting, and more closely with a Bausch and Lomb light microscope when needed. Fine-screen material was sorted with the aid of the microscope at powers ranging from 7-30x. Observations were made and recorded for as many taphonomic aspects as possible, including weathering, scavenging, breakage, cuts, burns, and use wear/utilization. Identifications were assigned to the taxonomic level of the lowest rank possible, ideally genus or species, to ensure accurate taxon representation (see Murray 2008 for discussion on taxonomic nomenclature and representation within a collection).

Specimens were assigned identification to the taxonomic rank with the most confidence.
An important example here derives from the Artiodactyla material. Numerous specimens are of dimensions comparable in size to Odocoileus (white-tailed deer) and Antilocapra (pronghorn). However, not enough of the individual specimen is preserved intact to support applying one or the other generic name. These items are necessarily assigned simply to Order Artiodactyla (eventoed ungulates), which is the next higher rank with a high degree of identification confidence. In this example, assignment skips the familylevel classification because an assignment to either Cervidae or Antilocapridae would narrow down the genera to Odocoileus or Antilocapra by default, as there are no other artiodactyls of this body size endemic to this region.

Since body size is an important consideration in the discussion of subsistence expansion and prey choices, a size class is also assigned: Artiodactyla, medium. The large artiodactyl in the local fauna would be Bison. Small artiodactyls in the regional fauna, not necessarily from this site, include mountain goats. Due to the fragmentary nature of much of the bone, classification was often possible only to the class or ordinal level. Because aspects of the overall site study focus on the trends in body size of prey species, bone fragments identifiable to class or order only were qualified with a body size.

This approach avoids the subjective and somewhat awkward taxonomic assignment of the form ?Genus or Genus ?species. As Murray (2008) documented in his dissertation, those question marks can get glossed over and lost in subsequent citations of faunal lists. In following this method, we hope to avoid, for example, Artiodactyla: ?Antilocapra (Artiodactyla, possibly Antilocapra) becoming in subsequent citations Artiodactyla: Antilocapra (Artiodactyla, positively Antilocapra). Avoiding this equivocal identification is critical to several aspects of site 
interpretation, especially when the more specific assignment of taxon (Antilocapra vs. Odocoileus, or the pocket gophers Thomomys vs. Geomys) can dramatically impact the interpretation of a site's environmental setting.

As mentioned above, body size of prey species is an important criterion in interpretation of subsistence trends. If all zooarchaeological specimens were identifiable to genus and species, sorting the faunal assemblage into body size groups would be straightforward and interpretations made simple. However, such is not the case. As the ancient people processed their quarry to varying degrees of thorough nutrient extraction by smashing and rendering bone, and then subsequent taphonomic processes took hold, zooarchaeologists are often left with fragmentary material that is not always assignable to genus or species.

Sichler et al. (2011) similarly faced the inevitable identification only to class, and provided size ranges when feasible for analysis of the Zatopec fauna. Similar practice is followed here, but we have elected to redefine the size groupings, opting to simplify classification into large, medium, small, and microfauna. While these groups are defined below, some are lumped in later analyses reported in this chapter. In addition, some materials in the fauna catalog are indicated as "medium to large" because they are fragments that could have come from a large deer or pronghorn or from a small Bison. Body size classification is based on modern analogs extant in the region historically.

\section{Mammalia, Large (318-907 kg)}

Bison is the only taxon observed in this collection with a body size exceeding that of Odocoileus/Antilocapra. Body mass for Bison ranges from $318 \mathrm{~kg}$ in small females to $907 \mathrm{~kg}$ in large males (Meagher 1986). This size category is presumed to include Bison only, and so is not used here.

\section{Mammalia, Medium (18-80 kg)}

This category includes deer (average 45-68 $\mathrm{kg}$, female and male, respectively); pronghorn (47 kg in small females to $70 \mathrm{~kg}$ in large males); and wolf (18-55 kg, female, and $20-80 \mathrm{~kg}$, male) (Mech 1974; O’Gara 1978; Smith 1991). The difference in size between Bison and Odocoileus or Antilocapra is great enough to warrant distinction on its own and with respect to approaches to utilization as prey species. Though wolf (Canis lupus) is included in this category, it was not recognized in this assemblage. It was included due to its known historic range and the occurrence of canids at other sites in the region, lending to the possibility of its occurrence here archaeologically (Schmidley and Davis 2004).

\section{Artiodactyla, Medium}

This category is restricted to consider only Odocoileus and Antilocapra-size ungulates; only these two genera occur locally.

\section{Mammalia, Small (1.5-26 kg)}

Small mammals considered here include coyote (11-20 kg) and beaver (11-26 kg) (Bekoff 1977; Daniel 1973; Jenkins and Busher 1979).

\section{Mammalia, Micro $(0.1-1.5 \mathrm{~kg})$}

This category includes cotton rat $(0.1-0.2 \mathrm{~kg})$, wood rat $(0.1-0.3 \mathrm{~kg})$, and cottontail rabbit (0.7$1.5 \mathrm{~kg}$ ) (Cameron and Spencer 1981; Chapman et al. 1980; Chapman and Willner 1978; Schmidley and Davis 2004). 


\section{Systematic Zooarchaeology}

\section{Approach to Systematic Zooarchaeology}

The Systematic Zooarchaeology section (Appendix F) contains taxonomic classification of the faunal material recovered from the six units excavated at 41HY165. Vertebrate systematics follows several sources. Herpetofauna classification (amphibians, snakes, and turtles) follows Holman (1995) and Dixon (2000). Avian terminology follows Peterson (1988). Mammalian taxonomy generally follows Jones and Manning (1992), Jones et al. (1985), and Wilson and Reeder (2005), except where noted. Bovid postcranial skeletal identifications follow Todd (2001). Some identification was aided by use of comparative material held in the Recent Osteology Collection in the Vertebrate Paleontology Laboratory of the Texas Natural Science Center, The University of Texas at Austin.

Klein and Cruz-Uribe (1984:20) state that criteria for identifiability of bone fragments should be stated as clearly and explicitly as possible. Also, they suggest noting which identifications were based on assumptions made on the population from which the faunal sample was taken. It would be prudent also to provide the assumptions on which identifications are based. As an example, the only large artiodactyl reported for prehistoric Central Texas post-Pleistocene is Bison sp. and not any camelid. Therefore, it could be presumed that large, tall-crowned selenodont tooth fragments would be assignable to Bison sp. In later, postcontact deposits, one must consider that European-introduced cattle may also be present, given other evidence in the archaeological assemblage. Since the archaeological assemblage from 41HY165 includes both pre- and postcontact deposits, this latter fact must be considered in the faunal analysis. Table 11-1 lists positively identified taxa from AUs at site 41HY165. Taxa with questionable identification are discussed in
Appendix F, and are not included in Table 111. NISP percent equals NISP for taxon divided by NISP for total assemblage, then multiplied by 100 . Similarly, Mass percent equals mass (g) of taxon material divided by mass for total assemblage, then multiplied by 100 .

\section{Taphonomy}

\section{General Observations}

Preservation of the bone itself is governed by taphonomic processes, both preburial and postburial. To say the bone was poorly preserved is not entirely accurate. Bone of larger animals is usually in small (often less than $5 \mathrm{~cm}$ along c-axis) pieces, but small-taxon elements are usually more intact. All the bone is robust enough to survive analytical handling under normal laboratory conditions. Overall, the bone condition preserves the anthropogenic influences and other preburial mistreatment, with nominal to moderate diagenetic overprinting.

There is some bone that exhibits weathering cracks that run longitudinally on the cortical surfaces of limb diaphysis fragments. Other bone appears to have endured more weathering, with rounding of the crack edges and advanced cortex degradation. This dichotomy is observed in the Late Archaic assemblages. Heavier degradation also is observed in Austin material. Burned bone comprises roughly one-third of the assemblage, ranging from charred to calcined.

\section{Breakage Patterns}

The majority of the broken bones have green or spiral breaks. Some specimens look like bone "shatter," fragments that spalled upon impact. Some of the bone fragments that were broken while fresh exhibit spiral scars overprinted by weathering or scavenging by carnivores and/or 
Table 11-1. Taxonomic Classification List with NISP and Mass Data.

\begin{tabular}{|c|c|c|c|c|}
\hline Taxon & NISP & NISP (\%) & Mass (g) & $\operatorname{Mass}(\%)$ \\
\hline \multicolumn{5}{|l|}{ Fish } \\
\hline Osteichthyes & 177 & 12.28 & 3.2 & 0.54 \\
\hline Lepisosteidae & 1 & 0.07 & 0.1 & 0.02 \\
\hline \multicolumn{5}{|l|}{ Amphibians } \\
\hline Amphibia & 5 & 0.35 & 0.7 & 0.12 \\
\hline Anura & 20 & 1.39 & 1.0 & 0.17 \\
\hline Rana sp. & 1 & 0.07 & 0.1 & 0.02 \\
\hline \multicolumn{5}{|l|}{ Reptiles } \\
\hline Reptile & 1 & 0.07 & $<0.1$ & 0.01 \\
\hline Lacertilia & 2 & 0.14 & 0.1 & 0.02 \\
\hline Serpentes & 28 & 1.94 & 1.2 & 0.20 \\
\hline Testudines & 78 & 5.41 & 17.0 & 2.86 \\
\hline \multicolumn{5}{|l|}{ Birds } \\
\hline Aves & 2 & 0.14 & 0.1 & 0.02 \\
\hline Anatidae & 1 & 0.07 & 0.9 & 0.15 \\
\hline \multicolumn{5}{|l|}{ Mammals } \\
\hline Leporidae & 1 & 0.07 & 1.5 & 0.25 \\
\hline Sylvilagus sp. & 1 & 0.07 & 0.7 & 0.12 \\
\hline Rodentia & 23 & 1.60 & 0.4 & 0.07 \\
\hline Sigmodon sp. & 16 & 1.11 & 1.0 & 0.17 \\
\hline Neotoma sp. & 1 & 0.07 & 0.2 & 0.03 \\
\hline Geomyidae & 2 & 0.14 & 0.2 & 0.03 \\
\hline Castor canadensis & 1 & 0.07 & 3.9 & 0.66 \\
\hline Homo sapiens & 1 & 0.07 & 0.5 & 0.08 \\
\hline Canidae & 1 & 0.07 & 7.6 & 1.28 \\
\hline Artiodactyla (medium) & 68 & 4.72 & 172.7 & 29.03 \\
\hline Odocoileus sp. & 21 & 1.46 & 69.2 & 11.63 \\
\hline Antilocapra sp. & 1 & 0.07 & 0.4 & 0.07 \\
\hline Bison sp. & 11 & 0.76 & 112.5 & 18.91 \\
\hline Mammalia & 574 & 39.83 & 53.9 & 9.06 \\
\hline Mammalia, micro & 12 & 0.83 & 0.2 & 0.03 \\
\hline Mammalia, small & 6 & 0.42 & 2.6 & 0.44 \\
\hline Mammalia, fetal/junvenile & 12 & 0.83 & 4.6 & 0.77 \\
\hline Mammalia, medium & 177 & 12.28 & 97.8 & 16.44 \\
\hline Mammalia, medium/large & 3 & 0.21 & 3.5 & 0.59 \\
\hline Vertebrata & 193 & 13.39 & 37.0 & 6.22 \\
\hline Total & 1441 & 100.00 & 594.8 & 100.00 \\
\hline
\end{tabular}


rodents (see below). Bone breakage does not appear to vary from $\mathrm{AU}$ to $\mathrm{AU}$.

The large amount of spirally fragmented bone strongly suggests bone grease extraction was conducted throughout the prehistory represented at 41HY165. Outram (2001) provides photographic descriptions of various ratings on a fracture freshness index (FFI) that have proven useful in interpreting some of the breaks observed on the artiodactyl material from 41HY165. Especially of note is Figure 4 (Outram 2001:406), which depicts the proximal and distal ends of a cattle radius. This specimen was boiled 10 minutes prior to breakage. The figure illustrates breaks that are both helical and step-like on the same break surface.

Medium-sized artiodactyl bone in several lots exhibit helical and step-like fractures that compare well with those described above, suggesting that these bones were probably boiled, then broken. This is a pattern closely linked with processing bone in order to extract fat. Specimen 299-44 is a humerus fragment from a small mammal, possibly beaver or canid, exhibiting a weak helical fracture alongside a more angular fracture on the same break surface (Figure 11-1). It also exhibits cut marks on the cranio-distal surface. This specimen suggests that bone-greasing activity was not restricted to the processing of only artiodactyl bone.

Other damage observed includes scavenging marks: rodent gnawing, carnivore gnawing (scalloping), and punctured bone. Rodent gnaw marks occur mainly on fragments of medium mammal and medium artiodactyl bone that also exhibit spiral breaks. Carnivore gnaw marks were observed at the articular ends of long bone fragments. Puncture marks occur infrequently and were observed on turtle shell fragments.

\section{Bone Tools}

A small number of bones analyzed in this study appear to have been modified beyond simple nutrient extraction. The following specimens exhibit some polish: 79-28, 299-32, 310-28, and 538-4 (possible broken awl tip; see Figure 11-1). Specimen 311-1 is an Odocoileus metapodial fragment with numerous grooves running longitudinally down the midline. It appears to be a waste fragment from bone tool production. Other bone fragments exhibit cuts consistent with dismemberment and butchery.

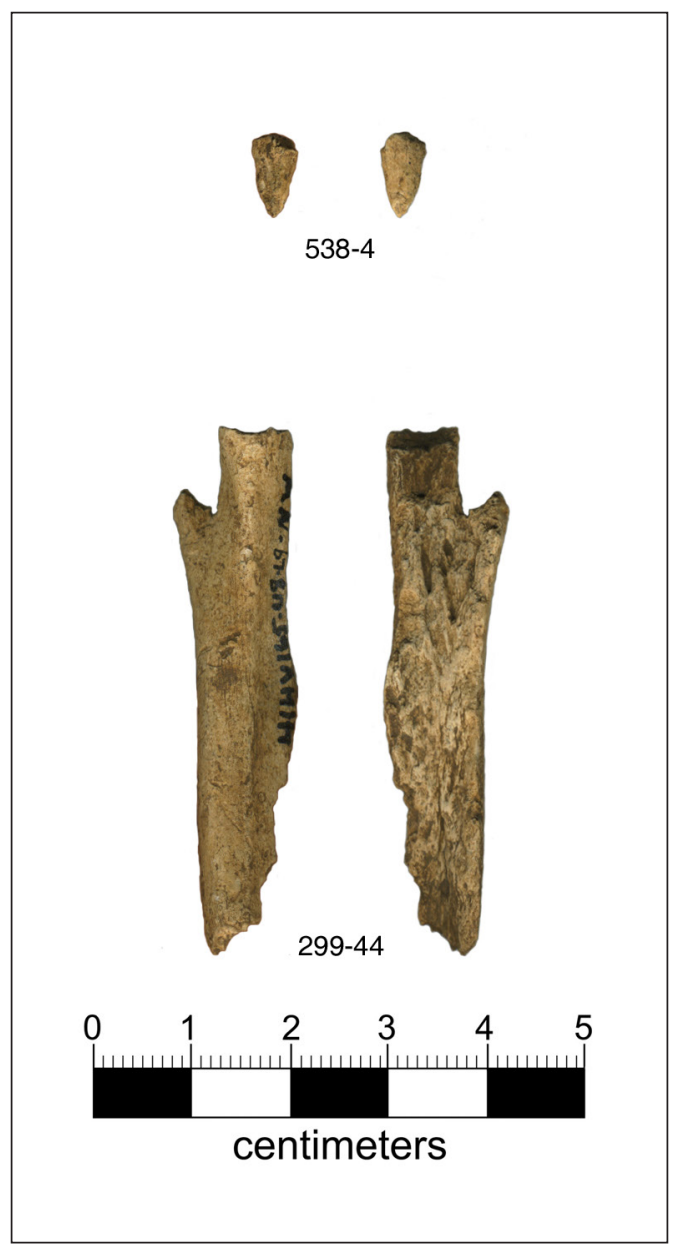

Figure 11-1. Possible awl tip and fragment of a humerus. 


\section{Quantitative Analyses}

In order to meaningfully discuss trends through time, the assemblage required a bit of manipulation. First, we wanted to compare the relative numbers of identifiable taxa from one $\mathrm{AU}$ to the next. To do so, we had to select the taxa to be considered "identifiable." We wanted to compare Bison to medium-size artiodactyls, to smaller mammals, and to lower vertebrates.

This list includes specimens classifiable to six categories: fishes, turtles, other lower vertebrates (Amphibia, Anura, Rana, Lacertilia, Serpentes, Aves, Anseriformes), small mammals (Leporidae, Sylvilagus, Rodentia, Sigmodon, Neotoma, Geomyidae, Castor canadensis, and Carnivora); medium-sized Artiodactyla (deer, pronghorn; Artiodactyla, medium), and Bison. This approach removed the ambiguous classifications Vertebrata and Mammalia (including micro, small, medium, and fetal/juvenile). The criteria were not based on taxonomic level of identification, but focused more on associations with habitat, diurnal/ nocturnal habits, and body size. These criteria affect hunting/procurement methodologies, and the prey categories probably played important roles in the content of contributions of various members of the social unit to the overall subsistence base. Appendix F details criteria for classifying specimens in the above categories.

\section{Number of Identifiable Specimens}

Present (NISP) and Minimum Number of Individuals (MNI)

Several researchers have proposed methods to quantify animal and element abundance in archaeological assemblages (Grayson 1984; Klein and Cruz-Uribe 1984; Lyman 1994; Marshall and Pilgram 1993). However, Marshall and Pilgram (1993) proposed that MNI may be less reliable an indicator of element frequency than NISP when applied to highly fragmented assemblages.
Analysis of faunal material from 41HY165 would not benefit from MNI application due to its highly fragmented nature.

Both NISP and MNI were initially calculated for each $\mathrm{AU}$, but per taxon/per $\mathrm{AU}, \mathrm{MNI}=1$ in most instances. This did not seem to be greatly informative, other than to say that some taxon was present or absent/unidentified in a given period. Several taxa had an MNI greater than one when taken across the entire assemblage, with a minimum of one individual per AU. Taxa with an MNI greater than one within an AU include Sigmodon (Toyah), Odocoileus (Late Archaic II), and probably also Osteichthyes, Serpentes, and Testudines. However, these lower vertebrate groups were not identified beyond the taxonomic rank aforementioned. Thus, only NISP and mass will be considered from here forward.

\section{Standardization}

In order to accurately compare and discuss the occurrence of each taxon and the faunal assemblage as a whole, the amounts of recovered material per AU must be standardized. This is a necessary first step because each AU was not sampled equally. NISP and Mass totals for each taxon per AU were calculated and are presented in Appendix F. These raw frequencies were then used to calculate standardized frequencies of NISP and Mass by AU presented in Table 11-2.

Standardization of occurrence per 100 years is achieved by the following equation:

$$
F_{S}=\left(\left(F_{R} / T\right) / V\right) \times 100
$$

Where $F_{S}=$ standardized frequency, $F_{R}=$ raw frequency (raw number or mass of items), $T=$ duration of $\mathrm{AU}$ in years, and $V=$ excavated volume of matrix per AU in $\mathrm{m}^{3}$.

Two sets of calculations are run, one to standardize the bone counts and the other to 
Table 11-2. Raw and Standardized Values of NISP and Mass, AU Duration, and Volume.

\begin{tabular}{|c|c|c|c|c|c|c|}
\hline $\mathbf{A U}$ & NISP & $\begin{array}{c}\text { Mass } \\
(\mathrm{g})\end{array}$ & $\begin{array}{l}\text { Duration } \\
\text { ( } T, \text { Years) }\end{array}$ & $\begin{array}{l}\text { Volume } \\
\left(V, \mathbf{m}^{3}\right)\end{array}$ & $\begin{array}{c}\text { Standardized } \\
\text { NISP }\end{array}$ & $\begin{array}{c}\text { Standardized } \\
\text { Mass }\end{array}$ \\
\hline $\begin{array}{l}\text { Historic NA } \\
\text { (AU 2) }\end{array}$ & 114 & 73.2 & 90 & 0.2 & 633.3 & 406.7 \\
\hline $\begin{array}{l}\text { Late Prehistoric-Toyah } \\
\text { (AU 3a) }\end{array}$ & 468 & 70.8 & 450 & 0.1 & $1,040.0$ & 157.3 \\
\hline $\begin{array}{l}\text { Late Prehistoric-Austin } \\
\text { (AU 3b) }\end{array}$ & 18 & 10.9 & 400 & 0.1 & 45.0 & 27.3 \\
\hline $\begin{array}{l}\text { Late Archaic II } \\
\text { (AU 4a) }\end{array}$ & 460 & 251.6 & 1,300 & 1.1 & 32.2 & 17.6 \\
\hline $\begin{array}{l}\text { Late Archaic I } \\
\text { (AU } 4 \mathrm{~b})\end{array}$ & 311 & 125 & 1,800 & 0.55 & 31.4 & 12.6 \\
\hline $\begin{array}{l}\text { Middle Archaic } \\
\text { (AU 5) }\end{array}$ & 70 & 64.2 & 1,300 & 0.3 & 17.9 & 16.5 \\
\hline
\end{tabular}

standardize bone mass for total NISP and Mass by AU (see Table 11-2).

Calculations were then run on taxon NISP and Mass by AU. This table is presented in Appendix F. The data set presented in Table F-1 was used to compile Figures 11-2 through 11-6. The graph of standardized burned rock mass frequency from Chapter 7 is reprised in Figure 11-2 to be compared against the NISP standardizations, as NISP change appears to be a better indicator of resource intensification than does bone mass (Marshall and Pilgram 1993; Outram 2001).

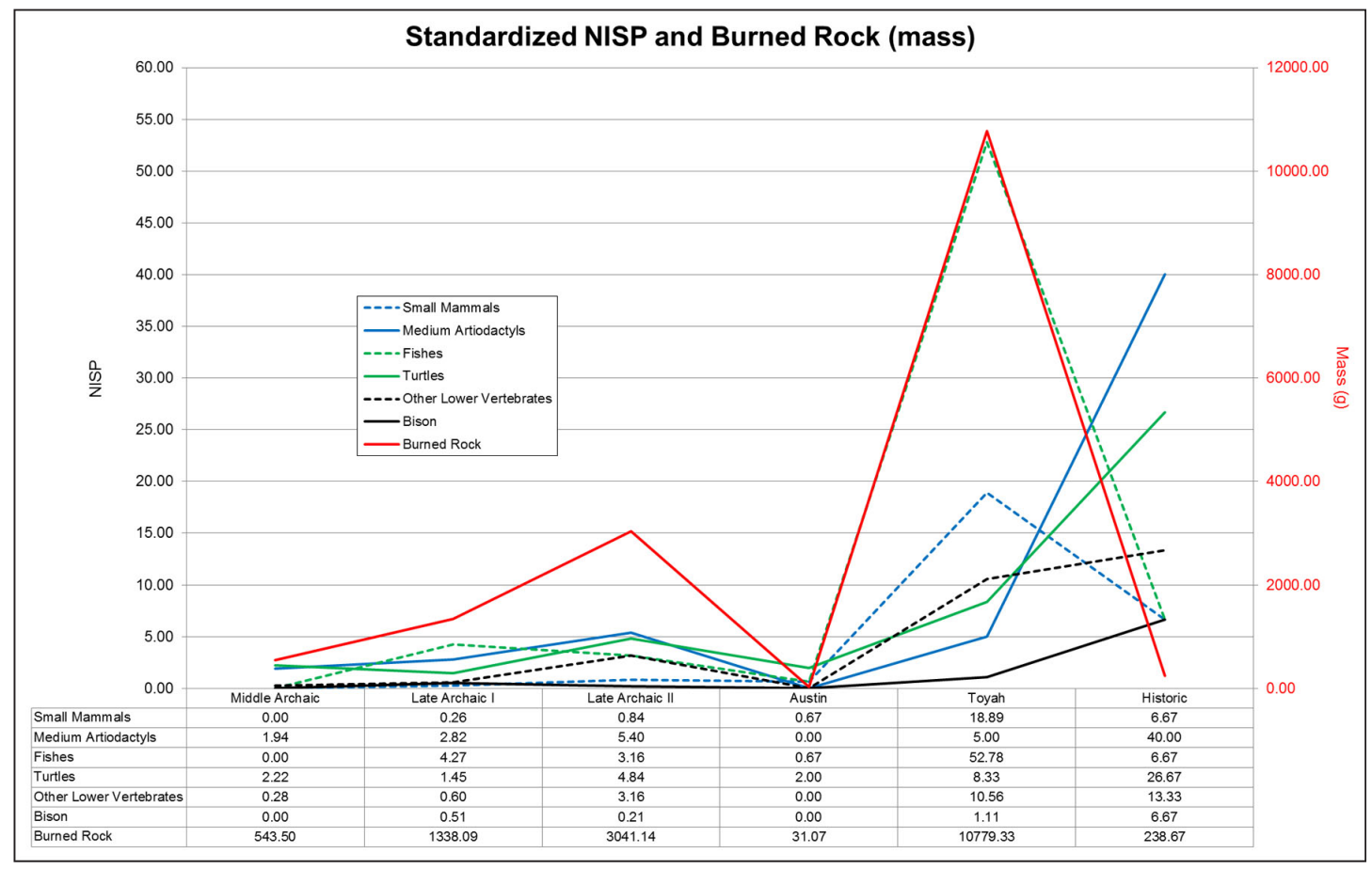

Figure 11-2. Standardized NISP compared to standardized mass of burned rock from 41HY165. 


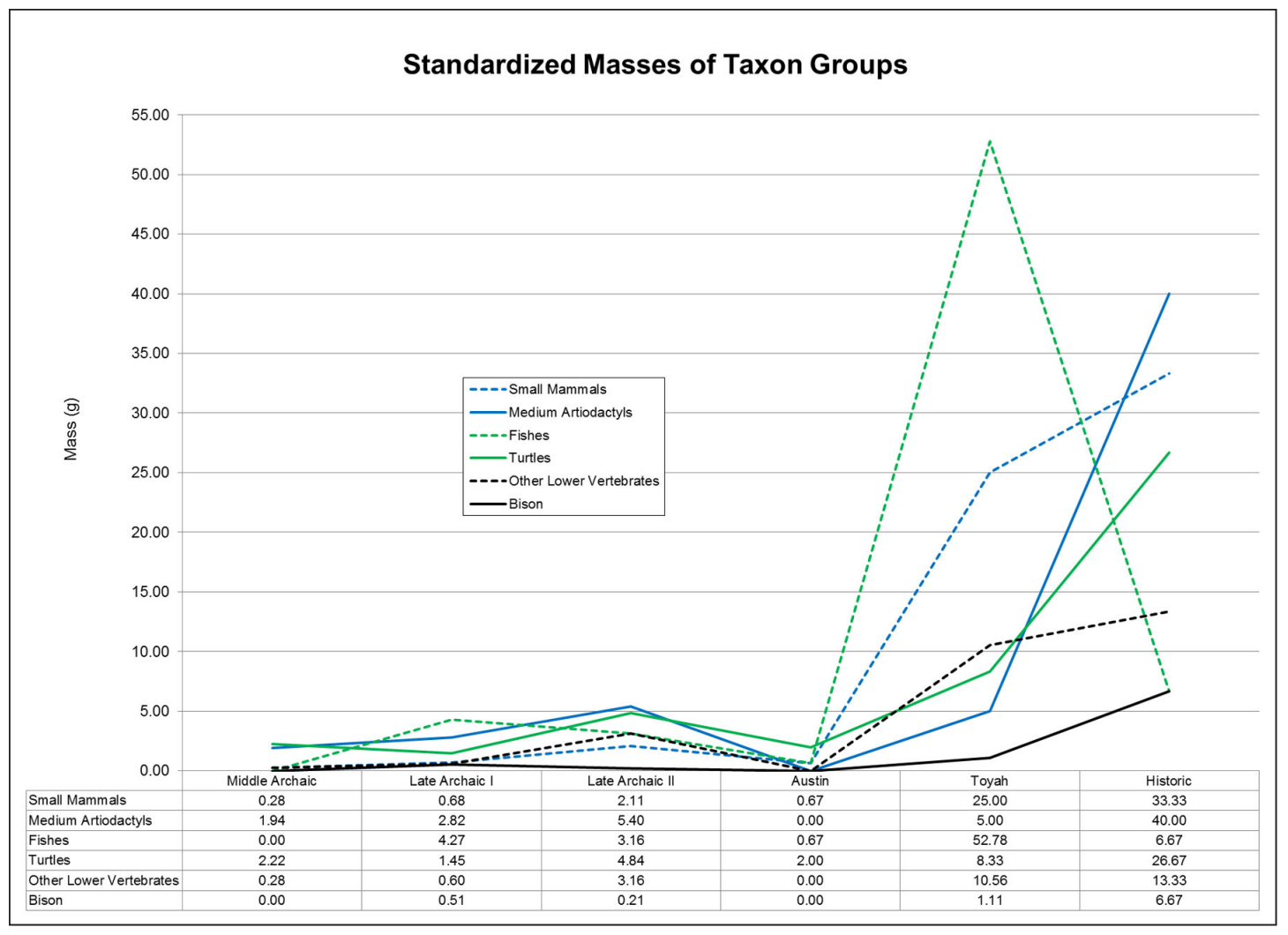

Figure 11-3. Standardized mass of faunal material from 41HY165.

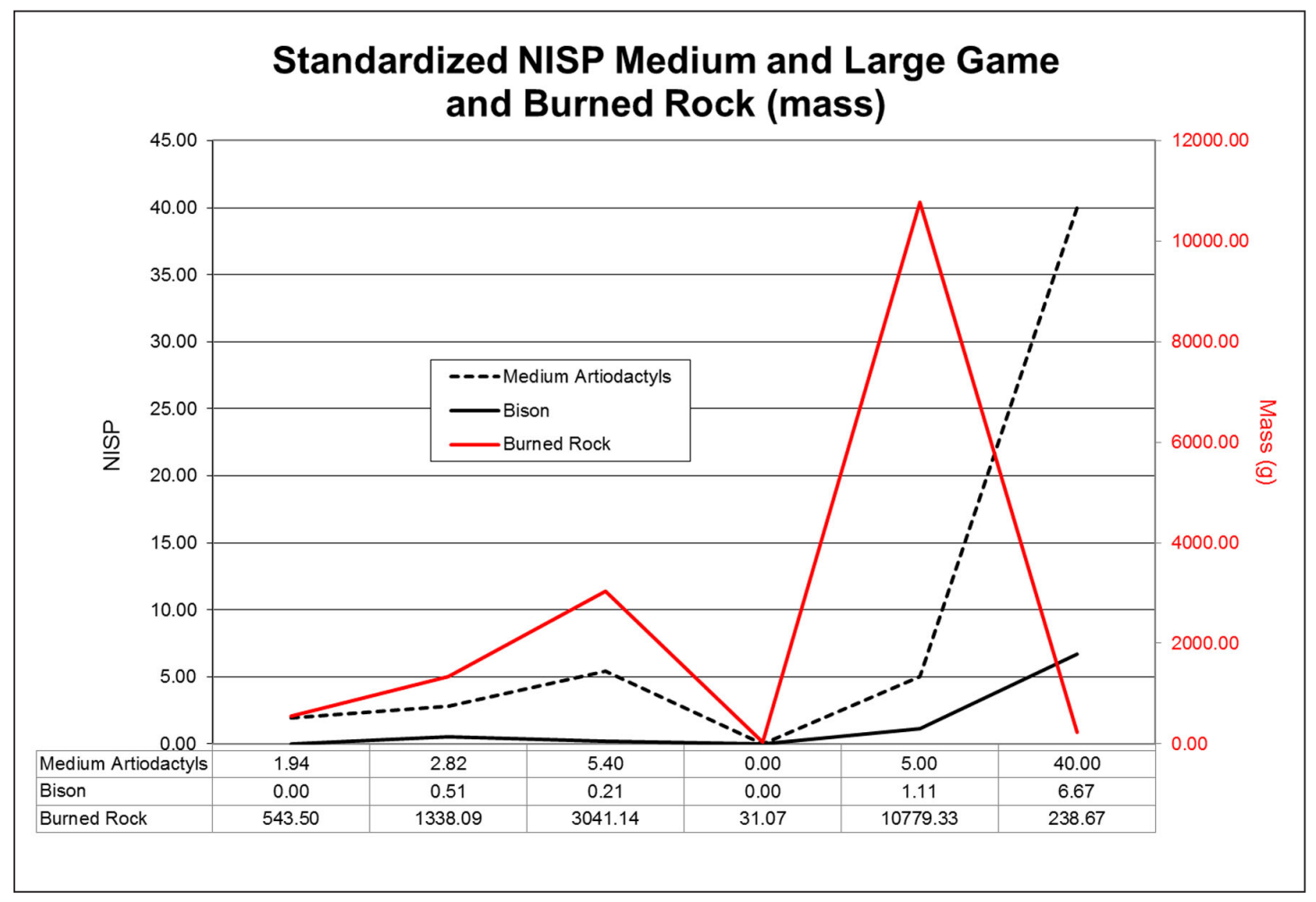

Figure 11-4. Comparison of standardized NISP of bison and all large and medium game through time. 


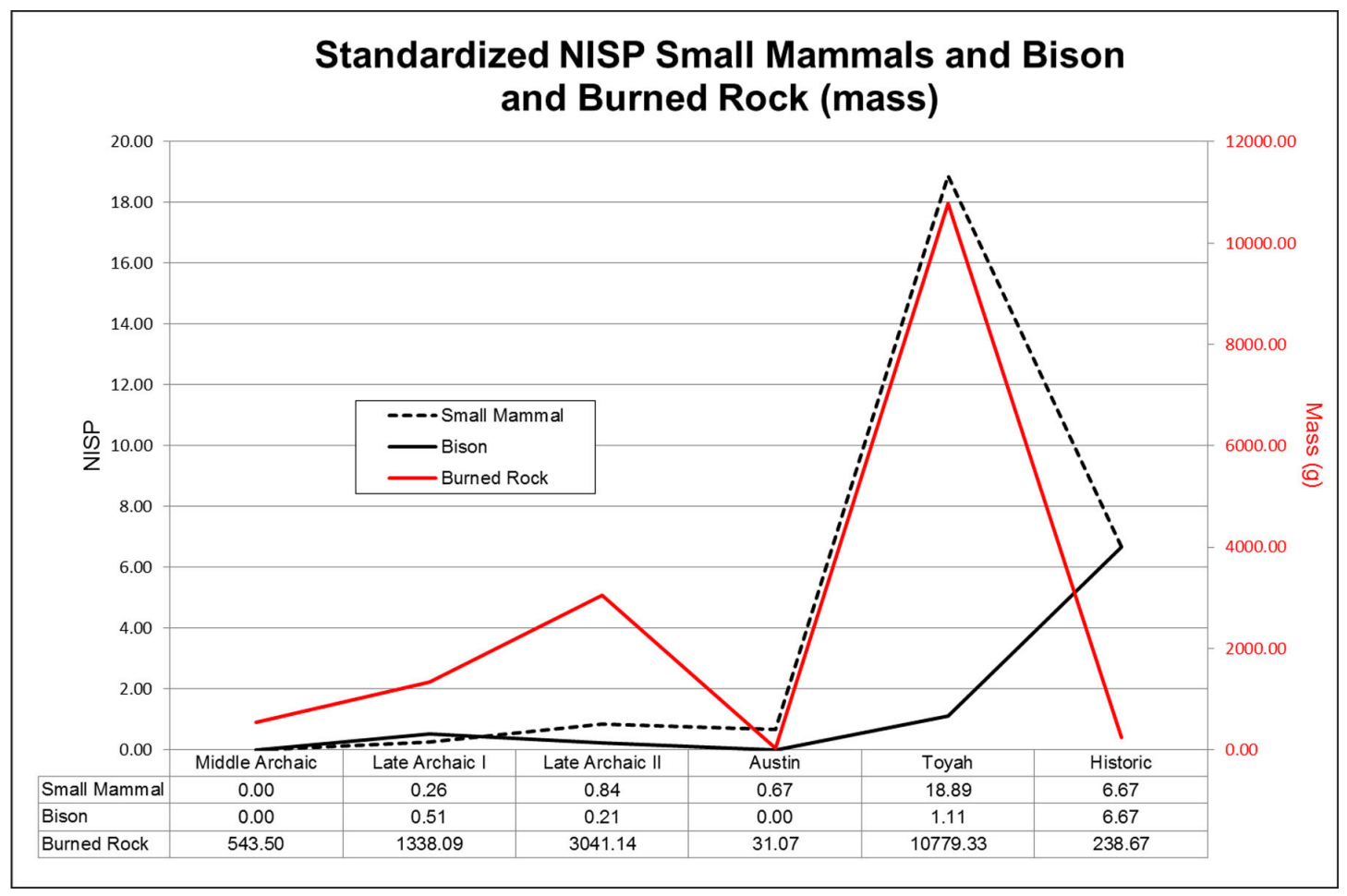

Figure 11-5. Standardized values for bison, small mammals, and burned rock.

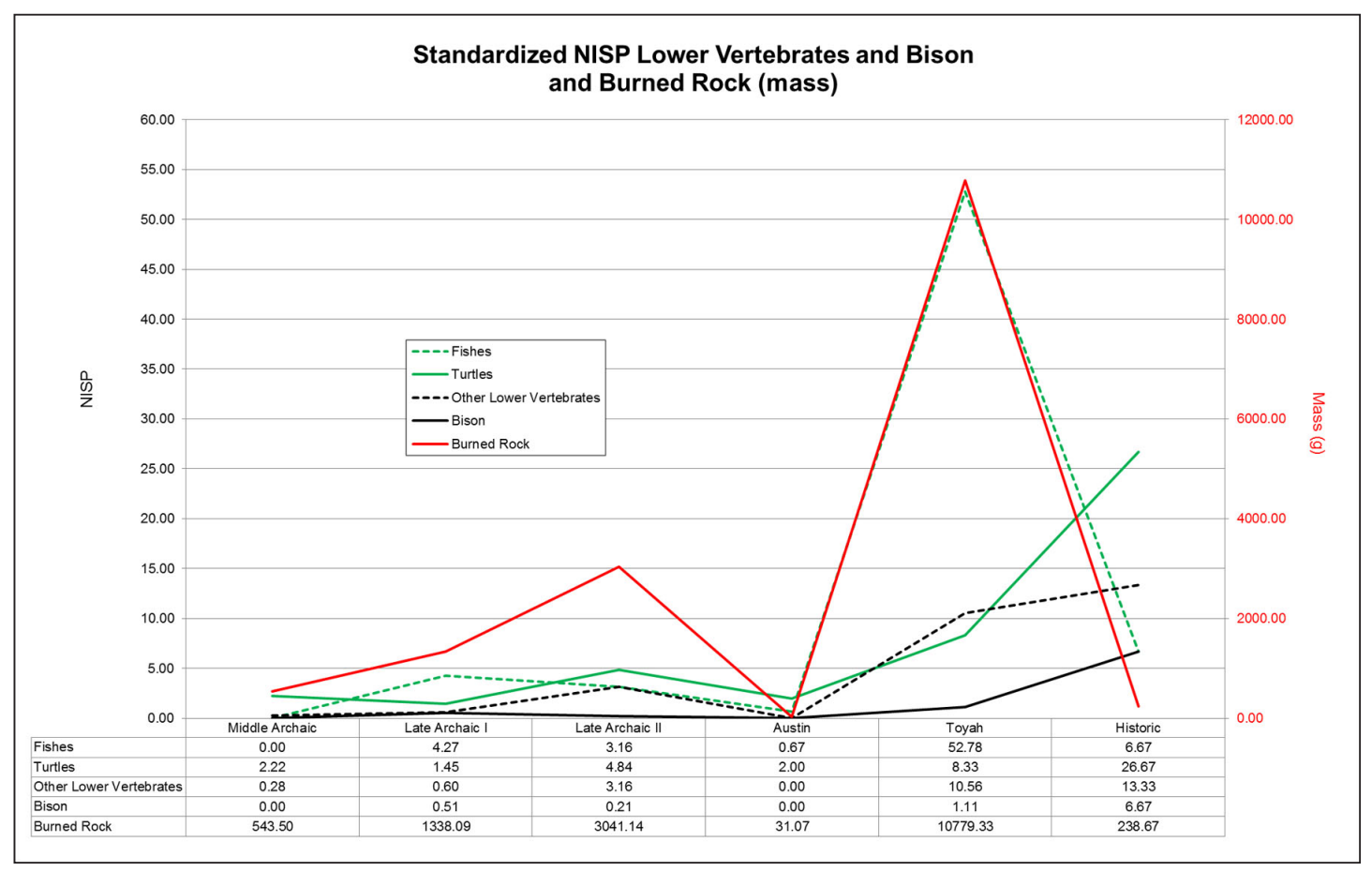

Figure 11-6. Standardized values for bison, non-mammalian lower vertebrates, and burned rock. 
Systematic Comparison of Taxonomic Groups with Burned Rock Proxy

In studying 41HY165 subsistence patterns, we are using the frequency of burned rock per AU as proxy. Burned rock mass is compared to bone NISP in this study based on the working hypothesis that an increase in burned rock mass indicates an increase in food processing and/or broadening of the subsistence base (see Figure 10-1 and Figure 11-2). Changes in NISP should also indicate changes in resource intensification. Bone mass was rejected as a comparative variable because it did not stand in well as a resource intensification proxy (see Figure 11-3). Given that, the following discussion will compare and contrast standardized NISP values (presented in Table F-1) with the standardized burned rock frequency data (see Chapter 10, this volume).

In Figure 11-2, the burned rock mass values have been divided by 100 in order to fit the scale of the standardized NISP faunal values. In general the curve trends for NISP are similar to burned rock mass except in the Protohistoric period, where burned rock mass drops dramatically following the Toyah phase. Generally, there is an increase in frequency from Middle Archaic to Late Archaic, then a drop at Austin before swinging up again at Toyah. This drop can be explained by the low volume of sediment recovered for this AU. Omitting the Austin phase, the curve would continue to climb from Late Archaic through the Prehistoric, before dropping again in the Protohistoric. This trend may be due to a continuing increase in population, or degradation of habitat as the local environment continues to dry through time, or a combination of these factors.

\section{Discussion of Bison and Other Taxa}

This section begins with a comparison of Bison with other taxa across time, held against the trends in burned rock occurrence (by mass). Medium Artiodactyla, Antilocapra, and Odocoileus are taken together as one group and compared with Bison. Both curves increase over time, excepting the dip in Austin phase (see Figure 11-4). The slope increases more rapidly for the medium Artiodactyla than for the Bison, which decreases from Late Archaic I through Austin. While Bison dips from Late Archaic I forward, burned rock is increasing through Late Archaic II and continues to increase with only the Austin phase dip and the Protohistoric cessation (see Figure 11-4). This trend suggests an everincreasing reliance on deer and pronghorn as top prey choice.

This peak of burned rock in Late Archaic II coincides with peaks in small mammal, turtle, and other non-piscean lower vertebrates (see Figures 11-5 and 11-6). Both bison and burned rock swing up again in Toyah. Along with bison, fish increases in Toyah, but at a higher rate than the other small-bodied taxa. This suggests a shift or broadening of the resource base to include fish where it had only played a minor role previously.

\section{Discussion}

\section{Changes in Faunal Composition Through} Time: A Discussion of Fauna by $A U$

This study focuses on a fraction of the 41HY165 assemblage, that portion to which temporal and cultural affiliation could be assigned. Selected levels in Units 1, 2, 3, 8, 10, and 11 were examined. As noted in Chapter 4, game focus shifted necessarily at the end of the Pleistocene when all the megafauna but bison went extinct in North America, to other large mammals: bison, deer, pronghorn.

\section{AU 5: Middle Archaic (5600-4300 BP)}

Taxa identified from this period include Vertebrata, Testudines, Mammalia 
(indeterminate, medium), and Artiodactyla (medium). Medium-sized mammals, including medium artiodactyls, are present and appear to be a more significant take than small mammals. The bone fragments are spirally broken and minimally weathered. Three fragments are burned. Specimen 310-28 has some polish. Specimen 311-1 is a deer metatarsal with numerous cuts and abrasion running parallel or slightly oblique to the long axis. Other metapodial fragments exhibit cuts as well. No bison was recovered from Middle Archaic sediments.

\section{AU 4b: Late Archaic I (4300-2550 BP)}

Taxa identified from this period include Vertebrata, Osteichthyes, Amphibia, Serpentes, Testudines, Mammalia (indeterminate, small, medium, fetal/juvenile), Rodentia, and Artiodactyla (medium-size, Odocoileus, Bison).

Vertebrata material comprises fragments less than $1.0 \mathrm{~cm}$ long. Weathering is variable, and fewer than one-half are burned. Osteichthyes material represents at least two sizes and species of fish. Less than 10 percent is burned. Two small specimens are tentatively identified as Amphibia. The turtle material represents smaller-sized kinosternids/emydids. One-third of this material is burned. Snake is poorly represented, burned, and degraded (digested?). Rodents and small mammal materials are scant in this AU. Homo sapiens is represented by one $3 \mathrm{rd}$ phalanx.

Medium Artiodactyla includes items identified to Odocoileus and Medium Artiodactyla. One deer tooth fragment may be a milk tooth. One specimen is burned black with calcined patches. Medium Mammal material may derive from Medium Artiodactyla, but the fragments are broken and poorly enough preserved that such a diagnosis is tentative at best. More than half of these fragments are burned, ranging from scorched black to calcined white.
Two small bone fragments appear to be fetal material. Five bison specimens are associated with this $\mathrm{AU}$, two of which provided radiocarbon dates. One juvenile dentary fragment is burned. The juvenile/fetal material associated with this AU suggests some spring/early summer hunting activities.

Specimen $538-4$ is $0.9 \mathrm{~cm}$ long, moderately polished, and appears to be a broken awl tip (see Figure 11-1).

Overall it appears that the reliance on smallbodied vertebrates has decreased with respect to the Medium Artiodactyla and bison.

Fish increase in occurrence from the Middle Archaic along with most other groups. Deer limb and dental material plus medium artiodactyl limb fragments indicate that these mammals were a consistent part of the subsistence base. Fetal/ juvenile material suggests at least one spring hunt event. Medium-sized artiodactyls appear to gain significance in Late Archaic I even as bison material increases in frequency from the Middle Archaic dearth.

\section{AU 4a: Late Archaic II (2550-1200 BP)}

Taxa identified from this period include Vertebrata, Osteichthyes, Lepisosteidae, Anura, Lacertilia, Serpentes, Testudines, Mammalia (indeterminate, small, medium, fetal), Leporidae, Rodentia (indeterminate, Sigmodon, Neotoma, Castor), Carnivora, Artiodactyla (medium, Antilocapra, Odocoileus, and Bison). Fish occurrence drops from Late Archaic I to II, and small mammal occurrences rises with turtles and other lower vertebrates.

Fish material comprises burned and unburned skull and vertebral elements, and one unburned gar scale. Amphibia are represented by anuran postcranial and cranial material mostly from Lot 522, with one ilium identified to Genus Rana, true 
frogs. More than one individual is represented, because limb elements are of two sizes. Two specimens from Lot 299 are also postcranial material from at least one small individual. The remainder of the anuran material is skull and limb elements, possibly also Rana, and none are burned. Reptile material includes garter snakesized vertebrae, some possibly digested, and a jaw fragment that could be lizard or snake. Turtle material comprises primarily fragments of plastron and carapace from small individuals, probably kinosternids and/or emydids. The fragments are heavily comminuted. About a third are burned black, evidence of having been cooked (Lemke and Timperley 2008). One Vertebrata specimen from this AU may be a snake vertebrae fragment.

Rodent material represents three genera: Sigmodon (craniodental), Neotoma (postcranial), and Castor (postcranial). Additionally, one Sigmodon-sized maxillary fragment is calcined. Leporid and canid material are scarce in this AU, with one specimen each. Two bison specimens from different units were identified and subsequently submitted for ${ }^{14} \mathrm{C}$ dating.

Medium Artiodactyla are represented by numerous fragments that exhibit green breaks. Specimen 291-14 is a limb diaphysis fragment with an old impact break and three mending fragments of the resulting bone shatter. This association suggests very little disturbance for at least this unit/level. Several specimens are cut. Deer has been positively identified, tentatively as white-tailed based on an astragalus and a lateral malleolus (Gilbert 1990:406; Jacobson 2003:294). Pronghorn is positively identified from a tooth fragment. Worked bone is present.

Slightly over half the material assigned to medium Mammalia is burned. The vast majority of material in this category may in fact derive from the medium artiodactyls. Specimens are heavily comminuted, with only two specimens over $3 \mathrm{~cm}$ along the c-axis. Mammalia material comprises over 50 percent burned fragments, between 0.4 and $2.3 \mathrm{~cm}$ along the c-axis. Body size was not assigned. Various breakage patterns are evident, from smooth spiral through rectilinear fracturing. Variable weathering is observed as well, especially on very small fragments, less than $2 \mathrm{~cm}$ along c-axis. Cortex is usually absent, and longitudinal cracks are common in unburned bone. Burned bone varies from scorched brown-black to calcined white, the surface from semiglossy and smooth to matte and cracked.

A small number of specimens derive from fetal or very young juvenile mammals, probably artiodactyls, and provide evidence for springtime activity at Spring Lake during this AU.

\section{AU 3b: Late Prehistoric-Austin (1200- 800 BP)}

Taxa identified from this period include: Osteichthyes, Mammalia, and medium Mammalia. One lot represents this AU in the faunal assemblage. The vertebrate recovery, outside the Osteichthyes, comprises fragments of cortical bone assigned to Mammalia or Mammalia, medium. The mammal fragments conceivably could be assignable to Artiodactyla, medium. Over two-thirds of the mammal bone is burned, ranging from black scorched to calcined white. One unburned fragment is cut. No bison material was recovered in the Austin phase at this site. A cautious interpretation would be that bison was not a significant part of the subsistence base, but poor recovery for this AU must be kept in mind. Scant recovery makes speculating on subsistence patterns difficult. 


\section{AU 3a: Late Prehistoric-Toyah (800-350 BP)}

Taxa identified from this period include Vertebrata, Osteichthyes, Amphibia (possible Cryptobranchidae, Anura), Reptilia (possible Eumeces, Serpentes, Testudines), Aves, Anseriformes, Mammalia (small and medium), Sigmodon, Geomyidae, and Artiodactyla (medium, Odocoileus, Bison).

Osteichthyes material consists of cranial bone, vertebrae, and spines of small- and medium-sized fish. The non-vertebral material is broken. At least two taxa are represented based on vertebrae morphology. Relatively little of the fish material is burned, only a few spines and vertebrae. Amphibians are sparsely represented. At least four individuals are represented by a humerus, scapula and two ilia, plus limb elements from small individuals. The ilia and humerus are anuran, and the scapula is possibly from a hellbender (Cryptobranchidae). Turtle material comprises one burned, several unburned, and a single red-stained fragment (Specimen 79-21). Snake remains and the suspect lizard jaw all derive from microsieved material, and are small bone fragments from small individuals. Less than 10 percent are burned. More avian material has been identified in this $\mathrm{AU}$ than the others, including a pelvis, phalanx, and wing elements. None are burned. Vertebrata material largely derives from microseived material, one-third of which is burned. These fragments exhibit varied weathering and degrees of burning. Rodent material is represented mostly by Sigmodon teeth, but also includes some pocket gopher teeth, Rodentia teeth, and micromammal postcranials likely assignable to taxa within Rodentia. Minimum number of individuals for Sigmodon is four based on one burned left upper second molar, one unburned left upper second molar, one unerupted right lower first molar, and one wellworn right lower third molar.
Indeterminate Mammalia material comprises mostly fragments smaller than $1.0 \mathrm{~cm}$ in length. They exhibit varied weathering, and breakage patterns reflect comminution at different stages of bone drying. Medium Mammalia bone is spirally broken, and the burned bone is variably broken, with spiral and irregular fractures observed. Burned material varies from glossy or semiglossy brown/black scorched to matte white calcined. The Medium Artiodactyla is represented largely by axial skeleton and hind limb fragments of a mature animal: vertebral, sacral, pelvic, proximal femur. Other isolated fragments and elements also are present. With virtually identical preservation, color, and surface textures, this association suggests use of a portion of a single animal. This could also possibly be evidence of resource distribution. Specimen 7928 is a portion of medium Artiodactyla limb diaphysis with spiral breaks. It tapers to a narrow end with an unusual side notch. This narrow end is somewhat smoothed and polished, and the cortex is flaked off from the narrow end to about one-third down the length of the bone fragment.

As with other AU where bison is present, only a few specimens represent the taxon. One is a tabulate fragment which could be rib, and a burned fragment which could be juvenile bone.

Vertebrates duck-sized and smaller, especially the cotton rat, appear to be at least equally represented when compared to Medium Artiodactyla and Bison.

\section{AU 2: Protohistoric}

Taxa identified from this period include Osteichthyes, Serpentes, Testudines, Mammalia (small, medium), Sylvilagus, Artiodactyla (medium), Odocoileus, and Bison. As noted previously in this report, Protohistoric period material was analyzed for more general content because the context is questionable. This 
subassemblage list serves to demonstrate that the same groups of animals continued to be exploited beyond the time of contact with European explorers, missionaries, and settlers.

\section{Bison Procurement/Utilization and Prey Choice}

Bison does not occur in Middle Archaic, is present in Late Archaic I, decreases from Late Archaic II to Austin where it is altogether absent, and then increases again in Toyah and the Protohistoric. In contrast, the use patterns of small mammals, aquatics, and deer/pronghorn exhibit the following trend. Medium-sized artiodactyls and small mammals start out in Middle Archaic in an apparently significant position in the subsistence regime, supported decreasingly by turtles, and other lower vertebrates. Medium artiodactyls continue in the Late Archaic I and drop significantly to take second place as bison dominate the assemblage, supported by small mammals, turtles, and other lower vertebrates. In Late Archaic II, bison drop and medium Artiodactyla peak significantly. Smaller vertebrates continue to increase. The Austin phase has poor recovery, thus creating in this author's opinion a false dip in significance for each group. If the Austin phase is skipped, and we move on to Toyah from Late Archaic II, small mammals do not show an increase, while turtles, fish, and other lower vertebrates appear to increase relatively significantly. It is difficult to interpret the relative occurrences in the Protohistoric recovery, as European technology and sociopolitical influences are likely to have dramatically altered subsistence strategies. Trend toward more intense utilization of available resources can be seen in Late Archaic II and Toyah. This might be attributed to younger sediments yielding volumetrically more identifiable material, but the Late Archaic recovery vastly outnumbers the other AU in both NISP and number of taxa identified.
When Bison is held as the baseline taxon, it appears to increase in importance during Late Archaic I and decreases until it is not present in the Austin phase. Bison increases again in Toyah phase recovery. While bison is on the decline in Late Archaic II, medium artiodactyls increase, as do small mammals and turtles. After the Austin phase drop, all taxa increase again. The smallbodied taxa increase more dramatically, with fish procurement relatively more prominent in Toyah. An increase reliance of fish can be perceived as greater prey resource intensification during this period. As stated above, however, poor recovery for the Austin phase AU must be kept in mind. Inadequate recovery from this $\mathrm{AU}$ makes speculating on subsistence patterns difficult.

\section{Evidence for Resource Distribution}

The units excavated at 41HY165 were scattered over the peninsula and did not comprise a contiguous block. This distribution made it possible to get some meaningful spatial relationship data regarding resource distribution. Several lots singly represent a portion of a mammal carcass (medium Artiodactyla, Odocoileus, Antilocapra, medium Mammal, etc.), which suggests that such might have been divided and passed out among the human occupants of the site; social organization, however, remains to be determined (family groups/households, clans, etc). Such resource distribution is noted in Late Archaic II and Late Prehistoric deposits, suggesting a practice with significant temporal endurance.

The medium artiodactyl materials from Late Archaic II suggest distribution of game resources, and a spring hunting event. Specific elements per lot discussed here can be found in Appendix F. XU 2, Lot 79, is a Toyah lot with fragments of a medium artiodactyl hind quarter that includes axial and upper limb material. Lot 79 appears to comprise fragments from a single element 
or skeletal section: a portion encompassing the lower vertebral (sacral) and pelvic region including the upper femur. XU 11, adjacent to the north of XU 2, Lot 256, is a Late Archaic II lot with elements of a medium artiodactyl forelimb. Craniodental material identified as Odocoileus also derives from this lot. XU 8 yielded three lots with such association. Lot 123 and 299 are Late Archaic II. Lot 123 appears to represent the lower fore and hind limb elements with corresponding axial elements. Fetal/juvenile material is also present, suggesting a spring kill. Lot 299 contains medium artiodactyl hind limb and fetal/ juvenile material. Lot 299 appears to represent an adult hind limb quarter and one fetal/juvenile bone, more evidence of a spring kill. Lot 310 is Protohistoric, and comprises medium artiodactyl and Odocoileus hind limb elements. Not only do these lots' components suggest resource distribution, Lot 299 material provides seasonal information.

These lots support spring hunting activity in the Late Archaic II. A single cheek tooth fragment of Antilocapra was also identified. A relatively small amount of bison material was recovered. This suggests a lesser reliance on bison in Late Archaic II than in Late Archaic I.

\section{Subsistence}

Farmore of the faunal assemblage is considered in discussions of subsistence in more recent studies than in work of even only a few decades ago (e.g., Outram 2001 in contrast with Klein and Cruz-Uribe 1984). Outram (2001, and other dates) has outlined and emphasized the contributions that "indeterminate" bone fragments can make to the discussion of subsistence, and in concert with lithic and other data, in the larger picture, to interpretation of site function and social dynamics. We returned to Klein and Cruz-Uribe (1984) as cited in Outram (2001) to understand the context of their statements. It appears that Klein and Cruz-Uribe are working toward the goal of cataloging taxonomic abundance, rather than subsistence activities. For the former activity, the indeterminate fragments can indeed be of little value. However, once upon a time, lithic debitage was treated with the same attitude. Now, expedient flake-tool utilization is a commonly addressed component of comprehensive lithic analyses.

Using diversity of taxa present as an indication of diet breadth, it appears that resource intensification also trends along the same pattern as the standardized data. The following counts include the broad classifications of Vertebrata and Mammalia in with the more specifics such as Leporidae and Odocoileus. These counts are not standardized. Middle Archaic recovery yielded six taxa. Late Archaic I yielded 14 taxa. Late Archaic II increased the count to 23 taxa. Austin phase yielded three taxa. Toyah phase yielded 18 taxa. Protohistoric yielded 10 taxa. If Austin phase were not included, again due to poor recovery, taxon count would only drop slightly from Late Archaic II to Toyah. From this trend, it appears that there is a response to decreasing bison presence in Late Archaic II that involves increasing hunting pressure on local fauna.

\section{Conclusions}

The zooarchaeological remains examined in this study represent Middle Archaic through Protohistoric subsistence residue. Twenty-eight taxa were identified in the time-controlled portion of the assemblage (see Table 11-1). These include identified material at order, family, and genus level, as well as broadly categorized material such as Vertebrata and size-classed Mammalia material. Trends in procurement and subsistence behavior can be seen as reliance on mediumsized artiodactyls supplemented by bison, rather than supplanted by bison. 


\section{Chapter 12}

\section{Conclusions}

\section{By Carole A. Leezer}

41HY165 located on the southeastern banks of Spring Lake on Texas State property in San Marcos, Hays County, is a multicomponent site visited recurrently by mobile hunter-gatherers over an approximate 10,000-year time span. The site was subject to several archaeological investigations conducted as SWT Archaeological Field Schools in the 1980s and 1990s. In 2010, the site was revisited as part of archaeological investigations associated with the SLAERP. Artifacts and samples collected by the archaeological field schools have been analyzed by CAS as part of the SLAERP. Results of these analyses and excavations are described and discussed in this report.

Occupation at 41HY165 has been documented as beginning near the end of the Late Paleoindian period, and extending through the Archaic into the Late Prehistoric, and even into the early Spanish Colonial period. Peaks in occupation have been noted for the Late Archaic (Late Archaic I to Late Archaic II) and the Toyah/Spanish Colonial period. As a result of erosion and disturbance, very little can be said about early Spanish Colonial occupation of the site; Colonial-era and Historic-era artifacts are found intermixed up to a depth of $40 \mathrm{cmbs}$ across the site (and as deep as $80 \mathrm{cmbs}$ in one location). In response to potential problems with stratigraphic integrity, analysts focused on definable and separate isolable components, based on all available stratigraphic and dating information, that were unmixed or relatively unmixed. The analyses reported here focused on this small sample.
Despite problems with stratigraphic integrity, analysis of the field school excavations, recovered artifacts, and associated data have been able to, through the research domains presented at the beginning of this report in conjunction with associated methodologies, present a detailed perspective on prehistoric cultural adaptations in the Central Texas region. This chapter discusses the most significant interpretations derived from these analytical investigations within the context of these research domains, particularly in terms of how they contribute to ongoing investigations into hunter-gatherer adaptations of prehistoric periods in Central Texas cultural chronology.

The result of this research reflects three fundamental approaches that shaped all analytical efforts. First, the record of cultural activity at 41HY165 was viewed as a process; emphasis was given throughout the analysis to identify and interpret changes from one period to the next. Second, and related to the first approach, this analysis is comparative in nature at a basic level. Not only are time-controlled components compared with and contrasted against one another to detect behavioral shifts from the Late Paleoindian through to the Historic period, but aspects of each component are compared to illustrate key trends and patterns within each period. Finally, we understand that the causes that produced many of the changes described here to be both external to the groups of people who occupied the site (e.g., climate, environment, resource availability) and internal to their sociocultural systems (e.g., individual aptitude 
and motivation, negotiated social labor roles, enculturation, and pattern of skill acquisition).

\section{Nature of Occupation by Analytical Unit}

Seven AUs were identified based on an analysis of diagnostic projectile points (see Table 5-1) and radiocarbon dates of bison bone (see Table 5-2) and charcoal (see Table 5-3). These AUs are: AU 1, Historic Euro-American; AU 2, Historic Native American; AU 3a, Late PrehistoricToyah; AU 3b, Late Prehistoric-Austin; AU 4a, Late Archaic II; AU 4b, Late Archaic I; AU 5, Middle Archaic; AU 6, Early Archaic; and AU 7, Late Paleoindian. While all temporal periods are represented within the collection, some AUs, specifically AU 1 and AU 2, were analyzed in a more general fashion due to the imprecise nature of these contexts (see discussion on this above). Additionally, several diagnostic projectile points, as well five additional bison bone dates were identified at depths associated with historic artifacts. While the projectile points in these contexts hold little utility for analysis, the bison dates are still useful for establishing a time frame for the presence or absence of bison around Aquarena Springs.

\section{AU 1: Historic Euro-American}

This AU represents the undefined Historic debris that was recovered primarily from the A Horizon. Recovered artifacts included ceramics, glass, metal, building materials, and a variety of other debris typically associated with EuroAmerican occupations in the region during the nineteenth and twentieth centuries. This debris occurred in the upper levels of all units and often appeared mixed with prehistoric projectile points, some as early as the Middle Archaic. As a result of this mixed stratigraphy, an analysis of this assemblage allowing for this unit to be further divided into Spanish Colonial, Texas Revolution, post-Civil War, etc., was not feasible. Therefore, analysis relied on diagnostic artifacts with the goal of establishing general periods of settlement with less consideration for spatial context.

\section{AU 2: Protohistoric Native American}

AU 2 consists of a diagnostic Guerrero (Mission) point and Goliad ware pottery, suggesting a Spanish Colonial-era Native American occupation of the site. These artifacts are characteristic of Native American styles from the time of the Spanish entradas and the establishment of missions during the Protohistoric period. The Guerrero point is a small lanceolate arrow point that is commonly found in association with occupations at Spanish missions (Tomka and Fox 1999:34). Due to their association with Spanish missions in Texas, these points generally date from the late seventeenth century into the eighteenth century. Goliad ware is bone tempered with a red-brown exterior and black interior, and originated with Native American groups in south Texas (Tomka and Fox 1998:20). This ceramic type is common among Spanish Colonial assemblages (Tomka and Fox 1998:20), but is also occasionally found outside of mission contexts. Unfortunately, due to the amount of mixing with historic material in this site's upper levels, it is not possible to identify specific lots that can be included in this AU. However, this AU supports a Native American presence and occupation at Spring Lake during the Spanish Colonial era.

\section{AU 3: Late Prehistoric (350-1200 BP)}

Analyzed AUs representing the Late Prehistoric assemblage at 41HY165 included arrow points, faunal remains, and ceramics overlying earlier Archaic components. This unit was further divided into AU $3 \mathrm{a}$ and $\mathrm{AU} 3 \mathrm{~b}$. 


\section{AU 3a: Toyah}

$\mathrm{AU}$ 3a denotes the Toyah phase of the Late Prehistoric and is distinguished by the Perdiz style arrow point. The Toyah phase extends from around $800 \mathrm{BP}$ to as late as $350 \mathrm{BP}$ in Central Texas (Johnson 1994:257-258; Johnson and Goode 1994:41). As these points were found in context with later historic material, they were not considered as contributing to the AU. Due to the uncertain context of the Perdiz points at the site, a single fragment of bison bone (Specimen 79-5), dating from 536 to $640 \mathrm{cal} \mathrm{BP}$, was used to establish AU 3a. Additional artifacts analyzed that are representative of the Toyah phase, but not considered to contribute to the AU 3a, include bone-tempered ceramic sherds. Analyzed faunal remains attributed to $\mathrm{AU}$ 3a included: fish, amphibians, reptiles, birds (including water fowl), rodents, deer, and bison. More avian material was identified in this AU than the others. While bison remains were present, only a few specimens represent the taxon; deer remains far outnumbered bison remains.

\section{AU 3b: Austin}

AU $3 b$ represents the Austin phase, characterized by Scallorn and Edwards style arrow points. The Austin phase extends from 1200 BP up to the onset of Toyah (Collins 2004:122). At 41HY165, Scallorn and Edwards points are found between depths of 33 and 43 cmbs. This AU is also entirely within the A Horizon. A piece of charred wood (Specimen 65-7) associated with an Edwards/Scallorn type projectile point was submitted for radiocarbon dating. The date returned from this sample was between 793 and 915 cal BP, well within the age range of the Austin interval.

Analysis indicated that lithic tool production was highest at 41HY165 during Austin times. EFTs, MRUs, and biface thinning via billet technology were most numerous during this period. In comparison with the other periods, the Austin phase of the Late Prehistoric is characterized by an increase in on-site core reduction, as well as an increase in later stages of tool production evidenced by billet flaking technology. A flake core recovered from a unit and level dating to the Austin period adds support to the evidence of on-site core reduction.

Based on analyses presented in Chapter 6, the Austin component at the site seems to stand out from all other periods in terms of stone tool production and technology. For instance, this period is characterized by more expedient flake tools and more minimally retouched unifaces than in any other period. Additionally, knappers were participating in more biface thinning, billet flaking, and flaking associated with core reduction during Austin occupation than in any other period. However, these conclusions should be viewed as provisional until a larger sample is available.

Only one lot representing AU $3 \mathrm{~b}$ was subject to faunal analysis. This lot consisted of fish and mammal remains that mostly represent deer. Notably absent from this $\mathrm{AU}$ is the presence of bison. Whatever cultural shifts that occurred with the transition from dart and atlatl to bow and arrow may have caused or can be associated with a fundamental shift in how 41HY165 was occupied and used during Austin times. From their sample of 46 AMS dates, Lohse and Cholak (2011) suggest that bison were absent from Central Texas for approximately 1,500 years prior to the Toyah phase of the Late Prehistoric period. Changes in the availability of key species, like bison, may have resulted in new technological approaches to ensure sustainability.

Other factors that may have resulted in prehistoric occupation of the site during this AU 
include climate. Around AD 1200, a drought affected parts of the Edwards Plateau (Johnson and Goode 1994), causing streams and rivers to dry up. This may have caused people to aggregate around the ever-present springs that currently form Spring Lake. The springs were capable of supporting smaller-bodied game like deer and fish, and probably supported larger human populations during times when water was scarce elsewhere. Chert resources were also readily available to 41HY165 occupants.

\section{AU 4: Late Archaic (1200-4300 BP)}

The Late Archaic is a long period that incorporates a large volume of meaningful cultural variation in terms of adaptive behaviors. Problems with recognizing this variation and refining its chronological schemes have to do with the degree to which remains from different Late Archaic intervals are often found compressed, mixed, or otherwise poorly resolved. This is often the result of climatic processes that are unfavorable to stratigraphic resolution and clarity. Coupled with cultural processes that involve digging shallow pits for earth ovens, strata from this period are commonly mixed or altogether absent. Still, given long enough spans of time, the Late Archaic can be subdivided into finer chronological units.

\section{AU 4a: Late Archaic II}

The Late Archaic II subperiod (2550-1200 BP) has been defined by the presence of Ensor, Fairland, and Marcos point styles, in addition to bison bone dates, and charcoal radiocarbon dates. This is the largest AU at 41HY165, with over 2,400 associated artifacts identified across different units and at different elevations (see Table 5-4).

The frequency of discarded projectile points in this $\mathrm{AU}$ suggests that there was a significant population increase at 41HY165 from the Late Archaic I to Late Archaic II. This is further supported by an increase in burned rock mass and associated faunal remains. This peak of burned rock in Late Archaic II coincides with peaks in small mammal, turtle, and other nonpiscean lower vertebrates. It also correlates with a decrease in bison and an increase in medium artiodactyla, suggesting an ever-increasing reliance on deer and pronghorn as top prey choice during this period.

\section{AU 4b: Late Archaic I}

AU $4 b$ represents the Late Archaic I component at the site, dating from $4300 \mathrm{BP}$ to 2550 BP (Johnson and Goode 1994:34). This AU is defined by a Pedernales point, a Morhiss point, and two bison bone dates. However, there is no indication that Pedernales and Morhiss points at 41HY165 represent the same occupation. Lithic analysis does, however, indicate that fashioned flake tools were more heavily used during the Late Archaic I, making them less expedient.

Faunal analysis suggests a reliance on small-bodied vertebrates has decreased with respect to the medium-sized Artiodactyla and bison. A reliance on fish, however, increases in occurrence from Middle Archaic, along with most other groups. Deer limb and dental material plus medium-sized artiodactyl limb fragments indicate that these mammals were a consistent part of the subsistence base. The presence of fetal/juvenile material indicates at least one spring hunting event occurred during this period. Medium-sized artiodactyls appear to gain significance in Late Archaic I even as bison material increases in frequency from the previous Middle Archaic scarcity. 
AU 5: Middle Archaic (5600-4300 BP)

The Middle Archaic at 41HY165 is represented by a single Travis point. The relative intensity of site occupation as indicated by discarded point frequency suggests a slight increase from the proceeding Early Archaic (AU 6). Biface frequency in comparison to time is also highest during the Middle Archaic, and minimally retouched unifaces appear to be used more heavily. These lithic observations point towards a more maintainable and curated tool kit, suggesting that people visiting 41HY165 during the Middle Archaic may have practiced collector strategies.

Faunal analysis indicates that mediumsized mammals, including medium artiodactyls, are present and appear to be a more significant resource than small mammals during this period. No bison remains were recovered from Middle Archaic sediments.

\section{AU 6: Early Archaic and Late Paleoindian}

These two periods are represented at 41HY165 by five projectile points. However, these artifacts derive from questionable contexts and were not included in this analysis. The Early Archaic period is represented by three projectile points, an Early Archaic Stemmed, an Early Archaic Split-Stemmed, and a Gower point. Two projectile points date to the Late Paleoindian period, and include a Golondrina point and a Big Sandy (early side-notched) point. The problematic (late) date from the Gower level also indicates a poor context for the lower points. Additional dates from the underlying levels also confirm a poor context for the Late Paleoindian projectile points; a charcoal sample from the same level as the Golondrina point dates from 1608 to 1724 cal BP (Specimen 12026). A charcoal sample from below this level and directly above the Big Sandy point was dated to 1871 to 1985 cal BP (Specimen 146-8). Finally, a charcoal sample from the level below the Early Stemmed point came back at 4162 to 4409 cal BP. The range of dates from the Gower point level to the level below the Early Stemmed point brackets these levels, and these Late Paleoindian points, within the Late Archaic and possibly as early as the late Middle Archaic. As such, the contexts of these points are all problematic, and this disparity cannot be explained. Although excavation notes do not indicate that there had been any disturbance within these units, the charcoal dates do not support the earlier dates indicated by the points. Therefore, AUs for the Early Archaic and the Late Paleoindian periods have not been established for 41HY165.

\section{Chronology}

Multiple lines of evidence were called upon to reconstruct the occupational history at 41HY165. Two dating techniques were used, cross-dating and radiocarbon dating, both characterized by various degrees of precision and certainty. Cross-dating was accomplished through the use of temporally diagnostic artifacts or artifact technologies that have been well-dated elsewhere. Absolute radiocarbon dates were collected through the use of AMS analysis of organic remains.

Radiocarbon dates can produce conflicting results depending on sampling procedures, which in turn may lead to different interpretations about site chronology. Of the twenty-four absolute dates from 41HY165, twenty-two of these were obtained during the analysis conducted by CAS. Samples submitted for dating were selected to simultaneously address several questions, most importantly those establishing chronological control. There was also a need to verify earlier analysis that concluded that intact Late 
Paleoindian strata were present here. Additionally, a directed study (Giesecke 1998) identified bison presence during the Middle Archaic. The absence of any bison from excavated Middle Archaic contexts elsewhere at Spring Lake (Lohse and Cholak 2011) casts doubt on this conclusion. Consequently, providing a more robust sample of directly-dated bison remains was a second priority for the current analysis.

Twelve samples of bison bone were selected from across the stratigraphic column at 41HY165 (see results by provenience in Appendix B). The results of these assays, determined to be in proper stratigraphic order, were used to help further define AUs. An additional 12 radiocarbon assays on carbon, wood, or carbonized wood supplemented the bison dates. All but two samples (Beta-117967 and ISGS-A1966) were pretreated at the University of Oregon Radiocarbon Laboratory, with the prepared targets submitted to the AMS Laboratory at the University of California at Irvine. Bone samples were pretreated using the XAD purification technique developed by Thomas Stafford (Stafford et al. 1988, 1991). The result is highly reliable, highprecision AMS dates with standard deviations of as little as 15 years in some cases, and 20 years for most samples.

Cross-dating diagnostic artifacts (projectile points and ceramics known to have been manufactured at specific times in the past) with recovered archaeological deposits indicated that the range of occupation and/or use of 41HY165 extended, at minimum, from the Early Archaic/ Late Paleoindian through Spanish Colonial and Historic times. In terms of projectile point chronology, the site is best represented by those dated to the Late Archaic. This is further supported by bison and charcoal radiocarbon dates. Ceramic data support occupation and/or use of the site during Toyah, Spanish Colonial, and Historic periods.

Through combining all temporal diagnostic data, the following site chronology appears (Table 12-1). Note that two absolute dates were obtained for a Scallorn and a Marcos Point from organic material recovered from the same provenience. Earlier analysis concluded that intact Late Paleoindian strata were present at 41HY165; however, CAS was unable to verify this through the current project. While projectile points attributed to this period were recovered, the associated radiocarbon dates returned from contexts in which the points were recovered were problematic, and did not correspond to currently established radiocarbon years for Late Paleoindian archaeological periods. The chronological data do, however, support a robust prehistoric occupation of the site during the Late Archaic period (Late Archaic I and Late Archaic II).

\section{Subsistence Economy and Technological Variation}

\section{Bison in Local and Regional Economies}

Mauldin et al. (2012) have observed a marked increase in a reliance on bison by the beginning of the Toyah period. This shift in resource utilization coincided with changing climate and may have been in partial response to it, as weather patterns became both drier and more variable. Faunal evidence recovered from 41HY165 supports an increase reliance on bison resources during the Toyah period, placing $41 \mathrm{HY} 165$ well within the regional cultural pattern identified by Mauldin et al. (2012). A previous study (Giesecke 1998), however, identified bison present during the Middle Archaic at 41HY165. This conclusion contradicted the results of analysis conducted by CAS on the recovered faunal remains, as no bison 
Table 12-1. 41HY165 Chronology.

\begin{tabular}{|c|c|c|c|}
\hline Point Type & Bison Dates & $\begin{array}{c}\text { Charcoal } \\
\text { Dates }\end{array}$ & Period \\
\hline & $575 \mathrm{BP}$ & & Late Prehistoric-Toyah \\
\hline \multicolumn{4}{|c|}{ Edwards/Scallorn } \\
\hline Scallorn & & $930 \mathrm{BP}$ & Late Prehistoric-Austin \\
\hline \multicolumn{4}{|l|}{ Darl } \\
\hline Marcos & & $1580 \mathrm{BP}$ & \\
\hline \multicolumn{4}{|l|}{ Ensor } \\
\hline \multicolumn{4}{|l|}{ Fairland } \\
\hline & & $1760 \mathrm{BP}$ & \multirow{4}{*}{ Late Archaic II } \\
\hline & & $1965 \mathrm{BP}$ & \\
\hline & $2205 \mathrm{BP}$ & $2210 \mathrm{BP}$ & \\
\hline & & $2300 \mathrm{BP}$ & \\
\hline \multicolumn{4}{|c|}{$2475 \mathrm{BP}$} \\
\hline & & $2435 \mathrm{BP}$ & \multirow{2}{*}{ Late Archaic } \\
\hline & & $2435 \mathrm{BP}$ & \\
\hline \multicolumn{4}{|l|}{ Pedernales } \\
\hline \multicolumn{4}{|l|}{ Morhiss } \\
\hline & 2965 BP & $2905 \mathrm{BP}$ & Late Archaic I \\
\hline & $3000 \mathrm{BP}$ & & \\
\hline & $3065 \mathrm{BP}$ & & \\
\hline & & $3860 \mathrm{BP}$ & Late Archaic I/Middle Archaic \\
\hline Travis & & $4490 \mathrm{BP}$ & Middle Archaic \\
\hline
\end{tabular}

Note: Dates calibrated using IntCal09 (Reimer et al. 2009).

remains could be unquestionably placed within Middle Archaic AUs. Bison instead appears to increase in importance during Late Archaic I, then to decrease until it becomes absent in the Austin phase, only to dramatically increase in importance again during the Toyah phase. These data lead to the questioning of the importance of bison resources to the prehistoric occupants of $41 \mathrm{HY} 165$.
In contrast to a reliance on bison resources, the prehistoric occupants of 41HY165 appear to have focused instead on deer or pronghorn antelope, small mammals, and aquatics. The Middle Archaic is characterized by a dependence on deer and pronghorn antelope and other small mammals, supported by turtles and lower vertebrates. By the Late Archaic I, deer and antelope remains drop significantly as bison 
dominates the assemblage, which continues to be supported by small mammals, turtles, and other lower vertebrates. However, during the Late Archaic II period, bison is replaced by deer and antelope, while small vertebrates continue to increase. While the absence of bison during the Austin phase can be attributed to poor recovery, the Toyah phase displays a dramatic increase of bison remains. Interestingly, the Toyah phase is also characterized by a significant increase of turtle, fish, and other lower vertebrates; small mammals, however, do not show an increase during this period.

When considered together, these data begin to sketch a scenario in which the inhabitants of 41HY165 maintained a relatively stable and continuous occupation characterized by a reliance on locally available riverine faunal resources. At times, this included bison, but as indicated by the faunal assemblage, this reliance was always supported by small mammals and aquatics. The dramatic increase of not only bison remains but of turtle, fish, and other lower vertebrates during the Toyah phase may be an indicator of population increase that resulted in local resource intensification. Overall, the small amounts of recovered bison remains suggests that bison did not play a significant role in the local and regional economies of prehistoric occupants of 41HY165.

\section{Burned Rock Technology}

A review of the standardized frequency of burned rock weights indicates peaks in the Late Archaic II (AU 4a) and the Toyah phase (AU 3a) with the Toyah phase displaying a much larger increase in burned rock in relation to the other AUs. The frequency of burned rock weights is often used as a proxy for measuring subsistence intensification within a local or regional population. These increases are often perceived as indicators of a subsistence economy shifting towards bison exploitation or the intensification of plant resources (Thoms 2008). However, this increase in burned rock may also reflect changing mobility and settlement patterns related to increased regional population.

In regards to $41 \mathrm{HY} 165$, there appears to be a steady increase in the standardized frequency of burned rock weights from the Middle Archaic through both phases of the Late Archaic (Late Archaic I and Late Archaic II), with a peak during Late Archaic II. This is followed by a significant decrease during the Austin phase, which may be indicative of a reduced use of the site or a lack of archaeological material that can be securely dated to this analytical period. The Toyah phase, however, is characterized by a dramatic increase in frequency of burned rock.

In an exploration of the relationship between faunal remains and burned rock frequencies, faunal analysis included a comparison of burned rock mass with faunal bone NISP based on the hypothesis that an increase in burned rock mass indicates an increase in food processing and/or broadening of the subsistence base. In general, standardized faunal bone NISP trends followed that of the standardized burned rock mass in all periods except for the Protohistoric, where burned rock mass drops off dramatically following the Toyah phase. An increase in frequency from the Middle Archaic to Late Archaic was noted, with a drop in the Austin prior to the upswing presented in the Toyah phase. As noted in the faunal analysis section of this report, the Austin phase drop may be the result of poor sampling. Contrary to the belief that increase in burned rock mass correlates with increase in bison exploitation, there appears to be a dip in bison remains from the Late Archaic I forward, as burned rock mass appears to increase with a peak during the Late Archaic II. This decrease, however, is replaced 
by an upswing during the Toyah phase, when burned rock mass reaches its maximum extent along with a slight increase in bison remains. There does appear to be a correlation between medium-sized Artiodactyla (deer and pronghorn antelope) and burned rock mass frequencies. Faunal analysis indicated that deer and pronghorn antelope remains tend to correlate with increase burned rock mass frequencies, suggesting an ever-increasing reliance on deer and pronghorn as top prey choice for the prehistoric occupants of $41 \mathrm{HY} 165$.

Eighteen burned rock samples were submitted to AEL at Texas A\&M University to recover and identify plant microfossil remains from the surfaces of the rocks. Samples were chosen from levels that correspond to AUs. Of the 18 samples submitted, only 12 contained plant microfossils that included starch granules and phytoliths. Analysis was conducted by Dr. Timothy E. Riley, and is presented in Chapter 9.

Dr. Riley indicated that several of the FCR samples contained starch granules consistent with geophytes in the Araceae family, with the most likely source as arrow arum (Peltandra sp.). While this was an important ethnographic food resource in the Eastern Woodlands (Messner 2008), there is no historic record of this resource being consumed in Texas. At least one species, Peltandra virginica, however, does occur in the state. There were also several granules morphologically consistent with the starch encountered in Yucca sp. throughout the assemblage. This could be the result of roasting yucca flower stalks as a food resource, or the use of yucca leaves as a packing material during roasting.

The other identifiable starch granules occurring in features placed with in the Late
Archaic I (AU 4b) AU are most likely associated with packing material. One such large granule encountered was consistent with starch from Hordeum sp. As this starch is associated with a grass seedhead, there is little reason to infer the purposeful roasting of this resource, although it is possible that the granule is associated with stone boiling. Grass phytoliths were also recovered in small quantities from several other features, indicating that grass stems were commonly used as packing material. Approximately 20 granules consistent with a Polygonum sp. fruit were also recovered from a Late Archaic I feature. Again, this is likely to be from the use of this botanical resource as a packing material, although it could also be associated with stone boiling.

In addition to the above-described starch granules, four unknown morphotypes were also encountered during the analysis. One, labeled Unknown D, was the most common starch granule encountered in the study. It has some similarities with a mesquite starch type in Giovannetti et al. (2008), but the large facets and overall angularity limit a secure identification. Based on the size, angular shape, and open hilum, the botanical source for this starch morphotype is probably a geophyte or aquatic type resource.

In consideration of the presented data, it appears that the prehistoric occupants of 41HY165 utilized burned rock technology as a means of processing acquired game animals, most likely deer and pronghorn antelope. Faunal analysis has indicated the presence of burned faunal remains, with peaks in frequency during the Late Archaic I, Late Archaic II, and the Toyah phase, corresponding to peaks of burned rock frequency. This evidence, coupled with the microfossil analysis indicating that plant remains encountered on submitted burned rock samples are indicative of packing material and not plant 
food processing, supports the conclusion that the occupants of 41HY165 focused on meat roasting and not plant processing in the utilization of burned rock technology.

\section{Conclusions}

The springs that feed Spring Lake and serve as the headwaters of the San Marcos River have attracted human populations for over 11,500 years. Their location within an ecotonal zone (a transition area between two adjoining largescale environmental provinces) provided a diversity of fauna and flora resources capable of supporting dense human occupations. It may have been these springs in conjunction with the abundant resources of the area that first attracted prehistoric inhabitants to 41HY165.

Temporally diagnostic projectile points suggest that early occupation may have occurred during the Early Archaic/Paleoindian period. This is further confirmed by absolute dates, conclusively placing early occupation of the site in the Middle Archaic period. During this time, the inhabitants of 41HY165 utilized burned rock technology most likely in the roasting of acquired local game animals, with deer and/or antelope appearing as the prey of choice.

Occupation of 41HY165 continued through Late Archaic I, with an increase utilization of burned rock technology and the inclusion of bison in the diet breadth. Deer/antelope remain an important component, and fish utilization increases from the Middle Archaic. The recovery of juvenile/fetal bison remains from this period suggests a spring occupation of the site. Increased burned rock technology continues through the Late Archaic II, where it peaks. There is a decreased reliance on fish during this period, but a rise in small mammals and lower vertebrates. A slight decrease in bison remains is supplanted by an increase in deer/antelope, including juvenile/fetal remains, again suggesting a spring occupation of the site.

Based on the recovered material, a cautious interpretation would be that $41 \mathrm{HY} 165$ experienced a significant drop in occupation during the Austin phase. This, however, may be the result of sampling error due to poor recovery of material dated to this period. With this in mind, it is difficult to speculate on the nature of occupation of 41HY165 during this time. The site was most likely utilized, as faunal remains, burned rock, and projectile points dating to this period have been recovered; nevertheless, there are insufficient data to infer the nature of this occupation.

The low frequency of remains from the Austin phase is quickly replaced by an abundance of material recovered from Toyah phase contexts. A sharp spike in burned rock technology indicates the greatest use of this technology at $41 \mathrm{HY} 165$ during this period. This is coupled with increases in all faunal remains, including bison. The presence of limb fragments is suggestive of resource distribution. Again, the presence of juvenile bone supports a spring occupation. It is also during this period that ceramic remains first appear.

Spanish Colonial era occupation of the site continues as supported by the recovery of a Guerrero projectile point and Goliad style ceramics. Undefined Historic debris (ceramics, glass, metal, building materials, etc.) recovered from the upper levels of 41HY165 support a continued occupation through the nineteenth and twentieth centuries. 
In general, it appears that 41HY165 was actively occupied from at least the Middle Archaic through to the Historic period. Prehistoric occupation of the site was characterized by a utilization of burned rock technology for roasting locally acquired game animals, which at times included bison. A strong argument can be made for the occupations/utilization of this site during the spring season, due to the recovery of juvenile/ fetal deer and bison remains. 


\section{REFERENCES CiTED}

Aery, Deidra A.

2007 Organization of Lithic Technology in Archaic Texas: An Example from 41 HY160 in San Marcos, Texas. Unpublished Master's thesis, Department of Anthropology, Texas State University-San Marcos.

Anaya, Roberto

2004 Conceptual Model for the Edwards-Trinity (Plateau) Aquifer System, Texas. In Aquifers of the Edwards Plateau, edited by R. E. Mace, E. S. Angle, and W. F. Mullican, III, pp. 21-62. Report 360. Texas Water Development Board, Austin.

Anderson, Patricia C.

1980 A Testimony of Prehistoric Tasks: Diagnostic Residues on Stone Tool Working Edges. World Archaeology 12(2):181-194.

Andrefsky, Wiliam, Jr.

2005 Lithics: Macroscopic Approaches to Analysis. 2nd ed. Cambridge University Press, Cambridge.

Adrefsky, William, Jr. (editor)

2008 Lithic Technology: Measures of Production, Use and Curation. Cambridge University Press. Cambridge.

Arnn, John W., III

2005 Chronology, Technology, and Subsistence: Is That All There Is? Council of Texas Archeologists Newsletter 29(2):17-28.

2007 Transformation and Persistence of Indigenous Cultural Identity during the Early Colonial and Late Prehistoric Periods in Texas. Unpublished PhD dissertation, University of Kentucky, Lexington. University Microfilms, Ann Arbor.

Autio, K.

2001 Light Microscopic Techniques to Understand Starch Digestibility. Manipulating Pig Production 8:235-239.

Babot, M. del P.

2003 Starch Grain Damage as an Indicator of Food Processing. In Phytolith and Starch Research in the Australian-Pacific-Asian Regions: The State of the Art, edited by D. M. Hart and L. A. Wallis, pp. 69-82. Terra Australis, Vol. 19. Pandanus Books, Canberra.

Badenhuizen, N. P.

1965 Occurence and Development of Starch in Plants In Starch: Chemistry and Technology, edited by R. L. Whistler and E. F. Paschall, pp. 65-104. Academic Press, London. 
Bamforth, Douglas B.

1991 Flintknapping Skill, Communal Hunting, and Paleoindian Projectile Point Typology. Plains Anthropologist 36:309-322.

Barton, Huw, and Richard Fullagar

2006 Microscopy. In Ancient Starch Research edited by R. Torrence and H. Barton, pp. 47-52. Left Hand Press, Walnut Creek, California.

Batte, Charles D.

1984 Soil Survey of Comal and Hays Counties, Texas. United States Department of Agriculture, Soil Conservation Service, in cooperation with the Texas Agricultural Experiment Station.

Baugh, Susan T.

1986 Late Prehistoric Bison Distribution in Oklahoma. Plains Anthropologist 31(114, part 2): 83-96.

Bekoff, Marc

1977 Canis latrans. Mammalian Species 79:1-9.

Bell, Robert E.

1993 Guide to the Identification of Certain American Indian Projectile Points. Special Bulletin No. 2. Oklahoma Anthropological Society, Norman, Oklahoma.

1996 Guide to the Identification of Certain American Indian Projectile Points. Special Bulletin No. 1. Oklahoma Anthropological Society, Norman, Oklahoma.

Bement, Leland C.

1999 Bison Hunting at the Cooper Site: Where Lightning Bolts Drew Thundering Herds. University of Oklahoma Press, Norman.

Bement, Leland C., Ernest L. Lundelius, Jr., and Richard A. Ketcham

2005 Hoax or History: A Bison Skull with Embedded Calf Creek Projectile Point. Plains Anthropologist 50:221-226.

Bettinger, Robert L.

1991 Hunter-Gatherers: Archaeological and Evolutionary Theory. Plenum Press, New York.

Bettinger, Robert L., Ripan Malhi, and Helen McCarthy

1997 Central Place Models of Acorn and Mussel Processing. Journal of Archaeological Science 24:887-899.

Binford, Lewis

1962 Archaeological Systematics and the Study of Culture Process. American Antiquity 31:203210. 
1979 Organization and Formation Processes: Looking at Curated Technilogies. Journal of Anthropological Research 32:255-273.

1980 Willow Smoke and Dogs' Tails: Hunter-Gatherer Settlement Systems and Archaeological Site Formation. American Antiquity 45:4-10.

2001 Constructing Frames of Reference: An Analytical Method for Archaeological Theory Building Using Hunter-Gatherer and Environmental Data Sets. University of California Press, Berkeley.

Black, Stephen L.

1989 Central Texas Plateau Prairie. In From the Gulf Coast to the Rio Grande: Human Adaptation in the Central, South, and Lower Pecos Texas, edited by Thomas R. Hester, Stephen L. Black, D. Gentry Steele, Ben W. Olive, Anne A. Fox, Karl J. Reinhard, and Leland C. Bement, pp. 17-38. Research Series No. 33. Arkansas Archeological Survey, Fayetteville.

1993 Nailing the Coffin Shut on the Traditional Approach to Prehistoric Archeology in Texas: An Epitaph and Inquiry into the Afterlife. Cultural Resource Management News \& Views 5:16-19.

1995 Archeological and Ethnohistorical Background. In Archeological Investigations at the Loma Sandia Site (41LK28): A Prehistoric Campsite in Live Oak County, Texas, Vol. 1, edited by Anna Jean Taylor and Cheryl Lynn Highley, pp. 31-45. Studies in Archeology No. 20. Texas Archeological Research Laboratory, The University of Texas at Austin.

1997 Oven Cookery at the Honey Creek Site. In Hot Rock Cooking on the Greater Edwards Plateau: Four Burned Rock Midden Sites in West Central Texas, by Stephen L. Black, Linda W. Ellis, Darrell G. Creel, and Glenn T. Goode, pp. 255-268. Studies in Archeology 22. Texas Archeological Research Laboratory, The University of Texas at Austin.

Black, Stephen L., and Darrell G. Creel

1997 The Central Texas Burned Rock Midden Reconsidered. In Hot Rock Cooking on the Greater Edwards Plateau: Four Burned Rock Midden Sites in West Central Texas, by Stephen L. Black, Linda W. Ellis, Darrell G. Creel, and Glenn T. Goode, pp. 269-305. Studies in Archeology 22. Texas Archeological Research Laboratory, The University of Texas at Austin.

Black, S., L. W. Ellis, D. G. Creel, and G. T. Goode

1997 Hot Rock Cooking on the Greater Edwards Plateau: Four Burned Rock Midden Sites in West Central Texas. 2 vols. Studies in Archaeology 22. Texas Archaeological Research Laboratory, The University of Texas at Austin.

Black, Stephen L., and Al J. McGraw

1985 The Panther Springs Creek Site: Cultural Change and Continuity in the Upper Salado Creek Drainage, South-Central Texas. Archaeological Survey Report No. 100. Center for Archaeological Research, The University of Texas at San Antonio. 
Bolton, Herbert E.

1970 [1915] Texas in the Middle Eighteenth Century: Studies in Spanish Colonial History and Administration, Vol. 3. University of California Publications in History. University of California, Berkeley.

Bomar, George W.

1983 Texas Weather. University of Texas Press, Austin.

Bonner, Franklin T.

2008 Melia azerdach L. Chinaberry. In Woody Plant Seed Manual, coordinated by Franklin T. Bonner, pp. 718-719. Agriculture Handbook 727. U.S. Department of Agriculture, Forest Service, Washington DC. Electronic document, http://www.nsl.fs.fed.us/wpsm/Melia.pdf (accessed September 8, 2011).

Bousman, C. Britt, Barry W. Baker, and Anne C. Kerr

2004 Paleoindian Archeology in Texas. In The Prehistory of Texas, edited by Timothy K. Perttula, pp. 15-97. Texas A\&M Press, College Station.

Bousman, C. Britt., Michael B. Collins, Paul Goldberg, Thomas Stafford, Jan Guy, Barry W. Baker, D. Gentry Steele, Marvin Kay, Anne Kerr, Glen Fredlund, Phil Dering, Vance Holliday, Diane Wilson, Wulf Gose, Susan DIal, Paul Takac, Robin Balinsky, Marilyn Masson, and Joseph F. Powell 2002 The Paleoindian-Archaic Transition: New Evidence from Texas. Antiquity 76:980-990.

Bousman, C. Britt, and David L. Nickels, assemblers

2003 Archaeological Testing of the Burleson Homestead at 41HY37, Hays County, Texas. Archaeological Studies Report No. 4. Center for Archaeological Studies, Texas State University-San Marcos.

Boyd, M., C. Surette, and B. A. Nicholson

2006 Archaeobotanical Evidence of Prehistoric Maize (Zea mays) Consumption at the Northern Edge of the Great Plains. Journal of Archaeological Science 33(8):1129-1140.

Brown, David O.

1983 The Berger Bluff Site (41GD30A): Excavations in the Upper Deposits, 1979. Archaeological Survey Report No. 115. Center for Archaeological Research, The University of Texas at San Antonio.

Bureau of Economic Geology

1974 Geologic Atlas of Texas, Seguin Sheet. Bureau of Economic Geology, The University of Texas at Austin. 
Bush, Leslie L.

2008 Appendix E: Analysis of Macrobotanical Remains. In Hunters and Gatherers of the North Bosque River Valley: Excavations at the Baylor, Britton, McMillan, and Higginbotham Sites, Waco Lake, McLennan County, Texas, by Gemma Mehalchick and Karl W. Kibler, pp. 435457. Report of Investigations No. 156. Prewitt and Associates, Inc., Austin, Texas. Submitted to U.S. Army Corps of Engineers, Fort Worth District. PAI No. 202008.

Cameron, Guy N., and Stephen R. Spencer

1981 Sigmodon hispidus. Mammalian Species 158:1-9.

Campbell, T. N., and T. J. Campbell

1985 Indian Groups Associated with Spanish Missions of the San Antonio Missions National Historical Park. Special Report No. 16. Center for Archaeological Research, The University of Texas at San Antonio.

Canti, M. G.

1997 An Investigation of Microscopic Calcerous Spherulites from Herbivore Dungs. Journal of Archaeological Science 24:219-231.

1998 The Production and Preservation of Faecal Spherulites: Animals, Environment, and Taphonomy. Journal of Archaeological Science 26:251-258.

1999 The Micromorphological Identification of Faecal Spherulites from Archaeological and Modern Materials. Journal of Archaeological Science 25:435-444.

Carr, John T., Jr.

1967 The Climate and Physiography of Texas. Report No. 53. Texas Water Development Board, Austin.

Carr, Lucien

1895 The Food of Certain American Indians and Their Methods of Preparing It. Proceedings of the American Antiquarian Society 10:155-90.

Chapman, Joseph A, J. Gregory Hockman, and Magaly M. Ojeda C.

1980 Sylvilagus floridanus. Mammalian Species 136:1-8.

Chapman, Joseph A., and Gale R. Willner

1978 Sylvilagus audubonii. Mammalian Species 106:1-4.

Clifton, Robert T.

1970 Barbs, Prongs, Points, Prickers, and Stickers: A Complete and Illustrated Catalogue of Antique Barbed Wire. University of Oklahoma Press, Norman. 
Collins, Michael B.

1994 Evidence of Early Archaic Occupation. In Archaic and Late Prehistoric Human Ecology in the Middle Onion Creek Valley, Hays County, Texas, by Robert A. Ricklis and Michael B. Collins, pp. 67-100. Studies in Archeology 19. Texas Archeological Research Laboratory, The University of Texas at Austin.

1995 Forty Years of Archaeology in Texas. Bulletin of the Texas Archeological Society 66:361400.

2004 Archeology in Central Texas. In The Prehistory of Texas, edited by Timothy K. Perttula, pp. 101-126. Texas A\&M University Press, College Station.

Collins, Michael B., and Kenneth M. Brown

2000 The Gault Gisement: Some Preliminary Observations. Current Archeology in Texas 2(1):163166.

Cortella, Alicia R., and Maria L. Pochettino

1994 Starch Grain Analysis as a Microscopic Diagnostic Feature in the Identification of Plant Material. Economic Botany 48:171-181.

Crabtree, Don E.

1972 An Introduction to Flintworking. Occasional Papers No. 28. Idaho State University, Pocatello.

Creel, Darrell

1990 Excavations at 41TG91, Tom Green County, 1978. Publications in Archeology, No. 38. Texas State Department of Highways and Public Transportation, Austin.

1991 Bison Hides in Late Prehistoric Exchange in the Southern Plains. American Antiquity 56(1):40-49.

Cummings, Linda Scott

1992a Pollen and Starch Analysis of Stratigraphic and Housepit Samples from 48SU595, Wyoming. Manuscript on file with Archaeological Services, Western Wyoming College, Rock Springs.

1992b Preliminary Examination of Five Pieces of Groundstone from Lander County, Central Nevada, for Pollen, Phytoliths, Starch Granules, and Blood Residue. Manuscript on file with Dames and Moore, Las Vegas, Nevada.

1992c Pollen, Phytolith, Starch, Parasite, and Macrofloral Analyses on a Coprolite from Luster Cave, Utah. Manuscript on file with Kae McDonald, Glenwood Springs, Colorado.

1993a Pollen and Starch Analysis of Features in a Pithouse at the Paquet Gulch Bridge Site (35WS125), Oregon. Manuscript on file with State Museum of Anthropology, University of Oregon, Eugene.

1993b Exploratory Pollen and Starch Analysis of Three Samples from the Big M Site, Fort Rock Basin, Oregon. Manuscript on file with the Department of Anthropology/State Museum of Anthropology, University of Oregon, Eugene.

1993c Phytolith, Starch, and Blood Residue Analysis of Artifacts from Site 41MU55, Texas. Manuscript on file with Department of Anthropology, Texas A\&M University, College Station. 
1994 Pollen, Phytolith, Macrofloral, and Charcoal Analyses at the Mustang Branch Site (41HY209) and the Barton Site (41HY202). In Archaic and Late Prehistoric Human Ecology in the Middle Onion Creek Valley, Hays County, Texas, by Robert A. Ricklis and Michael B. Collins, pp. 387-402. Studies in Archaeology 19. Texas Archaeological Research Laboratory, The University of Texas, Austin.

1997a Pollen, Phytolith, and Starch Granule Analysis of a Piece of Ground Stone, 35JE355, Oregon. PRI Technical Report 97-59. Manuscript on file with Sisters Ranger District, U.S. Forest Service, Sisters, Oregon.

1997b Stratigraphic Pollen Analysis at 48CK1409 and 48CK1416, and Pollen/Starch Analysis of Groundstone at 48CK1417, Wyoming. PRI Technical Report 97-18. Manuscript on file with TRC Mariah Associates, Inc., Laramie, Wyoming.

Czaja, A.

1978 Structure of Starch Grains and the Classification of Vascular Plant Families. Taxon 27:463470 .

Daniel, W. S.

1973 Investigation of Factors Contributing to Subnormal Fawn Production and Herd Growth Patterns. Job Progress Report No. 10. Texas Parks and Wildlife Department, Austin.

de la Teja, Jesús F.

1995 San Antonio de Bexár: A Community on New Spain's Northern Frontier. University of New Mexico Press, Albuquerque.

Densmore, Francis

1974 How Indians Use Wild Plants for Food, Medicine and Crafts. Reprinted. Dover Publications, New York. Originally published 1928, 44th Annual Report, Bureau of American Ethnology, pp. 279-397. Smithsonian Institution, Washington DC.

Dering, Phil

1998 Carbonized Plant Remains. In Wilson-Leonard: An 11,000-year Archeological Record of Hunter-Gatherers in Central Texas, edited by Michael B. Collins, pp. 1609-1636. Studies in Archeology 31, Texas Archeological Research Laboratory, The University of Texas, Austin. Archeology Studies Program, Report 10, Texas Department of Transportation, Environmental Affairs Division, Austin.

1999 Earth-Oven Plant Processing in Archaic Period Economies: An Example from the Semi-Arid Savannah in South-Central North America. American Antiquity 64(4):659-674.

2006 Netleaf Hackberry, Desert Hackberry, Sugar Berry. Electronic document, http://www. texasbeyondhistory.net/st-plains/nature/images/hackberry.html (accessed November 2009).

2008 Late Prehistoric Subsistence Economy on the Edwards Plateau. Plains Anthropologist 53(205):59-77. 
Diamond, David D., David H. Riskind, and Steve L. Orzell

1987 A Framework for Plant Community Classification and Conservation in Texas. Texas Journal of Science 39:203-221.

Diamond, David D., and Fred E. Smeins

1985 Composition, Classification, and Species Response Patterns of Remnant Tallgrass Prairie in Texas. American Midland Naturalist 113:294-309.

1993 The Native Plant Communities of the Blackland Prairie. In The Texas Blackland Prairie: Land, History, and Culture, edited by M. Rebecca Sharpless and Joe C. Yelderman, Jr., pp. 66-81. Program for Regional Studies, Baylor University, Waco, TX.

Dillehay, Thomas D.

1974 Late Quaternary Bison Population Changes on the Southern Plains. Plains Anthropologist 19(64):180-196.

Dillon, C. L.

1958 Current Trends in Glass Technology. American Journal of Enology 9(2):59-63.

Dixon, James R.

2000 Amphibians and Reptiles of Texas. Texas A\&M University Press, College Station.

Dobie, Dudley R.

1932 The History of Hays County, Texas. Unpublished Master's thesis, The University of Texas at Austin.

Duffield, Lathel F.

1963 The Wolfshead Site: An Archaic-Neo-American Site in San Augustine County, Texas. Bulletin of the Texas Archeological Society 34:83-141.

Dunn, William E.

1911 Apache Relations in Texas, 1718-1750. Southwestern Historical Quarterly 14:198-274.

Eckhardt, Gregg

2010 The Edwards Aquifer Website. Electronic document, http://www.edwardsaquifer.net/index. html (accessed December 2010).

Edwards Aquifer Authority

2004 Edwards Aquifer Authority Hydrologic Data Report for 2003. Edwards Aquifer Authority, San Antonio. 
Ellis, Linda W.

1997 Hot Rock Technology. In Hot Rock Cooking on the Greater Edwards Plateau: Four Burned Rock Midden Sites in West Central Texas, edited by Stephen L. Black, Linda W. Ellis, Darrell G. Creel, and Glenn T. Goode, pp. 43-82. Studies in Archeology 22. Texas Archeological Research Laboratory, The University of Texas at Austin.

Epstein, Diana, and Millicent Safro

1991 Buttons. Harry N. Abrams, Inc., New York.

Evers, A. D.

1979 Cereal Starches and Proteins. In Food Microscopy, edited by J. G. Vaughan, pp. 139-191. Academic Press, London.

Figueroa, Antonia L, and Raymond P. Mauldin

2005 Test Excavations and Monitoring at 41BX1598: A Multicomponent Site in Bexar County, Texas. Archaeological Report No. 360. Center for Archaeological Research, The University of Texas at San Antonio.

Fike, Richard E.

1987 The Bottle Book: A Comprehensive Guide to Historic Embossed Medicine Bottles. Peregrine Smith Books, Salt Lake City, Utah.

Fisher, Lewis F.

1998 The Spanish Missions of San Antonio. Maverick Publishing Company, San Antonio.

Flint, Olga

1994 Food Microscopy: A Manual of Practical Methods, Using Optical Microscopy. Microscopy Handbooks 30. BIOS Scientific Publishers, Oxford.

Ford, Owen A., and Anthony S. Lyle

1998 Archaeological Investigation of a Spring Lake Lot for Joe's Crab Shack Parking. Archaeological Survey Report No. 277. Center for Archaeological Research, The University of Texas at San Antonio.

Foster, William C.

1995 Spanish Expeditions into Texas 1689-1768. University of Texas Press, Austin.

Frison, George C.

1998 The Northwestern and Northern Plains Archaic. In Archaeology on the Great Plains, edited by W. Raymond Wood, pp. 140-172. University of Kansas Press, Lawrence.

Fullagar, Richard, and Judith Field

1997 Pleistocene Seed Grinding Implements from the Australian Arid Zone. Antiquity 71:300-307. 
Fullagar, Richard, Judith Field, Tim Denham, and Carol Lentfer

2006 Early and Mid Holocene Tool-Use and Processing of Taro (Colocasia esculenta), Yam (Dioscorea sp.) and Other Plants at Kuk Swamp in the Highlands of Papua New Guinea. Journal of Archaeological Science 33(5):595-614.

Fullagar, Richard, Judith Furby, and Bruce Hardy

1996 Residues on Stone Artefacts: State of a Scientific Art. Antiquity 70:740-745.

Fullagar, Richard, Thomas H. Loy, and S. Cox

1998 Starch Grains, Sediments and Stone Tool Function: Evidence from Bitokara, Papua New Guinea. In A Closer Look: Recent Australian Studies of Stone Tools, edited by Richard Fullagar, pp. 49-60. Series 6. Sydney University Archaeological Methods, Sydney.

Galehouse, John S.

1971 Point Counting. In Procedures in Sedimentary Petrology, edited by Robert E. Carver, pp. 385-407, Wiley-Interscience, New York.

Garber, James F.

1983 State of Texas Archeological Site Data Form. Texas Historical Commission Texas Archeological Sites Atlas, s.v. “41HY160,” http://nueces.thc.state.tx.us/ (accessed July 6, 2009).

1984 State of Texas Archeological Site Data Form. Texas Historical Commission Texas Archeological Sites Atlas, s.v. “41HY165,” http://nueces.thc.state.tx.us/ (accessed July 6, 2009).

Garber, James F., Susan Bergman, Billy Dickinson, Robert W. Hays, III, Jane Simpson, and Jeffrey Stefanoff

1983 Excavations at Aquarena Springs, San Marcos, Texas. La Tierra 10:2:28-38.

Garber, James F., and David M. Glassman

1992 Excavation of Human Remains from the Fish Pond Site, 41HY161, in San Marcos, Hays County, Texas. Texas Antiquities Permit Number 338. Department of Sociology and Anthropology, Southwest Texas State University, San Marcos.

Gardner, Paul S.

1986 Appendix F: Analysis of Plant Remains from Lesesne and Fairbank Plantations (38BK202), Berkeley County, South Carolina. In Home Upriver: Rural Life on Daniel's Island, Berkeley County, South Carolina, by Martha A. Zierdan, Lesley M. Drucker, and Jeanne Calhoun, pp. F1-F23. Report prepared for the South Carolina Department of Highways and Public Transportation by Carolina Archaeological Services and The Charleston Museum, Charleston, South Carolina.

1997 The Ecological Structure and Behavioral Implications of Mast Exploration Strategies. In People, Plants and Landscapes: Studies in Paleoethnobotany, edited by Kristen J. Gremillion, pp. 161-178. University of Alabama Press, Tuscaloosa. 
Gaudette, Paul, and Deborah Slaton

2007 Preservation of Historic Concrete. Preservation Brief 15. National Park Service, Government Printing Office, Washington DC.

Gerstle, Andrea, Thomas C. Kelly, and Cristi Assad

1978 The Fort Sam Houston Project: An Archaeological and Historical Assessment.

Archaeological Survey Report No. 40. Center for Archaeological Research, The University of Texas at San Antonio.

Giesecke, J.

1998 Faunal Analysis from 41HY165: An Independent Study. Manuscript on file, Anthropology Department, Southwest Texas State University, San Marcos.

Gilbert, B. Miles

1990 Mammalian Osteology. Gilbert, Laramie, WY

Giovannetti, M. A., V. S. Lema, C. G. Bartoli, and A. Capparelli

2008 Starch Grain Characterization of Prosopis chilensis (Mol.) Stuntz and P. flexuosa DC, and the Analysis of Their Archaeological Remains in Andean South America. Journal of Archaeological Science 35(11):2973-2985.

Glover, Jack

1969 The "Bobbed Wire" Bible. Sunset Trading Post, Sunset.

Goelz, Melinda A.

1999 Geoarchaeological Assessment of the Texas Rivers Center, San Marcos Springs. Technical Reports, No. 40. Prewitt \& Associates, Inc., Austin.

Goode, Glenn T.

1989 Archaeological Testing and Recommendations for the Kennedy Bluffs Site, 41BP19, in Bastrop County, Texas, Appendix II. In Excavations at 41BP19, the Kennedy Bluffs Site, Bastrop County, Texas, edited by Leland C. Bement, pp. 155-180. Contract reports in Archaeology, Report 5. Texas State Department of Highways and Public Transportation, Highway Design Division, Austin.

Grayson, Donald K.

1984 Quantitative Zooarchaeology: Topics in the Analysis of Archaeological Faunas. Academic Press, Orlando, Florida

Griffith, Glen E., Sandra A. Bryce, James M. Omernik, Jeffrey A. Comstock, Anne C. Rogers, Bill Harrison, Stephen L. Hatch, and David Bezanson.

2004 Ecoregions of Texas. U.S. Environmental Protection Agency, Corvallis, Oregon. 
Gurcke, Karl

1987 Bricks and Brickmaking; A Handbook for Historical Archaeology. The University of Idaho Press, Moscow, Idaho.

Gurven, Michael, and Kim Hill

2009 Why Do Men Hunt? A Reevaluation of "Man the Hunter" and the Sexual Division of Labor. Current Anthropology 50:51-74.

Habig, Marion A.

1977 The Alamo Mission: San Antonio de Valero, 1718-1793. Franciscan Herald Press, Chicago.

Hagemeir, Harold

2001 Barbed Wire: Identification Encyclopedia. 3rd ed. Morris Publishing, Kearney, Nebraska.

Hall, Grant D.

1981 Allens Creek: A Study in the Cultural Prehistory of the Brazos River Valley, Texas. Texas Archaeological Survey Research Report No. 61. The University of Texas at Austin.

2000 Pecan Food Potential in Prehistoric North America. Economic Botany 54(1):103-112.

Hall, Grant D., Stephen L. Black, and Carol Graves

1982 Archaeological Investigations at Choke Canyon reservoir, South Texas: The Phase I Findings. Choke Canyon Series, Vol. 5. Center for Archaeological Research, The University of Texas at San Antonio.

Hammett, Julia E.

1997 Interregional Patterns of Land Use and Plant Management in Native North America. In People, Plants and Landscapes: Studies in Paleoethnobotany, edited by Kristen J. Gremillion, pp. 195-216. University of Alabama Press, Tuscaloosa.

Haslam, M.

2006 Potential Misidentification of In Situ Archaeological Tool-Residues: Starch and Conidia. Journal of Archaeological Science 33(1):114-121.

Hawkes, Kristen

1991 Showing Off: Test of an Hypothesis about Men's Foraging Goals. Ethology and Sociobiology 12:29-54.

Hawkes, Kristen and Rebecca Bliege Bird

2002 Showing Off, Handicap Signaling, and the Evolution of Men's Work. Evolutionary Anthropology 11:58-67.

Hawkes, Kristen, Kim Hill, and James F. O'Connel

1982 Why Hunters Gather: Optimal Foraging and the Aché of Eastern Paraguay. American Ethnologist 9:379-398. 
Hayden, Brian and W. Karl Hutchings

1989 Whither the Billet Flake? In Experiments in Lithic Technology, edited by Daniel S. Amick and Raymond P. Mauldin, pp. 235-257. BAR International Series 528. Oxford.

Hester, Thomas R.

1983 Late Paleo-Indian Occupations at Baker Cave, Southwestern Texas. Bulletin of the Texas Archeological Society 53:101-119.

1995 The Prehistory of South Texas. Bulletin of the Texas Archeological Society 66:427-459.

2004 The Prehistory of South Texas. In The Prehistory of Texas, edited by Timothy Perttula, pp. 127-151. Texas A\&M University Press, College Station.

Hollenbach, Kandace D.

2011a Plant Remains from the Zatopec Site (41HY163). In Prehistoric Life, Labor, and Residence in Southeast Central Texas: Results of Data Recovery at 41HY163, the Zatopec Site, San Marcos, Texas, edited by Jon C. Lohse, pp. 404-413. Archaeological Studies Report No. 18. Center for Archaeological Studies, Texas State University-San Marcos.

$2011 \mathrm{~b}$ Plant Remains from 41HY160, a Prehistoric Site in Hays County, Texas. Report submitted to Center for Archaeological Studies, Texas State University-San Marcos. Archaeological Research Laboratory, The University of Tennessee, Knoxville.

Holliday, Vance T.

1997 Paleoindian Geoarchaeology of the Southern High Plains. University of Texas Press, Austin.

Holman, J. Alan

1995 Pleistocene Amphibians and Reptiles in North America. Oxford Monographs on Geology and Geophysics No. 32. Oxford University Press, New York.

Horrocks, Mark, Geoff Irwin, Martin Jones, and Doug Sutton

2004 Starch Grains and Xylem Cells of Sweet Potato (Ipomoea batatas) and Bracken (Pteridium esculentum) in Archaeological Deposits from Northern New Zealand. Journal of Archaeological Science 31(3):251-258.

Horrocks, Mark, Martin D. Jones, R. E. Beever, and Doug G. Sutton

2002 Analysis of Plant Microfossils in Prehistoric Coprolites from Harataonga Bay, Great Barrier Island, New Zealand. Journal of the Royal Society of New Zealand 32(4):617-628.

Horrocks, Mark, and Ian Lawlor

2006 Plant Microfossil Analysis of Soils from Polynesian Stonefields in South Auckland, New Zealand. Journal of Archaeological Science 33(2):200-217.

Horrocks, Mark, and Patrick D. Nunn

2007 Evidence for Introduced Taro (Colocasia esculenta) and Lesser Yam (Dioscorea esculenta) in Lapita-Era (ca. 3050-2500 cal. yr BP) Deposits from Bourewa, Southwest Viti Levu Island, Fiji. Journal of Archaeological Science 34(5):739-748. 
Horrocks, Mark, and Marshall I. Weisler

2006 A Short Note on Starch And Xylem of Colocasia esculenta (Taro) in Archaeological Deposits from Pitcairn Island, Southeast Polynesia. Journal of Archaeological Science 33(9):11891193.

Houk, Brett, and Jon Lohse

1993 Archeological Investigations at the Mingo Site, Bandera County, Texas. Bulletin of the Texas Archeological Society 61:193-247.

Houk, Brett A., Kevin A. Miller, and Eric R. Oksanen

2009 The Gatlin Site and the Early-to-Middle Archaic Chronology of the Southern Edwards Plateau, Texas. Bulletin of the Texas Archeological Society 80:51-75.

Huebner, Jeffery A.

1991 Late Prehistoric Bison Populations in Central and Southern Texas. Plains Anthropologist 36(137):343-358.

Hunter, Frederick W.

1950 Stiegel Glass. Dover Publications, Inc., New York, New York.

Husfloen, Kyle

2000 Antique Trader Pottery and Porcelain Ceramics, Price Guide. 3rd ed. Krause Publications, Iola, Wisconsin.

Irwin, G. J., L. J. WIlliams, M. Horrocks, H. J. Hall, M. S. McGlone and S. L. Nichol

2004 Evidence for Diet, Parasites, Pollen, Phytoliths and Diatoms in Prehistoric Coprolites from Kohika. In Kohika: The Archaeology of a Late Māori Lake Village in the Ngāti Awa Rohe, Bay of Plenty, New Zealand, edited by Geoffrey J. Irwin, pp. 217-238. University of Auckland Press, Auckland.

Israel, Fred L. (editor)

19681897 Sears, Roebuck Catalog. Chelsea House, New York.

Jackson, Thomas L.

1991 Pounding Acorn: Women's Production as Social and Economic Focus. In Engendering Archaeology: Women and Prehistory, ed. by Joan M. Gero and Margaret W. Conkey, pp. 301-325. Basil Blackwell, Oxford.

Jacobson, Jodi A.

2003 Identification of Mule Deer (Odocoileus hemionus) and White-tailed Deer (Odocoileus virginianus) Postcranial Remains as a Means of Determining Human Subsistence Strategies. Plains Anthropologist 48(187):287-297. 
Jenkins, Stephen H., and Peter E. Busher

1979 Castor canadensis. Mammalian Species 120:1-8.

Johannessen, Sissel

1993 Food, Dishes, and Society in the Mississippi Valley. In Foraging and Farming in the

Eastern Woodlands, edited by C. Margaret Scarry, pp. 182-205. University Press of Florida, Gainesville.

Johnson, Amber L., and Robert J. Hard

2008 Exploring Texas Archaeology with a Model of Intensification. Plains Anthropologist 53(205):137-153.

Johnson, Eileen, and Vance T. Holliday

1984 Comments on Large Springs and Early American Indians by Joel L. Shiner. Plains

Anthropologist 29(103):65-70.

Johnson, Jack G.

2009 Fire in the Hole: Archaeological Analysis and Interpretation of the Barnett Site (41MI77), a Burned Rock Midden on Pecan Bayou in Mills County, Texas. Unpublished Master's thesis, Department of Anthropology, Texas Tech University, Lubbock.

Johnson, LeRoy, Jr.

1987 A Plague of Phases: Recent Sociocultural Taxonomy in Texas Archeology. Bulletin of the Texas Archeological Society 57:1-26.

1994 The Life and Times of Toyah-Culture Folk; the Buckhollow Encampment Site 41KM16, Kimble County, Texas. Office of State Archeologist Report 38. Texas Department of Transportation and the Texas Historical Commission, Austin.

Johnson, LeRoy, Jr., and T. N. Campbell

1992 Sanan: Traces of a Previously Unknown Aboriginal Language in Colonial Coahuila and Texas. Plains Anthropologist 37(140):185-212.

Johnson, LeRoy, Jr., and Glenn T. Goode

1994 A New Try at Dating and Characterizing Holocene Climates, as well as Archeological Periods, on the Eastern Edwards Plateau. Bulletin of the Texas Archeological Society 65:1-51.

Jones J. Knox, Jr., David M. Armstrong, and Jerry R. Choate

1985 Guide to Mammals of the Plains States. University of Nebraska Press, Lincoln.

Jones, J. Knox, Jr., and Richard W. Manning

1992 Illustrated Key to Skulls of Genera of North American Land Mammals. Texas Tech University Press, Lubbock, Texas. 
Jones, Olive, and Catherine Sullivan

1989 The Parks Canada Glass Glossary for the Description of Containers, Tableware, Flat Glass, and Closures. National Historic Parks and Sites Branch, Canadian Parks Service, Ottawa.

Jones, Richard

2002 Archaeological Trench Monitoring Near Prehistoric Site 41HY161, Hays County, Texas. Technical Report No. 3. Center for Archaeological Studies, Texas State University-San Marcos.

Jurney, David H.

1988 Cut and Wire Nails: Functional and Temporal Interpretations. In Historic Farming on the Hogwallow Prairies: Ethnoarchaeological Investigations of the Mountain Creek Area, North Central Texas, Joe Pool Lake Archaeological Project, Volume 2, compiled by David H. Jurney, Susan A. Lebo, and Melissa M. Green, pp. 315-324. Archaeology Research Program, Institute for the Study of Earth and Man, Southern Methodist University, Dallas, Texas.

Justice, Noel

1987 Stone Age Spear and Arrow Points of the Midcontinental and Eastern United States. Indiana University Press, Bloomington.

Karbula, James W., Rachel Feit, and Timothy B. Griffith

2001 Changing Perspectives on the Toyah: Data Recovery Investigations of 41TV441, the Toyah Bluff Site, Travis County, Texas. Archeology Series No. 94. Hicks \& Company, Austin.

Keating, R. C.

2004 Systematic Occurrence of Raphide Crystals in Araceae. Annals of the Missouri Botanical Garden 91(3):495-504

Keen, Sharon

1982 Metal Container Artifact Class. In Artifact Analysis Manual for Historical Archaeology, edited by Dana-Mae Grainer. Manuscript report. Parks Canada, Prairie Region, Winnipeg, Manitoba.

Kelley, J. Charles

1947 The Lehmann Rock Shelter: A Stratified Site of the Toyah, Uvalde, and Round Rock Foci. Bulletin of the Texas Archeological and Paleontological Society 18:115-128.

Kendrick, Grace

1968 The Mouth-Blown Bottle. Edwards Brothers, Ann Arbor, Michigan. 
Kennedy, Harvey E., Jr.

1990 Sugarberry. In Silvics of North America, Volume 2: Hardwoods, coordinated by Russell M. Burns and Barbara H. Honkala. Agriculture Handbook 654. U.S. Department of Agriculture, Forest Service, Washington DC. Electronic document, http://www.na.fs.fed.us/spfo/pubs/ silvics_manual/volume_2/celtis/laevigata.htm (accessed September 8,2011$)$.

Kindscher, Kelly

1987 Edible Wild Plants of the Prairie. University Press of Kansas, Lawrence.

Klein, Richard G., and Kathryn Cruz-Uribe

1984 The Analysis of Animal Bones from Archaeological Sites. University of Chicago Press, Chicago, Illinois.

Krajicek, John E., and Robert D. Williams

1990 Hackberry. In Silvics of North America, Volume 2: Hardwoods, coordinated by Russell M. Burns and Barbara H. Honkala. Agriculture Handbook 654. U.S. Department of Agriculture, Forest Service, Washington DC. Electronic document, http://www.na.fs.fed.us/spfo/pubs/ silvics_manual/volume_2/celtis/occidentalis.htm (accessed September 8, 2011).

Krieger, Alex D.

2002 We Came Naked And Barefoot: The Journey of Cabeza De Vaca Across North America. University of Texas Press, Austin.

Kuhnlein, Harriet V., and Nancy J. Turner

1991 Traditional Plant Foods of Canadian Indigenous Peoples: Nutrition, Botany and Use. Gordon and Breach Science Publishers, Philadelphia.

Kurz, Don

1997 Shrubs and Woody Vines of Missouri. Missouri Department of Conservation, Jefferson City.

Larkin, Thomas J., and George W. Bomar

1983 Climatic Atlas of Texas. Publication LP-192. Texas Department of Water Resources, Austin.

Leach, Jeff D., David L. Nickels, Bruce K. Moses, and Richard Jones

1998 A Brief Comment on Estimating Rates of Burned Rock Discard: Results from an Experimental Earth Oven. La Tierra 25(3):42-50.

LeDoux, Spencer, and Jon C. Lohse

2011a Lithic Analysis: Projectile Points. In Prehistoric Life, Labor, and Residence in Southeast Central Texas: Results of Data Recovery at 41HY163, the Zatopec Site, San Marcos, edited by Jon C. Lohse, pp. 192-225. Archaeological Studies Report No. 18. Center for Archaeological Studies, Texas State University-San Marcos. 
2011b Flake Tools and Formal Unifaces. In Prehistoric Life, Labor, and Residence in Southeast Central Texas: Results of Data Recovery at 41HY163, the Zatopec Site, San Marcos, edited by Jon C. Lohse, pp. 245-264. Archaeological Studies Report No. 18. Center for Archaeological Studies, Texas State University-San Marcos.

Leezer, Carole, Julian A. Sitters, and Sarah Scogin

2010 Archaeological Assessment and Monitoring for Construction of a New Boiler Station at Jowers Center and Sewell Park, Texas State University-San Marcos, Hays County, Texas. Technical Report No. 38. Center for Archaeological Studies, Texas State University-San Marcos.

Leezer, Carole A., David M. Yelacic, Jon C. Lohse, and Frederick H. Hanselmann.

2011 Results of Cultural Resources Survey for the Spring Lake Section 206 Aquatic Ecosystem Restoration Project Texas State University San Marcos, Hays County, Texas. Technical Report No. 22. Center for Archaeological Studies, Texas State University-San Marcos.

Lemke, Ashley, and Cinda Timperley

2008 Preliminary Analysis of Turtle Material from the Gault Site, Texas. Current Research in the Pleistocene 25:115-117.

Lentfer, Carol, Michael Therin, and Robin Torrence

2002 Starch Grains and Environmental Reconstruction: a Modern Test Case from West New Britain, Papua New Guinea. Journal of Archaeological Science 29(7):687-698.

Lief, Alfred

1965 A Close-up of Closures. Glass Container Manufacturers Institute, New York.

Logan, Herschel C.

1959 Cartridges: A Pictorial Digest of Small Arms Ammunition. Bonanza Books, New York.

Lohse, Jon C.

1999 Lithics from the San Antonio de Valero Mission: Analysis of Materials for the 1979 Excavations of the Alamo. Bulletin of the Texas Archeological Society 70:265-279.

2012 Step By Step: The Influence of Reduction Sequence Models on Understanding Learning and Skill Transmission. Lithic Technology 36:97-108

Lohse, Jon C. (editor)

2011 Prehistoric Life, Labor, and Residence in Southeast Central Texas: Results of Data Recovery at 41HY163, the Zatopec Site, San Marcos. Archaeological Studies Report No. 18. Center for Archaeological Studies, Texas State University-San Marcos.

Lohse, Jon C., and Laly M. Cholak

2011 Toward a Useful Radiocarbon Chronology for Central Texas. Paper presented at the 82nd Annual Meeting of the Texas Archeological Society, Ft. Worth. 
Lohse, Jon C., C. Andrew Hemmings, and Michael B. Collins

2010 Putting the Specialization Back in Clovis: What Some Caches Reveal about Skill and the Organization of Production in the Terminal Pleistocene. Paper presented at the 75th Annual Meeting of the Society for American Archaeology, St. Louis.

Lohse, Jon C. and Carole Leezer

2011 Historic Properties Treatment Plan for Mitigation of the Spring Lake Section 206 Aquatic Ecosystem Restoration Project, San Marcos, Hays County, Texas. Manuscript on file, Center for Archaeological Studies, Texas State University-San Marcos.

Loy, $\mathrm{T}$.

2006 Optical Properties of Potential Look-Alikes. In Ancient Starch Research, edited by R. Torrence and H. Barton, pp. 123-124. Left Coast Press, Walnut Creek, California.

Loy, Thomas H., Matthew Spriggs, and Stephen Wickler

1992 Direct Evidence for Human Use of Plants 28,000 Years Ago: Starch Residues on Stone Artefacts from the Northern Solomon Islands. Antiquity 66:898-912.

Lukowski, Paul D., with contributions by Robert F. Scott, IV, and Richard F. Shoup 1988 Archaeological Investigations at 41BX1, Bexar County, Texas. Archaeological Survey Report No. 135. Center for Archaeological Research, The University of Texas at San Antonio.

Lyle, Anthony, Christopher Horrell, Steve A. Tomka, and Diane A. Cargill

2000 Archaeological Testing at the Headwaters of the San Marcos River: Southwest Texas State University Raw Water Supply Project. Archaeological Survey Report No. 293. Center for Archaeological Research, The University of Texas at San Antonio.

Lyman, R. Lee

1994 Vertebrate Taphonomy. Cambridge University Press.

Lynott, Mark J.

1979 Prehistoric Bison Populations of North Central Texas. Bulletin of the Texas Archeological Society 50:89-101.

Mackay, James

2002 Antiques at a Glance: Ceramics. PRC Publishing Ltd, London.

Marshall, Fiona, and Tom Pilgram

1993 NISP vs. MNI in Quantification of Body-Part Representation. American Antiquity 58(2):261269.

Martin, Alexander C., and William D. Barkley

1961 Seed Identification Manual. University of California, Berkley. 
Mauldin, Raymond P., Jennifer Thompson, and Leonard Kemp

2012 Reconsidering the Role of Bison in the Terminal Late Prehistoric (Toyah) Period of Texas. In The Toyah Phase of Central Texas: Late Prehistoric Economic and Social Processes, edited by Nancy A. Kenmotsu and Douglas K. Boyd, pp. 90-110. Texas A\&M University Press, College Station.

McGraw, Al J., John W. Clarke, Jr., and Elizabeth A. Robbins (editors)

1991 A Texas Legacy: The Old San Antonio Road and the Caminos Reales, A Tricentennial

History, 1691-1991. Texas State Department of Highways and Public Transportation, Austin.

McKearin, Helen, and Kenneth M. Wilson

1978 American Bottles \& Flasks and Their Ancestry. Crown Publishers, Inc., New York.

Meagher, Mary

1986 Bison bison. Mammalian Species 266:1-8.

Mech, L. David

1974 Canis lupus. Mammalian Species 37:1-6.

Messner, Timothy C.

2008 Woodland Period People and Plant Interactions: New Insights from Starch Grain Analysis. PhD dissertation, Department of Anthropology, Temple University, Philadelphia, Pennsylvania. University Microfilms, Ann Arbor, Michigan.

Messner, Timothy C., and Bill Schindler

2010 Plant Processing Strategies and their Affect upon Starch Grain Survival When Rendering Peltandra virginica (L.) Kunth, Araceae Edible. Journal of Archaeological Science 37:328336.

Metcalfe, Duncan, and K. Renee Barlow

1992 A Model for Exploring the Optimal Trade-off between Field Processing and Transport. American Anthropologist 94:340-356.

Miller, George

1980 Classification and Economic Scaling of the 19th Century Ceramics. Historical Archaeology, 14:1-40.

1991 A Revised Set of CC Index Values for Classifi cation and Economic Scaling of English Ceramics from 1787 to 1880. Historical Archaeology 25:1-23.

Moerman, Daniel E.

1998 Native American Ethnobotany. Timber Press, Portland, Oregon. 
Moir, Randall W.

1987a Refined Earthenwares and Ritual Ceramics Traditions. In Historic Buildings, Material, Culture, and People of the Prairie Margin, edited by David H. Jurney and Randall W. Moir, pp. 97-120. Richland Creek Technical Series, Volume V. Archaeology Research Program, Institute for the Study of Earth and Man, Southern Methodist University, Dallas, Texas.

1987b Socioeconomic and Chronometric Patterning of Window Glass. In Historic Buildings, Material Culture, and People of the Prairie Margin, edited by David H. Jurney and Randall W. Moir, pp. 73-82. Richland Creek Technical Series, Volume V. Archaeology Research Program, Institute for the Study of Earth and Man, Southern Methodist University, Dallas, Texas.

1988 Windows and Window Glass. In Historic Farming on the Hogwallow Prairies: Ethnoarchaeological Investigations of the Mountain Creek Area, North Central Texas, complied by David H. Jurney, Susan A. Lebo, and Melissa M. Green, pp. 263-272. Joe Pool Lake Archaeological Project, Volume II. Archaeology Research Program, Institute for the Study of Earth and Man, Southern Methodist University, Dallas, Texas.

Moss, G. E.

1976 The Microscopy of Starch. In Examination and Analysis of Starch and Starch Products, edited by J. A. Radley, pp. 1-31. Applied Science Publishers, London.

Munoz, Cynthia M., Raymond Mauldin, and Robert J. Hard

2011 Stable Isotope Analysis of Human Skeletal Remains from 41HY163, with Comparative Analysis of Remains from 41HY161. In Prehistoric Life, Labor, and Residence in SoutheastCentral Texas: Results of Data Recovery at 41HY163, the Zatopec Site, San Marcos, Texas, edited by Jon C. Lohse, pp. 343-350. Archaeological Studies Report No. 18. Center for Archaeological Studies, Texas State University-San Marcos.

Munsey, Cecil

1970 The Illustrated Guide to Collecting Bottles. Hawthorn Books, Inc. Publishers, New York.

Murray, Lyndon K.

2008 Effects of Taxonomic and Locality Inaccuracies on Biostratigraphy and Biochronology of the Hueso and Tapiado Formations in the Vallecito Creek-Fish Creek Section, AnzaBorrego Desert, California. Unpublished PhD dissertation, Department of Geosciences, The University of Texas at Austin.

Nelson, Lee H.

1968 Nail Chronology as an Aid to Dating Old Buildings. Technical Leaflet 48. American Association for State and Local History, Nashville.

Newcomb, William W., Jr.

1961 The Indians of Texas From Prehistoric to Modern Times. University of Texas Press, Austin.

1993 Historic Indians of Central Texas. Bulletin of the Texas Archeological Society 64:1-63. 
Nickels, David L., and C. Britt Bousman

2010 Archaeological Testing at San Marcos Springs (41HY160) for the Texas Rivers Center, Hays County, Texas. Archaeological Studies Report No. 13. Center for Archaeological Studies, Texas State University-San Marcos.

Niethammer, Carolyn

1974 American Indian Food and Lore. Macmillan, New York.

Noël Hume, Ivor

1969 A Guide to Artifacts of Colonial America. University of Pennsylvania Press, Philadelphia.

Nordt, Lee C.

2010 Chapter 6: Geology, Landscape Evolution, and Geoarchaeology. In Texas River Center Archaeology, Test Excavations at 41HY160, Hays County, Texas, assembled by David L. Nickels and C. Britt Bousman, pp. 47-60. Archaeological Studies Reports No. 13. Center for Archaeological Studies, Texas State University-San Marcos.

O'Gara, Bart W.

1978 Antilocapra americana. Mammalian Species 90:1-7.

Oksanen, Eric

2006 Proposed Fiber Optic Conduit Route at the Aquarena River Center and Golf Course, San Marcos, Hays County, Texas. Technical Report No. 22. Center for Archaeological Studies, Texas State University-San Marcos.

2008 Archaeological Investigations at the Icehouse Site, 41HY161: A Revaluation of Early Archaic Technology, Subsistence and Settlement along the Balcones Escarpment and Central Texas. Unpublished Master's thesis, Department of Anthropology, Texas State University-San Marcos.

Outram, A. K.

2001 A New Approach to Identifying Bone Marrow and Grease Exploitation: Why the "Indeterminate" Fragments Should Not Be Ignored. Journal of Archaeological Science 28:201-410.

Palmer, Edward

1871 Food Products of the North American Indians. Report of the Commission for 1870, pp. 404-428. U.S. Department of Agriculture, Washington DC.

Panati, Charles

1987 Panati's Extraordinary Origins of Everyday Things. Harper \& Row, New York.

Parry, William J., and Robert L. Kelly

1987 Expedient Core Technology and Sedentism. In The Organization of Core Technology, edited by Jay K. Johnson and Carole A. Morrow, pp. 285-304. Westview Press, Boulder, Colorado. 
Patterson, Leland W.

1995 The Archeology of Southeast Texas. Bulletin of the Texas Archeology Society 66:239-264.

Pearsall, Deborah M., Karol Chandler-Ezell, and James A. Zeidler

2004 Maize in Ancient Ecuador: Results of Residue Analysis of Stone Tools from the Real Alto Site. Journal of Archaeological Science 31(4):423-442.

Perino, Gregory

1985 Selected Preforms, Points, and Knives of the North American Indians, Vol. I. Points \& Barbs Press, Idabel, Oklahoma.

1996a Guide to the Identification of Certain American Indian Projectile Points. Special Bulletin No. 3, Oklahoma Anthropological Society, Norman, Oklahoma.

1996b Guide to the Identification of Certain American Indian Projectile Points. Special Bulletin No. 4, Oklahoma Anthropological Society, Norman, Oklahoma.

Perry, Linda

2004 Starch Analyses Reveal the Relationship Between Tool Type and Function: An Example from the Orinoco Valley of Venezuela. Journal of Archaeological Science 31(8):1069-1081.

2005 Reassessing the Traditional Interpretation of "Manioc" Artifacts in the Orinoco Valley of Venezuela. Latin American Antiquity 16(4):409-426.

2008 Appendix F: Starch Analyses from the BLM Landis Site: A Pilot Study. In Final Interim Report: Phase I of the Data Recovery at Three Prehistoric Sites (41PT185, 41PT186, and 41PT245) Located within the Landis Property in Potter County, Texas, by: J. Michael Quigg, Charles D. Frederick, Paul M. Matchen, and Kendra G. DuBois, pp. 174-192. Technical Report 1508323. TRC Environmental Corporation, Austin, Texas.

Perry, Linda, Ruth Dickau, Sonia Zarrillo, Irene Hotst, Deborah M. Pearsall, Dolores R. Piperno, Mary Jane Berman, Richard G. Cooke, Kurt Rademaker, Anthony J. Ranere, J. Scott Raymond, Daniel H. Sandweiss, Franz Scaramelli, Kay Tarble, and James A. Zeidler

2007 Starch Fossils and the Domestication and Dispersal of Chili Peppers (Capsicum spp. L.) in the Americas. Science 315(5814):986-988.

Peterson, Lee Allen

1977 Edible Wild Plants of Eastern and Central North America. Houghton Mifflin, New York.

Peterson, Roger Tory

1988 Birds of Texas. Peterson Field Guide Series. Houghton Mifflin Company, New York.

Piperno, Dolores R.

1998 The Presence of Starch Grains on Prehistoric Stone Tools from the Humid Neotropics: Indications of Early Tuber Use and Agriculture in Panama. Journal of Archaeological Science 25(8):765-776. 
Piperno, Dolores R., and Irene Holst

1998 The Presence of Starch Grains on Prehistoric Stone Tools from the Humid Neotropics: Indications of Early Tuber Use and Agriculture in Panama. Journal of Archaeological Science 25(8):765-776.

Piperno, Dolores R., Ehud Weiss, Irene Holst, and Dani Nadel

2004 Processing of Wild Cereal Grains in the Upper Palaeolithic Revealed by Starch Grain Analysis. Nature 430(7000):670-673.

Pool, Juliann C.

1987 Appendix V: Fanthrop Inn: A Study of Nineteenth and Twentieth Century Buttons. In Archaeological Excavations at Fanthrop Inn State Historic Site (41GM79), Grimes County, Texas, by J. David Ing and John Hart, pp. 277-293. Texas Parks and Wildlife Department, Austin.

Prewitt, Elton R.

1974 Preliminary Archeological Investigations in the Rio Grande Delta Area of Texas. Bulletin of the Texas Archeological Society 45:55-65.

1981 Cultural Chronology in Central Texas. Bulletin of the Texas Archeological Society 52:65-89.

1983 From Circleville to Toyah: Comments on Central Texas Chronology. Bulletin of the Texas Archeological Society 54:201-238.

1995 Distributions of Typed Projectile Points in Texas. Bulletin of the Texas Archeological Society 66:83-173.

Prilliman, Keith L. and C. Britt Bousman

1998 Unifacial Tools. In Wilson-Leonard: An 11,000-Year Archeological Record of HunterGatherers in Central Texas, Volume II: Chipped Stone Artifacts, edited by Michael B. Collins, pp. 597-632. Studies in Archeology 31, Texas Archeological Research Laboratory, The University of Texas at Austin. Archeology Studies Program, Report 10, Texas Department of Transportation, Environmental Affairs Division, Austin.

Prychid, C. J., and P. J. Rudall

1999 Calcium Oxalate Crystals in Monocotyledons: A Review of Their Structure and Systematics. Annals of Botany 84:725-39.

Quigg, J. Michael

1997 The Sanders Site (41HF128): A Single Event Late Archaic Camp/Processing Site, Hansford County, Texas. Technical Report No. 19751. TRC Mariah Associates Inc., Austin.

Quigg, J. Michael, and Jay Peck

1995 The Rush Site (41TG346), A Stratified Late Prehistoric Locale in Tom Green County, Texas. Technical Report No. 816C. TRC Mariah Associates Inc., Austin. 
Radford, Albert E., Harry E. Ahles, and C. Ritchie Bell

1964 Manual of the Vascular Flora of the Carolinas. University of North Carolina Press, Chapel Hill.

Ramsey, Dawn

1997 Archaeological Survey of Aquarena Springs Park, Hays County, Texas. Manuscript on file, Anthropology Department, Southwest Texas State University, San Marcos.

Reichert, E. T.

1913 The Differentiation and Specificity of Starches in Relation to Genera, Species, Etc. Carnegie Institute, Washington DC.

Reimer, P. J., M. G. L. Baillie, E. Bard, A. Bayliss, J. W. Beck, P. G. Blackwell, C. Bronk Ramsey, C. E. Buck, G. S. Burr, R. L. Edwards, M. Friedrich, P. M. Grootes, T. P. Guilderson, I. Hajdas, T. J. Heaton, A. G. Hogg, K. A. Hughen, K. F. Kaiser, B. Kromer, F. G. McCormac, S. W. Manning, R. W. Reimer, D. A. Richards, J. R. Southon, S. Talamo, C. S. M. Turney, J. van der Plicht, and C. E. Weyhenmeyer.

2009 IntCa109 and Marine09 Radiocarbon Age Calibration Curves, 0-50,000 Years Cal BP. Radiocarbon 51(4):1111-1150.

Reitz, Elizabeth J., and C. Margaret Scarry

1985 Reconstructing Historic Spanish Subsistence with an Example from Sixteenth Century Spanish Florida. Special Publications Series 3. Society for Historical Archaeology, Pleasant Hill, California.

Ricklis, Robert A.

1994 Toyah Components: Evidence for Occupation in the Project Area During the Latter Part of the Late Prehistoric Period. In Archaic and Late Prehistoric Human Ecology in the Middle Onion Creek Valley, Hays County, Texas, by Robert A. Ricklis and Michael B. Collins, pp. 207-316. Studies in Archeology 19. Texas Archeological Research Laboratory, The University of Texas at Austin.

2005 Analysis of Findings at the Buckeye Knoll Site (41TV98), Victoria County, Texas. Quarterly Report No. 5. Report submitted to the United States Army Corps of Engineers. Electronic document, http://www.swg.usace.army.mil/pe/41VT98/ (accessed September 1, 2009).

Ricklis, Robert A., and Michael B. Collins

1994 The Environmental Context. In Archaic and Late Prehistoric Human Ecology in the Middle Onion Creek Valley, Hays County, Texas, edited by Robert A. Ricklis and Michael B.

Collins, pp. 27-36. Studies in Archeology 19. Texas Archeological Research Laboratory, The University of Texas at Austin. 
Ringstaff, Christopher W.

2000 A Study of Landform Evolution and Archaeological Preservation at Site 41HY165, San Marcos, Texas. Unpublished Master's thesis, Department of Geography, Southwest Texas State University, San Marcos, Texas.

Scarry, C. Margaret

2003 Patterns of Wild Plant Utilization in the Prehistoric Eastern Woodlands. In People and Plants in Ancient Eastern North America, edited by Paul E. Minnis, pp. 50-104. Smithsonian Books, Washington DC.

Schmidley, David J., and William B. Davis

2004 The Mammals of Texas. University of Texas Press, Austin.

Shiner, Joel L.

1979 Survey and Testing of the Ice House Site, San Marcos, Hays County, Texas. Unpublished manuscript, Southern Methodist University, Dallas.

1981 History, Economy, and Magic at a Fresh Water Spring. In The Realms of Gold, Proceedings of the Tenth Conference on Underwater Archaeology, edited by Wilburn A. Cockrell, pp. 202-203. Fathom Eight, San Marino, California.

1983 Large Springs and Early American Indians. Plains Anthropologist 28:99:1-7.

1984 A Reply to Johnson and Holliday. Plains Anthropologist 29:103:71-72.

Shibutani, Ayako

2008 Starch Residues on Stone Tools from the Tachikiri, Kakuriyama, Soujiyama and Okunonita Sites. Cultura Antiqua 60(1):130-140 (in Japanese).

Sichler, Judith A., Jessica L. Vavrasek, Kandace D. Hollenbach, and Jon C. Lohse

2011 Faunal Remains and Analysis. In Prehistoric Life, Labor, and Residence in Southeast Central Texas, edited by Jon C. Lohse, pp. 351-386. Archaeological Studies Report No. 18. Center for Archaeological Studies, Texas State University-San Marcos.

Sitters, Julian A., Jon C. Lohse, and R. Zac Selden

2011 Flake Cores. In Prehistoric Life, Labor, and Residence in Southeast Central Texas: Results of Data Recovery at 41HY163, the Zatopec Site, San Marcos, edited by Jon C. Lohse, pp. 299-307. Archaeological Studies Report No. 18. Center for Archaeological Studies, Texas State University-San Marcos.

Slade, Raymond J., Jr.,

1986 Large Rainstorms along the Balcones Escarpment, Central Texas. In The Balcones Escarpment, Central Texas, pp. 15-20, edited by Patrick L. Abbott and C. M. Woodruff, Geological Society of America, Annual Meeting, San Antonio, Texas. 
Smith, Craig S., William Martin, and Kristine A. Johansen

2001 Sego Lilies and Prehistoric Foragers: Return Rates, Pit Ovens, and Carbohydrates. Journal of Archaeological Science 28(2):169-183.

Smith, Eric Alden

1981 The Application of Optimal Foraging Theory to the Analysis of Hunter-Gatherer Group Size. In Hunter-Gatherer Foraging Strategies: Ethnographic and Archaeological Analyses, edited by Bruce P. Winterhalder and Eric Alden Smith, pp. 36-65. University of Chicago Press, Chicago.

Smith, Eric Alden, and Bruce P. Winterhalder (editors)

1992 Evolutionary Ecology and Human Behavior. Aldine De. Gruyter, New York.

Smith, Winston Paul

1991 Odocoileus virginianus. Mammalian Species 388:1-13.

Sobolik, Kristin D.

1992 Microscopic Epidermal Identification of Yucca and Agave for Archaeological Use. The Texas Journal of Science 44(2):187-199.

Soucie, Shawn, and David L. Nickels

2003 Archaeological Monitoring of a Tree Planting Project and Installation of the Front Door Welcoming Drive for Texas State University-San Marcos, Hays County, Texas. Technical Report No. 11. Center for Archaeological Studies, Texas State University-San Marcos.

Soucie, Shawn, David L. Nickels, Kevin L. Shubert, and Colby J. Mischefsky

2004 Archaeological Trench Monitoring at the Aquarena Springs Golf Course, San Marcos, Hays County, Texas. Technical Report No. 16. Center for Archaeological Studies, Texas State University-San Marcos.

Stafford, T. W., Jr., K. Brendel, and R. Duhamel

1988 Radiocarbon, ${ }^{13} \mathrm{C}$ and ${ }^{15} \mathrm{~N}$ Analysis of Fossil Bone: Removal of Humates with XAD-2 Resin. Geochimica et Cosmochimica Acta 52:2257-2267.

Stafford, T. W., Jr., P. E. Hare, L. A. Currie, A. J. T. Jull, and D. Donahue

1991 Accelerator Radiocarbon Dating at the Molecular Level. Journal of Archaeological Science 18:35-72.

Stanford, Dennis, and Frank Broilo

1981 Frank's Folsom Campsite. The Artifact 19(3-4):1-11. 
Steele, D. Gentry

1986 Appendix V: Analysis of Vertebrate Faunal Remains from 41LK201, Live Oak County, Texas. In Archaeological Investigations at 41LK201, Choke Canyon Reservoir, Southern Texas, edited by Cheryl Lynn Highley, pp. 200-249. Choke Canyon Series, Volume 11. Center for Archaeological Research, The University of Texas at San Antonio.

Stoops, George

2003 Guidelines for Analysis and Description of Soil and Regolith Thin Sections. Soil Science Society of America, Madison, Wisconsin.

Story, Dee Ann

1985 Adaptive Strategies of Archaic Cultures of the West Gulf Coastal Plain. In Prehistoric Food Production in North America, edited by Richard I. Ford, pp. 19-56. Anthropological Papers No. 75. Museum of Anthropology, University of Michigan, Ann Arbor.

Stothert, Karen E., Anne Fox, Kevin Gross, and Amelia Sánchez Mosquera

1992 Early Nineteenth Century Settlements and Ceramics of the Tambo River, Southwest Coast of Ecuador. Paper presented at the 1992 Conference of Historical and Underwater Archaeology, Society of Historical Archaeology, Kingston, Jamaica.

Stull, Kyra

2009 Bioarchaeological Report on Human Remains from 41HY161. Report on file at the Center for Archaeological Studies, Texas State University-San Marcos.

Stull, Kyra, and Michelle D. Hamilton

2011 Descriptive Analysis of Three Individual Remains from Zatopec, with Comparative Analysis of Two Additional Sets from 41HY161; Chapter 8: Bioarchaeological Analysis of Human Remains from Zatopec. In Prehistoric Life, Labor, and Residence in Southeast-Central Texas: Results of Data Recovery at 41HY163, the Zatopec Site, San Marcos, Texas, edited by Jon C. Lohse, pp. 337-342. Archaeological Studies Report No. 18. Center for Archaeological Studies, Texas State University-San Marcos.

Sullivan, Alan P., III, and Kenneth C. Rozen

1985 Debitage Analysis and Archaeological Interpretation. American Antiquity 50:755-779.

Swanton, John R.

1946 The Indians of the Southeastern United States. Bureau of American Ethnology, Bulletin 137. Smithsonian Institution, Washington DC.

Takac, Paul R.

1990 "Homes Bases" and the Paleoindian/Archaic Transition in Central Texas. Paper presented at the 55th Annual SAA Meeting, Las Vegas.

1991a Underwater Excavations at Spring Lake: a Paleoindian Site in Hays County, Texas. Current Research in the Pleistocene 8:46-48. 
1991b Paleoindian Occupations at Spring Lake, Hays Co., Texas, Dissertation Research Proposal. Submitted to the Faculty, Department of Anthropology, Southern Methodist University, Dallas.

Talalay, Laurie, Donald R. Keller, and Patrick J. Munson

1984 Hickory Nuts, Walnuts, Butternuts, and Hazelnuts: Observations and Experiments Relevant to Their Aboriginal Exploitation in Eastern North America. In Experiments and Observations on Aboriginal Wild Plant Food Utilization in Eastern North America, edited by Patrick J. Munson, pp. 338-359. Prehistory Research Series 6(2). Indiana Historical Society, Indianapolis.

Taylor, Walter W.

1948 A Study of Archeology. American Anthropologist Memoir Number 69. American Anthropological Association, Washington DC.

Tennis, Cynthia L.

1997 Ceramic Patterns and Variation. In Archaeology at the Alamodome: Investigations of a San Antonio Neighborhood in Transition, Volume III: Artifacts and Special Studies, edited by Anne Fox, Marcie Renner, and Robert J. Hard, pp. 1-37. Archaeological Survey Report No. 238. Center for Archaeological Research, The University of Texas at San Antonio.

Texas Historical Commission [THC]

1987 State Archeological Landmark Form. Texas Historical Commission Texas Archeological Sites Atlas, s.v. “41HY161,” http://nueces.thc.state.tx.us/ (accessed July 6, 2009).

1999a State Archeological Landmark Form. Texas Historical Commission Texas Archeological Sites Atlas, s.v. “41HY147,” http://nueces.thc.state.tx.us/ (accessed July 6, 2009).

1999b State Archeological Landmark Form. Texas Historical Commission Texas Archeological Sites Atlas, s.v. “41HY160,” http://nueces.thc.state.tx.us/ (accessed July 6, 2009).

1999c State Archeological Landmark Form. Texas Historical Commission Texas Archeological Sites Atlas, s.v. “41HY37,” http://nueces.thc.state.tx.us/ (accessed July 6, 2009).

Thomas, David J., and William A. Atwell

1999 Starches. Eagan Press, St. Paul, Minnesota.

Thoms, Alston V.

2008 The Fire Stones Carry: Ethnographic Records and Archaeological Expectations for Hot-Rock Cookery in Western North America. Journal of Anthropological Archaeology 27(4):443-460.

2009 Rocks of Ages: Propagation of Hot-Rock Cookery in Western North America. Journal of Archaeological Science 36:573-591. 
Timperley, Cinda L.

n.d. Chapter 7: Faunal Analysis of 41HY160 Rivers Center, An Analysis of the Vertebrate Remains from the 2001-2006 Field School Block with Focus on Faunal Procurement and Utilization Patterns. Manuscript on file, Center for Archaeological Studies, Texas State University-San Marcos.

Todd, Lawrence C.

2001 Zooarchaeology, Colorado State University AP465, http://lamar.colostate.edu/ lctodd/ zooarch.htm (accessed November 13, 2009).

Tomka, Steve A., and Anne A. Fox

1998 Mission San José Indian Quarters Wall Base Project, Bexar County, Texas. Archaeological Survey Report No. 278. Center for Archaeological Research, The University of Texas at San Antonio.

1999 Archaeological Investigations of Rainwater Catchment Basins along the South Wall of Mission San José, San Antonio, Texas. Archaeological Survey Report No. 287. Center for Archaeological Research, The University of Texas at San Antonio.

Torrence, Robin, and Huw Barton

2006 Ancient Starch Research. Left Coast Press, Walnut Creek, California.

Toulouse, Julian H.

1969 Fruit Jars. Thomas Nelson \& Sons, New York.

Turner, Ellen S., and Thomas R. Hester

1999 A Field Guide to Stone Artifacts of Texas Indians. 3rd ed. Texas Monthly Field Guide Series. Gulf Publishing Company, Houston.

Twiss, P. C., E. Suess, and R. M. Smith

1969 Morphological Classification of Grass Phytoliths. Soil Science Society of America Proceedings 33(1): 109-115.

U.S. Department of Agriculture, Agricultural Research Service, Nutrient Data Laboratory [USDANDL]

2004 USDA National Nutrient Database for Standard Reference, Release 17. Electronic document, http://www.nal.usda.gov/fnic/foodcomp (accessed January 30, 2005).

U.S. Department of Agriculture, Natural Resources Conservation Service [USDA-NRCS]

2011 PLANTS Database. National Plant Data Center, Baton Rouge. Electronic document, http:// plants.usda.gov/index.html (accessed September 2011).

Ugent, Donald, Shelia Pozorsky, and Thomas Pozorsky

1981 Prehistoric Remains of the Sweet Potato from the Casma Valley of Peru. Phytologia 49:401415. 
1982 Archaeological Potato Tuber Remains from the Casma Valley of Peru. Economic Botany 36(2):182-192.

1984 New Evidence for Ancient Cultivation of Canna edulis in Peru. Economic Botany 38:417432.

Vullo, Romain, Jean-Claude Rage, and Dider Neraudeau

2011 Anuran and Squamate Remains from the Cenomanian (Late Cretaceous) of Charentes, Western France. Journal of Vertebrate Paleontology 31(2):279-291.

Wade, Maria F.

2002 Appendix C: Patterns of Buffalo Seasonality During the Protohistoric and Historic Periods in Texas. In The Smith Creek Bridge Site (41DW270); a Terrace Site in De Witt County, Texas, edited by Dale Hudler, Keith L. Prilliman, and Thomas C. Gustavson, pp. 171-186. Studies in Archeology 35, Texas Archeological Research Laboratory, The University of Texas at Austin. Archeology Studies Program, Report No. 17, Environmental Affairs Division, Texas Department of Transportation, Austin.

Waguespack, Nicole M. and Todd A. Surovell

2003 Clovis Hunting Strategies, or How to Make Out on Plentiful Resources. American Antiquity 68:333-352.

Wandsnider, LuAnn

1997 The Roasted and the Boiled: Food Composition and Heat Treatment with Special Emphasis on Pit-Hearth Cooking. Journal of Anthropological Archaeology 16:1-48.

Wang, Yang, A. Hope Jahren, and Ronald Amundson

1997 Potential for ${ }^{14} \mathrm{C}$ Dating of Biogenic Carbonate in Hackberry (Celtis) Endocarps. Quaternary Research 47:337-343.

Weaver, Robert

2003 Rediscovering Polarized Light Microscopy. American Laboratory 35:55-61.

Webb, Clarence H., Hoel L. Shiner, and E. Wayne Roberts

1971 The John Pearce Site (16CD56): A San Patrice Site in Caddo Parish, Louisiana. Bulletin of the Texas Archeological Society 42:1-49.

Weber, Carey

1994 A Replication Technique for Andice/Bell Points. In Archaic and Late Prehistoric Human Ecology in the Middle Onion Creek Valley, Hays County, Texas, by Robert A. Ricklis and Michael B. Collins, pp. 629-651. Studies in Archeology 19. Texas Archeological Research Laboratory, The University of Texas at Austin. 
Weir, Frank A.

1976 The Central Texas Archaic. Unpublished PhD dissertation, Anthropology Department, Washington State University, Pullman.

Weinstein, Abby

2005 Investigations at an Antelope Creek Phase Isolated Homestead (41PT109). Unpublished Master's thesis, Department of Anthropology, Texas State University-San Marcos.

Wenke, Robert J.

1990 Patterns in Prehistory: Humankind's First Three Million Years. 3rd ed. Oxford University Press, Oxford, England.

Willey, Gordon R., and Phillip Phillips

2001 Method and Theory in American Archaeology. University of Alabama Press, Tuscaloosa. Originally published 1958, University of Chicago Press, Chicago.

Williams, P. C.

1968 Bulletin of the Association of Operative Millers:3048.

Wilson, Don E., and DeeAnn M. Reeder (editors)

2005 Mammal Species of the World. 3rd ed. Johns Hopkins University Press.

Wilson, Kenneth

1972 New England Glass \& Glassmaking. Thomas Y. Crowell Co., New York

Wright, Karen

2006 The Road to Dr Pepper, Texas : The Story of Dublin Dr Pepper. State House Press/McMurry University, Abilene.

Wyckoff, Don G.

1994 Introduction to the 1991 Bulletin: Recognizing the Calf Creek Horizon: Background and Some Problems. Bulletin of the Oklahoma Anthropological Society 40:1-8.

1995 A Summary of the Calf Creek Horizon in Oklahoma. Bulletin of the Oklahoma Anthropological Society 42:179-210.

Yanovsky, Elias

1936 Food Plants of the North American Indians. U.S. Department of Agriculture Miscellaneous Publication No. 237. Washington DC.

Yarnell, Richard A.

1982 Problems of Interpretation of Archaeological Plant Remains of the Eastern Woodlands. Southeastern Archaeology 1(1):1-7. 
Yarnell, Richard A., and M. Jean Black

1985 Temporal Trends Indicated by a Survey of Archaic and Woodland Plant Food Remains from Southeastern North America. Southeastern Archaeology 4(2):93-106.

Yelacic, David M., and Jon C. Lohse

2011 Features and Chronology. In Prehistoric Life, Labor, and Residence in Southeast Central Texas: Results of Data Recovery at 41HY163, the Zatopec Site, San Marcos, edited by Jon C. Lohse, pp. 111-159. Archaeological Studies Report No. 18. Center for Archaeological Studies, Texas State University-San Marcos.

Yelacic, David M., R. Zac Selden, and Jon C. Lohse

2008a Results of Archaeological Monitoring at the Fish Ponds, Texas State University-San Marcos, Hays County, Texas. Technical Report No. 33. Center for Archaeological Studies, Texas State University-San Marcos.

2008b Results of Archaeological Trench Monitoring at Clear Springs Apartments, Texas State University-San Marcos, Hays County, Texas. Technical Report No. 34. Center for Archaeological Studies, Texas State University-San Marcos.

Yu, Pei-Lin

2006 Pit Cooking and Intensification of Subsistence in the American Southwest and Pacific Northwest. Unpublished PhD dissertation, Department of Anthropology, Southern Methodist University, Dallas.

Zarrillo, Sonia, and Brian Kooyman

2006 Evidence for Berry and Maize Processing on the Canadian Plains from Starch Grain Analysis. American Antiquity 71(3):473-499.

Zumwalt, Betty

1980 Ketchup, Pickles, Sauces: 19th Century Food in Glass. Mark West Publishers, Fulton, California. 


\section{Appendix A}

\section{INVENTORY OF ARTIFACTS FROM Analytical Units}

Table A-1. Historic Artifacts from AU 1.

\begin{tabular}{|c|c|c|c|}
\hline Class & Type & Count & $\begin{array}{c}\text { Weight } \\
\text { (g) }\end{array}$ \\
\hline \multirow[t]{6}{*}{ Building Material } & brick & 95 & 420.3 \\
\hline & asphalt & 18 & 346.6 \\
\hline & concrete & 99 & 494.9 \\
\hline & mortar & 1 & 8.8 \\
\hline & cement & 11 & 20.9 \\
\hline & plaster & 3 & 2.7 \\
\hline \multirow[t]{8}{*}{ Ceramic } & white earthenware & 13 & 19.8 \\
\hline & pipe & 1 & 35.7 \\
\hline & creamware & 3 & 3.0 \\
\hline & terra cotta & 5 & 5.5 \\
\hline & Spanish Colonial & 2 & 5.4 \\
\hline & pearlware & 1 & 0.3 \\
\hline & stoneware & 1 & 3.0 \\
\hline & porcelain & 5 & 22.4 \\
\hline \multirow[t]{3}{*}{ Glass } & unknown & 41 & 31.2 \\
\hline & window & 399 & 401.8 \\
\hline & bottle & 397 & 939.9 \\
\hline \multirow[t]{9}{*}{ Metal } & bottle cap & 17 & 36.5 \\
\hline & firearms and munitions & 26 & 46.8 \\
\hline & tools & 5 & 479.1 \\
\hline & scrap & 1,907 & $1,105.2$ \\
\hline & other & 334 & 442.8 \\
\hline & hardware & 393 & 912.1 \\
\hline & unknown & 62 & 249.7 \\
\hline & round nail & 2,162 & $3,027.6$ \\
\hline & square nail & 91 & 202.7 \\
\hline Plastic & plastic & 41 & 9.3 \\
\hline Coal & coal & 6 & 5.9 \\
\hline Personal Items & buttons, snaps, etc. & 27 & 48.4 \\
\hline Total & & 8,493 & $10,912.5$ \\
\hline
\end{tabular}


Table A-2. Historic Native American Artifacts from AU 2.

\begin{tabular}{|c|c|c|c|c|c|c|c|c|c|}
\hline Lot & Specimen & Unit & Quad & Level & $\begin{array}{l}\text { Depth } \\
\text { (cmbs) }\end{array}$ & Class & Type & Count & $\begin{array}{c}\text { Weight } \\
\text { (g) }\end{array}$ \\
\hline 131 & 1 & 3 & NW & 2 & $5-15$ & lithic & $\begin{array}{l}\text { projectile } \\
\text { point }\end{array}$ & 1 & 0.7 \\
\hline 131 & 2 & 3 & NW & 2 & $5-15$ & lithic & $\begin{array}{l}\text { projectile } \\
\text { point }\end{array}$ & 1 & 1.9 \\
\hline 131 & 3 & 3 & NW & 2 & $5-15$ & bone & faunal & 1 & 16.8 \\
\hline 131 & 4 & 3 & NW & 2 & $5-15$ & bone & faunal & 1 & 1.9 \\
\hline 131 & 5 & 3 & NW & 2 & $5-15$ & bone & faunal & 1 & 1.8 \\
\hline 131 & 6 & 3 & NW & 2 & $5-15$ & bone & faunal & 1 & 0.2 \\
\hline 131 & 7 & 3 & NW & 2 & $5-15$ & lithic & burned rock & 3 & 35.8 \\
\hline 131 & 8 & 3 & NW & 2 & $5-15$ & bone & faunal & 1 & 0.2 \\
\hline 131 & 9 & 3 & NW & 2 & $5-15$ & metal & other & 2 & 5.9 \\
\hline 131 & 10 & 3 & NW & 2 & $5-15$ & glass & bottle & 1 & 1.5 \\
\hline 131 & 11 & 3 & NW & 2 & $5-15$ & glass & window & 1 & 0.5 \\
\hline 131 & 12 & 3 & NW & 2 & $5-15$ & lithic & debitage & 2 & 0.3 \\
\hline 131 & 12 & 3 & NW & 2 & $5-15$ & lithic & broken flake & 218 & 135.8 \\
\hline 131 & 13 & 3 & NW & 2 & $5-15$ & shell & snail & 3 & 0.3 \\
\hline 131 & 14 & 3 & NW & 2 & $5-15$ & lithic & biface & 1 & 3.2 \\
\hline 131 & 15 & 3 & NW & 2 & $5-15$ & bone & faunal & 1 & 0.4 \\
\hline 131 & 16 & 3 & NW & 2 & $5-15$ & bone & faunal & 1 & 0.7 \\
\hline 131 & 17 & 3 & NW & 2 & $5-15$ & bone & faunal & 1 & 1.1 \\
\hline 131 & 18 & 3 & NW & 2 & $5-15$ & bone & faunal & 1 & 1.8 \\
\hline 131 & 19 & 3 & NW & 2 & $5-15$ & bone & faunal & 1 & 2.1 \\
\hline 131 & 20 & 3 & NW & 2 & $5-15$ & bone & faunal & 1 & 0.7 \\
\hline 131 & 21 & 3 & NW & 2 & $5-15$ & bone & faunal & 1 & 0.3 \\
\hline 131 & 22 & 3 & NW & 2 & $5-15$ & bone & faunal & 1 & 0.4 \\
\hline 131 & 23 & 3 & NW & 2 & $5-15$ & bone & faunal & 3 & 1.4 \\
\hline 131 & 24 & 3 & NW & 2 & $5-15$ & bone & faunal & 14 & 4.1 \\
\hline 131 & 25 & 3 & NW & 2 & $5-15$ & bone & faunal & 1 & 0.3 \\
\hline 131 & 26 & 3 & NW & 2 & $5-15$ & bone & faunal & 8 & 4.1 \\
\hline 131 & 27 & 3 & NW & 2 & $5-15$ & bone & faunal & 2 & 0.6 \\
\hline 131 & 28 & 3 & NW & 2 & $5-15$ & bone & faunal & 1 & 0.1 \\
\hline 131 & 29 & 3 & NW & 2 & $5-15$ & lithic & other & 1 & 0.4 \\
\hline 131 & 30 & 3 & NW & 2 & $5-15$ & lithic & r-flake & 2 & 0.4 \\
\hline 131 & 31 & 3 & NW & 2 & $5-15$ & lithic & biface & 1 & 8.5 \\
\hline 131 & 32 & 3 & NW & 2 & $5-15$ & lithic & uniface & 1 & 6.7 \\
\hline 131 & 33 & 3 & NW & 2 & $5-15$ & lithic & uniface & 1 & 3.2 \\
\hline 131 & 34 & 3 & NW & 2 & $5-15$ & lithic & uniface & 1 & 1.7 \\
\hline 131 & 35 & 3 & NW & 2 & $5-15$ & lithic & $\begin{array}{l}\text { burned non- } \\
\text { flake debitage }\end{array}$ & 33 & 32.9 \\
\hline
\end{tabular}


Table A-2 (continued). Historic Native American Artifacts from AU 2.

\begin{tabular}{|c|c|c|c|c|c|c|c|c|c|}
\hline Lot & Specimen & Unit & Quad & Level & $\begin{array}{l}\text { Depth } \\
\text { (cmbs) }\end{array}$ & Class & Type & Count & $\begin{array}{l}\text { Weight } \\
\text { (g) }\end{array}$ \\
\hline 131 & 36 & 3 & NW & 2 & $5-15$ & lithic & DEB flake & 1 & 2.5 \\
\hline 131 & 37 & 3 & NW & 2 & $5-15$ & lithic & complete flake & 27 & 28.2 \\
\hline 131 & 38 & 3 & NW & 2 & $5-15$ & lithic & proximal flake & 66 & 58.2 \\
\hline 158 & 1 & 3 & NW & 3 & $15-25$ & bone & unknown & 59 & 33.3 \\
\hline 158 & 1 & 3 & NW & 3 & $15-25$ & bone & unknown & 1 & 0.3 \\
\hline 158 & 2 & 3 & NW & 3 & $15-25$ & lithic & debitage & 1 & 0.2 \\
\hline 158 & 2 & 3 & NW & 3 & $15-25$ & lithic & broken flake & 224 & 126.1 \\
\hline 158 & 3 & 3 & NW & 3 & $15-25$ & lithic & burned rock & 3 & 100.4 \\
\hline 158 & 4 & 3 & NW & 3 & $15-25$ & metal & tool & 1 & 0.1 \\
\hline 158 & 5 & 3 & NW & 3 & $15-25$ & bone & unknown & 1 & 0.2 \\
\hline 158 & 6 & 3 & NW & 3 & $15-25$ & organic & seed & 1 & 0.1 \\
\hline 158 & 7 & 3 & NW & 3 & $15-25$ & lithic & other & 2 & 0.2 \\
\hline 158 & 8 & 3 & NW & 3 & $15-25$ & lithic & proximal flake & 68 & 48.1 \\
\hline 158 & 9 & 3 & NW & 3 & $15-25$ & lithic & complete flake & 44 & 42.4 \\
\hline 158 & 10 & 3 & NW & 3 & $15-25$ & lithic & DEB flake & 1 & 1.4 \\
\hline 158 & 11 & 3 & NW & 3 & $15-25$ & lithic & notching flake & 1 & $<0.1$ \\
\hline 158 & 12 & 3 & NW & 3 & $15-25$ & lithic & r-flake & 2 & 0.2 \\
\hline 158 & 13 & 3 & NW & 3 & $15-25$ & lithic & $\begin{array}{l}\text { burned non- } \\
\text { flake debitage }\end{array}$ & 3 & 0.8 \\
\hline 158 & 14 & 3 & NW & 3 & $15-25$ & lithic & uniface & 1 & 6.2 \\
\hline 158 & 15 & 3 & NW & 3 & $15-25$ & lithic & uniface & 1 & 0.3 \\
\hline 158 & 16 & 3 & NW & 3 & $15-25$ & bone & unknown & 3 & 0.2 \\
\hline 543 & 1 & 3 & NW & - & $8-23$ & lithic & broken flake & 18 & 2.3 \\
\hline 543 & 2 & 3 & NW & - & $8-23$ & bone & unknown & 20 & 2.9 \\
\hline 543 & 3 & 3 & NW & - & $8-23$ & float sample & $<0.5 \mathrm{~mm}$ & & \\
\hline 543 & 4 & 3 & NW & - & $8-23$ & float sample & $>0.5 \mathrm{~mm}$ & & \\
\hline 543 & 5 & 3 & NW & - & $8-23$ & float sample & $>1 \mathrm{~mm}$ & & \\
\hline 543 & 6 & 3 & NW & - & $8-23$ & float sample & $>2 \mathrm{~mm}$ & & \\
\hline 543 & 7 & 3 & NW & - & $8-23$ & lithic & $\begin{array}{l}\text { burned non- } \\
\text { flake debitage }\end{array}$ & 3 & 0.2 \\
\hline 543 & 8 & 3 & NW & - & $8-23$ & lithic & complete flake & 3 & 0.4 \\
\hline \multirow[t]{2}{*}{543} & 9 & 3 & NW & - & $8-23$ & lithic & proximal flake & 3 & 3.3 \\
\hline & & & & & & & Total & 873 & 737.2 \\
\hline
\end{tabular}


Table A-3. Late Prehistoric, Toyah Phase Artifacts from AU 3a.

\section{Lot Specimen Unit Quad Level $\begin{gathered}\text { Depth } \\ (\mathrm{cmbs})\end{gathered}$ Class Type Count $\begin{gathered}\text { Weight } \\ \text { (g) }\end{gathered}$}

\begin{tabular}{|c|c|c|c|c|c|c|c|c|c|}
\hline 79 & 1 & 2 & SW & 4 & $23-33$ & lithic & broken flake & 159 & 88.6 \\
\hline 79 & 2 & 2 & SW & 4 & $23-33$ & lithic & burned rock & 35 & $1,700.0$ \\
\hline 79 & 3 & 2 & SW & 4 & $23-33$ & shell & snail & 13 & 4.3 \\
\hline 79 & 4 & 2 & SW & 4 & $23-33$ & other prehistoric & burned clay & 10 & 3.1 \\
\hline 79 & 5 & 2 & SW & 4 & $23-33$ & bone & faunal & 1 & 20.0 \\
\hline 79 & 6 & 2 & SW & 4 & $23-33$ & $\mathrm{C} 14$ & charcoal & NA & NW \\
\hline 79 & 7 & 2 & SW & 4 & $23-33$ & lithic & biface & 1 & 0.8 \\
\hline 79 & 8 & 2 & SW & 4 & $23-33$ & lithic & $\begin{array}{l}\text { burned non- } \\
\text { flake debitage }\end{array}$ & 30 & 26.0 \\
\hline 79 & 9 & 2 & SW & 4 & $23-33$ & lithic & DEB flake & 1 & 0.3 \\
\hline 79 & 10 & 2 & SW & 4 & $23-33$ & lithic & complete flake & 34 & 25.6 \\
\hline 79 & 11 & 2 & SW & 4 & $23-33$ & lithic & r-flake & 1 & 0.3 \\
\hline 79 & 12 & 2 & SW & 4 & $23-33$ & lithic & notching flake & 1 & 0.2 \\
\hline 79 & 13 & 2 & SW & 4 & $23-33$ & lithic & proximal flake & 79 & 57.7 \\
\hline 79 & 14 & 2 & SW & 4 & $23-33$ & lithic & burned rock & 1 & 146.3 \\
\hline 79 & 15 & 2 & SW & 4 & $23-33$ & lithic & burned rock & 1 & 199.2 \\
\hline 79 & 16 & 2 & SW & 4 & $23-33$ & bone & faunal & 1 & 0.3 \\
\hline 79 & 17 & 2 & SW & 4 & $23-33$ & bone & faunal & 1 & 0.2 \\
\hline 79 & 18 & 2 & SW & 4 & $23-33$ & bone & faunal & 1 & 0.1 \\
\hline 79 & 19 & 2 & SW & 4 & $23-33$ & bone & faunal & 1 & 0.1 \\
\hline 79 & 20 & 2 & SW & 4 & $23-33$ & bone & faunal & 6 & 1.7 \\
\hline 79 & 21 & 2 & SW & 4 & $23-33$ & bone & faunal & 1 & 0.3 \\
\hline 79 & 22 & 2 & SW & 4 & $23-33$ & bone & faunal & 1 & 1.1 \\
\hline 79 & 23 & 2 & SW & 4 & $23-33$ & bone & faunal & 1 & 0.9 \\
\hline 79 & 24 & 2 & SW & 4 & $23-33$ & bone & faunal & 1 & 0.1 \\
\hline 79 & 25 & 2 & SW & 4 & $23-33$ & bone & faunal & 1 & 0.3 \\
\hline 79 & 26 & 2 & SW & 4 & $23-33$ & bone & faunal & 1 & 0.1 \\
\hline 79 & 27 & 2 & SW & 4 & $23-33$ & bone & faunal & 1 & 5.3 \\
\hline 79 & 28 & 2 & SW & 4 & $23-33$ & bone & faunal & 1 & 8.4 \\
\hline 79 & 29 & 2 & SW & 4 & $23-33$ & bone & faunal & 1 & 3.1 \\
\hline 79 & 30 & 2 & SW & 4 & $23-33$ & bone & faunal & 1 & 1.4 \\
\hline 79 & 31 & 2 & SW & 4 & $23-33$ & bone & faunal & 1 & 1.3 \\
\hline 79 & 32 & 2 & SW & 4 & $23-33$ & bone & faunal & 1 & 3.8 \\
\hline 79 & 33 & 2 & SW & 4 & $23-33$ & bone & faunal & 1 & 1.2 \\
\hline 79 & 34 & 2 & SW & 4 & $23-33$ & bone & faunal & 1 & 0.3 \\
\hline 79 & 35 & 2 & SW & 4 & $23-33$ & bone & faunal & 1 & 0.4 \\
\hline 79 & 36 & 2 & SW & 4 & $23-33$ & bone & faunal & 1 & 3.7 \\
\hline 79 & 37 & 2 & SW & 4 & $23-33$ & bone & faunal & 1 & 0.1 \\
\hline 79 & 38 & 2 & SW & 4 & $23-33$ & bone & faunal & 6 & 1.8 \\
\hline 79 & 39 & 2 & SW & 4 & $23-33$ & bone & faunal & 4 & 1.5 \\
\hline 79 & 40 & 2 & SW & 4 & $23-33$ & bone & faunal & 24 & 4.1 \\
\hline 79 & 41 & 2 & SW & 4 & $23-33$ & bone & faunal & 1 & 1.8 \\
\hline
\end{tabular}


Table A-3 (continued). Late Prehistoric, Toyah Phase Artifacts from AU $3 a$.

Lot Specimen Unit Quad Level $\begin{gathered}\text { Depth } \\ \text { (cmbs) }\end{gathered}$ Class Type Count $\begin{gathered}\text { Weight } \\ \text { (g) }\end{gathered}$

\begin{tabular}{|c|c|c|c|c|c|c|c|c|c|}
\hline 79 & 42 & 2 & SW & 4 & $23-33$ & bone & faunal & 3 & 1.8 \\
\hline 79 & 43 & 2 & SW & 4 & $23-33$ & bone & faunal & 1 & 0.6 \\
\hline 94 & 1 & 2 & SW & 4 & $23-33$ & lithic & broken flake & 41 & 19.4 \\
\hline 94 & 2 & 2 & SW & 4 & $23-33$ & lithic & $\begin{array}{l}\text { burned non- } \\
\text { flake debitage }\end{array}$ & 3 & 4.4 \\
\hline 94 & 3 & 2 & SW & 4 & $23-33$ & shell & snail & NA & 14.9 \\
\hline 94 & 4 & 2 & SW & 4 & $23-33$ & shell & snail & 2 & 1.3 \\
\hline 94 & 5 & 2 & SW & 4 & $23-33$ & shell & snail & NA & 3.7 \\
\hline 94 & 6 & 2 & SW & 4 & $23-33$ & $\mathrm{C} 14$ & charcoal & NA & NW \\
\hline 94 & 7 & 2 & SW & 4 & $23-33$ & lithic & burned rock & 73 & 59.7 \\
\hline 94 & 8 & 2 & SW & 4 & $23-33$ & lithic & burned rock & 6 & 17.5 \\
\hline 94 & 9 & 2 & SW & 4 & $23-33$ & lithic & micro-debitage & 263 & 7.9 \\
\hline 94 & 10 & 2 & SW & 4 & $23-33$ & lithic & proximal flake & 13 & 6.4 \\
\hline 94 & 11 & 2 & SW & 4 & $23-33$ & lithic & complete flake & 10 & 6.3 \\
\hline 106 & 1 & 2 & SW & 4 & $23-33$ & sediment & non cultural & & 146.6 \\
\hline 106 & 2 & 2 & SW & 4 & $23-33$ & bone & faunal & 27 & 0.3 \\
\hline 106 & 3 & 2 & SW & 4 & $23-33$ & $\mathrm{C} 14$ & charcoal & & 0.6 \\
\hline 106 & 4 & 2 & SW & 4 & $23-33$ & lithic & micro-debitage & 515 & 3.4 \\
\hline 106 & 5 & 2 & SW & 4 & $23-33$ & bone & faunal & 35 & 0.3 \\
\hline 106 & 6 & 2 & SW & 4 & $23-33$ & bone & faunal & 23 & 0.3 \\
\hline 106 & 7 & 2 & SW & 4 & $23-33$ & bone & faunal & 2 & $<0.1$ \\
\hline 106 & 8 & 2 & SW & 4 & $23-33$ & bone & faunal & 2 & $<0.1$ \\
\hline 106 & 9 & 2 & SW & 4 & $23-33$ & bone & faunal & 1 & $<0.1$ \\
\hline 106 & 10 & 2 & SW & 4 & $23-33$ & bone & faunal & 21 & 0.2 \\
\hline 106 & 11 & 2 & SW & 4 & $23-33$ & bone & faunal & 3 & 0.1 \\
\hline 106 & 12 & 2 & SW & 4 & $23-33$ & bone & faunal & 4 & 0.1 \\
\hline 106 & 13 & 2 & SW & 4 & $23-33$ & bone & faunal & 5 & 0.1 \\
\hline 106 & 14 & 2 & SW & 4 & $23-33$ & bone & faunal & 61 & 0.4 \\
\hline 106 & 15 & 2 & SW & 4 & $23-33$ & bone & faunal & 1 & $<0.1$ \\
\hline 106 & 16 & 2 & SW & 4 & $23-33$ & bone & faunal & 1 & $<0.1$ \\
\hline 106 & 17 & 2 & SW & 4 & $23-33$ & bone & faunal & 1 & 0.1 \\
\hline 106 & 18 & 2 & SW & 4 & $23-33$ & bone & faunal & 1 & $<0.1$ \\
\hline 106 & 19 & 2 & SW & 4 & $23-33$ & bone & faunal & 1 & $<0.1$ \\
\hline 106 & 20 & 2 & SW & 4 & $23-33$ & bone & faunal & 1 & 0.1 \\
\hline 106 & 21 & 2 & SW & 4 & $23-33$ & bone & faunal & 1 & $<0.1$ \\
\hline 106 & 22 & 2 & SW & 4 & $23-33$ & bone & faunal & 7 & 0.1 \\
\hline 106 & 23 & 2 & SW & 4 & $23-33$ & bone & faunal & 9 & 0.1 \\
\hline 106 & 24 & 2 & SW & 4 & $23-33$ & bone & faunal & 1 & 0.1 \\
\hline 106 & 25 & 2 & SW & 4 & $23-33$ & bone & faunal & 1 & $<0.1$ \\
\hline 106 & 26 & 2 & SW & 4 & $23-33$ & bone & faunal & 1 & $<0.1$ \\
\hline 106 & 27 & 2 & SW & 4 & $23-33$ & bone & faunal & 1 & $<0.1$ \\
\hline 106 & 28 & 2 & SW & 4 & $23-33$ & bone & faunal & 3 & 0.1 \\
\hline
\end{tabular}


Table A-3 (continued). Late Prehistoric, Toyah Phase Artifacts from AU 3a.

\begin{tabular}{cccccccccc} 
Lot & Specimen & Unit & Quad & Level & $\begin{array}{c}\text { Depth } \\
\text { (cmbs) }\end{array}$ & Class & Type & Count & $\begin{array}{c}\text { Weight } \\
\text { (g) }\end{array}$ \\
\hline 106 & 29 & 2 & SW & 4 & $23-33$ & bone & faunal & 6 & 0.1 \\
106 & 30 & 2 & SW & 4 & $23-33$ & bone & faunal & 2 & $<0.1$ \\
106 & 31 & 2 & SW & 4 & $23-33$ & bone & faunal & 2 & $<0.1$ \\
106 & 32 & 2 & SW & 4 & $23-33$ & bone & faunal & 15 & 0.2 \\
106 & 33 & 2 & SW & 4 & $23-33$ & bone & faunal & 1 & $<0.1$ \\
106 & 34 & 2 & SW & 4 & $23-33$ & bone & faunal & 146 & 1.4 \\
106 & 35 & 2 & SW & 4 & $23-33$ & bone & faunal & 1 & $<0.1$ \\
106 & 36 & 2 & SW & 4 & $23-33$ & bone & faunal & 1 & 0.1 \\
106 & 37 & 2 & SW & 4 & $23-33$ & bone & faunal & 1 & $<0.1$ \\
106 & 38 & 2 & SW & 4 & $23-33$ & bone & faunal & 1 & 0.1 \\
106 & 39 & 2 & SW & 4 & $23-33$ & bone & faunal & 1 & $<0.1$ \\
106 & 40 & 2 & SW & 4 & $23-33$ & bone & faunal & 1 & 0.1 \\
106 & 41 & 2 & SW & 4 & $23-33$ & bone & faunal & 1 & 0.1 \\
106 & 42 & 2 & SW & 4 & $23-33$ & bone & faunal & 1 & $<0.1$ \\
106 & 43 & 2 & SW & 4 & $23-33$ & bone & faunal & 1 & 0.1 \\
106 & 44 & 2 & SW & 4 & $23-33$ & bone & faunal & 1 & 0.1 \\
106 & 45 & 2 & SW & 4 & $23-33$ & bone & faunal & 1 & $<0.1$ \\
106 & 46 & 2 & SW & 4 & $23-33$ & bone & faunal & 1 & 0.1 \\
106 & 47 & 2 & SW & 4 & $23-33$ & bone & faunal & 1 & $<0.1$ \\
106 & 48 & 2 & SW & 4 & $23-33$ & bone & faunal & 2 & 0.2 \\
106 & 49 & 2 & SW & 4 & $23-33$ & lithic & other & 18 & 0.2 \\
106 & 50 & 2 & SW & 4 & $23-33$ & organic & wood & 6 & 0.1 \\
\hline & & & & & & & Total & 1,784 & $2,615.6$ \\
\hline & & & & & & & & & \\
\hline
\end{tabular}


Table A-4. Late Prehistoric, Austin Phase Artifacts from AU 3b.

\section{Lot Specimen Unit Quad Level $\begin{aligned} & \text { Depth } \\ & \text { (cmbs) }\end{aligned}$ Class Type Count $\begin{gathered}\text { Weight } \\ \text { (g) }\end{gathered}$}

\begin{tabular}{|c|c|c|c|c|c|c|c|c|c|}
\hline 65 & 1 & 2 & SE & 5 & $33-43$ & lithic & proximal flake & 96 & 64.1 \\
\hline 65 & 2 & 2 & SE & 5 & $33-43$ & shell & bivalve & 1 & 1.1 \\
\hline 65 & 2 & 2 & SE & 5 & $33-43$ & lithic & projectile point & 1 & 1.5 \\
\hline 65 & 3 & 2 & SE & 5 & $33-43$ & shell & snail & 9 & 5.9 \\
\hline 65 & 4 & 2 & SE & 5 & $33-43$ & lithic & burned rock & 5 & 4.1 \\
\hline 65 & 5 & 2 & SE & 5 & $33-43$ & other prehistoric & burned clay & 1 & 0.8 \\
\hline 65 & 6 & 2 & SE & 5 & $33-43$ & lithic & core & 1 & 133.9 \\
\hline 65 & 7 & 2 & SE & 5 & $33-43$ & $\mathrm{C} 14$ & charcoal & NA & NW \\
\hline 65 & 8 & 2 & SE & 5 & $33-43$ & lithic & biface & 1 & 1.4 \\
\hline 65 & 9 & 2 & SE & 5 & $33-43$ & lithic & uniface & 1 & 0.8 \\
\hline 65 & 10 & 2 & SE & 5 & $33-43$ & lithic & uniface & 1 & 0.4 \\
\hline 65 & 11 & 2 & SE & 5 & $33-43$ & lithic & blade & 1 & 0.4 \\
\hline 65 & 12 & 2 & SE & 5 & $33-43$ & lithic & broken flake & 191 & 82.9 \\
\hline 65 & 13 & 2 & SE & 5 & $33-43$ & lithic & notching flake & 1 & 0.2 \\
\hline 65 & 14 & 2 & SE & 5 & $33-43$ & lithic & notching flake & 42 & 37.7 \\
\hline 65 & 15 & 2 & SE & 5 & $33-43$ & lithic & DEB flake & 3 & 4.3 \\
\hline 65 & 16 & 2 & SE & 5 & $33-43$ & lithic & r-flake & 3 & 1.1 \\
\hline 65 & 17 & 2 & $\mathrm{SE}$ & 5 & $33-43$ & lithic & $\begin{array}{l}\text { burned non- } \\
\text { flake debitage }\end{array}$ & 11 & 13.4 \\
\hline 66 & 1 & 2 & SW & 5 & $33-43$ & lithic & proximal flake & 100 & 55.4 \\
\hline 66 & 2 & 2 & SW & 5 & $33-43$ & shell & snail & 1 & 0.9 \\
\hline 66 & 3 & 2 & SW & 5 & $33-43$ & lithic & burned rock & 3 & 13.6 \\
\hline 66 & 4 & 2 & SW & 5 & $33-43$ & bone & faunal & 1 & 1.1 \\
\hline 66 & 5 & 2 & SW & 5 & $33-43$ & lithic & projectile point & 1 & 0.9 \\
\hline 66 & 6 & 2 & SW & 5 & $33-43$ & lithic & projectile point & 1 & 3.1 \\
\hline 66 & 7 & 2 & SW & 5 & $33-43$ & lithic & uniface & 1 & 9.0 \\
\hline 66 & 8 & 2 & SW & 5 & $33-43$ & lithic & blade & 2 & 1.8 \\
\hline 66 & 9 & 2 & SW & 5 & $33-43$ & lithic & biface & 1 & 0.5 \\
\hline 66 & 10 & 2 & SW & 5 & $33-43$ & lithic & $\begin{array}{l}\text { burned non- } \\
\text { flake debitage }\end{array}$ & 29 & 12.6 \\
\hline 66 & 11 & 2 & SW & 5 & $33-43$ & lithic & complete flake & 36 & 43.4 \\
\hline 66 & 12 & 2 & SW & 5 & $33-43$ & lithic & broken flake & 115 & 55.6 \\
\hline 66 & 13 & 2 & SW & 5 & $33-43$ & lithic & notching flake & 1 & 0.3 \\
\hline 66 & 14 & 2 & SW & 5 & $33-43$ & lithic & DEB flake & 3 & 5.3 \\
\hline 66 & 15 & 2 & SW & 5 & $33-43$ & lithic & r-flake & 3 & 1.3 \\
\hline 66 & 16 & 2 & SW & 5 & $33-43$ & bone & faunal & 1 & 0.7 \\
\hline 66 & 17 & 2 & SW & 5 & $33-43$ & bone & faunal & 5 & 2.8 \\
\hline 66 & 18 & 2 & SW & 5 & $33-43$ & bone & faunal & 11 & 6.3 \\
\hline 66 & 19 & 2 & SW & 5 & $33-43$ & lithic & uniface & 1 & 0.7 \\
\hline 66 & 20 & 2 & SW & 5 & $33-43$ & organic & wood & 2 & 0.1 \\
\hline \multirow[t]{2}{*}{66} & 21 & 2 & SW & 5 & $33-43$ & lithic & other & 1 & 0.3 \\
\hline & & & & & & & Total & 688 & 569.7 \\
\hline
\end{tabular}


Table A-5. Late Archaic II Artifacts from AU 4a.

\section{Lot Specimen Unit Quad Level $\begin{aligned} & \text { Depth } \\ & (\mathrm{cmbs})\end{aligned} \quad$ Class Type Count $\begin{gathered}\text { Weight } \\ \text { (g) }\end{gathered}$}

\begin{tabular}{|c|c|c|c|c|c|c|c|c|c|}
\hline 123 & 1 & 8 & NW & 4 & $25-35$ & lithic & projectile point & 1 & 11.5 \\
\hline 123 & 2 & 8 & NW & 4 & $25-35$ & bone & faunal & 1 & 3.4 \\
\hline 123 & 3 & 8 & NW & 4 & $25-35$ & bone & faunal & 1 & 1.2 \\
\hline 123 & 4 & 8 & NW & 4 & $25-35$ & bone & faunal & 1 & 3.7 \\
\hline 123 & 5 & 8 & NW & 4 & $25-35$ & bone & faunal & 1 & 1.2 \\
\hline 123 & 6 & 8 & NW & 4 & $25-35$ & bone & faunal & 1 & 1.0 \\
\hline 123 & 7 & 8 & NW & 4 & $25-35$ & bone & faunal & 1 & 0.4 \\
\hline 123 & 8 & 4 & NW & 4 & $35-45$ & lithic & burned rock & 16 & $1,715.0$ \\
\hline 123 & 9 & 8 & NW & 4 & $25-35$ & lithic & complete flake & 7 & 21.0 \\
\hline 123 & 10 & 8 & NW & 4 & $25-35$ & lithic & biface & 1 & 2.3 \\
\hline 123 & 11 & 8 & NW & 4 & $25-35$ & lithic & core & 1 & 54.1 \\
\hline 123 & 12 & 8 & NW & 4 & $25-35$ & shell & snail & 53 & 48.3 \\
\hline 123 & 13 & 8 & NW & - & $30-40$ & lithic & micro-debitage & 4 & 0.1 \\
\hline 123 & 14 & 8 & NW & - & $30-40$ & bone & faunal & 3 & 0.1 \\
\hline 123 & 15 & 8 & NW & - & $30-40$ & lithic & micro-debitage & 9 & 0.1 \\
\hline 123 & 16 & 8 & NW & - & $30-40$ & bone & faunal & 1 & 0.1 \\
\hline 123 & 17 & 8 & NW & - & $30-40$ & sediment & non cultural & & 5.1 \\
\hline 123 & 18 & 8 & NW & - & $30-40$ & float sample & $<0.5 \mathrm{~mm}$ & & \\
\hline 123 & 19 & 8 & NW & - & $30-40$ & float sample & $>0.5 \mathrm{~mm}$ & & \\
\hline 123 & 20 & 8 & NW & - & $30-40$ & float sample & $>1 \mathrm{~mm}$ & & \\
\hline 123 & 21 & 8 & NW & - & $30-40$ & float sample & $>2 \mathrm{~mm}$ & & \\
\hline 123 & 22 & 8 & NW & 4 & $25-35$ & lithic & uniface & 1 & 2.9 \\
\hline 123 & 23 & 8 & NW & 4 & $25-35$ & lithic & broken flake & 22 & 19.8 \\
\hline 123 & 24 & 8 & NW & 4 & $25-35$ & lithic & proximal flake & 16 & 29.3 \\
\hline 123 & 25 & 8 & NW & 4 & $25-35$ & lithic & $\begin{array}{l}\text { burned non- } \\
\text { flake debitage }\end{array}$ & 7 & 4.1 \\
\hline 123 & 26 & 8 & NW & 4 & $25-35$ & lithic & debitage & 6 & 35.5 \\
\hline 123 & 27 & 8 & NW & 4 & $25-35$ & lithic & r-flake & 1 & 2.0 \\
\hline 123 & 28 & 8 & NW & 4 & $25-35$ & lithic & DEB flake & 2 & 3.2 \\
\hline 123 & 29 & 8 & NW & 4 & $25-35$ & lithic & burned rock & 1 & 435.0 \\
\hline 123 & 30 & 8 & NW & 4 & $25-35$ & lithic & burned rock & 1 & 415.0 \\
\hline 123 & 31 & 8 & NW & 4 & $25-35$ & bone & faunal & 1 & 0.3 \\
\hline 123 & 32 & 8 & NW & 4 & $25-35$ & bone & faunal & 1 & 0.7 \\
\hline 123 & 33 & 8 & NW & 4 & $25-35$ & bone & faunal & 5 & 0.7 \\
\hline 123 & 34 & 8 & NW & 4 & $25-35$ & bone & faunal & 2 & 1.8 \\
\hline 123 & 35 & 8 & NW & 4 & $25-35$ & bone & faunal & 1 & 0.3 \\
\hline 123 & 36 & 8 & NW & 4 & $25-35$ & bone & faunal & 1 & 1.1 \\
\hline 123 & 37 & 8 & NW & 4 & $25-35$ & bone & faunal & 1 & 1.7 \\
\hline 123 & 38 & 8 & NW & 4 & $25-35$ & bone & faunal & 1 & 0.9 \\
\hline 123 & 39 & 8 & NW & 4 & $25-35$ & bone & faunal & 1 & 0.6 \\
\hline 123 & 40 & 8 & NW & 4 & $25-35$ & bone & faunal & 1 & 0.4 \\
\hline 123 & 41 & 8 & NW & 4 & $25-35$ & bone & faunal & 3 & 0.1 \\
\hline
\end{tabular}


Table A-5 (continued). Late Archaic II Artifacts from AU 4a.

\section{Lot Specimen Unit Quad Level $\begin{aligned} & \text { Depth } \\ & (\mathrm{cmbs})\end{aligned} \quad$ Class $\quad$ Type Count $\begin{gathered}\text { Weight } \\ \text { (g) }\end{gathered}$}

\begin{tabular}{|c|c|c|c|c|c|c|c|c|c|}
\hline 123 & 42 & 8 & NW & 4 & $25-35$ & bone & faunal & 3 & 0.1 \\
\hline 123 & 43 & 8 & NW & 4 & $25-35$ & bone & faunal & 11 & 0.4 \\
\hline 123 & 44 & 8 & NW & 4 & $25-35$ & organic & wood & 1 & 0.1 \\
\hline 124 & 1 & 8 & SE & 8 & $65-75$ & lithic & projectile point & 1 & 4.5 \\
\hline 124 & 2 & 8 & SE & 8 & $65-75$ & lithic & projectile point & 1 & 11.0 \\
\hline 124 & 4 & 8 & SE & 8 & $65-75$ & bone & faunal & 1 & 15.6 \\
\hline 128 & 1 & 7 & SW & 4 & 25 & lithic & projectile point & 1 & 3.2 \\
\hline 238 & 1 & 3 & $\mathrm{NE}$ & 6 & $45-55$ & lithic & complete flake & 25 & 23.9 \\
\hline 238 & 2 & 3 & $\mathrm{NE}$ & 6 & $45-55$ & bone & faunal & 4 & 2.7 \\
\hline 238 & 3 & 3 & $\mathrm{NE}$ & 6 & $45-55$ & lithic & burned rock & 27 & $1,515.0$ \\
\hline 238 & 4 & 3 & $\mathrm{NE}$ & 6 & $45-55$ & lithic & core & 1 & 49.4 \\
\hline 238 & 5 & 3 & $\mathrm{NE}$ & 6 & $45-55$ & lithic & biface & 1 & 9.2 \\
\hline 238 & 6 & 3 & $\mathrm{NE}$ & 6 & $45-55$ & lithic & biface & 1 & 9.0 \\
\hline 238 & 7 & 3 & $\mathrm{NE}$ & 6 & $45-55$ & bone & faunal & 1 & 3.2 \\
\hline 238 & 8 & 3 & $\mathrm{NE}$ & 6 & $45-55$ & lithic & biface & 1 & 2.6 \\
\hline 238 & 9 & 3 & $\mathrm{NE}$ & 6 & $45-55$ & bone & faunal & 1 & 1.1 \\
\hline 238 & 10 & 3 & $\mathrm{NE}$ & 6 & $45-55$ & lithic & proximal flake & 29 & 26.5 \\
\hline 238 & 11 & 3 & $\mathrm{NE}$ & 6 & $45-55$ & lithic & broken flake & 119 & 100.5 \\
\hline 238 & 12 & 3 & $\mathrm{NE}$ & 6 & $45-55$ & lithic & $\begin{array}{l}\text { burned non- } \\
\text { flake debitage }\end{array}$ & 2 & 1.3 \\
\hline 240 & 1 & 11 & - & 7 & $54-64$ & bone & faunal & 1 & 8.6 \\
\hline 240 & 2 & 11 & - & 7 & $54-64$ & lithic & burned rock & 75 & $8,950.0$ \\
\hline 240 & 2 & 11 & - & 7 & $54-64$ & lithic & burned rock & 9 & $2,040.0$ \\
\hline 240 & 3 & 11 & - & 7 & $54-64$ & $\mathrm{C} 14$ & charcoal & 2 & NW \\
\hline 240 & 4 & 11 & - & 7 & $54-64$ & lithic & broken flake & 46 & 27.5 \\
\hline 240 & 5 & 11 & - & 7 & $54-64$ & lithic & burned rock & 1 & 49.8 \\
\hline 240 & 6 & 11 & - & 7 & $54-64$ & shell & snail & 4 & 3.0 \\
\hline 240 & 7 & 11 & - & 7 & $54-64$ & lithic & burned rock & 1 & 470.0 \\
\hline 240 & 8 & 11 & - & 7 & $54-64$ & lithic & burned rock & 1 & 565.0 \\
\hline 240 & 9 & 11 & - & 7 & $54-64$ & bone & faunal & 2 & 1.2 \\
\hline 240 & 10 & 11 & - & 7 & $54-64$ & lithic & proximal flake & 20 & 7.5 \\
\hline 240 & 11 & 11 & - & 7 & $54-64$ & lithic & complete flake & 8 & 3.9 \\
\hline 249 & 1 & 11 & - & 9 & $74-84$ & bone & faunal & 1 & 0.6 \\
\hline 249 & 2 & 11 & - & 9 & $74-84$ & lithic & broken flake & 20 & 18.7 \\
\hline 249 & 3 & 11 & - & 9 & $74-84$ & shell & snail & 7 & 8.6 \\
\hline 249 & 4 & 11 & - & 9 & $74-84$ & $\mathrm{C} 14$ & charcoal & 2 & NW \\
\hline 249 & 5 & 11 & - & 9 & $74-84$ & lithic & burned rock & 15 & 934.0 \\
\hline 249 & 6 & 11 & - & 9 & $74-84$ & lithic & complete flake & 4 & 2.2 \\
\hline 249 & 7 & 11 & - & 9 & $74-84$ & lithic & proximal flake & 12 & 22.7 \\
\hline 256 & 1 & 11 & - & 4 & $24-34$ & bone & faunal & 1 & 1.2 \\
\hline 256 & 2 & 11 & - & 4 & $24-34$ & lithic & biface & 1 & 53.1 \\
\hline 256 & 3 & 11 & - & 4 & $24-34$ & lithic & biface & 1 & 10.0 \\
\hline
\end{tabular}


Table A-5 (continued). Late Archaic II Artifacts from AU 4a.

\section{Lot Specimen Unit Quad Level $\begin{gathered}\text { Depth } \\ (\mathrm{cmbs})\end{gathered} \quad$ Class $\quad$ Type Count $\begin{gathered}\text { Weight } \\ \text { (g) }\end{gathered}$}

\begin{tabular}{|c|c|c|c|c|c|c|c|c|c|}
\hline 256 & 4 & 11 & - & 4 & $24-34$ & $\mathrm{C} 14$ & charcoal & & 1.4 \\
\hline 256 & 4 & 11 & - & 4 & $24-34$ & lithic & projectile point & 1 & 3.1 \\
\hline 256 & 5 & 11 & - & 4 & $24-34$ & lithic & projectile point & 1 & 0.5 \\
\hline 256 & 6 & 11 & - & 4 & $24-34$ & lithic & projectile point & 1 & 3.6 \\
\hline 256 & 7 & 11 & - & 4 & $24-34$ & lithic & broken flake & 359 & 207.6 \\
\hline 256 & 8 & 11 & - & 4 & $24-34$ & lithic & burned rock & 56 & 264.0 \\
\hline 256 & 9 & 11 & - & 4 & $24-34$ & $\mathrm{C} 14$ & charcoal & 3 & NW \\
\hline 256 & 10 & 11 & - & 4 & $24-34$ & shell & snail & 188 & 83.9 \\
\hline 256 & 11 & 11 & - & 4 & $24-34$ & shell & bivalve & 6 & 9.4 \\
\hline 256 & 11 & 11 & - & 4 & $24-34$ & other prehistoric & burned clay & 68 & 4.6 \\
\hline 256 & 12 & 11 & - & 4 & $24-34$ & lithic & other & 2 & $<0.1$ \\
\hline 256 & 13 & 11 & - & 4 & $24-34$ & glass & bottle & 1 & 1.3 \\
\hline 256 & 14 & 11 & - & 4 & $24-34$ & organic & seed & 1 & $<0.1$ \\
\hline 256 & 15 & 11 & - & 4 & $24-34$ & shell & snail & & 22.5 \\
\hline 256 & 16 & 11 & - & 4 & $24-34$ & lithic & biface & 1 & 1.0 \\
\hline 256 & 17 & 11 & - & 4 & $24-34$ & sediment & other & & 45.5 \\
\hline 256 & 18 & 11 & - & 4 & $24-34$ & other & non cultural & & 108.6 \\
\hline 256 & 19 & 11 & - & 4 & $24-34$ & float sample & $<0.5 \mathrm{~mm}$ & & \\
\hline 256 & 20 & 11 & - & 4 & $24-34$ & float sample & $>0.5 \mathrm{~mm}$ & & \\
\hline 256 & 21 & 11 & - & 4 & $24-34$ & float sample & $>1 \mathrm{~mm}$ & & \\
\hline 256 & 22 & 11 & - & 4 & $24-34$ & float sample & $>2 \mathrm{~mm}$ & & \\
\hline 256 & 23 & 11 & - & 4 & $24-34$ & lithic & burned rock & 1 & 90.5 \\
\hline 256 & 24 & 11 & - & 4 & $24-34$ & bone & faunal & 15 & 0.2 \\
\hline 256 & 25 & 11 & - & 4 & $24-34$ & bone & faunal & 8 & 0.3 \\
\hline 256 & 26 & 11 & - & 4 & $24-34$ & bone & faunal & 1 & 1.2 \\
\hline 256 & 27 & 11 & - & 4 & $24-34$ & bone & faunal & 5 & 0.5 \\
\hline 256 & 28 & 11 & - & 4 & $24-34$ & bone & faunal & 20 & 1.0 \\
\hline 256 & 29 & 11 & - & 4 & $24-34$ & bone & faunal & 6 & 0.2 \\
\hline 256 & 30 & 11 & - & 4 & $24-34$ & bone & faunal & 1 & 0.1 \\
\hline 256 & 31 & 11 & - & 4 & $24-34$ & bone & faunal & 41 & 2.3 \\
\hline 256 & 32 & 11 & - & 4 & $24-34$ & bone & faunal & 63 & 4.4 \\
\hline 256 & 33 & 11 & - & 4 & $24-34$ & bone & faunal & 1 & 0.2 \\
\hline 256 & 34 & 11 & - & 4 & $24-34$ & bone & faunal & 5 & 0.4 \\
\hline 256 & 35 & 11 & - & 4 & $24-34$ & bone & faunal & 1 & 0.1 \\
\hline 256 & 36 & 11 & - & 4 & $24-34$ & bone & faunal & 1 & $<0.1$ \\
\hline 256 & 37 & 11 & - & 4 & $24-34$ & bone & faunal & 1 & 0.1 \\
\hline 256 & 38 & 11 & - & 4 & $24-34$ & bone & faunal & 1 & 0.1 \\
\hline 256 & 39 & 11 & - & 4 & $24-34$ & bone & faunal & 1 & 0.1 \\
\hline 256 & 40 & 11 & - & 4 & $24-34$ & bone & faunal & 1 & 0.1 \\
\hline 256 & 41 & 11 & - & 4 & $24-34$ & bone & faunal & 1 & 0.1 \\
\hline 256 & 42 & 11 & - & 4 & $24-34$ & bone & faunal & 1 & 0.1 \\
\hline 256 & 43 & 11 & - & 4 & $24-34$ & bone & faunal & 1 & 3.1 \\
\hline
\end{tabular}


Table A-5 (continued). Late Archaic II Artifacts from AU 4a.

\section{Lot Specimen Unit Quad Level $\begin{aligned} & \text { Depth } \\ & \text { (cmbs) }\end{aligned}$ Class Type Count $\begin{gathered}\text { Weight } \\ \text { (g) }\end{gathered}$}

\begin{tabular}{|c|c|c|c|c|c|c|c|c|c|}
\hline 256 & 44 & 11 & - & 4 & $24-34$ & bone & faunal & 1 & 3.1 \\
\hline 256 & 45 & 11 & - & 4 & $24-34$ & bone & faunal & 1 & 9.9 \\
\hline 256 & 46 & 11 & - & 4 & $24-34$ & bone & faunal & 1 & 0.3 \\
\hline 256 & 47 & 11 & - & 4 & $24-34$ & bone & faunal & 1 & 1.6 \\
\hline 256 & 48 & 11 & - & 4 & $24-34$ & bone & faunal & 1 & 3.5 \\
\hline 256 & 49 & 11 & - & 4 & $24-34$ & bone & faunal & 1 & 2.9 \\
\hline 256 & 50 & 11 & - & 4 & $24-34$ & bone & faunal & 1 & 3.9 \\
\hline 256 & 51 & 11 & - & 4 & $24-34$ & bone & faunal & 1 & 90.5 \\
\hline 256 & 52 & 11 & - & 4 & $24-34$ & bone & faunal & 1 & 90.5 \\
\hline 256 & 53 & 11 & - & 4 & $24-34$ & ceramic & & 1 & 0.1 \\
\hline 256 & 54 & 11 & - & 4 & $24-34$ & organic & plant & 1 & $<0.1$ \\
\hline 256 & 55 & 11 & - & 4 & $24-34$ & lithic & other & 19 & 1.2 \\
\hline 256 & 56 & 11 & - & 4 & $24-34$ & lithic & $\begin{array}{l}\text { burned non- } \\
\text { flake debitage }\end{array}$ & 6 & 12.6 \\
\hline 256 & 57 & 11 & - & 4 & $24-34$ & lithic & uniface & 1 & 8.6 \\
\hline 256 & 58 & 11 & - & 4 & $24-34$ & lithic & uniface & 1 & 5.6 \\
\hline 256 & 59 & 11 & - & 4 & $24-34$ & lithic & uniface & 1 & 4.5 \\
\hline 256 & 60 & 11 & - & 4 & $24-34$ & lithic & proximal flake & 91 & 105.6 \\
\hline 256 & 61 & 11 & - & 4 & $24-34$ & lithic & complete flake & 48 & 92.7 \\
\hline 256 & 62 & 11 & - & 4 & $24-34$ & bone & faunal & 1 & 0.1 \\
\hline 256 & 63 & 11 & - & 4 & $24-34$ & bone & faunal & 1 & 0.1 \\
\hline 287 & 1 & 8 & NW & 8 & $65-70$ & bone & unknown & 8 & 16.5 \\
\hline 287 & 2 & 8 & NW & 8 & $65-70$ & bone & faunal & 2 & 2.3 \\
\hline 287 & 3 & 8 & NW & 8 & $65-70$ & bone & faunal & 1 & 6.3 \\
\hline 287 & 4 & 8 & NW & 8 & $65-70$ & bone & faunal & 4 & 3.0 \\
\hline 287 & 5 & 8 & NW & 8 & $65-70$ & bone & faunal & 1 & 0.6 \\
\hline 287 & 6 & 8 & NW & 8 & $65-70$ & bone & unknown & 9 & 3.1 \\
\hline 287 & 7 & 8 & NW & 8 & $65-70$ & lithic & broken flake & 157 & 148.2 \\
\hline 287 & 8 & 8 & NW & 8 & $65-70$ & shell & snail & 36 & 40.5 \\
\hline 287 & 8 & 8 & NW & 8 & $65-70$ & shell & snail & 45 & 39.4 \\
\hline 287 & 9 & 8 & NW & 8 & $65-70$ & lithic & biface & 1 & 2.2 \\
\hline 287 & 10 & 8 & NW & 8 & $65-70$ & lithic & burned rock & 42 & 177.0 \\
\hline 287 & 11 & 8 & NW & - & $70-80$ & lithic & debitage & 1 & $<0.1$ \\
\hline 287 & 12 & 8 & NW & - & $70-80$ & bone & unknown & 1 & $<0.1$ \\
\hline 287 & 13 & 8 & NW & - & $70-80$ & shell & snail & 1 & 0.3 \\
\hline 287 & 14 & 8 & NW & - & $70-80$ & lithic & debitage & 8 & 0.9 \\
\hline 287 & 15 & 8 & NW & - & $70-80$ & lithic & burned rock & 5 & 82.1 \\
\hline 287 & 16 & 8 & NW & - & $70-80$ & bone & unknown & 2 & 0.3 \\
\hline 287 & 17 & 8 & NW & - & $70-80$ & sediment & non cultural & & 7.2 \\
\hline 287 & 18 & 8 & NW & - & $70-80$ & float sample & $<0.5 \mathrm{~mm}$ & & \\
\hline 287 & 19 & 8 & NW & - & $70-80$ & float sample & $>0.5 \mathrm{~mm}$ & & \\
\hline 287 & 20 & 8 & NW & - & $70-80$ & float sample & $>1 \mathrm{~mm}$ & & \\
\hline 287 & 21 & 8 & NW & - & $70-80$ & float sample & $>2 \mathrm{~mm}$ & & \\
\hline
\end{tabular}


Table A-5 (continued). Late Archaic II Artifacts from AU 4a.

\begin{tabular}{|c|c|c|c|c|c|c|c|c|c|}
\hline Lot & Specimen & Unit & Quad & Level & $\begin{array}{l}\text { Depth } \\
\text { (cmbs) }\end{array}$ & Class & Type & Count & $\begin{array}{l}\text { Weight } \\
\text { (g) }\end{array}$ \\
\hline 287 & 22 & 8 & NW & 8 & $65-70$ & lithic & biface & 1 & 2.0 \\
\hline 287 & 23 & 8 & NW & 8 & $65-70$ & lithic & other & 1 & 0.6 \\
\hline 287 & 24 & 8 & NW & 8 & $65-70$ & lithic & $\begin{array}{l}\text { burned non- } \\
\text { flake debitage }\end{array}$ & 11 & 16.9 \\
\hline 287 & 25 & 8 & NW & 8 & $65-70$ & lithic & proximal flake & 54 & 55.2 \\
\hline 287 & 26 & 8 & NW & 8 & $65-70$ & lithic & complete flake & 42 & 115.0 \\
\hline 287 & 27 & 8 & NW & 8 & $65-70$ & organic & nutshell & 1 & $<0.1$ \\
\hline 287 & 28 & 8 & NW & 8 & $65-70$ & bone & unknown & 1 & 0.4 \\
\hline 291 & 1 & 8 & SE & 4 & $25-35$ & bone & unknown & 3 & 0.5 \\
\hline 291 & 2 & 8 & SE & 4 & $25-35$ & bone & faunal & 3 & 0.3 \\
\hline 291 & 3 & 8 & SE & 4 & $25-35$ & lithic & broken flake & 110 & 71.4 \\
\hline 291 & 4 & 8 & SE & 4 & $25-35$ & $\mathrm{C} 14$ & charcoal & 4 & NW \\
\hline 291 & 5 & 8 & SE & 4 & $25-35$ & lithic & biface & 1 & 3.3 \\
\hline 291 & 6 & 8 & SE & 4 & $25-35$ & bone & faunal & 1 & 0.2 \\
\hline 291 & 7 & 8 & SE & 4 & $25-35$ & bone & faunal & 1 & 1.5 \\
\hline 291 & 8 & 8 & SE & 4 & $25-35$ & bone & faunal & 4 & 1.0 \\
\hline 291 & 9 & 8 & $\mathrm{SE}$ & 4 & $25-35$ & bone & faunal & 1 & 0.2 \\
\hline 291 & 10 & 8 & SE & 4 & $25-35$ & bone & faunal & 1 & 1.5 \\
\hline 291 & 11 & 8 & SE & 4 & $25-35$ & bone & faunal & 2 & 1.0 \\
\hline 291 & 12 & 8 & SE & 4 & $25-35$ & bone & faunal & 1 & 0.7 \\
\hline 291 & 13 & 8 & SE & 4 & $25-35$ & bone & faunal & 6 & 2.3 \\
\hline 291 & 14 & 8 & SE & 4 & $25-35$ & bone & faunal & 4 & 4.7 \\
\hline 291 & 15 & 8 & SE & 4 & $25-35$ & bone & faunal & 1 & 0.7 \\
\hline 291 & 16 & 8 & SE & 4 & $25-35$ & bone & faunal & 1 & 3.7 \\
\hline 291 & 17 & 8 & SE & 4 & $25-35$ & bone & faunal & 1 & 1.8 \\
\hline 291 & 18 & 8 & SE & 4 & $25-35$ & organic & wood & 1 & 0.2 \\
\hline 291 & 19 & 8 & SE & 4 & $25-35$ & lithic & uniface & 1 & 1.3 \\
\hline 291 & 20 & 8 & SE & 4 & $25-35$ & lithic & $\begin{array}{l}\text { burned non- } \\
\text { flake debitage }\end{array}$ & 16 & 20.0 \\
\hline 291 & 21 & 8 & SE & 4 & $25-35$ & lithic & proximal flake & 35 & 30.7 \\
\hline 291 & 22 & 8 & SE & 4 & $25-35$ & lithic & complete flake & 31 & 46.7 \\
\hline 299 & 1 & 8 & NW & 9 & $70-75$ & bone & faunal & 1 & $<0.1$ \\
\hline 299 & 2 & 8 & NW & 9 & $70-75$ & bone & faunal & 1 & $<0.1$ \\
\hline 299 & 3 & 8 & NW & 9 & $70-75$ & bone & faunal & 2 & $<0.1$ \\
\hline 299 & 4 & 8 & NW & 9 & $70-75$ & bone & faunal & 2 & 0.1 \\
\hline 299 & 5 & 8 & NW & 9 & $70-75$ & bone & unknown & 1 & 1.8 \\
\hline 299 & 5 & 8 & NW & 9 & $70-75$ & bone & unknown & 4 & 1.1 \\
\hline 299 & 8 & 8 & NW & 9 & $70-75$ & lithic & burned rock & 13 & 256.6 \\
\hline 299 & 9 & 8 & NW & 9 & $70-75$ & shell & snail & 25 & 21.2 \\
\hline 299 & 9 & 8 & NW & 9 & $70-75$ & shell & snail & 16 & 16.2 \\
\hline 299 & 10 & 8 & NW & 9 & $70-75$ & lithic & broken flake & 33 & 70.5 \\
\hline 299 & 11 & 8 & NW & - & $80-90$ & lithic & debitage & 2 & $<0.1$ \\
\hline
\end{tabular}


Table A-5 (continued). Late Archaic II Artifacts from AU 4a.

\section{Lot Specimen Unit Quad Level $\begin{aligned} & \text { Depth } \\ & (\mathrm{cmbs})\end{aligned} \quad$ Class $\quad$ Type Count $\begin{gathered}\text { Weight } \\ \text { (g) }\end{gathered}$}

\begin{tabular}{|c|c|c|c|c|c|c|c|c|c|}
\hline 299 & 12 & 8 & NW & - & $80-90$ & bone & unknown & 3 & 0.8 \\
\hline 299 & 13 & 8 & NW & - & $80-90$ & sediment & non cultural & & 25.4 \\
\hline 299 & 14 & 8 & NW & - & $80-90$ & lithic & burned rock & 4 & 47.7 \\
\hline 299 & 15 & 8 & NW & - & $80-90$ & lithic & debitage & 24 & 5.0 \\
\hline 299 & 16 & 8 & NW & - & $80-90$ & bone & unknown & 1 & $<0.1$ \\
\hline 299 & 17 & 8 & NW & - & $80-90$ & float sample & $<0.5 \mathrm{~mm}$ & & \\
\hline 299 & 18 & 8 & NW & - & $80-90$ & float sample & $>0.5 \mathrm{~mm}$ & & \\
\hline 299 & 19 & 8 & NW & - & $80-90$ & float sample & $>1 \mathrm{~mm}$ & & \\
\hline 299 & 20 & 8 & NW & - & $80-90$ & float sample & $>2 \mathrm{~mm}$ & & \\
\hline 299 & 21 & 8 & NW & - & $80-90$ & lithic & notching flake & 2 & 0.4 \\
\hline 299 & 22 & 8 & NW & - & $80-90$ & lithic & complete flake & 10 & 23.0 \\
\hline 299 & 23 & 8 & NW & - & $80-90$ & lithic & proximal flake & 14 & 23.3 \\
\hline 299 & 24 & 8 & NW & - & $80-90$ & lithic & $\begin{array}{l}\text { burned non- } \\
\text { flake debitage }\end{array}$ & 3 & 5.7 \\
\hline 299 & 25 & 8 & NW & - & $80-90$ & lithic & uniface & 1 & 2.6 \\
\hline 299 & 26 & 8 & NW & 9 & $70-75$ & lithic & burned rock & 1 & 40.2 \\
\hline 299 & 27 & 8 & NW & 9 & $70-75$ & lithic & burned rock & 1 & 38.2 \\
\hline 299 & 28 & 8 & NW & 9 & $70-75$ & shell & snail & 1 & 0.1 \\
\hline 299 & 28 & 8 & NW & 9 & $70-75$ & bone & faunal & 1 & 10.4 \\
\hline 299 & 29 & 8 & NW & 9 & $70-75$ & bone & faunal & 1 & 1.7 \\
\hline 299 & 30 & 8 & NW & 9 & $70-75$ & bone & faunal & 2 & 7.6 \\
\hline 299 & 31 & 8 & NW & 9 & $70-75$ & bone & faunal & 1 & 4.9 \\
\hline 299 & 32 & 8 & NW & 9 & $70-75$ & bone & faunal & 2 & 27.2 \\
\hline 299 & 33 & 8 & NW & 9 & $70-75$ & bone & faunal & 1 & 3.6 \\
\hline 299 & 34 & 8 & NW & 9 & $70-75$ & bone & faunal & 7 & 0.2 \\
\hline 299 & 35 & 8 & NW & 9 & $70-75$ & bone & faunal & 1 & 0.2 \\
\hline 299 & 36 & 8 & NW & 9 & $70-75$ & bone & faunal & 1 & 0.1 \\
\hline 299 & 37 & 8 & NW & 9 & $70-75$ & bone & faunal & 1 & 0.5 \\
\hline 299 & 38 & 8 & NW & 9 & $70-75$ & bone & faunal & 1 & $<0.1$ \\
\hline 299 & 39 & 8 & NW & 9 & $70-75$ & bone & faunal & 1 & $<0.1$ \\
\hline 299 & 40 & 8 & NW & 9 & $70-75$ & bone & faunal & 1 & 1.1 \\
\hline 299 & 41 & 8 & NW & 9 & $70-75$ & bone & faunal & 1 & 7.2 \\
\hline 299 & 42 & 8 & NW & 9 & $70-75$ & bone & faunal & 3 & 3.1 \\
\hline 299 & 43 & 8 & NW & 9 & $70-75$ & bone & faunal & 3 & 1.9 \\
\hline 299 & 44 & 8 & NW & 9 & $70-75$ & bone & faunal & 1 & 3.0 \\
\hline 299 & 45 & 8 & NW & 9 & $70-75$ & bone & faunal & 1 & 0.4 \\
\hline 299 & 46 & 8 & NW & 9 & $70-75$ & bone & faunal & 1 & 0.3 \\
\hline 299 & 47 & 8 & NW & 9 & $70-75$ & bone & faunal & 1 & 0.6 \\
\hline 299 & 48 & 8 & NW & 9 & $70-75$ & bone & faunal & 1 & 0.8 \\
\hline 299 & 49 & 8 & NW & 9 & $70-75$ & bone & faunal & 1 & 0.5 \\
\hline 299 & 50 & 8 & NW & 9 & $70-75$ & bone & faunal & 1 & 0.9 \\
\hline 299 & 51 & 8 & NW & 9 & $70-75$ & bone & faunal & 2 & 1.6 \\
\hline
\end{tabular}


Table A-5 (continued). Late Archaic II Artifacts from AU 4a.

\section{Lot Specimen Unit Quad Level $\begin{gathered}\text { Depth } \\ (\mathrm{cmbs})\end{gathered} \quad$ Class $\quad$ Type Count $\begin{gathered}\text { Weight } \\ \text { (g) }\end{gathered}$}

\begin{tabular}{|c|c|c|c|c|c|c|c|c|c|}
\hline 299 & 52 & 8 & NW & 9 & $70-75$ & bone & faunal & 1 & 7.6 \\
\hline 299 & 53 & 8 & NW & 9 & $70-75$ & organic & rhizolith & 1 & 0.8 \\
\hline 299 & 54 & 8 & NW & 9 & $70-75$ & organic & rhizolith & 2 & $<0.1$ \\
\hline 299 & 55 & 8 & NW & 9 & $70-75$ & lithic & other & 1 & 0.1 \\
\hline 336 & 1 & 10 & NW & 5 & $35-45$ & bone & faunal & 1 & 0.8 \\
\hline 336 & 2 & 10 & NW & 5 & $35-45$ & bone & faunal & 1 & 0.3 \\
\hline 336 & 3 & 10 & NW & 5 & $35-45$ & shell & snail & 1 & $<0.1$ \\
\hline 336 & 4 & 10 & NW & 5 & $35-45$ & glass & unknown & 1 & 0.2 \\
\hline 336 & 5 & 10 & NW & 5 & $35-45$ & lithic & broken flake & 55 & 32.0 \\
\hline 336 & 6 & 10 & NW & 5 & $35-45$ & lithic & burned rock & 6 & 29.6 \\
\hline 336 & 7 & 10 & NW & 5 & $35-45$ & lithic & projectile point & 1 & 3.8 \\
\hline 336 & 8 & 10 & NW & 5 & $35-45$ & lithic & complete flake & 16 & 34.5 \\
\hline 336 & 9 & 10 & NW & 5 & $35-45$ & lithic & proximal flake & 19 & 16.0 \\
\hline 336 & 10 & 10 & NW & 5 & $35-45$ & lithic & $\begin{array}{l}\text { burned non- } \\
\text { flake debitage }\end{array}$ & 4 & 2.4 \\
\hline 336 & 11 & 10 & NW & 5 & $35-45$ & lithic & notching flake & 1 & $<0.1$ \\
\hline 336 & 12 & 10 & NW & 5 & $35-45$ & lithic & uniface & 1 & 2.0 \\
\hline 336 & 13 & 10 & NW & 5 & $35-45$ & lithic & uniface & 1 & 2.2 \\
\hline 336 & 14 & 10 & NW & 5 & $35-45$ & bone & faunal & 1 & 0.1 \\
\hline 336 & 15 & 10 & NW & 5 & $35-45$ & bone & unknown & 1 & 0.6 \\
\hline 336 & 16 & 10 & NW & 5 & $35-45$ & bone & unknown & 2 & 0.8 \\
\hline 336 & 17 & 10 & NW & 5 & $35-45$ & lithic & other & 1 & 0.1 \\
\hline 385 & 1 & 8 & - & 9 & & lithic & burned rock & 62 & $7,215.0$ \\
\hline 385 & 2 & 8 & NW & 9 & $70-75$ & $\mathrm{C} 14$ & charcoal & 1 & NW \\
\hline 522 & 1 & 11 & - & 4 & $24-34$ & other prehistoric & burned clay & 10 & 8.3 \\
\hline 522 & 2 & 11 & - & 4 & $24-34$ & glass & unknown & 1 & 1.9 \\
\hline 522 & 3 & 11 & - & 4 & $24-34$ & lithic & debitage & 231 & 53.4 \\
\hline 522 & 4 & 11 & - & 4 & $24-34$ & $\mathrm{C} 14$ & charcoal & 2 & 0.3 \\
\hline 522 & 5 & 11 & - & 4 & $24-34$ & shell & snail & 84 & 17.5 \\
\hline 522 & 6 & 11 & - & 4 & $24-34$ & lithic & burned rock & 16 & 60.6 \\
\hline 522 & 7 & 11 & - & 4 & $24-34$ & bone & faunal & 1 & 0.4 \\
\hline 522 & 9 & 11 & - & 4 & $24-34$ & bone & faunal & 1 & 0.2 \\
\hline 522 & 10 & 11 & - & 4 & $24-34$ & lithic & burned rock & 10 & 38.3 \\
\hline 522 & 11 & 11 & - & 4 & $24-34$ & $\mathrm{C} 14$ & charcoal & & 0.7 \\
\hline 522 & 12 & 11 & - & 4 & $24-34$ & other & plastic & 19 & 0.1 \\
\hline 522 & 13 & 11 & - & 4 & $24-34$ & sediment & non cultural & & 205.4 \\
\hline 522 & 15 & 11 & - & 4 & $24-34$ & lithic & burned rock & 2 & 2.8 \\
\hline 522 & 16 & 11 & - & 4 & $24-34$ & shell & snail & 1 & 0.1 \\
\hline 522 & 17 & 11 & - & 4 & $24-34$ & float sample & $<0.5 \mathrm{~mm}$ & & \\
\hline 522 & 18 & 11 & - & 4 & $24-34$ & float sample & $>0.5 \mathrm{~mm}$ & & \\
\hline 522 & 19 & 11 & - & 4 & $24-34$ & float sample & $>1 \mathrm{~mm}$ & & \\
\hline 522 & 20 & 11 & - & 4 & $24-34$ & float sample & $>2 \mathrm{~mm}$ & & \\
\hline
\end{tabular}


Table A-5 (continued). Late Archaic II Artifacts from AU 4a.

\begin{tabular}{|c|c|c|c|c|c|c|c|c|c|}
\hline Lot & Specimen & Unit & Quad & Level & $\begin{array}{l}\text { Depth } \\
\text { (cmbs) }\end{array}$ & Class & Type & Count & $\begin{array}{c}\text { Weight } \\
\text { (g) }\end{array}$ \\
\hline 522 & 21 & 11 & - & 4 & $24-34$ & bone & faunal & 1 & $<0.1$ \\
\hline 522 & 22 & 11 & - & 4 & $24-34$ & bone & faunal & 1 & $<0.1$ \\
\hline 522 & 23 & 11 & - & 4 & $24-34$ & bone & faunal & 1 & $<0.1$ \\
\hline 522 & 24 & 11 & - & 4 & $24-34$ & bone & faunal & 1 & $<0.1$ \\
\hline 522 & 25 & 11 & - & 4 & $24-34$ & bone & faunal & 2 & 0.1 \\
\hline 522 & 26 & 11 & - & 4 & $24-34$ & bone & faunal & 1 & 0.1 \\
\hline 522 & 27 & 11 & - & 4 & $24-34$ & bone & faunal & 1 & 0.1 \\
\hline 522 & 28 & 11 & - & 4 & $24-34$ & bone & faunal & 1 & 0.1 \\
\hline 522 & 29 & 11 & - & 4 & $24-34$ & bone & faunal & 1 & $<0.1$ \\
\hline 522 & 30 & 11 & - & 4 & $24-34$ & bone & faunal & 1 & 0.2 \\
\hline 522 & 31 & 11 & - & 4 & $24-34$ & bone & faunal & 4 & 0.2 \\
\hline 522 & 32 & 11 & - & 4 & $24-34$ & bone & faunal & 1 & 0.1 \\
\hline 522 & 33 & 11 & - & 4 & $24-34$ & bone & faunal & 4 & 0.1 \\
\hline 522 & 34 & 11 & - & 4 & $24-34$ & bone & faunal & 1 & 0.1 \\
\hline 522 & 35 & 11 & - & 4 & $24-34$ & bone & faunal & 1 & 0.1 \\
\hline 522 & 36 & 11 & - & 4 & $24-34$ & bone & faunal & 3 & 0.6 \\
\hline 522 & 37 & 11 & - & 4 & $24-34$ & bone & faunal & 2 & 0.1 \\
\hline 522 & 38 & 11 & - & 4 & $24-34$ & bone & faunal & 1 & 0.2 \\
\hline 522 & 39 & 11 & - & 4 & $24-34$ & bone & faunal & 1 & 0.1 \\
\hline 522 & 40 & 11 & - & 4 & $24-34$ & bone & faunal & 1 & 0.6 \\
\hline 522 & 41 & 11 & - & 4 & $24-34$ & bone & faunal & 7 & 3.2 \\
\hline 522 & 42 & 11 & - & 4 & $24-34$ & bone & faunal & 8 & 3.4 \\
\hline 522 & 43 & 11 & - & 4 & $24-34$ & bone & faunal & 43 & 3.0 \\
\hline 522 & 44 & 11 & - & 4 & $24-34$ & bone & faunal & 2 & 0.3 \\
\hline 522 & 45 & 11 & - & 4 & $24-34$ & bone & faunal & 8 & 1.0 \\
\hline 522 & 46 & 11 & - & 4 & $24-34$ & bone & faunal & 9 & 0.8 \\
\hline 522 & 47 & 11 & - & 4 & $24-34$ & bone & faunal & 1 & 0.2 \\
\hline 522 & 48 & 11 & - & 4 & $24-34$ & organic & plant & 1 & $<0.1$ \\
\hline 522 & 49 & 11 & - & 4 & $24-34$ & organic & rhizolith & 1 & $<0.1$ \\
\hline 522 & 50 & 11 & - & 4 & $24-34$ & organic & & 1 & $<0.1$ \\
\hline 584 & 1 & 11 & - & 4 & $24-34$ & bone & faunal & 1 & 0.1 \\
\hline 584 & 2 & 11 & - & 4 & $24-34$ & sediment & non cultural & NA & 0.2 \\
\hline \multirow[t]{2}{*}{584} & 3 & 11 & - & 4 & $24-34$ & shell & snail & NA & 0.2 \\
\hline & & & & & & & Total & 3,223 & $28,405.8$ \\
\hline
\end{tabular}


Table A-6. Late Archaic I Artifacts from AU 4b.

\section{Lot Specimen Unit Quad Level $\begin{gathered}\text { Depth } \\ \text { (cmbs) }\end{gathered} \quad$ Class $\quad$ Type $\quad$ Count $\begin{gathered}\text { Weight } \\ \text { (g) }\end{gathered}$}

\begin{tabular}{|c|c|c|c|c|c|c|c|c|c|}
\hline 69 & 1 & 2 & $\mathrm{NE}$ & 10 & $82-92$ & lithic & $\begin{array}{c}\text { burned non-flake } \\
\text { debitage }\end{array}$ & 21 & 14.4 \\
\hline 69 & 2 & 2 & $\mathrm{NE}$ & 10 & $82-92$ & shell & snail & 2 & 0.4 \\
\hline 69 & 3 & 2 & $\mathrm{NE}$ & 10 & $82-92$ & lithic & burned rock & 12 & 620.0 \\
\hline 69 & 4 & 2 & $\mathrm{NE}$ & 10 & $82-92$ & lithic & projectile point & 1 & 18.1 \\
\hline 69 & 5 & 2 & $\mathrm{NE}$ & 10 & $82-92$ & lithic & micro-debitage & 2 & $<0.1$ \\
\hline 69 & 6 & 2 & $\mathrm{NE}$ & 10 & $82-92$ & lithic & burned rock & 2 & 0.3 \\
\hline 69 & 7 & 2 & $\mathrm{NE}$ & 10 & $82-92$ & lithic & uniface & 1 & 0.6 \\
\hline 69 & 8 & 2 & $\mathrm{NE}$ & 10 & $82-92$ & lithic & notching flake & 1 & 0.2 \\
\hline 69 & 9 & 2 & $\mathrm{NE}$ & 10 & $82-92$ & lithic & broken flake & 72 & 53.7 \\
\hline 69 & 10 & 2 & $\mathrm{NE}$ & 10 & $82-92$ & lithic & complete flake & 15 & 24.7 \\
\hline 69 & 11 & 2 & $\mathrm{NE}$ & 10 & $82-92$ & lithic & proximal flake & 49 & 43.2 \\
\hline 69 & 12 & 2 & $\mathrm{NE}$ & 10 & $82-92$ & lithic & debitage & 6 & 26.3 \\
\hline 69 & 13 & 2 & $\mathrm{NE}$ & 10 & $82-92$ & lithic & burned rock & 1 & 199.1 \\
\hline 69 & 14 & 2 & $\mathrm{NE}$ & 10 & $82-92$ & lithic & uniface & 1 & 10.8 \\
\hline 74 & 1 & 2 & $\mathrm{NE}$ & 11 & $92-102$ & lithic & broken flake & 75 & 57.7 \\
\hline 74 & 2 & 2 & $\mathrm{NE}$ & 11 & $92-102$ & lithic & burned rock & 32 & $3,823.4$ \\
\hline 74 & 3 & 2 & $\mathrm{NE}$ & 11 & $92-102$ & other prehistoric & burned clay & 4 & 4.0 \\
\hline 74 & 5 & 2 & $\mathrm{NE}$ & 11 & $92-102$ & lithic & core & 1 & 41.6 \\
\hline 74 & 6 & 2 & $\mathrm{NE}$ & 11 & $92-102$ & lithic & micro-debitage & 4 & $<0.1$ \\
\hline 74 & 7 & 2 & $\mathrm{NE}$ & 11 & $92-102$ & lithic & burned rock & 1 & 700.0 \\
\hline 74 & 8 & 2 & $\mathrm{NE}$ & 11 & $92-102$ & lithic & burned rock & 1 & 291.6 \\
\hline 74 & 9 & 2 & $\mathrm{NE}$ & 11 & $92-102$ & lithic & $\begin{array}{l}\text { burned non-flake } \\
\text { debitage }\end{array}$ & 7 & 21.7 \\
\hline 74 & 10 & 2 & $\mathrm{NE}$ & 11 & $92-102$ & lithic & proximal flake & 27 & 235.0 \\
\hline 74 & 11 & 2 & $\mathrm{NE}$ & 11 & $92-102$ & lithic & complete flake & 20 & 35.1 \\
\hline 114 & 1 & 2 & $\mathrm{NE}$ & 11 & $92-102$ & shell & snail & 7 & 0.9 \\
\hline 114 & 2 & 2 & $\mathrm{NE}$ & 11 & $92-102$ & shell & snail & NA & 5.0 \\
\hline 114 & 3 & 2 & $\mathrm{NE}$ & 11 & $92-102$ & $\mathrm{C} 14$ & charcoal & NA & NW \\
\hline 114 & 4 & 2 & $\mathrm{NE}$ & 11 & $92-102$ & lithic & burned rock & 2 & 18.0 \\
\hline 114 & 5 & 2 & $\mathrm{NE}$ & 11 & $92-102$ & lithic & burned rock & 31 & 16.1 \\
\hline 114 & 6 & 2 & $\mathrm{NE}$ & 11 & $92-102$ & lithic & micro-debitage & 27 & 1.1 \\
\hline 114 & 7 & 2 & $\mathrm{NE}$ & 11 & $92-102$ & sediment & non cultural & & 39.2 \\
\hline 114 & 8 & 2 & $\mathrm{NE}$ & 11 & $92-102$ & bone & faunal & 1 & $<0.1$ \\
\hline 114 & 9 & 2 & $\mathrm{NE}$ & 11 & $92-102$ & $\mathrm{C} 14$ & charcoal & & $<0.1$ \\
\hline 114 & 10 & 2 & $\mathrm{NE}$ & 11 & $92-102$ & lithic & micro-debitage & 77 & 0.5 \\
\hline 114 & 11 & 2 & $\mathrm{NE}$ & 11 & $92-102$ & other & plastic & 1 & $<0.1$ \\
\hline 114 & 12 & 2 & $\mathrm{NE}$ & 11 & $92-102$ & sediment & non cultural & & 20.2 \\
\hline 114 & 13 & 2 & $\mathrm{NE}$ & 11 & $92-102$ & lithic & debitage & 32 & 9.1 \\
\hline 114 & 15 & 2 & $\mathrm{NE}$ & 11 & $92-102$ & lithic & burned rock & 32 & 27.5 \\
\hline 114 & 16 & 2 & $\mathrm{NE}$ & 11 & 92-102 & bone & faunal & 4 & $<0.1$ \\
\hline 114 & 16 & 2 & $\mathrm{NE}$ & 11 & 92-102 & lithic & other & 2 & 0.6 \\
\hline
\end{tabular}


Table A-6 (continued). Late Archaic I Artifacts from AU 4b.

\section{Lot Specimen Unit Quad Level $\begin{aligned} & \text { Depth } \\ & (\mathrm{cmbs})\end{aligned} \quad$ Class $\quad$ Type $\quad$ Count $\begin{gathered}\text { Weight } \\ \text { (g) }\end{gathered}$}

\begin{tabular}{|c|c|c|c|c|c|c|c|c|c|}
\hline 114 & 17 & 2 & $\mathrm{NE}$ & 11 & $92-102$ & sediment & non cultural & & 24.7 \\
\hline 114 & 18 & 2 & $\mathrm{NE}$ & 11 & $92-102$ & float sample & $<0.5 \mathrm{~mm}$ & & \\
\hline 114 & 19 & 2 & $\mathrm{NE}$ & 11 & $92-102$ & float sample & $>0.5 \mathrm{~mm}$ & & \\
\hline 114 & 20 & 2 & $\mathrm{NE}$ & 11 & $92-102$ & float sample & $>1 \mathrm{~mm}$ & & \\
\hline 114 & 21 & 2 & $\mathrm{NE}$ & 11 & $92-102$ & float sample & $>2 \mathrm{~mm}$ & & \\
\hline 114 & 22 & 2 & $\mathrm{NE}$ & 11 & 92-102 & bone & faunal & 1 & $<0.1$ \\
\hline 114 & 23 & 2 & $\mathrm{NE}$ & 11 & $92-102$ & bone & faunal & 9 & 0.1 \\
\hline 114 & 24 & 2 & $\mathrm{NE}$ & 11 & $92-102$ & bone & faunal & 8 & 0.3 \\
\hline 114 & 25 & 2 & $\mathrm{NE}$ & 11 & $92-102$ & bone & faunal & 1 & 0.1 \\
\hline 114 & 26 & 2 & $\mathrm{NE}$ & 11 & 92-102 & bone & faunal & 7 & 0.1 \\
\hline 114 & 27 & 2 & $\mathrm{NE}$ & 11 & $92-102$ & bone & faunal & 2 & $<0.1$ \\
\hline 114 & 28 & 2 & $\mathrm{NE}$ & 11 & $92-102$ & bone & faunal & & \\
\hline 114 & 29 & 2 & $\mathrm{NE}$ & 11 & 92-102 & bone & faunal & & \\
\hline 114 & 30 & 2 & $\mathrm{NE}$ & 11 & 92-102 & bone & faunal & & \\
\hline 114 & 31 & 2 & $\mathrm{NE}$ & 11 & $92-102$ & bone & faunal & & \\
\hline 114 & 32 & 2 & $\mathrm{NE}$ & 11 & $92-102$ & bone & faunal & & \\
\hline 114 & 33 & 2 & $\mathrm{NE}$ & 11 & $92-102$ & bone & faunal & & \\
\hline 129 & 1 & 10 & NW & 6 & $45-55$ & lithic & projectile point & 1 & 17.4 \\
\hline 129 & 2 & 10 & NW & 6 & $45-55$ & bone & faunal & 1 & 0.1 \\
\hline 129 & 3 & 10 & NW & 6 & $45-55$ & lithic & broken flake & 26 & 25.5 \\
\hline 129 & 4 & 10 & NW & 6 & $45-55$ & shell & snail & 2 & 1.8 \\
\hline 129 & 5 & 10 & NW & 6 & $45-55$ & lithic & burned rock & 4 & 36.1 \\
\hline 129 & 6 & 10 & NW & 6 & $45-55$ & lithic & uniface & 1 & 0.4 \\
\hline 129 & 7 & 10 & NW & 6 & $45-55$ & bone & faunal & 1 & 1.1 \\
\hline 129 & 8 & 10 & NW & 6 & $45-55$ & lithic & uniface & 1 & 2.1 \\
\hline 129 & 9 & 10 & NW & 6 & $45-55$ & lithic & complete flake & 4 & 9.9 \\
\hline 129 & 10 & 10 & NW & 6 & $45-55$ & lithic & proximal flake & 9 & 18.2 \\
\hline 152 & 1 & 3 & $\mathrm{NE}$ & 7 & $55-65$ & lithic & broken flake & 272 & 201.5 \\
\hline 152 & 2 & 3 & $\mathrm{NE}$ & 7 & $55-65$ & $\mathrm{C} 14$ & charcoal & NA & NW \\
\hline 152 & 3 & 3 & $\mathrm{NE}$ & 7 & $55-65$ & bone & faunal & 1 & 3.0 \\
\hline 152 & 4 & 3 & $\mathrm{NE}$ & 7 & $55-65$ & bone & faunal & 1 & 0.5 \\
\hline 152 & 5 & 3 & $\mathrm{NE}$ & 7 & $55-65$ & bone & faunal & 1 & 41.0 \\
\hline 152 & 6 & 3 & $\mathrm{NE}$ & 7 & $55-65$ & lithic & burned rock & 24 & $1,355.0$ \\
\hline 152 & 6 & 3 & $\mathrm{NE}$ & 7 & $55-65$ & lithic & burned rock & 6 & 19.5 \\
\hline 152 & 7 & 3 & $\mathrm{NE}$ & 7 & $55-65$ & lithic & biface & 1 & 41.0 \\
\hline 152 & 8 & 3 & $\mathrm{NE}$ & 7 & $55-65$ & other prehistoric & burned clay & 5 & 2.9 \\
\hline 152 & 9 & 3 & $\mathrm{NE}$ & 7 & $55-65$ & lithic & burned rock & 62 & 362.2 \\
\hline 152 & 10 & 3 & $\mathrm{NE}$ & 7 & $55-65$ & other & unsorted & & 56.0 \\
\hline 152 & 11 & 3 & $\mathrm{NE}$ & 7 & $55-65$ & sediment & non cultural & & 6.9 \\
\hline 152 & 12 & 3 & $\mathrm{NE}$ & 7 & $55-65$ & lithic & uniface & 1 & 4.5 \\
\hline 152 & 13 & 3 & $\mathrm{NE}$ & 7 & $55-65$ & bone & faunal & 1 & 3.6 \\
\hline 152 & 14 & 3 & $\mathrm{NE}$ & 7 & $55-65$ & lithic & burned rock & 5 & 6.3 \\
\hline
\end{tabular}


Table A-6 (continued). Late Archaic I Artifacts from AU 4b.

\section{Lot Specimen Unit Quad Level $\begin{aligned} & \text { Depth } \\ & \text { (cmbs) }\end{aligned} \quad$ Class $\quad$ Type $\quad$ Count $\begin{gathered}\text { Weight } \\ \text { (g) }\end{gathered}$}

\begin{tabular}{|c|c|c|c|c|c|c|c|c|c|}
\hline 152 & 15 & 3 & $\mathrm{NE}$ & 7 & $55-65$ & other prehistoric & burned clay & 31 & 3.0 \\
\hline 152 & 16 & 3 & $\mathrm{NE}$ & 7 & $55-65$ & shell & snail & & 16.9 \\
\hline 152 & 17 & 3 & $\mathrm{NE}$ & 7 & $55-65$ & bone & faunal & 1 & 0.1 \\
\hline 152 & 18 & 3 & $\mathrm{NE}$ & 7 & $55-65$ & lithic & uniface & 1 & 1.3 \\
\hline 152 & 19 & 3 & $\mathrm{NE}$ & 7 & $55-65$ & shell & snail & & 1.6 \\
\hline 152 & 20 & 3 & $\mathrm{NE}$ & 7 & $55-65$ & other prehistoric & burned clay & & 0.5 \\
\hline 152 & 21 & 3 & $\mathrm{NE}$ & 7 & $55-65$ & organic & other & & 0.1 \\
\hline 152 & 22 & 3 & $\mathrm{NE}$ & 7 & $55-65$ & sediment & other & & 73.7 \\
\hline 152 & 23 & 3 & $\mathrm{NE}$ & 7 & $55-65$ & sediment & non cultural & & $<0.1$ \\
\hline 152 & 24 & 3 & $\mathrm{NE}$ & 7 & $55-65$ & float sample & $<0.5 \mathrm{~mm}$ & & \\
\hline 152 & 25 & 3 & $\mathrm{NE}$ & 7 & $55-65$ & float sample & $>0.5 \mathrm{~mm}$ & & \\
\hline 152 & 26 & 3 & $\mathrm{NE}$ & 7 & $55-65$ & float sample & $>1 \mathrm{~mm}$ & & \\
\hline 152 & 27 & 3 & $\mathrm{NE}$ & 7 & $55-65$ & float sample & $>2 \mathrm{~mm}$ & & \\
\hline 152 & 28 & 3 & $\mathrm{NE}$ & 7 & $55-65$ & lithic & biface & 1 & 1.0 \\
\hline 152 & 29 & 3 & $\mathrm{NE}$ & 7 & $55-65$ & bone & faunal & 1 & 0.2 \\
\hline 152 & 30 & 3 & $\mathrm{NE}$ & 7 & $55-65$ & bone & faunal & 1 & 0.1 \\
\hline 152 & 31 & 3 & $\mathrm{NE}$ & 7 & $55-65$ & bone & faunal & 1 & 0.2 \\
\hline 152 & 32 & 3 & $\mathrm{NE}$ & 7 & $55-65$ & bone & faunal & 2 & 0.5 \\
\hline 152 & 33 & 3 & $\mathrm{NE}$ & 7 & $55-65$ & bone & faunal & 1 & 0.1 \\
\hline 152 & 34 & 3 & $\mathrm{NE}$ & 7 & $55-65$ & bone & faunal & 6 & 2.0 \\
\hline 152 & 35 & 3 & $\mathrm{NE}$ & 7 & $55-65$ & bone & faunal & 2 & 0.2 \\
\hline 152 & 36 & 3 & $\mathrm{NE}$ & 7 & $55-65$ & bone & faunal & 2 & 0.6 \\
\hline 152 & 37 & 3 & $\mathrm{NE}$ & 7 & $55-65$ & bone & faunal & 1 & 1.3 \\
\hline 152 & 38 & 3 & $\mathrm{NE}$ & 7 & $55-65$ & bone & faunal & 1 & 0.6 \\
\hline 152 & 39 & 3 & $\mathrm{NE}$ & 7 & $55-65$ & bone & faunal & 22 & 14.8 \\
\hline 152 & 40 & 3 & $\mathrm{NE}$ & 7 & $55-65$ & bone & faunal & 1 & 1.3 \\
\hline 152 & 41 & 3 & $\mathrm{NE}$ & 7 & $55-65$ & bone & faunal & 1 & 1.0 \\
\hline 152 & 42 & 3 & $\mathrm{NE}$ & 7 & $55-65$ & bone & faunal & 1 & 0.5 \\
\hline 152 & 43 & 3 & $\mathrm{NE}$ & 7 & $55-65$ & bone & faunal & 4 & 3.0 \\
\hline 152 & 44 & 3 & $\mathrm{NE}$ & 7 & $55-65$ & bone & faunal & 7 & 2.8 \\
\hline 152 & 45 & 3 & $\mathrm{NE}$ & 7 & $55-65$ & bone & faunal & 8 & 1.0 \\
\hline 152 & 46 & 3 & $\mathrm{NE}$ & 7 & $55-65$ & bone & faunal & 2 & 0.2 \\
\hline 152 & 47 & 3 & $\mathrm{NE}$ & 7 & $55-65$ & bone & faunal & 2 & 0.2 \\
\hline 152 & 48 & 3 & $\mathrm{NE}$ & 7 & $55-65$ & bone & faunal & 1 & $<0.1$ \\
\hline 152 & 49 & 3 & $\mathrm{NE}$ & 7 & $55-65$ & bone & faunal & 1 & $<0.1$ \\
\hline 152 & 50 & 3 & $\mathrm{NE}$ & 7 & $55-65$ & bone & faunal & 12 & 0.1 \\
\hline 152 & 51 & 3 & $\mathrm{NE}$ & 7 & $55-65$ & bone & faunal & 1 & $<0.1$ \\
\hline 152 & 52 & 3 & $\mathrm{NE}$ & 7 & $55-65$ & bone & faunal & 1 & $<0.1$ \\
\hline 152 & 53 & 3 & $\mathrm{NE}$ & 7 & $55-65$ & bone & faunal & 4 & $<0.1$ \\
\hline 152 & 54 & 3 & $\mathrm{NE}$ & 7 & $55-65$ & bone & faunal & 1 & $<0.1$ \\
\hline 152 & 55 & 3 & $\mathrm{NE}$ & 7 & $55-65$ & shell & snail & 1 & \\
\hline 152 & 56 & 4 & $\mathrm{NE}$ & 7 & $55-65$ & $\mathrm{C} 14$ & charcoal & & \\
\hline
\end{tabular}


Table A-6 (continued). Late Archaic I Artifacts from AU 4b.

Lot Specimen Unit Quad Level $\begin{aligned} & \text { Depth } \\ & \text { (cmbs) }\end{aligned} \quad$ Class $\quad$ Type Count $\begin{gathered}\text { Weight } \\ \text { (g) }\end{gathered}$

\begin{tabular}{|c|c|c|c|c|c|c|c|c|c|}
\hline 152 & 57 & 4 & $\mathrm{NE}$ & 7 & $55-65$ & organic & wood & 1 & 0.6 \\
\hline 152 & 58 & 4 & $\mathrm{NE}$ & 7 & $55-65$ & organic & other & 1 & 0.2 \\
\hline 152 & 59 & 3 & $\mathrm{NE}$ & 7 & $55-65$ & lithic & r-flake & 1 & 12.0 \\
\hline 152 & 60 & 3 & $\mathrm{NE}$ & 7 & $55-65$ & lithic & $\begin{array}{l}\text { burned non-flake } \\
\text { debitage }\end{array}$ & 17 & 19.5 \\
\hline 152 & 61 & 3 & $\mathrm{NE}$ & 7 & $55-65$ & lithic & DEB flake & 1 & 2.0 \\
\hline 152 & 62 & 3 & $\mathrm{NE}$ & 7 & $55-65$ & lithic & proximal flake & 70 & 47.4 \\
\hline 152 & 63 & 3 & $\mathrm{NE}$ & 7 & $55-65$ & lithic & complete flake & 31 & 38.0 \\
\hline 252 & 1 & 11 & - & 10 & $84-94$ & bone & Testudines & 1 & $<0.1$ \\
\hline 252 & 2 & 11 & - & 10 & $84-94$ & bone & $\begin{array}{l}\text { Artiodactyla, } \\
\text { medium }\end{array}$ & 1 & 5.8 \\
\hline 252 & 3 & 11 & - & 10 & $84-94$ & bone & Homo sapiens & 1 & 0.5 \\
\hline 252 & 4 & 11 & - & 10 & $84-94$ & lithic & debitage & 67 & 112.2 \\
\hline 252 & 5 & 11 & - & 10 & $84-94$ & shell & snail & 41 & 14.6 \\
\hline 252 & 6 & 11 & - & 10 & $84-94$ & lithic & burned rock & 18 & 73.5 \\
\hline 252 & 7 & 11 & - & 10 & $84-94$ & lithic & projectile point & 1 & 6.5 \\
\hline 252 & 8 & 11 & - & 10 & $84-94$ & shell & snail & 15 & 12.0 \\
\hline 252 & 9 & 11 & - & 10 & $84-94$ & lithic & burned rock & 5 & 35.5 \\
\hline 252 & 10 & 11 & - & 10 & $84-94$ & lithic & debitage & 84 & 62.2 \\
\hline 252 & 11 & 11 & - & 10 & $84-94$ & lithic & burned rock & 6 & 42.2 \\
\hline 252 & 12 & 11 & - & 10 & $84-94$ & shell & snail & 19 & 16.5 \\
\hline 252 & 13 & 11 & - & 10 & $84-94$ & bone & Bison & 1 & 5.4 \\
\hline 252 & 14 & 11 & - & 10 & $84-94$ & bone & Mammalia & 1 & 0.3 \\
\hline 252 & 15 & 11 & - & 10 & $84-94$ & bone & Mammalia & 2 & 1.0 \\
\hline 252 & 16 & 11 & - & 10 & $84-94$ & bone & Testudines & 1 & 0.2 \\
\hline 252 & 17 & 11 & - & 10 & $84-94$ & bone & Mammalia & 5 & 1.3 \\
\hline 293 & 1 & 8 & NW & 11 & $80-85$ & bone & faunal & 1 & 24.0 \\
\hline 293 & 2 & 8 & NW & 11 & $80-85$ & bone & faunal & 1 & 0.2 \\
\hline 293 & 3 & 8 & NW & 11 & $80-85$ & lithic & broken flake & 44 & 91.6 \\
\hline 293 & 4 & 8 & NW & 11 & $80-85$ & lithic & complete flake & 8 & 38.8 \\
\hline 293 & 5 & 8 & NW & 11 & $80-85$ & lithic & proximal flake & 8 & 6.1 \\
\hline 293 & 6 & 8 & NW & 11 & $80-85$ & lithic & uniface & 1 & 14.0 \\
\hline 293 & 7 & 8 & NW & 11 & $80-85$ & lithic & burned rock & 3 & 25.9 \\
\hline 293 & 8 & 8 & NW & 11 & $80-85$ & bone & faunal & 1 & 0.4 \\
\hline 293 & 9 & 8 & NW & 11 & $80-85$ & lithic & DEB flake & 2 & 1.5 \\
\hline 293 & 10 & 8 & NW & 11 & $80-85$ & bone & faunal & 1 & 0.1 \\
\hline 293 & 11 & 8 & NW & 11 & $80-85$ & bone & faunal & 1 & 0.9 \\
\hline 293 & 12 & 8 & NW & 11 & $80-85$ & bone & faunal & 2 & 0.2 \\
\hline 293 & 13 & 8 & NW & 11 & $80-85$ & bone & faunal & 2 & 0.5 \\
\hline 293 & 14 & 8 & NW & 11 & $80-85$ & lithic & other & 1 & 0.5 \\
\hline 538 & 1 & 3 & $\mathrm{NE}$ & 7 & $55-65$ & other & non cultural & NA & 13.3 \\
\hline 538 & 2 & 3 & $\mathrm{NE}$ & 7 & $55-65$ & sediment & unsorted & NA & 36.1 \\
\hline
\end{tabular}


Table A-6 (continued). Late Archaic I Artifacts from AU 4b.

Lot Specimen Unit Quad Level $\begin{gathered}\text { Depth } \\ \text { (cmbs) }\end{gathered} \quad$ Class $\quad$ Type $\quad$ Count $\begin{gathered}\text { Weight } \\ \text { (g) }\end{gathered}$

\begin{tabular}{|c|c|c|c|c|c|c|c|c|c|}
\hline 538 & 3 & 3 & $\mathrm{NE}$ & 7 & $55-65$ & lithic & broken flake & 27 & 11.0 \\
\hline 538 & 4 & 3 & $\mathrm{NE}$ & 7 & $55-65$ & bone & faunal & 1 & 0.1 \\
\hline 538 & 5 & 3 & $\mathrm{NE}$ & 7 & $55-65$ & lithic & burned rock & 3 & 2.7 \\
\hline 538 & 6 & 3 & $\mathrm{NE}$ & 7 & $55-65$ & other prehistoric & burned clay & 12 & 2.2 \\
\hline 538 & 7 & 3 & $\mathrm{NE}$ & 7 & $55-65$ & shell & snail & NA & 11.8 \\
\hline 538 & 8 & 3 & $\mathrm{NE}$ & 7 & $55-65$ & other & non cultural & NA & 44.0 \\
\hline 538 & 9 & 3 & $\mathrm{NE}$ & 7 & $55-65$ & lithic & debitage & 123 & 0.3 \\
\hline 538 & 10 & 3 & $\mathrm{NE}$ & 7 & $55-65$ & bone & faunal & 9 & $<0.1$ \\
\hline 538 & 11 & 3 & $\mathrm{NE}$ & 7 & $55-65$ & C14 & charcoal & NA & 0.1 \\
\hline 538 & 12 & 3 & $\mathrm{NE}$ & 7 & $55-65$ & other & plastic & 1 & $<0.1$ \\
\hline 538 & 13 & 3 & $\mathrm{NE}$ & 7 & $55-65$ & lithic & complete flake & 11 & 2.8 \\
\hline 538 & 14 & 3 & $\mathrm{NE}$ & 7 & $55-65$ & lithic & proximal flake & 1 & 1.3 \\
\hline 538 & 15 & 3 & $\mathrm{NE}$ & 7 & $55-65$ & lithic & burned chert & 2 & $<0.1$ \\
\hline 538 & 15 & 3 & $\mathrm{NE}$ & 7 & $55-65$ & lithic & burned chert & 2 & $<0.1$ \\
\hline 538 & 15 & 3 & $\mathrm{NE}$ & 7 & $55-65$ & lithic & burned chert & 2 & $<0.1$ \\
\hline 538 & 16 & 3 & $\mathrm{NE}$ & 7 & $55-65$ & bone & faunal & 1 & $<0.1$ \\
\hline 538 & 17 & 3 & $\mathrm{NE}$ & 7 & $55-65$ & bone & faunal & 43 & 0.1 \\
\hline 538 & 18 & 3 & $\mathrm{NE}$ & 7 & $55-65$ & bone & faunal & 2 & $<0.1$ \\
\hline 538 & 18 & 3 & $\mathrm{NE}$ & 7 & $55-65$ & organic & & 28 & 0.1 \\
\hline 538 & 19 & 3 & $\mathrm{NE}$ & 7 & $55-65$ & bone & faunal & 4 & $<0.1$ \\
\hline 538 & 20 & 3 & $\mathrm{NE}$ & 7 & $55-65$ & bone & faunal & 3 & $<0.1$ \\
\hline 538 & 21 & 3 & $\mathrm{NE}$ & 7 & $55-65$ & bone & faunal & 4 & 0.6 \\
\hline 538 & 22 & 3 & $\mathrm{NE}$ & 7 & $55-65$ & bone & faunal & 1 & $<0.1$ \\
\hline 538 & 23 & 3 & $\mathrm{NE}$ & 7 & $55-65$ & bone & faunal & 5 & 0.5 \\
\hline 538 & 24 & 3 & $\mathrm{NE}$ & 7 & $55-65$ & bone & faunal & 87 & 0.3 \\
\hline 538 & 25 & 3 & $\mathrm{NE}$ & 7 & $55-65$ & lithic & burned chert & 2 & $<0.1$ \\
\hline 538 & 26 & 3 & $\mathrm{NE}$ & 7 & $55-65$ & lithic & burned chert & 2 & $<0.1$ \\
\hline 538 & 27 & 3 & $\mathrm{NE}$ & 7 & $55-65$ & lithic & burned chert & 2 & $<0.1$ \\
\hline 583 & 1 & 2 & $\mathrm{NE}$ & 10 & $82-92$ & lithic & complete flake & 4 & $<0.1$ \\
\hline 583 & 2 & 2 & $\mathrm{NE}$ & 10 & $82-92$ & bone & faunal & 1 & $<0.1$ \\
\hline 583 & 3 & 2 & $\mathrm{NE}$ & 10 & $82-92$ & $\mathrm{C} 14$ & charcoal & & $<0.1$ \\
\hline 583 & 4 & 2 & $\mathrm{NE}$ & 10 & $82-92$ & lithic & burned rock & 2 & 4.9 \\
\hline 583 & 5 & 2 & $\mathrm{NE}$ & 10 & $82-92$ & sediment & non cultural & & 19.3 \\
\hline 583 & 6 & 2 & $\mathrm{NE}$ & 10 & $82-92$ & float sample & $<0.5 \mathrm{~mm}$ & & \\
\hline 583 & 7 & 2 & $\mathrm{NE}$ & 10 & $82-92$ & float sample & $>0.5 \mathrm{~mm}$ & & \\
\hline 583 & 8 & 2 & $\mathrm{NE}$ & 10 & $82-92$ & float sample & $>1 \mathrm{~mm}$ & & \\
\hline 583 & 9 & 2 & $\mathrm{NE}$ & 10 & $82-92$ & float sample & $>2 \mathrm{~mm}$ & & \\
\hline 583 & 10 & 2 & $\mathrm{NE}$ & 10 & $82-92$ & lithic & proximal flake & 2 & 0.1 \\
\hline 583 & 11 & 2 & $\mathrm{NE}$ & 10 & $82-92$ & lithic & broken flake & 12 & $<0.1$ \\
\hline 583 & 12 & 2 & $\mathrm{NE}$ & 10 & $82-92$ & lithic & burned chert & 2 & 0.3 \\
\hline 583 & 13 & 2 & $\mathrm{NE}$ & 10 & $82-92$ & lithic & notching flake & 1 & $<0.1$ \\
\hline 583 & 14 & 2 & $\mathrm{NE}$ & 10 & $82-92$ & bone & faunal & 1 & $<0.1$ \\
\hline
\end{tabular}


Table A-6 (continued). Late Archaic I Artifacts from AU 4b.

\begin{tabular}{|c|c|c|c|c|c|c|c|c|c|}
\hline Lot & Specimen & Unit & Quad & Level & $\begin{array}{l}\text { Depth } \\
\text { (cmbs) }\end{array}$ & Class & Type & Count & $\begin{array}{c}\text { Weight } \\
\text { (g) }\end{array}$ \\
\hline 586 & 1 & 2 & $\mathrm{NE}$ & 11 & 92-102 & lithic & debitage & 10 & 1.0 \\
\hline 586 & 2 & 2 & $\mathrm{NE}$ & 11 & 92-102 & lithic & burned rock & 1 & 42.9 \\
\hline 586 & 3 & 2 & $\mathrm{NE}$ & 11 & $92-102$ & sediment & non cultural & & 20.3 \\
\hline 586 & 4 & 2 & $\mathrm{NE}$ & 11 & $92-102$ & float sample & $<0.5 \mathrm{~mm}$ & & \\
\hline 586 & 5 & 2 & $\mathrm{NE}$ & 11 & $92-102$ & float sample & $>0.5 \mathrm{~mm}$ & & \\
\hline 586 & 6 & 2 & $\mathrm{NE}$ & 11 & $92-102$ & float sample & $>1 \mathrm{~mm}$ & & \\
\hline \multirow[t]{2}{*}{586} & 7 & 2 & $\mathrm{NE}$ & 11 & 92-102 & float sample & $>2 \mathrm{~mm}$ & & \\
\hline & & & & & & & Total & 2,035 & $9,661.0$ \\
\hline
\end{tabular}


Table A-7. Middle Archaic Artifacts from AU 5.

\begin{tabular}{|c|c|c|c|c|c|c|c|c|c|}
\hline Lot & Specimen & Unit & Quad & Level & $\begin{array}{c}\text { Top } \\
\text { Depth } \\
\text { (cmbs) }\end{array}$ & Class & Type & Count & $\begin{array}{c}\text { Weight } \\
\text { (g) }\end{array}$ \\
\hline 29 & 1 & 1 & SE & 11 & $92-102$ & shell & snail & 3 & 1.9 \\
\hline 29 & 2 & 1 & $\mathrm{SE}$ & 11 & $92-102$ & bone & faunal & 1 & 0.6 \\
\hline 29 & 3 & 1 & SE & 11 & $92-102$ & lithic & biface & 1 & 42.1 \\
\hline 29 & 4 & 1 & SE & 11 & $92-102$ & lithic & projectile point & 1 & 7.8 \\
\hline 164 & 1 & 3 & $\mathrm{NE}$ & 14 (1998) & $125-135$ & bone & faunal & 1 & 2.3 \\
\hline 164 & 2 & 3 & $\mathrm{NE}$ & 14 (1998) & $125-135$ & lithic & uniface & 1 & 0.8 \\
\hline 164 & 3 & 3 & $\mathrm{NE}$ & 14 (1998) & $125-135$ & lithic & complete flake & 2 & 8.6 \\
\hline 164 & 4 & 3 & $\mathrm{NE}$ & 14 (1998) & $125-135$ & shell & snail & 9 & 8.5 \\
\hline 164 & 5 & 3 & $\mathrm{NE}$ & 14 (1998) & $125-135$ & $\mathrm{C} 14$ & charcoal & NA & 2.9 \\
\hline 164 & 6 & 3 & $\mathrm{NE}$ & 14 (1998) & $125-135$ & lithic & burned rock & 10 & 151.9 \\
\hline 164 & 8 & 3 & $\mathrm{NE}$ & 14 (1998) & $125-135$ & lithic & burned rock & 1 & 92.5 \\
\hline 164 & 9 & 3 & $\mathrm{NE}$ & 14 (1998) & $125-135$ & lithic & burned rock & 1 & 43.0 \\
\hline 164 & 10 & 3 & $\mathrm{NE}$ & 14 (1998) & $125-135$ & organic & rhizolith & 2 & 0.9 \\
\hline 164 & 11 & 3 & $\mathrm{NE}$ & 14 (1998) & $125-135$ & lithic & proximal flake & 1 & 0.3 \\
\hline 164 & 12 & 3 & $\mathrm{NE}$ & 14 (1998) & $125-135$ & lithic & broken flake & 6 & 5.1 \\
\hline 164 & 13 & 3 & $\mathrm{NE}$ & 14 (1998) & $125-135$ & lithic & uniface & 1 & 0.6 \\
\hline 164 & 14 & 3 & $\mathrm{NE}$ & 14 (1998) & $125-135$ & lithic & uniface & 1 & 0.2 \\
\hline 279 & 1 & 8 & NW & 14 & $95-100$ & bone & unknown & 45 & 19.8 \\
\hline 279 & 2 & 8 & NW & 14 & $95-100$ & bone & faunal & 1 & 0.9 \\
\hline 279 & 2 & 8 & NW & 14 & $95-100$ & bone & faunal & 1 & 2.4 \\
\hline 279 & 3 & 8 & NW & 14 & $95-100$ & bone & unknown & 2 & 4.5 \\
\hline 279 & 4 & 8 & NW & 14 & $95-100$ & lithic & burned rock & 7 & 560.0 \\
\hline 279 & 5 & 8 & NW & 14 & $95-100$ & lithic & biface & 1 & 219.5 \\
\hline 279 & 6 & 8 & NW & 14 & $95-100$ & lithic & broken flake & 97 & 91.5 \\
\hline 279 & 7 & 8 & NW & 14 & $95-100$ & shell & snail & 42 & 38.0 \\
\hline 279 & 8 & 8 & NW & 14 & $95-100$ & lithic & burned rock & 20 & 91.0 \\
\hline 279 & 9 & 8 & NW & 14 & $95-100$ & bone & unknown & 2 & 6.0 \\
\hline 279 & 10 & 8 & NW & 14 & $95-100$ & lithic & complete flake & 27 & 21.5 \\
\hline 279 & 11 & 8 & NW & 14 & $95-100$ & lithic & proximal flake & 36 & 22.5 \\
\hline 279 & 12 & 8 & NW & 14 & $95-100$ & lithic & burned non-flake debitage & 6 & 2.5 \\
\hline 279 & 13 & 8 & NW & 14 & $95-100$ & lithic & r-flake & 2 & 0.8 \\
\hline 284 & 1 & 8 & NW & 20 & $130-135$ & bone & faunal & 1 & 3.1 \\
\hline 284 & 1 & 8 & NW & 21 & $150-155$ & bone & faunal & 1 & 0.2 \\
\hline 284 & 2 & 8 & NW & 21 & $140-145$ & lithic & broken flake & 13 & 56.8 \\
\hline 284 & 3 & 8 & NW & 21 & $140-145$ & sediment & soil sample & NA & 445.3 \\
\hline 284 & 4 & 8 & NW & 21 & $140-145$ & lithic & proximal flake & 6 & 7.1 \\
\hline 284 & 5 & 8 & NW & 21 & $140-145$ & shell & snail & 36 & 25.2 \\
\hline 284 & 6 & 8 & NW & 21 & $140-145$ & lithic & burned rock & 14 & 464.0 \\
\hline 284 & 7 & 8 & NW & 21 & $140-145$ & lithic & complete flake & 4 & 25.0 \\
\hline 284 & 8 & 8 & NW & 21 & $140-145$ & lithic & burned non-flake debitage & 8 & 23.1 \\
\hline 310 & 1 & 8 & NW & 20 & $130-135$ & bone & faunal & 1 & 0.3 \\
\hline 310 & 2 & 8 & NW & 20 & $130-135$ & bone & faunal & 1 & 0.2 \\
\hline
\end{tabular}


Table A-7 (continued). Middle Archaic Artifacts from AU 5.

\begin{tabular}{|c|c|c|c|c|c|c|c|c|c|}
\hline Lot & Specimen & Unit & Quad & Level & $\begin{array}{c}\text { Top } \\
\text { Depth } \\
\text { (cmbs) }\end{array}$ & Class & Type & Count & $\begin{array}{c}\text { Weight } \\
\text { (g) }\end{array}$ \\
\hline 310 & 3 & 8 & NW & 20 & $130-135$ & lithic & burned rock & 12 & 334.7 \\
\hline 310 & 5 & 8 & NW & 20 (1998) & $190-200$ & lithic & debitage & 3 & 2.7 \\
\hline 310 & 5 & 8 & NW & 20 & $130-135$ & lithic & debitage & 32 & 42.3 \\
\hline 310 & 5 & 8 & NW & 20 & $130-135$ & lithic & broken flake & 16 & 6.5 \\
\hline 310 & 6 & 8 & NW & 20 & $130-135$ & shell & snail & 52 & 42.3 \\
\hline 310 & 7 & 8 & NW & 20 & $130-135$ & lithic & burned rock & 11 & 237.0 \\
\hline 310 & 8 & 8 & NW & 20 & $130-135$ & $\mathrm{C} 14$ & charcoal & 2 & NW \\
\hline 310 & 9 & 8 & NW & 20 & $130-135$ & lithic & other & 2 & 3.3 \\
\hline 310 & 10 & 8 & NW & 20 & $130-135$ & lithic & burned rock & 11 & 177.9 \\
\hline 310 & 11 & 8 & NW & 20 & $130-135$ & bone & faunal & 1 & 5 \\
\hline 310 & 12 & 8 & NW & 20 & $130-135$ & lithic & uniface & 1 & 125.7 \\
\hline 310 & 13 & 8 & NW & 20 & $130-135$ & lithic & biface & 1 & 41.1 \\
\hline 310 & 14 & 8 & NW & 20 & $130-135$ & lithic & uniface & 1 & 17.7 \\
\hline 310 & 15 & 8 & NW & 20 & $130-135$ & lithic & biface & 1 & 3.7 \\
\hline 310 & 16 & 8 & NW & 20 & $130-135$ & lithic & biface & 1 & 6.1 \\
\hline 310 & 17 & 8 & NW & 20 & $130-135$ & lithic & biface & 1 & 9.3 \\
\hline 310 & 18 & 8 & NW & 20 & $130-135$ & lithic & biface & 1 & 5.0 \\
\hline 310 & 19 & 8 & NW & 20 & $130-135$ & lithic & biface & 1 & 8.3 \\
\hline 310 & 20 & 8 & NW & 20 & $130-135$ & lithic & biface & 1 & 19.6 \\
\hline 310 & 21 & 8 & NW & 20 & $130-135$ & lithic & complete flake & 7 & 16.6 \\
\hline 310 & 22 & 8 & NW & 20 & $130-135$ & lithic & proximal flake & 10 & 20.2 \\
\hline 310 & 23 & 8 & NW & 20 & $130-135$ & lithic & burned non-flake debitage & 1 & 1.1 \\
\hline 310 & 24 & 8 & NW & 20 & $130-135$ & lithic & burned rock & 1 & 110.3 \\
\hline 310 & 25 & 8 & NW & 20 & $130-135$ & lithic & burned rock & 1 & 122.1 \\
\hline 310 & 26 & 8 & NW & 20 & $130-135$ & organic & rhizolith & 1 & 0.4 \\
\hline 310 & 27 & 8 & NW & 20 & $130-135$ & bone & faunal & 2 & 3.3 \\
\hline 310 & 28 & 8 & NW & 20 & $130-135$ & bone & faunal & 1 & 0.8 \\
\hline 310 & 29 & 8 & NW & 20 & $130-135$ & bone & faunal & 8 & 9.4 \\
\hline 310 & 30 & 8 & NW & 20 & $130-135$ & bone & faunal & 1 & 0.1 \\
\hline \multirow[t]{2}{*}{310} & 31 & 8 & NW & 20 & $130-135$ & bone & faunal & 1 & 5.5 \\
\hline & & & & & & & Total & 601 & $3,879.2$ \\
\hline
\end{tabular}




\section{Appendix B}

\section{RADIOCARBON ASSAYS FROM $41 \mathrm{HY} 165$ \\ EXCAVATIONS}




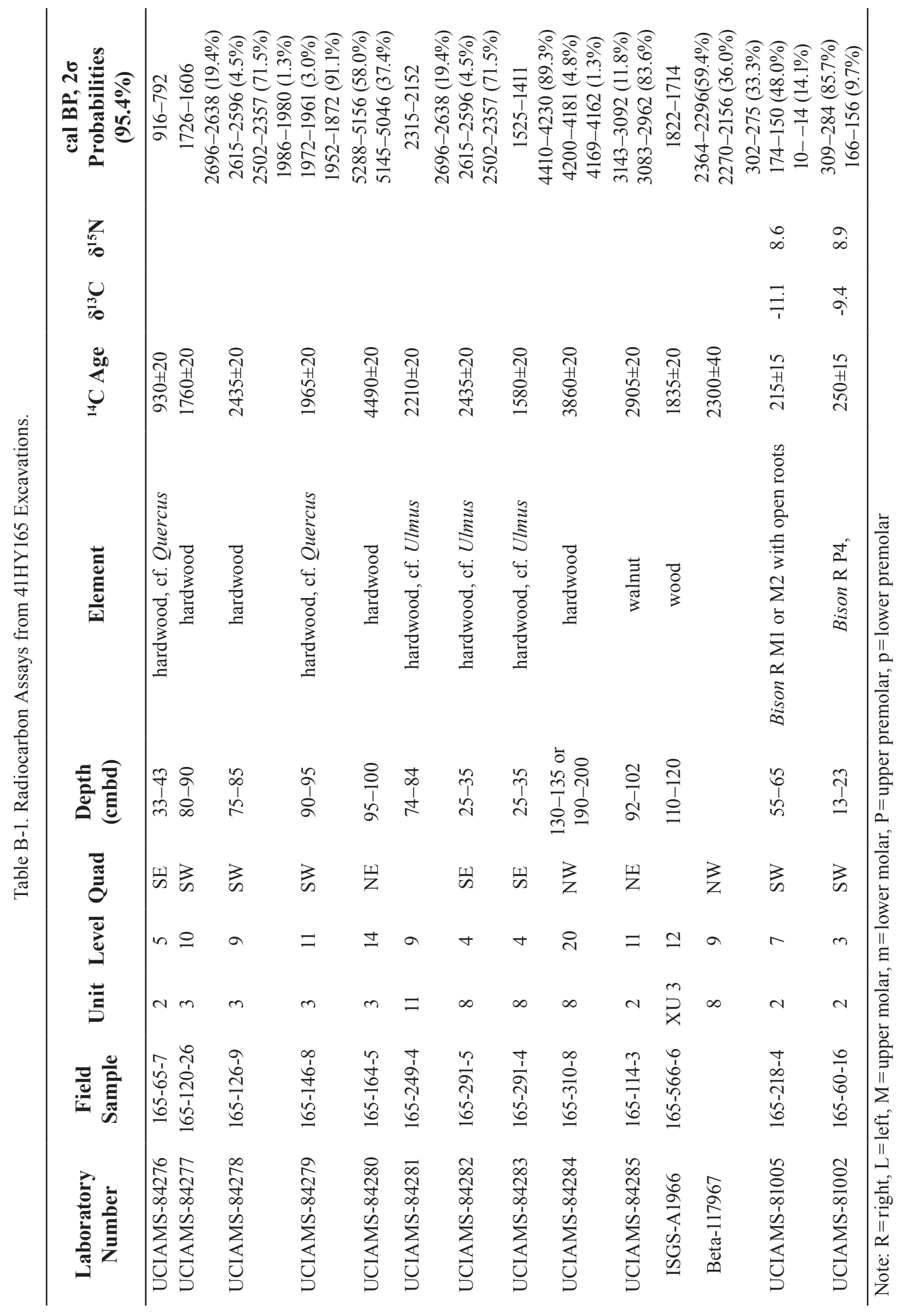




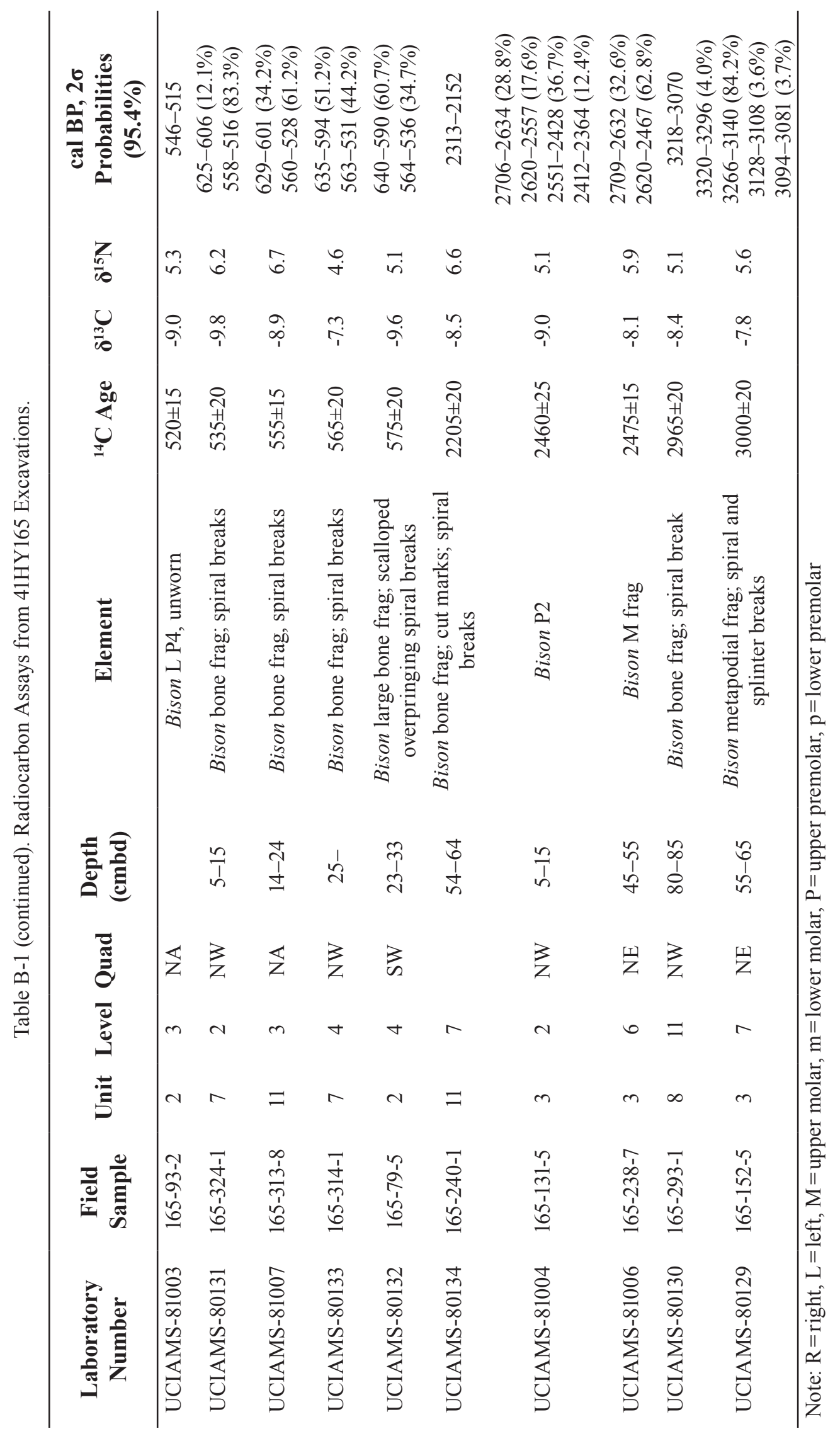




\section{Appendix C}

\section{Lithic Analysis Tables}




\begin{tabular}{|c|c|c|c|c|c|c|c|c|c|c|c|c|c|}
\hline 同 & $\stackrel{m}{-}$ & $\stackrel{\check{g}}{\curvearrowright}$ & $\underset{n}{\stackrel{n}{n}}$ & $\stackrel{\mathbb{O}}{\stackrel{0}{0}}$ & $\overrightarrow{\tilde{n}}$ & I & ' & I & $\underset{\forall}{\exists}$ & $\begin{array}{l}\infty \\
i \\
i\end{array}$ & $\stackrel{o}{i}$ & $\stackrel{\sim}{+}$ & 1 \\
\hline 空 & $\begin{array}{l}\tilde{\hat{~}} \\
\text { ה }\end{array}$ & $\mid \begin{array}{l}\text { fo } \\
\stackrel{+}{\sim}\end{array}$ & $\begin{array}{l}\vec{n} \\
\dot{ \pm}\end{array}$ & $\begin{array}{l}\vec{\sigma} \\
\infty \\
-\end{array}$ & $\underset{\sigma}{\overrightarrow{6}}$ & $\begin{array}{l}n \\
\infty \\
-1\end{array}$ & $\begin{array}{l}\hat{\widehat{\vartheta}} \\
\underline{6}\end{array}$ & $\mid \begin{array}{l}\infty \\
\ddot{n}\end{array}$ & $\begin{array}{l}n \\
\infty \\
\end{array}$ & $\underset{\hat{\sigma}}{\sigma}$ & $\begin{array}{l}\stackrel{o}{0} \\
\stackrel{\infty}{-}\end{array}$ & 亩 & 1 \\
\hline 氞 & $\begin{array}{l}0 \\
\infty \\
\infty\end{array}$ & ' & $\begin{array}{c}n \\
\tilde{n} \\
n\end{array}$ & 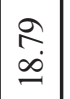 & $\begin{array}{l}\stackrel{g}{+} \\
\stackrel{\oplus}{g}\end{array}$ & $\begin{array}{l}\hat{\sigma} \\
\dot{0}\end{array}$ & $\begin{array}{l}\hat{\widehat{N}} \\
\stackrel{0}{ }\end{array}$ & $\mid \begin{array}{l}0 \\
0 \\
0 \\
0\end{array}$ & $\begin{array}{l}\tilde{\sigma} \\
\dot{d} \\
-\end{array}$ & $\ddot{n}$ & $\stackrel{\hat{2}}{\stackrel{2}{2}}$ & ' & $\stackrel{\grave{\lambda}}{\grave{\lambda}}$ \\
\hline क 臣 & $\begin{array}{l}0 \\
n \\
a\end{array}$ & ' & 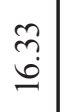 & $\stackrel{?}{=}$ & 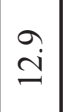 & $\begin{array}{l}n \\
0 \\
0 \\
0\end{array}$ & $\begin{array}{l}\vec{\infty} \\
\stackrel{\Xi}{=}\end{array}$ & $\vec{\nabla}$ & $\begin{array}{l}\hat{b} \\
\dot{ \pm}\end{array}$ & $\begin{array}{l}0 \\
m \\
n \\
n\end{array}$ & $\stackrel{\circ}{\circ}$ & ' & $\begin{array}{l}\hat{\sigma} \\
\stackrel{2}{0}\end{array}$ \\
\hline$\geqslant 00$ & $\stackrel{m}{n}$ & $\begin{array}{l}\sim \\
\ddot{n} \\
\ddot{Z}\end{array}$ & ণֶ. & $\begin{array}{l}\infty \\
\check{\simeq}\end{array}$ & $\stackrel{0}{-}$ & $\stackrel{\infty}{\stackrel{0}{r}}$ & $\begin{array}{l}+ \\
\infty \\
\infty\end{array}$ & $\stackrel{+}{n}$ & 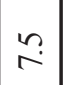 & $=$ & $\stackrel{+}{\stackrel{\Delta}{\Xi}}$ & $\stackrel{9}{-}$ & $\infty$ \\
\hline$\sum \widehat{\Xi}$ & \begin{tabular}{l}
0 \\
\multirow{2}{*}{} \\
$\stackrel{i}{0}$
\end{tabular} & $\overrightarrow{\stackrel{\vec{\lambda}}{\Delta}}$ & , & $\vec{m}$ & , & 守 & 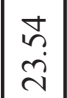 & 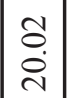 & $\begin{array}{l}\tilde{m} \\
\tilde{n} \\
0 \\
\tilde{N}\end{array}$ & $\begin{array}{l}\hat{6} \\
\dot{0}\end{array}$ & $\begin{array}{l}\vec{t} \\
\dot{d} \\
\dot{n}\end{array}$ & , & $\begin{array}{l}\text { aे } \\
\dot{m}\end{array}$ \\
\hline 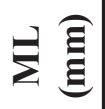 & ' & ' & & & & $\begin{array}{l}\infty \\
0 \\
\dot{0} \\
i\end{array}$ & $\frac{\sigma}{i}$ & ' & $\overrightarrow{\tilde{n}}$ & $\frac{1}{3}$ & $\frac{\mathbb{R}}{\pi}$ & ' & 1 \\
\hline$-\widehat{\underline{\mathrm{E}}}$ & $\begin{array}{l}8 \\
0 \\
0\end{array}$ & $\stackrel{\infty}{\stackrel{\infty}{\curvearrowright}}$ & 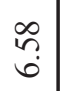 & $\left|\begin{array}{l}\infty \\
\infty \\
\infty\end{array}\right|$ & 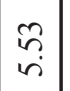 & $\underset{⿱}{\stackrel{J}{\sim}}$ & $\stackrel{0}{\stackrel{0}{+}}$ & $\left|\begin{array}{l}\hat{\alpha} \\
\infty\end{array}\right|$ & $\vec{m}$ & స్తి & ते & $\stackrel{\vartheta}{\sigma}$ & $\stackrel{๋}{\curvearrowright}$ \\
\hline & 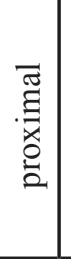 & 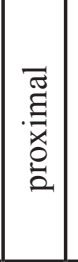 & 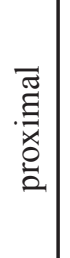 & 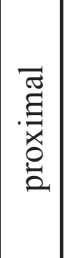 & 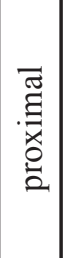 & \begin{tabular}{|l}
$\frac{0}{0}$ \\
$\frac{0}{2}$ \\
0 \\
0
\end{tabular} & 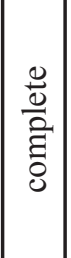 & 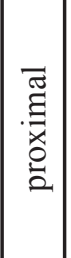 & $\begin{array}{l}\frac{0}{0} \\
\frac{0}{2} \\
\overline{0} \\
0\end{array}$ & $\begin{array}{l}\frac{0}{0} \\
\frac{0}{2} \\
\text { : } \\
0\end{array}$ & $\begin{array}{l}\frac{0}{0} \\
\frac{0}{0} \\
\overline{0} \\
0\end{array}$ & 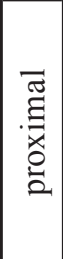 & $\begin{array}{l}\text { चే } \\
\text { : } \\
\text { : } \\
\vdots\end{array}$ \\
\hline 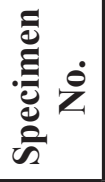 & $\stackrel{\overrightarrow{1}}{\beth}$ & ì & $\begin{array}{l}\vec{b} \\
\stackrel{\jmath}{ }\end{array}$ & $\begin{array}{l}\frac{1}{1} \\
0 \\
-1\end{array}$ & $\begin{array}{c}T \\
\dot{J}\end{array}$ & $\begin{array}{l}+ \\
\dot{a} \\
\text { ปे }\end{array}$ & $\frac{n}{\infty}$ & $\begin{array}{l}0 \\
0 \\
1 \\
0 \\
n \\
n\end{array} \mid$ & à & 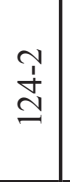 & ปิ & $\frac{N}{m}$ & 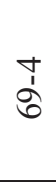 \\
\hline$\stackrel{0}{0}^{2}$ & 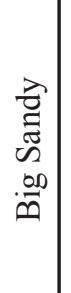 & 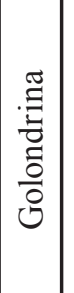 & $\begin{array}{l}\overrightarrow{0} \\
0 \\
0 \\
0\end{array}$ & 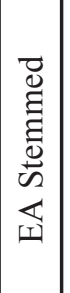 & 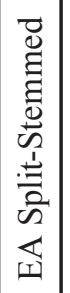 & & 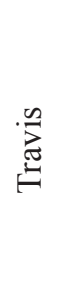 & & & $\begin{array}{l}\frac{y}{\pi} \\
\frac{0}{0} \\
\frac{0}{0}\end{array}$ & & & 总 \\
\hline 总 & & & 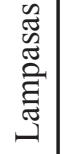 & & & & $\begin{array}{l}0 \\
0 \\
0 \\
0\end{array}$ & & & $\begin{array}{l}0 \\
0 \\
0 \\
0\end{array}$ & & & ' \\
\hline & 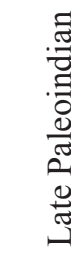 & 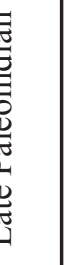 & & 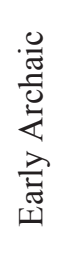 & & & 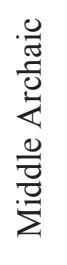 & & & & 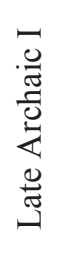 & & \\
\hline
\end{tabular}




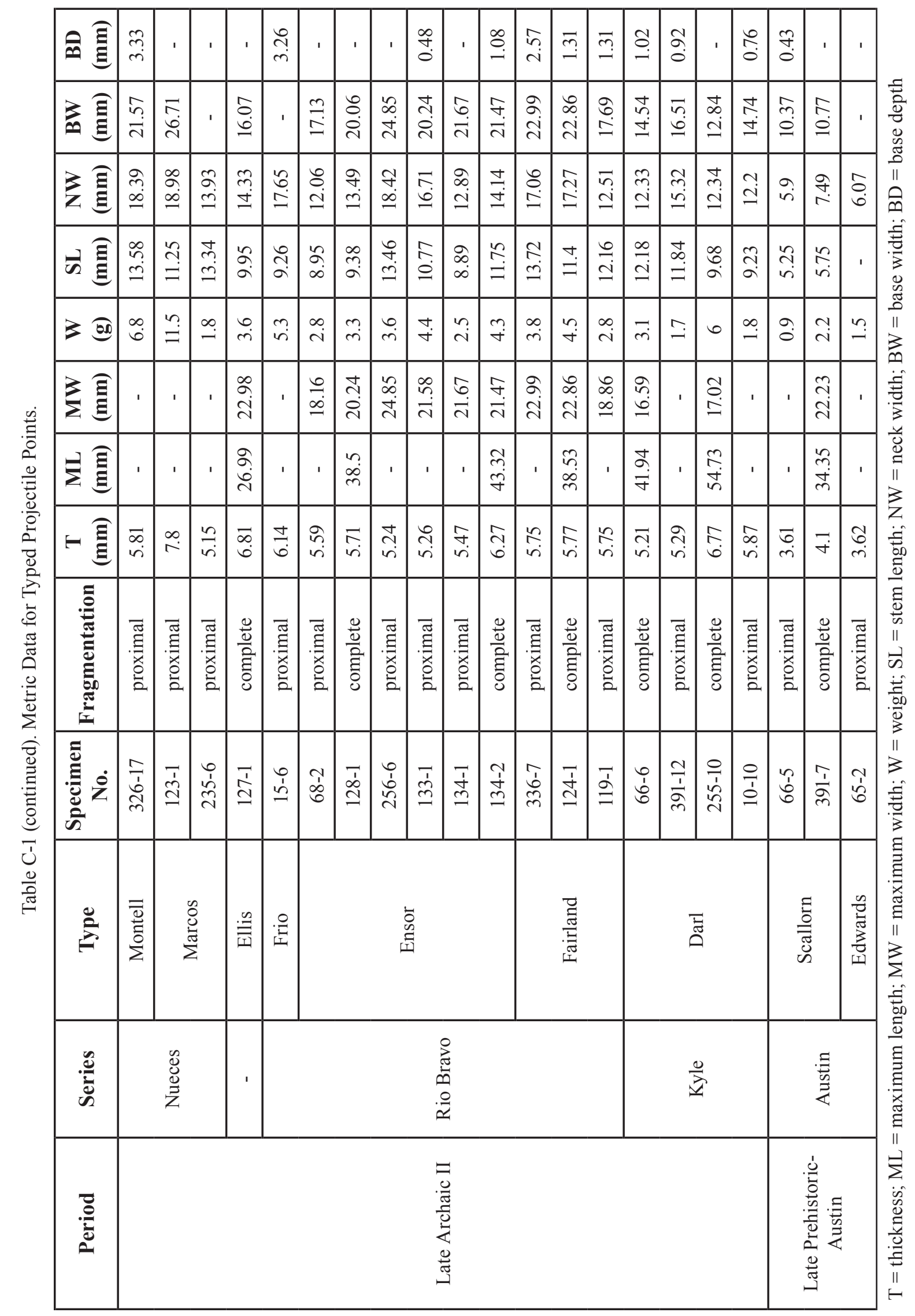




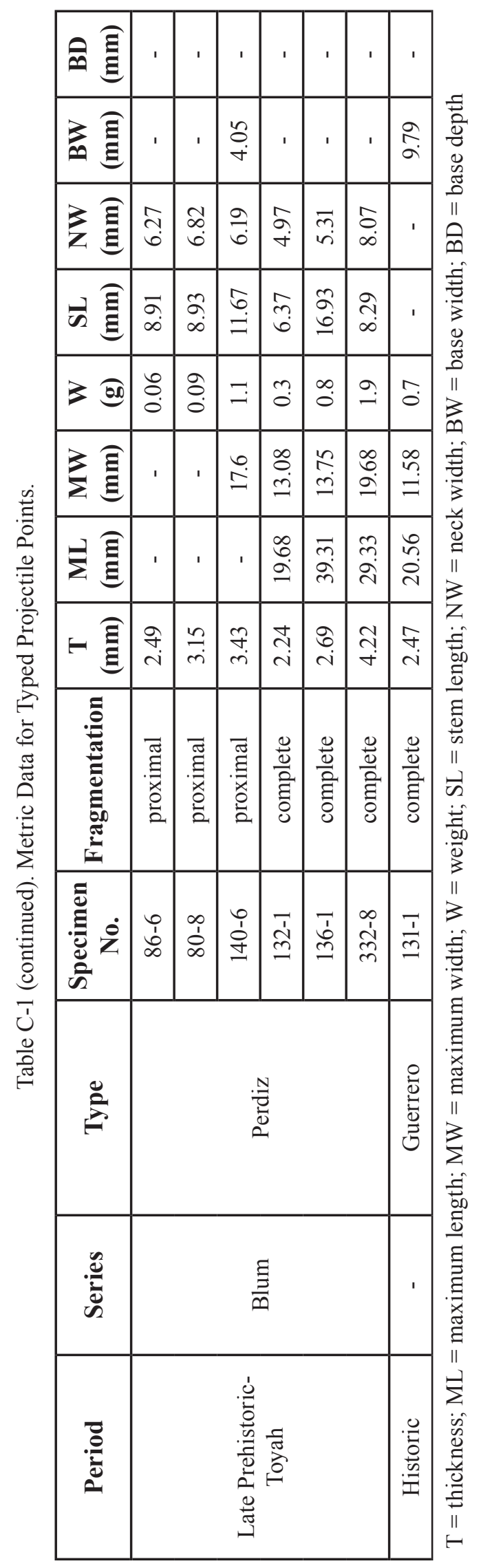




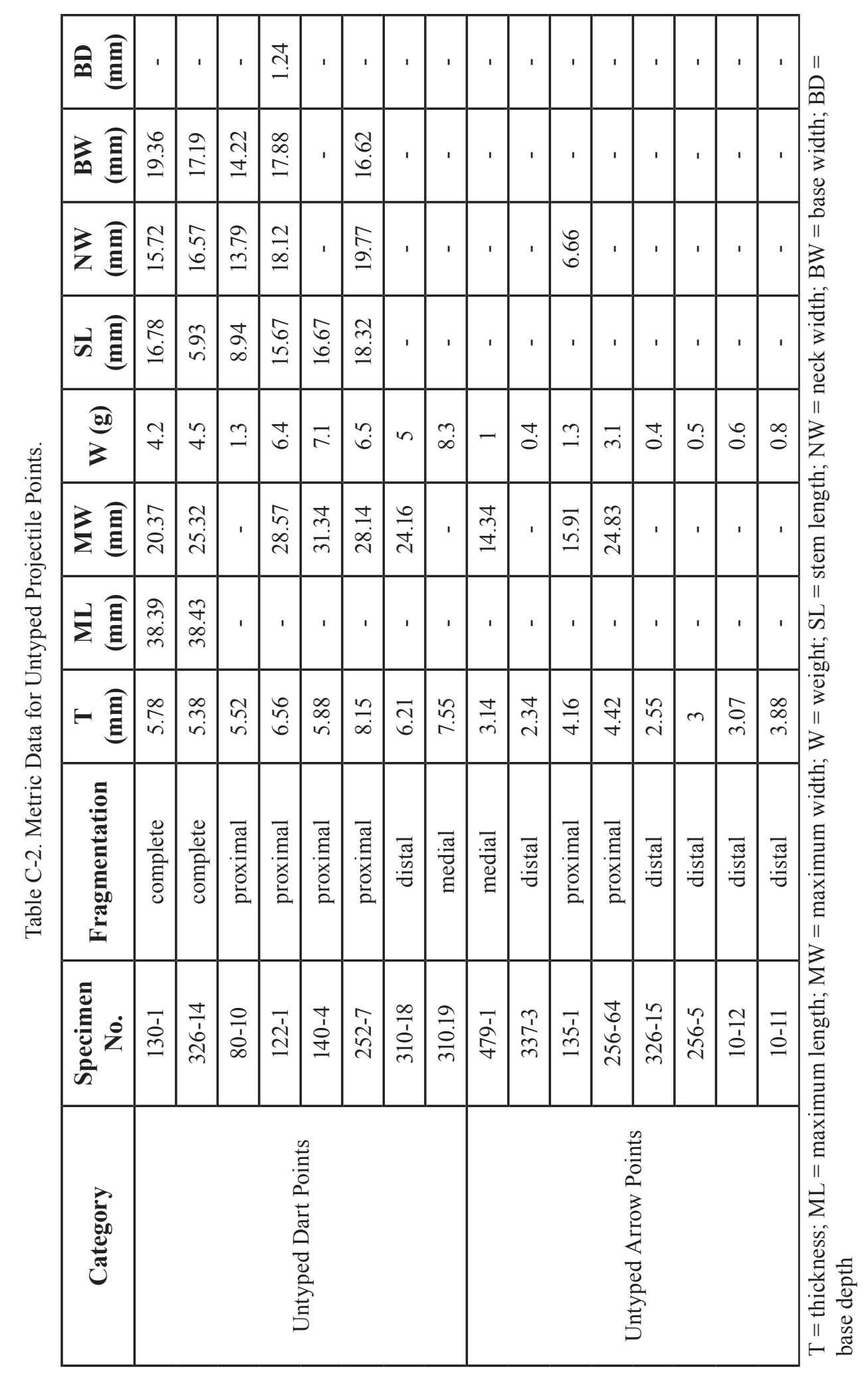




\begin{tabular}{|c|c|c|c|c|c|c|c|c|c|c|c|c|c|c|c|c|c|}
\hline \multirow{4}{*}{ 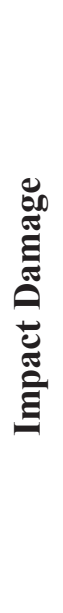 } & 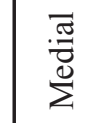 & ' & ' & & & U & 1 & 1 & $n$ & ' & & 10 & 1 & & 1 in & $\begin{array}{lll}n & 1\end{array}$ & ' \\
\hline & $\begin{array}{l}\frac{n}{\tilde{d}} \\
\frac{0}{0} \\
\frac{0}{n}\end{array}$ & 1 & ' & $\begin{array}{l}m \\
\dot{n}\end{array}$ & & ' & 1 & u & 1 & \begin{tabular}{l|l}
1 & 0
\end{tabular} & 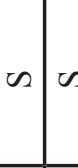 & 21 & 0 & is & $\infty 1$ & \begin{tabular}{l|l}
1 & 1
\end{tabular} & 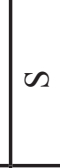 \\
\hline & $\begin{array}{l}0 \\
\tilde{D} \\
\ddot{D} \\
\ddot{n}\end{array}$ & ' & I & & & ' & $\infty$ & 0 & ' & $\infty$ & 1 & 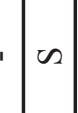 & $\infty$ & $\left|\begin{array}{c}0 \\
\tilde{n}\end{array}\right|$ & \begin{tabular}{l|l}
$u$ & s \\
$\tilde{n}^{\prime}$ &
\end{tabular} & $n 1$ & $\infty$ \\
\hline & $\cong$ & $\begin{array}{c}m \\
\dot{\omega}\end{array}$ & $\begin{array}{l}\boldsymbol{L} \\
\dot{\omega}\end{array}$ & $\infty$ & $\begin{array}{l}\dot{1} \\
\dot{s}\end{array}$ & ' & ' & $\infty$ & 1 & ' & ' & 1 & $\begin{array}{l}n \\
\omega^{\prime}\end{array}$ & $\begin{array}{l}u \\
\dot{n}\end{array}$ & $\infty 1$ & ' & $\begin{array}{l}L \\
\text { is }\end{array}$ \\
\hline \multirow{5}{*}{ 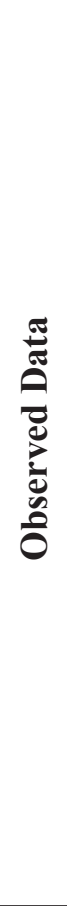 } & 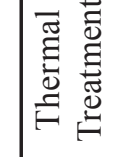 & z & $\mathrm{Z}$ & $\mathrm{z}$ & Z & $\lambda$ & Z & Z & z & z & $z / z$ & $z$ & $\mathrm{z}$ & Z & $\mathrm{z} / \mathrm{z}$ & $\mathrm{z} / \mathrm{z}$ & z \\
\hline & 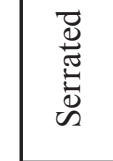 & Z & $\mathrm{Z}$ & Z & $\lambda$ & ' & z & Z & Z & z & $z \mid>$ & $-1 z$ & $\mathrm{z}$ & Z & Z & ' $\mathrm{Z}$ & z \\
\hline & 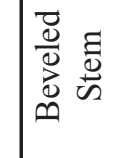 & z & $\mathrm{z}$ & $\mathrm{Z}$ & Z & ' & $\mathrm{z}$ & $\mathrm{z}$ & $>1$ & Z & $z / z$ & 21 & z & $\mathrm{z}$ & $>z$ & $\mathrm{Z}:>$ & z \\
\hline & 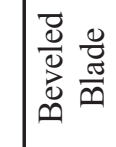 & 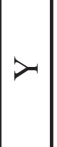 & Z & $\mathrm{Z}$ & Z & ' & $\lambda$ & Z & ' & $>1$ & $>1>$ & $\begin{array}{lll}-1 & 1\end{array}$ & $\mathrm{z}$ & Z & Z & \begin{tabular}{l|l}
1 & 1
\end{tabular} & $\lambda$ \\
\hline & 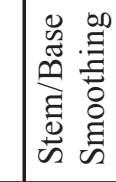 & z & $\lambda$ & $\lambda$ & $\lambda$ & $\lambda$ & $>1$ & $\lambda$ & $\mathrm{z}$ & $>2$ & $z \mid>$ & $-z$ & $\lambda$ & Z & $z \mid>$ & Z & 7 \\
\hline \multicolumn{2}{|c|}{ 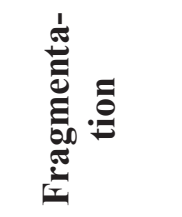 } & 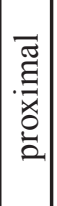 & 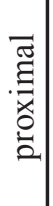 & 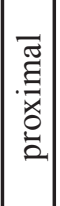 & 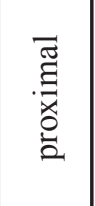 & 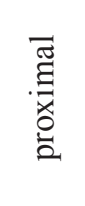 & 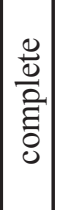 & $\mid \begin{array}{l}\frac{0}{0} \\
\frac{0}{2} \\
\stackrel{2}{\Xi} \\
0 \\
0\end{array}$ & 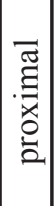 & $\begin{array}{l}\frac{0}{0} \\
\frac{0}{0} \\
\text { : } \\
\text { ठ }\end{array}$ & 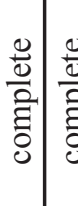 & 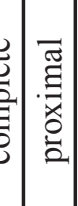 & 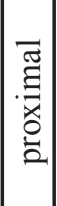 & 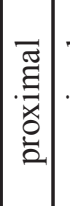 & 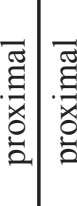 & 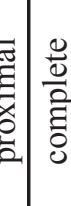 & 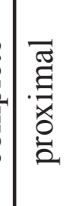 \\
\hline \multicolumn{2}{|c|}{ 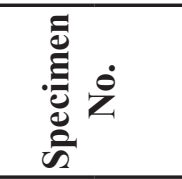 } & $\stackrel{I}{I}$ & $\overrightarrow{\grave{\beth}}$ & $\begin{array}{l}\vec{b} \\
\stackrel{0}{N}\end{array}$ & $\frac{\sqrt{1}}{n}$ & $\begin{array}{r}\tilde{J} \\
\dot{J}\end{array}$ & $\begin{array}{l}\dot{1} \\
\stackrel{2}{2}\end{array}$ & $\frac{r}{\infty}$ & $\begin{array}{l}0 \\
1 \\
b \\
\sim \\
\sim\end{array}$ & $\begin{array}{l}ت \\
\stackrel{1}{c}\end{array}$ & 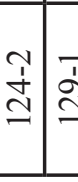 & 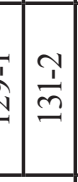 & $\begin{array}{c}7 \\
0 \\
0 \\
0\end{array}$ & 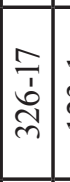 & 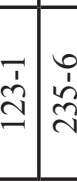 & 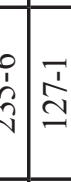 & $\begin{array}{l}0 \\
1 \\
\end{array}$ \\
\hline \multicolumn{2}{|c|}{$\sum_{\text {Dે }}^{\infty}$} & 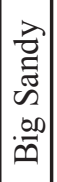 & 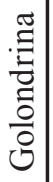 & \begin{tabular}{|l|} 
\\
$\overrightarrow{0}$ \\
$\vdots$ \\
0 \\
0
\end{tabular} & 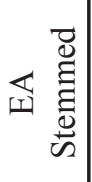 & 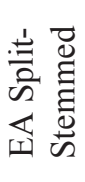 & & $\sum_{\stackrel{⿹}{\leftrightarrows}}^{\infty}$ & & & 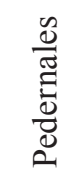 & & 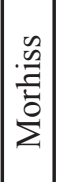 & $\mid \begin{array}{l}\overline{0} \\
\stackrel{0}{0} \\
\stackrel{0}{\Sigma}\end{array}$ & 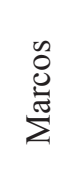 & $\stackrel{\text { 竎 }}{ }$ &.$\stackrel{9}{9}$ \\
\hline
\end{tabular}




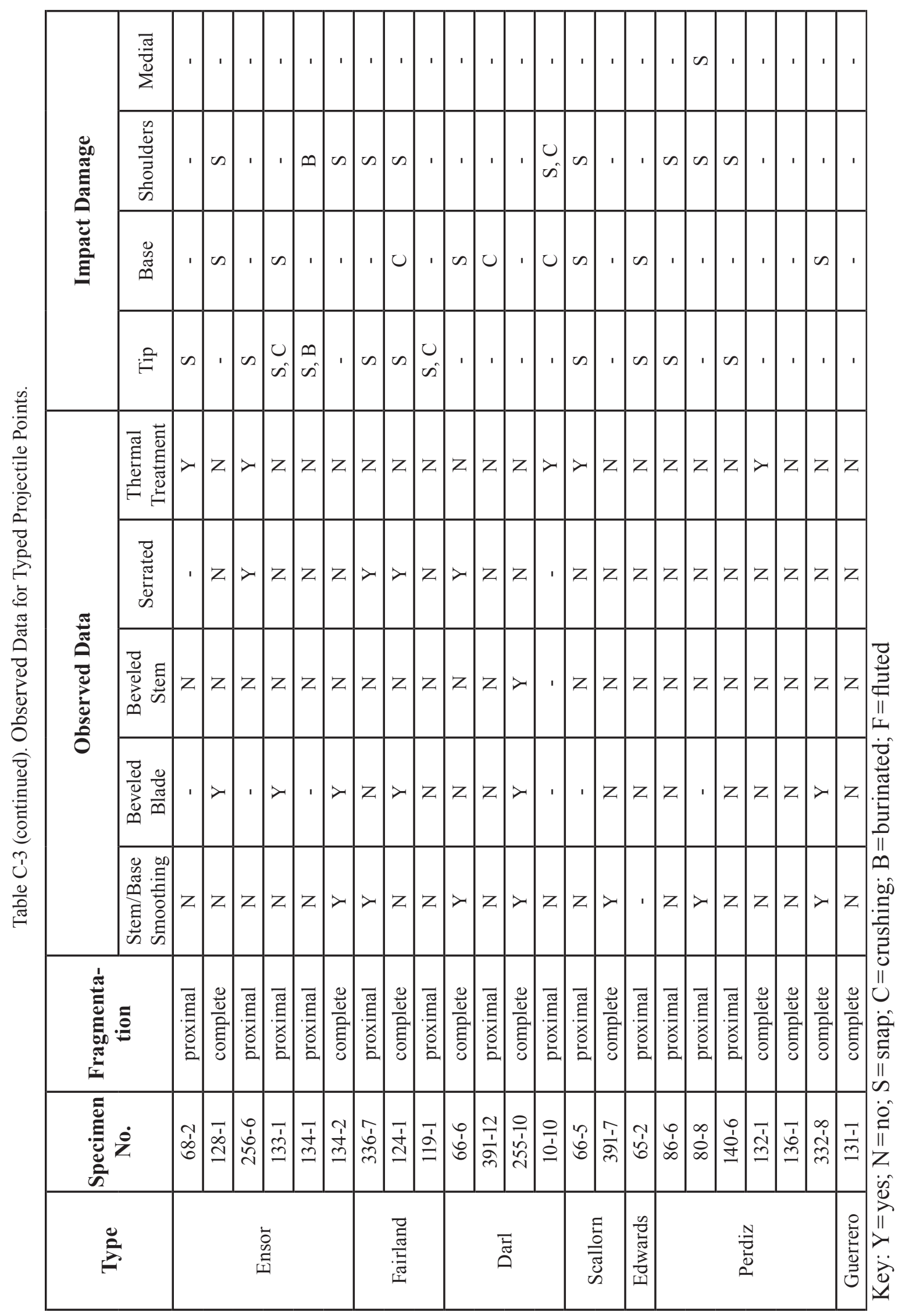




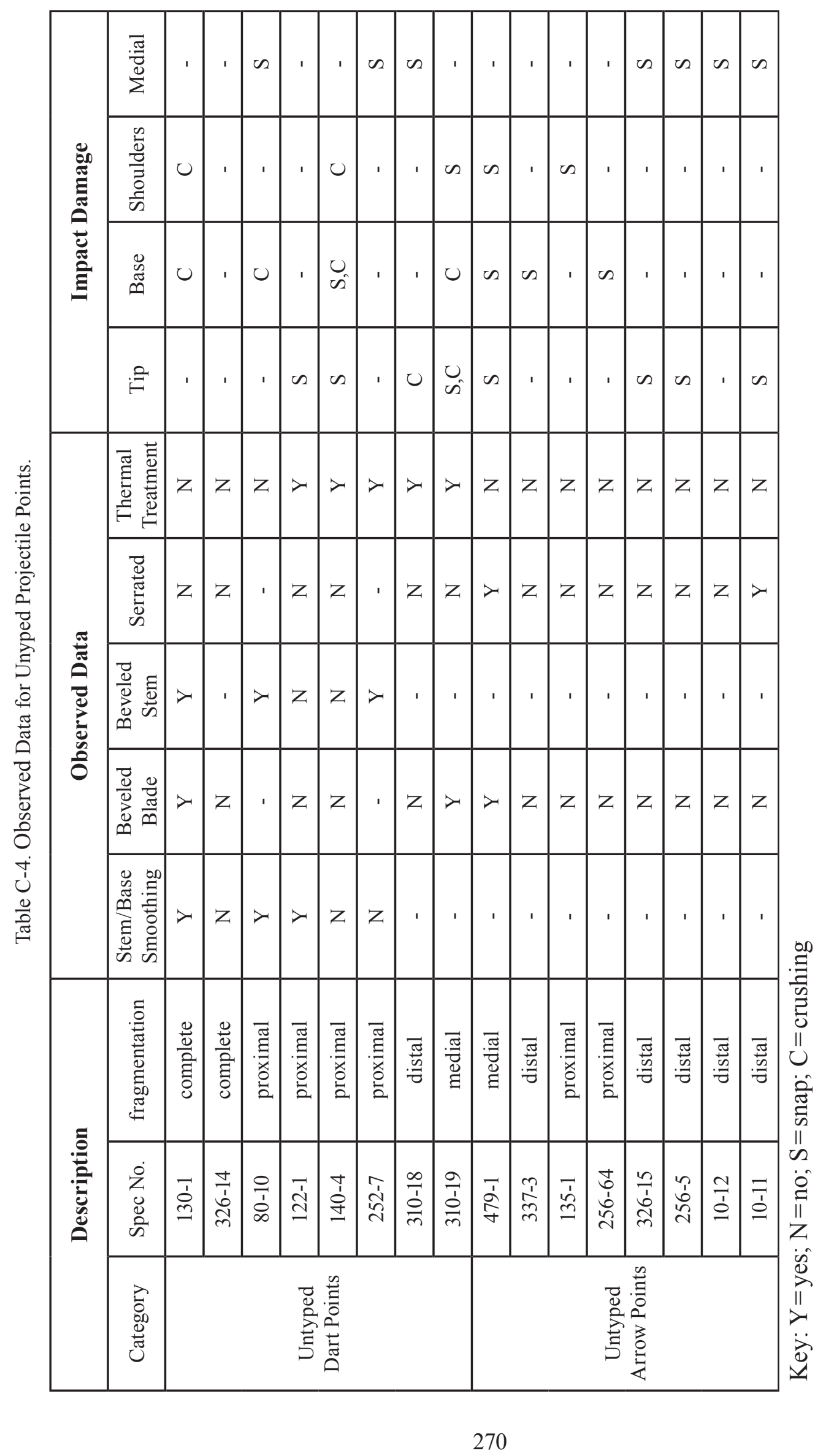


Table C-5. Metric Measurements for Reduction-Stage Bifaces.

\begin{tabular}{|c|c|c|c|c|c|c|c|}
\hline Reduction Stage & $\begin{array}{c}\text { Specimen } \\
\text { No. }\end{array}$ & $\mathbf{A U}$ & $\begin{array}{c}\text { ML } \\
(\mathbf{m m})\end{array}$ & $\begin{array}{l}\text { MW } \\
(\mathbf{m m})\end{array}$ & $\begin{array}{c}\text { MT } \\
(\mathbf{m m})\end{array}$ & $\begin{array}{c}\text { W/T } \\
\text { Ratio }\end{array}$ & W (g) \\
\hline \multirow{6}{*}{ Intermediate } & $238-5$ & $4 a$ & 61.48 & 52.31 & 15.31 & 3.42 & 9.20 \\
\hline & $256-2$ & $4 a$ & 73.10 & 42.65 & 21.72 & 1.96 & 53.10 \\
\hline & $152-7$ & $4 b$ & - & - & 7.19 & - & 41.00 \\
\hline & $29-3$ & 5 & - & - & 19.17 & - & 42.10 \\
\hline & $279-5$ & 5 & 124.56 & 84.24 & 22.91 & 3.68 & 219.50 \\
\hline & $310-20$ & 5 & - & 34.93 & 11.67 & 2.99 & 19.60 \\
\hline \multirow{4}{*}{ Late Intermediate } & $238-6$ & $4 a$ & - & - & 7.30 & - & 9.00 \\
\hline & $256-3$ & $4 a$ & - & - & 9.36 & - & 10.00 \\
\hline & $310-13$ & 5 & 80.11 & 34.36 & 17.48 & 1.97 & 41.10 \\
\hline & $310-17$ & 5 & - & 27.88 & 7.08 & 3.94 & 9.30 \\
\hline \multirow{4}{*}{ Late } & $238-8$ & $4 a$ & - & - & 4.85 & - & 2.60 \\
\hline & $256-16$ & $4 a$ & - & - & 3.53 & - & 1.00 \\
\hline & $291-5$ & $4 a$ & - & - & 5.63 & - & 3.30 \\
\hline & $310-16$ & 5 & - & - & 4.91 & - & 6.10 \\
\hline
\end{tabular}

$\mathrm{ML}=$ maximum length; $\mathrm{MW}=$ maximum width; $\mathrm{MT}=$ maximum thickness; $\mathrm{W} / \mathrm{T}$ Ratio $=$ width to thickness ratio; $\mathrm{W}=$ weight

Table C-6. Metric Measurements for Biface Fragments.

\begin{tabular}{|c|c|c|}
\hline Specimen No. & Analytical Unit & Weight (g) \\
\hline $131-14$ & 2 & 3.2 \\
\hline $131-31$ & 2 & 8.5 \\
\hline $79-7$ & $3 \mathrm{a}$ & 0.8 \\
\hline $65-8$ & $3 \mathrm{~b}$ & 1.4 \\
\hline $66-9$ & $3 \mathrm{~b}$ & 0.5 \\
\hline $123-10$ & $4 \mathrm{a}$ & 2.3 \\
\hline $287-9$ & $4 \mathrm{a}$ & 2.2 \\
\hline $287-22$ & $4 \mathrm{a}$ & 2.0 \\
\hline
\end{tabular}




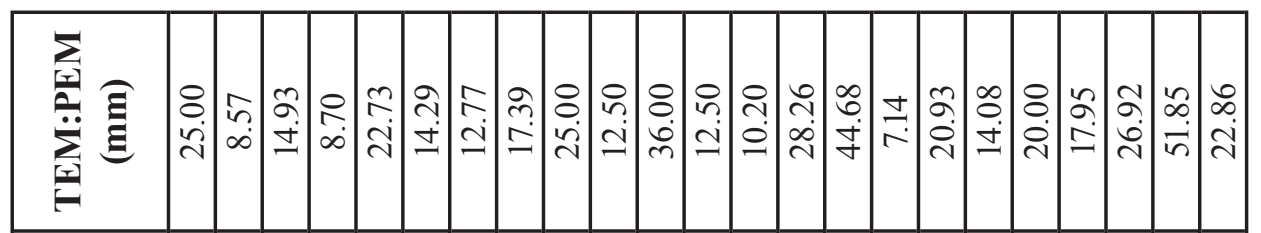

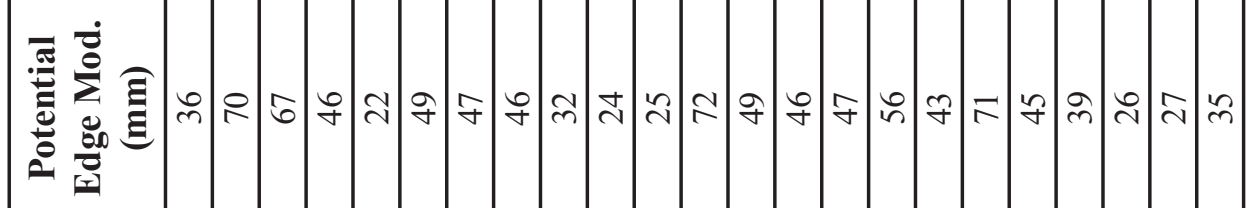

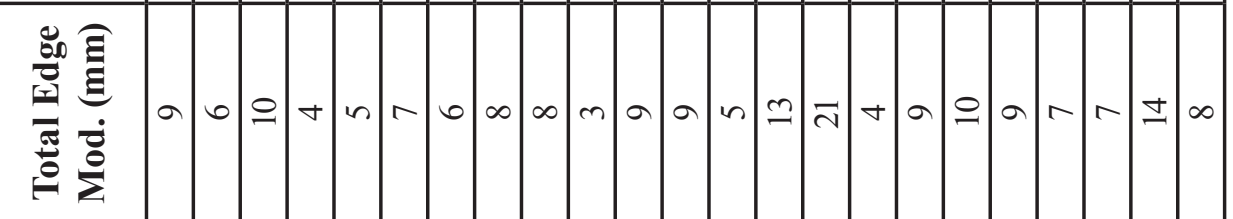

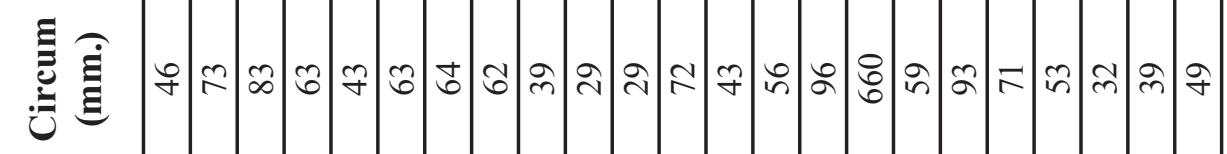

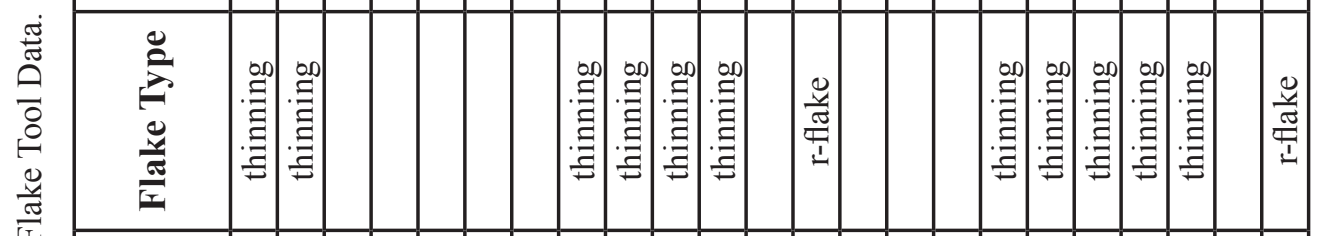
0
0
0
0
0
0
0
0
0
0
0
0
0

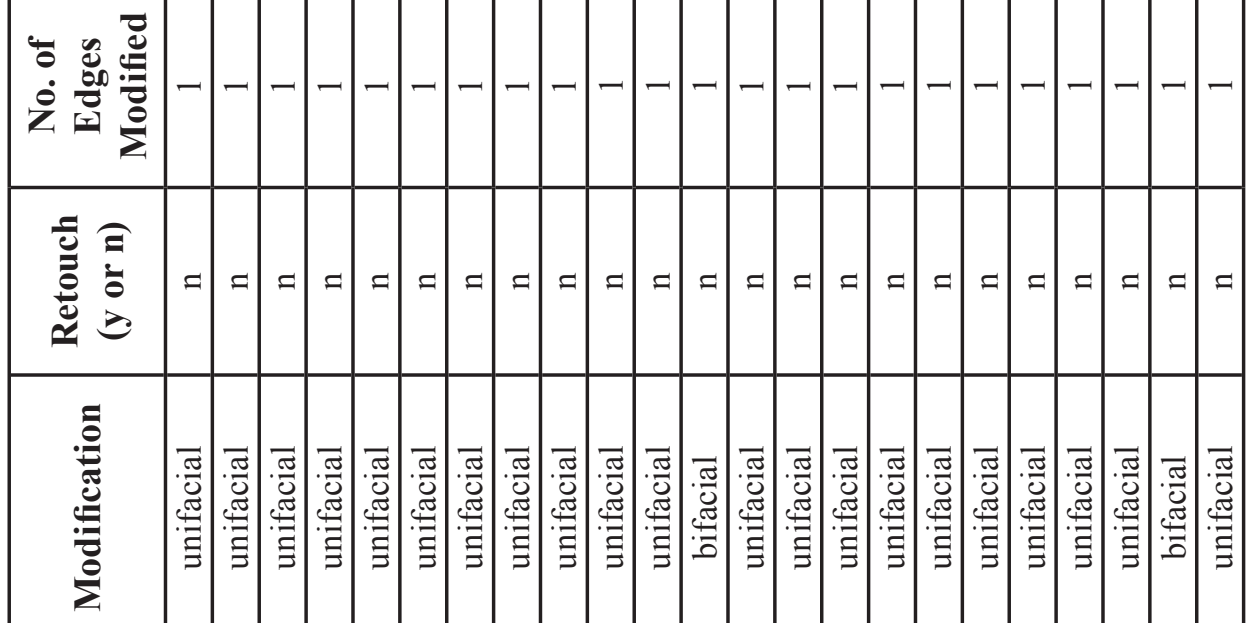

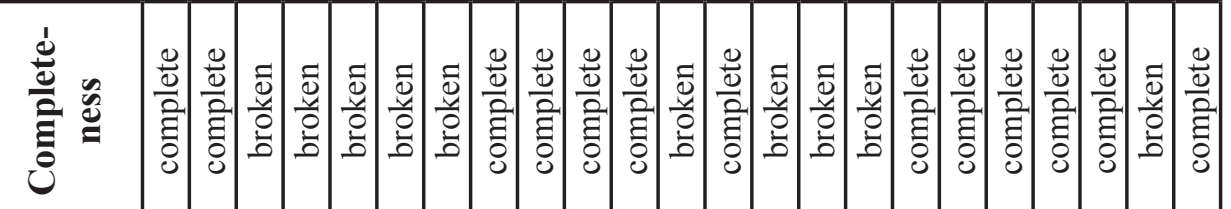

岪安

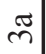




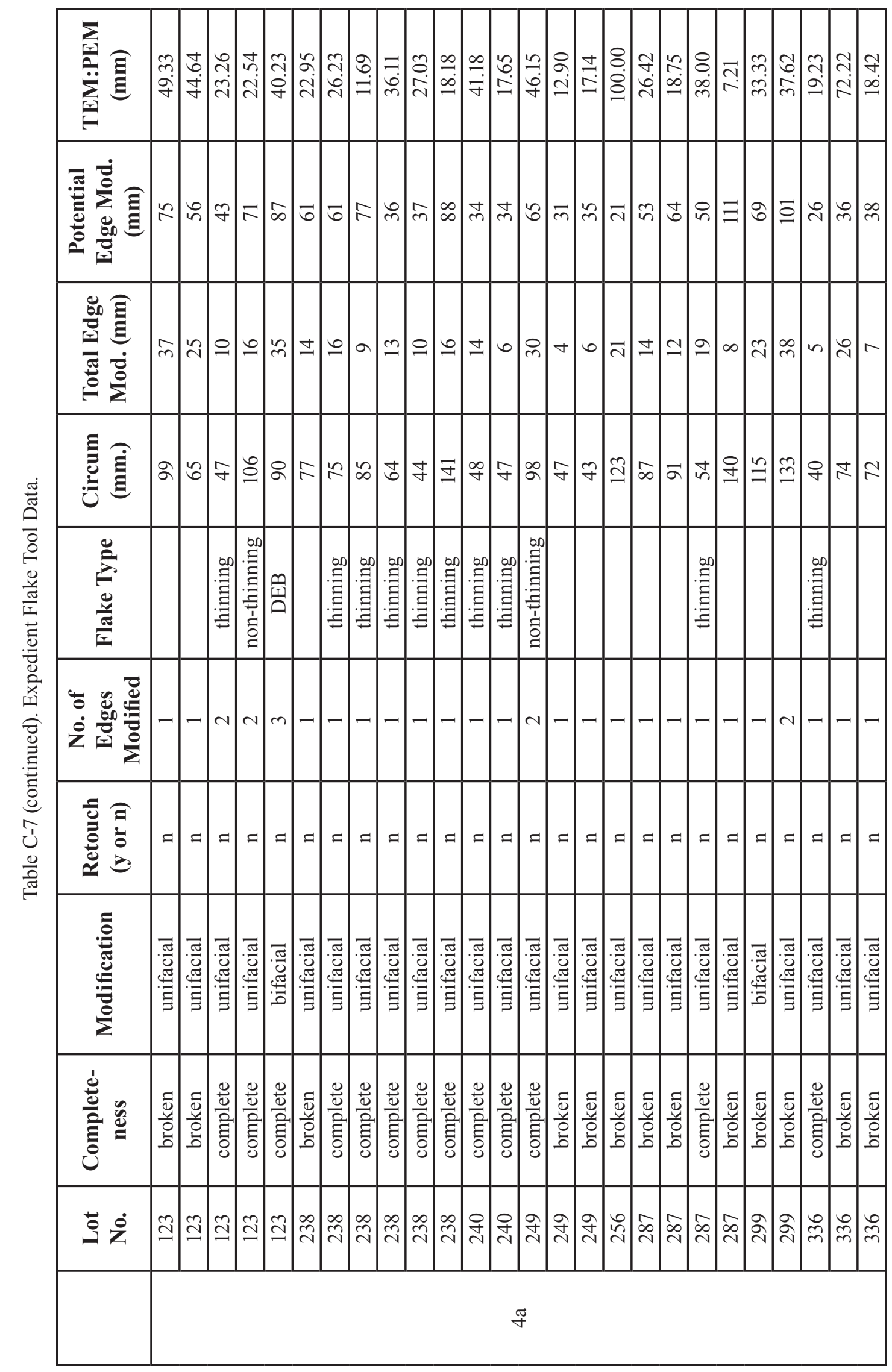




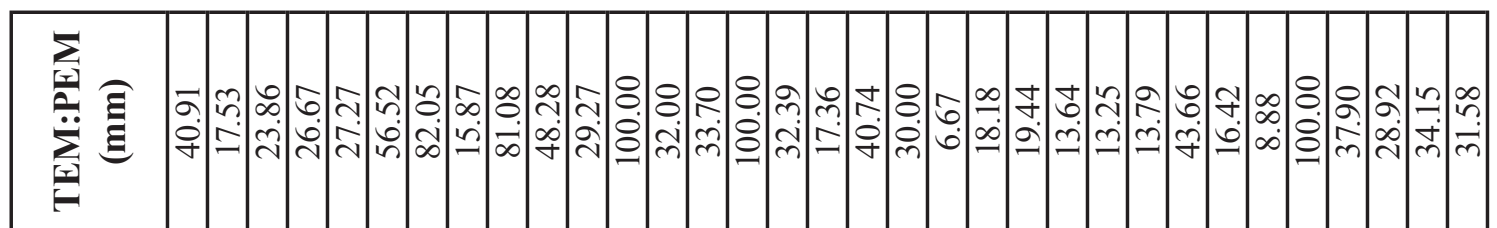

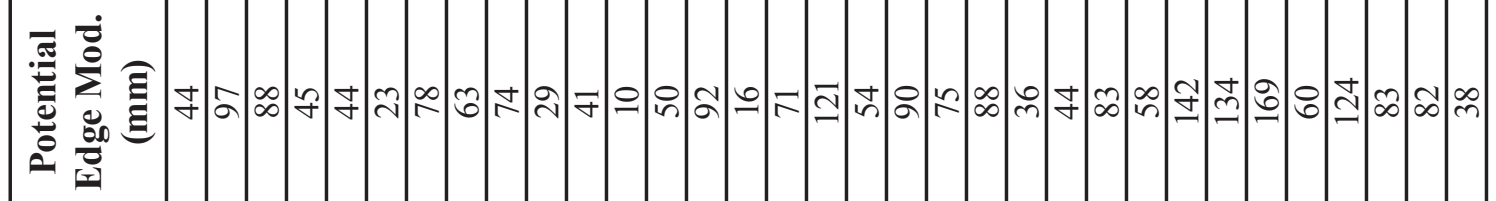

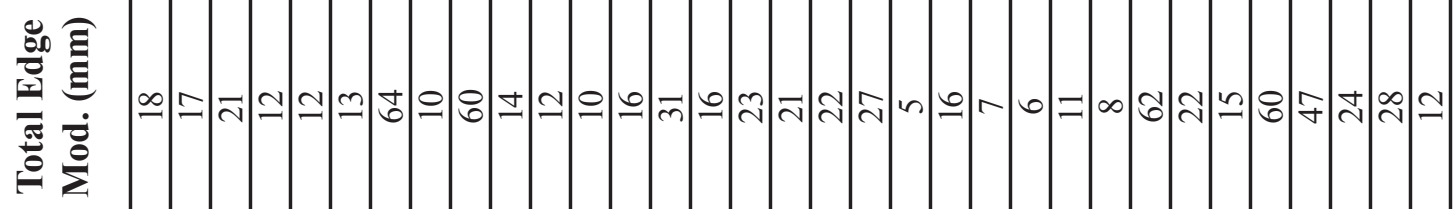

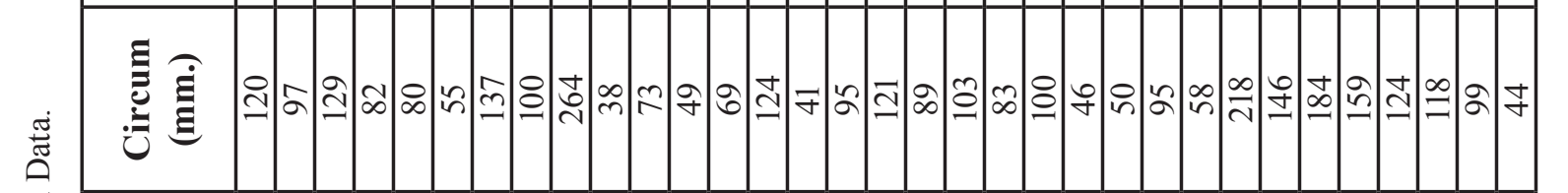

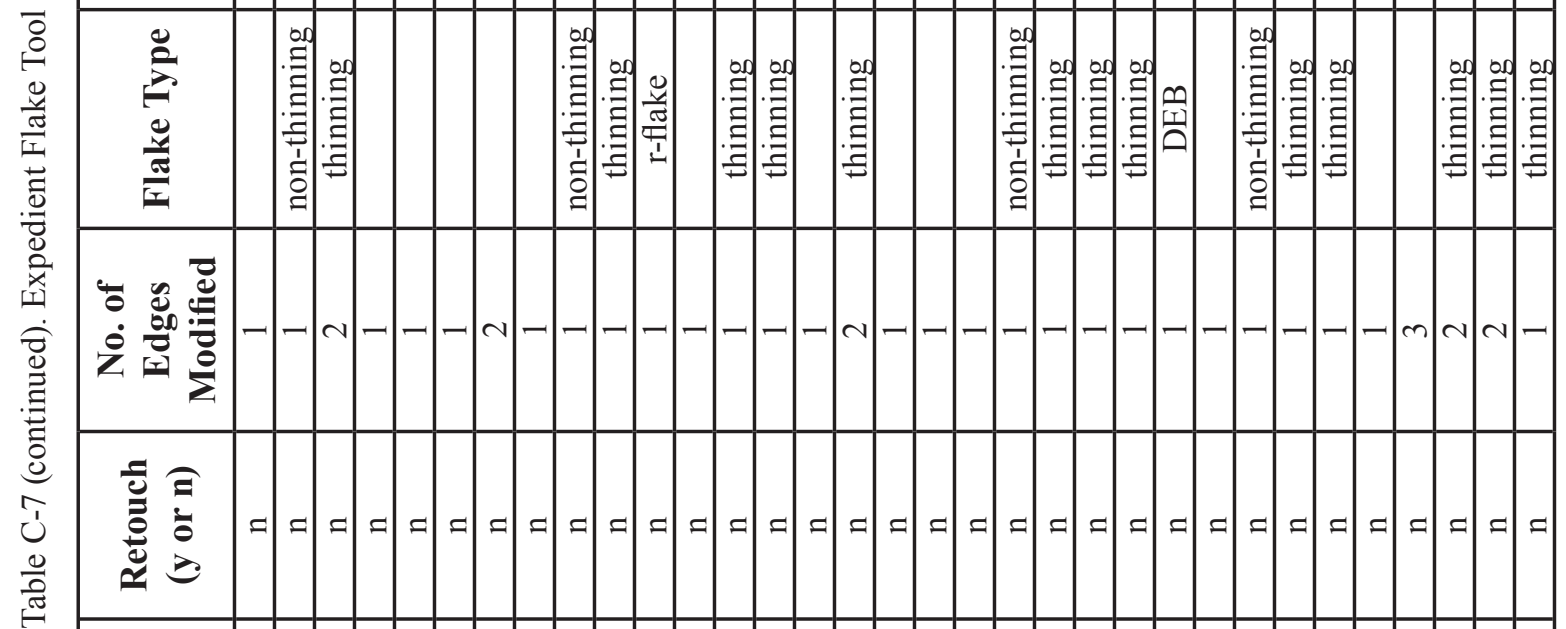

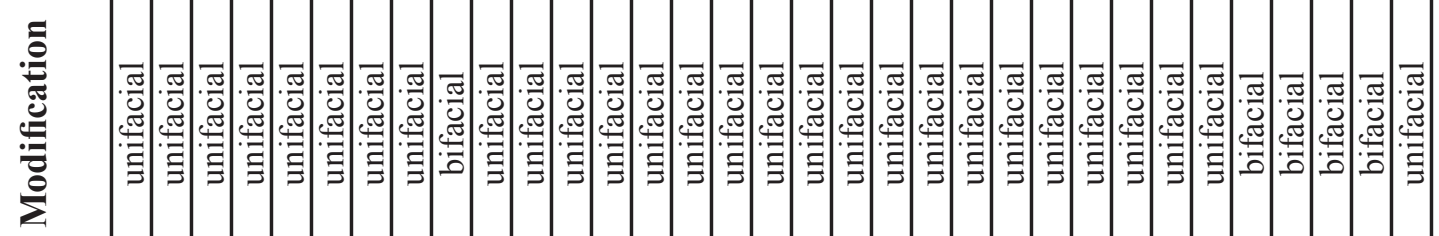

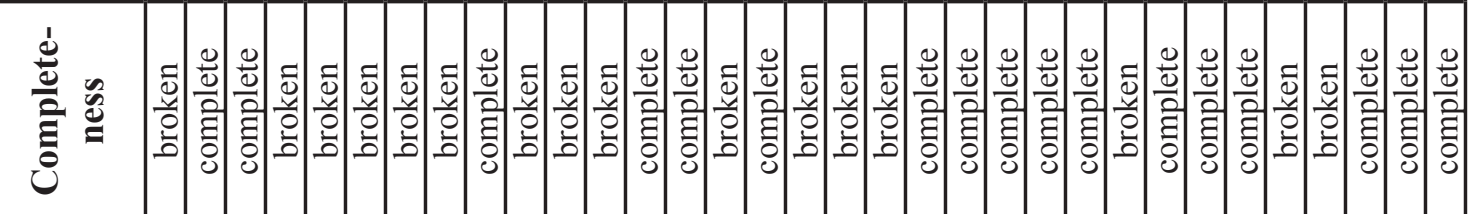

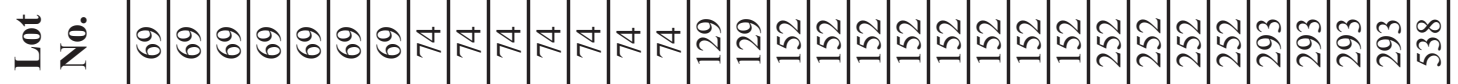




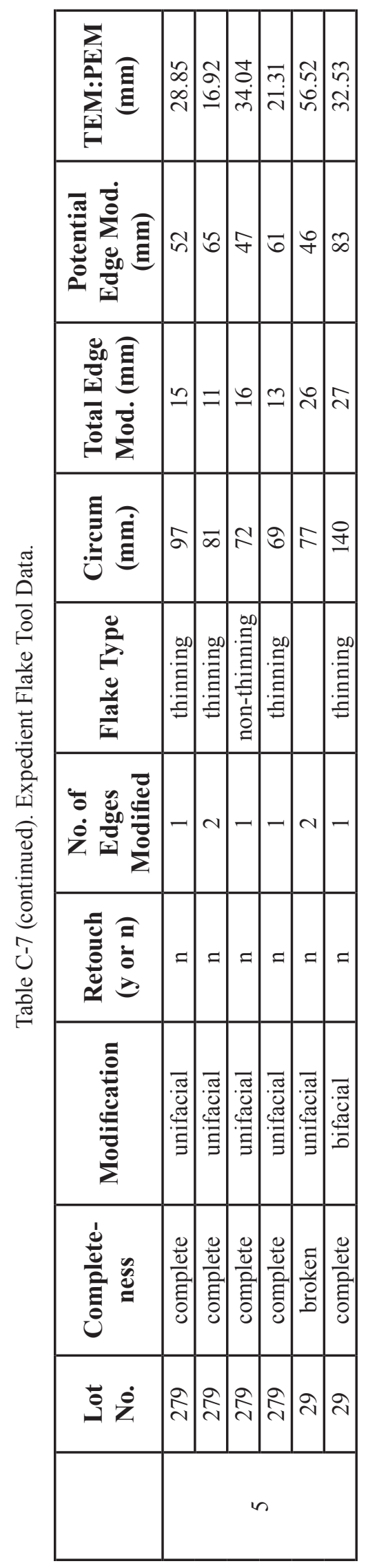




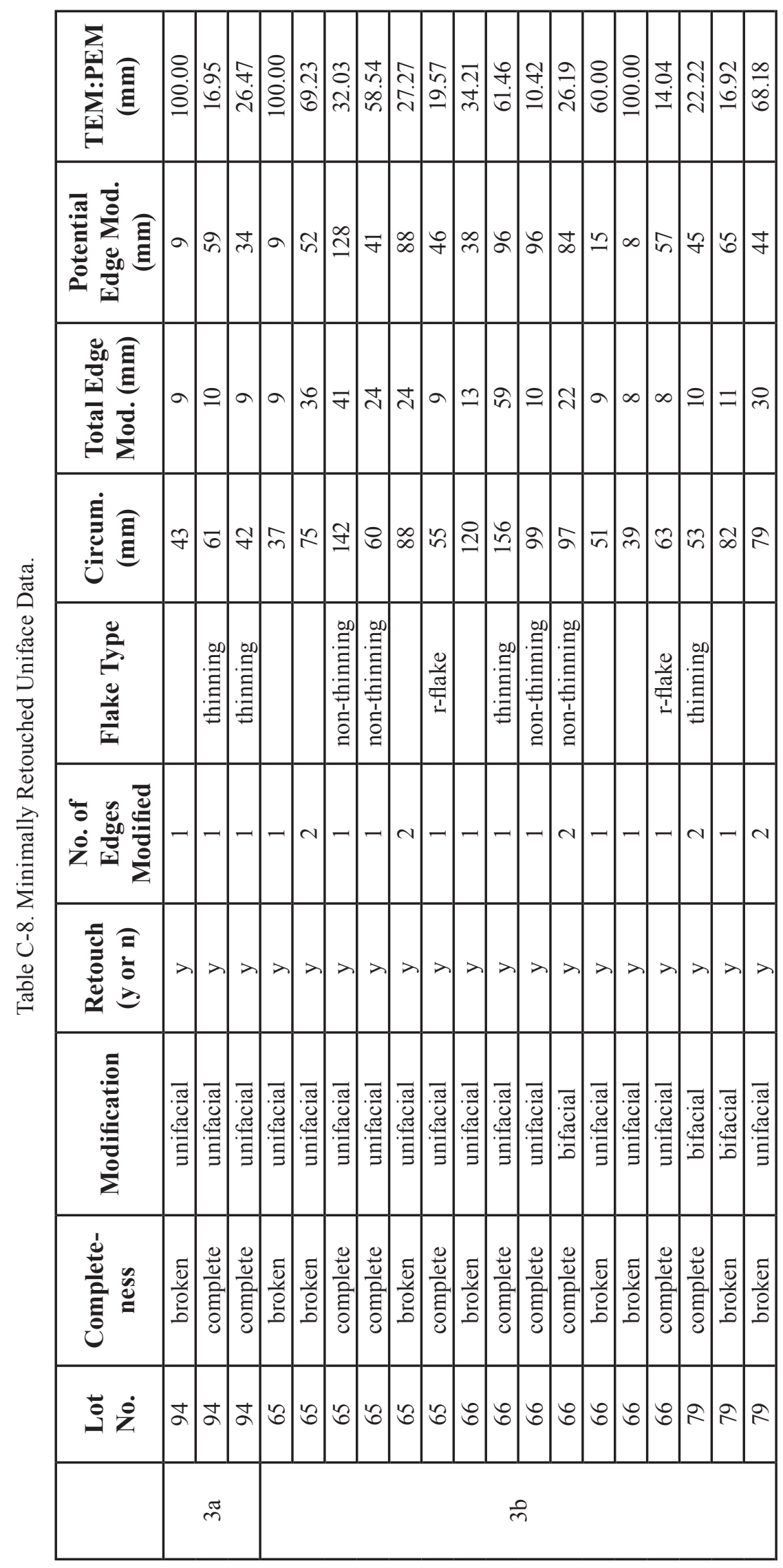




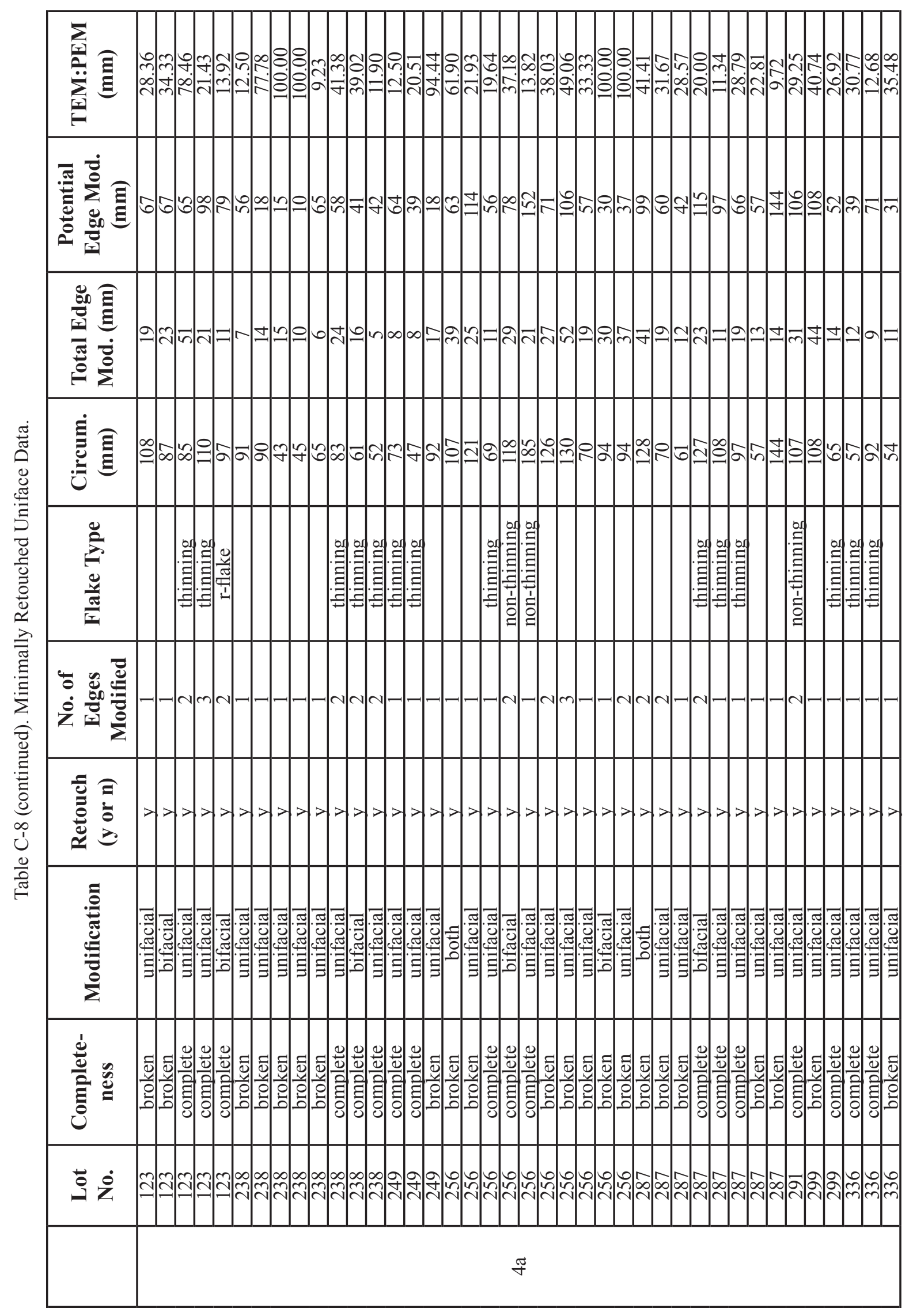




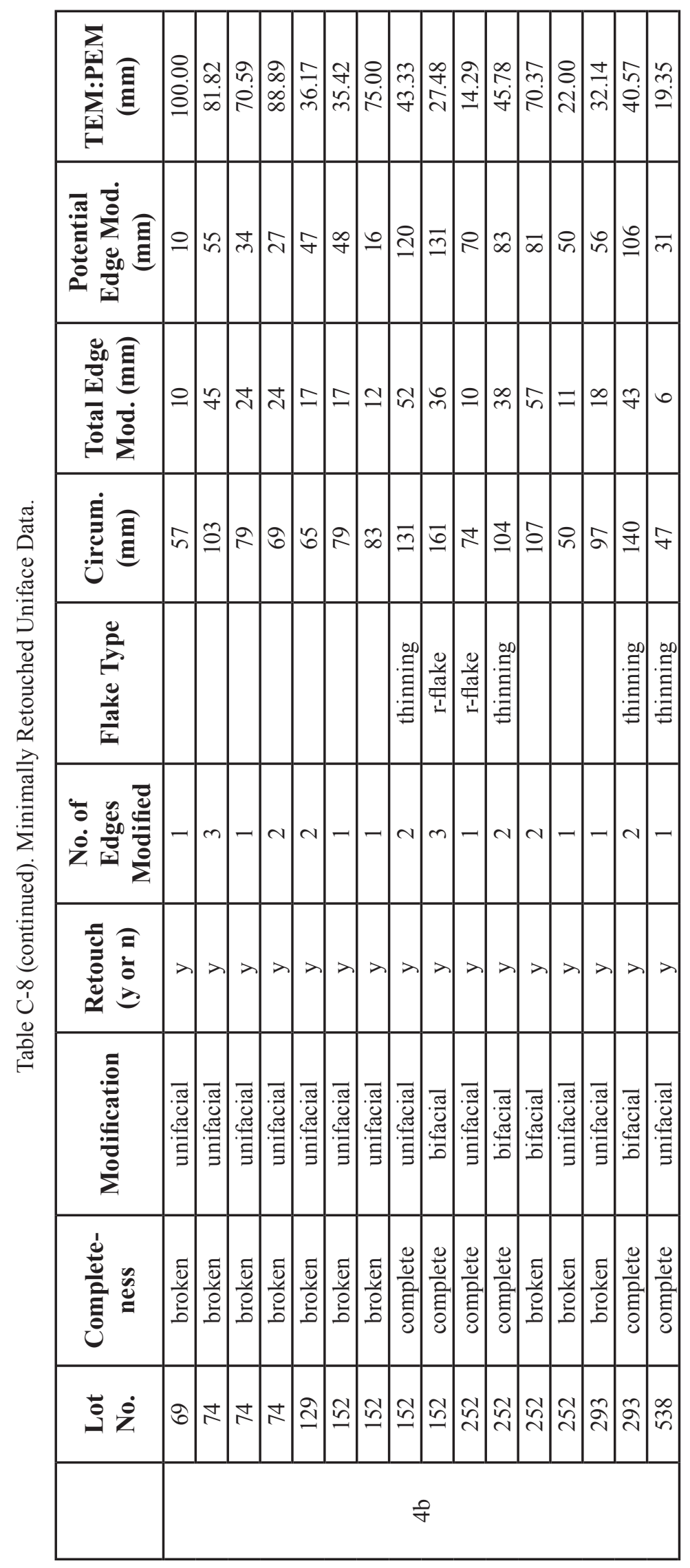




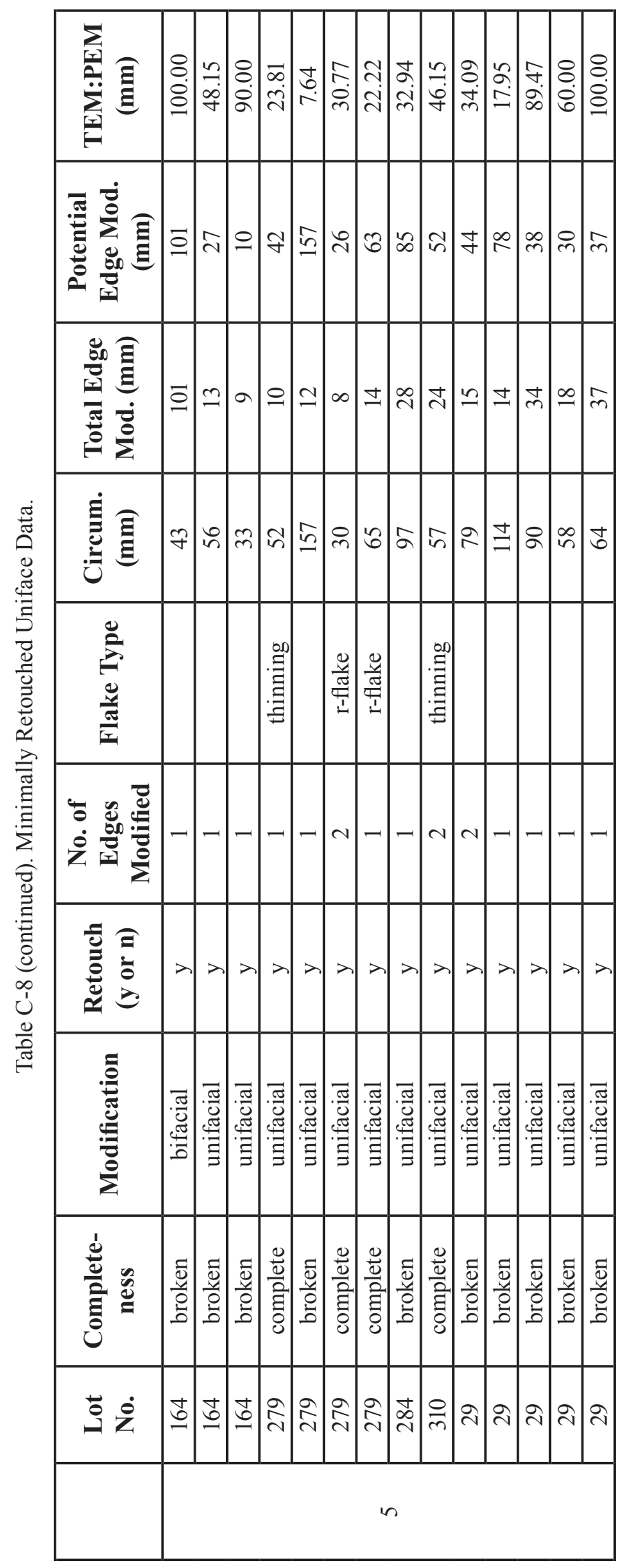


Table C-9. Debitage Counts for AUs.

\begin{tabular}{|c|c|c|c|c|c|c|c|c|}
\hline $\mathbf{A U}$ & $\begin{array}{l}\text { Lot } \\
\text { No. }\end{array}$ & Burned & $\begin{array}{l}\text { Shatter/ } \\
\text { Chunks }\end{array}$ & $\begin{array}{c}\text { Flake } \\
\text { Fragments }\end{array}$ & $\begin{array}{c}\text { Proximal } \\
\text { Flake } \\
\text { Fragments }\end{array}$ & $\begin{array}{c}\text { Complete } \\
\text { Flakes }\end{array}$ & Total & Billet \\
\hline \multirow{2}{*}{$3 a$} & 79 & 30 & 0 & 159 & 76 & 32 & 297 & 1 \\
\hline & 94 & 3 & 0 & 40 & 13 & 7 & 63 & 0 \\
\hline \multirow{2}{*}{$3 b$} & 65 & 11 & 0 & 189 & 90 & 40 & 330 & 3 \\
\hline & 66 & 29 & 0 & 113 & 97 & 38 & 277 & 5 \\
\hline \multirow{9}{*}{$4 a$} & 123 & 7 & 6 & 21 & 14 & 4 & 52 & 1 \\
\hline & 238 & 2 & 0 & 115 & 27 & 17 & 161 & 0 \\
\hline & 240 & 0 & 0 & 46 & 20 & 6 & 72 & 0 \\
\hline & 249 & 0 & 0 & 18 & 10 & 2 & 30 & 0 \\
\hline & 256 & 6 & 0 & 354 & 91 & 43 & 494 & 0 \\
\hline & 287 & 11 & 0 & 154 & 49 & 38 & 252 & 0 \\
\hline & 291 & 16 & 0 & 110 & 35 & 30 & 191 & 0 \\
\hline & 299 & 3 & 0 & 33 & 12 & 11 & 59 & 0 \\
\hline & 336 & 4 & 0 & 54 & 19 & 14 & 91 & 0 \\
\hline \multirow{8}{*}{$4 b$} & 69 & 21 & 6 & 68 & 48 & 14 & 157 & 0 \\
\hline & 74 & 7 & 0 & 71 & 23 & 18 & 119 & 0 \\
\hline & 129 & 0 & 0 & 26 & 9 & 3 & 38 & 0 \\
\hline & 152 & 17 & 0 & 269 & 70 & 26 & 382 & 0 \\
\hline & 252 & 1 & 0 & 87 & 84 & 7 & 179 & 0 \\
\hline & 293 & 0 & 0 & 42 & 8 & 7 & 57 & 2 \\
\hline & 538 & 0 & 0 & 27 & 1 & 9 & 37 & 0 \\
\hline & 583 & 0 & 0 & 12 & 2 & 5 & 19 & 0 \\
\hline \multirow{4}{*}{5} & 164 & 0 & 0 & 6 & 1 & 2 & 9 & 0 \\
\hline & 279 & 6 & 0 & 96 & 36 & 1 & 139 & 0 \\
\hline & 284 & 8 & 0 & 13 & 5 & 4 & 30 & 0 \\
\hline & 310 & 1 & 0 & 16 & 10 & 6 & 33 & 0 \\
\hline
\end{tabular}




\section{APPEndix D}

\section{Petrographic Analysis Coding Sheet}


Project: CAS Petroconthe $41 \mathrm{H}$ H

Sample Number: $62-A=7$

Date: $4|7| 1 \mid$

Microscope: Leica

Objective Lens:

$10 \times$

Interval:

Am

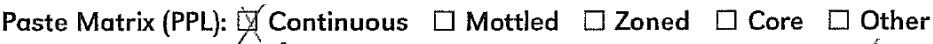

Paste Color (PPL) yell pu is brown $10 \times \mathrm{R}$. $6 / 6$

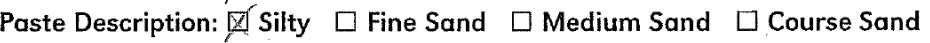

B-Fabric (XPL): $\square$ Undifferentiated $\square$ Speckled $\square$ Striated $\square$ Zoned $\square$ Other

$\square$ Active ख⿰亻 Slightly Active Notes

Slip Present: $\square$ Yes $\square$ No $\square$ Indeterminate $\square$ One side $\square$ Two side

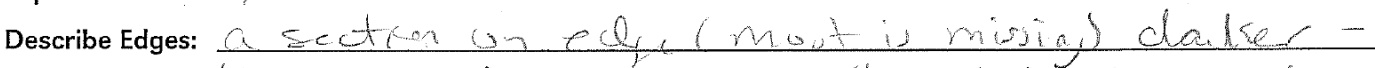

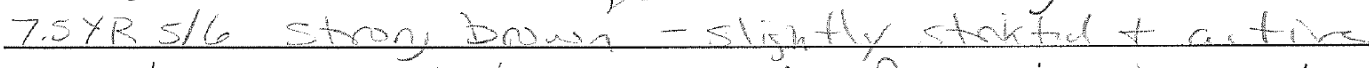

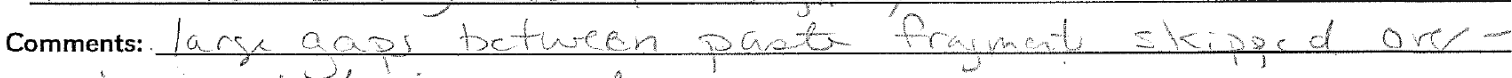
raterot in ouids

quentesmant conded

Description of Unknowns:

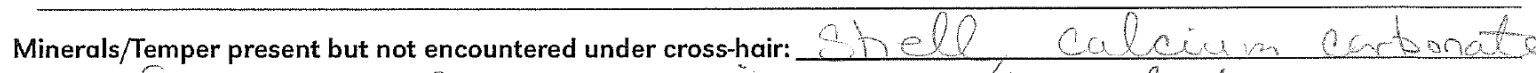

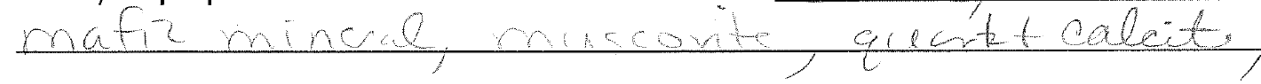

\section{Photos - File Name}

Ga-p-7-Pate- $-4 x$

$60-A-7-E d ;-10 x$
Description

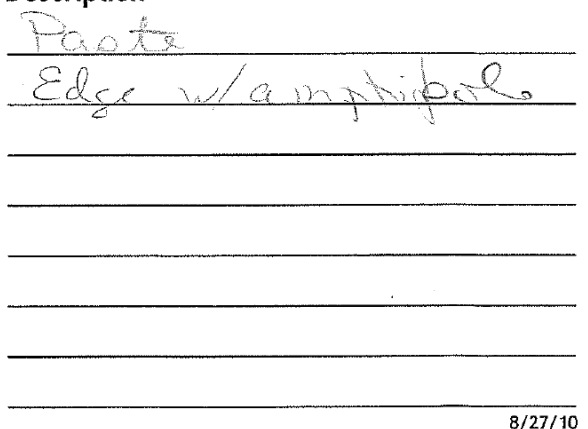




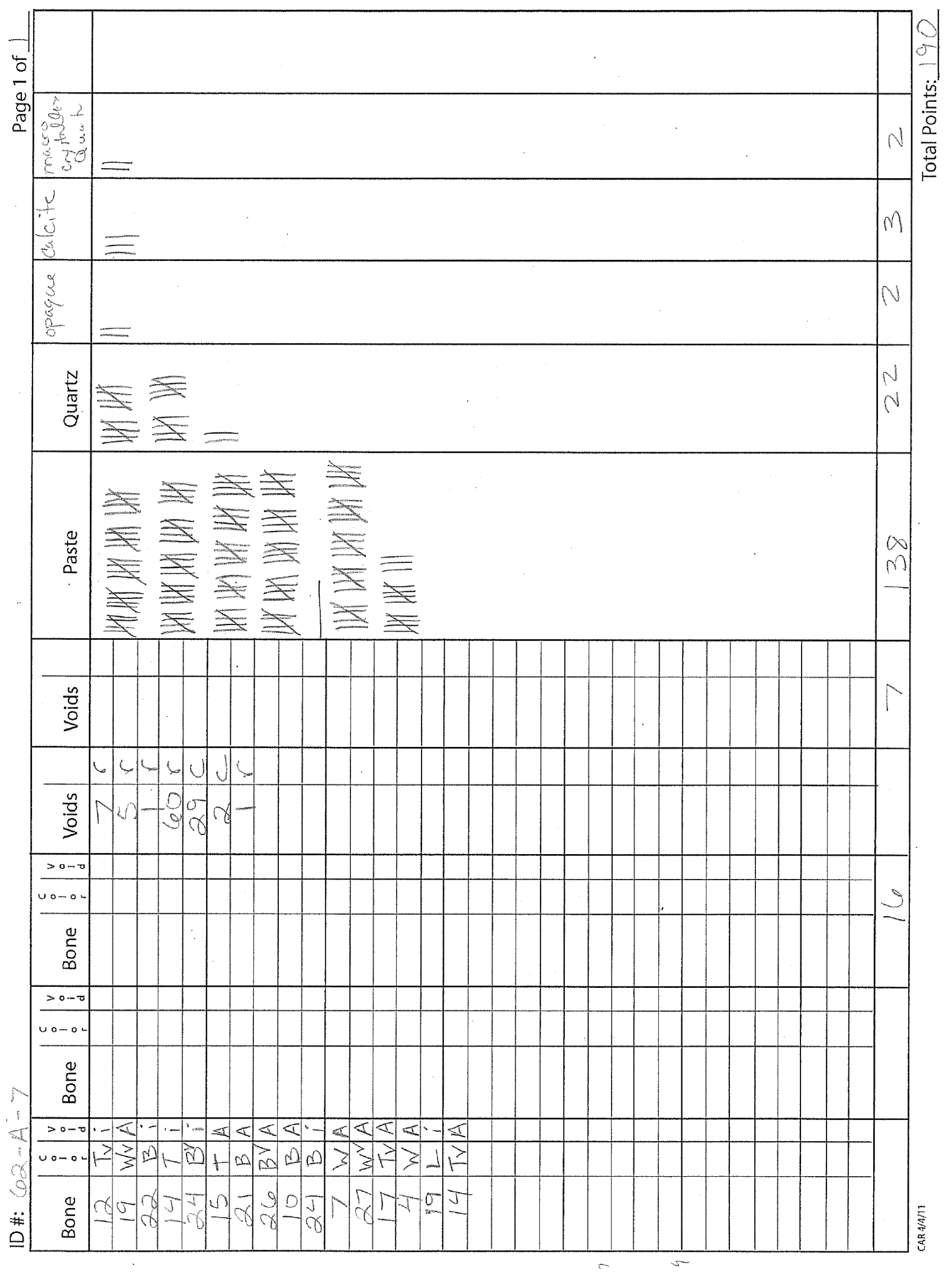




\section{Appendix E}

\section{Botanical Analysis Tables}




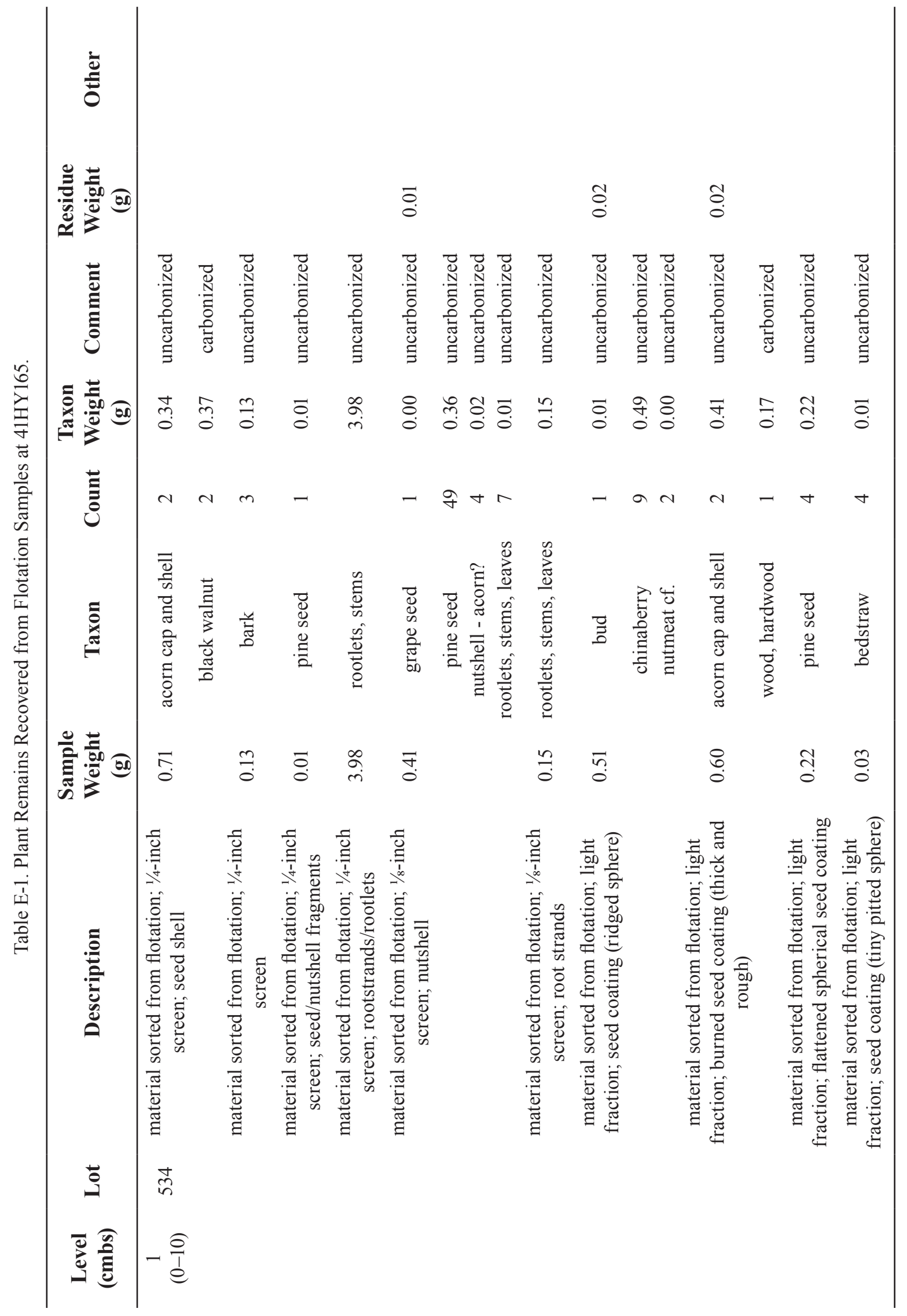




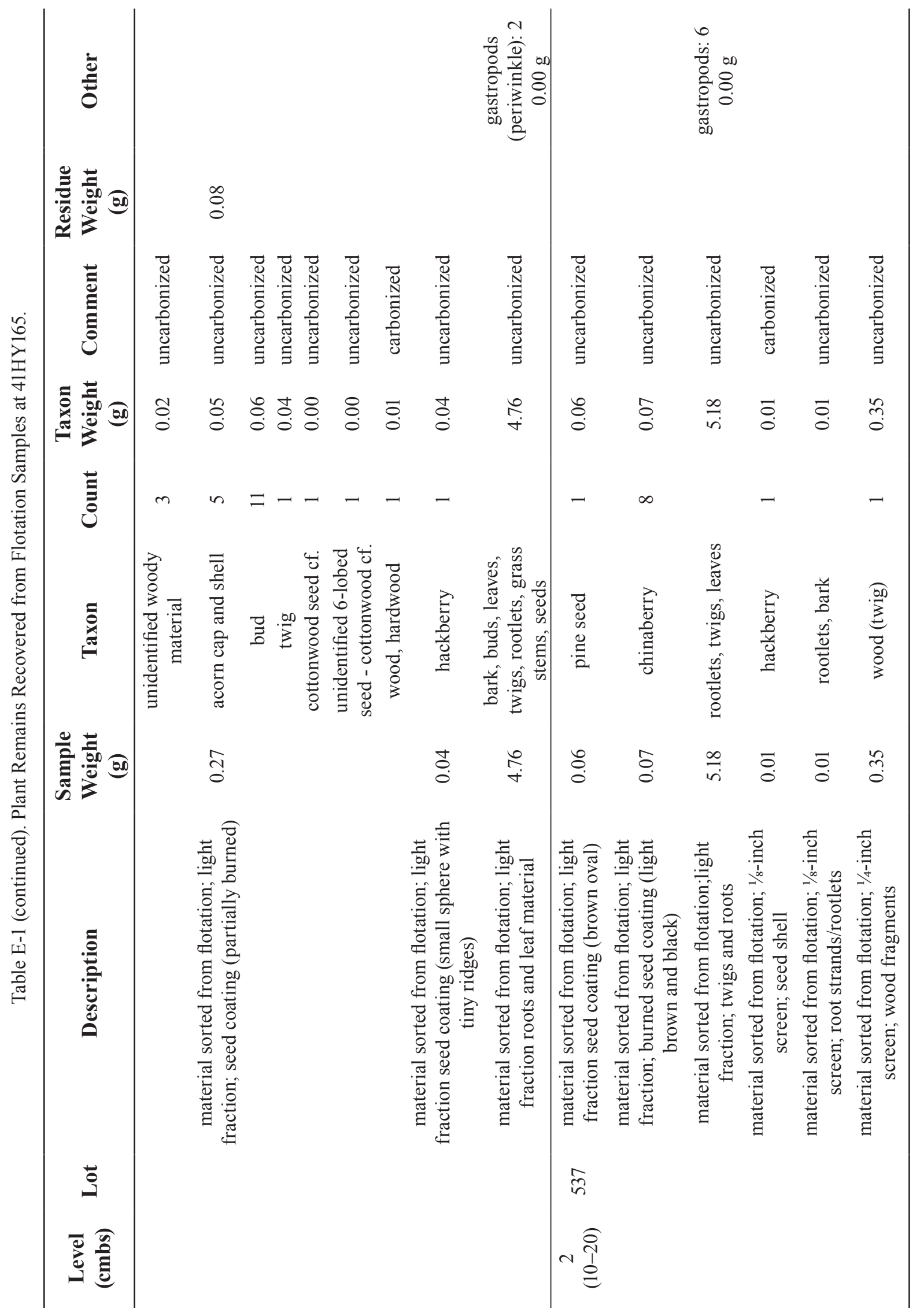




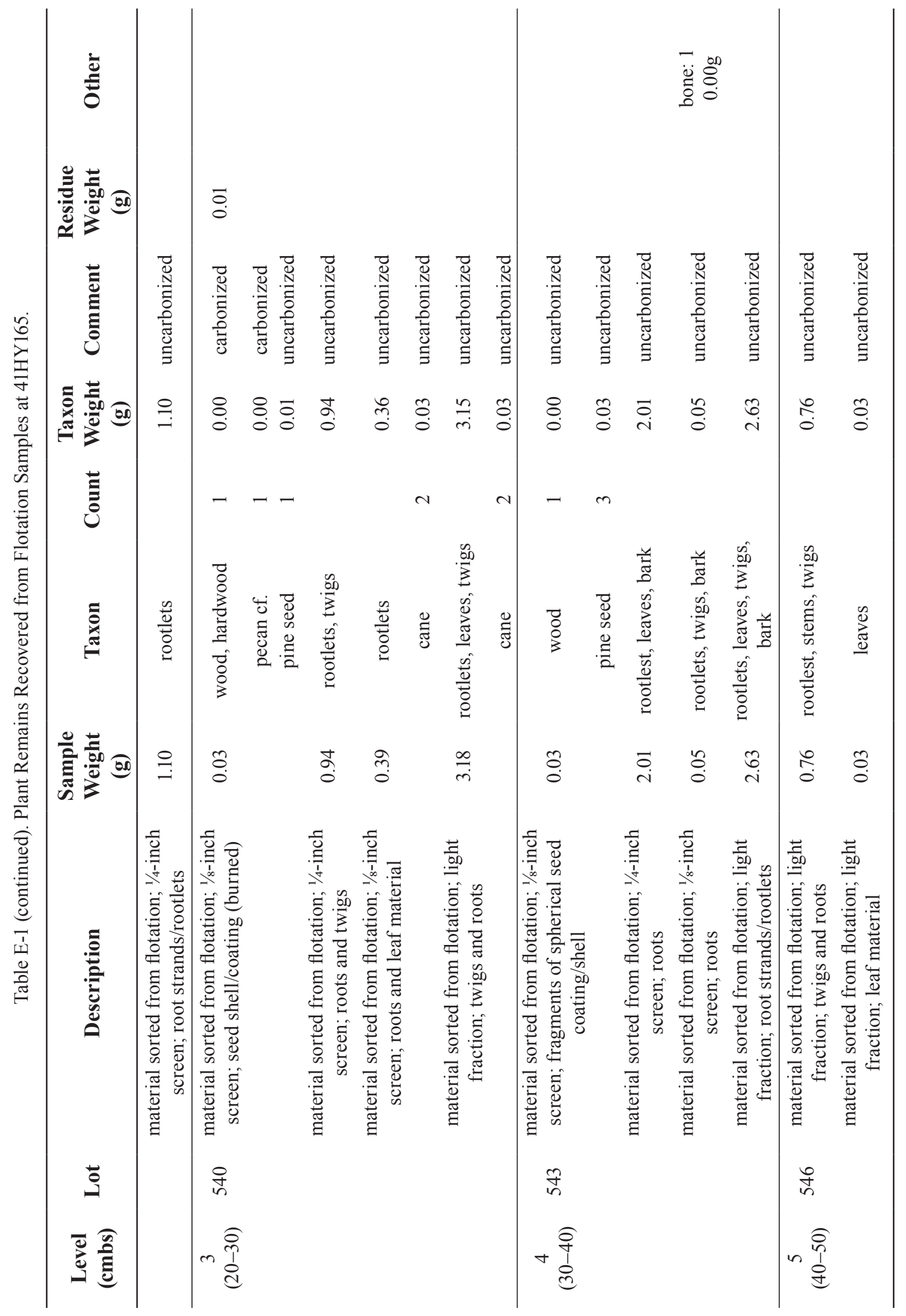




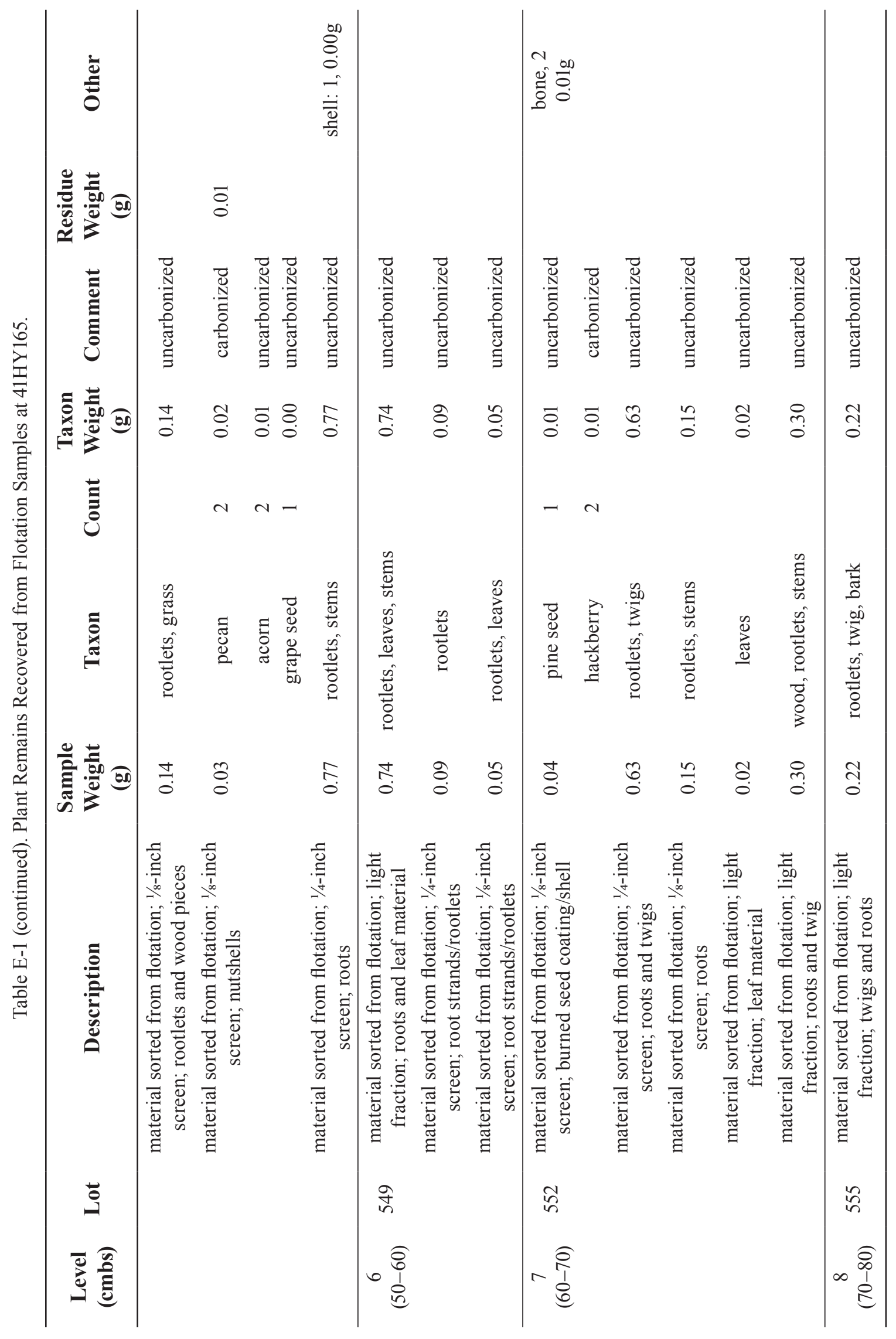




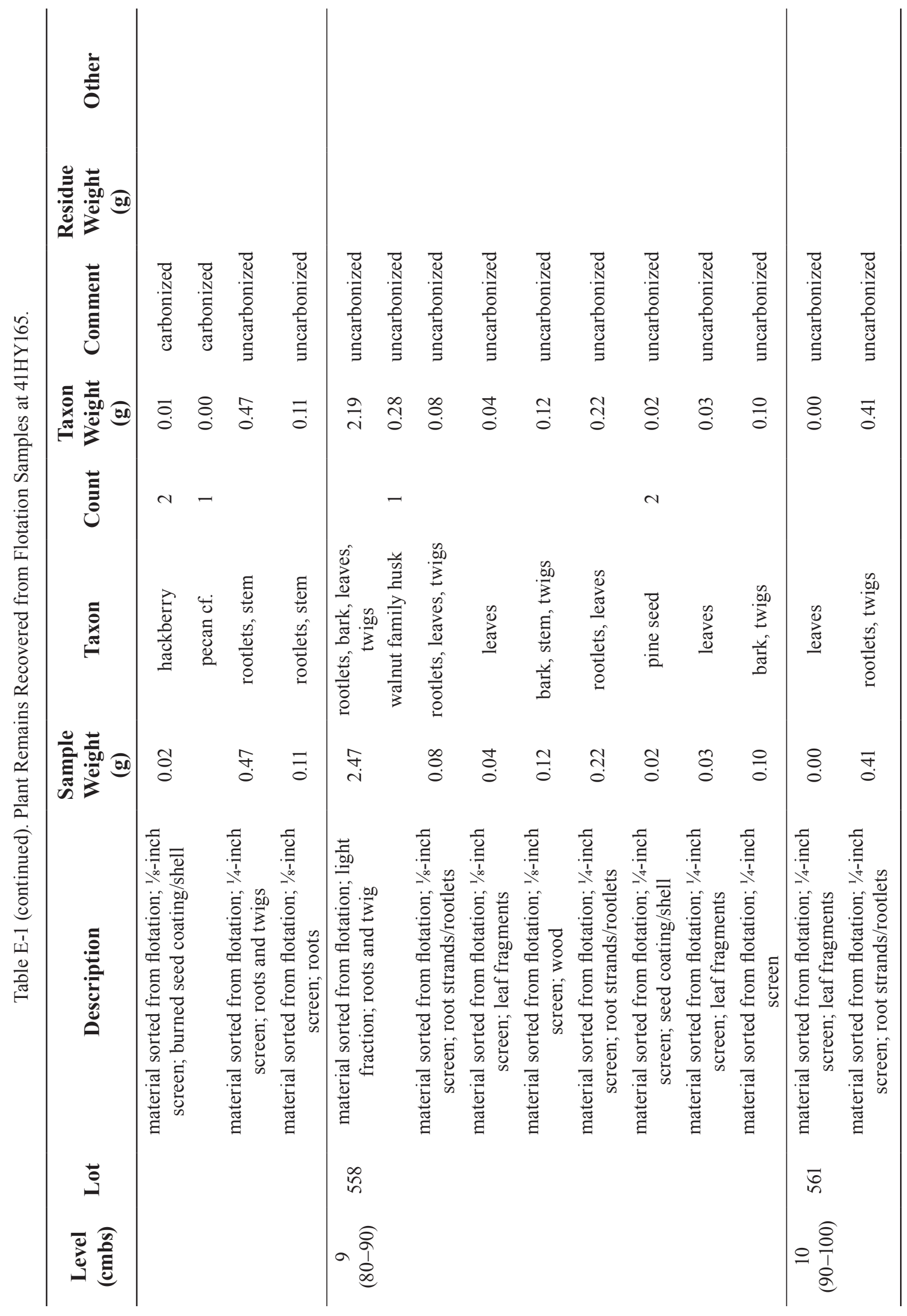




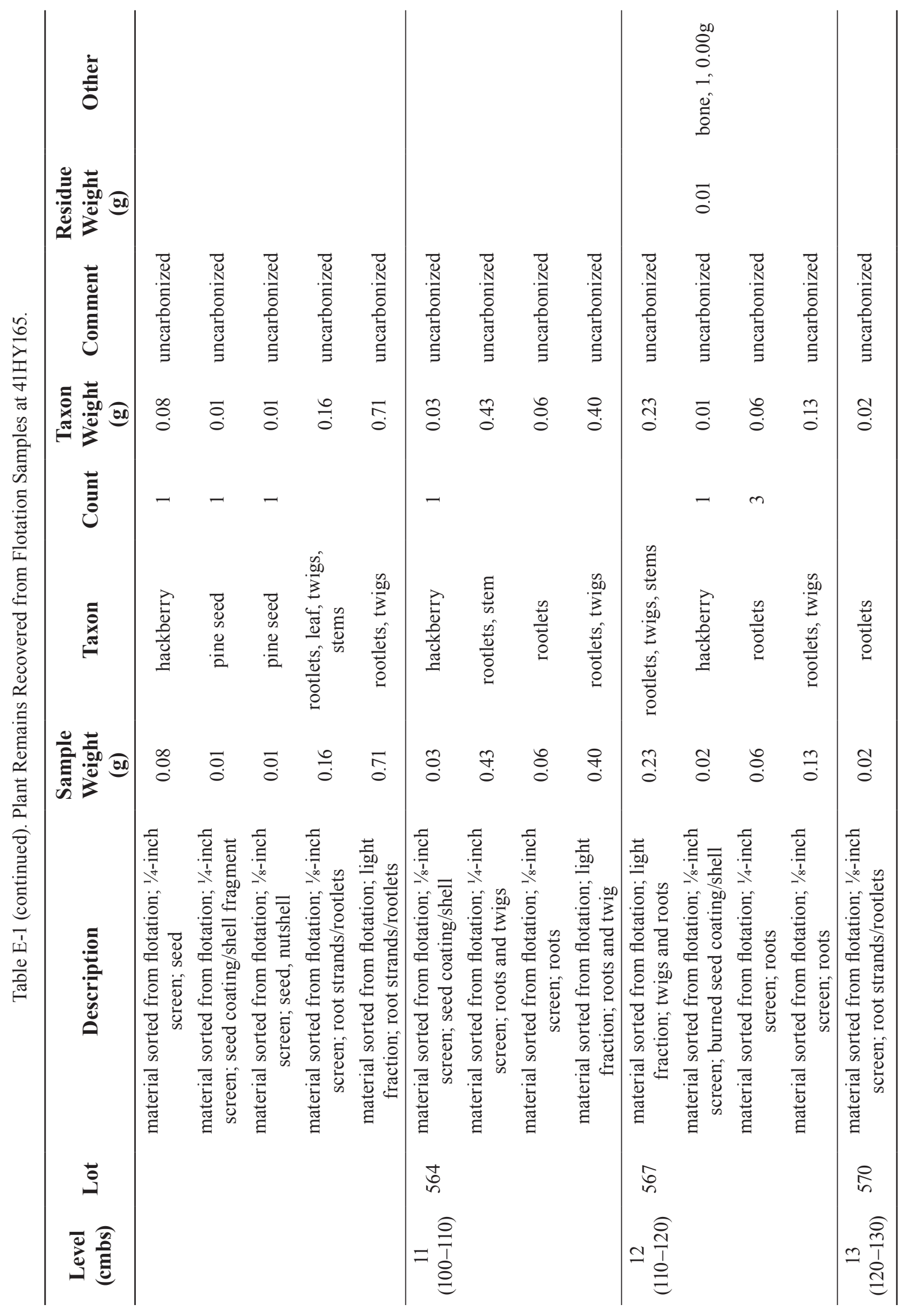




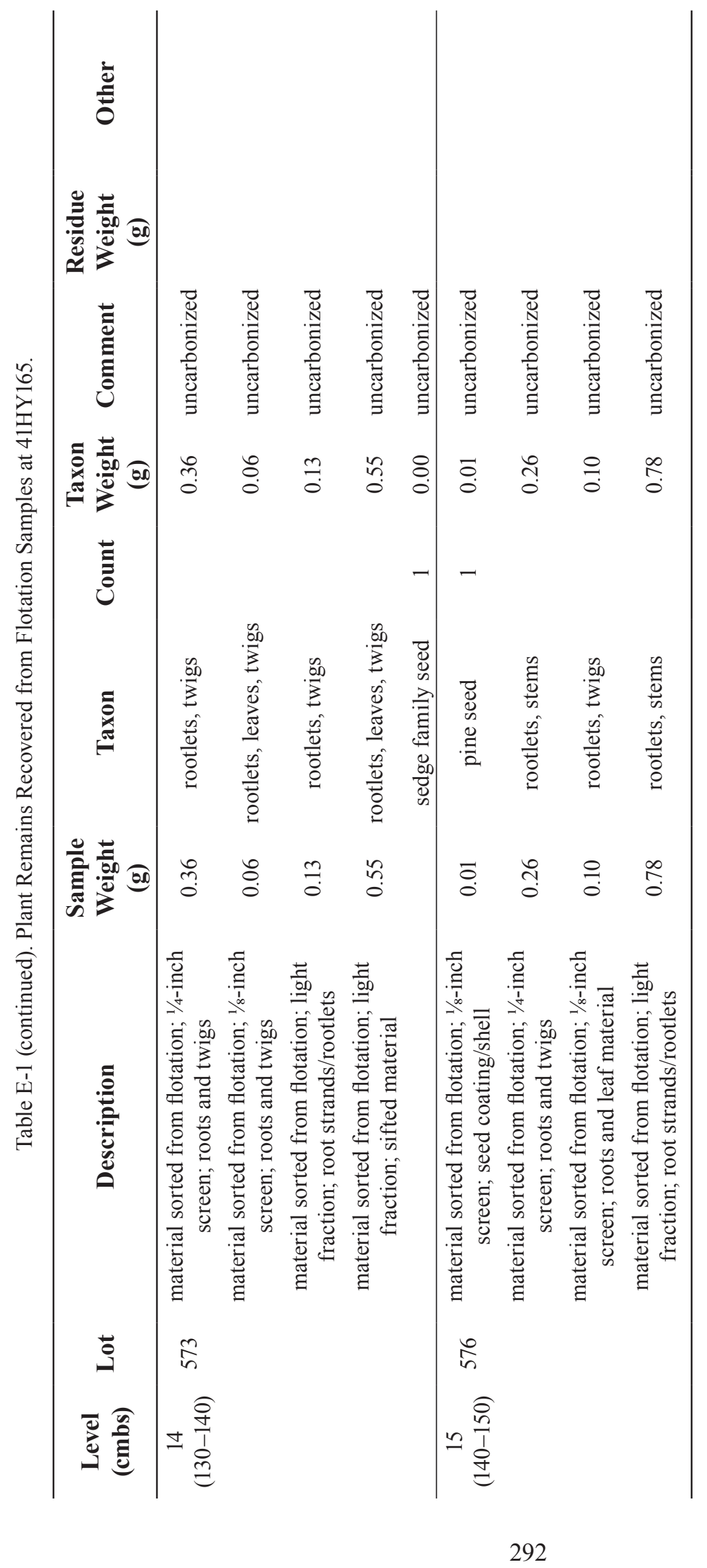




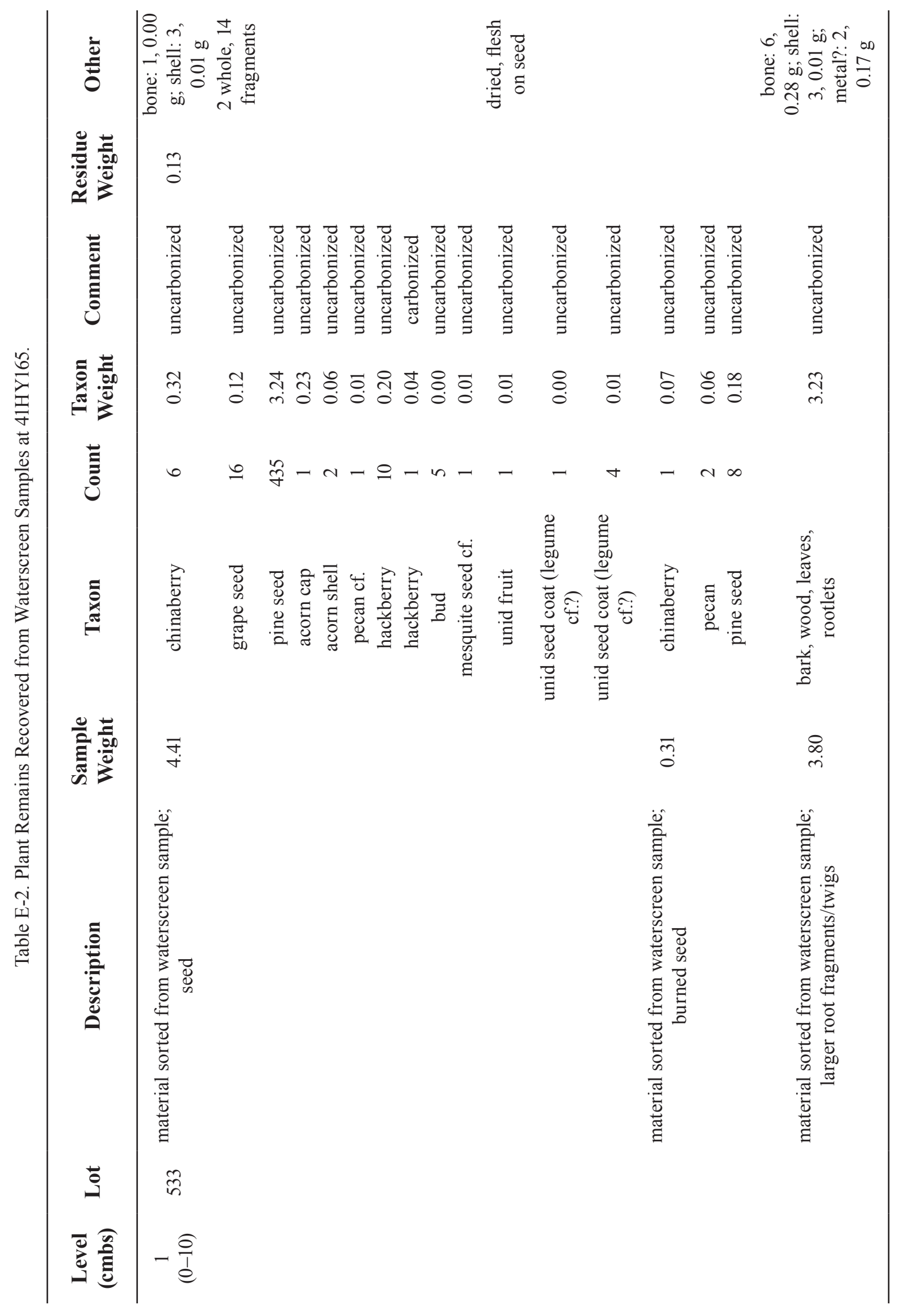




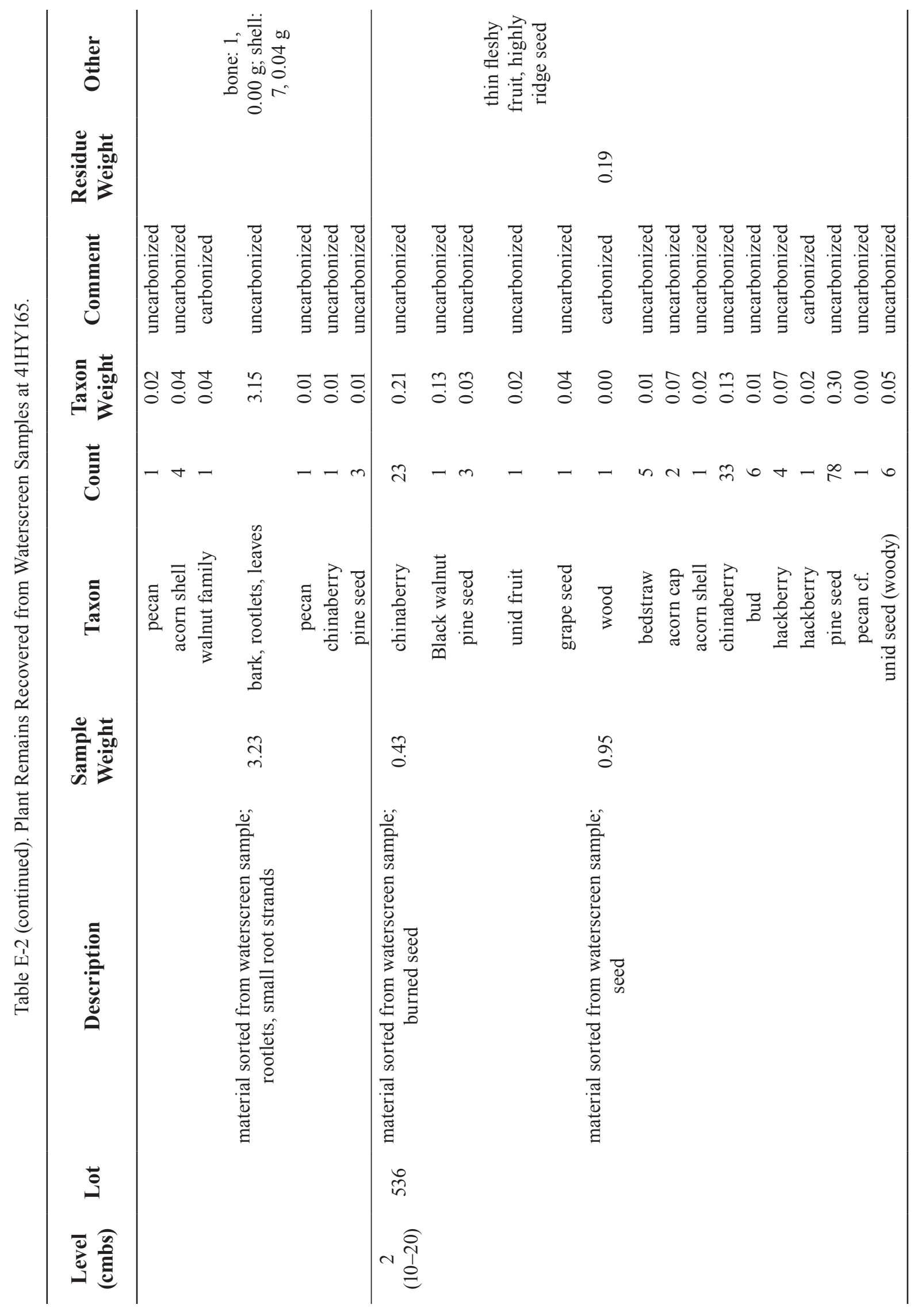




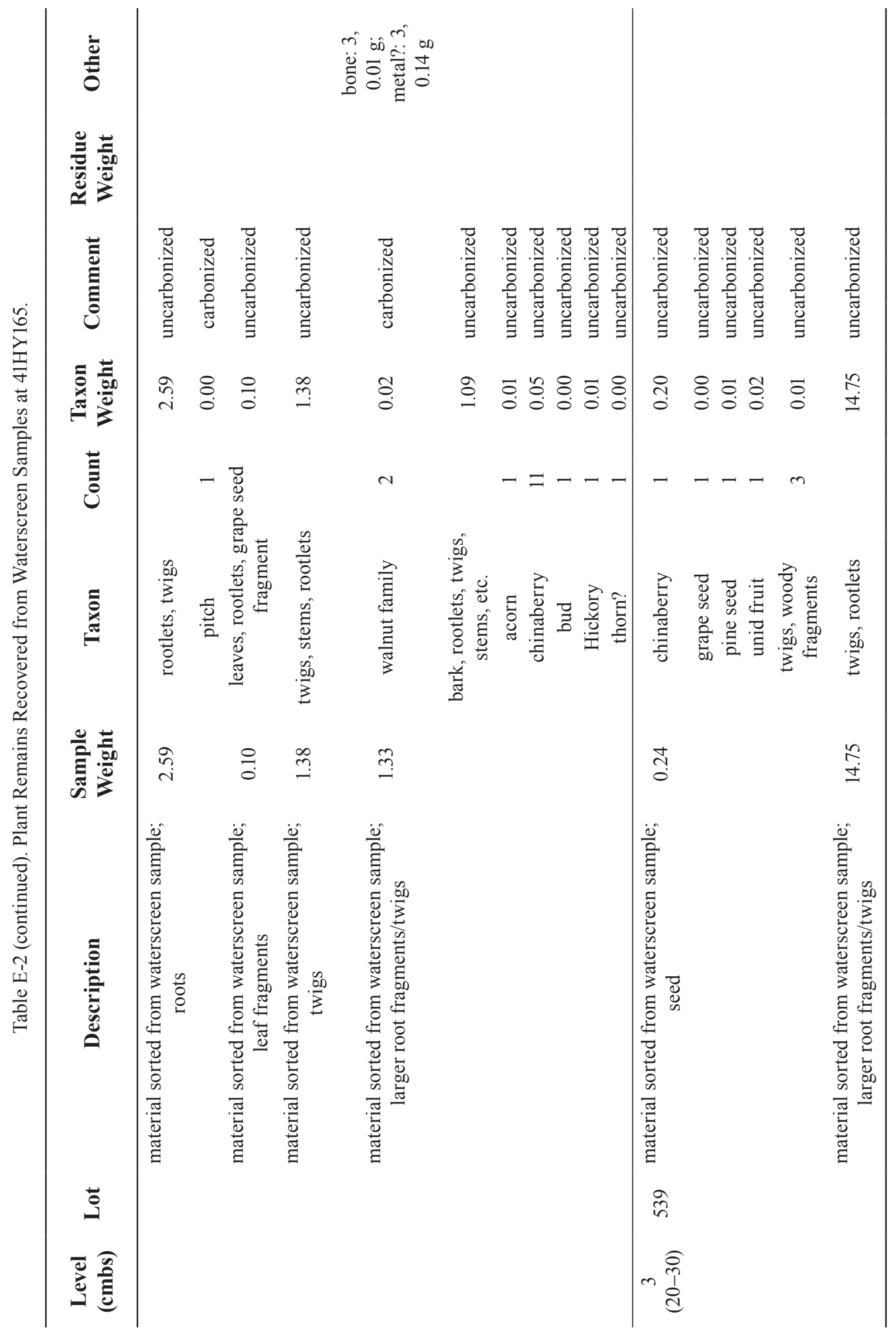




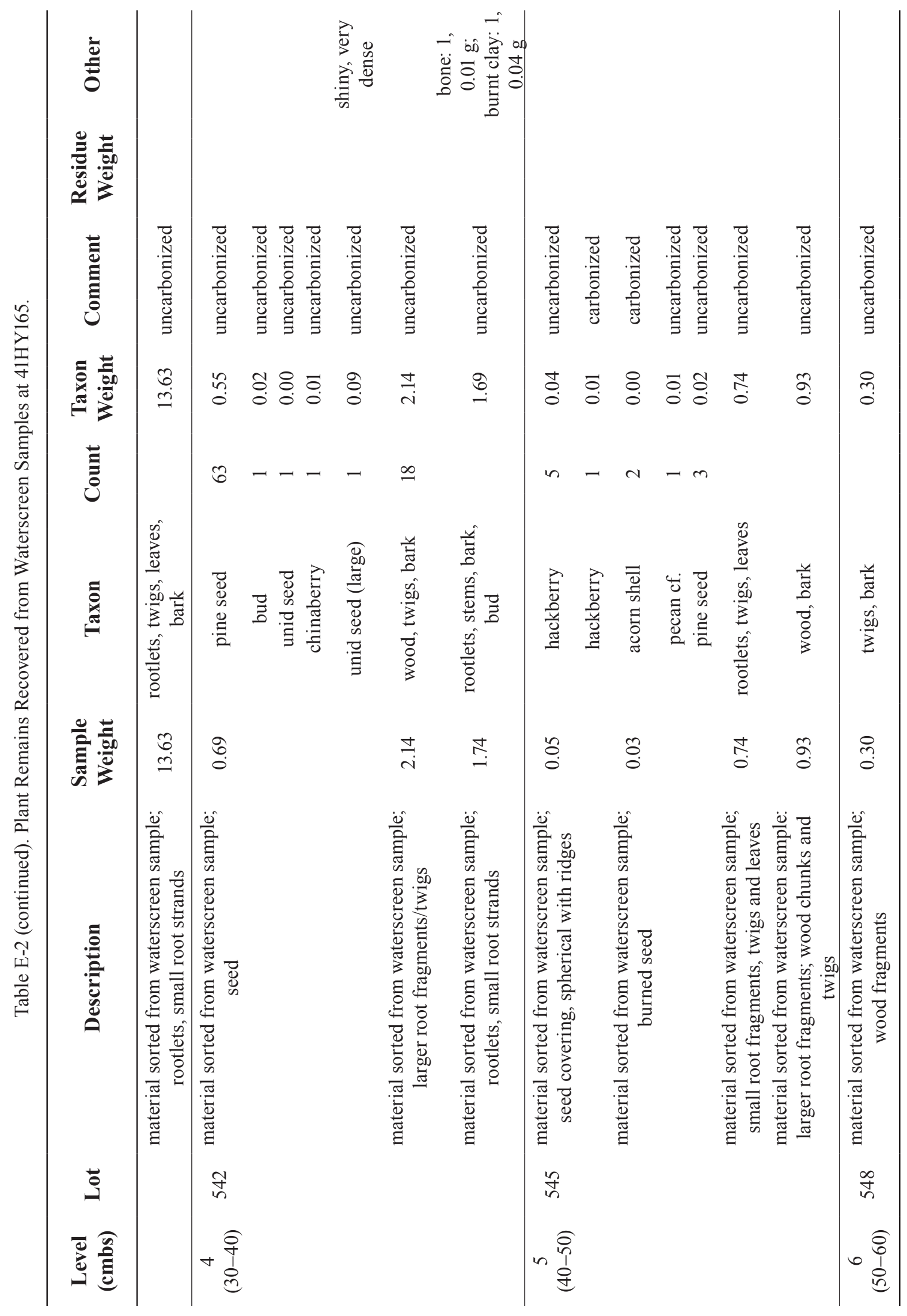




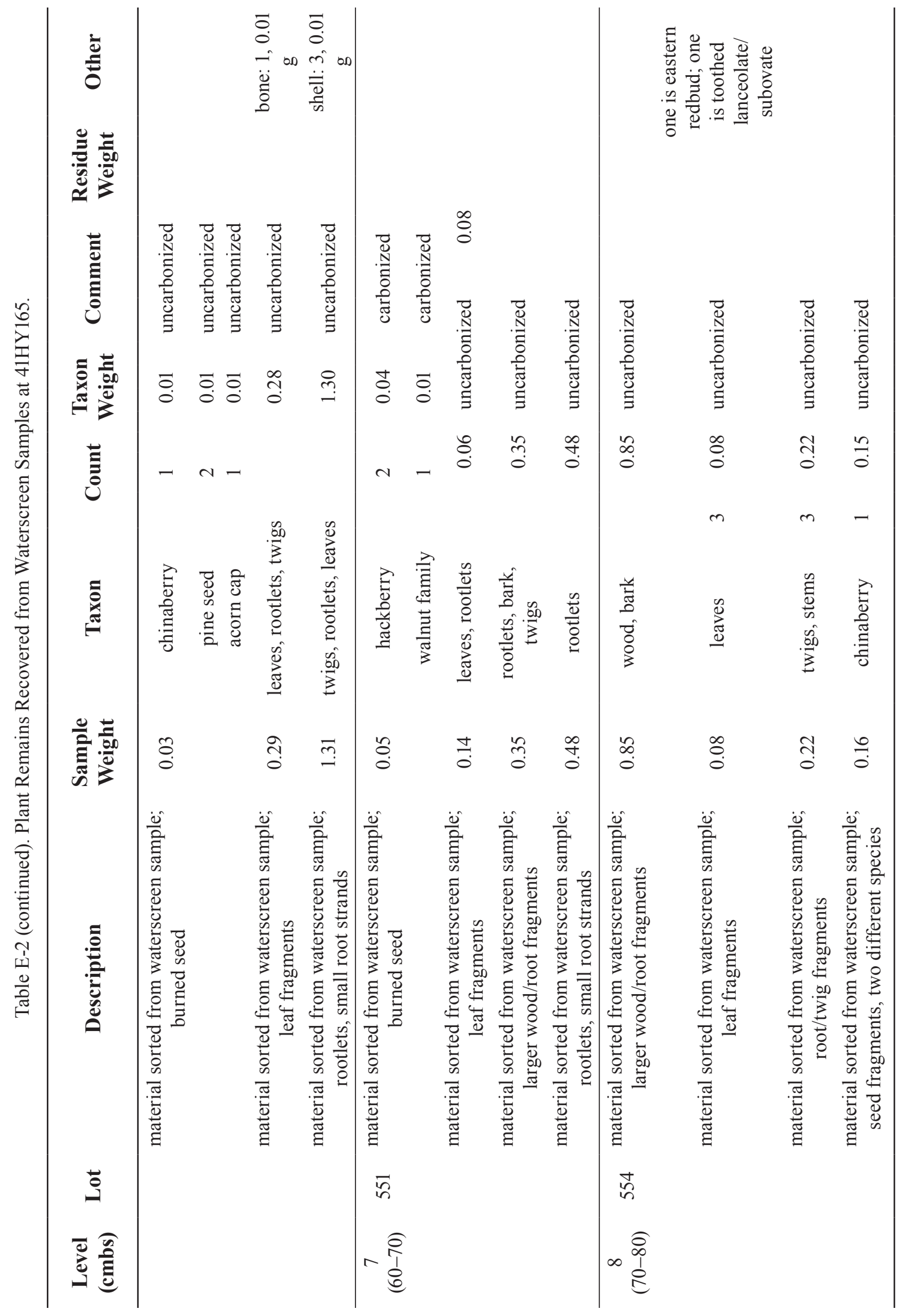




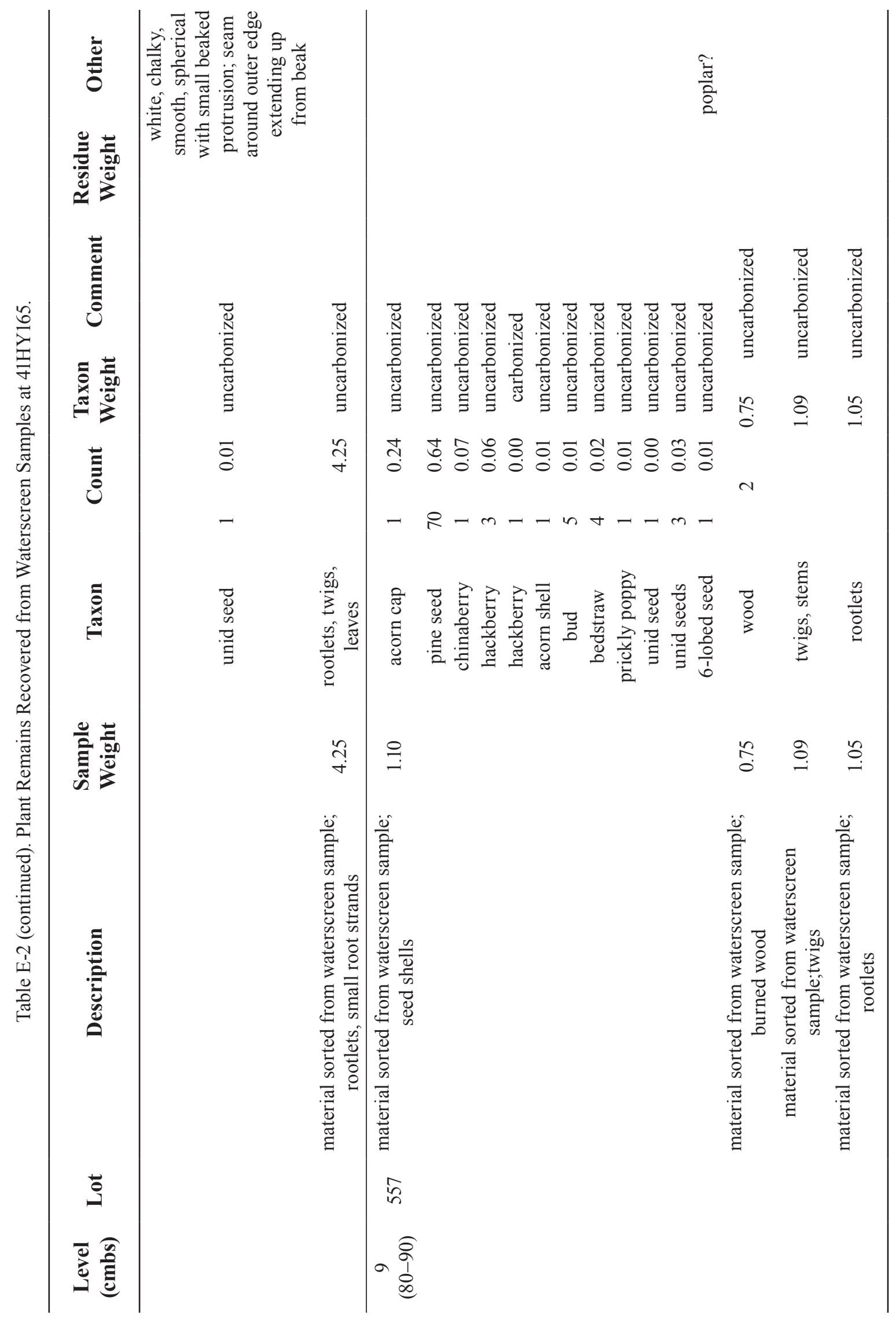




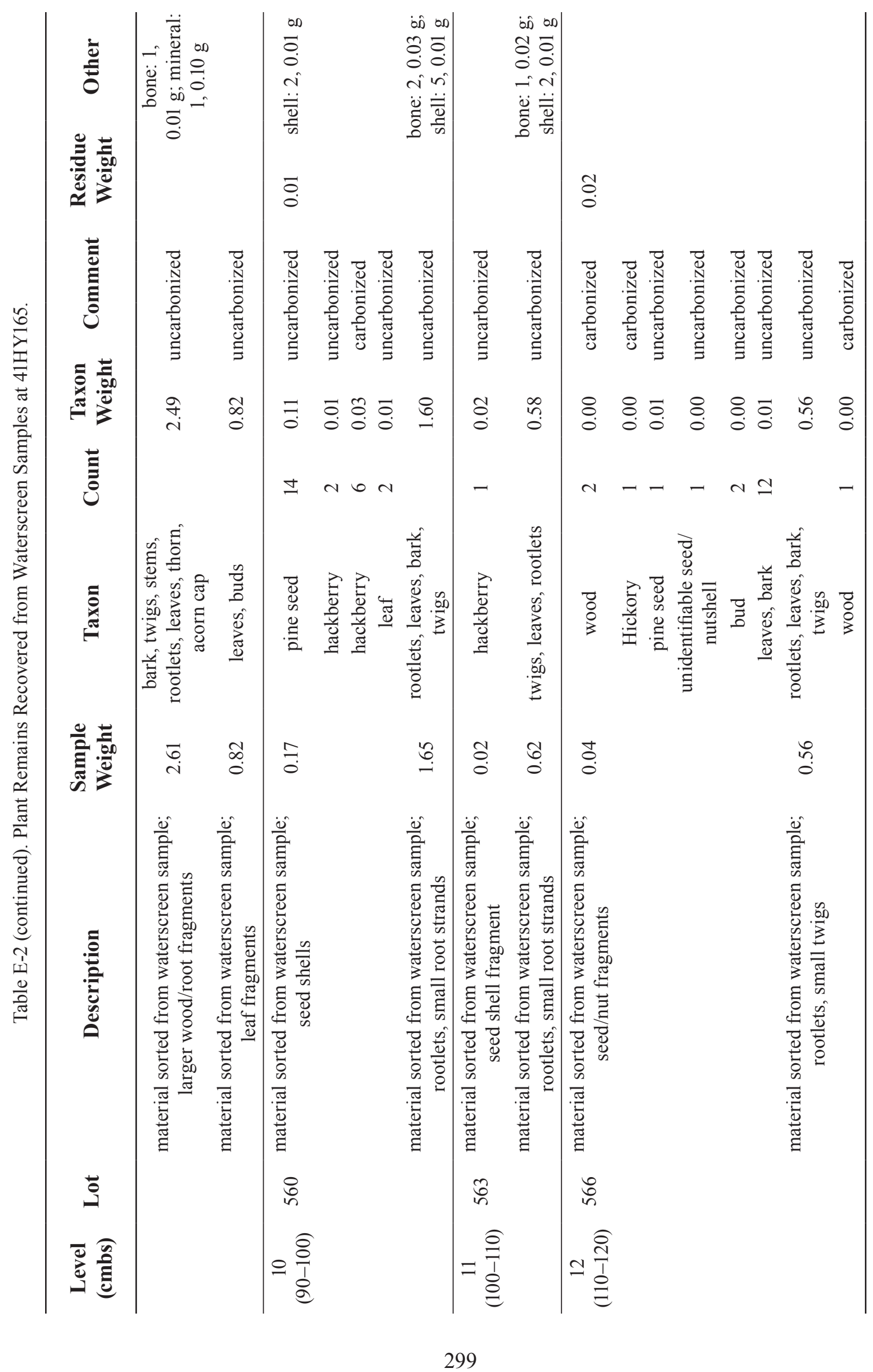




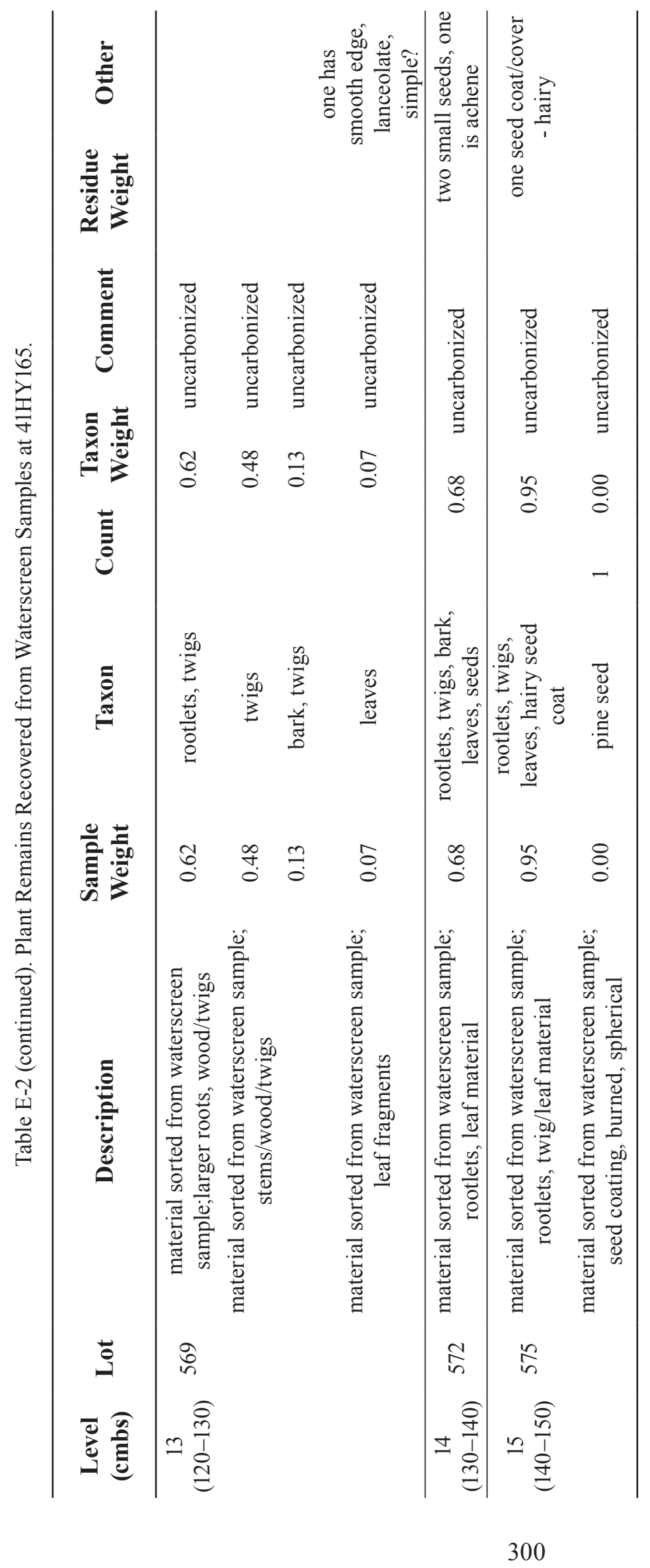




\section{Appendix F}

\section{Systematic Catalog of Taxa \\ IDENTIFIED AT $41 \mathrm{HY} 165$}

\section{Subphylum Vertebrata (Cuvier, 1812)}

\section{Referred Specimens}

79-16, vertebra fragment; 79-17, identifiable bone (Mammalia or Aves); 79-25, bone fragment; 106-2, burned bone fragment; 106-5, bone fragments; 106-6, identifiable postcranials; 106-7, burned bone fragment; 106-8, small rib, fragment; 106-9, calcined phalanx fragment; 114-8, cut bone fragment; 114-16, burned bone fragments; 114-22, vertebra(?); 114-23, burned bone fragment; 114-24, bone fragments; 152-53, burned bone fragments; 299-01, Osteichthyes(?) bone; 310-1, Mammalia or Aves limb fragment; 522-7, Anura(?) humerus fragment; 522-9, Anura(?) skull fragment; 522-21, vertebra fragment; 538-10, burned bone; 583-14, Mammalia(?) burned bone fragment.

\section{Archaeological Context}

AU 3a: 79-16, 79-17, 79-25,, 106-2, 106-5, 106-6, 106-7, 106-8, 106-9; AU 4a: 299-1, 522-7, 522-9; AU 4b: 114-8, 114-16, 114-22, 114-23, 114-24, 152-53, 538-10, 583-14; AU 5: 310-1

\section{Superclass Osteichthyes (Howes, 1894)}

\section{Referred Specimens}

66-4, bone; 79-18, bone; 106-10,vertebra fragments; 106-11, vertebrae; 106-12, spines; 106-13, burned spines; 106-14, skull and postcranial bones/fragments; 106-15, tooth in jaw fragment (Osteichthyes?); 114-27 bone and vertebra; 123-16, vertebra; 129-2, vertebra; 131-28, translucent bone; 152-17, vertebra; 152-48, jaw fragment; 152-49, vertebra; 522-22, vertebra with spine; 522-23, vertebral spine; 522-24, jaw fragment; 522-25, vertebrae; 538-16, bone; 538-17, jaw fragment.

\section{Archaeological Context}

AU 2: 131-28; AU 3a: 79-18, 106-10, 106-11, 106-12, 106-13, 106-14, 106-15; AU 3b: 66-4, AU 4a: $123-$ 16, 522-22, 522-23, 522-24, 522-25; AU 4b: 114-27, 129-2, 152-17, 152-49, 538-16, 538-17.

\section{Remarks}

A fair amount of fish skeletal material was recovered, especially in fine screen and float samples. Some of this material is burned. 


\section{Order Lepisosteiformes (Hay, 1929)}

Family Lepisosteidae (Cuvier, 1825)

Referred Specimens

522-26, scale.

Archaeological Context

AU 4a: 522-26.

Class Amphibia (Linnaeus, 1758)

Subclass Lissamphibia (Haeckel, 1866)

Referred Specimens

106-16, limb element, burned; 538-18, postcranial.

Archaeological Context

AU 3a: 106-16; AU 4b: 538-18.

\section{Order Caudata (Oppel, 1811)}

\section{Family, Genus, Species Indeterminate}

\section{Referred Specimens}

106-20, scapula(?), burned.

Archaeological Context

AU 3a: 106-2.

\section{Remarks}

A burned bone that resembles a Cryptobranchus (hell-bender) scapula, figured in Holman (1995:Figure $30,107)$ has been identified from Lot 106-2. Final identification of this specimen is suspect, as there currently is no known record of Cryptobranchidae from the Pleistocene of Texas (Holman 1995). 


\section{Order Anura (Merrem, 1820 [Fischer von Waldheim, 1813]*) \\ Family, Genus, Species Indeterminate}

\section{Referred Specimens}

79-19, humerus proximal articular condyle; 106-17, ilium fragment; 106-18, ilium fragment; 10619, limb element; 299-2, proximal radius, 299-3, limb fragment; 522-27, humerus fragment; 522-28, humerus; 522-29, humerus fragment; 522-30, skull frag; 522-31, skull fragment; 522-32, radio-ulna; 522-33, postcranial.

\section{Archaeological Context}

AU 3a: 79-19; 106-17, 106-18, 106-19; AU 4a: 299-2, 299-3, 522-27, 522-28, 522-29, 522-30, 522-31, 522-32, 522-33.

* as cited in Vullo et al. (2011).

\section{Remarks}

A relatively large number of frog or toad remains were identified from one lot, with a few specimens from three other lots in two AUs. Certainly across AU 3a and AU 4a this represents more than one individual, but may also within AU 4a.

\section{Genus Rana (Linnaeus, 1758) \\ Rana cf. Rana areolata (Baird and Girard, 1852)}

\section{Referred Specimens}

522-34, left ilium fragment.

\section{Archaeological Context}

AU 4a: 522-34.

\section{Remarks}

This specimen may derive from an individual represented by the material in Lot 522 assigned to Order Anura, described above. 


\section{Class Reptilia (Laurenti, 1768)}

\section{Order Testudines (Linnaeus, 1758)}

\section{Referred Specimens}

79-20, shell fragments; 79-22, burned shell fragment; 79-21, burned and ochre-stained shell fragment; 106-22, shell fragments, very small individual; 123-32, shell fragments; 123-31, peripheral shell fragment, 123-7, burned peripheral shell fragment; 131-15, sculpted pleural; 152-30, carapace fragment; 152-31, burned shell fragment; 152-32, shell fragment; 152-35, burned shell fragments; 152-36, peripheral shell fragment; 252-1, plastron fragment; 252-16, shell fragment; 256-1, plastron fragment; 256-26 plastron fragment; 256-27, burned shell fragment; 256-28, shell fragment; 291-1, peripherals; 291-2, pleural fragments; 291-6, burned shell fragments; 293-12, shell fragments; 299-5, plastron fragment; 310-2, shell fragment; 522-36, shell fragments; 522-37, burned shell fragments; 584-1, burned shell fragment.

\section{Archaeological Context}

AU 2: 131-15; AU 3a: 79-20, 79-21, 79-22, 106-22; AU 4a: 123-7, 123-31, 123-32, 256-1, 256-26, 256-27, 256-28, 291-1, 291-2, 291-6, 299-5, 522-36, 522-37; 584-1; AU 4b: 152-30, 152-31, 152-32, 152-35, $152-$ 36, 293-12; AU 5: 252-1, 252-16, 310-2.

\section{Remarks}

Turtle material was found in all AUs except 3b, where very little faunal material was recovered overall. Much of the turtle assemblage derives from shells that were probably no more than $30 \mathrm{~cm}$, cranialcaudal. Scute lines and sculpting suggest families Kinosternidae and Emydidae, present at Spring Lake today, are represented. However, the material is heavily comminuted and no diagnostic material was recognized.

\section{Order Lacertilia (Günther, 1867)}

\section{Referred Specimens}

106-21, jaw fragment; 522-35, jaw fragment.

\section{Archaeological Context}

AU 3a: 106-21; AU 4a: 522-35.

\section{Remarks}

Specimen 106-21 may be assignable to genus Eumeces. 


\section{Suborder Serpentes (Linnaeus, 1758)}

\section{Referred Specimens}

106-23, vertebra; 106-24, vertebrae; 106-25, jaw fragment with tooth; 123-41, vertebra fragments; 1318 , vertebra; 152-29, vertebra fragments; 256-29, vertebra fragments; 299-4, vertebra fragments; 538-19, vertebra fragments.

\section{Archaeological Context}

AU 2: 131-8; AU 4a: 123-41, 256-29, 299-4; AU 3: 106-23, 106-24, 106-25; AU 4b: 152-29, 538-19.

\section{Remarks}

Snake material consists largely of vertebrae with one jaw fragment. Identification beyond Serpentes was not attempted for this study, but it appears that a majority may be assignable to Colubridae.

\section{Class Aves (Linnaeus, 1758)}

\section{Referred Specimens}

79-24, bone fragment; 106-26 phalanx, small.

\section{Archaeological Context}

AU 3a: 79-5, 106-26.

\section{Order Anseriformes (Wagler, 1831)}

\section{Referred Specimens}

79-23, duck pelvis fragment.

\section{Archaeological Context}

AU 3a: 79-23.

\section{Class Mammalia (Linnaeus, 1758)}

\section{Mammalia, Indeterminate}

\section{Referred Specimens}

66-17, bone fragments; 66-18, burned bone fragment; 79-37, skull fragment; 79-40, bone fragments; 106-27, rib fragment, digested(?); 106-28, tooth fragments; 106-34, bone fragments; 114-26, bone fragments; 123-14, bone fragments; 123-33, bone fragments; 123-42, bone fragments; 123-43, burned bone fragments; 152-45, bone fragments; 152-46, burned bone fragments; 152-54, tooth fragment; 252- 
14, bone fragments; 252-15, bone fragments; 252-17, bone fragments; 256-31, burned bone fragments; 256-32, bone fragment; 256-36, burned tooth fragment; 291-8, bone fragments; 293-10, bone fragment; 299-34, bone fragments; 299-35, burned bone fragment; 299-36, burned bone fragments; 299-38, bone fragment; 299-39, bone fragment; 299-40, bone fragments; 310-30, bone fragment; 336-14, burned bone fragment; 522-47, burned bone fragments; 522-46, burned bone fragments; 522-45, burned bone fragments; 522-13, bone fragments; 538-4, bone fragment with polish; 538-22, caudal vertebra; 538-23, burned bone fragments; 538-24, bone fragments; 583-2, burned bone.

\section{Archaeological Context}

AU 2: 131-6, 131-22, 131-23, 131-25, 131-26, 131-27; AU 3a: 79-37, 79-40; 106-27, 106-28, 106-34; AU 3b: 66-17, 66-18; AU 4a: 123-14, 123-33, 123-42, 123-43, 256-31, 256-32, 256-36, 291-8, 299-34, 29936, 299-38, 299-39, 299-40, 336-14, 522-43, 522-45, 522-46, 522-47; AU 4b: 114-8, 152-45, 152-46, 152-54, 293-10, 538-4, 538-22, 538-23, 538-24, 583-2; AU 5: 310-30.

\section{Mammalia, Small and Micro}

\section{Referred Specimens}

106-29, (micro) 1st, 2nd, and 3rd phalanges; 106-32, upper and lower incisor fragments (Rodentia?); 106-33, burned incisor fragment (Rodentia?); 131-19, bone fragments; 131-21, auditory structure (Sylvilagus?); 152-33, innominate fragment (not Sylvilagus); 152-52, tooth fragment; 152-51, (micro) 1st phalanx; 256-33, Lepus-size proximal radius; 256-34, limb diaphysis fragment; 256-35, calcined limb diaphysis fragment; 256-37, skull fragment; 291-9, Leporidae(?) limb diaphysis fragment.

\section{Archaeological Context}

AU 2: 131-19, 131-21; AU 3a: 106-29, 106-32, 106-33; AU 4a: 256-33, 256-34, 256-35, 256-37, 291-9; AU 4b: 152-33, 152-51, 152-52.

\section{Remarks}

The micro category includes such mammals as bats, shrews and mice. Small mammals include volesize up through raccoon-size for taxonomic purposes and comparison of prey choices.

\section{Mammalia, Medium}

\section{Referred Specimens}

29-2, burned limb diaphysis; 66-16, bone fragment with cuts (medium Artiodactyla?); 79-34, rib fragment; 79-35, rib fragment, 79-38, burned bone fragment; 79-42, bone fragments; 79-43, rib fragment; 123-4, innominate fragment; 123-34, limb diaphysis fragments; 129-7, limb bone fragment; 131-18, limb diaphysis fragment; 131-19, bone fragment; 131-24, bone fragments; 152-34, burned bone; 152-40, burned tabular bone fragment; 152-41, limb diaphysis fragment; 152-43, burned bone fragments; 15244, bone fragments; 164-1, medium or large mammal limb diaphysis fragment calcined; 238-2, bone fragments; 240-9, scorched bone fragments; 249-1, tabular bone fragment; 256-30, tooth fragments; 
256-49, identifiable bone fragments; 291-10, skull fragment; 291-12, cut and burned bone with sulcus; 291-13, burned bone fragment; 293-11, limb diaphysis fragment (medium-size Artiodactyla?); 299-5, right humerus fragment (non-Artiodactyla); 299-37, sacrum; 299-42, burned bone fragments; 299-43, bone fragments; 299-45, bone fragments; 299-46, burned bone fragment; 299-47, skull fragment; 29948, skull fragment; 310-28, polished bone fragment; 310-29, bone fragments; 336-2, podial fragment; 336-15, burned bone fragments; 336-16, bone fragments; 522-40, limb diaphysis fragment; 522-41, bone fragments; 522-42, burned bone fragments.

\section{Archaeological Context}

AU 2: 131-18, 131-19, 131-24; AU 3a: 66-16, 79-34, 79-35, 79-38, 79-42, 79-43; AU 4a: 123-4, 123-34, 238-2, 240-9, 249-1, 256-30, 256-49; 291-10, 291-12, 291-13; 299-5, 299-37, 299-42, 299-43, 299-45, 299-46, 299-47, 299-48, 336-2, 336-15, 336-16, 522-42, 522-40, 522-41; AU 4b: 129-7, 152-34, 152-40, 152-43, 152-44, 152-41, 293-11; AU 5: 29-2, 164-1, 310-28, 310-29.

\section{Remarks}

A large percentage of this material could probably be assigned to Artiodactyla, medium, but with a low degree of confidence on the part of the analyst. Some specimens may also be assignable to such taxa as Canidae, but lack diagnostic features to allow such.

\section{Mammalia, Fetal/Juvenile}

\section{Referred Specimens}

123-35, fetal burned bone; 152-47, fetal/juvenile bone fragments; 291-11, juvenile(?) bone fragments; 299-40, bone fragment; 299-49, bone fragment, 299-51, burned bone fragment; 299-50, burned fetal bone fragment; 522-44, degraded bone.

\section{Archaeological Context}

AU 4a: 123-35, 291-11, 299-40, 299-49, 299-51, 299-50, 522-44; AU 4b: 152-47.

\section{Remarks}

Specimens described here as fetal mammal exhibit porous cortex, unfused and very spongy epiphyseal surfaces, and fall into the small mammal size category. They would be comparable in size to a small house cat. Logically, as a perinate or neonate, skeletal material of this size would probably belong to a mammal that, upon reaching full growth, would likely fall in to the medium mammal or medium artiodactyl size category. 
Order Primate (Linnaeus, 1758)

Family Hominidae (Gray, 1825)

Genus Homo (Linnaeus, 1758)

Homo sapiens (Linnaeus, 1758)

\section{Referred Specimen}

252-3, pes digit II or III 3rd phalanx.

Archaeological Context

AU 5: 252-3.

\section{Family Leporidae (Fischer, 1817)}

\section{Referred Specimens}

291-7, femur distal articular condyle.

Archaeological Context

AU 4a: 291-7.

\section{Genus Sylvilagus (Gray, 1867)}

\section{Referred Specimens}

131-16, atlas.

Archaeological Context

AU 2: 131-16.

\section{Order Rodentia (Bowdich, 1821)}

\section{Referred Specimens}

106-30, caudal vertebrae; 106-31, caudal vertebrae, burned; 106-35, burned palate fragment with suture (Sigmodon?); 114-25, jaw diastema fragment; 256-39, tibia fragment, distal articular end; 538-20, tooth fragments.

\section{Archaeological Context}

AU 3a: 106-30, 106-31, 106-35; AU 4b: 114-25, 256-39, 538-20. 


\title{
Genus Sigmodon (Say and Ord, 1825)
}

\author{
Sigmodon sp.
}

\section{Referred Specimens}

106-36, $\mathrm{R} \mathrm{m} / 1$; 106-37, isolated upper molar; 106-38, dentary with $\mathrm{m} / 1$ partial alveolus; 106-39, L M2/; 106-40, L M2/; 106-41, L M/1; 106-42, L m/3; 106-43, R m/1; 106-44, R m/3, burned; 106-45, R m/3; 106-46, Right dentary fragment with I/1, burned; 106-47, isolated tooth; 256-38, Sigmodon(?) maxilla fragment with alveoli, calcined; 256-40, Sigmodon(?) zygomatic plate; 256-41, Left m/1, broken; 25642, left dentary fragment with $\mathrm{i} / 1-\mathrm{m} / 2, \mathrm{~m} / 3$ (broken); 299-16, R M1/ in alveolar fragment.

\section{Archaeological Context}

AU 3a: 106-36, 106-37, 106-38, 106-39, 106-40, 106-41, 106-42, 106-43, 106-44, 106-45, 106-46, 10647; AU 4a: 256-38, 256-40, 256-41, 256-42, 299-16.

\section{Remarks}

It is of interest to note that Sigmodon is nearly but not entirely ubiquitous throughout the archaeostratigraphy at 41HY165. Two species of Sigmodon are reported in Texas. Sigmodon ochrognathus occurs in the Chisos Mountains, Big Bend area, and S. hispidus occurs widespread across the state (Schmidley and Davis 2004). Steele (1986) gives a tentative identification of S. hispidus occurring in nearly all strata sampled at 41LK201. He notes the presence of S. ochrognathus in Texas also, reviews its western occurrence, and therefore justifies an ecological interpretation of grassland habitat at the time of deposition at 41LK201.

\section{Genus Neotoma (Say and Ord, 1825)}

\section{Referred Specimens}

$522-38$, left humerus.

\section{Archaeological Context}

AU 4a: 522-38.

\section{Remarks}

Several species of this genus occur in Texas today, but two have records in Hays County. Neotoma floridana (Eastern wood rat) ranges in the eastern 1/3 of the state up to the edge of the Balcones Escarpment, and Neotoma albigula (white-throated wood rat) in western Texas down through the Panhandle and on the Edwards Plateau to include the very western corner of Hays County (Schmidley and Davis 2004). Specimens of dental and skeletal material from nearby $41 \mathrm{HY} 160$ have been compared with N. floridana and N. albigula, and appear to have traits of both taxa (Timperley, n.d.). N. albigula prefers cactus, mesquite, forbes, and to lesser extent, grasses. N. floridana prefers wooded, brushy 
habitat. Given these preferences, it is inferred that the Spring Lake area could conceivably host both species. Due to the paucity of material in this study, no species designation is provided here, but the immediate area of the site would be preferable to N. floridana today.

\author{
Family Castoridae (Hemprich, 1820) \\ Genus Castor (Linnaeus, 1758) \\ Castor Canadensis (Kuhl, 1820)
}

\title{
Referred Specimens
}

256-50, right ulna, proximal end.

Archaeological Context

AU 4a: 256-50.

\section{Family Geomyidae (Bonaparte, 1845)}

\section{Referred Specimens}

106-48, isolated cheek tooth.

Archaeological Context

AU 3a: 106-48.

\section{Order Carnivora (Bowdich, 1821)}

\section{Referred Specimens}

299-52, atlas vertebra (Canidae?).

Archaeological Context

AU 4a: 299-52.

\section{Family Canidae (Fischer, 1817)}

\section{Referred Specimens}

299-44, right humerus fragment, posterior aspect.

Archaeological Context

AU 4a: 299-44. 


\title{
Order Artiodactyla (Owen, 1848)
}

\author{
Family Antilocapridae (Gray, 1866)
}

Genus Antilocapra (Ord, 1818)

\section{Referred Specimens}

123-40, cheek tooth fragment.

\section{Archaeological Context}

AU 4a: 123-40.

\section{Family Bovidae (Gray, 1821) \\ Genus Bison (H. Smith, 1827)}

\section{Referred Specimens}

79-5, large bone fragment; 79-36, burned fetal bone; 131-5, P2/; 238-7, M/ fragment; 240-1, bone fragment; 152-5, long bone fragment; 252-13, carpal; 293-1 bone fragment; 293-2, tooth fragment; 293-8, tooth fragment.

\section{Archaeological Contex}

AU 2: 131-5; AU 3a: 79-5, 79-36; AU 4a: 238-7, 240-1; AU 4b: 152-5, 293-1, 293-2, 293-8; AU 5: 25213.

\section{Order Artiodactyla, Medium}

\section{Referred Specimens}

79-5, vertebra fragment; 79-11, burned bone fragment; 79-27, innominate fragment; 79-28, limb diaphysis fragment; 79-29, sacrum fragment; 79-30, femoral head; 79-31, neural spine; 79-32, vertebral centrum; 79-33, naviculo-cuboid (?); 123-2, ulna fragment; 123-3, lateral malleolus; 123-4, innominate fragment; 123-6, metapodial articular keel; 123-36, 1st phalanx fragment; 123-37, astragalus fragment (Antilocapra?); 123-38, vertebral centrum fragment; 123-39, vertebral process; 131-3, calcaneum fragment (Odocoileus?); 131-4, naviculo-cuboid (Odocoileus?); 131-17, tarsal fragment (Odocoileus?); 152-37, limb diaphysis fragments; 152-39, bone fragments; 238-9, 1st phalanx fragment; 252-2, metapodial distal epiphysis; 256-45, burned right scapula fragment; 256-46, cut cortex fragment; 25647, limb proximal end fragment, burned; 256-48, vertebra fragment; 291-15, metatarsal fragment; 29116, metacarpal fragment; 291-17, worked diaphysis fragment; 299-28, right astragalus; 299-29, medial epicondyle of femur; 299-30, limb diaphysis fragment; 299-31, burned limb diaphysis fragment; 29932, tibia fragments; 299-33, limb diaphysis fragment; 299-41, distal humerus or femur fragment; 336- 
1, burned metapodial fragment; 538-21, bone fragments; 310-11, limb diaphysis fragment; 310-26, metatarsal fragment (Odocoileus?); 310-27, metapodial fragments; 311-2, burned femoral head.

\section{Archaeological Context}

AU 2: 131-3, 131-4, 131-17; AU 3a: 79-5, 79-11, 79-27, 79-28, 79-29, 79-30, 79-31, 79-32, 79-33; AU 4a: 123-2, 123-3, 123-4, 123-6, 123-36, 123-37, 123-38, 123-39, 238-9, 256-45, 256-46, 256-47, 256-48, 291-15, 291-16, 291-17, 299-28, 299-29, 299-30, 299-31, 299-32, 299-33, 299-41, 336-1; AU 4b: 152-39, 152-37, 538-21; AU 5: 252-2, 310-11, 310-27, 310-11, 311-2.

\section{Remarks}

This classification category includes specimens of the size and morphology to be assignable to either of the medium artiodactyls otherwise represented at the site, but whose generic identity cannot be ascertained from the material at hand. Much of it exhibits spiral or otherwise green break (impact or shatter) signature.

\section{Family Cervidae (Goldfuss, 1820)}

\section{Genus Odocoileus (Rafinesque, 1832)}

\section{Referred Specimens}

79-26: accessory metapodial fragment; 123-5, third phalanx; 124-4, left dentary fragment w/ p/4 posterior root and $\mathrm{m} / 1-2 ; 256-43$, left dentary fragment with $\mathrm{m} / 1$ (broken alveolus) and $\mathrm{m} / 2$ alveolus (broken), 256-44, isolated $\mathrm{m} \mathrm{1/;} \mathrm{522-39,} \mathrm{tooth} \mathrm{fragment;} \mathrm{152-3:} \mathrm{isolated} \mathrm{left} \mathrm{m} / 2$; 152-4, lower tooth fragment; 152-13, right ulna olecranon fragment; 152-38, isolated upper cheek tooth fragment; 152-42, auditory structure; 311-1, metatarsal fragment.

\section{Archaeological Context}

AU 3a: 79-26; AU 4a: 123-5, 124-4, 256-43, 256-44, 522-39; AU 4b: 152-3, 152-4, 152-5; AU 5: 311-1. 
Table F-1. Taxon Standardization by AU.

\begin{tabular}{|c|c|c|c|c|c|c|c|c|c|c|c|c|}
\hline \multirow[b]{2}{*}{ Taxon } & \multicolumn{2}{|c|}{ AU 2} & \multicolumn{2}{|c|}{ AU 3a } & \multicolumn{2}{|c|}{$\mathbf{A U} \mathbf{3 b}$} & \multicolumn{2}{|c|}{$\mathbf{A U} 4 \mathbf{a}$} & \multicolumn{2}{|c|}{$\mathbf{A U} \mathbf{4 b}$} & \multicolumn{2}{|c|}{ AU 5} \\
\hline & NISP & $\begin{array}{c}\text { Mass } \\
\text { (g) }\end{array}$ & NISP & $\begin{array}{c}\text { Mass } \\
\text { (g) }\end{array}$ & NISP & $\begin{array}{c}\text { Mass } \\
\text { (g) }\end{array}$ & NISP & $\begin{array}{c}\text { Mass } \\
\text { (g) }\end{array}$ & NISP & $\begin{array}{c}\text { Mass } \\
\text { (g) }\end{array}$ & NISP & $\begin{array}{c}\text { Mass } \\
\text { (g) }\end{array}$ \\
\hline \multicolumn{13}{|l|}{ Fish } \\
\hline Osteichthyes & 1 & 0.1 & 95 & 1 & 1 & 1.1 & 30 & 0.7 & 50 & 0.3 & & \\
\hline Lepisosteidae & & & & & & & 1 & 0.1 & & & & \\
\hline \multicolumn{13}{|l|}{ Amphibians } \\
\hline Amphibia & & & 1 & 0.1 & & & 2 & 0.6 & 2 & 0 & & \\
\hline Anura & & & 4 & 0.2 & & & 16 & 0.8 & & & & \\
\hline Rana sp. & & & & & & & 1 & 0.1 & & & & \\
\hline \multicolumn{13}{|l|}{ Reptiles } \\
\hline Reptile & & & 1 & 0 & & & & & & & & \\
\hline Lacertilia & & & 1 & 0 & & & 1 & 0.1 & & & & \\
\hline Serpentes & 2 & 0.4 & 10 & 0.2 & & & 11 & 0.4 & 5 & 0.2 & & \\
\hline Testudines & 4 & 1.2 & 15 & 3.2 & & & 45 & 8 & 12 & 2 & 2 & 2.6 \\
\hline \multicolumn{13}{|l|}{ Birds } \\
\hline Aves & & & 2 & 0.1 & & & & & & & & \\
\hline Anatidae & & & 1 & 0.9 & & & & & & & & \\
\hline \multicolumn{13}{|l|}{ Mammals } \\
\hline Homo sapiens & & & & & & & & & 1 & 0.5 & & \\
\hline Leporidae & & & & & & & 1 & 1.5 & & & & \\
\hline Sylvilagus sp. & 1 & 0.7 & & & & & & & & & & \\
\hline Rodentia & & & 18 & 0.2 & & & 2 & 0.2 & 3 & 0 & & \\
\hline Sigmodon sp. & & & 12 & 0.7 & & & 4 & 0.3 & & & & \\
\hline Neotoma sp. & & & & & & & 1 & 0.2 & & & & \\
\hline Geomyidae & & & 2 & 0.2 & & & & & & & & \\
\hline Castor canadensis & & & & & & & 1 & 3.9 & & & & \\
\hline Canidae & & & & & & & 1 & 7.6 & & & & \\
\hline Artiodactyla (medium) & 17 & 8.8 & 9 & 26.7 & & & 36 & 118.7 & 2 & 7.1 & 4 & 11.4 \\
\hline Odocoileus sp. & 5 & 24 & 1 & 0.1 & & & 9 & 31.4 & 5 & 8.2 & 1 & 5.5 \\
\hline Antilocapra sp. & & & & & & & 1 & 0.4 & & & & \\
\hline Bison sp. & 1 & 1.8 & 2 & 23.7 & & & 2 & 12.8 & 6 & 74.2 & & \\
\hline Mammalia & 52 & 14.8 & 180 & 7.2 & 5 & 2.8 & 184 & 18.1 & 152 & 10.9 & 1 & 0.1 \\
\hline Mammalia, micro & & & 8 & 0.1 & & & & & 4 & 0.1 & & \\
\hline Mammalia, small & 4 & 2.3 & & & & & 1 & 0.2 & 1 & 0.1 & & \\
\hline Mammalia, fetal/juvenile & 3 & 0.8 & & & & & 7 & 3.6 & 2 & 0.2 & & \\
\hline Mammalia, medium & 20 & 17 & 11 & 4.5 & 12 & 7 & 95 & 37.7 & 29 & 20.8 & 10 & 10.8 \\
\hline Mammalia, medium/large & & & & & & & 2 & 1.2 & & & 1 & 2.3 \\
\hline Vertebrata & 4 & 0.4 & 95 & 1.7 & & & 6 & 3 & 37 & 0.4 & 51 & 31.5 \\
\hline Total & 114 & 72.3 & 468 & 70.8 & 18 & 10.9 & 460 & 251.6 & 311 & 125 & 70 & 64.2 \\
\hline
\end{tabular}





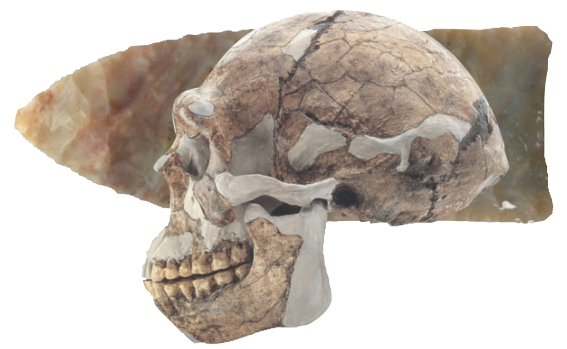

Center for Archaeological Studies

Texas State University-San Marcos 601 University Dr.

San Marcos, TX 78666

www.txstate.edu/anthropology/cas/

\section{TEXAS $*$ STATE \\ UNIVERSITY \\ SAN MARCOS \\ The rising STAR of Texas}

A member of the Texas State University System 